\title{
Political ecology of conservation in the 'Alagol, Ulmagol, and Ajigol' glocal wetlands, Turkmen Sahra, northeast Iran
}

\author{
by \\ Parastu Mirabzadeh-Ardakani \\ A thesis submitted to the Faculty of Graduate and Postdoctoral Affairs \\ in partial fulfillment of the requirements for the degree of \\ Doctor of Philosophy \\ in
}

Geography and Environmental Studies

Carleton University

Ottawa, Ontario

(C) 2014

Parastu Mirabzadeh-Ardakani 


\section{Abstract}

A post-structural political ecology approach, and relational thinking of place, space, scale and power, are used to conceptualize Wetlands of International Importance as 'glocal wetlands' and to develop an analytical framework to study relevant peopleenvironment interactions. This framework is applied for the analysis of the powerrelations affecting the Alagol, Ulmagol, Ajigol (AUA) wetlands in the Turkmen Sahra, Iran, and its Turkmen population. It demonstrates: (A) The Turkmen were knowledgeable stewards of their natural resources, and were active agents in shaping the AUA landscape that was the source of their livelihoods, and in attracting the biodiversity that led to the AUA being designated as a Ramsar Site. This finding provides a strong basis for acknowledgement of their rights to tenure and access to their ancestral lands, water and natural resources. (B) Nation-state building, territoriality, and control over natural resources are critical political issues. The past and present exercise of state power includes: coercive sedentarization to control the Turkmen and convert them to citizens; exclusionary land use and water policies by the Shahs and the Islamic state; 'fortress' conservation facilitated by international conservation organizations and implemented by the Islamic state; and the power geometry of place in the Turkmen Sahra, including citizenship, ethnicity, and minority rights. (C) The approach of the Islamic state and Ramsar Convention Secretariat in interpreting the current AUA landscape as being a successful conservation project, as reflected in the Ramsar's Advisory Mission Report, was remarkably ahistorical. A major ongoing concern is that the discourse on 
conservation in Iran has experienced a period of stagnation since the 1979 revolution, with the consequence that the concepts of 'wise use' and participatory management have not been adopted. This thesis asserts that employment of the glocal wetlands analytical framework leads to better understanding of Ramsar Sites, in Iran and elsewhere, by providing for the carrying out of place- and context-specific studies and the analysis of hidden power relations that shape wetlands and the topology of place. Such analysis provides a platform for setting realistic policy goals and facilitates decision-making processes that are both ecologically and socially just. 
To the Turkmen of Iran

With hope for a better future 


\section{Acknowledgement}

This project would not have been possible without the support of many people. Many thanks to my co-supervisers Kenneth Torrance, who constantly and persuasively helped me survive my doubts, read my numerous revisions with precision and gave me valuable advice, and Scott Mitchell, who believed in me and provided me with the financial support to carry out my field work, read my drafts and had also provided valuable advice. I would also like to thank Derek Smith for his useful comments. My gratitude goes to two university professors in Tehran who made this field work possible. Furthermore, I acknowledge, with much appreciation, the help and support I received from Natalie Pressburger who patiently and kindly answered my questions. Moee jan and Sara jan, thank you for consistently being there for me and offering your support with kindness. Fereidoon, you endured this long process with me with unconditional love, support and care. I love you and appreciate you in my life. Finally, Mom and Dad thank you for sensitizing me to issues of human rights and social justice. 
Table of contents

\begin{tabular}{lc} 
Abstract & ii \\
\hline Dedication & iv \\
\hline Acknowledgment & $\mathrm{v}$ \\
\hline Table of contents & $\mathrm{vi}$ \\
\hline List of Tables & $\mathrm{xi}$ \\
\hline List of Illustrations & $\mathrm{xi}$ \\
\hline List of Appendices & xii \\
\hline List of Abbreviations & xiii \\
\hline Glossary & xiv \\
\hline
\end{tabular}

CHAPTER I- Introduction 1

1.1. Context of the research 1

1.2. Purpose of the research 2

1.3. Conceptual underpinnings: political ecology, relational thinking, and glocal 7 wetlands

1.4. Background 11

1.4.1. The Convention on Wetlands 11

1.4.2. The Alagol, Ulmagol and Ajigol (AUA) Wetlands of International 12 Importance

1.5. Dissertation structure and organization 17

CHAPTER II- Theory

2.1. Nature and society 21

2.1.1. Social Nature 22

2.1.2. Socionature/nature-society hybrids in Actor-network theory (ANT) 27

2.2. Place, space, and scale 34

2.2.1. Place and space 34 
2.2.2. Scale and space

2.3. Power and space

2.3.1. Power-geometry

2.3.2. Power/ Knowledge, and governmentality

2.3.3. Territoriality and environmental governmentality

2.3.5. Power as composition

2.4. Glocal wetlands and their analytical framework

CHAPTER III- Methodology and methods

3.1. Context-specific methodologies

3.1.2. 'Insiders' and 'outsiders' in qualitative methodologies

3.2. Participatory approaches and methods

3.2.1. Conservation territories and participatory mapping 100

3.2.2. Focus groups 109

3.2.3. Interviews

3.3. Research design and methods

3.3.1. Site selection and preparation

3.3.2. Preliminary investigation

3.3.3. Structured interviews: Questionnaire

3.3.4. Participatory exercises

CHAPTER IV- The Turkmen Sahra and Atrekians: landscape, politics and history

4.1. The Turkmen Sahra: ecosystem

4.2. Social construction of the Turkmen Sahra: a political and historical review

4.3. The Turkmen territories: a socio-ecological system

4.3.1. The Turkmen in Central Asia: livelihood strategies, and land and water use

4.3.2. The Atrekians: livelihood strategies, and traditional land and water use 
and management

CHAPTER V-Livelihood strategies of the Tenglians- current status

5.1. Village profile

5.1.1. Population and households structure

5.1.2. Age groups, gender, and labor force

5.1.3. Education status

5.2. Livelihood Strategies analysis

5.2.1. Past, present (2008), and future

5.2.2. Wealth categories

5.3. Obstacles: access to resources and livelihood $\quad 170$

5.4. Loans and debts: access to credits -173

5.5. Needs

5.6. Conclusion $\quad 176$

CHAPTER VI- The politics of state natural resource control 179

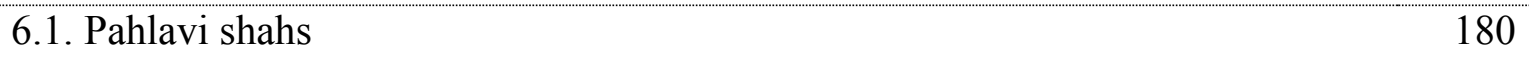

6.1.1. State building practices $\quad 182$

6.1.2. Coercive sedentarization of the Turkmen 191

6.1.3. Land policies, rural development and the Turkmen 195

6.2. The Iranian Islamic State 205

6.2.1. Land use, conversion and transfer: institutions, regulations, and 208 processes

6.2.2. Water management and allocation: institutions, regulations, and $\quad 219$ processes

6.2.3. Nature protection 226

6.2.4. Spatial planning and development plans: decision-making processes $\quad 239$ and structures 
CHAPTER VII- Current land uses and conflicts in the AUA region

7.1. Land use change in the AUA region 251

7.1.1. Rangelands 253

7.1.2. Agricultural lands 256

7.1.3. Fish farms 261

7.1.4. Housing 264

7.2. Water 265

7.3. Fishing and hunting 275

7.4. Biodiversity, wildlife, and habitats 278

7.5. Conclusion 288

CHAPTER VIII- The 'rule of law', and political and civil rights 293

8.1. The Islamic State of Iran and its power structure 293

8.1.1. The 'rule of law': The paradox of the Islamic State of Iran 296

8.2. Political decentralization and access to decision-making process 314

8.2.1. Islamic Rural Councils 316

8.3. Minority rights 324

8.3.1. Turkmen identity and nationhood 328

8.3.2. Politics of place: resistance and opportunities in the AUA region 337

8.3.3. Global sense of place $\quad 340$

8.4. Conclusion 343

CHAPTER IX- Conservation: from discourse to practice 345

9.1. Discourse of conservation: from 'fortress' and 'command-and-control' to 345 socially-just

9.2. Ramsar Convention on Wetlands: 'wise use' of wetlands 359

9.3. Discourse of conservation in Iran 366

9.3.1. Social science research 369

9.3.2. Experts, academia, intellectuals, and NGOs 372

9.3.3. The State's political agenda 376

9.3.4. The AUA Ramsar Advisory Mission: discourse of 'wise use' 380 
CHAPTER X- Conclusion 392

10.1. Contribution to Knowledge: Theory

List of References 403

Appendix A- Fieldwork calendar 448

Appendix B- Fieldwork verbal script 453

Appendix C- The Atrekians' old documents 455

Appendix D- Participatory map 


\section{List of Tables}

3.1. Research summary: analytical framework, questions, methodology, and methods

\section{List of Illustrations}

\section{Figures}

3.1. A comparison of Participatory Action Research, Participatory Rural Appraisal, and Rapid Rural Appraisal

3.2. Degree of local participation in participatory exercises

5.1. Population of Tengli, by gender (\%) and age groups

5.2. Population of Tengli, classified by age groups

5.3. Education status of Tenglians

5.4. Education status of Tengli, by gender (\% to total population)

5.5. Livelihood strategies of Tenglians

5.6. Livelihood strategies of Tenglians differentiated by wealth categories

5.7. Problems Tenglians encounter: access to resources and livelihood

5.8. Tenglians' debt

5.9. Usage of the borrowed money

5.10. Tenglians' needs

9.1. Socially-just conservation and access rights

Maps

1.1. Map of Iran

1.2. The AUA region 
4.1. The Atrek River transboundary basin

4.2. The AUA region in 1958

4.3. The AUA region in 1921

4.4. Participatory map (modified, simplified, and translated)

7.1. The AUA region- satellite image

\section{List of Appendices}

Appendix A- Fieldwork calendar

Appendix B- Fieldwork verbal script

Appendix C- Atrekians' old documents

Appendix D- Participatory map 


\title{
List of Abbreviations
}

\author{
AUA: Alagol, Ulmagol and Ajigol \\ DOE: Department of Environment \\ COP: Conference of the Parties
}

EIA: Environmental Impact Assessment

FAO: United Nations Food and Agricultural Organization

GEF: Global Environment Facility

IRGC: Islamic Revolutionary Guard Corps

ICDP: Integrated Conservation and Development Project

IUCN: International Union for Conservation of Nature/ World Conservation Union

IRBM: Integrated River Basin Management

IWRM: Integrated Water Resource Management

MA: Millennium Ecosystem Assessment

MPO: Management and Planning Organization

NGO: Non-Governmental Organizations

PAR: Participatory Action Research

PRA: Participatory Rural Appraisal

RBM: River Basin Management

RRA: Rapid Rural Appraisal

RIS: Ramsar Information Sheet

STRP: The Scientific, Technical and Technological Panel

UNDP: United Nations Development Programme 


\section{Glossary}

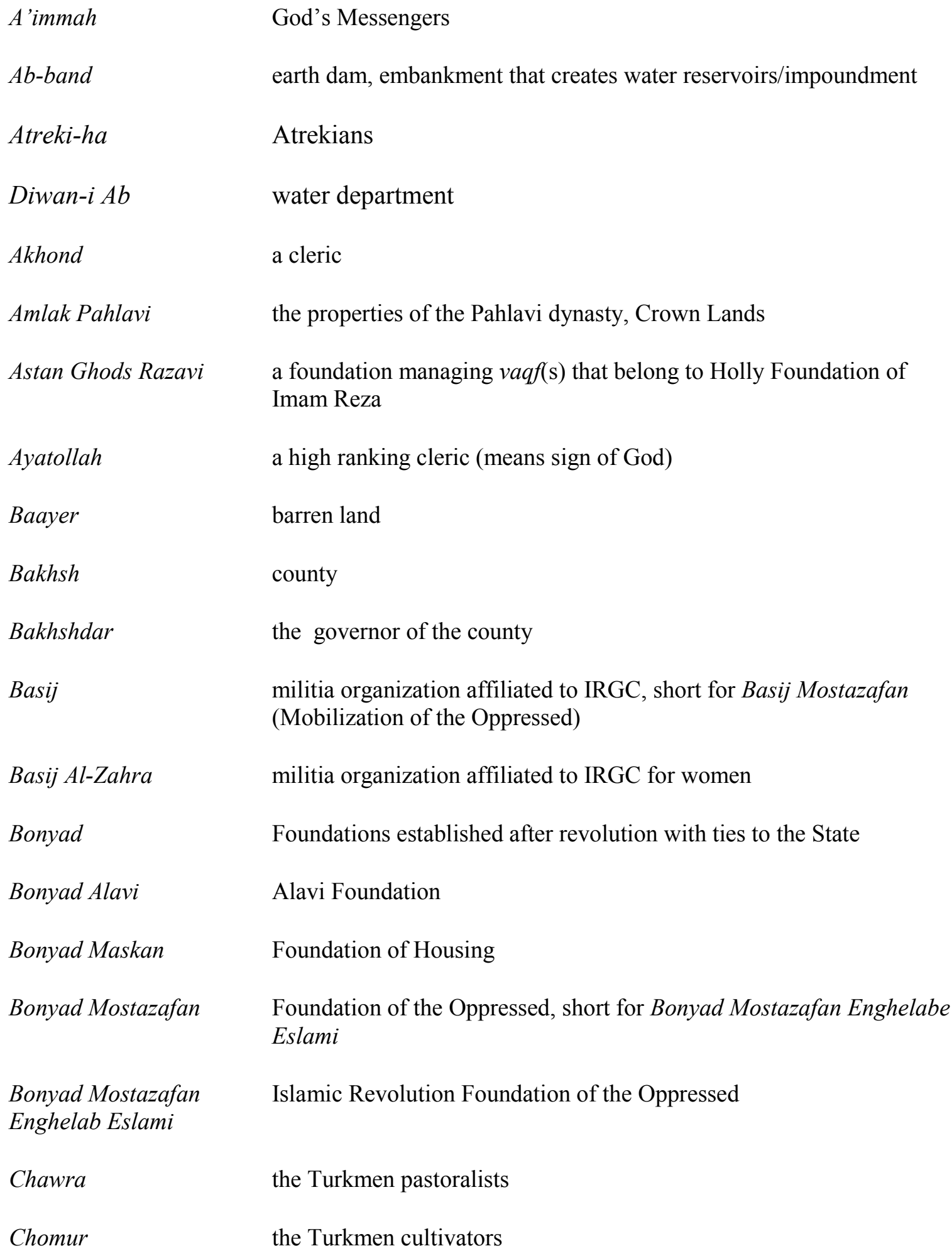




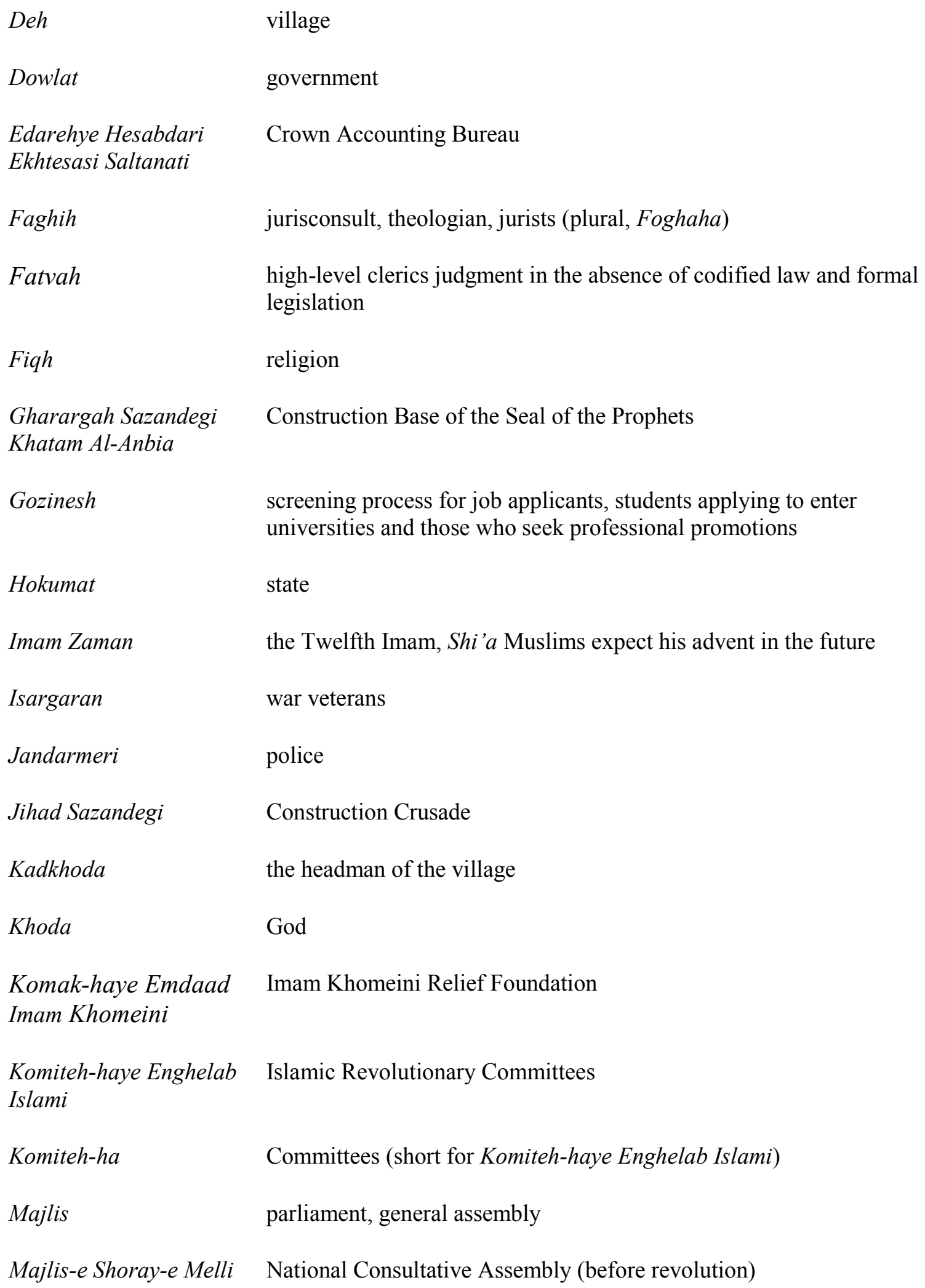




\begin{tabular}{|c|c|}
\hline $\begin{array}{l}\text { Majlis-e Shoray-e } \\
\text { Islami }\end{array}$ & Islamic Consultative Assembly (after the revolution) \\
\hline Marja-e taghlid & most senior authority of the Isalmic law \\
\hline Mihan & country, homeland \\
\hline Mir-ab & water regulator, water master \\
\hline Mofsed Fel Arz & a person who extends vice on earth \\
\hline Mohareb & a person in enmity to God \\
\hline Nasaq & the total amount of land and water available to a village \\
\hline Ostan & province \\
\hline Ostandari & the Governor-General's Office \\
\hline Pasdars & guards (working for Sepah) \\
\hline Qanat & traditional system of underground water channels \\
\hline Quishlaq & winter pastures \\
\hline Rish sefids & white-beards \\
\hline Rokn dovom & a division of Shah's security agency \\
\hline $\begin{array}{l}\text { Sepah Pasdaran } \\
\text { Enghelab Islami }\end{array}$ & Islamic Revolutionary Guard Corps \\
\hline Sepah & short for Sepah Pasdaran Enghelab Islami \\
\hline Shahrdari-ha & municipalities \\
\hline Shahrestan & district \\
\hline Shari'a & Islamic religious laws \\
\hline Shoray-e Khebregan & Expediency Council \\
\hline Shoray-e Negahban & Guardian Council \\
\hline Tepe & hill \\
\hline
\end{tabular}




$\begin{array}{ll}\begin{array}{l}\text { Umumi Gheir Dowlati } \\ \text { Ulama }\end{array} & \begin{array}{l}\text { public non-governmental } \\ \text { Shma }\end{array} \\ \text { the community of Islamic believers } \\ \text { Vali-e Faghih } & \text { Islamic jurisconsult, the Islamic Leader, Supreme Leader } \\ \text { Vaqf } & \begin{array}{l}\text { properties that are religious endowments and belong to charitable } \\ \text { organizations (plural Ouqaf) }\end{array} \\ \text { Velayat-e Faghih } & \text { guardianship of the jurist, rule of the Islamic jurists } \\ \text { Yashuli } & \text { elder, chief of the tribe (Turkmen language) } \\ \text { Yashulilar Yighaigh } & \text { the Turkmen Council of Elders (Turkmen language) } \\ \text { Yaylaq } & \text { summer camps } \\ \text { Yurt } & \text { Central Asian type of tents (Turkmen language) }\end{array}$




\section{CHAPTER I- Introduction}

\subsection{Context of the research}

There is a huge gap between rhetoric and exercise of conservation. Experience in working with international conservation organizations and national-level nature protection agencies has made me aware that the achievements claimed in conservation project reports and what has been achieved in practice are often quite different. In seeking the reasons for the discrepancies, one very soon realizes that, at all levels, the interactions among international organizations engaged in environmental policy setting processes, national governments, that establish national policy, and the working of conservation projects at local levels, are not straight forward and linear processes happening in a vacuum, independent of their wider social, political and economic networks. Untangling this complexity requires an intellectual journey that seeks to understand how conservation policies are: developed in a multi-layered world; understood, interpreted, and practiced at the national level; and applied at local levels of social-ecological systems, including how they impact the local people. This untangling requires engagement with the issue of power relations and its implications in shaping people-environment interactions in any specific place and, thereby, encounters the concept of socially-just conservation.

This thesis focuses on Wetlands of International Importance and seeks a theoretical answer to the complexity of people-environment interactions in these socioecological systems, develops an analytical framework to study change in terms of peopleenvironment interaction in these systems and applies it to the case of the Alagol, Ulmagol, and Ajigol (AUA) Wetlands of International Importance and their adjacent local community, the village of Tengli, in Turkmen Sahra, located east of the Caspian Sea, Northern Iran. In doing so, this dissertation provides insights into the complexities of 
people-environment interactions, conservation discourse and conservation practice in the Iranian context. By examining the past and present power-geometries involved in the formation of the AUA region, it is hoped that this study will contribute to the envisioning and development of a space for change and the enhancement of conservation policy analyses to produce more realistic policies and more ecologically and socially-just results.

\subsection{Purpose of the research}

The Secretariat of the Convention of Wetlands, upon a request from Contracting Parties, may delist a Ramsar Site from the List of Wetlands of International Importance (Ramsar List) due to adverse change in its ecological characters, caused by human interventions, and put it on a red list known as the Montreux Record. Montreux Record Sites arise as a consequence of interacting social-ecological complexities. Processes involved in change in the ecological character of wetlands through adverse human impacts on ecosystems encompass a wide range of issues crossing many fields of study including: conservation discourse and practice from the international to the local level; people-environment interactions and their socio-political contexts; scale-mismatch management usually intertwined with political trajectories; and bad governance of commons. Montreux Sites present excellent research projects for both conservationists and social scientists because their formation is related to intertwined social, political, and ecological networks that interact simultaneously but do not achieve the 'wise use' of wetlands, a major goal of the Convention and its Contracting Parties.

The Alagol, Ulmagol, and Ajigol (AUA) wetland complex, was designated as a Ramsar Site in 1975, then listed on the Montreux Record in 1995, and relisted as a 
Ramsar Site in December 2008. The Ramsar database, Ramsar Information Sheet (RIS) ${ }^{1}$ (Ramsar Convention Secretariat, 2013a), and the Directory of Wetlands of the Middle East (Mansoori, 1995, p. 100) have detailed information about the flora and fauna of the AUA wetlands but contain no information on their local human inhabitants. This approach is similar to the 'myth of emptiness' used by European colonizer notions who regarded colonial lands in Africa, and elsewhere, as being 'empty' and 'available' for conservation (Neumann, 2004 p. 185). A paradigm shift in conservation discourse has addressed this issue but it has not been widely and consistently reflected in the practice of conservation (see Section 9.1). The embedded notion of the separation of nature and society in the practices of conservation institutions needs to be re-evaluated.

Identification and designation of the AUA as a Ramsar Site was based on the contemporary global discourse of conservation that built upon the notion of purified nature and separation of nature from society. The simple fact that the AUA Ramsar Site was designated as a Montreux Site, 20 years after its designation, negates the purified ideology surrounding its establishment, because simply listing it on the Montreux Record indicated the existence of unresolved problems in its socio-ecological context. The subsequent delisting of the AUA from the Montreux Record and relisting it as Wetlands of International Importance provides the opportunity to examine the cross-scale power relations and hidden processes that shape and influence conservation and peopleenvironment interaction in the AUA.

\footnotetext{
${ }^{1}$ The Ramsar Information Sheet for Wetlands of International Importance (RIS), is (Ramsar Convention Secretariat, 2009b): “designed to provide essential data on all designated Wetlands of International Importance, in order to allow analysis of Ramsar-listed wetlands around the world at any given time, provide baseline data for measuring changes in the ecological character of wetlands listed under the Ramsar Convention, and provide material for publications which inform the public about Ramsar sites. Completed RISs are only accepted from the officially-appointed "Administrative Authority" in each Contracting Party or Member State".
} 
The removal of the AUA Ramsar Site from the Montreux Record and the Ramsar Convention endorsement of the success of the government of Iran in conservation and wise use of wetlands has been promoted in Iranian media and on the Ramsar Secretariat website. The Secretariat ascribes this success to the appropriate measures taken by the government of Iran to control hunting, allocate water to the wetlands, control water abstraction from wetlands, and provide alternative livelihood for local people (Moser, 2009 , p. $1,8, \& 10)$. It asserts that 'there is every indication that these improvements will be sustained' (Moser, 2009, p. 1). This 'successful' conservation project, which claims to have a technical explanation, has underlying social and political elements and driving forces, as well as social implications, which are invisible in the report. Measures such as water allocation to wetlands, abstraction of water from wetlands, land-use change, livelihood of local people, and control of illegal hunting are not technical issues in a vacuumed space; rather, in a real world, they are political statements and actions. Will we have a different perception of the AUA as a successful conservation case if we examine it in its social, political and economic context and if we have knowledge about the spatialtemporal changes in terms of the people-environment interactions in the area? Addressing this gap in knowledge is a critical component of the case study.

The above question fosters the formation of the main theoretical question of this thesis: What are the implications of using a post-structural political ecology approach to understanding and analyzing change in terms of people-environment interactions in Wetlands of International Importance?

This question has been addressed by delving into relational thinking about place, space, scale and power. Consequently, this thesis conceptualizes Wetlands of International Importance as being glocal wetlands and provides an analytical framework 
for studying change in terms of people-environment interactions related to those wetlands (see Section 2.4). With this perspective, designation of any Ramsar Site, and its inclusion in and removal from the Montreux Record raise questions regarding hidden driving forces and power relations and imbalances that constitute any Ramsar Site or conservation territory ${ }^{2}$, and calls for a 'contextual analysis of multiple scales of influence' (Jones, 2008 , p. 672). The glocal wetlands analytical framework developed herein is used to formulate and address major research questions regarding people-environment interactions in the AUA region and their adjacent local community, the village of Tengli, that entail examination of the socio-political history of the AUA Ramsar Site, and study of the power-relations involved in the making of this place in its social, political and economic contexts, at multiple levels, revealing complexities underlying the claims in the Advisory Mission Report and providing insight on the terms of its proclaimed success. Application of the analytical framework for studying glocal wetlands to the AUA examines the site not in terms of abstract, certainty, and linear connections but in the midst of numerous volatile networks in action (see Section 2.4). This approach leads to a series of questions that will be addressed in Chapters IV to IX of this thesis. Overall, this thesis constructs a narrative to argue that:

(A) The AUA Ramsar Site, which is constituted through a discourse of conservation and the notion of purified nature, is really a nature-society hybrid. This argument will be elaborated by addressing the following questions:

\footnotetext{
${ }^{2}$ In this study, conservation territories, (after Zimmerer, 2006a, p. 8) are referred to as any spatial arrangements and designated spaces for the purpose of nature protection. Management goals of these territories may vary from strict nature protection (e.g. IUCN category I) to sustainable utilization of resources (e.g. Wetlands of International Importance/Ramsar sites).
} 
Question 1: How have people-environment interactions formed the AUA landscape as part of the Turkmen Sahra, and how has it changed over time?

Question 2: What are contemporary people-environment interactions in the AUA region?

(B) The AUA Ramsar Site owes its existence to embedded, uneven, and dynamic relations of power, crossing global to local levels. Therefore, local conditions, life of the local people and daily practices of conservation in the AUA region emerge in practice and are articulated, through interaction between actors and intertwined political and economic processes (access to resources, land use and management of commons, governance, and conservation policies and discourse) crossing multiple levels from global to local. This argument will be elaborated by addressing the following questions:

Question 3: How is the state's power exercised in the region, and what are territorial approaches in the Turkmen Sahra?

Question 4: How do the state's territorial land, water and conservation policies affect the AUA landscape and the Tenglians in pursuit of their livelihood strategies and access to resources?

Question 5: Where has the control over rights been located in the Islamic State?

(C) Conservation discourse in Iran is codified and implemented by national and international actors and is part of the state's territorial policies and actions. Conservation and wise use of AUA wetlands should be understood and practiced in that context. This argument will be elaborated by addressing:

Question 6: How is conservation perceived and understood in Iran? 


\subsection{Conceptual underpinnings: political ecology, relational thinking, and glocal wetlands}

My choice of political ecology to guide this inquiry is due to: a) its dual commitment to promote policies for social justice and empowerment of disadvantaged social groups and for sound environmental management and conservation (Bryant, 1992; Neumann, 2008; Zimmerer, 2000, p. 364); b) its ability to go beyond disciplinary biases and its flexibility to be transdicisplinary (Kepe, Bissonnette, \& Roberts, 2008, p. 2542), which is the 'fine interweaving of disciplinary analysis' (Zimmerer \& Bassett, 2003a, p. 16); and c) its view of the world as multi-scale and multi-level, exploring connections and interactions across levels and scales (Armitage, 2008, p. 19; Zimmerer, 2006a).

Political ecology is not a theory; it is an evolving approach (Watts \& Peet, 2004; Zimmerer \& Bassett, 2003a) to conceptualizing and understanding human-environment relations mostly through case studies (Kepe, Bissonnette, \& Roberts, 2008, p. 2539). Watts describes political ecology as an approach which (Watts, 2000a, p. 257):

seeks to understand the complex relations between nature and society through a careful analysis of what one might call the forms of access and control over resources and their implications for environmental health and sustainable livelihoods.

Forsyth elaborates on Blaikie's approach, in the 1980s, to political ecology as being (Forsyth, 2008, p. 762):

more than either the deconstruction of environmental narratives (in the manner of much post-structuralists' analysis), nor trying to explain environmental change more accurately by 'peeling the onion' (in the critical realist sense). Rather it is a politicized acknowledgement of the co-production of environmental knowledge and social values in ways that, tentatively, try to reconstruct environmental explanations and interventions in the favour of vulnerable people. 
Political ecology in the 1990 s was influenced by social theories, including poststructural $^{3}$, postcolonial, and feminist perspectives. Post-structuralists understand politics in terms of 'power relations that shape and pervade all human interactions, are characterized by challenge and negotiation, and are infused with symbolic and discursive meanings' (Paulson, Genzon, \& Watts, 2005, p. 29). Peet mentions that post-structuralism explains the modern society as a system of power; is critical to totalitarian politics (both capitalist and communist); takes the side of marginal groups; and values difference over sameness (Peet, 1998). Watts shows the post-structural nature of political ecology by identifying its goal as to 'explain environmental conflicts especially in terms of struggle over knowledge, power, and practice' and 'politics, justice and governance' (Robbins, 2012, p. 16; Watts, 2000a, p. 263). The post-structuralist turn in the field addressed the same topics in the 1980s including access to land and natural resources, ecological degradation, social marginalization, poverty, and social justice, but with more focus on: a) political forces and power relations; b) culturally and historically situated knowledges and discourses; c) institutions and governance; and d) gender and ethnic identities (Paulson, Gezon, \& Watts, 2003, p. 208).

Blaikie explains that (Blaikie, 1999, p. 131):

by internalizing diverse notions from its eclectic origins, political ecology is able to throw light on new contradictions and paradoxes that are brought together from different networks of scholars, activities, and other actors.

Zimmerer and Bassett assert that political ecology contributes to bridging the gap between social and biophysical sciences in human-environmental studies and

\footnotetext{
${ }^{3}$ Post-structuralism rejects "certain readily identifiable modernist conception of knowing, the knower and the known. Knowledge is understood within a modernist frame as singular, cumulative, and neutral, however from a poststructural perspective knowledge is multiple, contradictory, and powerful" (GibsonGraham, 2005, p. 95).
} 
environmental-development analysis; however its main contribution lies in interweaving and fusing the two themes instead of studying them in parallel (Zimmerer \& Bassett, $2003 a$, p. 2, 2003b, p. 276). Spatial and temporal integration of scale is the core of this linkage and fusion (Brunckhorst, 2005; Zimmerer \& Bassett, 2003a).

In brief, political ecology with its dual commitment, i.e. contribution to sound environmental management and nature conservation, and 'empowerment of disadvantaged social groups' (Zimmerer, 2000, p. 357): investigates issues such as social justice, inequity, and poverty; brings many different voices and perspectives to conservation; and opens the discussion to who benefits and who loses, who has access to land, and natural and genetic resources, who has the power, and therefore, who has the power to exploit, who runs the institutions, and what are the environmental narratives and interpreted facts and values. Forsyth argues that, 'the challenge for political ecology lies in understanding both environmental and political change in ways that enhance social justice, but which do not impose a priori notions about each' (Forsyth, 2008, p. 763).

This research is informed by critical political ecology perspectives and the insights that this approach offers to study and understand: global expansion of conservation; the practice of conservation and its impacts at multiple levels; and the formation of conservation territories as spatial configurations through which 'physical extent' is 'fused with social intent' (Zimmerer, 2006a, p. 9). This thesis uses the core concepts of post-structural political ecology about socio-nature and nature-society hybrids, and relational/non-essentialist understanding of place, space, scale, and power as interlinked key topics for the understanding of conservation territories, conceptualizes Wetlands of International Importance as glocal wetlands, and offers an analytical framework for their study (see Section 2.4). 
Glocal wetlands are global localities and are simultaneously social and natural. This research argues the formation of glocal wetlands encompasses complex and interwoven socio-ecological, economic, political, cultural and institutional queries about the networks they function within and their power geometry. Power, scale and their interactions across levels are the core themes. In glocal wetlands, environmental changes are perceived as a complex network of material settings and ramifications of political processes and socio-economic inequalities; consequently, social dynamics should be studied along with the physical environment. By employing this framework in the AUA region, this research examines people-environment interaction, envisions the AUA in its social, political and geographical contexts and involved networks, and sheds light on otherwise invisible power relations in the construction of the AUA glocal wetland.

Political ecology research projects 'work backward in time and outward in space' (Vayda \& Walters, 1999, p. 169), which implies the need to understand temporal and spatial scaling of environmental change in nature-society hybrids (Gezon \& Paulson, 2005; Zimmerer, 2000). The six questions of this thesis, developed based on the glocal wetlands analytical framework, followed logically to fulfill the above requirement by engaging the AUA, as a Ramsar Site, with its historical, social and political dimensions, to demonstrate the dialectical unity of nature-society in the AUA area by demystifying its 'socionature' characteristics; examining dynamic interactions of the local and extra-locals through analysis of social forms of access and control over resources, livelihood, and the conflicts in the temporal and spatial distribution of the benefits and burdens of socialenvironmental change. They also demonstrate how conservation, access to resources and management of commons intersect with other socio-political, administrative and 
economic processes at multiple social and geographical scales to shape practice of conservation in Iran and construct the AUA glocal wetlands.

\subsection{Background}

\subsubsection{The Convention on Wetlands}

The Convention on Wetlands, also known as the Ramsar Convention, is an intergovernmental treaty adopted in 1971, in the Iranian city of Ramsar, which came into force in December $1975^{4}$. It was the first of the modern global intergovernmental treaties on the conservation and sustainable use of natural resources with a focus on wise use and maintenance of the ecological character of wetlands. Its provisions, when compared with more recent wetland treaties, are relatively straightforward and general (Ramsar Convention Secretariat, 2007, p.1). Countries joining the convention forward their instrument of ratification or accession ${ }^{5}$, signed by the Head of State or Government or the Minister of Foreign Affairs, along with their obligatory first Ramsar Site ${ }^{6}$ designation, to the Director General of UNESCO ${ }^{7}$ (Ramsar Convention Secretariat, 2013b, p. 6).

The Montreux Record is a list of Ramsar Sites which are facing change in their ecological character and require priority conservation attention. A Wetland of International Importance (Ramsar Site) can be put on the Montreux Record with the approval of the Contracting Party concerned, on the basis of information on adverse

\footnotetext{
${ }^{4}$ Article 9.2. of the Convention on Wetlands states that "Any member of the United Nations or of one of the Specialized Agencies or of the International Atomic Energy Agency or Party to the Status of the International Court of Justice may become party to this Convention" (Ramsar Convention on Wetlands, 1987b)

5 "An act by which a State signifies its agreement to be legally bound by terms of a particular treaty." (Moore, 2010, p. 2)

${ }_{7}^{6}$ Designated Wetlands of International Importance are known as Ramsar Sites

${ }^{7}$ United Nations Education, Social and Cultural Organization (UNESCO) as "the Depositary receives, reviews, and accepts the instruments of accession of each country member of the treaty, keeps the official text of the Convention in six official languages, and provides legal interpretations of the text when required. The Depositary does not have a role in the administration and/or implementation of the treaty"(Ramsar Convention Secretariat, 2013b, p. 6).
} 
change in its ecological character provided by the Contracting Party and upon request from the Ramsar National Administrative Authority (Finlayson, 1996; Ramsar Convention on Wetlands, 1996). Removal of a listed site from the Montreux Record is possible by a request from 'the Contracting Party in whose territory the site is included' that suggests that there is no longer a risk of change in the ecological character of the listed site and also after consideration of independent advice (Finlayson, 1996). The Ramsar Secretariat (Ramsar Convention Secretariat, 2013b, p. 12) asserts that joining the Convention can provide the Contracting Parties with:

access to expert advice on national and site-related problems of wetland conservation and management through contacts with Ramsar Secretariat personnel and collaborators and through application of the Ramsar Advisory Mission when appropriate.

The Secretariat of the Convention has the responsibility to 'organize Ramsar Advisory Missions at the request of Contracting Parties and contribute to follow-up of RAM reports' (Ramsar Convention Secretariat, 2013b, p. 39). The Secretariat explains that the Ramsar Advisory Mission, as a technical support mechanism, provides international expertise in giving advice and assistance on appropriate actions on issues related to ecological character change (Ramsar Convention Secretariat, 2010a, p. 11). The Secretariat (Ramsar Convention Secretariat, 2010a, p. 24) stresses that:

The expertise contributed is sometimes the decisive added value required to find a solution. On other occasions the independent authoritative "brokerage" provided through a RAM can break political deadlock and may be decisive in moving toward consensus.

\subsubsection{The Alagol, Ulmagol and Ajigol (AUA) Wetlands of International Importance}

Iran is a signatory to the Convention on Wetlands. Iran has designated 24 Ramsar

Sites including 33 wetlands (Ramsar Convention Secretariat, 2012, p. 9) of which six are 
on the Montreux Record. The Alagol, Ulmagol, and Ajigol (AUA) wetland complex, including their surrounding steppes located east of the Caspian Sea in northeast Iran was designated as a single Ramsar Site ${ }^{8}$ (Wetland of International Importance) in June 1975.

The wetlands are part of the Turkmen Sahra, home to the Turkmen in Iran (see Section 4.1). Map 1.1 shows the approximate extent of Turkmen Sahra and the AUA region. In this dissertation, the territory of Atrekians is identified as the AUA region, and it extends from Dashliburun to Sofikem. Atrekians were the Turkmen from the Atrek area whose livelihoods were dependent on the Atrek River and the steppes around it. Their territory from Inchehburun to Sofikem includes: Alagol, Ulmagol, and Ajigol wetlands, their surrounding steppes and rangelands; and its local communities. Map 1.2 shows major features of the region. Atrekians in this region were settled in four villages: Tengli, Oghi Tepe ${ }^{9}$, Daleshman ${ }^{10}$ and Inchehburun ${ }^{11}$. Tengli is chosen as the case study of this research for being close to all the three wetlands and adjacent to Ulmagol.

\footnotetext{
${ }^{8}$ The criteria for designation of these lakes as a Ramsar Site as recorded in the Ramsar Information Sheet (Ramsar Convention Secretariat, 2013a) are: Criteria 1a: Lakes Alagol, Ulmagol and Ajigol are good representative examples of natural brackish and freshwater lakes characteristic of the vast plains to the east of the Caspian Sea. Criteria 2a: The lakes provide wintering habitat for four threatened species of birds, Pelecanus crispus, Anser erythropus, Aquila heliaca and Oxyura leucocephala. Criteria 3a: The three lakes regularly support over 20,000 waterfowl in winter. Criteria 3c: The lakes support over $1 \%$ of the regional Middle East breeding population of Anas strepera, Aythya fuligula and Fulica atra.

${ }^{9}$ Persians refer to it as 'Okhi Tepe'.

${ }^{10}$ Persians refer to it as 'Daneshmand'.

${ }^{11}$ Recently, the last one has become a city.
} 


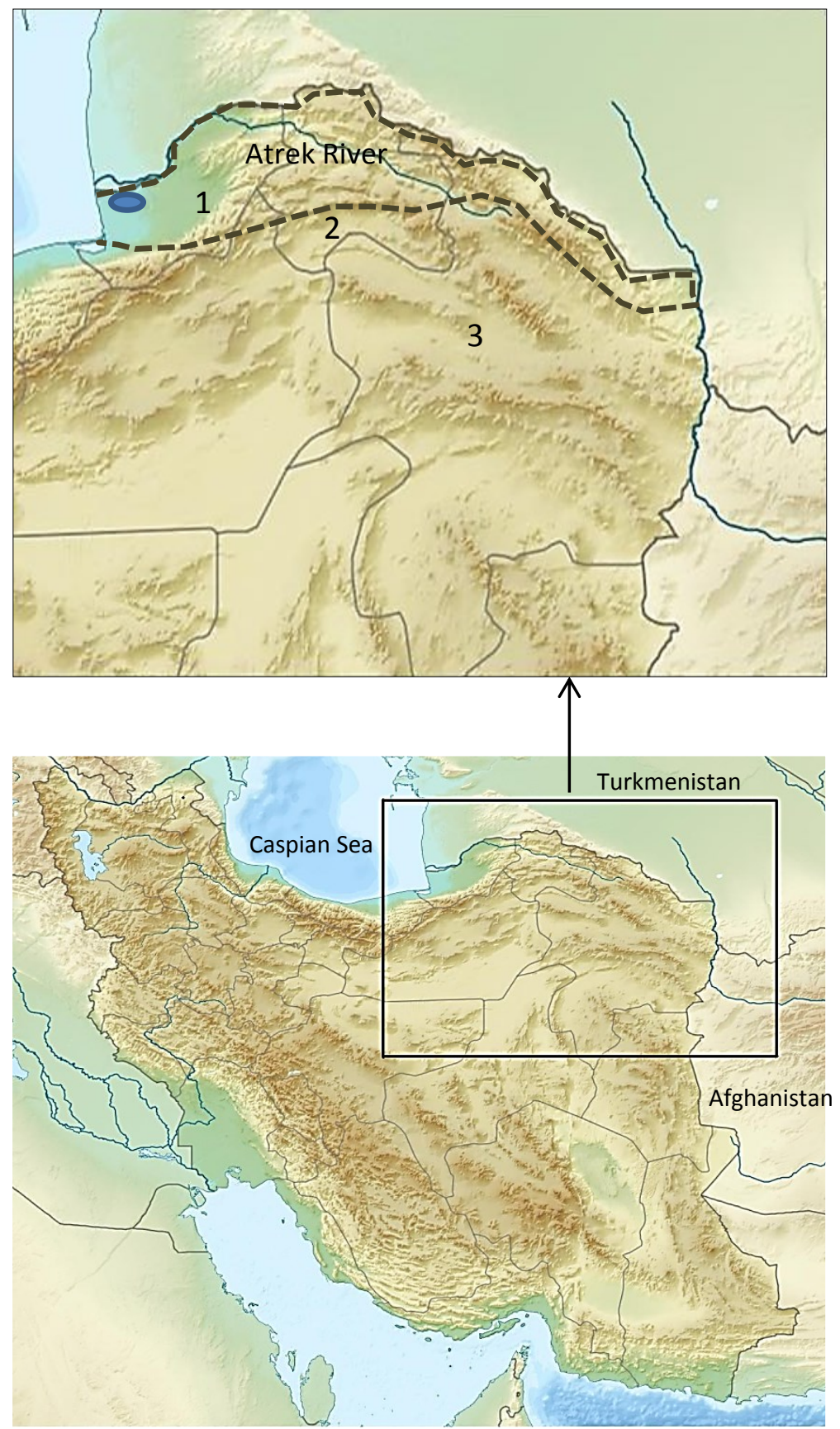

Map 1.1. Map of Iran (adapted from Dedering 2010)

The enlarged section shows:

- The AUA region (approximate)

Approximate extend of Turkmen Sahra

The Atrek River crossing three provinces:

1- Golestan 2- Khorasan Shomail 3-Khorasan Razavi 


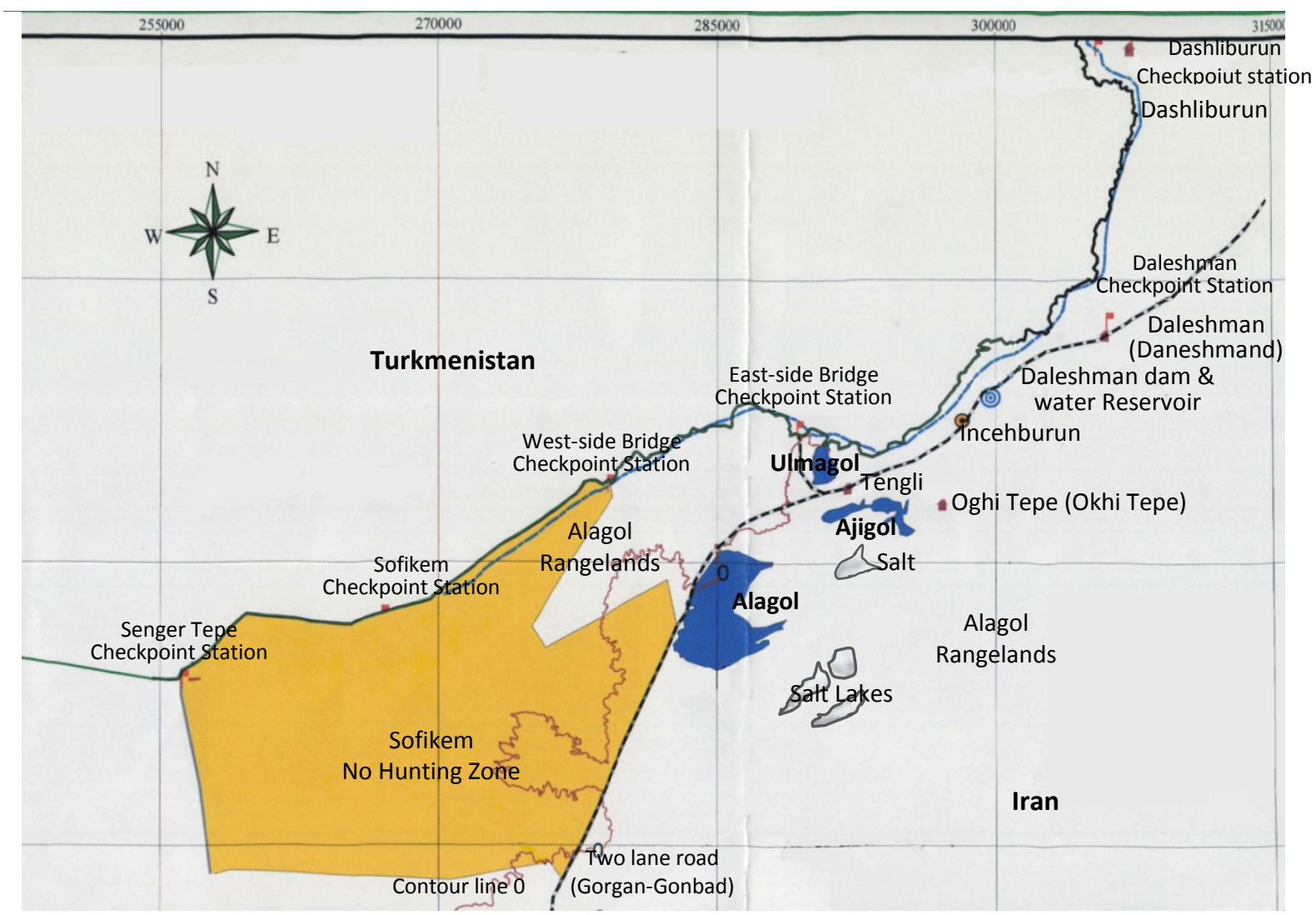

Map 1.2. The AUA region (Modified from the Advisory Mission Report, 2009 (Moser, 2009))

The Ramsar Site was listed on the Montreux Record in June 1993. When I started the field work, in October 2008, the site was still on the Montreux Record and the Government of Iran had not yet requested its removal from the list. I became aware of the official request for removal and the endorsement of the Ramsar Secretariat only after the Secretariat heralded the removal of the site from the Montreux Record and relisted it as a Ramsar Site in 2009.

The AUA was listed on the Montreux Record due to adverse changes in its ecological character. In November 2008, the Government of Iran sent a request along with a very brief report to the Ramsar Secretariat to remove the site from the Montreux Record (Department of Environment-Iran, 2008). The Ramsar Secretariat hired an 
international consultant to carry out an Advisory Mission ${ }^{12}$. The consultant visited the site from 14 to 16 May 2009, and reported to the Secretariat in July 2009. The consultant's report indicated that the documentation regarding inclusion of the site in the Montreux Record was not available (Moser, 2009, p. 3); hence, he referred to the information in the Ramsar Information Sheet (RIS), and reported that the main threats to the wetlands were recorded as 'high levels of disturbance from wildfowl hunters and the extraction of water for irrigation purposes' (Moser, 2009, p. 3). He reported that before 1993 Ulmagol and Ajigol were threatened by waterbird hunters and overharvesting and that Alagol had a lower hunting pressure but was threatened by water extraction for irrigation and a 500hectare fish hatchery, especially in summer (Moser, 2009, p. 5). The consultant in his brief report (Moser, 2009, p.1) concluded that:

The threats have both been reduced to levels which no longer threaten the ecological character of the Ramsar site. Furthermore, the water supply to the wetland (and limits to any extraction from it) has been secured and improved through an agreement with the Water Authority, including special arrangements for drought periods. There is every indication that these improvements will be sustained.

As a result he endorsed the removal of the AUA from the Montreux Record and identified a list of 'essential actions' and 'desirable actions' for the Government of Iran to implement (Moser, 2009, p. 10). Both the Secretariat and the consultant, 'warmly congratulated' the Department of Environment for what had been achieved in the AUA and for reducing the threats to the wetlands (Moser, 2009; Ramsar Convention

\footnotetext{
${ }^{12}$ The objectives of the AUA Advisory Mission are stated as (Moser, 2009, p. 4): a) "to meet with local settlers, government officials and other relevant stakeholders" to gather information on threats to lakes before inclusion in the Montreux Record, describe the actions taken by the government and other stakeholders actions to address those threats, verify the claims of the government [report to the Secretariat in 2008] indicating that the threats to the lakes have been addressed, and recommend the removal of the site from the Montreux Record if the government report is verified; b) "to visit the AUA Ramsar site to verify the statements made from meetings with the various stakeholders"; and c) to provide recommendations on further monitoring and management of the site "to maintain the ecological character of the Alagol, Ulmagol, and Ajigol Ramsar site and the livelihoods of the local stakeholders."
} 
Secretariat, 2009a). Thus, the AUA is portrayed as a success story by both the Government of Iran and the Convention's Secretariat. This thesis presents reasons to seriously question that portrayal.

\subsection{Dissertation structure and organization}

Chapter I, the introduction of the thesis, presents the context of the research, its main purpose, theoretical approach and arguments, major questions and organization of the dissertation. It also provides the background information about the working of the Convention on Wetlands and the AUA as a Montreux and Ramsar Site, which is required to understand the case study of this thesis.

Chapter II addresses the main theoretical question of this research: what are the implications of using a post-structural political ecology approach in understanding and analyzing change in Wetlands of International Importance? Discussions in this chapter, drawing on knowledge from the literature and a number of the core concepts of poststructural political ecology, offer insight into the following interlinked key topics in understanding conservation territories: socionature and nature-society hybrids; and relational and non-essentialist understanding of place, space, scale and power. Finally, it theorizes Ramsar Sites, introduces a new term, 'glocal wetlands' and an analytical framework to study people-environment interaction in those places. The questions of this research are formulated based on this theorization.

Chapter III discusses what context means in studying glocal wetlands and argues that participatory methods, particularly counter-mapping fits well with conceptual and epistemological underpinnings of glocal wetlands and is useful in understanding their complexity. It presents the methodological framework of this dissertation and its 
limitations. The empirical data of the thesis derives from two months (November and December 2008) of fieldwork, from a base in the village of Tengli which is adjacent to Ulmagol. It explains the research design, organization of the fieldwork, methodology and methods used to address the six major questions of this research (see Table 3.1). The six questions have been addressed in Chapters IV to IX, respectively:

Chapter IV fills in the map of the AUA area with its integrated, though forgotten, social and political contexts, demystifies the social construction of the AUA and describes it as socio-nature. This chapter applies political ecology's relational conceptualization of place and space and unity of human and non-humans to describe the formation of the AUA and its surrounding environment in interaction with people of Tengli. This chapter answers the question: how have people-environment interactions formed the AUA as part of the Turkmen Sahra, and how has it changed over time? This question is addressed through a historical investigation, which describes how peopleenvironment interaction is shaped the AUA landscape. Understanding the historical relationship dismantles the divide between the natural and social.

Chapter V addresses: what are contemporary people-environment interactions in the AUA region? It examines and describes the people-environment relationship, in the AUA area, through analysis of livelihood strategies of Tenglians and their trends and demonstrates the uniqueness of the place.

Chapter VI draws on relational conceptualization of power and examines the working of webs of power relations, which constitute the AUA glocal wetland and its surrounding area including the state-building processes and state's territorial approaches: access to resources; land use and management of commons; coercive sedentarization of the Turkmen, and pre- and post- revolution natural resource governing priorities including 
land, water and nature policies, processes and regulations, and spatial and development planning. This chapter addresses: how is the state's power exercised in the region, and what are territorial approaches in the Turkmen Sahra?

Chapter VII addresses: how do the state's territorial land, water and conservation approaches affect the AUA landscape and the Tenglians in pursuit of their livelihood strategies and accessing resources? This chapter demonstrates who loses and who benefits from the Islamic State's territorial policies in the AUA region.

Chapter VIII draws on relational conceptualizations of space, scale and power and examines what political alliances are formed and what power relations are in action in the AUA. It analyses power relations of the Iranian Islamic nation-state in making of the AUA region, and examines Iran's political system, administrative and governance system and ethnicity, and minority rights. This chapter answers the question: where has the control over rights been located in the Islamic State?

Chapter IX addresses: how is conservation perceived and understood in Iran? To address this question this chapter addresses the following sub-issues: what kind of conservation is the goal and how can states engage in socially-just conservation discourse and practice; how is conservation discourse in Iran codified; what power relations and alliances are involved in that network; what is the position of the AUA in the wider power geometry from global to local; how did the interests of the Islamic Republic of Iran and the advisory mission of the Secretariat of the Convention on Wetlands come into alignment behind the AUA conservation project: and how did a representation of the local environment emerge in this process?

Chapter $\mathbf{X}$, highlights the findings of this dissertation as being relevant to a wide range of natural resource and conservation policy-setting processes at different levels and 
emphasizes its contribution to theory: a) the conceptualization of Ramsar Sites as glocal wetlands, and development of an analytical framework to studying change in terms of people-environment interactions in those places by using a post-structural political ecology approach and relational thinking of place, space, scale and power, and b) elaboration of the socially-just conservation concept. 


\section{CHAPTER II- Theory}

This chapter addresses the main theoretical concern of this thesis: what are the implications of using a post-structural political ecology approach in understanding and analyzing change in Wetlands of International Importance? This chapter examines the core concepts of post-structural political ecology and offers insight into socionature and nature-society hybrids, and relational/non-essentialist understanding of place, space, scale, and power as interlinked key topics for the understanding of people-environment interaction in conservation territories. Based on these arguments this thesis conceptualizes Wetlands of International Importance as glocal wetlands and provides an analytical framework to study change in terms of people-environment interaction in those places.

\subsection{Nature and society}

'If the world exists for us as 'nature', this designates a kind of relationship, and achievement among many actors, not all of them human, not all of them organic, not all of them technological.' (Haraway, 1992, p. 297)

Our understanding of 'nature' and 'society' shapes our notions and practices of conservation and development. Notions of nature, purified or contested, lead to different questions regarding ecological degradation and biodiversity loss, thereby to different solutions in terms of conservation practices and policies. Fortress conservation and command-and-control management of commons and biodiversity Conservation discourse (discussed in Chapter IX) are deeply rooted in the separation of nature and wildlife, from society and humans; and the notion of 'nature' as a biophysical realm existing outside the social world.

Discussion on the wide spectrum of strong to moderate views on the social construction of nature will serve to clear some of the misunderstandings between 
conservationists and political ecologists. The non-essentialist view of nature rejects dualism between 'social' and 'natural', a division that can only happen 'through practices of purification' and assignment of objects to either one as separate realms (Braun, 2009, p. 27; Castree \& Braun, 1998, p. 33). Understanding Social Nature and socionature, and overcoming the dualistic view of nature and society provides an insight into issues of ecological and environmental change to (Borgerhoff, Coppolillo, \& Copolillo, 2005): a) question the role of science as the only answer to understanding environmental change; $b$ ) see the social and economic processes (and human and non-human assemblages) shaping and affecting conservation practices crossing multiple scales and levels; and c) facilitate more effective political interventions.

\subsubsection{Social Nature}

Post-structural political ecologists are well known for their endeavour for denaturalization of nature ${ }^{13}$ (Castree, 2005a, p. 27). Castree explains that denaturalization of nature, within human geography in the 1990s, had two folds (Castree, 2005a, p. 27): a) focus on both human and non-human nature and a debate that what seems to be natural is either wholly or partly social, cultural and economic or is the product of such practices; and b) no natural (or seemingly natural) phenomenon can be explained only by its assumed 'natural qualities'. During the late 1980s and into the 1990s, postmodernism ${ }^{14}$,

\footnotetext{
${ }^{13}$ Demeritt explains one objective of denaturalization is to (Demeritt, 2002, p. 769): "show that something is bad and that we would be better off if it were radiclly changed, which becomes conceivable once we realize it is socially constructed and within our power to change."

${ }^{14}$ According to Peet there is no coherent set of positions that constitute post-modern theory (Peet, 1998). He explains post-modernism is "anti-modern rather than anti-capitalist and nihilistic rather than radical". Postmodernism rejects any meta-narratives and believes that there is no Truth to be found (neither by science nor religion) (Castree, 2005a, p. 92).
} 
post-structuralism and post-colonialism ${ }^{15}$ contributed to the ideas of denaturalization of nature, deconstruction ${ }^{16}$, and the politics of representation.

Conflict between conservationists and social scientists is largely due to conservationists misunderstanding social constructionism by failing to acknowledge that it is a spectrum of thinking and not a single theory that totally denies the existence of nature. Differentiation between 'strong' social construction of nature and 'moderate' and 'heterogeneous' construction of nature might clear up some of these misunderstandings.

\section{Different readings of social construction of nature rely upon diverse epistemological}

and ontological foundations, and hence generate a spectrum from 'strong' to 'moderate' social construction thinking ${ }^{17}$. Social constructionism is not another version of classic idealism (Proctor, 2001) but some critics, particularly conservationists, argue that it opens up the way to relativism ${ }^{18}$ (Demeritt, 2001a, p. 27, 28). Soule (1995), Soule and Lease (1995), and Sokal (1996) are examples of those conservationists who have shown concern about development of the emerging relativism by social constructivism (Sokal, 1996). Their concerns are both political and theoretical. Soule and Lease (1995) associate social

\footnotetext{
${ }^{15}$ Postcolonialism is strongly based on concepts of representation and identity, which are entwined in relations of power. Edward Said used the concept of 'imaginative geographies' of Oriental culture and identity. Derek Gregory writes about 'imaginative geographies' as constructions that " fold distance into difference through a series of spatializations. They multiply partitions and enclosures that demarcate "the same" from "the other," at once constructing and calibrating a gap between the two by designating in one's mind a familiar space which is "ours" and an unfamiliar space beyond "ours" which is "theirs." (Gregory, 2004, p. 183).

${ }^{16}$ Deconstruction, a term associated with post-structuralism and coined by Jacques Derrida, "refers to any attempt to reveal the 'symptomatic silence' that lies within any given claim about what nature is, how it works, what it does and how it should be treated." (Castree, 2005a, p. 27). Deconstruction in essence is emasculating, destabilizing, and challenging dominant truth claims (Robbins, 2004). Poststructuralists argue that material reality is not differentiated from the social representation of it and language is not a mere reflection of social reality or people's perception of it but is a "constitutive" of it (Castree, 2005a; Escobar, 1996).

${ }^{17}$ Paul Robbins calls them hard and soft constructivism (Robbins, 2004, p. 113, 116).

${ }^{18}$ Ontological relativism claims that reality is determined by the observer and there is no real world/objective reality; epistemological relativism claims that truth is relative and we never know reality. Epistemologies are related to ontologies and there is no accurate separation between the two (Braun \& Wainwright, 2001).
} 
constructivism with a radical form of postmodern deconstruction that 'asserts that all we ever perceive about the world are shadows' (Soule \& Lease, 1995, p. xv) and thus denies the external existence of nature and Soule (1995) argues that this thinking feeds antienvironmental politics (Neumann, 2005, p. 48, 50). They fear that the political implications of social constructivism will lead to a situation in which there is no 'epistemologically secure foundation from which to speak truth to power' and can lead to more pollution and environmental disasters under the banner of social constructionism (Demeritt 2001a, p. 27, 28). Soule argues (Soule, 1995, p. 151, 154):

the nihilism and relativism of radically constructionist critiques of science and the materiality of nature.... is sophomoric. Further, it is harmful, because... it undermines efforts to save wilderness and biodiversity.

Soule and Sokal are against strong constructivists' view of nature, which poststructural political ecologists are also not proponents of. Strong constructivists ${ }^{19}$ perceive the real world as the product of discourse and language and deny the role of non-human actors, processes and the material world in the construction of knowledge (Robbins, 2004; Braun and Wainwright, 2001).

On the other side of the spectrum is 'moderate' social constructivism (Demeritt 2001a), argument of post-structural political ecologists. The 'moderate' side of social constructivism encompasses varied approaches to understand nature and the naturesociety dialectic but at its core discusses the process of construction of our ideas and concepts about nature and also the process of constructing nature in its reality (Demeritt 2001a). In other words, it emphases the 'dynamic and two-way relationship of mutual

\footnotetext{
${ }^{19}$ Steve Woolgar and Collins and Pinch are proponents of strong social constructionism (Demeritt, 1998, p. 178; Robbins, 2004, p. 114), what Demeritt calls neo-Kantian constructivism. Woolgar insists, (Woolgar, 1988, p. 89) "nature and reality are the by-products rather than the pre-determinants of scientific activity" and "the presumed relationship between representation and object, [claiming] that representation gives rise to the object' (Woolgar, 1988, p. 65).
} 
influence and adjustment' between nature and society (Castree, 2005a, p. 155); and a wide variety of social influences on how reality is presented (Demeritt, 2002).

A common feature across the spectrum of social constructionism is rejection of epistemological realism and any epistemological truth that holds for all time. It implies a rejection of orthodox realism and its universalistic approach. Truth is a discursive effect that is not absolute and is historically and culturally variable, however, this does not deny the materiality of the world (Braun \& Wainwright, 2001; Demeritt, 2001a; Proctor, 2001). Braun states, 'What counts as 'nature' is not separate from its representation' (Braun, 2009, p. 20). Representation might be verbal, written or visual (Castree, 2005a, p. 90). We usually confuse our interpretations and ideas about 'nature' with the things they represent ${ }^{20}$. For example, satellite imagery of a wetland (i.e. a visual representation of a wetland) is an effective resource for identifying change in extent of a wetland in a certain period of time and the findings are usually not disputable from one researcher to the other, as is the case for positivists' knowledge claims. However, the interpretations of land reclamation by local and traditional land use practices and 'illegal' aquaculture by local people for their livelihood in a Wetland of International Importance, as a practice of unsustainable use, can be contested.

Social construction of nature contributes to discarding the notion of purified nature but, in its nonessential view, the purified notion of social also needs to get discarded (Latour, 2005, p. 164). Demeritt (2001a,b) calls the mutual construction of nature,

\footnotetext{
${ }^{20}$ Castree and MacMillan explain 'representation' in geographical discourses as follow (Castree \& MacMillan, 2004, p. 471): “A set of practices wherein a putative representative....claims to depict or stand for something separate from and not reducible to either that representative or its depiction (the representation). In theoretical terms these practices can be seen as ideological (as in Marxian analysis), as hegemonic (as in several post-Marxist accounts), or as expansive discursive grids (as in certain Derridean and Foucauldian analysis)."
} 
science, and society as a 'heterogeneous construction of nature ${ }^{21}$ and identifies its two aspects as follow (Demeritt, 2001b): (1) He poses a challenge to the authority of scientific knowledge and criticizes the notion of science as a uniquely privileged vehicle to 'truth' (Demeritt 2001a, p. 329). 'Heterogeneous construction of nature' neither questions ontological existence nor refutes our knowledge of environmental problems but argues that scientific knowledge is a representation of reality and not 'the reality'. Our knowledge of the world is partial and situated and not ontologically pre-given (Demeritt, 1998, p. 181). He states that the question is not dealing with environmental problems without science, but is how to understand and live with it better. What is needed is a more reflexive understanding of science as a social practice and as contextualizing knowledge claims (Demeritt, 2001b, p. 329; Neumann, 2004). (2) Demeritt argues, the facts of nature 'emerge artifactually as the heterogeneously constructed result of contingent social practices' (Demeritt, 2001b, p. 311). These practices simultaneously include machines, institutions, and social relations. He draws on Latour and Haraway and emphasises that social includes not just 'us' but also 'other humans, non-humans, and even machines and other non-organic actors' (Demeritt, 1998, p. 181). Therefore, he looks at social actors in a web of relations, networks, and assemblages.

Further discussions on social nature lead to an array of thoughts known as 'postnatural' thinking ${ }^{22}$, which rejects the duality of nature and society and focuses on socionature (Castree, 2005a, p. 234-242). In 'post-natural' thinking, 'social' and 'natural' cannot be studied separately, and instead, 'interrelations', interactions and networks are

\footnotetext{
${ }^{21}$ The positions of 'heterogeneous construction of nature' and 'artifactual constructivism' fit into 'critical realism' within political ecology (Neumann, 2005, p. 51).

${ }^{22}$ New ecology, resilience theory, and the deliberations of Zimmerer on nature-society hybrids, the nonrepresentational approach of Nigel Thrift, the Actor-network theory (ANT) of Bruno Latour, and the postnatural ethics of Sarah Whatmore are all in the direction of post-natural thinking (Castree, 2005a, p. 223, 242).
} 
considered. Actor-network theory of Bruno Latour is a critical component of these relational thinkings.

\subsubsection{Socionature/nature-society hybrids in Actor-network theory (ANT)}

Latour argues that the false separation of nature from society and the notion of epistemological certainty is a modernism project (Latour, 1998, p. 221). Actor-network theory speaks about the uncertainty of science and politics with regard to subjects and objects $^{23}$ (Latour, 1998). Latour explains that ecology is not about nature as modernism claims, and 'nature is not inhuman and ahistorical' (Latour, 1998, p. 229) rather it is about 'endless entanglements which always involve some level of human participation' (Latour, 1998, p. 228). He believes that what political ecology offers is noble in two ways (Braun \& Castree, 1998, p. 171): a) it considers 'complicated forms of associations between beings' (Latour, 1998, p. 229) including animals, plants, habitats, institutions, regulations, management plans, technical guidelines, equipment, people etc.; and b) it creates a space for humanity (Braun \& Castree, 1998, p. 171) and poses the question of what would a human be without plants, and animals and their relations as both means and ends. He explains that the role of political ecology is not to study 'nature', 'politics', or to simultaneously study the dual arena of nature and politics, but rather should study 'the single arena of collective' (Latour, 2004, p. 29, 30). To give a new meaning to political ecology, Latour suggests what political ecology could achieve in practice it should do in theory too. In his elaboration, he explains that political ecology (Latour, 2004, p. 30):

jointly forbids both the natural order and the social order to categorize in a definitive and separate way [could in practice analyze] what counts and what does not, what is connected and what must remain detached, what is inside and what is outside.

\footnotetext{
${ }^{23}$ For example, the uncertainty in what we know about the threshold of a river and also uncertain outcomes of involved entities such as a management plan (Latour, 1998, p. 234).
} 
He adds that this is also what should be done in theory (Latour, 2004, p. 30). In doing so, it should socialize non-humans and abandon the politics of the modernity era (separation of nature and society) and step into politics of a social world as associations (Latour, 1993, p. 30; 2004, p. 37). The modernity project claims that the science of ecology deals with facts; and politics with values. This notion of double assembly (i.e. two separate assemblies of natural and social) is what threatens our public life in the modern era (Latour, 2004, p. 31). Ecologically undisputable matters of fact do not/cannot unify the world. Instead of universality, we need a 'pluriverse' and a 'composition' of its participating entities by establishing relations among all the entities that participate in the 'pluriverse' (Latour, 2011, p. 9). The practice of science is not about naturalism. Today's ecological crisis, a threat to human life support, and also the urgency of poverty alleviation, happen at the 'back of modernizers' and the notion of growth and development as 'double assembly' of nature and society, 'without attachment and entanglement' (Latour, 2011, p. 6). We need to visualize the unintended consequences of our actions when considering the complexity of ecological problems, and also the effects of time lag and space, and scale rupture (Latour, 2011, p. 9). This requires consulting with some experts, uses various techniques and instruments, creates feedback loops encompassing humans and non-humans, and builds a collective public (Latour, 2011, p. 10).

Actor-network theory, associated with Bruno Latour, Michel Callon and John Law, is an explanation about the hybrid world and 'socionature', in which social and natural are closely entwined and are 'co-constitutive within myriad networks' (Castree \& MacMillan, 2001, p. 213). Latour explains that (Latour, 2005, p. 131) '[n]etwork is a 
concept, not a thing out there. It is a tool to help describe something, not what is being described'. In an ANT approach, no entity or phenomenon exists in isolation, and therefore, cannot be studied separately. ANT sees the world as multiple connected networks, in which every network is also an actor and studies reality in its process of 'becoming' through networks, and as interactions of actors. ANT extends the temporal and spatial scale of analysis to encompass all the actors and their associations (across any 'conceptual divisions' such as local-global or cultural-natural) and recognizes that topology of networks goes beyond local (Burgess, Clark, \& Harrison, 2000). Everything in the world, human and non-human, is connected through multiple networks and every network is extended through space and time. Every member (human and non-human) of the network is tied to other entities and shapes its identity through interaction with others in multiple networks. Hybridity can be understood as (Whatmore, 2002, p. 3):

the intimate, sensible and hectic bonds through which people and plants; devices and creatures; documents and elements take and hold their shape in relation to each other in the fabric-actions of everyday life.

ANT refuses generalization and does not consider one entity responsible for construction of a network. It considers the drive towards stabilization in each network to be internal to that network and also does not count a particular process as a drive that works for every network. No two networks are the same, and therefore, the tendency of ANT research is towards detailed case studies (Burgess et al., 2000).

In post-dualist thinking, existence of an entity is a group activity of 'being-withone-another' (Braun, 2009, p. 31). This is different from pluralism, which encompasses distinct and isolated varied things (Braun, 2009, p. 31). Every entity is 'a community of singularities' which is 'constituted through what circulates between them' (Braun, 2009, p. 31). This thinking opens the path to develop processes and spaces that allow us 'to 
work through, in an agnostic manner, how this composition of common worlds should proceed' (Braun, 2009, p. 31).

\subsubsection{Association of humans and non-humans}

ANT argues against duality of nature/society; object/subject; agency/structure and calls for a symmetrical view of these divides. Latour socializes nonhumans (Latour, 1993, p. 42) and uses 'the word 'collective' to describe the association of humans and nonhumans' (Latour, 1993, p. 4). This collective association challenges the notion of autonomous agency. Actants (humans, social groups, texts, artifacts, machines, entities, etc.) are social and natural (socionatural) and do not necessarily require 'intentionality' or 'linguistic competence', however only actors are free agents and can bring other actants to the network (Castree \& MacMillan, 2001, p. 213; Castree, 2005a). In ANT, humans and non-humans are in a relational symmetry. Latour's response to those accusing the ANT approach as being an absolute symmetry between humans and non-humans is that (Latour, 2005, p. 76):

ANT is not, I repeat is not, the establishment of some absurd 'symmetry between humans and non-humans'. To be symmetric, for us, simply means not to impose a priori some spurious asymmetry among human intentional action and a material world of causal relationship.

Existence and effects of all the actants are related to everything in the network in present and past. ANT does not define actants separately; they are defined in relation and association to other actants and their position in the network, therefore, actors themselves 'define their respective identities, their mutual margins of manoeuvre, and the range of choices which are open to them' (Callon, 1986, p. 199).

The actor in ANT is not isolated, it is always regarded as being with its "large network of attachments making it act' (Latour, 2005, p. 217). That entails actors not being 
considered 'a source of initiative'. Action is what attachments make an actor do. An Actor-network exists by actors involved in many ties and the more the ties the longer it exists. What makes an actor act is not domination or enslaving but a large network of attachments. Any 'actant' has 'actency' a term aiming to explain that (Burgess et al., 2000, p. 125):

actors themselves hold identities, interests and beliefs drawn from participation in a multiplicity of networks which enable them to construe their worlds and act differently.

\subsubsection{Agency}

For Whatmore, agency is 'a relational achievement, involving the creative presence of organic beings, technological devices and discursive codes' (Whatmore, 2002, p. 26). The definition of agency redistributes it on both sides of the nature/society divide rather than as an exclusive property of humans alone. Haraway notes 'the actors are not all 'us' and expands the notion of agency to non-humans (Haraway, 1992, p. 297).

In ANT, a river is both a means and an end (Latour, 1998, p. 233). Those who try to manage nature as a modernized project consider a river as a means; however, it is both an end and a means in heterogeneous networks and 'socionature' approaches. A river can be canalized and dammed, and its gravels can be removed, but the river can take its 'revenge' by meandering again, or having a flood zone because it is 'a being in its own right with its own freedom and its own ends' (Latour, 1998, p. 233, 235, 239). In other words, in heterogeneous networks entities are simultaneously object and subject thus, entities are considered 'quasi-subjects, quasi-objects' that means they are simultaneously 
objects and subjects because they can 'receive affections from other entities' ${ }^{24}$ (Braun, 2009, p. 28).

ANT is different from other social theories in its definition of social, society, actor and agency. For Latour, agency is the capacity of an actor/actant, in terms of its collectivity and what it is composed of, to cause and affect irrespective of being a human or non-human. The singular preposition 'an' should not be misleading and obscure the notion of 'agencement ${ }^{25}$ which is behind Latour's actant. To act is not an innate property that belongs to things but an emergent effect of the ways in which entities enter into combination with others. Latour does not limit action to what 'intentional', 'meaningful' humans do. Latour explains actor or an actant as 'anything that does modify a state of affairs by making a difference,' (Emphasis is from the author) however, he does not claim that only 'humans' do things (Latour, 2005, p. 71). ANT actants have a spectrum of existence e.g. ideas, texts, chemicals, machines, organisms, processes, finances. Latour asks two questions about any agent (Latour, 2005, p. 71): 'Does it make a difference in the course of some other agent's action or not? Is there some trial that allows someone to detect this difference?'. Latour asserts that an actant can 'determine' an action, be a 'backdrop for human action', and also 'authorize, allow, afford, encourage, permit, suggest, influence, block, render possible, forbid, and so on'; it rather causes or imposes a change (for example a hammer imposes the hitting of a nail) and transforms from an object to a subject (Latour, 2005, p. 72).

\footnotetext{
${ }^{24}$ For example, a hill is an object and subject at the same time. A cyclist on a hill is affected by the resistance of the slope which reflects in the gears the cyclist uses and the pressure on her body.

${ }^{25}$ Latour has borrowed the word "actant" from the concept of 'agencement' by Deleuze and Guattari (Braun, 2009) p28. Agencement encompass two ideas of a) collectivity of things and b) the capacity of the collective to act. The act is an effect of the collective (Braun, 2009, p. 29).
} 
Symmetrical thinking of ANT may suggest a 'flat' ontology that ignores the disparity of power relations among actors. However, Latour explains that in ANT flatness is 'the default position of the observer' to be able to 'detect and register' differences and 'does not mean that the world of actors themselves has been flattened out' (Latour, 2005, p. 220). ANT suggests discarding a priori assumptions about zoom effects or macro, meso, and micro, and agency of human and non-human and instead lets the observer detect arrangements, procedures, and spaces that constitute actors with different power relations which are reflected in their capacity to cause effects (Braun, 2009, p. 29; Latour, 2005, p. 220). In other words, 'power is itself an emergent effect of heterogeneous networks, not an innate quality of autonomous bodies' (Braun 2009, p. 29) ${ }^{26}$. When members of an association act, that means 'they modify other actors through a series of trials' (Latour, 2004, p. 75). Any entity (human and non-human) that modifies other entities is an actor. It is the network that has power, agency and affect, not the individual elements in it. Such a network shapes space itself. ANT suggests that the social should be understood as associations through which 'dimensions are generated and maintained' (Latour, 2005, p. 172). The society-nature hybrid or 'socionature' is symmetrical on ecocentric and anthropocentric grounds, therefore, the hybrid politics of nature or politics of impurity consider all actants simultaneously, on a case by case basis, and do not prioritize one actor or group over the other, rather they 'highlight their ethical connectivity’ (Castree \& MacMillan, 2001, p. 220).

Understanding the dynamics of actor-networks operational logics entails relational thinking about power, scale and space, which focuses on the effectiveness of connections

\footnotetext{
${ }^{26}$ For example a bear may have less power in British Colombia's conservation than humans, but a human needs her car, binoculars and the science of conservation to have the same power (Braun 2009, p. 29) .
} 
(for example communication and operational links) between actors (Routledge, Cumbers, \& Nativel, 2007, p. 2577).

\subsection{Place, space, and scale}

'No place dominates enough to be global and no place is self-contained enough to be local.' (Latour, 2005, p. 204)

The conceptual underpinning of this thesis is a relational understanding of place, space, scale and power. I particularly draw on Massey's (1993, 1994, 1995; 1996, 1999; $2003 ; 2004 ; 2005 ; 2006 ; 2009 ; 2010)$ relational view of the making of place, space, and power relations, Agnew's $(1987 ; 1998 ; 2005 ; 2011)$ view on place and space, and power, Latour's (1986, 1998; 1999; 2004; 2005; 2011) Actor-network theory, and Swyngedouw's (1997; 2003; 2004; 2010) and Zimmerer's (2006; 2000) relational approaches to scale and power.

Post-structural political ecology research bridges across places, spaces, scales, and social groups by engaging with social relations (differentiating ethnicity, gender and socio-economic groups); examining extra-local forces (e.g. NGOs, international conventions) and local policies, processes, and structures; and exploring power relations 'among and between different social groups, resources and spaces' (Paulson et al., 2005, p. 28).

\subsubsection{Place and space}

Newtonian and Leibnizian approaches are two extremes in the theorization of location/space as opposed to place (Agnew, 2011). Agnew in his review of theoretical thinking of scale explains that the Newtonian view of space represents it as an absolute entity and a container of objects and events and that the other end of the spectrum is the Leibnizian view which considers space as relational with no power and a generalized 
location $^{27}$ (Agnew, 2011). In recent years, various theoretical approaches have tried to put space and place together and recognize space through both physical and social relations and processes (Agnew, 2011; Massey, 2005; Smith, 1984). Post-structural scholars, with their relational thinking, have tried to overcome the binary thinking of place/space.

Agnew uses three terms to describe different dimensions of place (Agnew, 1987, $\mathrm{p}$. 28): location, locale, and sense of place: (a) Location, a site in space, a geographic area, is related to other sites through interactions, movement and diffusion (Agnew, 1987, p. 28). (b) Locale is a setting, which may be considered a quality of a place (Staeheli \& Mitchell, 2009, p. 188). Social relations are constituted in 'locale' and it can be an institution, civil society or any setting in which politics is grounded (Agnew, 1987, p. 28; Staeheli \& Mitchell, 2009, p. 188). Individuals or institutions are not abstract rather they are connected to other locales through processes which go beyond a given locale. (c) Agnew explains that sense of place is the local 'structure of feeling ${ }^{28}$ (Agnew, 1987, p. 28). Sense of place can create a community, e.g. through a shared fate or ethnicity, which despite all the differences among its members makes them willing to work together and 'understanding sense of place is the core of how place shapes political processes and struggles' (Staeheli \& Mitchell, 2009, p. 190). Sense of place, identity, and 'othering' can be used in many ways in political projects that are conditioned by the power-geometries

\footnotetext{
27 'Subjectivists', who are usually Newtonian, in their understanding of space emphasize place; 'objectivists', who believe in causal forces, usually have a Leibnizian understanding of space. Place was subordinate to space in the seventeenth century and tentatively in the twentieth (Agnew, 2011). The assumption was that place associates with the past, traditional societies, and the Third World. The path to modernity and development has further devalued place. Place loses its significance to space when nationstates become the main geographic unit, and the unit of sovereign authority in the modern world (Agnew, 2011)

28 'Structure' and 'feeling' are mutually constitutive. 'Structure' refers to a set of social relations derived locally and extra-locally through ongoing social, economic and ideological practices (Staeheli \& Mitchell, 2009, p. 190). These practices are not fixed but are formed through historical residues of social relations which are not easy to shift, therefore, they are referred to as structured (Staeheli \& Mitchell, 2009, p. 190). 'Feeling' indicates how people live these practices; give meaning to a place and ultimately how those practices can be restructured (Staeheli \& Mitchell, 2009, p. 190).
} 
between networks. Massey uses the term 'global sense of place' and considers place as 'articulated moments in networks of social relations and understanding' (Cosgrove, 2000; Massey, 1993). She uses this term to engage with specificity and uniqueness of a place (or locality or region) in a more progressive way by insisting on the openness of place, and its story being many ongoing stories in a wider topography of space and powergeometries (Massey, 2005, p. 131, 196). This openness constructs a place-bounded politics (Massey, 2005, p. 192).

Massey's views on the making of place and space are the backbone of the arguments of this thesis. She argues: a) the notion of place should not be discarded but she is against the essentialization of local, which represents the authentic, natural, and primitive; and b) sense of place can be progressive and not self-closing and defensive. Massey situates places in an inclusive framework with a flow of social relations and argues that (Massey, 1994, p. 153-156): (1) Places are not static and are constituted by social interactions and processes. (2) Places cannot be described in terms of a single and coherent identity because they have heterogeneous structures and conflicts, which are volatile and not frozen in time and thus are in a constant state of becoming. Therefore, identification of a place with a coherent and homogenous community and identity, represented as flat and static, is 'misidentification'. (3) Places do not have solid boundaries for division and exclusion. Boundaries are porous and there are many interlinkages among places through porous boundaries. (4) The uniqueness and specificity of a place is in continuous reproduction and its character can be understood by 'linking that place to places beyond' or by exploring a 'global sense of place' or 'a global sense of local'. 
Massey and Agnew's explanations of place are similar to ANT in the way that they all have a relational approach to place. They see place as a setting being constituted by networks of economic, political and cultural relationships and processes and reject the grand narratives of modernity. Massey refers to these networks and relationships as power-geometries through which 'actors engage in political projects' (Staeheli \& Mitchell, 2009, p. 188). Staeheli and Mitchell explain how 'power-geometries shape the strategies of various political agents and the directions that political struggles follow' (Staeheli \& Mitchell, 2009, p. 189). In Massey's view, place is 'criss-crossing in the wider power-geometries which constitute both themselves and "the global" (Massey, 2004, p. 11). Massey's relational understanding of place clarifies that if place is 'the moments through which the global is constituted, invented, coordinated, produced then places are 'agents' in globalization' (Massey, 2004, p. 11). Massey clarifies that, within capitalist globalization, the local relation to the global varies from place to place 'through the unequal disposition of resources' (Massey, 2004, p. 13). Therefore, places are not only 'a medium through which differentiation is produced' (Massey, 2005, p. 199); rather they are active agents in the formation of both themselves and 'the global' (Massey, 2005, p. 199).

Relational construction of place and space, and the mutual constitution of global and local, give an understanding of the groundedness of the global in the local, leaving no space for arguments such as the essentialist view of place and identity as being closed and static, and the positioning of 'the local (good) against the global (bad)', or even the defense of place (Massey, 2004, p. 11). Swyngedouw with similar relational thinking, suggests the term 'glocalization', instead of globalization, to show that global and local are mutually constituted (Swyngedouw, 1997, 2004) (see Section 2.2.2.2). 
Whatmore argues that accepting the fluidity of global and local does not mean to 'ignore the potent of territorialization' but it requires that attention be paid 'to the labours of division that (re)iterate their performance and to the host of socio-material practices in which they inhere' (Whatmore, 2002, p. 6). Appadurai believes in the homogenizing effect of globalization, which he calls 'financescapes and mediascapes', and he suggests that flows of global capital and ideas go differently through dynamic networks of social, economic, technological and ecological components and result in specific and unpredictable local effects (Appadurai, 1996). Acceptance that 'space' is not as a contained and isolated physical space means that global economic, political and cultural flows are embedded in local processes and affect different places in different ways (Dalby, 1999, p. 147; Gezon \& Paulson, 2005, p. 9). In this regard, Katz writes 'not all places affected by capital's ambition are affected in the same way, and not all issues matter equally everywhere' (Katz, 2001, p. 1229). Massey believes that globalization of social relations leads to uneven development and that constitutes uniqueness (Massey, 1999). Uniqueness and particularity of a place is through its connections encompassing relations both internal and beyond and also includes elements of accumulated history of a place, which constitute linked layers of the local and the extra-local (Staeheli \& Mitchell, 2009). This uniqueness is a dimension of place, which can represent a sense of place or identification with a place (Agnew 2011). Massy explains (Massey, 2009, p. 22):

this is a notion of place where specificity (local uniqueness, a sense of place) derives not from some mythical internal roots not from a history of isolation -now to be disrupted by globalization- but precisely from the absolute particularity of the mixture of influences found together there. 
Agnew explains that collective actions and social solidarity require some sense of place but this 'need be neither totalistic, in the sense of excluding other objects of affection or identity, nor reactionary and exclusionary' (Agnew, 2011, p. 327).

Looking at place as relational, fluid and connected, as opposed to fixed, parochial and static, opens a political space for discussion on place-making by actors who are able to mobilize different kinds of resources. The politics of place can be manifested in placemaking such as territoriality, formation of conservation territories, nationalism, and resistance. Through place-making, 'political action and debate are intended to make (or remake) the place' (Staeheli \& Mitchell, 2009, p. 186) and usually entail demonstration of the importance of defining qualities of a place, which follows a political agenda. Placemaking manifests power relations performing in society at large. Through place-making, the place is defined by certain characteristics and establishes a normative vision about what this place is and should be, therefore, who belongs to this place and who does not. Place-making is a political agenda for legitimizing inclusion and exclusion, which often requires policing, regulating, and managing. Ethnic cleansing is an extreme act of placemaking (Staeheli \& Mitchell, 2009) and coercive command-and-control conservation practices are extreme acts of place-making for conservation purposes.

Massey's non-purifying notion of place, and relational thinking of space open the question of 'other' and imply that space and multiplicity are mutually constitutive (Massey, 2009, p. 17). She explains that the term 'space' encompasses simultaneity of stories (finished and unfinished) and dynamic simultaneous multiplicity of other trajectories, which means the coexistence of more than one thing, of difference, and plurality (Massey, 2003, p. 3, 2005, p. 59, 2009, p. 17). Massey argues that understanding a place and its identity requires a study of space and time together; in other words, both 
geography and history should be studied (Massey, 1995). Space is not without temporality (Massey, 2009, p. 17) and is not a sealed 'envelope of space-time' (Massey, 1995, p. 191); rather it is 'open, multiple and relational, unfinished and always becoming', therefore, a place is a 'conjunction of many histories and many spaces' and the real character of a place is not some distant past which is interrupted (Massey, 1995, p. 191). Multiplicity refers to 'the continuous production and reconfiguration of heterogenity', from physical structures to cultural practices, including any kind of diversity, difference and conflicting interests (Massey, 2005, p. 61, 198). If one accepts the relational construction of space (mutual constitution of local and global), the nonpurifying notion of place, and place as a site of negotiation then the 'hegemonic identity of place' is challenged (Massey, 2004, p. 7). Massey argues that 'place' is not an area on maps or a sealed 'envelope of space-time' (Massey, 1995, p. 191) rather it is 'constantly shifting articulations of social relations through time', and therefore, she rejects the claims about coherence, homogenous, static and a singular particular meaning of a place $\left(\right.$ Massey, 2005, p. 188) ${ }^{29}$.

\footnotetext{
${ }^{29}$ Lady Jenny Tonge, a member of the U.K. House of Lords, in a public debate about development in Botswana, referred to the Gana and Gwi people as living 'in the stone age' and then 'later explained that she used the word primitive to mean belonging to 'another age"' (Massey, 2010). Massey explains that it is this characterization of a community that is problematic, not the mode of development (primitive). There are obvious preferences, such as clean water being better than polluted water, but characterizing a community as primitive and in the queue of time to become developed is the issue of concern (Massey, 2010). A letter from Jumanda Gakelebone and Roy Sesane, of the First People of the Kalahari, reflects this concern (Massey, 2010):

"We, as the organization of Bushmen of the Central Kalahari in Botswana, are very offended by comments made by Jenny Tonge...that we are 'mesolithic', or middle stone age. She says it is not an insult. But if you call someone Stone Age or primitive, it sounds like you think they are inferior to you. As a matter of fact, we use radios and some of us have mobile phones. But that is not the point. We just want the opportunity to be allowed to choose our lifestyles. We want to go back to our land to be with our ancestors and we want to be allowed to live there in peace by hunting and gathering-not as 'exhibits in a museum', but because it is a very clever way to survive in the desert. Tonge obviously does not respect us enough to think we know how to choose what is best for ourselves."
} 
No place (nation, region, location) is a bounded territory with essential characteristics emerging out of the soil (Massey, 2006, p. 6). Therefore, places can be explained by what happens 'outside', 'within', 'among', and 'between' them through connections and networks. One important implication of this insight is the anti-essentialist vs. essentialist views of identity. Massey explains that if place is the articulation of social relations and the 'intensity, depth, and directions of connections and influences all change over time' then the identity of a place is a never-ending process of formation (Massey, 2005, p. 186).

The essentialist view of identity considers it an authentic and unalterable attribute. The anti-essentialist view emphasizes that identity and culture are products of belonging and difference, and homogeneity and hybridity rather than isolation, exclusion, and separation. Identities, having specific origins and histories, are not interrupted or tainted by hybridity, rather they are in the process of 'becoming', 'evolving' vs. 'being' and 'having'. Marston and Smith note that discussions on identity politics in the last three decades have been a 'consummate expression of the restructuring of spatial scale' (Marston \& Smith, 2001, p. 618). Every member (human and non-human) of an actornetwork is tied to other entities and shapes its identity through interaction with others in multiple networks. All place identities are effects of their relationships with others and elsewhere and involve networks of productions, constructions and performances crossing through body, household, community, regional, national and global levels (Massey, 2005; Braun, 2009). Rejecting the essentialist view of identity as fixed and pure applies to both human and non-human. Binary thinking of nature/society and place/space leads to the essentialist view of wildlife as a fixed and pure identity and invokes an assumption that wildlife can be explained in the abstract and as a fixed entity (Whatmore, 2002, p. 23). 
Whatmore explains that leopards were used in combat between gladiators and animals as 'performance of wildlife' in a network of humans and non-humans (Whatmore, 2002, p. 23). She argues 'animality of the creatures' which are engaged in 'performances of wildlife' disappears when they become 'symbolic and material units' in the human context, for example blood and death for the Roman people (Whatmore, 2002, p. 23) and biodiversity resources for conservation practices.

Resistance is part of the politics of place. Sense of place is mobile and contingent, however 'various agencies seek to fix and control place's meanings and identity' (Cosgrove, 2000). Conservation treaties and environmental movements, for different reasons, have indigenous people and issues pertinent to them in their work plans and agendas, and therefore, develop different fixed identities for them. Indigenous people's struggle to claim their rights on land and resources around conservation territories is usually structured based on a proof of authenticity and place-making. However, any claim to property rights which is based on an identity has an exclusionary dimension and follows a political goal. Local communities claiming rights to their ancestral lands is an argument that challenges power relations acting in the place and across scales. Escobar believes that the collective actions of some local community and grassroots' initiatives do not necessarily render 'essentialized identity construction' (Escobar, 1995, p. 216) rather they are flexible and sometimes 'tactical articulations arising out of the conditions and practices of daily life' (Watts, 2000b, p. 31). Escobar argues that this kind of collective action is a defense for the local which is a "prerequisite to engaging with the global....[and represents] the principal elements for the collective construction of alternatives' (Escobar, 1995, p. 226). Nevertheless he further explains that defense of a place can be a viable project if it is about 'a particular construction of place and the 
reorganization of place' (Escobar, 2001, p. 166). Even those networks of resistance to environmental projects that operate transnationally are 'born locally through activists' sense and experience of place' (Routledge et al, 2007, p. 2586). For most grassroots activists, their locality, its protection, land and environment are the reason for their mobilization (Routledge et al., 2007, p. 2588). Massey argues that the nature of agency has a key role in this understanding and explains that agency of the local should not be characterized as a 'defense' of place per se (Massey, 2004, p. 11). There are some constructions of a place, 'webs of power relations', 'the way its resources are mobilized' which are simply not defensible and, in fact, they are what need to be challenged (Massey, 2004, p. 12).

With this relational thinking, defense of a place does not entail persistent defense of 'local' without regard to social relations and its place in the web of power geometry to which it is connected. If construction of space and place are relational and 'the local is implicated in the production of global' (Massey, 2004, p. 11; 2005, p. 102) then 'places are criss-crossings in the wider power-geometries which constitute both themselves and the global' (Massey, 2004, p. 11). Therefore, any challenge of globalization means also challenging construction of certain local places, their role, arrangements and power relations (Massey, 2005). This highlights the local responsibility in the formation and becoming of space, and therefore, dilutes the persistent notion of 'power over' and resistance. She concludes that accepting the politics of connectivity means that globalization varies from place to place, so place strategy should not always be revolved around 'defense' but rather it can be about collaboration and co-constitution of relations of power (Massey, 2005; Massey, 2004, p. 17). These arguments highlight local responsibility in the formation and becoming of 'space'. Also, overcoming the binary 
thinking of space/place leads to questioning the relationships of space/place assemblages and scale.

\subsubsection{Scale and space}

Overcoming the binary thinking of space/place leads us to assemblages of relations across scales. Production of scale is implicated in the production of space Marston and Smith suggest that 'scaled social processes pupate specific production of space while the production of space generates distinct structures of geographical scale' (Marston \& Smith, 2001, p. 616). Scale is the means by which spatiotemporal differences are produced and by which any kind of change (ecological or socio-economic) becomes political (Haripriya \& Kull, 2009, p. 35, 36; Paasi, 2004). Theorization of scale has direct implications for political ecology (Paasi, 2004).

Swyngedouw in his review of the theorization of scale, explains that before the 1980s scale was used either for measurement of size and distance or to refer to an absolute space which is given and fixed (Swyngedouw, 2010, p. 7). An absolute and fixed spatial scale was an attribute of absolute and fixed space (Meentemeyer, 1989, p. 164) ${ }^{30}$, The fixed and closed space was conceptualized as 'a static slice through time' which was 'the representative of history/life/the real world' (Massey, 2005, p. 30, 59). Geographical scales were considered 'independent of any matter' and the containers of non-scale processes. In the last three decades, political economists have engaged with scale trying to explain globalization and its relevant socio-spatial transformations, internationalization of production, state restructuring, and global environmental issues (Brown \& Purcell, 2005, p. 606; Swyngedouw, 2010, p. 8). Peter Taylor theorizes scale and considers the

\footnotetext{
${ }^{30}$ For example neighbourhoods, cities, regions, and states were considered fixed and given or at the best would be considered as having slow changes in time.
} 
higher scale i.e. global has priority over lower ones and also has more power (Taylor, 1982, p. 22). He understands the world as a configuration of independent and interdependent scales, with given and fixed geographical formations, like global, state and region (Swyngedouw, 2010, p. 7), reinforcing top-down hierarchial relations (Sayre, 2009, p. 103). Neil Smith (1984), building on Henri Lefebvre and David Harvey, criticizes geography for taking 'localities, regions, nations and so forth' for granted and just as a methodological preference (Sayre, 2009, p. 103). Smith argues against a given and fixed scale and explains scale in terms of processes and dynamic relations ${ }^{31}$ (Swyngedouw, 2010, p. 7).

Theoretical stances on scale have serious implications for the perception of political and economic life, and therefore, for political ecology research. Neumann argues that political ecologists need to theorize scale and incorporate the theoretical insights of the politics of scale into their research agenda and study 'scalar practices of social actors', otherwise they will be caught up in local and other scalar traps ${ }^{32}$ (Neumann, 2009, p. 404). Not all political ecologists theorize scale as a social construct and consequently they are led into the local trap assumptions and hide the fact that "political economy, culture and ecology all exist and operate simultaneously at a range of scale' (Brown \& Purcell, 2005, p. 612). The structuralist political-economy approach to scale is criticized because political ecology studies in the early 1980s were dominated by the notion of 'chain of explanation', that seeks to explain the local through the uni-directional effects of national

\footnotetext{
${ }^{31}$ Since then, literature on scale has emerged with varied propensities including (Swyngedouw \&Heyden, 2003): social construction of scale and its contestation; social, political and economic scales of organizations and regulations and their making and remaking; horizontal and vertical sociospatial relations in networks; environmental governance and political ecology; and state territoriality and sovereignty.

${ }^{32}$ Recently, geographers and political ecologists have paid more attention to the perspectives that political economy provides by trying to theorize scale and deal with the politics of scale. Scale in political ecology is not theorized and even citation on the politics of scale in political economy literature rarely has a central role in political ecology research (Brown \& Purcell, 2005, p. 611).
} 
and global scales and a tendency towards 'essentialized local-scale arrangements' (Neumann, 2009, p. 403). Swyngedouw and Zimmerer have important input into conceptualization of scale in political ecology and their approaches to scale are influenced by a turn in political ecology towards post-structural perspectives in the 1990s (Brown \& Purcell, 2005, p. 611, 612).

Post-structural political ecologists accept scales as being socially constructed and relational, and therefore, contingent and contested. They incorporate this perception into an existing framework which has power relations and a 'dialectical approach towards nature-society relations' as its kernel (Neuman, 2009, p. 404). Post-structural political ecologists have gone beyond local, regional, national, and global scaling schemes, that entailed considering the spatiality of social life and social processes, which creates certain conditions of resource access, use, and management that changes under changing conditions. The aim is not to find a linear cause and effect relationship but to study the network of actors and processes (Paulson et al., 2005; Zimmerer, 2000). Society-nature interactions and conservation practices consist of many simultaneous processes, and therefore, have different sorts of 'scaling or spatial manifestation'.

Implications of introducing this notion into empirical research require the studying and coupling of ecological processes with political-economic processes, such as governance and natural resources management (Sayre, 2009, p. 103). Swyngedouw's concept of scale is built on a combination of political-economy theorization of scale, social production of nature and network and assemblages, which he views as being compatible and overlapping (Neuman, 2009, p. 402; Swyngedouw, 2003, p. 904). In his view, spatial scales are contested and heterogeneous and are constantly restructuring in terms of their content, interrelations, and importance; in other words, spatial scalar 
arrangements and levels are the result and product of many related processes ranging from local to global (Cox, 1997). Prioritizing scale as a starting point of analysis is misleading and instead what is required is understanding process (Cox, 1997).

The above approach to scale will be discussed through three interlinked and overlapping arguments about scale: socially constructed; relational; and process-based.

\subsubsection{Socially constructed and always fluid}

Production of scale and space are interrelated (Marston \& Smith, 2001; Marston, 2000). Everyday life is a production of space(s) and temporal-social-relations. In political ecology, analytical centering of reified scales, such as the national, results in an inability to integrate general patterns of interconnections with various kinds of data, such as ethnographic and ecosystemic data (Engel-Di Mauro, 2009, p. 117), and the local trap becomes manifested in approaches that lead to the 'tragedy of the commons'. Instead of prioritizing global over local or vice versa, the core to studying scaled spaces involves the politics of scale (Brenner, 2001, p. 599).

Theorizing scale as a social construct helps us to escape the local trap and the assumption that certain scales can be inherently tied to particular processes and end results. Scales, global to local, are not absolute, finished and self-sufficient geographical categories, containers, or objects in interaction. The difference between local and global is that longer networks reach further than shorter ones. The anti-essentialist position on scale indicates that there is nothing inherent about scale and that the local, national and global have no a priori given characteristics. Geographical scales are produced through economic, political and social processes, actions and relations so they are changeable (Marston, 2000). Scale is not an ontologically given category of analysis but is 
constructed by social actors through geographical structures of social interaction, political struggle and power geometries (Brown \& Rurcell, 2005, p. 609). If we accept that scale is socially produced through political struggle then there can never be anything inherent about any particular scale (Brown \& Rurcell, 2005, p. 613, 614) and scale can be considered as a point of observation without having an ontological attribute or claim (Sayre, 2009, p. 104).

Swyngedouw renders scale as both territorial and network based which overcomes the tensions between fixed/non-fixed space (Swyngedouw, 2004, p. 33). He argues that scalar arrangements are being made and remade and fluidity is total (Swyngedouw, 2010). Swyngedouw suggests that there is a simultaneous, nested 'yet partially hierarchical relationship between territorial scales, while networked scales can relationally stretch or contract' (Swyngedouw, 2004, p. 33, 34). Brown and Purcell explain that scales and scalar arrangements are perpetually shifting, fluid and procedural and also can be 'routinized into relatively enduring and hegemonic structures for certain period of times' (Brown \& Rurcell, 2005, p. 610). He emphasises that scales do not have inherent or eternal characteristics but in certain periods of time some features can be temporarily (not inherently) associated with specific scales and demonstrate particular social processes and characteristics (Brown \& Purcell, 2005). For example, dominant national-scale sovereignty can become hegemonic for a time and have real and important effects on the exercise of power, however it is expected to be challenged and eventually overcome or modified by other projects that imagine sovereignty at other scales (Brown \& Purcell, 2005). 


\subsubsection{Relational and nested}

In the literature on 'scale, 33 , the term is used to refer to size, level and relation and it is necessary to distinguish among these three facets to prevent confusion. Scale as size implies that space and time are not scales until they are broken into parts that can be measured (Sayre, 2005, p. 281) and compared, after which, spatial and temporal relations among things can be studied.

Using spatial 'scale' in reference to size (bigger or smaller in size) and level (more or less complex) instead of relation (links, flows and processes) inflicts the risk of reducing it to a set of given labels (such as local and global) which show and say nothing but are a priori assumptions about size and complexity in the abstract and hide the processes and relations shaping the world (Howitt, 2008, p. 151; Sayre, 2009).

Sayre notes that in 'almost all' literatures on scale the term (scale) is used as both 'level' (where scale and level are interchangeable) and 'relation' (where scale and level are not interchangeable) without considering the controversy it may cause (Sayre, 2009, p. 104). He insists that level and scale should not be confused. However, level and relation, the two epistemological and ontological moments of scale ${ }^{34}$, are in dialectical relation (Sayre, 2009, p. 104). Scale, indicating level, has ordering and hierarchy. For example, households and cities are levels of social organizations, not scales per se. Scales are fluid, and produced by 'human-social, geophysical or biological processes' (Sayre, 2005, p. 105) and exist only as relations 'either between levels or among components of

\footnotetext{
${ }^{33}$ Gibson et al. define scale as (Gibson, Ostrom, \& Ahn, 2000, p. 219): "the spatial, temporal, quantitative, or analytical dimensions used to measure and study phenomena" and levels refer to "units of analysis that are located at the same position on a scale", which may or may not be hierarchial.

${ }^{34}$ Sayre explains ontological moment of scale can be explained as operational scale which refers to "the idea that phenomena occur at determinate spatial (and temporal) scales in the real world: that scale is an actual material property of processes, not simply a matter of how they are observed', which is observational scale (Sayre, 2009, p. 98). Therefor scales have an ontological moment 'insofar as they are integral to the constitution of material processes; they have an epistemological moment, insofar as one's scale of observation determines the patterns (or lack thereof) that one observes' (Sayre, 2009, p. 104).
} 
the system' (Sayre, 2005, p. 284). The problem is that when scale as 'level' and scale as 'relation' are not distinguished, assumptions and confusion relating to scale become inherent attributes of scale (Sayre, 2005, p. 28, 2009, p. 104).

Particular social or ecological scales do not have any given political or theoretical priority; what is important is the dynamics of social and environmental scale production (Neumann, 2009, p. 4; Swyngedouw \& Heynen, 2003; Swyngedouw, 2010, p. 9). Swyngedouw explains (Swyngedouw, 2010, p. 9):

socioecological processes give rise to scalar forms of organization- such as states, local governments, interstate arrangements and the like - and to a nested set of related and interacting soioecological spatial scales.

Swyngedouw argues that scales are intertwined, operate simultaneously (not hierarchically), and the relationships between them are nested (Swyngedouw, 1997, p. 138; 2010). He adds 'as power geometries shift so do scale configurations in terms of nesting and spatial extent' (Swyngedouw, 1997, p. 142). Some aspects of scale are hierarchical ${ }^{35}$. Many scales contain levels that are ordered either hierarchically or have other kinds of ordering, however not all levels are linked to one another in a hierarchical manner (Biermann et al., 2010; Cash et al., 2006; Sayre, 2009, p. 105). Brenner argues that social processes create 'uneven scalar geometries' which are superimposed and interlayered and do not produce 'an absolute pyramid of neatly interlocking scales' (Brenner, 2001, p. 606); therefore, hierarchical relations among levels do not exist like some 'grand chain of command' (Sayre, 2005, p. 285).

\footnotetext{
${ }^{35}$ Examples of lower levels as part of more inclusive higher levels along a scale are: spatial scale (when the term is used to address level) includes patches, landscape, region, globe or neighborhood, village, municipal, regional, national and global; jurisdictional/administrative scale includes municipality, provincial, national, intergovernmental, global; institutional scale includes constitutions, laws and regulations, and operating rules; and temporal scale includes a range of slow to fast rates, durations and frequencies such as daily, seasonal, and annual or includes present, past, and future.
} 
Marginalized groups challenge entrenched structure of scale to turn the balance of power to their advantage. The present structure is not given or eternal, but is nevertheless real, and it favors certain groups over others. Scales may go through stretching or contracting (shrinking) processes (e.g. changing boundaries of states) and also relationships between scales may change (e.g. local institutions performing at national level), which can be defined as 'scale jumping' (Marston \& Smith, 2001). Sayre argues the operational scales of governance and regulation can be shifted and this shift happens between levels (Sayre, 2005, p. 285). Social actors, people, and organizations can contest and transform levels at which some processes occur (e.g. decision-making, production, regulation and accumulation) to achieve their goal (Sayre, 2005 p. 285; 2009, p.104). Social production of scale and relationships among scales are part of the same process. In analyzing political ecology, or any political agenda, both scale and scalar arrangements i.e. relations among scales need to be studied (Neumann, 2009, p. 400) in order to highlight the hegemony in those arrangements and shed light on the political struggles that shape the scalar interrelationships (Brown \& Purcell, 2005, p. 610-612). How the relationships among scales are continually socially produced, dismantled, and reproduced through political struggle must be examined. In this examination, scales and scalar relationships are always seen as the outcome of particular political projects, which requires analysis of the agendas of those political interests involved (Brown \& Purcell, 2005, p. 611; Silver, 2008).

Conceptualization of scalar hierarchies does not strip localities of agency (Marston, 2000; Neumann, 2009, p. 400). Global and local need to be seen as components and facets of the same set of social and ecological processes because 'local scales are always embedded in and part of the global scales, and the global scale is constituted by 
the various local scales' (Brown \& Purcell, 2005, p. 612). Latour asked if a railway is global or local (Latour, 1993, p. 117) and he answered neither (Massey, 2004, p. 8). In one sense, a railway is global, going from A to B, but it is also local in terms of stations, workers and points (Massey, 2004, p. 8). A railway cannot be global if it is not grounded and emplaced in the local. In Latour's words: 'The words 'local' and 'global' offer points of view on networks that by nature are neither local nor global but are more or less long and more or less connected' (Latour, 1993, p. 122).

Swyngedouw suggests using the term 'glocalisation' instead of globalization (Swyngedouw, 1997). Glocalization considers global and local mutually constituted and focuses on scale as relation, 'captures the combination of upward and downward shifts in the scale of accumulation and regulation' (Sayre, 2009, p. 102), and also highlights change and transformation of the geometry of social power. Massey clarifies that 'global' and 'local' are still meaningful and useful terms but should not be used as binary opposites; they should be thought of as mutually constituted ("Doreen Massey on Space [Interview with Doreen Massey, 2013, February 1],” 2013).

\subsubsection{Process-based}

ANT suggests that whatever space and scale we encounter needs to be understood as a 'sociomaterial product' and an achievement of actors (Blok, 2010, p. 898). Climate change (environmental change) is a 'hybrid' social reality encompassing relational social processes and 'long chains of translation between human and nonhuman entities' (Blok, 2010, p. 898). However, conservation scientists often take the 'global' of global environmental change as unproblematic. 
ANT has 'relational-scalar' analytics (Blok, 2010, p. 897). Actor-networks are 'neither local nor global' (Latour, 1993, p. 122). Law studied the issue of global as size or scale and argued that 'the global is situated, specific, and materially constructed in the practices which make each specificity' (Law, 2004, p. 24). In other words there are many situated 'globalities' which can 'be made bigger or smaller at this site or that' and all can be specific to each location (Law, 2004, p. 24). He concludes that (Law, 2004, p. 24):

There is no system, global order, or network. These are at best partially enacted romantic aspirations. Instead there are local complexities and local globalities, and the relations between them are uncertain.

Latour in his book 'Reassembling the Social' explains that our tendency is to think of scale as a well-ordered zoom of macro, meso, micro when placing things into their context in social realm (Latour, 2005). He notes that 'size and zoom should not be confused with connectedness' (Latour, 2005, p. 187). Latour argues scale is the actor's achievement and it is not the social scientists' 'business' to label any interaction with 'micro', 'middle-range' or 'macro' and develop a fixed standard for scale (Latour, 2005, p. 184, 185). He explains that (Latour, 2005, p. 185):

if there is one thing you cannot do in the actor's stead it is to decide where they stand on a scale going from small to big, because at every turn of their many attempts at justifying their behavior they may suddenly mobilize the whole of humanity, France, capitalism, and reason while, a minute later, they might settle for a local compromise. Faced with such sudden shifts in scale, the only possible solution for the analyst is to take the shifting itself as her data and to see through which practical means 'absolute measure' is made to spread.

Latour argues that ANT does not claim that interaction, which happens at the local level and in a framework of global context, does not exist (Latour, 2005, p. 170, 172) instead he suggests we need to follow actors to connect the sites as part of associations with 'many ingredients already in place that come from other times, other spaces and other agents' (Latour, 2005, p. 171), without stopping at the limits of local and global, 
interactions and context, which some sociologists assume as given (Latour, 2005, p. 171). These continuous connections from one to another do not encompass only human-tohuman or object-to-object connections rather those connections are in a zigzag manner. Rather than theoretical or empirical prioritizing of one spatial scalar regime to another in shaping our lives, we need to identify how scales are intertwined and what processes are involved. Scale does not stand for fixed relationships between processes; rather it is a 'relationship [that is] continuously being defined, contested, and reconstructed based on power relations between actors across many political and economic levels' (Silver, 2008, p. 925).

Zimmerer (2000) in his study of irrigation in highland South America, escaped the local trap not through the theory of scale but by empirical investigation of the involved processes. A process-based approach to scale recommends 'procedural analyses of scale politics' (A. Moore, 2008, p. 214), and shifts our orientation toward 'scalar dimensions of practice, rather than practices occurring at different scales' (Mansfield, 2005, p. 468). The process-based approach to scale will be further elaborated under three headings: a) regulation and organization of social power relations- scaled networks; b) political strategy- categories of practice and analysis; and c) socio-ecological processes and scaling- scale mismatch.

\section{a) Regulation and organization of social power relations - scaled networks}

Swyngedouw explains that '[scale] embodies a temporal compromise, solidifies existing power relationships, regulates forms of cooperation, and defines competitive and other power strategies' (Swyngedouw, 1997, p. 147). In other words scaled spaces are entangled processes of negotiation, contestation, compromise, conflict, domination, 
marginalization, transformation, change and becoming. Haripriya and Kull explain that (Haripriya \& Kull, 2009, p. 36):

Scale is produced by combining space, time, and power into different forms, functions, measures, symbol, and sensibilities and is used to articulate relations, controls, and representations of social and biophysical landscapes.

Sociospatial processes and changes in the geometry of social power give importance to a geographical scale, driven along gender, class, ethnic or ecological line (Swyngedouw, 2004, p. 42). Global, local or any other 'scale levels' are the results of processes of sociospatial change, and social struggle for power and control (Swyngedouw, 1997, p. 140). Therefore, spatial scale, both discursively and materially, is contested, negotiated and reproduced 'in terms of their extent, content, relative importance and interrelations' (Swyngedouw, 1997, p. 140).

Spatiotemporal organization of ecological networks at scales that are labeled as 'landscapes', 'ecosystems', or other collective entities cannot automatically be assumed to be appropriate for a particular study, rather the scale of study depends on the "nature of specific objects and interaction processes that are of interest' and includes both vertical and horizontal scalar processes (Berkes, 2004, p. 626, 2007; Zimmerer \& Bassett, 2003b, p. 289; Zimmerer, 2000b). Horizontal interplay involves interactions occurring at the same level of social organizations and vertical interplay is the result of interactions between different levels of social organizations (van Lieshout, Dewulf, Aarts, \& Termeer, 2011). Examples of vertical processes are hierarchical forms of resource management and control, and decision-making (from global to local or from leaders to marginalized groups); and horizontal processes are connections across levels of organization, sectoral interest groups, ministries, and communities in different parts of the country (Zimmerer \& Bassett, 2003b, p. 289). 
Rocheleau explains that polycentric governance structures are 'a point of departure to visualize multiple actors as simultaneous centers of power, influence, and action, rather than single structures, central actors, and simple linear hierarchies' (Rocheleau, 2011, p. 216). Therefore, power works in forms of 'from above and below, including power with, power alongside, and power in spite of' rather than only power over (to control) and against (to resist) (Rocheleau, 2011, p. 222). However, we cannot assume, a priori, that localization of decision-making will lead to socially- and ecologically-just outcomes (Brown \& Purcell, 2005, p. 614). In this regard Brown and Purcell state that (Brown \& Purcell, 2005, p. 614):

the social and ecological outcomes of any particular scalar arrangement are the result of the political strategies of particular actors, not the inherent qualities of particular scales.

Empowerment of local people and greater local control means that they will use their power towards their own agenda in their particular circumstances and does not mean that it will always lead to greater ecological sustainability or justice (Brown \& Purcell, 2005, p. 619; Schroeder, 2000). Multi-level governance and local access to resources may not be sufficient, or a guarantee, for equality because they may still allow unequal access to resources which can undermine agency and redistribution of resources (Moncrieffe, 2011, p. 78). This process is related to power relations and the use of authoritative resources' (see Section 2.3.3). 


\section{b) Political strategy- categories of practice and analysis}

In the social sciences, many terms operate as both categories of practice and analysis $^{36}$; examples include scale, nation, identity, place, and class. Moore suggests that reifying scales and utilizing them as categories of analysis is problematic and argues that 'scalar narratives, classifications and cognitive schemes constrain or enable certain ways of seeing, thinking and acting' (A. Moore, 2008, p. 219). Instead of adopting reified scales as categories of analysis, research needs to be directed towards practical aspects of scale which highlight flows and processes (A. Moore, 2008). Doing so will prevent 'dubious epistemological assumptions about scale politics and pay more attention to scalar practices and sociospatial locations of social actors' (Brown \& Purcell, 2005, p. 221). By dividing and ordering politics and political projects are inherently geographical and scalar (A. Moore, 2008). As Moore explains (A. Moore, 2008, p. 218):

actors use scale categories not just to interpret spatial politics, but to frame and define, and thereby constitute and organize, social life: to 'shape a particular mental map or worldview that is persuasive and politically powerful'.

Therefore, scalar representation and practices are part of a strategic deployment of geographical knowledge related to power and political struggles (Brown \& Purcell, 2005; A. Moore, 2008, p. 218). Moore notes that, especially in political-economic tradition, scale is used as a substantial category of analysis and is the central spatial 'units' through which the world 'hangs together' (A. Moore, 2008, p. 209). He argues this approach is a commitment to 'an ontology of spatial politics' that rests upon reified scales with given and a priori assumptions about scale (A. Moore, 2008, p. 209). Utilizing scales as

\footnotetext{
${ }^{36}$ Scale as categories of practice is defined as 'categories of everyday experience, developed and deployed by ordinary social actors', and as categories of analysis is defined as 'experience-distant categories used by social scientists' (A. Moore, 2008, p. 207).
} 
analytical categories deviates attention from the various social actors and practices involved in scale politics.

Brubaker suggests that a way of escaping the trap of scale reification is by shifting our focus from scale as a category of analysis to scale as practices and processes (Brubaker, 1996). For example, we can study nationalist practices, nationhood, and the process of nationalization without assuming that nation, with fixed and given characteristics, as a category of analysis exists. By shifting our focus to practices and processes rather than concrete things and 'units' we are opening a space for studying the consequences and effects of these processes on wider social, political, economic and cultural relations (A. Moore, 2008, p. 213). In line with this thinking, Agnew argues that a 'state' does not have inherent and eternal national characters. He suggests that state is socially produced as national, and territorial state sovereignty is constructed through motivations and strategies of actors at different scales such as city, continent and globe in a particular historical era (Brown \& Purcell, 2005, p. 609).

Moore gives an example of the reifying of scales and utilizing them as starting points of analysis being problematic (A. Moore, 2008). Considering that scale and identity are closely linked both in practice and analysis (A. Moore, 2008, p. 207), Moore explains that the violence in Bosnia (1989-1994), if explained by clashes of reified ethnic identities as a local scale of analysis, has a few downsides (A. Moore, 2008, p. 211): (1) Place, space and ethnicity can never be defined in the abstract and an essentialist view of ethnic identity entails homogeneity and assumedly known and taken for granted characteristics. (2) Focusing on the ethnic basis of conflict deviates attention from broader social interactions involved in the problem. Closer examination of the situation in Bosnia showed that escalating violence on many instances was related to conflicts and 
fights among criminal networks. (3) There were political actors and organizations involved in creating conflict and framed it as ethnic. Moore argues that (A. Moore, 2008, p. 211):

it is precisely the ethnic reifying practice of these actors and organizations that should be the focal point of our research, not the political fiction of ethnic groups that they invoke and attempt to crystallize as seemingly 'real' in order to further certain political projects.

Agnew adds another perspective to these scalar analyses. He argues that the course of conflict was critically influenced and shaped by external connections beyond the local and that what appears to be local distribution of power and economic benefits of the local groups: Serbs, Croats, Bosnian Muslims and others (Agnew, 1998, p. 3). The German and U.S. governments, with different globally defined interests ${ }^{37}$, were allied to different parts of the conflict and these 'powerful external actors contributed to the conflict, even though each was rhetorically devoted to resolving it' (Agnew, 1998, p. 4).

\section{c) Socio-ecological processes and scale mismatch}

Scale is important in cross-disciplinary research on the governance of socialecological systems because conservation and sustainability issues in the context of a globalizing world, cut across traditional jurisdictions and scopes of organizations, and stretch across local to global scale levels.

Understanding the global-local intersecting scales of analysis means that local ecological problems need to be explored through rural spaces and also through spaces that affect the rural condition but are not in proximity of local spaces, such as international policy setting institutions, national legislatures, corporations, and media. Human-

\footnotetext{
${ }^{37}$ The US political and military priority was to maintain the territorial integrity of the country as a buffer state between the Soviet Union and the west. The German government had a different stance and encouraged the political independence of Slovenia, Croatia, and Bosnia because of investment and trade potentials (Agnew, 1998, p. 4).
} 
environmental relationships must be examined at 'multiple scales', across scales', and 'among scales'. What happens in local places is affected by human-environmental factors at different scales and is connected to wider power relations.

Definition and explanation of the interaction of social and nonhuman systems entails understanding the scale of interaction and the scale of environmental and social processes (Engel-Di Mauro, 2009, p. 117). The spatial scales are produced through ecological means, and never solely through social processes and discourses. Neumann in his article on regional scale, argues that the reproduction and transformation of society, space and nature are simultaneous processes 'within prevailing relations of power' (Neumann, 2010). Zimmerer and Basset argue that fusing bio-geographical processes with social ones at different scales is the focus of political ecology (Zimmerer \& Basset 2003a, p. 18). The challenge is to 'integrate socially produced scales with those produced through ecological or biophysical processes' (Neumann, 2009, p. 403; Rocheleau, 2008, p. 720), and calls for attention to ecological processes in the examination of scale and scalar politics (Neumann, 2009; Zimmerer \& Bassett, 2003a). Swyngedouw argues that (Swyngedouw, 2010, p. 9):

the ongoing and continual processes of societal and material arrangement recreating themselves, spatially and temporally, are always already a result, an outcome of the perpetual movement of the flux of socio-spatial and environmental dynamics.

He concludes that there is no theoretical or political priority in particular social or ecological scales. What is important is the 'socio-ecological process through which particular social and environmental scales become constituted and subsequently reconstituted' (Swyngedouw, 2010, p. 9). Swyngedouw notes that 'ecological scales are transformed as and when the socio-ecological transformation of nature takes new or 
different forms' (Swyngedouw, 2010, p. 13). For example, multi-scalar configurations of monoculture cash-cropping agriculture are fundamentally different from less extended scales of peasant subsistence farming.

Swyngedouw believes that concepts of scale build on political-economic theorization of scale and also on the social production of nature and networks and assemblages, which he views as compatible and overlapping (Neumann, 2009, p. 402). He notes "production of nature" is an integral part of a process of "producing scale"" (Neumann, 2005, p.10), therefore, socionature is a process of co-production of nature and society ${ }^{38}$. Socionature is a term that captures the dialectical character of social and ecological change in scale production and is meant to incorporate the social and ecological, material and symbolic, and spatial and temporal dynamics' (Neumann, 2009, p. 403). Neumann explains that this multi-scalar focus reflects, in some works, a focus on the role of ecological scaling in shaping social and economic dynamics, and in other works, a mutual reconstitution of nature and society and hybridity (Neumann, 2009, p. 403).

Sayre notes that 'scale is inherent in observation' and changing the resolution of one's analytical lens can lead to significantly different questions and results (Sayre, 2005, p. 281). Therefore, 'determining the relevant processes involved and their operational scales' are crucial questions in both research and management. Scale in ecological research is understood from the observer's eye. Observers 'define the spatial (and temporal) scale at which his or her research will be cast.' (A. Moore, 2008, p. 206). The

\footnotetext{
${ }^{38}$ For example, Swyngedouw and Heyden explain that the 'socioecological footprint of the city' is a complex 'intermingling of the social and the natural' and an outcome of the 'urban form of social organization’ (Swyngedouw \& Heynen, 2003).
} 
scale at which a problem is defined and the scale at which it should be solved are challenging. Sneddon suggests that (Sneddon, 2003, p. 2235):

[a] similar moment occurs with ANT methodologies when analysts must cleave off the 'ends' of networks, or decide in the first instance which particular network to follow and why.

Conservation based on a binary understanding of nature/society justifies demarcation of social and physical components of scale, and inhibits an incisive investigation of environmental conflicts. Management plans for conservation territories or river basins cannot be done around scales with measurable material qualities without giving due attention to the cultural, 'political, and economic construction of scales that almost never reflect the physical scale of the entity in question' (Sneddon, 2003, p. 2235). Cumming et al. argues that (Cumming, Cumming, \& Redman, 2006, p. 16):

Scale mismatch occurs when the scale of environmental variation and the scale of the social organization responsible for management are aligned in such a way that one or more functions of the social-ecological system are disrupted, inefficiencies occur, and/or important components of the system are lost.

This problem is particularly critical in conservation research and management, for which 'global' undertakings happen at 'local' scales. Some attribute unsustainable resource use to mismatches of scale between human and natural processes (Cumming et al., 2006; Sayre, 2009, p. 101). In a global environmental change, the scale mismatch (fit) between the scale of resource governance systems and the scale of the resource systems that they are supposed to govern is a scale problem for environmental issues. 'Mismatches of scale' between human and natural processes and scales of observation and operation lead to unsustainable resource use and are crucial for both conservation research and management and political ecology studies (Sayre, 2009, p. 100, 101). The command-and-control approach to resource management is dominant in the current field 
of environmental governance even though it is also the most criticized one. Commandand-control involves decision-making institutions whose decisions cross multi levels and scales but provide 'little to no opportunity for input or feedback' from those who are affected (Silver, 2008, p. 925). An outcome of this is a scale mismatch between the governed social and ecological systems (Silver, 2008, p. 925). When the scales of social organizations (people who use and those who manage resources) and environmental conditions and variations are mismatched, problems inevitably arise in either the social institutions that are responsible for management or the ecological systems that are being managed (Cumming et al., 2006).

The connection between representation and power contributes to a sociological concept of scale in which different levels of an organizational hierarchy respond and act at particular spatial and temporal scales that may range from small to very large. Recognition of the importance of social scale has been an underlying motive for the development of political ecology, which focuses first on local land users and their social relations and then traces those relations to higher scales of decision-making power (Cumming et al., 2006, p. 15). Ecological concerns such as biodiversity loss and wetland ecological change may require topographical management but also requires consideration of fluid topological processes and power relations which are associated with conservation and topographical territories (Pothukuchi, 2007, p. 101). The topological view of a specific time-space configuration of a network draws some locations closer to each other while others are pushed away, irrespective of their physical proximity.

\subsection{Power and space}

'Understanding space as the constant open production of the topologies of power points to the fact that different 'places' will stand in contrasting 
relations to the global. They are differentially located within the wider power-geometries.' (Massey, 2005, p. 101)

The above discussions on actor-networks, relational approaches to place, space, and scale, and politics of scale lead to better understanding of relational power. In complex environmental conflicts power, space and scale are intimately related. Power can be explained 'in the ways in which people, resources, and places are constituted' (Paulson et al., 2005, p. 28). Space is a product of on-going 'establishing' and 're-fusing' relations, that implicates space as always being open to the future. Space is always under construction through making, unmaking, and re-making relations (Massey, 2009, p. 17). The production of space, as open to the future and to change, is a political task, therefore, space is imbued with power. Relational thinking of place, space and scale requires relational thinking of power and entails both variation and change. Relational views of power, which are useful for discussions of this thesis, are discussed under the following topics: power-geometry; power/knowledge; governmentality; territoriality and environmental governmentality; discourse; state power; power as composition; and context. These arguments mainly refer to works by Doreen Massey, Michel Foucault, and Bruno Latour.

\subsubsection{Power-geometry}

Massey’s (2009; 2007; 2005) 'power geometry' has often been misunderstood and misrepresented in political ecology literature as being sometimes close to a 'geometric fetishism', which is very different from its original idea (Paasi, 2011, p. 301). Powergeometry is the conceptualization of relational space and power and does not imply that there is a specific form or geometry of power (Massey, 2009, p. 19). For Massey, power is not an internal force of being which exists in vacuum; rather it is social and relational 
(Massey, 2009, p. 19). Power is not given and does not exist as an external or internal drive, and is never abolished; rather it is exercised relationally in interaction with other entities in a network (Massey, 2009, p. 19). Therefore, any social study is ultimately about power relations (Massey, 2009, p. 19). Massey explains power-geometry in spatial relations as being two-sided, i.e. 'space is imbued with and a product of relations of power', and also power 'always has a spatiality' (Massey, 2009, p. 18). She explains that political, economic, and cultural social formations have their own power-geometries, and are at the same time related to each other. Spaces, territorial or fluid, are made through relations, processes and practices, and therefore, are not absolute; rather the 'flows and territories are conditions of each other'. Power is not 'concentrated' in a place, for example the financial city of London; rather 'power-relations' are focused there and its 'power is exercised relationally in interaction with other places' such as any other countries or institutions (Massey, 2009, p. 19). This connection changes/modifies all the involved components and their political groupings, therefore, there is a political process of building alliances, connections, and disconnections (Rocheleau, 2011). Massey's relational conceptualization of place, space and power ties Actor-network theory to place (Rocheleau, 2011) and highlights the importance of building alliances and politics of relations.

Massey explains that power-geometry in action is potentially a critique instrument (Massey, 2009, p. 19). She explains that it can be 'a concept through which to analyse the world in order to, perhaps, highlight inequalities, or deficiencies in democracy' and also 'an instrument through which to imagine, and maybe to begin to build, more equal and democratic societies' (Massey, 2009, p. 19). She applied the concept of power-geometry in Venezuela after she was invited to participate in the 'Bolivarian project of building a 
socialism of the twenty-first century' led by Hugo Chavez in 2007. Application of the relational concept of place, space and power in political practice does not imply a particular outcome by itself; rather the political agenda of its application is an important element (Massey, 2009, p. 19). Her reflection on power-geometry from the point of view of political practice, in the Bolivarian project, has four points (Massey, 2009, p. 21-23):

(1) When the starting point is a deep inequality then we need to understand the wider power geometry of the society and answer questions such as: where control over the distribution of resources to and between rural communities is located? This approach can contribute in establishing structures and rights for recognition and assertion of multiplicity of voices that should be parallel with expanding human and physical resources and capabilities for underendowed areas. (2) From policy statement to reaching the goal of new situations (power-geometry) in countries with less democratic foundations is a long, complex and difficult process that includes 'processes of sociopolitical contestation' to recognize, and believe them and to implement. This probably entails different temporality ${ }^{39}$. (3) A new power-geometry in Venezuela cannot be established only through political processes. There is reinforcement among the powergeometries of every dimension of society including, economic, cultural, and educational spheres. (4) Development of local communal councils is 'an evolving result of the process of building participatory democracy' but that does not mean that the community can be taken as an 'already existing coherent' input to this project and expect a fixed output.

\footnotetext{
${ }^{39}$ Massey argues we need to consider that maybe there is more than one temporality in the existing powergeometry in Venezuela which needs to be considered for building a new one. Setting laws and regulations and establishing enabling structures will not translate to immediate development of popular forces and multiplicity of voices. However, the disparity between two temporalities of development of Chavez's power-resources and communal councils is extremely vast and dislocated. Chavez can pass a law almost immediately but developing the power-resources of communal councils and rural small communities entails difficult and complex economic, cultural and social trajectories that may take years. These processes are not straight forward and linear and may change their course in time (Massey, 2009, p. 22).
} 
There are many arrangements of power besides those of domination and resistance.

John Allen believes territorial and networked spatial arrangements answer certain questions about power and its institutional order; however he looks for more subtle working of and 'quieter' forms of strategic and information modes of power such as manipulation, and charisma (Griffin, 2012, p. 218). He uses the term topology of power and explains that many international and territorial arrangements and relations use power as a force of constraint, domination, coercion, discipline, and surveillance (Allen, 2009). He argues although that is not a wrong statement about power but is a partial one (Allen, 2009, p. 106). Allen believes power relations are produced in practice and are located in complex relational topologies related to actors' social relations (Griffin, 2012). Allen argues that power relations compose the spaces they are part of, and therefore, practices of power define proximity, distance and reach (Allen, 2011a, p. 290; 2009, p. 206) . He stresses the intensive spatial relationships as being (Allen, 2011a, p. 290):

the mediated exercise of power that accounts for why the presence of a close and powerful body cannot be assumed to simply deliver authority and control or why a distant authority has the dexterity to manipulate the outcomes of a dispersed set of interests.

For Allen shifts of power relations can be understood through a topological sense of space and time 'and make sense of the twists and turns in the entangled relations under scrutiny' (Allen, 2011b, p. 317). He suggests the word topology, instead of scalar and territorial vocabularies, can be useful to talk about 'reach' as intensive, not extensive or 'connections' as composing the spaces of which they are a part, not simply lines drawn on a map' (Allen, 2011b, p. 317). He explains that using the term topology does not mean creating heterogeneity and multiplicity by bringing together multiple things from here and there, it rather provides an opportunity to think about (Allen, 2011b, p. 318): 
how it is that events elsewhere seem to be folded or woven into the political fabric of daily life, or about how powerful actors, including non-humans, register their presence, despite their physical absence, or what it means to put sweatshop exploitation beyond reach when distance is not part of the equation.

The space of power topology is not about reaching extensively across territories or about longer or shorter networks. In power topology, distances and proximity are understood locally through 'relations of connection and simultaneity' (Allen, 2009, p. 198). Power of connection and power of reach are the modalities of space of powertopology.

\subsubsection{Power/ Knowledge, and governmentality}

Foucault uses the term 'archeology' to compare different formations of thinking in history (Foucault, 1972). Foucault, through 'archeology', explores the hidden history of things and meanings and reveals the instability of taken-for-granted notions, concepts and things including body, gender, race, sexuality, truth, and knowledge (Castree, 2005a; Robbins, 2004). He later uses the term 'genealogy' to explain that certain systems of thoughts do not have natural and inevitable trends of formation but are contingent to particular social and political conditions (Foucault, 1977). 'Archeology' deals with production and operation of discourse but 'genealogy' is about truth in relation to the system of power (Murdoch, 2006, p 32). Foucault (1977), in a 'genealogical' study of imprisonment in modern Europe, explains how the function of power from pre-modern to modern Europe shifted from 'punitive' to 'disciplinary' (Foucault, 1977, 113, 215). He examined the European legal system and argued that the pre-modern mode of power with public executions, torture and display of force changed to disciplinary modes of power with surveillance, enclosure and self-discipline (Foucault, 1977). He identifies 'discipline' as a modality to exercise power, which encompasses an array of entities 
including 'instruments, techniques, procedures, levels of application, [and] targets' (Foucault, 1977, 215). Formation of a disciplinary society is through specialized institutions and the 'state apparatus whose major, if not exclusive, function is to assure that discipline reigns over society as a whole (the police)' (Foucault, 1977, 216). $\mathrm{He}$ argues that the disciplinary modality of power links together all the other modes of power and makes it possible to 'bring the effects of power to the most minute and distant elements' and ensures distribution of the power relations (Foucault, 1977, 216). This genealogical study is an analytical approach to discourse and practices (institutions, regulations, administrative measures, and scientific and expert statements) that opens the discussion to power, knowledge, practice and space and concept of governmentality (Allen, 2008; Murdoch, 2006) and the 'art of government' (Fletcher, 2010, p. 173). The 'art of government' is governmental practice which deals with issues such as 'the problems raised, the tactics chosen, the instruments employed, forged, remodeled' (Foucault, 2008, p. 2). He explains that governmentality develops with the fall of feudalism and the formation of capitalism. For Foucault, shifts in discourse bring about new knowledges, and new spatial relations and modalities of power (Murdoch, 2006, p. 31). Governmentality gives power an enabling dimension because government indirectly 'limits the possible range of people's action' at-a-distance and at the same it is exercised through people's own conduct (Allen, 2008, p. 103). Allen explains that (2008 p103):

through a process of mobilization, the truth claims of a range of accredited authority figures - under the guise of neutrality and efficiency - set out the norms of conduct that enable distant events and people to be governed at arm's length.

Knowledges, including scientific knowledge, and institutions developing experts claim representing the truth, are necessary to direct governmentality. Foucault is against objective 'truth' and believes that discursive truths, which become dominant, including 
truth generated by science, are an effect (result) of 'power relations' in society. Certain knowledges become accepted as truth through discourse and social systems, institutions and practices; and then power operates through those knowledges, known as truth and norm (Robbins 2004; Braun and Wainwright 2001). Therefore, power hides behind the common belief of scientific knowledge as value-free and objective enabling scientific knowledge to serve government purposes and legitimize their policies and actions, as has happened since the Enlightenment (Scott, 1998). The Foucauldian way of explaining the relationship between power and knowledge opens up the possibilities of the rising of voices other than those of authority. Monopolizing the right to represent and speak of certain places or things is a means of 'enframing spaces within particular regimes of "truth"” (Allen, 2008, p. 102). As Foucault clearly explains (Foucault, 1984, p. 72, 73):

Truth is a thing of this world: it is produced only by virtue of multiple forms of constraint. And it induces regular effects of power. Each society has its regime of truth, its general politics of truth: that is, the types of discourse that it accepts and makes function as true.

Focauldian analysis of power encompasses links between knowledge, state power, and tactics of governing (Rutland \& Aylett, 2008, p. 638). Foucault's view(s) of individuals and groups are governed from within as they internalize the interests of the state. Hajer explains that Foucault identifies deployment of power along three axes (Hajer \& Versteeg, 2005, p. 180): 'institutional centralization around government agencies, the emergence of new instrumental knowledge, and the diffusion of power effects over society as a whole'. Governmentality entails intertwined processes of power struggle and knowledge formation, which articulates techniques to control populations and also to institutionalize certain form/new forms of knowledge. Universities have a crucial role in this process by being a place to produce scientific knowledge about nature, and represent 
the environment as complex systems only understood by experts. Scientific argumentation can halt or facilitate public debates about nature (Hajer \& Versteeg, 2005, p. 108).

Foucault (2008), distinguishes between disciplinary governmentality which is internalization of social norms and ethical standards by individuals who impose them on themselves and others; and neoliberal governmentality which always involves economic growth and cost-benefit analysis with the state providing structures and incentives so that actors voluntarily exhibit appropriate behaviours (Fletcher, 2010, p. 173). Understanding governmentality as relationships between the state and the individuals/groups it governs in terms of knowledge, state power and governing tactics (Rutland \& Aylett, 2008, p. $638,639)$ leads us to issues of territoriality, environmental governmentality, and discourse and practice and further highlights power relations among entities and networks, beyond state's institutions and structures.

\subsubsection{Territoriality and environmental governmentality}

Modern states frame what conventionally belongs to the natural world through processes of territorialization. Territorialization is 'the use of space to control and regulate nature' and has two functions (Whitehead, Jones, \& Jones, 2007, p. 16). Their first function is constructing space to centralize production of standardized knowledge about nature, and facilitating and ordering the collection of political knowledge to know nature (e.g. mapping exercises, institutional arrangements, and herbariums) (Robbins, 2008; Whitehead et al., 2007). Second, modern states frame nature and use territorial strategies to physically control nature and its interaction with the social through 'territorial borders, institutional structures, and laws' (Whitehead et al., 2007, p. 20). This 
entails a wide range of practices to frame nature, separate it from its social context, and therefore, control any socio-ecological interactions, for example, by land use and zoning plans, conservation territories, property rights, natural resource planning and laws (see Sections 3.2.1., 3.2.1.1, 3.2.1.2, and 9.1).

Neumann explains that the fortress conservation model and practices such as sedentarization, and concentration in Africa happened in every colonial and postcolonial state from the late nineteenth century to the present and argues that the reason is that these practices constitute the characteristic of modern states seeking 'progress', 'development', and transformation of its 'citizen-subject' ('backward', and 'traditional' citizens of the state to 'modern', 'civilized', and 'observable') (Neumann, 2004, p. 200, 201). Fortress conservation was spatial organization of society and nature through ownership and property claims over the commons, natural resources of the territory and all vacant lands (consistent with European colonization and 'myth of emptiness') (Neumann, 2004; Peluso \& Vandergeest, 2001; Scott, 1998).

The modern and universal Western scientific discourse links the establishment of conservation territories and modernity projects of states. Equilibrium ecology, and the presumed superiority of Western science to other kinds of knowledge generated environmental degradation narratives that considered African land use practices as destructive and inefficient; this provided rhetorical justification for proprietary claims, and territorial control of the state (Neumann, 2004, p. 203; Peluso \& Vandergeest, 2001). Establishment of conservation territories entails separation of intertwined social and natural entities of these territories and zoning is about remaking of associations of heterogeneous entities and emergence of new and ongoing relations between humans and non-humans. Therefore, politics of zoning in conservation territories is the politics of 
place-making and becoming (Pothukuchi, 2007, p. 102). Conservation strategies from the beginning were geared towards boundary making and the science and politics of boundary making in the rural poor of the Third World have worked together and are part of the same process of place-making and exclusion (them) and inclusion (us) (Zimmerer, 2000; Neumann, 2005). Conservation boundary making is associated with production of territory, and scale, therefore, is an institutional process of exclusion and inclusion (Zimmerer, 2000, p. 362). Separation of nature and society is a modernity project (Murdoch, 2006, p. 108) and '[m]odern states practiced internal boundary making to marginalize people and serve the state's economy' (Sletto, 2002, p. 188).

The state is an actor-network and there are competing interests within its territory regarding certain natures. This has two implications: a) political processes of decisionmaking regarding national natures and their management and the question of who makes those decisions; and b) ideological and material priorities to justify those decisions. Decisions regarding national natures are commonly regarded as scientific, technical, and managerial expertise separated from politics. Therefore, planners and scientists, as part of the state apparatus, define and frame nature as technical (Whitehead et al., 2007, p. 121) . The state apparatus, the 'set of institutions and organizations through which state power is exercised' (Whitehead et al., 2007, p. 171), is multi-faceted and plural. Modern states develop regulatory agencies to control use of nature and become the centralized hub for gathering and storing information and for monitoring and management. The state and its apparatus are both heterogeneous associations that frame nature as multiple, varied and in continuous production and reproduction. They need to be understood as exercising power in both space and time (Whitehead et al., 2007, p. 55, 17). 
Albert (1999) argues that globalization leads to de-territorialization and reterritorialization at substate (indigenous territories within a national state) and superstate (European community, transboundary reserves) levels (Albert, 1999). Conservation planning is an active axis of de/re-territorialization in both developed and developing countries (Sletto, 2002). Global conservation institutions run the conservation machinery, which provides the scientific justification and mobilizes major funding for conservation territories in the Third World. Any conservation unit irrespective of its management scheme is a bounded global-local space, which reflects interests of powerful actors in a complex arena of global, state and local power dynamic networks. Conservation territories are 'differentiated' spaces, constructed by scientific discourses of biodiversity and conservation and serve the purpose of policing, enclosure, and containment, which restricts access to local commons and communal resources and 'criminalizes' local users (Zimmerer 2000, p. 362). This process entails place-contingent outcomes including local reconfiguration of power relations, change in local practices, economy, and 'resistance' and 'accommodation' tactics and strategies (Perramond, 2007; Sletto, 2002, p. 205).

Conservation, a science-based policy making process, is a good example of how governmentality works when the state empowers citizens 'to make choices based on good information provided by the state' (Hajer \& Versteeg, 2005, p. 108), and therefore, to self-regulate themselves (Rutland \& Aylett, 2008, p. 639). It creates practices which function as the societies' broad discourse and then justifies its own actions by the same scientific facts and public discourse (Hajer \& Versteeg, 2005, p. 108). In this process certain discourses get institutionalized in university curricula (Hajer \& Versteeg, 2005, p. 178) and gain popularity as facts of nature. 
In this thesis, governmentality is used as an analytical tool ${ }^{40}$, which Agrawal explains as modern forms of power which regulate social practices by 'turning people into accomplices of state' to achieve state goals (Agrawal, 2005, p. 217). Drawing on Foucault's governmentality, Agrawal uses the term 'environmentality' to refer to (Agrawal, 2005, p. 226):

the knowledges, politics, institutions, and subjectivities that come to be linked together with the emergence of the environment as a domain that requires regulation and protection.

He explains that environmental governmentality/environmentality asks questions such as (Agrawal, 2005, p. 224): when and how are conservation and development problems and questions formed?; why are certain solutions and strategies of government dominant and with what effect?; "what are the techniques, forms, and representations of knowledge for those strategies'?; what is the 'relationship between government and selfconstruction' and 'integration of institutional and other social changes with changes in subjectivity'?

The embodied governmentality in different state conservation practices can be seen as disciplinary (more focus on subjects' internal state) and sovereign power over territory, with a focus on external structures and the creation and enforcement of regulations within which subjects act. Disciplinary forms of conservation governmentality entail formation and prevalence of ethical norms for people who care about nature and sustaining life (human and non-human), which mainly happen through decentralized institutions, NGOs, and media. The IUCN (International Union for Conservation of Nature) system of national parks and national focal points, located in the state apparatus, serves to maximize

\footnotetext{
${ }^{40}$ Governmentality is not a descriptive tool because does not provide a comprehensive view of different world views and sources of influence, it rather is an analytical tool which provides a framework to simplify complex relationships in order to analyse a phenomena (Rutland \& Aylett, 2008, p. 638).
} 
the total extent of protected areas according to that classification, and is an example of structures which are required for developing disciplinary governmentality. The objects of intervention are human and non-human populations including university students, academia, intellectuals, and whatever usually falls into the nature category (Fletcher, 2010, p. 175). Governmentality raises the issue of the institutional arrangements and national and transnational governance in which power is dispersed. Environmental debates happen in institutional arrangements with blurry rules where "politics is to be conducted and policy measures are to be agreed upon' (Hajer \& Versteeg, 2005, p. 182). The view of a purified nature or the nature as contested is an integral part of institutional games, their rules, and negotiations (Hajer \& Versteeg, 2005, p. 182). Debates about environmental problems and solutions are enacted on international and transnational levels and any policy paper or technical and policy guideline 'unintentionally provides a succinct summary of the multi-scalar dissemination of power' crossing many levels. One immediate implication of this is that those policy papers and guidelines cannot be considered universal.

\subsubsection{Discourse}

In this thesis, discourse is defined as Hajer and Versteeg explain it (Hajer \& Versteeg, 2005, p. 175):

an ensemble of ideas, concepts and categories through which meaning is given to social and physical phenomena, and which is produced and reproduced through an identifiable set of practices.

Discourse is a combination of speech, writing and action, all of which is the product of institutional practices and individual activities (Hajer \& Versteeg, 2005; Keely \& Scoones, 2000, p. 91). Discourse reflects particular types of knowledge, therefore, it a) 
reflects certain political interests, and b) has a role in structuring certain interests. Foucault argues (Foucault, 1978, p. 100, 101):

Discourses are not once and for all subservient to power or raised up against it, any more than silences are. We must make allowances for the complex and unstable process whereby a discourse can be both an instrument and an effect of power, but also a hindrance, a stumbling point of resistance and a starting point for an opposing strategy. Discourse transmits and produces power; it reinforces it, but also undermines and exposes it, renders it fragile and makes it possible to thwart.

Discourse needs to be understood in terms of its embedded cultural and lingustic struggle in practices, which are part of power realtions of everyday life (Peluso, 1994; Keeley \& Scoones, 2000, p. 91). Analysing the discourses underlying different policies is a way of understanding policy conflicts and challenges. Discourse and discussions about nature, as a contested or a purified notion, are at the core of conservation practices and environmental politics, and frames both problems and solutions and available possibilities (Hajer \& Versteeg, 2005, p. 178).

Conservation discourses (see Section 9.1) are crucial in shaping/reshaping conservation practices and legitimize/delegitimize certain courses of action (Whittle, Suhomlinova, \& Mueller, 2010, p. 18). Discourse is viewed as a 'strategic resource' when it is used as a tool to shape the meaning of change for a specific target (Whittle et al., 2010, p. 18). Discourse can be used by actors to 'fix understandings, shape interpretations, and justify practices', and therefore, is important in shaping change and processes of negotiations and dismantlement of existing practices (Whittle et al., 2010, p. 19). The power of discourse lies in performance of actors in a conflict by rethinking, challenging, and revising stable policy discourses and mobilizing new/other discourses to 'reconnect the previously unconnected' (Hajer \& Versteeg, 2005, p. 182). Actors exercise power by employing certain discourses and frames of understanding to control or direct a 
process. Therefore, discourse analysis explores 'the historical, cultural and political context in which a particular account of 'truth' arises' and can help 'to illuminate why certain definitions do or do not catch on at a particular place and time and to explain the mechanisms by which a policy does or does not come about' (Hajer \& Versteeg, 2005, p. 176, 177). Universities, media and international and intergovernmental institutions play a crucial role in this process. Therefore, dominant conservation discourse (policy and practice) reflects interplay of power in different forms of disciplinary governmentality.

Discourse has a role in understanding how actor-networks shape the world and promote and establish certain relations. It is essential in the translation process and discursive construction of interests and alignment of those interests by various actors (Whittle et al., 2010, p. 17: Keely \& Scoones, 2000, p. 91). In ANT actors are convinced, and therefore, enrolled into networks through discourse. Burgess and her colleagues explain that (Burgess et al., 2000, p. 123):

The concept of translation recognizes that the content of texts, conversations, objects and so forth is not simply transferred unchanged between actors, but may be transformed as things pass from hand to hand.

Whittle et al. argue that 'discourse actually makes things happen and shapes the social and organizational reality' (Whittle et al., 2010, p. 19). The terms conservation, protection, command-and-control, sustainability, Integrated Conservation and Development Projects, and co-management and their conceptualization can shape: a) the meaning of change for actors involved and its intended targets; and b) legitimize and delegitimize certain courses of action. Therefore, involved actors can use discourses that suit their particular interests to advance their goals and preferred practices, hence, they can be used to develop a new practice or disrupt an existing practice and arrangement. 
The state is the mediating entity in conservation practices, translating discourses of conservation and setting and applying conservation policies and practices. Nevertheless, the state is not a monolithic entity, rather is a network of connections and disconnection, and its particular form at a certain time is the product of flow between civil society, ecosystem processes and economic and political entities (Robbins, 2004, p. 210).

\subsubsection{State power}

Political ecologists study structures, centers where power relations are focused and relations between economic and political processes that create uneven development. Power, understood as instrumental (a means to an end) or facilitative (means of enablement. i.e. constraint and enablement of social actions) is exercised extensively and intensively (Allen, 2009). Power is not stored in certain levels of organization or contained within a territory, rather it is 'an effect which is generated through the actions of groups or organizations', when they mobilize their resources over space to secure and control certain distant outcomes (Allen, 2009, p. 8). Power can be sustained through action and when there is no action 'it simply vanishes' (Allen, 2009, p. 99).

For John Agnew ( Agnew, 2005, p. 39), power can be hierarchical, network based, territorial or contiguous, and is exercised from different sites with different geographic reach, therefore, what is important is 'the balance between levels of hierarchies of powers that determines the spatiality or configuration of political power' (Agnew, 2005). Relational spaces and theories of place, as well as actor-networks and territories tie networks to place and to different 'territories of production and consumption' (Rocheleau, 2011). Power is not distributed over space, rather it 'is constituted by the many networked relationships which compose it' (Allen, 2009, p 98). 
Territorial power, as given and absolute, faded with spatial understanding of scale and power as an achievement, produced and practiced (Agnew, 1998, 2005; Allen, 2011). The power-geometry of state becomes more flexible considering diverse supranational institutions and also decentralized power structures and devolution (Allen, 2011a, p. 286). Although economic and administrative spaces are embedded in state territories, they are part of wider geographical authorities, which effect regulations and control (Allen, 2011a, p. 287). Therefore, territory is not a container or a source of power, which is capable of uncomplicated extensive reach but rather is (Allen, 2011a, p. 287):

one of its possible effects; an outcome of the mediated relationships and leveraged co-presence which draws different groups, decision-makers and institutional actors into the interplay between states in all kind of powerful and not so powerful ways.

Sociospatial classificatory practices by the state, as a central actor, is development of national systems through which the nation-state is the central scale of identity and political power and establishes the scale categories of hierarchical scalar order of spatiolegal jurisdictions such as district, municipality, province, and region (A. Moore, 2008, p. 215). The state is not a single actor nor a monolithic agent. Reifying state as a single actor has the danger of rendering its existence as an abstract entity which contains and holds certain power and acts in certain ways. Abrams is cautious about the use of the term state. He argues that this term is (Abrams, 1988, p. 77):

a triumph of concealment. It conceals the real history and relations of subjection behind an a-historical mask of legitimating illusion: contrives to deny the existence of connection and conflicts which would if recognized be incompatible with the claimed autonomy and integration of the state.

Regarding a state as an actor-network entails that states are both actors and complex networks developed through practices and processes. The state in this context means 'seeing the state as not a thing but as the ongoing relational outcome of practices and 
processes which iteratively expand and protect it while other practices and processes disband and unravel it' (Rowland, 2010, p. 828). In this relational thinking, states are no longer obvious, given, powerful, stable and static entities existing out there, but rather are made of 'interwoven conditions of statehood and political decision-making'. These interwoven processes bring about 'stateness' that we understand as modern statehood (Rowland, 2010, 825). Therefore, an army or distinctive institutions of the modern state are not the product of the state as single entity but are the effect of certain processes, discursive and non-discursive practices, and power relations (Rowland, 2010, p. 824). The question about the state in the ANT view is not 'what a state is', as 'how states are' (Rowland, 2010, p. 826).

\subsubsection{Power as composition}

Foucault is criticized because, in his governmentality project, he considers the state as a 'mythicized' and 'composite reality' and independent actor (Rutland \& Aylett, 2008). Dean and Henman (2004, p. 491) argue that governmentality does not describe how a specific object of government is constituted and how political priorities are emerged and critically explain (Dean \& Henman, 2004, p. 491):

the 'ship of state' appears to be a lonely vessel on the open seas for Foucault. In reality, it meets and passes or engages in commercial, diplomatic, and military relationships with other such ships.

Foucault's conception of power is relational thinking. This is commonly interpreted as the 'power relationship' working as a network of actors (e.g. individuals and groups of society, sectors, institutions, or states) and is a manifestation of 'action' (Castree \& MacMillan, 2001; Robbins, 2004). For Foucault power is not held by a group or an individual but rather 'exercised', meaning it emanates through society 'in a capillary 
fashion as multiple discourses do their daily work on people's minds and bodies' (Castree, 2005a, p. 147). He clarifies that power is not something to be imposed from 'those who govern to those who are governed' but it is a transaction/action between the two through a series of 'conflicts, agreements, discussions and reciprocal concessions' from which the effect is finally 'what is to be done and what is not to be done' (Foucault, 2008 , p. 12). For Foucault, power relations are unequal and power operates 'from the top down and also from the bottom up'; from outside and from within; as a result, power is available to all actors, not only to the 'powerful', and therefore, it can be a point of resistance anywhere in the power relations which restructure it (Dreyfus \& Rainbow, 1983; Robbins, 2004). Power in ANT is built on Foucault's conception of power. Latour also thinks power emerges from inside the networks and is not the property or ability of an actor but emerges from established relationships between actors and many entities of the network. Murdoch, in his book Post-structuralist Geography: A Guide to Relational Space (2005), refers to Foucault and Latour and argues that the relational view of space and power entails heterogeneous assembly of humans and non-humans and their association in actor-networks and power relations as embedded and transported through these networks (Pothukuchi, 2007, p. 101).

Deleuz argues that power is not a possession, it is a manifest, as it is used (S. Fox, 2000). Latour explains (Latour, 1986, p. 264, 265): 'when you simply have power - in potentia - nothing happens and you are powerless; when you exert power -in actu others are performing the action and not you...'. That means power in actu is a 'composition' performed by many actors but attributed to one of them (Murdoch \& Marsden, 1995, p. 372). Murdoch and Marsden, using the ANT approach, explain that power is the outcome of collective actions and those who are powerful (a person, a class, 
an ethnic group, or any social structure) are not so because they possess and hold power (Murdoch \& Marsden, 1995, p372); rather, it is their ability to represent others and speak for them (Burgess et al., 2000) through enrolling, convincing and enlisting others into associations makes them powerful (Murdoch \& Marsden, 1995, p372). Social processes can give rise to power as an effect but they are in constant (re)making; therefore, to explain power and 'trace power geometry', we need to study relations and processes of associations (Murdoch \& Marsden, 1995, p372).

ANT makes a useful contribution in describing the spatial mechanisms of alignment of powers at work and highlights how the 'subjects and objects of politics come together in processes of consultation and contestation' (Rutland \& Aylett, 2008, p. 642). Therefore, it enables us to go beyond institutions and see alignment of spatial relations among sites and scales and explore the assemblages of humans and non-humans. In ANT despite the governmentality of Foucault, there is no single central figure (Rutland \& Aylett, 2008, p. 632). ANT can reveal how power and scale are co-created (Sneddon, 2003 , p. 2246). The ways in which power and scale matter hinge crucially on the density (network of networks) and length (local to global) of networks consisting of multiple

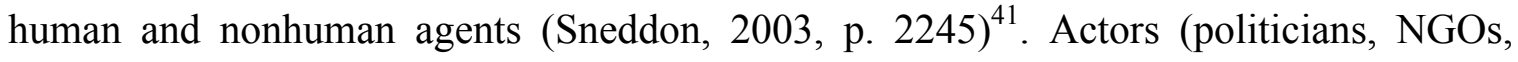
corporations, government officials, etc.) use scale categories of spatially to provide meaning to events and relations, and 'frame' both problems and solutions. Whitehead et al. explain that actors employ framing processes to 'include or exclude certain actors, legitimate political projects, rework relations of power and coalesce political processes

\footnotetext{
${ }^{41}$ In this regard Sneddon quotes Whatmore and Throne (Sneddon, 2003, p. 2234): “The power associated with global reach has to be understood as a social composite of the actions and competences of many actants: an attribute not of a single person or organization but of the number of actants involved in its composition'
} 
around particular scalar order' (Whitehead et al., 2007). Representation of power cannot be isolated in terms of individual actions; nor is power some innate quality of specific people or groups. Power over something or someone is a composition made by many people [and things] and this composition is made visible in part by its effects on other sets of actor networks. Power effects become more comprehensible when actor-networks (academics, NGOs, people's organizations, and a range of non-humans) show resistance to each other or have different interests (Sneddon, 2003, p. 2241).

Power in actor-network theory can be explained through the processes of translation, enrolment and purification of human culture and nonhuman nature (Castree \& Braun, 2001; Burgess et al., 2001) to make actions durable through space and time (Murdoch, 2006, p. 78). The concept of translation includes the processes of negotiation, representation, and displacement, which establish relations between actors, entities, and places, and how actors and organizations mobilize, juxtapose and hold together in heterogeneous association so that they can act (Murdoch, 1998). Relational theory of space, place and power allows us to tie networks to place (Rocheleau, 2012). All connections in ANT are treated as an asset (Rocheleau, 2011), therefore, the question is whose network is bigger. Actors become powerful by extending their network over greater distance through enrolling other actors. There are 'power relations in both the patterns and the processes of connection', which can vary from coerced to voluntary, and encompass relations from slavery to partnership and free association (Rocheleau, 2011). Through the enrolment process, interests of actors are 'identified, attracted, and transformed', but actors can act either 'with or against the schemes in which they are enrolled' (Whitehead et al., 2007, p. 20). Actors in a network are 'enrolled' with different intentions and capacities, but along a similar interest. The actor builds its network by 
translating the other entities, giving each an identity, interests, a role to play, a course of action to follow and projects to carry out (Burgess et al., 2000).

Burgess and her colleagues elaborate on power and translation as follows (Burgess et al., 2000, p. 123, 124):

Actors gain power and interest by translating the interests of other entities into their own and thereby enrolling others in their actor world... The actor decides their attributes, links them together, and draws up the scenarios in which they take part. Translation is thus about attempting to gain rights of presentation, to speak for others and to impose particular definitions and roles on them.... Building networks depends on actors' capacities to direct the movement of intermediaries such as texts, technologies, materials and money. The achievement of action-at-adistance is as much dependent on mobilizing such resources as it is on persuading other actors to become enrolled. But success does depend on what these other actors do: whether they conform and continue to conform, to their allotted roles.

The extension of networks is more than transmission of resources; rather it involves a mediated exercise of power where distances are overcome by the successful enrolment of others to form what amounts to a single will across the network (Allen, 2009, p. 204). Therefore, the networks are not pre-given and fixed because there is always an act of bridging what were previously separated and unconnected elements, to bring them into alignment ${ }^{42}$ (Allen, 2009, p. 205).

\subsection{Glocal wetlands and their analytical framework}

Relational thinking of space, place and scale and accepting the existence of coeval others do not mean that we fall into the 'depthlessness of the postmodern era' and flattened relativism; rather they require a change of vision from singular modernist narrative to open the space to time (Massey, 1994, 1995, 2004, 2005) so: a) instead of the space of abstract places in the 'historical queue', we think about the space of flows; b) instead of singularity, we think about alternatives, and pluralism; c) instead of one

\footnotetext{
${ }^{42}$ Mediators are active forces transforming and translating what is not connected into some form of association, whilst intermediaries appear to work towards stabilizing the network (Allen, 2009, p. 204).
} 
dimensional-territories, we think of networks and relations; d) instead of an 'already constituted holism', we think of continuous and never ending processes of becoming and making, re-making, and not-making relations ${ }^{43}$; and e) instead of using 'global' and 'local' as binary opposites, we think of scale as relational and mutually constituted. This change of vision is a political reminder that "whatever we do has wider implications than perhaps we commonly recognize' (Massey, 2003, p. 118).

Viewing conservation territories through the lens of socionature and relational thinking of space, place and scale, and relational notions of power rather than as pristine nature and bounded and static territories, opens the analytical framework to a broader range of understanding and explanations for people-environment (nature-society) relations and 'the ways in which environmental protection intersects with other political processes at multiple social and geographical scales' and levels (Sundberg, 2006, p. 260).

The discussions of this chapter lead me to identify the Wetlands of International Importance (Ramsar Sites) as glocal wetlands. This theorization is pivotal in order to reassemble the social and natural and to escape any kind of scalar trap. Such identification recognizes that these wetlands are natural and social (mutually constructed); relational; and process-based. Place, defined as a collective of humans and non-humans, open and always becoming, is recognized as a political project. Designation of any piece of ecosystem as a conservation territory is a place-making process, which reinforces power relations performing in society and also crossing many scales. By using the term 'glocal wetlands': a) the spatial formation and becoming of these wetlands in terms of practices, processes and relations crossing multiple levels and scales are highlighted, and b) apolitical readings of conservation discourse involving these wetlands are challenged.

\footnotetext{
${ }^{43}$ Those connections that could not be made are also important.
} 
As a result of the above theorization of place and space, I conceptualize the spatial characteristics of glocal wetlands, in relational terms. Glocal wetlands:

(a) are products of complex networks of associations and connections between actants, humans and non-humans, social and natural, from global to local;

(b) are porous localities which are made in relation to other places such that every glocal wetland is a unique place;

(c) have multiplicity, 'coexisting heterogeneity', and 'simultaneous coexistence of more than one thing' (Massey, 2009, p. 17; 2005, p. 9, 99), and are at the juncture of more than one trajectory which leads to a space for politics where humans and non-humans, economics, culture, text and politics come together; and

(d) are not static/fixed rather are always in the process of becoming and being made, hence there is constant change of identities and transformation in the context of shift in their power relation.

In summary, glocal wetlands: are parts of networks, and multitudes of trajectories; never finished products; never fully connected/not connected; and constantly being made, remade and changed. In such flux, there is both opportunity and constraint.

Global conservation discourse is produced and practiced through 'places' with the goal of having impact at a range of local systems (habitats, ecosystems, landscapes). Conservation is a place-based production going through global-local processes and crisscrossing wider power-geometries. Thereby, in glocal wetlands, the local relations to global conservation discourse and practice varies from place to place. This variation 
originates from: a) differences in the way conservation is perceived and practiced at national and local levels, and b) how conservation practices go through the dynamic ecological, social, economic, cultural, and political intertwined networks which make the place.

By accepting political readings of conservation and people-environment relations, adopting the post-structural political ecology approach, and arguing that glocal wetlands are not the product of the neutral action of science and technical processes happening in an apolitical vacuum, this thesis argues that AUA as a glocal wetland is constituted through webs of power relations crossing multiple levels and scales. Formation of a glocal wetland is about making of space and engaging with multitude of trajectories, and therefore, is open to politics (Massey, 2005, p. 83) and possibilities and constraints. This understanding of glocal wetlands indicates that conservationists are hence social planners, instead of simply the source of generalized and blanket technical recommendations. Conservation and management of glocal wetlands require approaches which are context specific and consider the uniqueness of each place. It follows that any changes in the ecological character of glocal wetlands that are on the Montreux Record should be perceived as a complex network of material settings and ramifications of political processes and socio-economic inequalities. This relational understanding of glocal wetlands has two major interrelated implications for studying change in terms of peopleenvironment interaction in these places that build an analytical framework with three major components:

First, individual instances and cases are context specific, and should be studied on the basis of their intertwined socio-economic processes and networks and through their 
power relations crossing global to local levels. Salient features of these multi-scale and multi-level analyses are:

(A) they situate ecological studies in history (Borgerhoff et al., 2005; Paulson et al, 2005; Neumann, 2005). Through this analysis, biophysical entities (e.g. flora and fauna, soil and hydrology) become 'coactors' and 'codeterminants' of a social and physical history (Cronon, 1992; Neumann, 2005);

(B) they take into account power geometry of the broader network of actors (humans and non-humans e.g. political players, and river basin) and stakeholders (different social groups, people, government, national and international organizations) crossing global to local, considering social and cultural contexts of actors and stakeholders, and being attentive to local knowledge, and perceptions. This requires examining socio-economic factors in making of the place with special attention to power relations in and between places and along issues like race, class, gender, and being sensitive to rights, and social justice.

Second, conservation is not a taken-for-granted term and conservation discourse and practice do not have universal ecological and social functions and consequences. Hence:

(C) contextual analysis of any glocal wetland requires examining how conservation and wise use of wetlands and goals of the Ramsar Convention are perceived and practiced in a place and what political agendas are involved. In each case, the conservation discourse must be investigated by asking what kind of conservation is being practiced, and what the goal is. In this process, the answers are found to questions such as: 
Conservation to whose benefit and for what purpose? Whose discourse of conservation is privileged? Whose is silenced and to what effect?

Glocal wetlands denaturalize and re-politicize anything that is presented as truth, evident, or neutral by state and international conservation organizations, and therefore, is hoping to make a space for change. This conceptualization has a serious consequence for the Convention on Wetlands, Contracting Parties to the Convention and NGOs. The Convention needs to acknowledge its social impacts the same way that development agencies questioned their practices. Those who speak for nature, are as political as they are technical and do not have a higher moral status to development agencies. The Convention on Wetlands needs to assess its social footprints and stay accountable for whatever impact it has on life of local people and prevalence of conservation discourse.

The three components of the glocal wetlands analytical framework are the bases for articulation of the six questions of this thesis. The next chapter discusses the methodological strategy of this dissertation, which fits the above conceptual and epistemological underpinnings of glocal wetlands and describes methodologies and methods used to answer questions of this research. 


\section{CHAPTER III- Methodology and methods}

The conceptual underpinnings of glocal wetlands that are based on relational thinking about place, space, scale and power require a research methodology ${ }^{44}$ that is context-specific and sensitive to the power relations involved in the formation of a place. This chapter discusses what 'context' means in the study of glocal wetlands and argues that participatory methods, particularly participatory mapping, are best suited to studying their complexity and gaining knowledge about the working of their power geometry. It then proceeds to discuss the research design and the methods used.

\subsection{Context-specific methodologies}

Studying phenomena in context means different things for different scholars. Context may be any concrete or empirical thing, or the scale of everyday life (Castree, 2005b). Routledge et al. explains 'contexts are constructed around/by specific projects (out of materials, resources, etc.) that are available 'locally' to the project' (Routledge et al., 2007, p. 2577). Cox and Mair believe context is about processes that can be isolated conceptually and is multi-scalar (Castree, 2005b; Cox \& Mair, 1989). For Anssi Paasi, context is 'social life and culture that have their impact on how increasingly relational, stretching spaces are shaped and how the narratives on geographies and identities are situated' (Paasi, 2011, p. 301). John Allen, using topological understandings of space and time and entangled relationships and shifting geographies of power relations, believes that context changes according to 'which events become known to us' and also (Allen, 2011b, p. 316):

\footnotetext{
${ }^{44}$ A methodology is a conceptual rationale that links the conceptual bases of a study with appropriate techniques and methods that fit research questions and methods are ways of gathering evidence.
} 
[contexts] shape our experiences of, say, what is near and what is far, what is past and what is present, even how it is possible for others elsewhere to be more or less present in the here and now of daily life.

Jessop explains context as (Jessop, Brenner, \& Jones, 2008, p. 395):

sociospatial relations, understood as strategically selective TPSN [Territory, Place, Scale, and Network] ensembles, interact in specific historical-geographical contexts to produce distinctive ordering and reordering of sociospatial landscape, including new geographies of accumulation, state power, and hegemony.

Jessop et al. further explain that studying sociospatial projects requires analysis of at least two dimensions (out of four: territory, place, scale and network) of sociospatial relations (Jessop et al., 2008, p. 399). Swyngedouw's concept of scale is built on the political-economic theorization of scale, the social production of nature and also on network and assemblages, which in his view are all compatible and overlapping (Swyngedouw \& Heynen, 2003, p. 904; Neumann 2009, p. 402). In his view, spatial scales are contested and heterogeneous and are in constant restructuring in terms of their content, interrelations, and importance. In other words, spatial scalar arrangements and levels are the product of many related processes ranging from local to global (Cox, 1997).

The common ground shared by ANT and Foucault's conception of power, as being relational and arising from within situated activities, elucidate these approaches to context. For them, analysis should not acquire theoretical assumptions about 'objective socio-historical context' and presumed macro and micro actors; instead analysis should seek to explain the existence of these actors, of any sort, through nests of practices that are reproduced and have emerged within networks (S. Fox, 2000, p. 858). Latour explains that context is never pre-given and is (re)made in processes and emergent in practice (Routledge et al., 2007, p. 2577; S. Fox, 2000, p. 858). This means that position in a social structure (class, ethnic group, gender) or scale (from global to local) does not 
always determine a particular result (Murdoch \& Marsden, 1995, p. 371) and that it is not about a single level of analysis (global or local) or a single sector (environment or economics). Context for Latour 'flow[s] locally through networks' of different kinds (e.g. economics, medicine, sociology) (Latour, 1999, p. 18) and contextualization needs to be done without a taken-for-granted zoom effect of scale, i.e. it requires a well ordered and abstract zoom through the macro, meso and micro (Latour, 2005, p. 184-186). In ANT, the concern of analysis is "how any actor, however large or abstract (e.g. organization, state, class, patriarchy) comes to be and functions like an actor' (S. Fox, 2000, p. 858), and to understand how processes 'give rise to power as an effect'. This entails focusing on the ways in which local actors are tied into sets of relations, whatever social-spatial scales they cross, and without assuming any single pre-given identity for those localities (Massey, 1991; Murdoch \& Marsden, 1995, p. 370).

This thesis approaches 'context' as described by post-structural political ecologists. Going beyond local, regional, national, and global scaling schemes entails considering the spatiality of social life and social processes, which further creates certain conditions of resource access, use, and management that will be changed under changing conditions. Contextualizing glocal strategies means being more sensitive towards territorially mediated political, social and economic regulatory regimes which, when mobilized, create spatial connections and disconnections. Formation of glocal wetlands encompasses complex and interwoven socio-ecological, economic, political, cultural and institutional queries about the networks they function within and their power geometry. The aim is not to find a linear cause and effect relationship but to study the network of actors and processes (Paulson et al., 2005; Zimmerer, 2000). Sayre explains that societynature relations and conservation practices consist of many simultaneous processes, and 
therefore, have different sorts of 'scaling or spatial manifestation' (Sayre, 2009, p. 103). The implication of this notion for empirical research is that ecological processes are coupled with political-economic processes, such as resource use and management of commons, access to resources, conservation policies and discourse, and governance, in detailed localized case studies (Sayre, 2009, p. 103). Sneddon, drawing on ANT, describes contextualizing as recognizing that localized case studies of environmental conflict are 'simultaneously 'local' and 'global' depending on their location within networks of actors and processes' (Sneddon, 2003, p. 2234).

Political ecology research, which may be place-based (e.g. land use conflicts) or non place-based (e.g. market, and international policies), does not have a fixed methodology although it usually employs ethnographic methods (Peluso, 1994; Watts \& Peet, 2004) and participatory practices. Political ecology opens a space in research for normative agendas, such as social justice and participatory research, in order to facilitate the involvement of delegitimized people and social groups in the process of conservation and resource management and in the formation of environmental knowledge (Forsyth, 2008; Peluso, 1993; Robbins, 2012).

\subsection{2. 'Insiders' and 'outsiders' in qualitative methodologies}

Not only are knowledge of conservationists and local knowledge situated, the knowledge produced by research is situated, contextualized, and contested. Researchers' perceptions, values, methods, and decisions, render research knowledge claims partial. The subjectivity of a researcher is manifested in both the research and writing process. Researchers need to be 'self-reflective about their role within the research process particularly about their political commitment' (Mohammad, 2001, p. 114). Katz argues 
that ethnographic work entails displacement from home and ethnographers are 'displaced persons - first to see, then to speak' (Katz, 1994). Katz writes (Katz 1994, p. 68):

There is the power to define 'the field' which imposes me/the fieldworker on the time-space of others. I am an outsider in this context, but once there, of course am not outside the power dynamics of the space so marked.

This power dynamic does not have an apparent impact on research, but it has a sly and definite presence in all its processes. As a researcher, my position is "neither inside, nor outside' (Katz, 1994). The issue of insider/outsider is not binary with a clear order; rather it entails complexity and volatile dynamics. It involves the way that the researcher positions herself, the way local people position the researcher, and the ongoing negotiation of positioning between the researcher and the researched. Heterogeneity of the community and local people's different interests and agendas play an important role in the process of the above negotiation (Dwyer \& Limb, 2001, p. 10; Mohammad, 2001, p. 112). What is important is acknowledging: a) 'the implications and significance of the researcher's choices as both observer and writer' (Bryman, 2001, p. 470); and b) that the production of knowledge is a version of truth out of other possible truths (Mohammad, 2001, p. 112). Therefore, it is important that the researcher be explicit about (Mohammad, 2001, p. 113):

'which truth?' Or 'whose truth?' is being told. Whose interests are being served by a particular representation? In this way it is possible and indeed necessary to affirm the legitimacy of some representations over others. It is, therefore, the researcher's/author's responsibility to choose and affirm his or her political commitment through the types of representations he or she seeks to make, irrespective of his or her social position, color or gender.

\subsection{Participatory approaches and methods}

There is increasing interest in participatory approaches in geography, anthropology, sociology, environmental and cultural studies and new methodologies are 
being developed through on-going research on sustainable development, sustainable rural livelihoods, and political ecology. Although the participatory practices, Participatory Action Research (PAR), Participatory Rural Appraisal (PRA) and Rapid Rural Appraisal (RRA) have different starting points and different goals, they share a general interest in participatory techniques. These approaches are well suited to the study of glocal wetlands due to their consideration for plurality and sensitivity to the power relations of those involved.

Figure 3.1 compares Participatory Action Research, Participatory Rural Appraisal, and Rapid Rural Appraisal in terms of local people empowerment and ownership of data. Participatory Rural Appraisal is a common term used to identify approaches and methods that try to incorporate local knowledge into planning processes by enabling local people to conduct their own analysis and share and enhance their knowledge.

\begin{tabular}{|l|l|l|}
\hline Participatory methods & $\begin{array}{l}\text { Outsider's ownership } \\
\text { of data and results }\end{array}$ & $\begin{array}{l}\text { Local empowerment } \\
\text { and ownership }\end{array}$ \\
\hline Participatory Action Research & & \\
\cline { 1 - 2 } Participatory Rural Appraisal & & \\
\hline Rapid Rural Appraisal & & \\
\hline
\end{tabular}

Figure 3.1. A comparison of Participatory Action Research, Participatory Rural Appraisal, and Rapid Rural Appraisal

Participatory Rural Appraisal is experiential, meaning that its theory has been generated from practice and not from propositions (Chambers, 1994a, p. 1449). The PRA methods and approaches have benefitted from Participatory Action Research methods, field research on farming, agro-ecosystem analysis, land improvement and development, and agrarian reform, and have directly evolved from Rapid Rural Appraisal (Chambers, 1994a, p. 1437; Rass, 2013). RRA was developed in the 1970s and 1980s while PRA 
evolved in the late 1980s and the $1990 \mathrm{~s}^{45}$. PRA shares some components with RRA, such as pluralism and direct learning from local people, but it has essential differences. The main difference is that PRA pays attention to the behaviour of outsiders, aims for empowerment of local people and has more emphasis on facilitating processes (outsiders act more as facilitators and catalysts), while RRA's objective is for outsiders to learn from local people (insiders) and is more extractive (outsiders are investigators) (Chambers, 1994a; Rass, 2013). Robert Chamber (1994b), the well-known proponent of PRA, goes further and describes PRA as a method that is intended to enable local people to conduct their own analysis (analyze their needs and identify solutions to fill those needs), to plan and to take action (Chambers, 1994b, p. 953). This view brings it very close to Participatory Action Research (also called Participatory Learning and Action), which is a more activist approach whereby facilitators work with local people to empower local communities to take more control of research agendas, methods, analysis, and outcomes, to ultimately develop and implement a plan of action. PAR methods explore how to mainstream the interests of the disadvantaged groups by putting the 'farmers first' (Borgerhoff et al., 2005, p. 295; Rass, 2013).

Participatory methods of sharing and analyzing information by local people are often visual. Visual participatory techniques include transect walking, matrix scoring, well-being group ranking, seasonal calendars, sketch maps, institutional diagramming (Chapati maps or Venn Diagrams), relationship flow diagrams, trend change analysis, and analytical diagramming (Chambers 1994a: 1437; Chambers, 1994c, p. 1257; King 2002).

\footnotetext{
${ }^{45}$ PRA spread from Africa and India and from 1994 is being quiet widely practiced in Africa, Asia and Latin America. NGOs are the main users of PRA methods and students and faculty in universities are increasingly exploring the use of PRA for field work (Chambers, 1994c, p. 1253; Chambers, 1994a, p. 1473).
} 
Participatory methods are not orthodox techniques without deviation; rather, they are creative approaches (Beazley \& Ennew, 2006). There is always the possibility of developing new kinds of maps and diagrams to address a particular issue in a particular community.

The degree of local participation involved is compatible with the objectives and tasks of projects which are not always geared towards maximum participation. Figure 3.2 illustrates how increasing degrees of participation in initiatives in terms of 'insiders' relative to 'outsiders' roles in controlling the process affects the ownership of information and knowledge produced. From lowest to highest, the four levels of participation, associated with the objectives and purposes of projects are:

(1) Facilitation/extraction: Participation is promoted to facilitate an external project and improve its efficiency (McCall, 2004). Outsiders, researchers (including academia) and planners, determine the topics and extract and exploit the local knowledge for better planning (Chambers, 1994a; Hutchinson \& Toledano, 1993; McCall, 2004; Rass, 2013). The information extracted belongs to outsiders and local people are only informants (Chambers, 1994a; Rass, 2013).

(2) Collaboration/consultation: Participation is promoted to increase the effectiveness and efficiency of a project and essentially to legitimize an external project in top-down spatial planning (Harris \& Weiner, 2002, p. 248; Chambers 1994c). Outsiders define problems and solutions, refer them to local people for refinement or prioritization, and finally convert the analysis into scientific knowledge (McCall, 2004; Rass, 2013). This kind of consultative process is usually donor-driven and seeks to direct external interventions towards local needs (Rambaldi \& Weiner, 2004; McCall, 2004). Local people are collaborators and the outsiders elicit indigenous knowledge in seeking to 
understand and assess needs and problems, alternative solutions (mitigations) in social, economic, cultural and environmental contexts, and design, implement and monitor some of those alternatives (Chambers, 1994c; McCall, 2004). For example, although discussion and communication of information on planning scenarios, resolution of potential resource use conflicts, and land tenure are encouraged, the outsiders do not have any obligation to involve local people in the decision-making process (Quan, Oudwater, Pender, \& Martin, 2001; Rass, 2007).

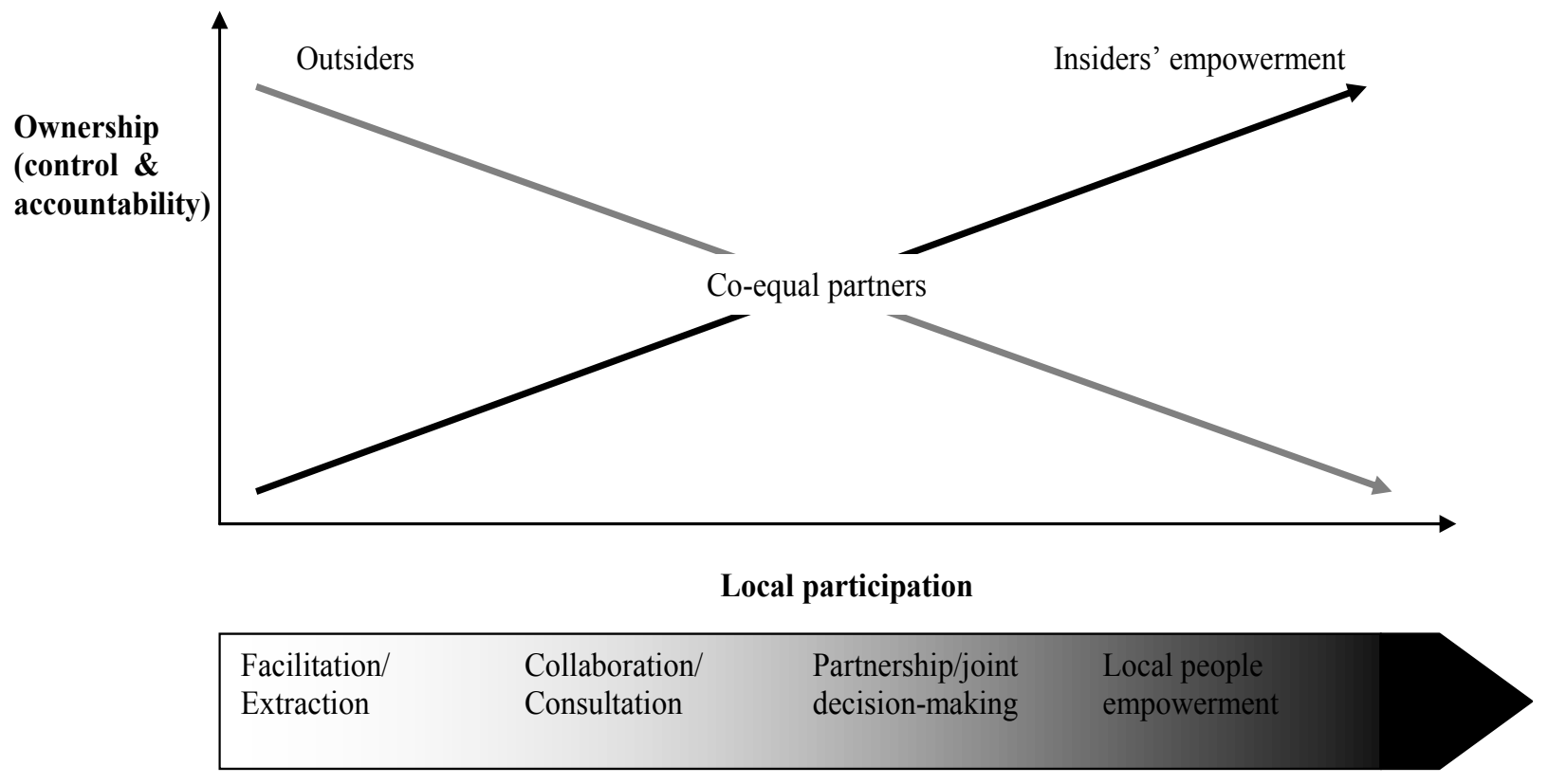

Figure: 3.2. Degree of local participation in participatory exercises

(3) Partnership/joint decision-making: Participation is externally initiated to promote local decision-making. Local people are involved in the tasks listed under collaboration and further into decision-making. They participate in joint analysis, are coequal partners with outsiders and share responsibility and power with them, but 
'democratic decision-making in practice does not necessarily lead to empowering disadvantaged members' (Rambaldi and Weiner 2004, p. 2).

(4) Empowerment: Participation is a local and self-mobilizing initiative through which local people control the process and are owners of the information and outsiders are supporters (Chambers 1994a). Empowerment will be achieved if full participation occurs throughout the process (identification of problem, data collection, spatial analysis, map representation and decision-making) and leads to action plans and formation of new local groups (or strengthening existing ones) that take control over local decisions (McCall, 2004; Rass, 2013). These projects ideally lead to 'equitable distribution of wealth and power' (Rambaldi \& Weiner 2004; Rass, 2013).

\subsubsection{Conservation territories and participatory mapping}

Conservation practices and spatial management are map-based and zoning is an important part of them (see Section 2.3.3). Scaling areas within conservation territories and map-based spatial management form the backbone of conservation management schemes and planning (Zimmerer, 2000). Designation of conservation territories entails the landscape and seascape being divided into polygonal territories of inclusion and exclusion, and acceptance and prohibited land uses (Rocheleau, 2008, p. 723). The spatial character of conservation practices makes counter-mapping, through exercise of participatory mapping, an essential practice in studying people-environment interactions in glocal wetlands.

\subsubsection{Mapping and spatial knowledge}

Maps are not an exact 'reflection of reality though they appear to have scientific objectivity' (Sletto, 2002). Harley (1989) suggests that cartography 'as a practice' and 
maps 'as social products' are embedded in various systems of power and knowledge and mapmaking has the tendency to 'codify, to legitimate, and to promote the world views which are prevalent in different periods and places' (Harley, 1989). (Del Casino \& Hanna, 2006, p. 37; Harris \& Hazen, 2006, p. 101). Rambaldi quotes Poole (1998) (Rambaldi, 2004, p. 6):

Maps produced by European explorers were exemplar expression of cartographic power: by ignoring indigenous names, and barely alluding to the presence of local settlements, in effect they declared the land to be empty and available.

Theoretically, production of 'multiple maps' is a step toward democratizing cartographic production (Del Casino \& Hanna, 2006). Maps shape our perception of place and are political and technical (Cahapin, 2006, p. 14). Their political nature comes to the surface particularly when they are put into use. Fox and his colleagues state (J. Fox, Suryannata, Hershock, \& Pramono, 2005, p. 7): 'Communities that do not have maps become disadvantaged as rights and power are increasingly framed in spatial terms.'

In one way or another mapping, spatial analysis, and GIS are necessary in almost all levels of biodiversity conservation planning, monitoring, and management of natural resources (Harris \& Hazen 2006, p. 100; Zimmerer, 2006a). These techniques, which are part of new 'place-making projects' (Agnew, 2011, p. 11), are used in: designing and mapping protected areas; zoning (land use and buffer); predicting resource use and land use conflicts; and development and land use in the broader landscape, etc. The term 'mapping for conservation' refers to 'linking conservation goals to specific territories' and, in general, encompasses the complex spatial and territorial mapping practices common to conservation strategies (Harris \& Hazen, 2006). 'Mapping for conservation' and cartographic advances need to respond to evolving biodiversity conservation 
strategies and the new understanding of protected areas and flexible and spatially unfixed conservation strategies (see Section 3.2.1.2).

Global conservation guidelines show the spatial primacy of conservation practices and that there is a trend for spatial knowledge (Zimmerer, 2006b), which is timeless and placeless. That comes from the notion of nature, as a globalized resource, which is neither situated in biological and social time, nor in biophysical and social space. In other words, nature is abstracted from its social and historical context (McAfee, 1999) to develop a one-dimensional spatial knowledge of it. There is a need to understand the space-time linkage of spatial knowledge. Massey explains that maps are not representations of space only, but rather of space-time, by representing things at a moment (Massey, 2003, p. 4). Gregory asserts that (Gregory, 2000, p. 772): 'Space is not a pre-existing void or a terrain to be filled or spanned or constructed but is instead practiced and performed' so it is timebounded. Therefore, any inventory or mapping is a space-time practice. A glance at the natural and social components of landscape does not reveal the inter-linkages of naturesociety hybrid. Cross-scale relations of space-time include the work routines of the land users interacting with their environment (e.g. herders living and working in rangelands, herders-rangelands) (Zimmerer, 2000). Rocheleau states (Rocheleau, 2008, p. 723):

Multiple and conflicting claims to land based on precedents for human use, rights of use and access, actual and perceived needs of humans and other species, all determine spatial re-structuring and new demarcation of territories across scale.

'Counter-mapping' or mapping against power refers to alternative representations and map forms (such as wave patterns, locally drawn sketch maps, and storytelling) generated through participatory mapping exercises are explicitly planned to overcome predominant power hierarchies, 'interspecies justice', and other power effects (Borgerhoff et al., 2005; Harris \& Hazen, 2006; King, 2002; McCall, 2003; Peluso, 
1995). Counter-maps are intended to represent the needs of marginalized and 'dispossessed' groups who are usually excluded from the scientific, social and institutional surveys and planning; they challenge existing spatial management documents (King, 2002; McCall, 2003; Peluso, 1995; Robbins, 2003). For example, a counter-map of resource use and management developed by rural women counters the more conventional resource maps made by men (McCall, 2004; Rocheleau, Thomas-Slayter, \& Edmunds, 1995). Counter-mapping (e.g. sketch maps, mental maps) that provides a depiction of local and indigenous, spatial and technical knowledge (including natural resource use) is particularly useful when local communities, that are affected by conservation, resource management, or development processes, are in conflict resolution with outsiders and in land use disputes where local livelihoods, rights and knowledge are subverted (Corbett et al., 2006). Local communities can take an active role in demarcating their resources, defending traditional territory, or reclaiming historical places by renaming them in vernacular language (Corbett et al., 2006; Poole, 1995). Counter-mapping can be initiated by local people, a local NGO or an international organization and may involve various degrees of local participation.

By counter-mapping, local communities map their lands instead of being mapped by others and being further marginalized. Participatory mapping exercises provide opportunities for local communities to use the maps for their own benefit: contribute information to convey their message; demonstrate their point of views; and participate in decision-making processes. However, participatory mapping exercises are viewed as simultaneously empowering and marginalizing local communities and indigenous people (Harris and Weiner, 1998; J. Fox et al., 2005) depending on how they are practiced and 
for what purpose. The following issues are some of the concerns at the empowermentmarginalization nexus:

Ownership: In a participatory mapping project, it is important to determine who owns the map (insiders as a community, or outsiders), how it is stored ${ }^{46}$, and who has access to its information (Tripathi \& Bhattarya, 2004, p. 7). Community ownership and control of confidential mapped-information generated by the community means they have control over and access to the information; this can lead to community empowerment and social change (J. Fox et al., 2005; S. Fox, 2000; Rambaldi, McCall, Kwaku Kyem, \& Weiner, 2006). However if local people do not have control over their maps, i.e. how they should be used and for what purpose, they might be better not mapping their lands (J. Fox et al., 2005, p. 10). Protection of local spatial data about the natural, physical and biological resources of a community has cultural, ethical and economic reasons. Examples of data layers to be protected include traditional hunting areas, birds' nests and honey trees, sacred sites, and customary property demarcations ${ }^{47}$. Identification of institutional and legal mechanisms for ensuring 'intellectual ownership of local knowledge' and 'communal right of privacy' is essential in order to safeguard rights of local people against rapid processes of globalization (McCall, 2003, 2004; Rambaldi, McCall, et al., 2006).

\footnotetext{
${ }^{46}$ Options for storing and protecting sensitive confidential layers proposed by Landcare Research in New Zealand are (McCall, 2003): "recording the information as concealed files linked to a GIS and needing a permission; recording the information as an overlay, e.g. a grid at crude scale, which prevents specific site identification; or, providing a hyperlink to a recognised (Maori Iwi) authority responsible to answer queries."

${ }^{47}$ Examples of confidential data layers from projects in USA, and New Zealand (McCall, 2003): a) "Traditional hunting, fishing, grazing, medicinal herbs collection", fuel collection lands, b) "customary boundaries and subdivisions of culture areas-tribes, neighborhoods, customary property, personal space", c) "historic places, neighborhoods, Holy sites, burial grounds, ceremonial areas, buried cultural objects", d) "indigenous sacred place names, cosmological locations, sacred pathways, song lines."
} 
Conflict resolution: Participatory mapping is intended to facilitate communication between insiders and outsiders and to enhance local community capacity to take part in negotiations and mediations regarding 'access, use, control and allocation of natural resources and management' between and among local people, between local communities and the state; and among communities, the state and the private sector (Rambaldi, McCall, et al. 2006, p. 3). Ideally, participatory mapping is supposed to assist in spatial decision making and conflict analysis through consensus building which results in decisions that are 'just' and acceptable to all stakeholders (McCall, 2005, p. 17) .

Increased conflict: Results of participatory mapping may be helpful in resolving disputes between local communities and government agencies but at the same time may lead to conflicts within and between local communities with regard to the management of natural resources. Customary boundaries are usually flexible, however, better, more, and detailed spatial information particularly for land claim disputes, land tenures, and decentralization processes requires delineation of boundaries (J. Fox et al. 2005, p. 11). Altering fuzzy, fluid, seasonal and overlapping boundaries and people's 'mental image of landscape' to fixed lines on maps results in fixed positions, less compromise in disputes, and sometimes more conflicts between local communities and villages (J. Fox et al. 2005, p. 11). Mapping by making local knowledge into public knowledge accessible to all and also by setting fixed boundaries may be initiated to recognize collective rights but may also weaken existing common property management systems and over-simplifies overlapping claims (J. Fox, Suryannata, Hershock, \& Pramono, 2006, p. 104; McCall, 2006, p. 116). Resource mapping which is carried out without acknowledging complex overlapping boundaries and hierarchical claims over resources may lead to land and 
resource privatization that is exclusive $e^{48}$, and may also cause dispossession ${ }^{49}$ (Abbot et al., 1998, p. 29; J. Fox et al., 2006, p. 103; J. Fox, 1998). Drawing sharp lines or outlining boundaries, during participatory mapping and participatory GIS projects, is advisable only to address specific boundary-related issues.

Increased tension: Any less advantaged and lower group in a community might be exposed to danger and abuse when the outsiders have left after a participatory project. This has occurred especially to women who contributed to participatory activities (Chambers, 2006, p. 7; Rambaldi, Chambers, McCall, \& Fox, 2006, p. 110).

Exposing people to danger or risk of forced eviction: There are examples of participatory mapping projects in which the extracted information has been used against people. For example, documented traditional logging practices in a village in Indonesia, carried out by the villagers, was used against them and put them in a position of illegality (Rambaldi, Chambers, et al., 2006, p. 109). Some categories of protected areas and conservation strategies exclude local people from the area with conservation value, therefore, participatory mapping practitioners should not ask indigenous people to map any information and/or spatial knowledge that may lead to their displacement or eviction (Rambaldi, Chambers, et al., 2006, p. 112).

\footnotetext{
${ }^{48}$ For example nomadic people who are generally not represented in the mapping process and do not claim any territory or when local people lose their right to collect food from wetlands

${ }^{49}$ For example a woman who facilitated the mapping of her village then sold the land to outsiders Some communities in Mosquitia region of Nicaragua blocked an overlapping subsistence area and excluded its neighboring community. Another project in Bolivia decided not to delineate fixed boundaries in its participatory mapping exercise to avoid conflicts (Chapin, Lamb, \& Threlkeld, 2005). A mapping and land titling in Thailand oversimplified overlapping claims and led to more conflicts (Ganjanapan, 1994).
} 
Identity building: Through the participatory mapping process local communities get a chance to foster their community cohesion by identity building, and preserving their intangible cultural heritage ${ }^{50}$.

Villagers sacrifice their time: Participatory mapping practitioners must avoid taking too much of people's time, especially during critical times of the year (e.g. during the rains or the time for weeding). That may cause hidden costs for villagers, particularly with small harvests, and further marginalize poor groups (Rambaldi, Chambers, et al., 2006, p. 109).

\subsubsection{Boundary making and zoning of conservation territories}

A widespread zoning practice for conservation territories is use of Biosphere Reserves structures (core, buffer and transition areas), and this is also encouraged by the Ramsar Convention. Conservation practices and spatial management are map-based and zoning is an important part of them. Scaling areas within conservation territories and map-based spatial management form the backbone of conservation management schemes and planning (Zimmerer, 2000). Zoning was a response to the need for more flexible borders in conservation management schemes but practically it has not solved the problem of fixed boundaries, rather it generated a number of new problems by making more fixed borders and rigid and bounded zones, which are legal, discursive, political, economic and environmental (Zimmerer, 2000, p. 363). A core zone is a strictly legislated, protection area in which no human activity is allowed; a buffer zone is a legislated boundary and protection area which allows for the activities such as ecosystem research and rehabilitation of landscapes damaged by humans; transition area is a

\footnotetext{
${ }^{50}$ Alcorn (cited in Rambaldi, McCall, et al. 2006, p. 3) states: “[...] old people share history with young people, passing on legends and religious beliefs, sacred rites and places so essential to conserving tradition" (Alcorn, 2000).
} 
variable, open boundary, sometimes referred to as the area for sustainable production or the area of cooperation and includes managed uses in harmony with biosphere reserves (UNESCO, 2013). A national park normally has a core area and a buffer zone and the Convention on Wetlands encourages use of the Biosphere Reserve structure (core, buffer and transition) for wetland management plans. Restriction is an important element of this scaling and each land-use zone has two fixed features: a) limited and specific resource use or practices are allowed; and b) it is geographically fixed (Zimmerer, 2000). The zoning of parks and reserves is a means to help managers of parks to meet conservation objectives and is expected to change or be modified in accordance with shifts in conservation goals. While the emergence of 'new ecology' and non-equilibrium landscapes is leading conservationists toward new conservation principles and policies, spatial approaches to conservation are still in accordance with the old notions of ecology and ignore the post-normal science of the non-linearity and unpredictability of complex systems. The shift to 'new' ecology spatial approaches requires fundamental spatial adjustments, such as: incorporation of local knowledge on land rights into the process of designing new conservation area boundaries; conserving and reinforcing local and traditional knowledge; designing multiple use conservation areas; developing innovative plans for protected areas (in terms of size and shape) with multiple, flexible or blurred boundaries and greater spatial and temporal flexibility against fixed notions of spaces of conservation (e.g. seasonal flexibility or other time based fluctuations); planning transboundary reserves and continental permeability for mega-fauna; and improving inter-part connectivity by linking parks through wildlife corridors, and buffer zones (Harris \& Hazen, 2006, p. 112; Zimmerer, 2000). 
The form and function of conservation territories need to be improved through engagement with local people and land and resource users by incorporating their perceptions and concepts of areas and scales. Instead of having fixed zones, scaling of conservation territories may have overlapping patchworks or multiple boundaries, which are negotiated through multi-scale cooperation of local communities and government institutions. Patchworks represent the heterogeneity of society-nature hybrids and land use areas. Each patchwork is conceptually distinct in accordance with local peoples' perceptions and land use practices, which present fluxes that may lead to overlap of buffer and core zones (Zimmerer, 2000).

\subsubsection{Focus groups}

The focus group is a primary qualitative research method for 'understanding and documenting attitudes, behaviours and the meaning of people's world' (Lloyd-Evans, 2006). The strengths of well-moderated focus groups in field research are that they can generate rich data on group views, experiences, beliefs and reasons for collective action. Data from focus groups: a) are not the result of community consensus and one needs to keep in mind that 'material collected in focus groups is a reflection of the views of the

group at that given space and time' (Lloyd-Evans, 2006); b) might be influenced by the group environment, the peer pressure, and dominant and powerful voices; and c) are not reducible to individuals' lives and behaviors (Lloyd-Evans, 2006). Group interactions, disputes and agreements are also points of interest for a researcher.

\subsubsection{Interviews}

Interviews can range from an unplanned and unstructured conversation (informal interviews) to fixed question-and-answer formats (Willis, 2006). They allow 'insights into 
individuals' lives which go beyond observations and questionnaire survey' and are also a good way of collecting factual information (that is not published) from government authorities or NGOs (Willis, 2006). The 'accuracy' and 'representativeness' of interviews are of concern (Willis, 2006, p. 150).

Representativeness: A small number of interviewees discussing issues pertinent to a wider group may not be representative of the whole group. In that case, any concern regarding representativeness of the interviewees must be identified and reported in the research results and analysis (Willis, 2006).

Accuracy: Interviews entail two agents: the 'interviewer' and 'interviewee', therefore, the dynamic between the contributors is embedded in the knowledges produced, which 'are always version' (Mohammad, 2001, p. 113). Researchers don't know if the interviewee is telling 'the truth' or what they think is the 'right answer'. Interviewers require skill to get better information and better answers. Willis writes 'your positionality and the way it will be interpreted by interviewees must always be considered' (Willis, 2006, p. 150).

\subsection{Research design and methods}

Research design describes what methods are used and what data are collected to answer the research questions. This research on glocal wetlands uses context-specific methodologies, and participatory approaches to develop a research design that ensures the collection of adequate data to allow the analysis of the people-environment interactions in the AUA landscape and the study of ecological processes in their political and economic context. This context-specific methodology has a particular reference to: resource use and management of commons; access to resources; governance; and conservation policies and 
discourse. Table 3.1 presents a summary of the research analytical framework, questions, methodology, and the research methods applied.

Rapid Rural Appraisal is used to investigate and examine people-environment interactions, livelihood strategies and their change over time using people's knowledge about their environment, their traditional land and water use, and their obstacles and needs. Participatory methods are used, in an extractive practice with minimum level of local people empowerment (Figure 3.1), to collect data that will belong to the researcher. Nonetheless, this research is empowering for local people because it directs its goals towards local needs and, for the first time, has involved the Tenglians in a participatory research setting that seeks their opinions and knowledge about the issues that concern them. It provides support for the Tenglian's rights to tenure over and access to their ancestral lands, water and natural resources.

Annex A presents a fieldwork calendar that includes interviews, places visited and other relevant research activities from October 13 to December 24, 2008. 
Table 3.1. Research summary: analytical framework, questions, methodology, and methods

\begin{tabular}{|c|c|c|c|c|}
\hline $\begin{array}{l}\text { Analytical framework } \\
\text { for studying change in } \\
\text { glocal wetlands }\end{array}$ & $\begin{array}{c}\text { People-environment } \\
\text { interaction in the AUA } \\
\text { region }\end{array}$ & Research questions & Methodology & Methods \\
\hline \multirow[t]{2}{*}{$\begin{array}{l}\text { (A) Wetlands (non- } \\
\text { human entities) and their } \\
\text { social construct cannot } \\
\text { be studied separately, } \\
\text { therefore, any change in } \\
\text { ecological character of a } \\
\text { wetland needs to be } \\
\text { examined in the context } \\
\text { of a nature-society } \\
\text { hybrid. }\end{array}$} & \multirow[t]{2}{*}{$\begin{array}{l}\text { The AUA Ramsar Site, } \\
\text { which is constituted } \\
\text { through discourse of } \\
\text { conservation and notion } \\
\text { of purified nature is a } \\
\text { nature-society hybrid. Its } \\
\text { study entails } \\
\text { examination of humans } \\
\text { and non-humans at the } \\
\text { same time. }\end{array}$} & $\begin{array}{l}\text { Question1: How have } \\
\text { people-environment } \\
\text { interactions formed the } \\
\text { AUA landscape as part } \\
\text { of the Turkmen Sahra, } \\
\text { and how has it changed } \\
\text { over time? } \\
\text { (Chapter IV) }\end{array}$ & $\begin{array}{l}\text { This question is addressed } \\
\text { through a historical } \\
\text { examination, which describes } \\
\text { how people-environment } \\
\text { interaction has shaped the } \\
\text { AUA landscape. } \\
\text { Understanding the historical } \\
\text { relationship dismantles the } \\
\text { divide between the natural and } \\
\text { social. }\end{array}$ & $\begin{array}{l}\text { Archival research, } \\
\text { literature review, } \\
\text { participatory } \\
\text { mapping, and } \\
\text { seasonal calendar }\end{array}$ \\
\hline & & $\begin{array}{l}\text { Question 2: What are } \\
\text { contemporary people- } \\
\text { environment interactions } \\
\text { in the AUA region? } \\
\text { (Chapter V) }\end{array}$ & $\begin{array}{l}\text { Examining and describing } \\
\text { contemporary livelihood } \\
\text { strategies of the Tenglians and } \\
\text { their trends in the AUA region } \\
\text { address this question. }\end{array}$ & $\begin{array}{l}\text { Structured and } \\
\text { semi-structured } \\
\text { interviews, and } \\
\text { quantitative } \\
\text { analysis }\end{array}$ \\
\hline
\end{tabular}

Continued... 
Table 3.1. Research summary: analytical framework, questions, methodology, and methods

\begin{tabular}{|c|c|c|c|c|}
\hline \multirow{3}{*}{$\begin{array}{l}\text { (B) Glocal wetlands like } \\
\text { any other conservation } \\
\text { territory are part of } \\
\text { intertwined socio- } \\
\text { political and economic } \\
\text { processes and networks } \\
\text { crossing multiple levels. } \\
\text { These networks and } \\
\text { relationships are referred } \\
\text { to as power geometries } \\
\text { through which every } \\
\text { actor engages in political } \\
\text { agendas. Therefore, } \\
\text { inclusion and removal of } \\
\text { any wetland in the } \\
\text { Montreux Record } \\
\text { requires a contextual } \\
\text { analysis. }\end{array}$} & \multirow{3}{*}{$\begin{array}{l}\text { The AUA Ramsar Site } \\
\text { owes its existence to } \\
\text { embedded, uneven, and } \\
\text { dynamic relations of } \\
\text { power, crossing global to } \\
\text { local levels. Therefore, } \\
\text { local conditions, life of } \\
\text { local people and daily } \\
\text { practice of conservation } \\
\text { in the AUA region } \\
\text { emerge in practice, and } \\
\text { are articulated, through } \\
\text { interaction between } \\
\text { actors and intertwined } \\
\text { political and economic } \\
\text { processes (access to } \\
\text { resources, land use and } \\
\text { management of } \\
\text { commons, governance, } \\
\text { and conservation } \\
\text { policies and discourse) } \\
\text { crossing multiple levels } \\
\text { from global to local. }\end{array}$} & $\begin{array}{l}\text { Question 3: How is the } \\
\text { state's power exercised } \\
\text { in the region, and what } \\
\text { are territorial approaches } \\
\text { in the Turkmen Sahra? } \\
\text { (Chapter VI) }\end{array}$ & $\begin{array}{l}\text { This question is addressed by } \\
\text { examining the working of } \\
\text { webs of power relations, which } \\
\text { constitute the AUA glocal } \\
\text { wetland and its surrounding } \\
\text { area including state building } \\
\text { processes and the state's } \\
\text { territorial approaches: access } \\
\text { to resources, and land use and } \\
\text { management of commons. }\end{array}$ & $\begin{array}{l}\text { Secondary data } \\
\text { analysis, literature } \\
\text { review, and semi- } \\
\text { structured } \\
\text { interviews }\end{array}$ \\
\hline & & $\begin{array}{l}\text { Question 4: How do the } \\
\text { state's territorial land, } \\
\text { water and conservation } \\
\text { policies affect the AUA } \\
\text { landscape and the } \\
\text { Tenglians in pursuit of } \\
\text { their livelihood } \\
\text { strategies and access to } \\
\text { resources? } \\
\text { (Chapter VII) }\end{array}$ & $\begin{array}{l}\text { This question is addressed } \\
\text { through explaining the current } \\
\text { land use and tenure, and access } \\
\text { to resources in the AUA } \\
\text { region. This analysis } \\
\text { demonstrates who loses and } \\
\text { who benefits from the Islamic } \\
\text { State's territorial policies in } \\
\text { the AUA region. }\end{array}$ & $\begin{array}{l}\text { Secondary data } \\
\text { analysis, } \\
\text { structured and } \\
\text { semi- structured } \\
\text { interviews, and } \\
\text { participatory } \\
\text { mapping }\end{array}$ \\
\hline & & $\begin{array}{l}\text { Question 5: Where has } \\
\text { the control over rights } \\
\text { been located in the } \\
\text { Islamic State? (Chapter } \\
\text { VIII) }\end{array}$ & $\begin{array}{l}\text { This question is addressed by } \\
\text { analysing power relations of } \\
\text { the Iranian Islamic nation-state } \\
\text { in making of the AUA region, } \\
\text { and examining Iran's political } \\
\text { system, administrative and } \\
\text { governance system and } \\
\text { ethnicity, and minority rights. }\end{array}$ & $\begin{array}{l}\text { Secondary data } \\
\text { analysis literature } \\
\text { review, and semi- } \\
\text { structured } \\
\text { interviews }\end{array}$ \\
\hline
\end{tabular}

Continued... 
Table 3.1. Research summary: analytical framework, questions, methodology, and methods

\begin{tabular}{|c|c|c|c|c|}
\hline $\begin{array}{l}\text { (C) Conservation and } \\
\text { wise use of wetlands } \\
\text { promoted by Convention } \\
\text { on Wetlands do not have } \\
\text { universal functions and } \\
\text { consequence. Contextual } \\
\text { analysis of any glocal } \\
\text { wetland requires } \\
\text { examining how } \\
\text { conservation and goals } \\
\text { of Ramsar Convention } \\
\text { are perceived and } \\
\text { practiced in a place and } \\
\text { what political agendas } \\
\text { are involved. }\end{array}$ & $\begin{array}{l}\text { The AUA Ramsar Site } \\
\text { and local practice of } \\
\text { conservation in the AUA } \\
\text { region is a product of, } \\
\text { among other things, the } \\
\text { conservation discourse } \\
\text { in Iran. }\end{array}$ & $\begin{array}{l}\text { Question 6: How is } \\
\text { conservation perceived } \\
\text { and understood in Iran? } \\
\text { (Chapter IX) }\end{array}$ & $\begin{array}{l}\text { This question is addressed by: } \\
\text { first, reviewing global } \\
\text { conservation and wise use } \\
\text { discourse and elaborating on } \\
\text { what kind of conservation is } \\
\text { the goal and how states can } \\
\text { engage in socially-just } \\
\text { conservation; second, } \\
\text { examining the processes } \\
\text { through which conservation is } \\
\text { codified in Iran and the power } \\
\text { relations and national and } \\
\text { international alliances that are } \\
\text { involved in that network with a } \\
\text { focus on the Ramsar } \\
\text { Convention and the AUA } \\
\text { Advisory Mission Report. }\end{array}$ & $\begin{array}{l}\text { Secondary data } \\
\text { analysis, literature } \\
\text { review, and } \\
\text { structured and } \\
\text { semi- structured } \\
\text { interviews }\end{array}$ \\
\hline
\end{tabular}




\subsubsection{Site selection and preparation}

This fieldwork was facilitated by two university professors in Tehran. They found a reliable local coordinator in Gorgan, and coordinated my interviews with university professors, consultancy firms, and the Government authorities in Gorgan and Tehran. The initial plan was that the local coordinator, who knew the elders of the village, would come to Tengli from Gorgan every few days to facilitate interviews and participatory exercises but after I found a local assistant the coordinator was no longer regularly needed in Tengli. He came back in the last day of my stay in Tengli and coordinated the interviews in Gorgan. I was advised that I would be able to conduct research in Tengli, for a time period that should not exceed three months. Various obstacles reduced the fieldwork period to one month.

Of the four Turkmen villages near the AUA, Tengli was selected for a case study because it is the only village adjacent to Ulmagol and the Tenglians have access to Alagol and Ajigol. Also, Tengli had previous experience of hosting outside research personnel (ecologists). During my first visit to Gorgan and Tengli, in November, 2007, I visited the Golestan Department of Environment and received approval to conduct fieldwork regarding 'public participation in the protection of the AUA Wetlands of International Importance'. I also met with two elders in Tengli and explained that I had approval to carry out research about the AUA and that I would like to stay in the village during the fieldwork. One of the elders invited me to stay at his house for as long as it took. The local coordinator explained that my host had previously let a few ecology researchers camp on his property but they had not been living in his house. Being a woman was 
probably the critical factor in being invited to stay with his family for as long as I required.

I returned to the village in October 2008, with the intention of staying for three months. In a three-hour meeting with the elders of Tengli and the local coordinator, I introduced myself and explained the goals of my research, the methods I would like to use that would require the Tenglians' involvement and, in compliance with Carleton University's ethics clearance for human participation research, mentioned every point indicated in the verbal script attached to the application (see Annex B). Considering the conversations we had I found it useful to add the following statement to the script, to prevent any potential misunderstandings between the interviewees and myself, and make my humble position clear:

I would like to emphasize that what I am doing is just a university research project and I have no executive power. In fact, you are the ones helping me to complete my education and I can't directly help you and have no power in changing your circumstances.

At the end of the meeting, the elders expressed interest in the research and stated their intended full cooperation with me. One even stated: 'we would like to thank you for choosing Tengli'. In one of the preliminary interviews for preparation of the research questionnaire, I asked an interviewee about his livelihood and well-being and what he thinks about conservation of the AUA and how it has impacted his life. I followed my questions with a repetition of the above statement stressing, that I am powerless in changing their circumstance. The interviewee responded:

In the last few years we lost our lands, water, rangelands and fish, but nobody asked us what we think and what we want. [I understand you have no power to change my circumstances] your presence gives warmth to my heart, at least now I know that there is someone who cares to ask me how I feel and what I think. 
My host's daughter-in-law, kind and caring hostess throughout my stay, introduced me to the village women at a baby shower. An enthusiastic young woman guest, a high school graduate, showed interest in becoming my research assistant. Regardless of no compensation being mentioned initially ${ }^{51}$, she wanted to 'work and be useful'. She arranged for her child care and had her husband's agreement. We met a few times and I explained the goal of the research and the fieldwork in detail and by her comments I realized that she could be a perfect assistant.

The efficiency of my research assistant, the capability of my hostess in planning and their effectiveness in social relations in Tengli were essential to the success of the fieldwork, irrespective of its limitations and twists. The women of Tengli unexpectedly changed the course of the fieldwork. Their unity and trust established a bond between myself and Tengli. There were difficult days filled with fear and tension when it was challenging to continue but I could not disappoint them and leave the village. They gave me strength to continue and I assume that I gave them hope that life could be different. Tenglians shared their stories and trusted that I will see their side and be their voice. The Tenglian women made that possible. I was still an 'outsider' but with the blessing of 'insiders'. How did that happen? I indeed do not know!

\subsubsection{Preliminary investigation}

The lack of recent research on socio-economic aspects of the AUA region made it necessary to conduct a preliminary investigation to obtain an overall idea about life in

\footnotetext{
${ }^{51}$ A few days later we discussed compensation for administering questionnaires and conducting structured interviews. The surveyors received the equivalent of $\$ 2.5$ per questionnaire and my research assistant in addition to that received approximately $\$ 180$. My hostess' kindness was priceless but as a small thank you I gave her presents: gold coins, food and treats. She gave me a beautiful Turkmen vest as a present and a souvenir from Turkmen Sahra and my stay at her house.
} 
Tengli as a guide to planning the field research activities ${ }^{52}$. Two sets of semi-structured interviews were conducted:

(1) Semi-structured interviews with the elders regarding wealth ranking of the Tenglians (see Section 5.2.2) and identifying their immediate concerns for their livelihoods and access to natural resources. In this preliminary investigation, I used a checklist of potentially important issues to investigate their relevance to Tenglians. The checklist included: customary/traditional wetland-related agriculture and land use; herding; fishing; hunting, salt extraction; water use (irrigation, domestic use, water mills, water transfer infrastructure); food preservation; culinary heritage; traditional craftsmanship (artifacts, tools, marketing, carpets, mats woven from perennial grasses, tanned skins, jewellery made from silver, nickel, domestic utensils; traditional building construction; tourism (eco- and cultural); leisure and sports; festivals and celebrations; practice of traditional medicine and use of plants; and spirituality and belief systems.

(2) Semi-structured interviews with heads of 12 households or their wives. These interviews were focused on collecting basic information regarding life in Tengli, Tenglians' livelihood strategies (past, present and future), their social and economic structure, obstacles and opportunities in accessing resources, their needs, and expenses and saving. The research assistant selected the households from four wealth categories through a snowballing technique based on their availability, knowledge and likely cooperation. I conducted ten interviews one day and the research assistant conducted two the next day.

\footnotetext{
52 The latest anthropological and social study research in the Turkmen Sahra belongs to William Irons and Carl Salzman in the 1960s and 1970s.
} 


\subsubsection{Structured interviews: Questionnaire}

\section{Preparation and administration:}

The research team was augmented by the hiring of 8 community members (surveyors) to assist in conducting the structured interviews. The research assistant chose the surveyors, and I trained all the research team members in how to administer the questionnaire and conduct structured interviews. The first training session explained: a) that the nine surveyors (including the research assistant) were to attain uniformity in asking the questions and in recording the answers; b) the purpose of every question, and what each question is intended to obtain; and c) the ethics of interviewing and the expectation that they would: be patient, and truthful; stop the interview anytime the interviewee would like to stop; discard the questionnaire that contains answers if the interviewee asked for it (and they would still be paid for that questionnaire); not put pressure on Tenglians to participate; not push for an interview if the head of the household or his wife were willing to participate but did not have the time; and to not manipulate the answers.

The research assistant and surveyors listed all the households ${ }^{53}$ of the village and divided the village into nine parts. Every surveyor administered 25 to 30 questionnaires and conducted interviews with the head of the households or their wives. Interviews were conducted and questionnaires completed for $225(96 \%)$ of the 235 of the households. The official government census in 2006 showed 243 families and a population of 1195 (Statistical Centre of Iran, 2006). The research assistant and surveyors believe that the discrepancy between the household and family numbers relates to how multigenerational

\footnotetext{
${ }^{53}$ This dissertation considers a household as "individuals who are all sharing a common kitchen or the same cooking pot and living under the same roof" (Evans, 1997, p. 18) and constitute one economic unit of production and consumption.
} 
families living in the same household have been counted. The 10 households not surveyed were excluded for reasons related to health, bereavement, absence or their unwillingness to be interviewed.

The questionnaires were numbered from 1 to 225 and the page number was written on every page. The first pages included personal data including the number of family members, age, gender and education, and were separated from the remaining pages immediately after the interview. I kept the first pages of the questionnaires and the remaining pages in different places in Tehran. The only person, other than myself, who had access to both the first page and the remaining pages was a reliable university student in Tehran who scanned them (see Annex A).

\section{Development:}

The questionnaire was developed, revised and redrafted in different stages. The initial draft was based on my limited knowledge of the area and was based mostly on the FAO guidelines for livelihood analysis (Messer \& Townsley, 2003) and research on natural resources and livelihood conducted in Laos in 2006 based on the DFID's (Department for International Development, UK) sustainable livelihood approach and framework (Leek, 2007). The second draft of the questionnaire was prepared after the preliminary investigation (see Section 3.3.2) and then revised and redrafted a few times after consultation with the research assistant and the surveyors. Interestingly, the research team member comments contributed to significantly improving the gender balance of the issues addressed. The final questionnaire was lengthy and covered a wide range of issues, not all of which have been analyzed in this dissertation. 
The questionnaire consists of five major sections including: livelihood strategies, well-being, land tenure and land use, and collection of reeds, jaroo ${ }^{54}$, mushroom and ejoveh $^{55}$. The organization and content of the questionnaire went through a process of revisions and redrafts by consultations with the research assistant and surveyors.

Analysis:

A database was developed in SPSS to which all the data from the questionnaire was transferred. Data from the questionnaire are analyzed quantitatively. The analysis includes simple frequency tables and graphs. Numerical data are used to identify trends and preferences of Tenglians and not to gain hard data. The results are triangulated with qualitative data collected through the participatory mapping exercise and interviews to support the arguments of this thesis, particularly those regarding the livelihood strategies of Tenglians and their change over time (Chapter V) and land use conflicts (Chapter VII). Although the Tenglians collect reeds, jaroo, mushroom and ejoveh, these are not included in livelihood strategy analysis because reeds are only used in the Tenglians' homes, income from jaroo is negligible, and mushroom and ejoveh are only for their consumption and do not constitute a big part of their diet.

\subsubsection{Participatory exercises}

\section{Participatory mapping:}

Village resource mapping was used for studying current land use and conflicts in space and landscape. Participatory mapping, carried out separately for men and women, produced counter-maps that present the collective interests and values of the men and the women of Tengli. The maps were quite different. Only the men's map has been used in

\footnotetext{
${ }_{55}$ A plant from the Gramineae family, used to make brooms.

${ }^{55}$ A plant (Allenia subaphylla) from the Chenopodiaceae family, typical of rangelands of arid and semi-arid zones of Central Asia, and used for food.
} 
this dissertation because it focused largely on the Tenglians' perception of resources, knowledge of wetlands and their reliance on their natural resources for their livelihood and cultural and spiritual practices. The women's map was largely mute on these aspects; its analysis addresses quite different issues ${ }^{56}$.

The participatory mapping exercise for men was conducted with the participation of three elders and one younger, knowledgeable man, selected using a snowballing technique. They mapped their living area and the status of their access to natural resources. This process shed light on social and economic conflicts among the Tenglians, but, after speaking in Turkmen among themselves, they informed me that they had decided not to focus on their internal affairs and instead they would discuss their main concerns, as a community: land use change in their area; their limitation in fishing and hunting; and the impediments they encounter to access their ancestral lands and water in order to continue farming. The resultant counter-map helped to make visible the conflicts over resources in the region. These issues were subsequently chosen as the core themes of my semi-structured interviews with government officials and university professors. Analyses of these data constitute the major arguments of Chapter VII.

\section{Seasonal calendar:}

Seasonal calendars were prepared for men and women, separately. People used to have busy days filled with the various activities relevant to farming, herding, fishing, and hunting, but recently their activities have been reduced mainly to work as wage laborers (livelihood strategies will be dicussed in Chapter V). These discussions were nostalgic and the participants used the past tense! The calendar that I developed using their information presents a picture of life in Tengli in the past (Chapter IV).

\footnotetext{
${ }^{56}$ The map could be an interesting topic for feminist research.
} 
Focus Groups:

I used focus groups mainly to support the findings of the Participatory Rural Appraisal methods I used. A few focus groups were conducted for understanding life in Tengli in the past and present and the Tenglians' traditional land and water use systems. My main interviewees were four knowledgeable Tenglian elders. Three of them remembered back to two generations ago in the community. The discussions were openended and were freely altered as new circumstances and information arose. The discussions centered on: customary resource and land use management systems, land tenure, common resources management, taboos and prohibitions, common beliefs and the cultural reliance of the local people on the wetlands.

\subsubsection{Secondary data analysis, literature review, and archival studies}

Secondary data analysis used in this research is mostly related to the structures and study of: political and administrative structures controlling land use, natural resource managements, and conservation practices; legal status of wetlands and regulatory provisions; land use change and water policies and regulations; fishing and hunting regulations; governance and administrative structures. These analyses shed light on stakeholders' partnerships, conflicts, and networks in the AUA area and identify the existing institutional and legal frameworks and patterns of interaction (at multiple levels) among those who make decisions or influence decisions about resources, those who have or need a resource, and those who are affected by use of a resource by others. The major source of the secondary data is Iranian Government websites, journalists and expert blogs relevant to the topic of study. Government websites are not consistently accessible, are not comprehensive and do not contain every rule and regulation. There were a few times 
that I used websites that, on attempted second visits after a few months, did not exist. I have not used such sources to support the arguments of this thesis. I have used only one political activist website. While the website no longer exists, I have a print of the page (Chapter VIII, first paragraph). There were some websites cited in Chapter VIII that I tried to access instead of cross-referencing them but I received alert messages stating that those web-sites are under attack. With these exceptions, all the Iranian Government, journalist, and blog on-line sources used in this thesis were all accessible, as of July 15, 2013.

Wide ranging literature reviews of different fields of enquiry including political ecology, wetland ecosystems, conservation and environmental management, management of commons, and global environmental governance were used for most chapters of this thesis.

Archival research was conducted for the analysis in Chapter IV that entailed the historical study of the AUA region, in order to dismantle the divide between the natural and the social. I conducted an on-line search for old maps, and studied travelers' stories from the $19^{\text {th }}$ century looking for information that was relevant to the Atrekians' social construct, bio-physical characteristics of the region, and the interaction between them and the AUA environment. 


\section{CHAPTER IV- The Turkmen Sahra and Atrekians: landscape, politics and history}

This chapter addresses: how people-environment interactions have formed the AUA as part of the Turkmen Sahra, and how the AUA has changed over the last two centuries. In a historical examination it describes how people-environment interactions have shaped the AUA landscape and argues that the AUA landscape is an assemblage of humans and non-humans interacting in an ongoing process of becoming, open spaces and non-fixed identity. It attempts to demystify the social construction of the AUA and describes it as socio-nature rather than a purified nature.

\subsection{The Turkmen Sahra: ecosystem}

The Turkmen Sahra (Turkmen Plain/Turkmen Steppes), is home to the Turkmen in Iran (Map 1.1). The region is not clearly delineated, there are different opinions on its geographical borders, and its name has changed through history. Since Reza Shah Persianized ethnic names, the Turkmen Sahra has also been referred to as the Dashte Gorgan (Gorgan Plain) ${ }^{57}$. This dissertation uses the name 'Turkmen Sahra' because it is the historical territory and ancestral lands of the Turkmen, it encompasses social, political, historical, and geographical elements of the region, and highlights the Turkmen as its integral part.

The Turkmen Sahra extends eastward and northeastward from the eastern coast of the Caspian Sea for about $200 \mathrm{~km}$ to Maraveh Tepe and Ghazan Ghieh towards the northeast; and about $460 \mathrm{~km}$ east towards Dareh $\mathrm{Gaz}^{58}$. It encompasses an approximate

\footnotetext{
${ }^{57}$ The American anthropologist, William Irons uses the name Gurgan Plain (Irons, 1971, p. 21). The Canadian anthropologist, Carl Salzman refers to the area as 'Gorgan region east of the Caspian Sea' (Salzman, 2004, p. 29). Iranian researchers usually use both names (Arshi, 1977; Pourkarim, 1968b).

${ }^{58}$ From the Caspian Sea to the east it includes northern parts of Bojnurd (about $300 \mathrm{~km}$ from the Caspian) and Quchan (about $400 \mathrm{~km}$ from the Caspian).
} 
area of $25,000 \mathrm{~km}^{2}$ (Arshi, 1977). Its southern and northern boundaries are the northern skirts of the Elborz Mountain Range ${ }^{59}$ and the Atrek River (Maps 1.1 and 4.1). The elevation of land increases gradually from the Caspian coast towards east ${ }^{60}$ (Ponomarenko \& Fet, 2013).

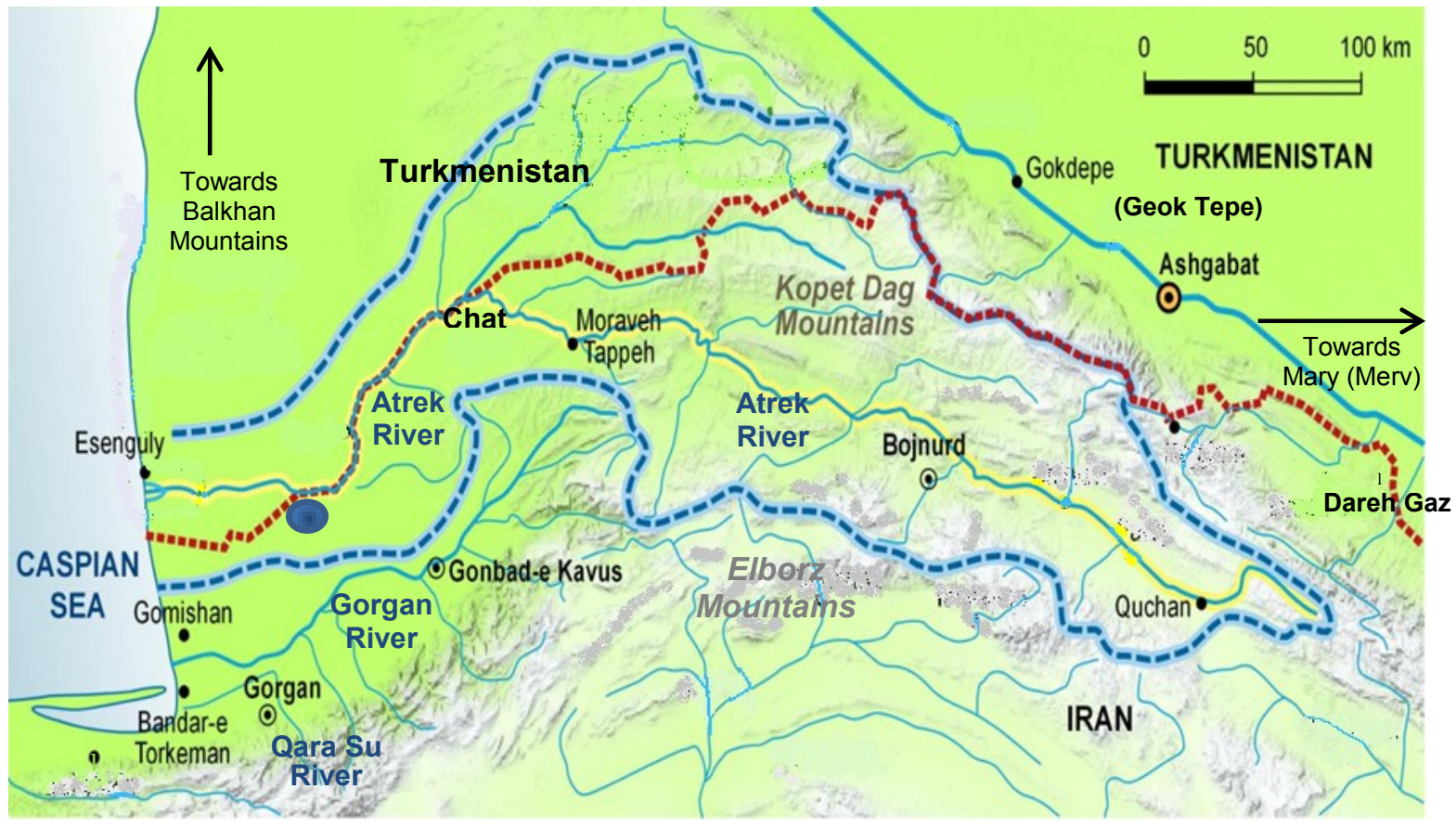

Map 4.1. The Atrek River transboundary basin (adopted from UNEP/GRID-Arendal 2008 (De Nartino \& Novikov, 2008, p. 60)).

Legend: .......... The Turkmenistan-Iran border ・ேー・ー・ーー The Atrek River Basin

The AUA region (approximate location)

The Turkmen Sahra between the Gorgan River and the Atrek has three distinctive zones (Irons, 1975, p. 22): (a) Forest Zone: the most southern part, extending north from the northern slopes of the Elborz Mountain Range to the Qare Su River and Gorgan River, is forested. Qare Su Basin is inhabited by Persian-speaking communities; (b) Humid Steppe Zone: the forested area extends northward from the Gorgan River as a

\footnotetext{
${ }^{59}$ With peaks of up to $3000 \mathrm{~m}$ ("Elborz Mountains," 2013)

${ }^{60}$ The elevation of land, from west to east, increases from the Caspian lowland of - $28 \mathrm{~m}$ (Ponomarenko \& Fet, 2013) to -20 in Bandar-e Turkmen, -10m in Aq Qala, 10m in Inchehburune and $24 \mathrm{~m}$ in Dashliburun (Mahab Ghods Consultancy, 1997, p. 21). However, the floodplain is not flat and is covered with small hills and temporary inundated zones.
} 
humid steppe zone which is mostly occupied by Turkmen engaged in agriculture; and (c) Steppe-desert Zone: the northernmost part, which includes the AUA, is a steppe-desert zone which is occupied by mostly pastoralist Turkmen. The lower Atrek has always had the flora and fauna typical for the Caspian coast ${ }^{61}$ (Kouzmina, 2006, p. 102). The steppedesert landscape continues into Turkmenistan.

The drastic change in climate and habitat, from the city of Gorgan at the skirt of mountains to the edge of the desert-steppe zone, happens in less than $40 \mathrm{~km}$. The temperature rises from the forested area to the Atrek in the north. Also, the temperature increases eastward from the Caspian towards the AUA and rainfall decreases ${ }^{62}$. The northernmost part has dry, hot summers and moderate winters and is prone to long periods of drought. The Atrek River built the Atrek Plains (Dewan \& Famouri, 1964, p. 23). In the Atrek plain alluvial materials and loess deposits are found in addition to the sediments of the Caspian type (Dewan \& Famouri, 1964, p. 27). The humus content of the soil decreases from the forested southern zones around the Gorgan River to the desertsteppe along the Atrek River. Lands around the Gorgan and the more humid parts of the Turkmen Sahra are the second great lowlands in the country (McLachlan, 1990, p. 17). The soil along the Atrek provides a desert-like habitat that supports arid-land vegetation.

The $530 \mathrm{~km}$ long Atrek River has a basin area of about 27,000 km² (De Nartino \& Novikov, 2008, p. 60); 70\% of its basin area is in Iran and 30\% in Turkmenistan (Chavoshian, Takeuchi, \& Funada, 2005, p. 191) (see Map 4.1). Its source is the Elborz Mountains and most of its streams arise in northeastern Iran (De Nartino \& Novikov,

\footnotetext{
${ }^{61}$ The soils of the greater part of the delta are Solonchaks, Takyrs, and Takyr-like Solonchaks (Zonn et al., 2010 , p. 45). Soil salinization is increased due to changes in catchment vegetation, irrigation, and the Caspian Sea level, and weak drainage ability (Kouzmina, 2006, p. 102).

${ }^{62}$ Average rain fall is less than $210 \mathrm{~mm} /$ year (Mahab Ghods Consultancy, 1997, p. 23).
} 
2008, p. 60). The main tributary of the Atrek is the Sumbar River (245 km long). It originates in Iran, flows into Turkmenistan and after a long stretch reaches the Atrek at Chat in Iran. From Chat to Dashliburun (about $150 \mathrm{Km}$ ), the Atrek forms the boundary between Iran and Turkmenistan (De Nartino \& Novikov, 2008, p. 60). At Dashliburun, the river divides into two branches. The northern branch flows through Turkmenistan and reaches the Caspian Sea at Esenguly (Map 4.1). After Chat, the southern branch in Iran flows through a shallow channel, and widens as it enters open terrain in the Inchehburun $\operatorname{area}^{63}$ (see Map 1.2). It then passes through the arid steppe lands of Sofikem (elevation of $0 \mathrm{~m}$ ) and the AUA region on its way toward the Caspian Sea. 50\% of the water flow in the Iranian branch of the Atrek, at the water station near Inchehburun and Tengli, is directed to Alagol Lake through constructed channels.

Interestingly, the humidity at Inchehburun is much higher than other climatology stations in the region because the proximity to Ulmagol, Ajigol and the Inchehburun water reservoir creates a high humidity microclimate (Mahab Ghods Consultancy, 1997, p. 26). Maximum evaporation is in July and minimum in January. The flood season is from March to May and flooding by localized rainfall can happen during the summer (Mahab Ghods Consultancy, 1997, p. 59, 62). The Atrek is one of the most turbid rivers in the world, carrying high amounts of suspended solids ${ }^{64}$, consisting of clay, shale and loess (Mahab Ghods Consultancy, 1997, p. 59). The lowest reaches of the river are a low-

\footnotetext{
${ }^{63}$ Data from a climatology station in Inchehburun shows that the absolute maximum temperature is $48.5 \mathrm{C}$ in July and average maximum temperature is $35 \mathrm{C}$ in the same month. The absolute minimum temperature is $-7.5 \mathrm{C}$ and average minimum temperature is $-1 \mathrm{C}$ in February (Mahab Ghods Consultancy, 1997, p. 25). Frosting days in a year is 33.5 which 13 days of it is in January. Maximum rain is $442 \mathrm{~mm} /$ year and minimum is $111 \mathrm{~mm} /$ year. Maximum number of days with precipitation is 13 in January and the total number of days with precipitation in a good year is 60 . In average the number of days with precipitation is 38 . In a drought period the days with precipitation is only 21 . The average humidity is $81 \%$ with the minimum of $79 \%$ in June (Mahab Ghods Consultancy, 1997, p. 23).

${ }^{64}$ Sometimes as high as 14,000-35,000 mg/l (Mahab Ghods Consultancy, 1997, p. 59).
} 
level 'flat sandy-clay delta cut by traces of old branches of the meandering river' (Zonn, Kostianoy, Kosarev, \& Glantz, 2010, p. 44). The dense clay surface in shallow depressed areas acts as a natural catchment. The marshy stretch from Inchehburun to the Caspian Sea is also due to the land elevation being only slightly above the Caspian Sea's level. The water of seasonal rains accumulates on vast areas of the arid steppe and makes temporary lakes with depths that some may not exceed $30 \mathrm{~mm}$. The flood regime of the Atrek is important for the native fish species in the permanent water bodies associated with the river and also for washing salt from the saline soil of the steppe during July until August, thereby allowing its preparation for farming.

The hydrologic flow of the Atrek River is completely regulated by dams and channels in Iran and three watering reservoirs in Turkmenistan ${ }^{65}$ (Kouzmina, 2006, p. 100). Before dam construction the Atrek River floods downstream from Inchehburun were enough to feed the Alagol, Ulmagol and Ajigol lakes, and other depressions of the area, including Incheh, Daneshmand, and Shur Lakes (Salt Lakes), and some water reached Gomishan Lake at the Caspian coast (Kiabi, Ghaemi, \& Abdoli, 1999, p. 150). Insufficient water in the lower reaches of the Atrek and complete regulation of flood and water flow have two immediate environmental impacts: ecologically sensitive areas, stretching from the Caspian coast to the AUA region, deteriorate; and endemic fish species of the region lose their habitats.

The use of water from the Atrek is a sensitive issue between Turkmenistan and Iran (De Nartino \& Novikov, 2008, p. 57). In the dry season the water no longer reaches the Caspian at Esenguli area, (De Nartino \& Novikov, 2008, p. 57), and in spring only

\footnotetext{
${ }^{65}$ Three off-channel reservoirs accumunate the the Atrek flow in Turkmenistan: Kizil-an (1965), Mamdkul (1964) and Delili (1970) (Zonn, Kostianoy, Kosarev, \& Glantz, 2010, p. 44).
} 
some floodwater may reach the sea (Zonn et al., 2010). Due to insufficient water flow towards the Caspian Sea the region is undergoing desertification processes (Kouzmina, 2006, p. 104). As a result, the fish ${ }^{66}$ catch dropped and commercial fishing in the Esenguly district in Turkmenistan, while was well established in the 1930s, gradually declined to almost nothing in the 1990s (De Nartino \& Novikov, 2008, p. 60).

The Convention on Protection and Use of Transboundary Watercourses and International Lakes reports agriculture represents almost $90 \%$ of water withdrawal in the Atrek Basin and that all of it happens in the Iranian part of the $\operatorname{basin}^{67}$ (Economic Commission For Europe, 2011, p. 69, 135).

\subsection{Social construction of the Turkmen Sahra: a political and historical review}

The Turkmen people of Central Asia live in Turkmenistan, along the TurkmenAfghan border in Afghanistan ${ }^{68}$, and in northeastern Iran, where more than 2 million Turkmen (Nichol, 2007, p. 2) are settled in Golestan, North Khorasan, and Khorasan Razavi provinces (Map 1.1). Central Asian Turkmen consist of several large descent groups $^{69}$. The Turkmen are Sunni Muslims and speak local dialects of Turkmen (a Turkic language) (Irons, 1975, p. 5). Their language is close to Azerbaijani and modern Turkish but culturally they are closer to Central Asian communities such as Kazakh, Kirghiz, and Uzbek (Irons, 1975, p. 5). The older generation of Turkmen in Iran has knowledge of Russian.

\footnotetext{
${ }^{66}$ Atrek is an important spawning ground for roach (Rutilus caspicus) and carp (Cyprinus carpio).

${ }^{67}$ Other pressure factors in the Atrek Basin are: high sediment load, riverbank alteration, discharge of untreated or insufficiently treated municipal wastewaters and discharge of inductrial wastewaters (Economic Commission For Europe, 2011, p. 70, 135).

${ }^{68}$ As of 2003, 85\% of the population of Turkmenistan is ethnic Turkmen and in Afghanistan, as of 2006, over 900,000 are ethnic Turkmen (Nichol, 2007, p. 2).

${ }^{69}$ Those major descent groups are: Yomut, Teke, Goklan, Salor, Sariq, Yemreli, and Ersari (Edgar, 2004, p. 21). Irons explains (Irons, 1974, p. 40): "There are written genealogies recounting the descent of all Turkmen from a single mythological chahacter Oghuz Khan".
} 
More than a millennium of the Turkmen history is documented ${ }^{70}$. Arabs defeated the Sasanid Empire in Iran in the sixth century and progressed eastwards to areas where some of the Turkmen tribes were settled (Arshi, 1977, p. 198). The Turkmen tribes began to adopt Islam in the tenth century (Irons, 1975, p. 8) and became a crucial part of the Seljuq dynasty and its success in expanding its borders to the Mediterranean Sea (Arshi, 1977, p. 199). In the 1220 s, nomadic Turkmen who retreated to Kazakhestan and the Caspian coast survived the Mongol invasion of Khiva and Merv region (the main centers of the Turkmen culture) ("History of Turkmenistan," 2012). By the sixteenth century, the Turkmen's territory had expanded west to the Caspian coast (Arshi, 1977, p. 200); by the mid-seventeenth century the Yomut Turkmen began crossing the desert of Uzboy (today in Turkmenistan) towards the Gorgan plain in Iran (Galafassi, 2010; Munkacsi, 1994), and by the mid-eighteenth century they completely occupied the region (Galafassi, 2010).

Since the mid-eighteenth century, the Yomut Turkmen have been divided into two geographically separate groups: Khiva Yomut ${ }^{71}$ and Gorgan Yomut ${ }^{72}$ (Edgar, 2004, p. 21; Irons, 1974, p. 636). The Gorgan Yomut occupied the area east of the Caspian Sea, Gorgan Plain, and lands along the Atrek River both in Persia and Russia up to the Balkhan Mountains, in the west and Akhal Mountains in the east (south of the Kara Kum desert) (Irons, 1975, p. 9). Turkmen in Iran occupied Turkmen Sahra as the winter territory of the Turkmen. In summer they moved towards Balkhan Mountains along the

\footnotetext{
${ }^{70}$ In the eight century a Chinese encyclopedia refers to 'Turkmen' (pronounced s Tö-kü-mömg) as a country also known as Sak-tak which in the beginning of the Christian calendar was extended up to the Sir Darya (Seyhun) in Central Asia(Arshi, 1977, p. 197).

${ }^{71}$ The Khiva Yomut occupied Khawrazm, north of the Kara Kum desert and along the Amu Darya (Edgar, 2004, p. 21, 27). The modern city of Khiva is located in Uzbekistan and the Khawrazm area is divided between Uzbekistan and Turkmenistan.

${ }^{72}$ Irons outline the genealogy of Khiva and Gorgan Yomut and their derivatives in detail (Irons, 1975, p. 40-46).
} 
Caspian coast, and north of the Atrek River (Pourkarim, 1965). At the time of Qajar, the lands of the Turkmen Sahra were called Yomutestan (see Section 6.1.2).

Turkmen in Iran are mostly of Yomut and Goklan, with a small population of Teke. The Yomut occupy the eastern coast of the Caspian Sea and along the Atrek River; the Guklans and Teke occupy the highlands on the east (Arshi, 1977, p. 210), in Khorasan Shomali and Khorasan Razavi. Gorgan Yomut in Iran consists of two major tribes Jeferbay and Ag-Atabay (Irons, 1975, p. 49). Jeferbays occupy the eastern coast of the Caspian Sea, and Ag-Atabays along the Atrek River (Arshi, 1977, p. 210).

Nomadism (regular, repeated and frequent mobility of the household) is a strategy that people use to carry out their livelihoods but it is not driven solely by economic necessity (Salzman, 2004, p. 40). Nomadism is tied in with productive activities, such as hunting and gathering, trade, providing services, and raising livestock in pastures, which are also practiced by sedentary populations (Salzman, 2004, p. 18). Salzman explains that grouping different kinds of people, naming them nomads, and expecting them to have universal characteristics is an essentialist way of looking at human reality (Salzman, 2004, p. 41). Peoples who have chosen mobile nomadic strategies, practice a customary habit, but do so for different reasons and pursue different goals. Their lives and cultures are complex with many dimensions and cannot be fully described by the single feature of nomadism (Salzman, 2004, p. 41). Nomadism had both political and economic advantages for the Turkmen. They chose nomadism as a way of rejecting the authority of states in addition to its being an economic lifestyle (Salzman, 2004, p. 163). Nomadic mobility has made it possible for the Yomut Turkmen to remain free of any neighboring 
sedentary state, to do their affairs independently, and to defend themselves ${ }^{73}$ (Salzman, 2004, p. 59-61; Irons, 1974, p. 647, 648). The 'Turkmen' was a political and ethnic label for those on the border 'between northeastern Iran and Central Asia [and they] took advantage of weak political control to raid neighboring sedentary areas but did not form states or confederations' (Barfield, 1990, p. 175). O'Donovan states (O'Donova, 1883, p. 269):

[the] portion of the plain, extending between Giurgen and the Kara-Su, is exceedingly luxuriant, owing to the excellent water supply combined with the heat of the sun, and I am much surprised that the nomads do not frequent the district more than they do. Possibly they fear to be in too close proximity to the central administration at Asterabad, a position which would greatly facilitate the extracting from them of additional funds by the local authorities.

Vambery believed the Turkmen could be much more peaceful if they were not harassed and subjected to imposed exaction and taxes by their neighbors. For these reasons the Yomuts, the Goklans, and the Teke (Vambery, 1880, p. 341):

rise in continual rebellion against the rulers of Tehran who, in their impotence to subdue these hardy nomads, have made devastating inroads which the haughty Persians are pleased to call "wars". These are repaid by Turcoman marauding parties, frequently in a more cruel and inhuman way.

Vambery suggested the reason for the Turkmens having a reputation as fierce soldiers and adventurers was partly because of 'the political condition of the neighboring countries, which forced them into continual warfare to preserve their independence' (Vambery, 1880, p. 341). He stated that the Turkmen were always ready to sacrifice their lives for their independence. He further wrote that (Vambery, 1880, p. 343, 344):

It is certainly a mistake to believe that the Tekkes or the Yomuts have no other means of subsistence than robbery and man stealing. [...] Let the more civilised Powers try justice and humanity instead of conquests and wars of extermination,

\footnotetext{
${ }^{73}$ For example, the Gorgan Yomut in response to Qajar's military actions against them could retreat easily, from Gorgan plain to Balkhan Mountains and also to the territory of the Khiva Yomut, crossing Kara Kum desert (Irons 1974, p. 647, 648).
} 
and the nomads will become more tractable and less apprehensive for their independence.

Contrary to the essentialist view of nomads as being isolated communities the Turkmen in the Turkmen steppes were completely aware of and in contact with outsiders. The Turkmen were familiar and in constant interaction with urban civilizations, state institutions and the urban market for at least a thousand years (Irons, 1975, p. 7) and their tribal life was an adaptation to political, military and economic circumstances (Irons, 1974, p. 635). The Turkmen tribes were at the center of the Great Silk Road, became traders along the Caspian, and connected to civilizations of the East and West ("History of Turkmenistan," 2012). At times they were mercenaries to various rulers in Central Asia and at the same time they were farmers, hunters, fishers, and traders.

Russia had constant struggles with the Turkmen in Transcaspia (part of the Russian Empire, east of the Caspian Sea) and finally gained control with the battle of Geok-Tepe in 1881 and conquest of Merv in $1884^{74}$ (Geiss, 2003, p. 173). Through the Akhal Convention between Persia and Russia, in 1881, the king of Persia ceded any claim over Central Asia (Sir Hertslet, 1891, p. 136). The greater part of the Turkmen tribal confederacies became a Tsarist jurisdiction when the Atrek River was confirmed as the border between Russia and Persia ${ }^{75}$ (Geiss, 2003, p. 193). The Atrek as the border was defined by the Akhal Convention, and was 'finely delineated via two protocols in 1886' (Mojtahed-Zadeh \& Hafeznia, 2003, p. 608). Nonetheless, the border with Iran was not fully controlled until the 1930s (Geiss, 2003, p. 193).

\footnotetext{
${ }^{74}$ Vembery explains the victory of Russians was due to military and science of that century which the courage and "bare breasts" of Akhal Tekkes could not resist (Vambery, 1885, p. 31).

${ }^{75}$ In 1863 Qara Su was known as the northern boundary east of the Caspian Sea. In an agreement between Russian and Persia in 1869, the Atrek was recognized as the boundary between two countries, east of the Caspian, but was partially enforced (Mojtahed-Zadeh, 2006, p. 110) .
} 
The Turkmen were involved in slaving and raiding until 1884, when the Tsarists Empire took control of most of the Turkmen region (Vambery, 1885, p. 31, 32). The Turkmen in Persia lost their main center of business, Khiva's slave market, and eventually had to cease raiding and slavery ${ }^{76}$ (Barfield, 1990, p. 175; Vambery, 1880). Vambery in an article in 1885 argued that Russians had slow advancement to control Yomut Turkmen (Vambery, 1885, p. 30). Their strategy, which worked in their advantage, was to divide Turkmen by setting the Atrek as the border between Persia and Russia. Russia did not have to deal with Turkmen along the southern part of the Atrek and gave that task to the Persians. Vambery called this Russian act presenting Iran with a Trojan horse (Vambery, 1885, p. 30).

The Turkmen in Iran had strong political structures that were not subordinate to the Qajar state. The Qajar dynasty (1794-1925) was established with the help of the Turkmen tribes but later was in constant clashes with them until the Constitutional Revolution ${ }^{77}$ 'Enghelab Mashrooteh', when the Turkmen stood by the Qajar kings (Abrahamian, 2009, p. 56; Arshi, 1977, p. 202, Irons, 1975, p. 8). In 1907, under the Anglo-Russian agreement, Russia and Britain divided Iran into three parts for their exclusive economic benefits ${ }^{78}$ (Abrahamian, 2009, p. 49). The second constitutional assembly in 1910 could not achieve anything. At this time Iran was bankrupted, the Qajar government was weak, and European countries were enjoying numerous economic

\footnotetext{
${ }^{76}$ O'Donovan reported that the Persian Governor of Asterabad issued a strict order to the Turkmen tribes on Persian soil and those "residing for the moment on Russian territory", reminded them of the Shah's authority, and ordered them to release any captive as slave (O’Donova, 1883, p. 121).

${ }^{77}$ In 1906, the revolutionaries were demanding formation of a national assembly, compilation of constitutional law and limitation to the Shah's power. Regardless of the Qajar government's use of severe force to fight the Constitutional Revolution, the first meeting of the parliament (National Consultative Assembly), a constitutional assembly, convened in 1906 and wrote a constitution modeled after the Belgian Constitution (Hirschl, 2010, p. 24).

${ }^{78}$ The three parts included: the northern part of Iran under Russian influence, the southern and eastern part in Britain's interest and both could compete for the middle zone (Abrahamian, 2009, p. 49).
} 
concessions. Russian military attacked and aggressively suppressed the Turkmen both in Iran and Russia. The Qajar government was still in crisis and had no power to react and Russia almost took hold of all the Turkmen territories in Iran (Toranly, 2006). During World War I (1914-1918) Iran could not maintain its neutral political position and British and Russians used Iran to their own benefits (Majd, 2013, p. 3). At the end of the war 'Iran was in political and economic ruins' (Katouzian, 1981, p. 66). In 1916 Turkmen joined the concerted effort against Russia, which was pressuring Central Asians to join the Tsarist troops in World War I. After the 1917 revolution in Russia and formation of Soviet Union (1917-1921), the socialist government withdrew its troops from northern Iran and the Caspian region (Mamedova, 2009) and strengthened its regional dominance by the establishment of its Central Asian Republics of Turkmenistan, Tajikistan and Uzbekistan. Reza Khan, a Qajar military commander, with the help of British, staged a coup d'etat in 1921 against the Qajar dynasty (Abrahamian, 2009, p. 63). He became the Shah of Persia in 1925 and called himself Reza Shah Pahlavi ${ }^{79}$ (Abrahamian, 2009, p. 65). During Reza Shah's era the Turkmen were disarmed, pacified and sedentarized (see Section 6.1.2). After 1921, the easy movement of the Turkmen between Russia and Iran was stopped temporarily, and the Iranian administration allowed the Yomut Turkmen who had fled to the Soviet side to return to Iran only if they surrendered their arms and accepted Reza Khan's authority (Arfa, 1964, p. 178). Sedentarization of the Turkmen by Reza Shah in the 1920s, land policies of his son in the 1960s, and the revolutionary government after 1979, affected the Turkmen in varied ways. These topics will be discussed in Chapter VI.

\footnotetext{
${ }^{79}$ The Majlis (National Consultative Assembly) deposed the last king of Qajar, Ahmed Shah, announced the dissolution of Qajar dynasty and declared Reza khan as the Shah of Persia (Abrahamian, 2009, p. 65).
} 


\subsection{The Turkmen territories: a socio-ecological system}

A spatial and temporal study of the place sheds light on the actors involved in shaping a place and dismantles the divide between the natural and social. The Turkmen territories including the AUA landscape is socionature (a nature-society hybrid), where humans and non-humans have been and are active agents in its formation. The Turkmen's livelihood and their intimate interaction with the land and water were essential parts of their social and cultural system. The strategy of land use as nomadic pastoralists was a process of trial and error interaction with their environment over long period of time (Beck, 1998, p. 58) that can be described as a critical part of their dynamic traditional knowledge.

\subsubsection{The Turkmen in Central Asia: livelihood strategies, and land and water use}

In the fourth millennium $\mathrm{BC}$, the prehistoric farmers in Turkistan managed to divert floodwaters and use small feeder channels to direct water to their fields (Barker \& Gilbertson, 2000, p. 7). In the $3^{\text {rd }}$ millennium $B C$, mixed-farming pastoralist tribes flourished in Central Asia (Sala, 2003). They were well adapted to the unstable and semidesert environment (Sala, 2003). Pastoralism, a multi-resource economy, has long been associated with two other major livelihood strategies: trade and warfare (Blench, 2001, p. 1). From the $2^{\text {nd }}$ millennium BC to the Russian conquest in the $1880 \mathrm{~s}$, the symbiosis, encounters, cooperation, rivalry and conflicts of pastoralist tribes and farming communities, along with the stratification of societies and militarization, shaped the history of the Turkmen territories (Sala, 2003, p. 13-15). Khiva's economy until conquered by Russians in 1873 was based on agriculture, livestock breeding, brigandage, and handicrafts ("Khiva, khanate of," 2013). The non-linear change in land use and livelihood strategies of people in this region did not happen at the same time, with the 
same intensity, in the same direction or for the same reasons. The presumption that land use development and the trend from pastoral to farming systems was linear, i.e. from simple to complex or from extensive to intensive, is not valid (Barker \& Gilbertson, 2000, p. 8). Uneven development in time and space occurred in ecological, climatic, economic and political contexts (Barker \& Gilbertson, 2000, p. 8).

Raising livestock, farming, and water management:

Pastoralist and farming communities can change their economic activities with environmental conditions and develop semi-settled farming, mixed-farming and pastoralist strategies (Sala, 2003, p. 16). In optimal conditions, livestock herders could settle and combine pastoralism with farming and, under unfavorable hydrological conditions settled farmers could abandon their water canals and move to another site. Under conditions of frequent hydrological change, farmers adjusted their activities, sometimes on a yearly basis (Sala, 2003, p. 15). As a result, this region had a flexible combination of animal husbandry, irrigated and dry farming, hunting, fishing, gathering, and trade.

The number and diversity of domestic animals increased in the fourth millennium BC (Lewis, 1996, p. 474). Raising livestock included horses, cattle, sheep, goats and camels (Lewis, 1996, p. 474). Horses were a means of sutaining life and horse-breeding gave nomads a strategic role and military superiority in the region (Mukhamejanov, 2000, p. 286, 287). Irrigation centers had to ally with pastoralists for protection (Mukhamejanov, 2000, p. 287; Sala, 2003, p. 13). Cattle were used for meat, milk, and as draught animals in agriculture. Fat-tailed sheep and lambskins were highly in demand. Sheep-rearing was important for meat, fat, milk, hides and wool (Mukhamejanov, 2000, p. 287). Sheep products were used in carpets, woolen fabrics, felt, rope, sacks, khurjin 
(saddle-bags), and tushak (floor covering) (Mukhamejanov, 2000, p. 287). Camels were important for their endurance and as the means of transport in the steppes and deserts of the region.

The farming societies in Central Asia were always in contact with the 'hydrological societies' in northern $\operatorname{Iran}^{80}$, Afghanistan, and India (Sala, 2003, p. 15). In Central Asia, within West Turkestan, irrigation arouse on the Kopet Dag piedmont in the fifth millennium $\mathrm{BC}$ and by second millennium $\mathrm{BC}$ appeared in other parts of the region (Sala, 2003). People in Central Asia developed hydraulic structures and the construction materials used were specific to the local topography, soil type, vegetation, fauna, and climate. Band(s) (ab-band) were common in the region (Mukhamejanov, 2000, 293, p. 294). It is a common term referring to dams or embankments (traditionally they were simple earth dams) that create water reservoirs and prevent soil erosion, protecting water quality by collecting and storing runoff water; they provide water for livestock, fish and wildlife, and for human consumption (Dzurik, 2003, p. 380; Thornton, Steel, \& Rast, 1996, p. 369). Tolstov ${ }^{81}$, explains that beween the twelfth and fourteenth century irrigation reached its maximum extension on the lower reaches of the Amu Darya and the Syr Darya with complex water management systems and irrigation networks which evolved in complexity with time ${ }^{82}$ (Mukhamejanov, 2000, p. 293). Archeological work and research on water management in the oases of Central Asia is particularly well

\footnotetext{
${ }^{80}$ Primitive wet farming practices in the Iranian Plateau are dated back to the $7^{\text {th }}$ millennium BC (Sala, 2003, p. 7).

${ }^{81}$ A Russian researcher who studied the extent of agriculture and irrigation systems in Central Asia from ancient pre-Islamic and medieval Islamic times in the 1960s (Mukhamejanov, 2000, p. 293).

${ }^{82}$ Khawrazm along with its vast irrigation systems, was destroyed by Timur in the late $14^{\text {th }}$ century ("Khwarazm," 2013). The reduction in irrigation economy in the $15^{\text {th }}$ century might be due to a wetter and cooler climate of that period, and therefore, irrigation was not vital so the irrigation systems was neglected (Boroffka et al., 2005). A sketch map of 1850 of the Khiva area shows many dams and impoundments for irrigation extended over a vast area (Wright, 2008, p. 2). The fertile delta of Amu-Darya and also its fertile pastures formed a complex landscape and ethnical population (Wright, 2008, p. 2).
} 
documented in Merv area. In the tenth century, A mir-ab (water commander, chief water master (Nesbitt \& O'Hara, 2000) in Merv was more powerful than the prefect of the city (Hill, 1992, p. 265). In the twelfth century, Merv had a Diwan-i Ab (water department) running by a few mir-ab(s) who were responsible for the main canal systems and irrigation system ${ }^{83}$ (Mukhamejanov, 2000, p. 297).

Preconditions for irrigation work were existence of natural features and also social organization, labor, and technical knowledge to conduct the work (Sala, 2003, p. 12). The irrigation work was the responsibility of the water users which usually was performed under a system of collective labor that included 'division of responsibilities between inhabitants of larger settlements managing the structural devices and village dwellers' (Sala, 2003, p. 12) responsible for peripheral work such as 'the removal of the sediments from the canals, the repair of the dams, the sealing of breaches, etc.' (Mukhamejanov, 2000, p. 297).

Trade:

Turkmen nomadic pastoralists in the arid steppe and desert regions of Central Asia raised sheep, goats, camels, and horses, consumed animal products such as milk, cheese, and wool and traded these products to settled peoples for grain, tea, sugar, and manufactured products such as guns and cloths (Edgar, 2004, p. 21). Yomut Turkmen had considerable trade with the cities of Asterabad and Khiva, commercial hubs of $18^{\text {th }}$ and $19^{\text {th }}$ centuries. The Turkmen from the Gorgan/Atrek area had trade with Khiva selling felt and horses 'remarkable for their beauty' (Wright, 2008, p. 3). Archer-Eloy, who traveled

\footnotetext{
${ }^{83}$ Mir-abs used to supervise as many as 12,000 men with distinctive work responsibilities. Mir-abs used to supervise: Band-Ban(s) (responsible for guarding the dams), Juy-Ban(s) (responsible for the leats, drench or ditch which conveys water to a mill wheel, or off take canals), Ab-Andaz(s) (water measurers responsible for releasing water from the upper reaches of the river) (Mukhamejanov, 2000, p. 297).
} 
to the region from 1830 to 1838 , reported waterfowl as a contemporary commercial item sold by Yomuts from Turkmen Sahra (Wright, 2010, p. 2). Yomut Turkmen's trade with Khiva and Persians in Asterabad included selling felt, horses, wool, carpets, packing bags, silk, wheat, barley, and rice and buying food staples, tea, salt, sugar, cloth, tools, rifles, gun powder, paper, and naphta ${ }^{84}$ (Arshi, 1977, p. 216; Wright, 2008, p. 4, 5, 2010, p. 1, 2; Irons, 1974, p. 26).

Fishing and hunting:

While Blench reported that few pastoralists in the world are hunters and farming communities often consider hunting a prestigious activity (Blench, 2001). In Central Asia fishing and hunting were integrated into nomadic life. Fishing was a secondary economic practice along the shores of the Caspian and the Aral Sea and along lakes and rivers of the region. The tradition was to fish during summer and it was regarded as a "popular festival' when they ate fish, 'accompanied by melon' (Mukhamejanov, 2000, p. 288). Hunting, using nooses, snares, nets, traps, and also falcons, hawks and golden eagles was also a secondary occupation for the nomadic and semi-nomadic tribes in Central Asia (Mukhamejanov, 2000, p. 288).

\subsubsection{The Atrekians: livelihood strategies, and traditional land and water use and management}

Using the word nomad for the Turkmen in Iran is not a point of identity, it is just one aspect of a group of people coming from a shared ancestry and belonging to a communal society. As a community, the Yomut Turkmen of the Turkmen Sahra have many identities as tribesmen, fierce warriors, pacific civilians, kind hosts, slave raiders, traders, pastoralists, cultivators, and environmentally knowledgeable people. The

\footnotetext{
${ }^{84}$ Flammable liquid mixtures of hydrocarbons
} 
Turkmen of the Turkmen Sahra developed 'Turkmen-ness' as an identity during the sedentarization process initiated by Reza Shah in the 1920s and his policies affecting tribes including nationalization of pastures, confiscation of their lands, and Persianization. His policies developed a 'politicized sense of ethnic and tribal identity' (Beck, 1990, p. 206) and heightened 'ethnic and national minority consciousness' to help them defend their interests (Beck, 1990, p. 207, 208).

By the late-nineteenth century, In Iran, 'nomadic and sedentary life formed a continuum among the Turkmen, with more arid regions relying to a greater extent on livestock herding and more fertile regions featuring greater dependence on agriculture' (Edgar, 2004, p. 23). Settlements were dispersed and irrigation systems were functioning in small scale cultivations (Nesbitt \& O'Hara, 2000, p. 114). The predominantly settled Turkmen were known as chomur (agricultural), while mainly nomadic Turkmen were known as chawra (pastoral) but they did not completely fit in this categorization as nomad-peasant dichotomy (Edgar, 2004, p. 23; Irons, 1974, p. 637) ${ }^{85}$. In the earlytwentieth century, very few Turkmen were purely pastural, and most practiced some combination of agriculture and livestock herding, which involved short migrations (Edgar, 2004, p. 23; Irons, 1974, p. 637). The circumstances, under which they acquired one of these livelihoods, or both, were volatile and had considerable over-lap, nevertheless being a chawra was considered superior and well-off (Irons, 1975, p. 26). Animal husbandry was more significant with increasing distance from the Caspian towards the east (Wright, 2010, p. 2).

\footnotetext{
${ }^{85}$ The economy of chawra and chomur 'combined subsitence production and production for marker exchange' (Irons, 1975, p. 26).
} 


\subsubsection{The AUA landscape and the Atrekians}

The Yomut Turkmen in Iran whose livelihoods were dependent on the Atrek River valley and the steppe lands to the south were called Atreki-ha, which means people from the Atrek area or Atrekians ${ }^{86}$ (Pourkarim, 1968a). Atrekians are of the Aq-Atabay descent group and they include nine sub-groups ${ }^{87}$. The Atrekians' territory comprised lands along the Atrak River in Iran and Russia. In an old document that current Tenglians possess (Annex C) the extent of Aq-Atabay lands and its distribution among Atrekians is described. In its east their territory included lands adjacent to Inchehburun in Iran, in its northwest, to Delili Tepe in the Soviet Union, and in the south, to the lands adjacent to Alagol (see Map 4.2). Local interviewees explained that, after the border was fully controlled in 1946, the western limit of their territory was the edge of the Sofikem pastures, and in the north, the Atrek River was the limit.

Sedentarization started in the 1920 s and was strictly enforced in the 1930 s. In 1946 four permanent settlements, Daleshman, Inchehburun, Oghi Tepe, and Tengli, were established on hills (Tepe) in the AUA region, where Atrekians used to have their winter camps (Pourkarim, 1968a). Each village had members of almost all the Ag-Atabay subgroups (Pourkarim, 1968a). The residents of Tengli, at the time of my field work, consisted of all the nine sub-groups, but some were represented by only one or two households. In Tengli the first mud house was built in 1971; and before that they lived in their $y u r t(s)^{88}$.

\footnotetext{
${ }^{86}$ Vambery used the word Atrekians for the first time (Vambery, 1864, p. 67).

${ }^{87}$ Aq-Atabay is one of the larger sub-divisions of Yomut Turkmen and is comprised of two sub-groups: Aq and Atabay. The Aq includes: Shirmemetli; Gothmemetli; Yolma; Hebibli; Thakhawi; and Gok. The Atabay includes three main sub-groups: Memetaliq; Ketherqo; and Duwinch (Pourkarim, 1968a).

${ }^{88}$ Yourt is a Central Asian type of tent, which is made of hemispherical and latticed-wooden frames covered with felt (Irons, 1975, p. 22).
} 
Vambery, a Hungarian Orientalist, described the abundance of water and flow of the Atrek, in its lower reaches in the early-1860s (Vambery, 1864). He writes that Atrek, which is the name of the river and also the adjacent inhabited area is a place of terror for Persians and is a curse when they say: 'May you be driven to Etrek' (Vambery, 1864, p. 67). He traveled in Persia from Gomishan, southeast Caspian coast, towards the Atrek but did not go further than Kara Sengher (Senger Tepe) west of the Sofikem (see Map 4.2.) due to the danger of raiding by the Aq-Atabay tribes camping to the east where Tengli is located today (Vambery, 1864). In early May, 1863 he bypassed the Atrek to the north at Kara Sengher and reached Delili Burun, north-west of the Tengli, which is now located in Turkmenistan (Map 4.2). He described the area visible from Delili Burun (Vambery, 1864, p. 84):

The hill [Delili Tepe]... which is but a sort of promontory jutting out from a long chain of inconsiderable hills stretching to the south-east, affords an extensive and fine view. To the west we discover the Caspian Sea like a range of blue clouds; the mountains of Persia are also distinguishable; but the greatest interest attaches to the mountain plain to our south, whose limit the eye cannot discern, on which the scattered groups of tents in many places have the appearance of mole-hills. Almost the whole of Etrek, with the river flowing through it, lies before us, and the places where the river spreads over both banks produce upon the eye the effect of lakes.

O'Donovan on October 2, 1879, traveled on the northern bank of the Atrek and spent a night in a village called Gudri (Map 4.2.), about 5 kilometers north of where Tengli is located today (O’Donova, 1883, p. 52). He observed 'great trains of cattle and horses' in those pastures. He noted that the lands west of Tengli were winter pastures of the Turkmen on the Persian bank. He described the land on the southern bank of the Atrek as follows (O’Donova, 1883, p. 52):

the ground partly enclosed by the numerous and very tortuous sinuosities of the river is densely overgrown with brushwood and tamarisk, the latter sometimes attaining the height of eight or ten feet. The antelope, wild boar, and colon, or wild ass, frequent the locality in great numbers. I saw some scores of large black 
hawks... subsist on the mice which abound, and on stranded fish. The most objectionable frequenters of the place are scorpions and enormous tarantula spiders.

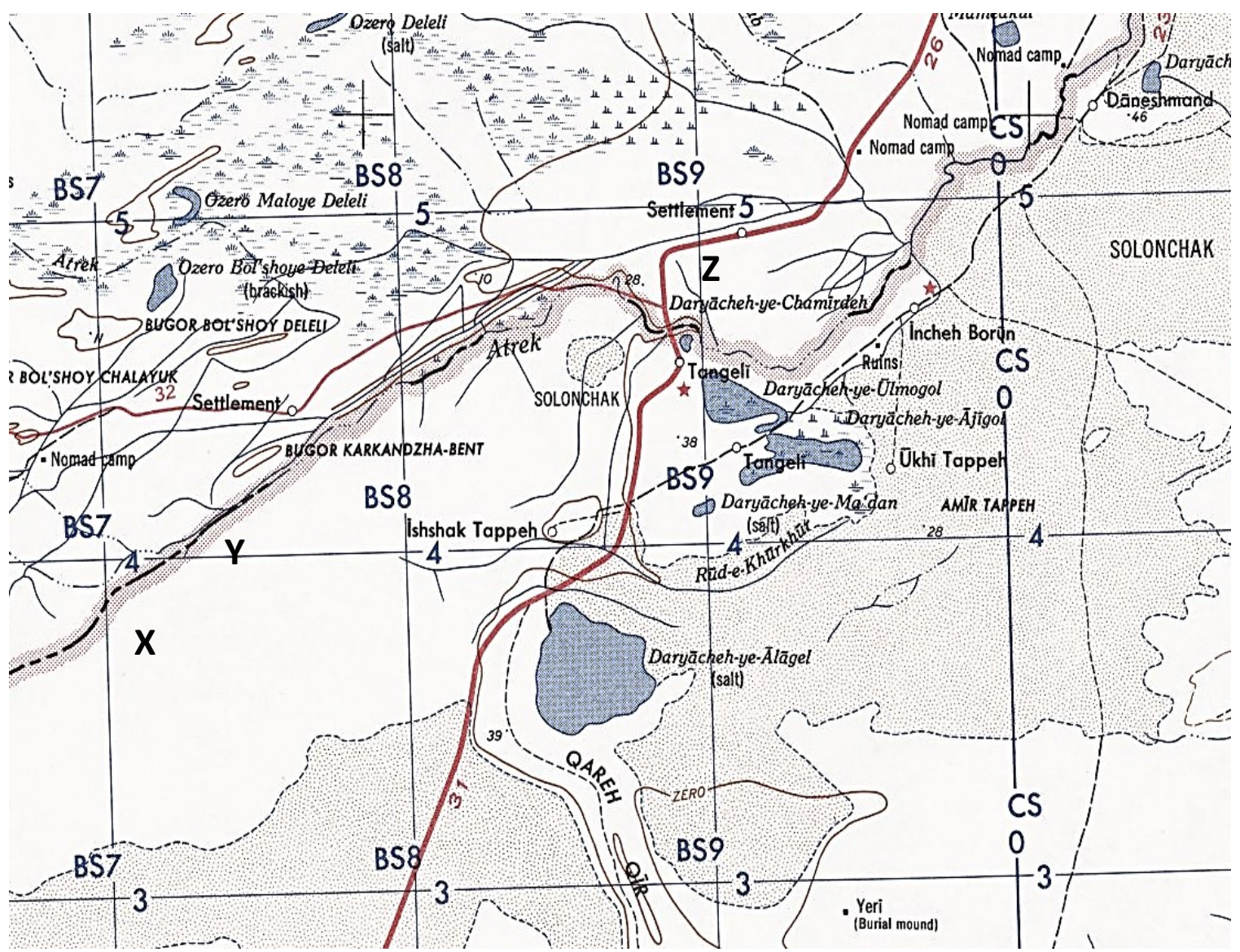

Map 4.2. The AUA region in 1958- Ulmagol, Ajigol, their adjacent paddy fields, and Alagol (U.S. Army Map Service, 1958). Approximate location of Senger Teppe (Kara Senger), Sofikem, and Gudri are marked by the author as $\mathrm{X}, \mathrm{Y}$ and $\mathrm{Z}$ respectively.

Further east towards Chat, along the Atrek, O'Donovan described the land around Daleshman and Douzolum as having the usual appearance of a desert 'a white earth expanse dotted with bunches of scrub. Not a single blade of grass of any kind'(O'Donova, 1883, p. 53). He also observed that, with a few hours of showers, the desert was under water as if the land had absolutely no drainage (O’Donova, 1883, p. 54).

Sykes on his travels from Astarabad to Chat, in the Turkmen territories, in a snow storm, passed Aq Qala (shown as Ak Kaleh in Map 4.3) and skirted two salt lakes before 
reaching Tengli, a camp of Ag-Atabay (Sykes, 1902, p. 15). Considering the route, the two lakes are assumed to be the current Alagol and Salt Lakes. The Times atlas map of 1922 (Bartholomew, 1922) shows water bodies around Tengli (see Map 4.3). In the map two lakes named Chamirda and Atagel (Father Lake) are identified on the lands of AqAtabays. The coordinates show that Atagel is now called Alagol; and Chamirda Lake no longer exists. The map does not show any open water bodies where the current Ulmagol and Ajigol Lakes are located.

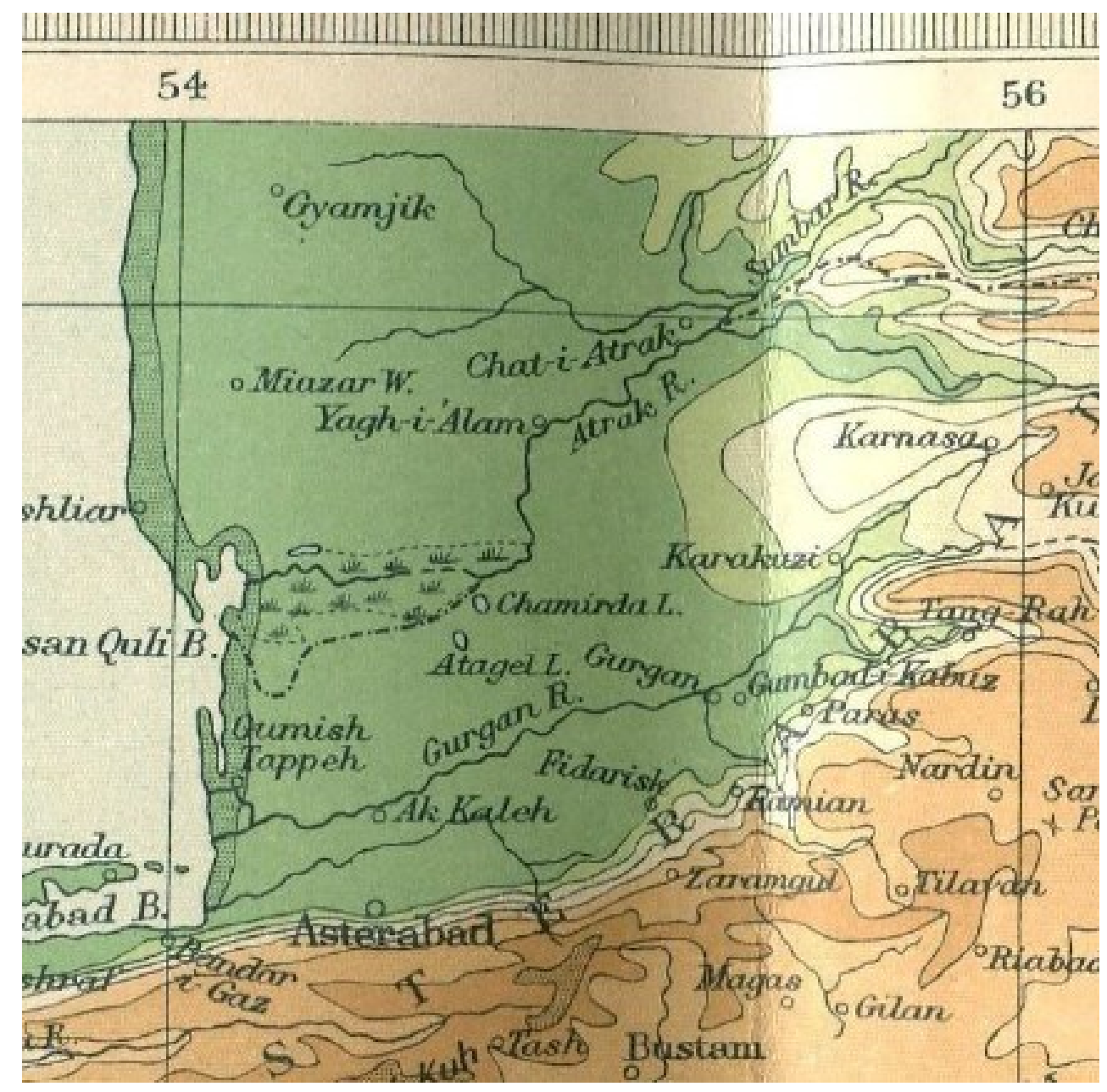

Map 4.3. The AUA region in 1921- Chamirda and Atagel Lakes in Times atlas map (Bartholomew, 1922) 
Ulmagol and Ajigol were one vast marshy area, which came to function as permanent lakes after the Atrekians developed an irrigation system composed of embankments and channels connecting them to the Atrek River in the 1930s. The US Army Map of Western Siberia ${ }^{89}$ (U.S. Army Map Service, 1958) shows the Chamirdah Lake, and also shows lakes Ulmagol and Ajigol as a large swamp that, with the paddy fields surrounding them comprises one wetland system (Map 4.2). In 1965, Moeeni wrote about the geography of the region and described Tengli as a village, which due to surrounding lakes was not easily accessible (Moinee, 1965).

After 1934, the Reza Shah administration changed non-Persian names to Persianize the country (Abrahamian, 2009, p. 86) (see Section 6.1.1), the Turkmen Sahra became Dasht-e Gorgan. In the same period Atagol (Father Lake) became Alagol (Colorful Lake) and Ulugol (Great Lake) became Ulmagol (Apple Lake) ${ }^{90}$.

\subsubsection{The Atrekians' livelihood strategies in the $A U A$ region}

Of the Yomut Turkmen who occupied the steppe and steppe-desert zones between the rivers Gorgan and Atrek, those living in the steppe specialized in dry grain cultivation and those in the steppe-desert specialized in sheep pastoralism. Each sub-tribe included both zones in its territory, and thus included both pastoralists (chawra) and cultivators (chomur) (Salzman, 2002, p. 254). The chomur who lived in north of the Gorgan River, before the sedentarization programme of the 1930s, lived in yurts, camped near their fields and had small flocks of sheep and goats. Their agriculture was limited to wheat and

\footnotetext{
${ }^{89}$ This map was compiled in 1951 from the map of U.S.S.R and Iran, 1:200,000, General Staff of the Red Army, 1942; medium scale map of U.S.S.R.; and U.S.S.R. hydrologic chart, 1943 (U.S. Army Map Service, 1958).

${ }^{90}$ In the same period, the Persian city of Asterabad officially changed to Gorgan; and Gorgan that was a major city in the Turkmen territories changed to Gonbad-kavous (originally the name of a village nearby). The Times Atlas of the World published in 1922 shows the original names of these cities (see Map 4.3).
} 
barley, except if water was available, when some small plots of rice were planted (Irons, 1974, p. 22) as was the case with Tenglians.

During WW II when the border was poorly controlled, Atrekians had seasonal use of their settlements in Iran and their summer camps in Russia. Atrekian's chawra of AqAtabay descendent group used to stay in Iran, close to good pastures, in winter and spring (November to March) and in dry season (summer and fall) they moved to their Summer camps (called yaylaq) across the Atrek in Russia' (Moinee, 1965; Zabihi, 1984, p. 152). Sometimes winter pastures (a quishlaq) could become a permanent site for the nomads who were involved in farming lands close to those sites; in these cases a quishlaq could also mean a village (McChesney, 2008). After 1947, they were completely settled and in winter a few men and shepherds took their livestock to pastures that were not very far from their villages and when they made only short-range migrations.

As part of my field work, a seasonal calendar was prepared with the participants, for the village in a good year, defined as a year that the village had access to water for farming and to their natural resources relevant to the wetlands for fishing and hunting. In this exercise the participants were nostalgic and used past tense. In summer, Tenglians grew melons around the rims of flooded areas. As flooded areas dried in the winter, Atrekians planted wheat and barley. Tenglians' traditional drainage and irrigation schemes were initiated within the wetlands with the aim of increasing productivity. The cultivation of melons with rice was a common practice. Rice was cultivated in lands closer to Ulmagol, which was the source of water. Atrekians used to cultivate a local variety of rice called Tengli. An interviewee said Tengli rice was the best in Iran. I asked

91 The Jeferbay Yomut used to migrate along the Caspian coast towards Balkhan mountiains (Zabihi, 1984, p. 152). 
a merchant in the Rice Market in Gorgan about Tengli rice. He said Tengli rice was wellknown for its 'splendid aroma' but its production decreased and in the last few years its supply has completely stopped. He said: "we used to crush a handful of Tengli rice in a bag of lower quality rice to make it sellable'.

Atrekians' land use and livelihood strategies were a multiple use and open access system. Pastoralism was pursued along with agriculture, hunting, fishing, and trade. Hunting and fishing played an important role in overall subsistence and life of Atrekians. A local interviewee said that almost all the men in the village were (and are) still engaged in fishing and hunting but with different intensity. He said 'the village is happy when we go hunting'. He remembers 50 years ago when water was abundant and the Atrek used to reach the Caspian in the wet season, that fish were abundant, he could fish with a forklike stick, and everybody could eat the fish. Both the Yomut pastoralists and cultivators, while producing for their own subsistence, were market-oriented, selling livestock, game meat, carpets, and grain in markets where they bought staples such as dry fruits, vegetables, fruits, rice, tea pots and cups (Pourkarim, 1967; Salzman, 2002, p. 254). The Yomut Turkmen had considerable trade with the cities of Asterabad and Khiva (Moradi, 2009).

\subsubsection{Traditional land and water use and management}

Long ago, the Turkmen dug networks of channels and built embankments to divert water from the Atrek system and store water for a longer time. Some of the water channels and embankments referred to in this discussion are shown in the participatory map prepared by Tenglian men (Annex D), and a modified, translated and simplified version of that map (Map 4.4). 


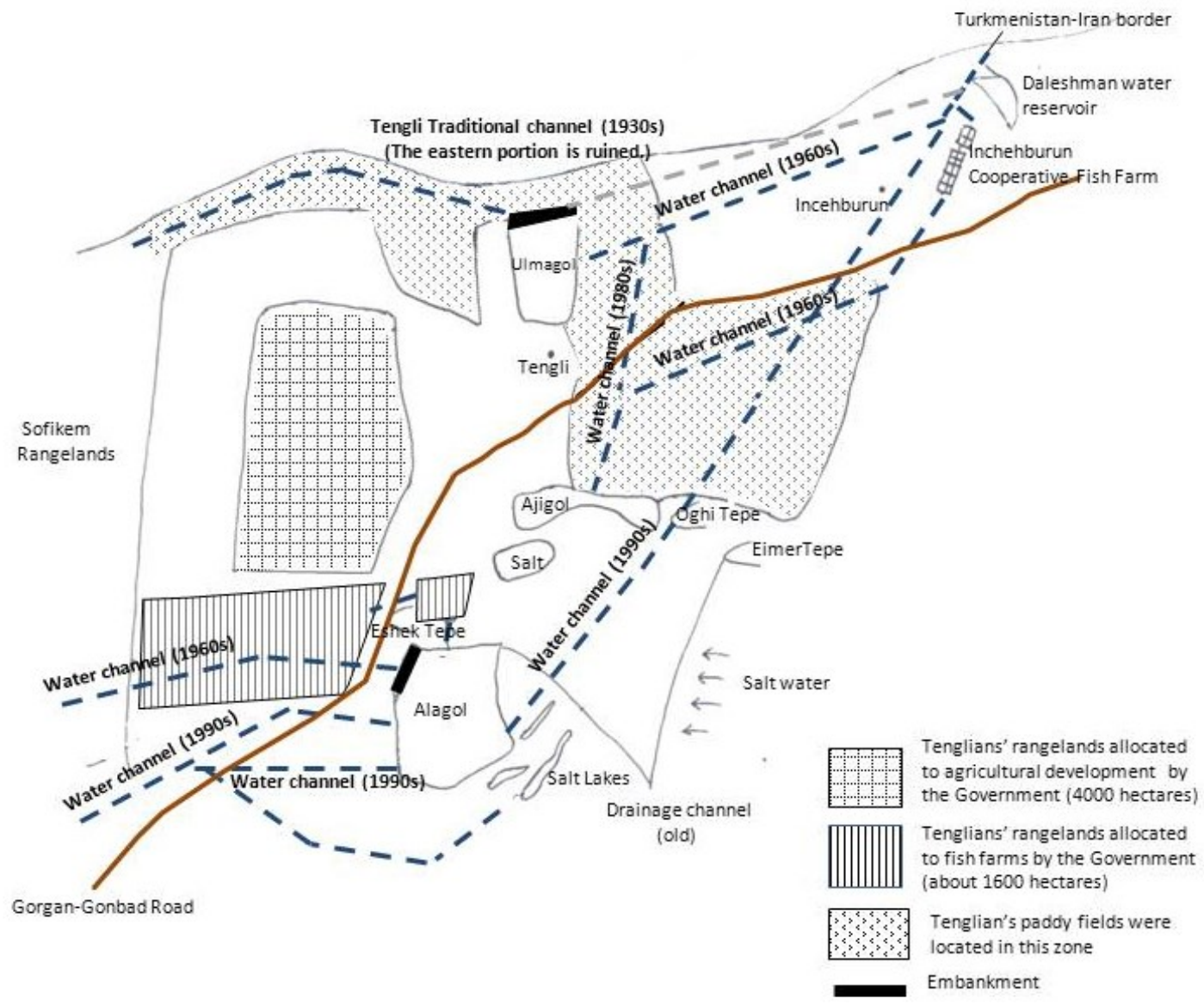

Map 4.4. Participatory map (modified, simplified and translated)

Water channels and simple irrigation systems were developed in the Sumber-Atrek system and in the Atrek's down reaches (Zonn et al., 2010, p. 45). The mir-ab(s) of Yomut Turkmen were familiar with the know-how and social management of irrigation systems and dam building as was practiced by the Turkmen in Central Asia. Rabino noted that traces of old channels and agriculture to the south of the Atrek are abundant (Rabino, 1928, p. 97).

The local people possess two old documents, which they believe prove their agricultural background, explain how they used their resources, and managed land and 
water, and indicate the extent of their ancestral lands (Annex C). The documents are in Turkmen and they have been translated into Persian by a university professor. These two documents confirm that since 1814, Aq-Atabays have operated a system of water management. The first document is an agreement, signed in 1933 by a mir-ab, a few Yashuli(s), and an akhund (a cleric), and the second one is signed in 1943 by the fourth generation mir- $a b$ and a few elders. The first agreement includes a history of the AqAtabay people and their nine sub-groups who occupied the lands along the Atrek and were conducting agriculture in their territorial lands. In 1820, the Aq-Atabay people, collectively, under the supervision of a mir-ab called Niazbay, constructed a dam on the Atrek in a place, Ukkiz Garshan ${ }^{92}$, between Delili Burun and Tengli Tepe (Pourkarim, 1968b). The document describes that the timber used was transferred from Asterabad and the document explained the details of sacrifices and efforts that people made to make this water blockade. They spend a great amount of money and time. The Atrekians then dug irrigation channels, from the dam along the Atrek, to irrigate their lands. O'Donovan, the day before reaching the bank of the Atrek, camped in Delili Burun and writes that a few verst ${ }^{93}$ further 'the Turcomans have dammed up the river to turn it further south' (O’Donova, 1883, p. 51).

Local interviewees remember that, in the 1930s, the Atrekians had built a channel from the Atrek, near Inchehburun, into Iran under the leadership of a mir-ab. This channel, from Inchehburun to Ulmagol and towards the Caspian, is known as the 'Tengli Traditional Channel', and parts of it, west of Ulmagol, still exist but the eastern side is

\footnotetext{
${ }^{92}$ The Atrekians' old document refers to this place as Garshan (Annex C). Pourkarim and local people use the name Ukkiz Garshan.

${ }_{93}^{1} 1$ verst $=1.67 \mathrm{~km}$
} 
ruined (Map 4.4). It was an effective waterway, similar to a river, which in the wet season reached the Caspian Sea and filled inundated marshy depressions including those that formed two permanent lakes northeast and south of Tengli (later called Ulugol (today called Ulmagol) and Ajigol respectively). During seasons with good rain, and the Atrek's floodwater, Ulugol and Ajigol became one and extended to Inchehburun. The Atrekians used simple techniques to block the outlet of a shallow water reservoir (where Ulmagol is located today); they created a simple $a b$-band to store water and then built channels to irrigate adjacent lands. They built an embankment (approximately $900 \mathrm{~m}$ width, $1 \mathrm{~m}$ height) at the north side of a swamp that contributed to it becoming a permanent lake (Ulugol and later called Ulmagol). The irrigation system was affected by hydrographic changes of the delta arms and was comprised of the main river channel, primary and secondary distributaries channels, diversion channels, earth bunds ${ }^{94}$, and irrigation ditches in the field (Mukhamejanov, 2000). Local interviewees remember that the Soviet Union used to extract water from Ulugol and import it in water tankers to their country. The embankment and channel system built by the Atrekians brought good cropping seasons to this area until the early 1950s. Both the Atrekian chomur and chawra had cereal cultivation, which did not need irrigation; only rice was irrigated.

Purkarim (Pourkarim, 1968a) argues that the Atrekians learned how to cultivate rice from farmers of the Astarabad area due to the similarity of agricultural terms used by the Atrekian and Astrabad farmers. He suggests that the dam and water channels were for irrigation of the Atrekian's rice. Local interviewees said they had rice cultivation as long as they can remember and Purkarim (Pourkarim, 1968a) quotes Atrekians who

\footnotetext{
${ }^{94}$ An embankment that surrounds rice fields
} 
remembered that their fathers cultivated rice. They always had melons, wheat, and barley cultivation using flood irrigation when water was available.

They had successful rice cultivation until the early 1950s, when the Atrek could no longer provide water due to excessive water extraction upstream and because the Soviet Union changed the Atrek's route. In that period, no water ran in the channels which the Atrekians had built and maintained along the Atrek River. An interviewee explained that the Soviet Union redirected the Atrek towards its land and the extreme decrease of water and the extinction of rice cultivation had forced many Atrekian families to migrate to other Turkmen cities and villages away from the Atrek. This condition changed after 1957, when Iran and Soviet Union agreed on joint management of water and power resources of the Atrek (Mojtahed-Zadeh, 2006, p. 114) and after the 1965 Iran-Soviet Union agreement that settled their border differences (Mojtahed-Zadeh, 2006, p. 115). After that water from Atrek reached the AUA region again.

There were 292 families remaining in the AUA region (84 in Tengli), in winter 1966 (Pourkarim, 1968a). Purkarim explained the Atrekians ${ }^{95}$ in the mid-1960s, in order to harvest runoff water and make the best use of the available water from the Atrek, dug a channel from the Atrek near Inchehburun towards a depression, which was a swamp (north of Tengli) and called it Ulugol (Great Lake) (Pourkarim, 1968b). He described Ulugol as a beautiful water reservoir used for irrigation (Pourkarim, 1968a). Local interviewees confirmed that development of the second channel, in the 1960s, restored the ab-band, Ulugol, and it again became a source of fresh water for irrigation of more lands, their daily use and a site for fishing and hunting.

${ }^{95} 260$ out of 292 resident households were involved (Pourkarim, 1968a) 
Local interviewees explained that Atrekians, as part of their water impoundment strategies for optimal use of their natural resources, constructed an embankment (approximately $300 \mathrm{~m}$ width and $1 \mathrm{~m}$ height) at the north-west end of Alagol to partially control floods (not to stop them) and to store runoff water for longer periods. He explained that the floodwater was useful for better pastures. The floodwater deposits fertile minerals and organic debris, and recharges groundwater and the soil profile. They had rich pastures and successful agriculture. Alagol, Ulmagol, and Ajigol have acted as flood control wetlands by delaying and lowering the peak flood flows so the flood would be slower to rise and last longer. A local interviewee indicated that for Tenglians drought was not a disaster, it rather was an opportunity to let the soil rest. The wetlands could store excess water and were part of a strategy for Atrekians to cope with drought. The increase in surface water evaporation created a microclimate which enhanced the local humidity, was particularly useful for rice cropping, and provided a suitable habitat for migratory birds.

Much of the AUA complex, like seasonal wetlands, is inundated during the wet season and subsequently most of it becomes exposed in the dry season and supports fresh pasture. Ajigol is a pasture in the dry season. The floodplain grasslands provided pasture which is vital for the survival of herds which often spend the dry season elsewhere. They could adapt to change. The steppe desert is gently undulating grassland with low sandy hills that are not even noticed by an untrained eye. On my first visit to the steppe with local people, I realized I could not distinguish the places the local called, tepe (hill); I saw flat plains. Floodplains are not flat in their natural formation (Doolittle, 2006, p. 184). Alluvial deposits create land forms which differ every season. Arid land soils are generaly 
fertile ${ }^{96}$ but they are low in organic matter, and alluvial soils are the most fertile/richest among them (Doolittle, 2006, p. 184). Floodwaters periodically deposit silt and some organic matter which forms fertile land when it is inundated (Doolittle, 2006, p. 184; Adams, 1993, p. 211). This is particularly important in dry lands because fallowing would not be necessary under this condition (Adams, 1993, p. 211). Adaptation to floodwater (versus complete water control) is crucial in enriching the soil in these ecosystems.

The Atrekians used to grow crops in the most fertile areas and graze livestock on the less fertile land on a yearly basis. Local interviewees explained that rangelands were usually in lower lands and farming was on higher lands but they did not have a fixed plot of land for dry farming and a different one for grazing. These parcels of lands had to be changed annually or every two years according to deposition of soil by floodwater and formation of new lands with rich soil behind small embankments. Lands for rice cultivation were those closer to Ulmagol but lands for dry farming and those used as pasture were not fixed plots. The best lands for rice cultivation were those closer to Ulmagol; along the water channels; and the flooded areas with more fertile soil on it. Lands away from water resources were considered inferior in quality and only good for dry farming. The beginning of the flood season was the time to decide which pieces of the land should be prepared for farming and which parts will be used as pasture. Next, they had to plan for diverting flood water towards the lands allocated for farming. Dry farming included barley and wheat which could grow on recently deposited flood-loams. Rice was always irrigated by water from Ulmagol. Melons were usually grown at the margin of rice fields or on plots near rice fields and flooded areas. Tenglians remember having wheat,

\footnotetext{
${ }^{96}$ They are fertile because leaching of minerals and nutrients in the soil by rain are limited (Doolittle, 2006, p. 184)
} 
barley, rice, cotton, melons and sesame cultivation. The low hills and shallow depressions were vital to the Turkmen for farming and for water for their livestock. An interviewee stated 'I know the land so well I can look at it and identify the depressions which can be used for water storage and plan the whereabouts of proper channels.'

The Atrekian's knowledge about their land, its elevations and depressions, quality of soil, and the Atrek's water system, and flooding system made them capable of building simple irrigation systems and water reservoirs, using flood water and Atrek runoff, in order to make the optimum use of spatial and temporal variability of their resources in the Turkmen Sahra. The result was a landscape that supported their livelihood and enhanced biodiversity of the region.

\subsubsection{Social arrangements}

The Turkmen's livelihood and use of land were essential parts of their social and cultural system. Climatic variability across space and time, land and water use, tenure rights, and traditional social structures were related (Salzman, 2004, p. 39). The strategy of land use by pastoralists (both farmers and herders) was a process of trial and error over long time periods (Beck, 1998, p. 58) and in constant interaction with their dynamic environment. The changing characteristics of land features, with the dynamics of climate, rainfall, and flooding, were integrated into the customary land use and water and land management in the AUA area. Salzman emphasized (Salzman, 2004, p. 40):

access does not mean unbridled use, for collective social, political, and ritual mechanisms are in force to control the use of territorial resources and conserve the environment to guarantee continued availability of resources in the future.

Yomut Turkmen had controlled their territories within a customary habit and land tenure was always collective and access to pasture and water resources was open (Salzman, 2004, p. 40). Only tents and animals were private properties. Land and water 
were held in common by communities and individual members had specific rights. Members of a community had rights to sufficient land for their tent, to hunt and fish, and to graze cattle on common lands.

The two agreements (Annex C) discussed above name four generations of AqAtabay mir-ab(s) of Atrekians in 123 years (1814 to 1943), who were elected with the people's consent: Niazbay, Ana, Niazbay the second, and Nazar-Mohamed. The agreement, dated 1933, explains how to pay the mir-ab, and who paid the expenses. The people chose a Yashuli to supervise the digging of water channels and to divide the lands between the nine Aq-Atabay tribes 'equally' and 'fairly'. Then, each of the nine Turkmen groups chose a white beard to divide the land among its members equally. The wage of the mir-ab was paid with a few pieces of land, which was privately owned by the mir-ab and was inherited by his descendants, but others had common ownership of land.

The mir-ab(s) were responsible for construction of the main river channel and primary distributaries channels and the remaining irrigation system (earth bunds, secondary distributaries and diversion channels, and irrigation ditches in the field) was planned and organised by the Yashuli(s). Water channels belonged to those who dug them and the sharing of water from the dams was correlated to the manpower every tribe put into their construction. In the beginning of each year, the heads of nine tribes in the AUA region discussed what channels needed to be dug, what to cultivate and on which piece of land. Those with herds could graze animals on the stubble and other crop residues after the harvest were completed. In summer when the natural pasturage was depleted, the grazing relied on the remnants in these fields. They cannot remember any constraint on the quality and quantity of pasture. 
Land was the territory of the tribe and was available temporarily to individuals for farming. Land was allocated among the tribes and the Yashuli, were responsible to allocate lands among members until the next annual lottery. Every year, the heads of tribes, Yashuli(s) used a lottery system for dividing land between the tribes fairly. The lottery was by picking names of the tribes, carved on a stick, from a hat, called Chak. Each tribe had a stick and they used to draw the sticks and allocate lands, in order, from the best to the least fertile. The length away from the channels of the farming lands for each tribe was more or less the same but the plot width was determined by their contribution in the construction of water channels. Each Yashuli had the authority to decide what to sow and what part needed to fallow. Every tribe had sharecropping and if a member for any reason moved to another village the land and water share would be returned to the community. The land was divided temporarily only for farming, while grazing, hunting and fishing were on common resources. There was no legal documentation for any of their arrangements. Farming and fishing was market oriented for Tenglians. The farm products and fish were divided between the families of each clan equally and then the surplus was sold. The buyers came to them and traded vegetables, fruits, and textiles.

The Turkmen's traditional land and water management and their open access land tenure system were affected by coercive sedentrazation (see Section 6.1.2) and nationalization of land and water (see Section 6.1.3) and eliminated after they gradually lost access to the Atrek water in the 1980s (see Sections 7.1 and 7.1.2). Five years after the Islamic revolution, the nine Atrekian tribes carried out their last lottery. After that every tribe divided their lands among their members. Local interviewees stated that in Tengli the majority of families received a few hectares (less than 10 hectares), and less 
than 30 families received above 10 hectares, but most of them did not know the exact amount or proximity of their lands (see Section 7.1.2).

\subsection{Conclusion}

This chapter has examined the Turkmen Steppes ecosystem, including the ecological and social importance of the Atrek River, given a brief description of the political and social context of the Yomut Turkmen in history, their fragmentation and sedentarization, and then explored and examined the transforming peculiarities of the pastoralist life of Gorgan Yomut and Atrekians under political and military forces of Russia and Iran.

Theoretical discussions on socio-nature, place, space, and scale are the basis for demystifying the social construction of the AUA glocal wetlands and explaining that it is not an isolated and static 'place' waiting for conservation, rather it is a nature-society hybrid that is shaped by the mutual relationships between humans and the non-humans. The AUA landscape which became a subject of 'fortress' conservation in 1975 was originally shaped as a result of the intimate interaction of the Turkmen with the harsh environment of the Turkmen Sahra, and the Atrek River, and was interwoven with the politics and military actions of their neighboring states, Iran and Russia.

This chapter has described the historical and social conditioning of the livelihood strategies of the Tenglians. Historical investigation in this chapter shows that the Turkmen were active agents in bringing about the AUA wetland complex. Building embankments and water channels for water harvesting and irrigation were major Atrekian water management mechanisms. Atrekians' knowledge of their land, including its elevations and depressions, quality of soil, the Atrek's water regime and flooding system, 
plus their social organization, provided them the competence to control runoff and floodwater, increase crop and forage yields, and build simple irrigation systems, embankments and water reservoirs in order to make the optimum use of the spatial and temporal variability of their resources. This traditional integrated system of land and water management did not allow categorization of land into separate plots for farming and grazing.

The traditional land and water management by the Turkmen in the AUA region resulted in creation of water reservoirs and a microclimate with relatively high humidity in middle of the desert steppes of the Turkmen Sahra, consequently shaping the landscape, which was the source of their livelihood (farming, herding, fishing and hunting) and shaped and augmented the biodiversity of the region. Alagol, Ulmagol, and Ajigol wetlands and their surrounding steppes, which were the result of intimate peopleenvironment interaction, were designated as a Wetland of International Importance in June 1975, for supporting 20,000 wintering birds, including threatened species in the IUCN Red List.

The contemporary people-environment interactions in the AUA region and the Tenglians' current livelihood strategies, their trends and preferences, will be addressed in the next chapter. 


\section{CHAPTER V-Livelihood strategies of the Tenglians- current status}

The Turkmen, the AUA wetlands and the surrounding steppes have been undergoing constant change and shaping one another for centuries. This chapter examines the contemporary people-environment interactions in the AUA region by analyzing the livelihood strategies ${ }^{97}$ of residents of the village of Tengli. This livelihood analysis of the Tenglians will reveal the topology of the village in terms of proximity and distance and reach and connection, i.e. what is connected and what is in proximity but out of reach. The overall access ${ }^{98}$ of Tenglians to various types of resources (natural, physical, social, financial, and political) and trade-offs between those capital assets are reflected in their livelihood practices. This dissertation uses livelihood strategy analysis as an analytical tool that seeks to reveal and understand people's livelihood preferences and trends, and to address conflicts and obstacles; it does not aim to gain 'hard' data. The data were collected through structured interviews, and questionnaires completed for 225 households out of 235 in Tengli during November and December 2008 (see Section 3.3).

\subsection{Village profile}

\subsubsection{Population and households structure}

In 1965, the total number of households in Tengli was 84 (Pourkarim, 1968a). As of December 2008, when the current fieldwork was conducted, Tengli had 235 households and a total population of 1225 (see Section 3.3.3). The 225 households interviewed (i.e. $96 \%$ of the total households) reside in 216 housing units. $75 \%$ of the households are single families and $25 \%$ are multigenerational families. The village has

\footnotetext{
${ }^{97}$ The term livelihood "best expresses the idea of individuals and groups striving to make a living, attempting to meet their various consumption and economic necessities, coping with uncertainties, responding to new opportunities, and choosing between different value positions" (Long, 1997, p. 11).

98 Access is the ability to benefit from things and ability is akin to a bundle of powers (Ribot \& Peluso, 2003, p. 155, 156).
} 
only one female-headed household, due to the Turkmen tradition that, when the head of the family dies, the first-born male assumes headship.

\subsubsection{Age groups, gender, and labor force}

The population of Tengli is almost equally divided between males and females ${ }^{99}$ (see Figure 5.1). Tenglians consider boys and girls over 13 to have full labor capacity. They have a full workload unless disabled. $71.5 \%$ of males and $72.6 \%$ of female are capable of full workload. The total disabled population ${ }^{100}$ is $3.4 \%$. The age distribution of Tengli (Figure 5.2) shows that just over half of the population is in the 14-29 age range. Over $72 \%$ of the villagers can potentially carry a full workload (after 13), taking into consideration the disabled population.

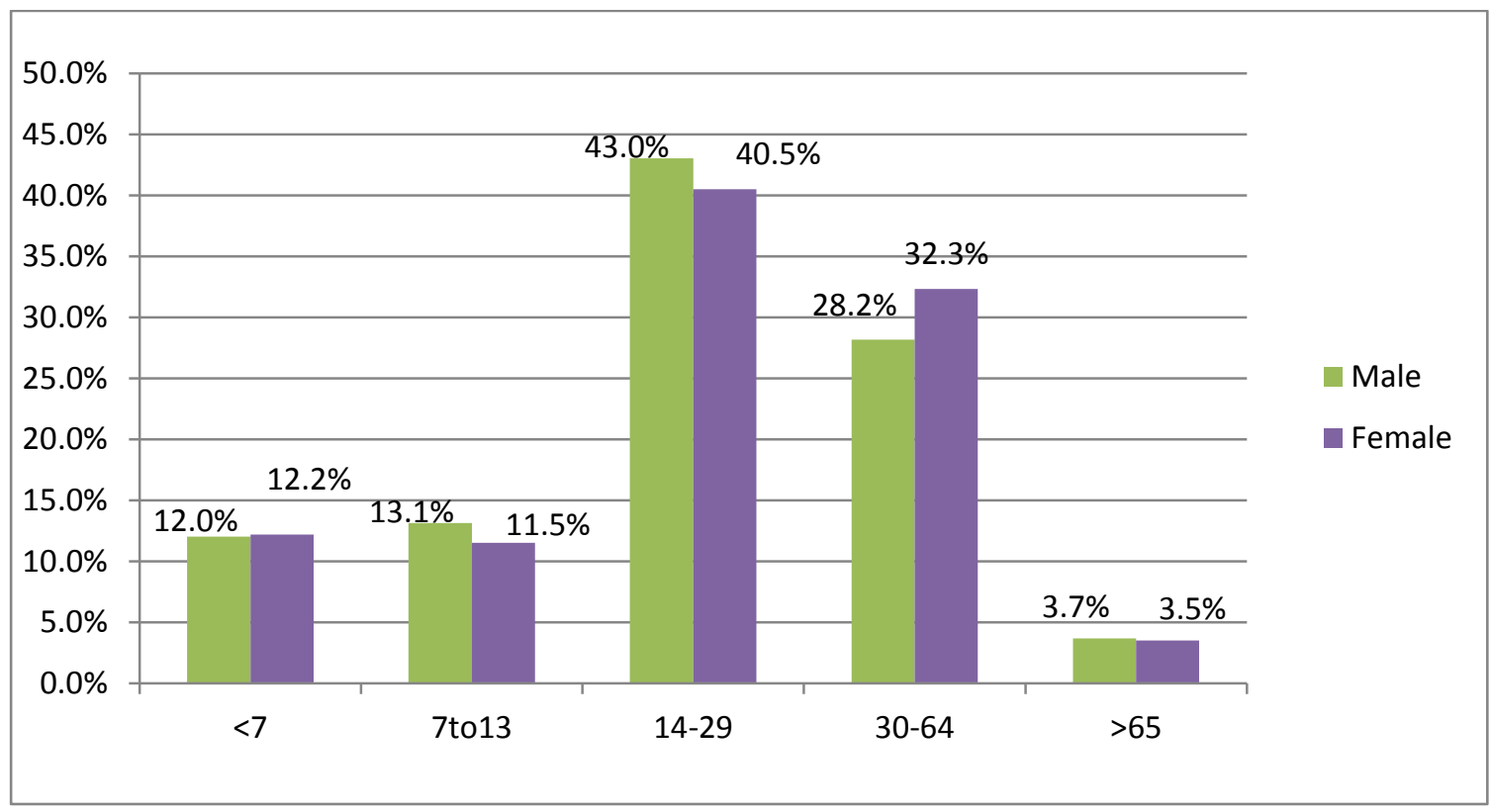

Figure 5.1. Population of Tengli, by age groups and gender

\footnotetext{
${ }^{99}$ Males constitute $50.8 \%$ and females $49.1 \%$ of the population.

${ }^{100}$ Disabled males are 19, and disabled females 23.
} 


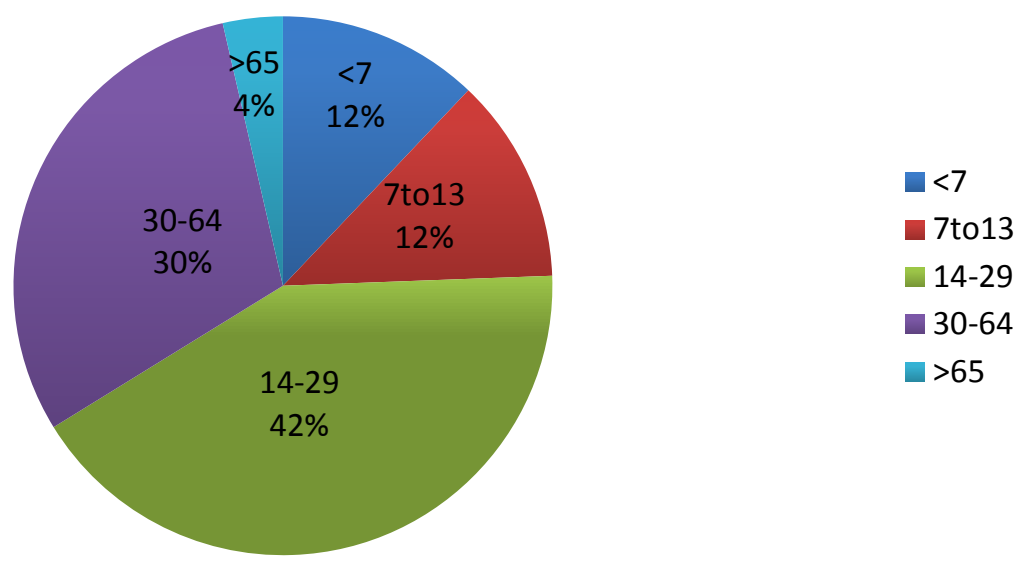

Figure 5.2. Population of Tengli, classified by age groups

\subsubsection{Education status}

Figure 5.3 shows the educational status of Tenglians who are 7 years old and older and Figure 5.4 shows the education status in Tengli by genders. The illiterate population consists of those who have limited ability to read and write and have not received formal education. Those who completed or attended a few years of education consist of: primary school (5 years), middle school (3 years), high school (4 years), and university (4 years).
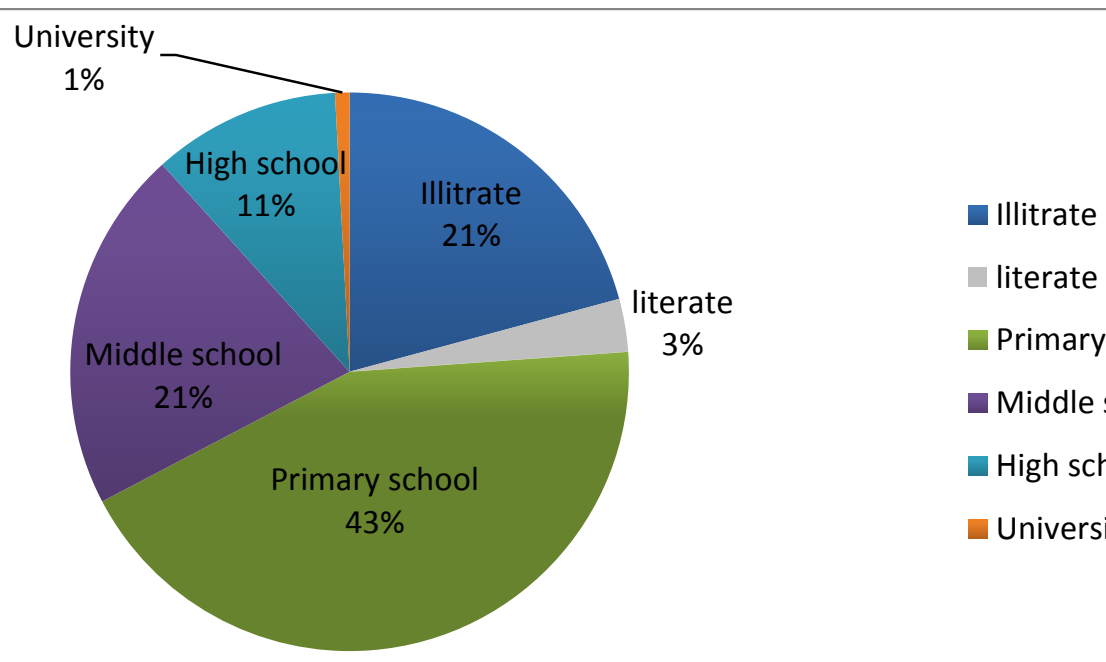

literate

- Primary school

- Middle school

- High school

- University

Figure 5.3. Education status of Tenglians 


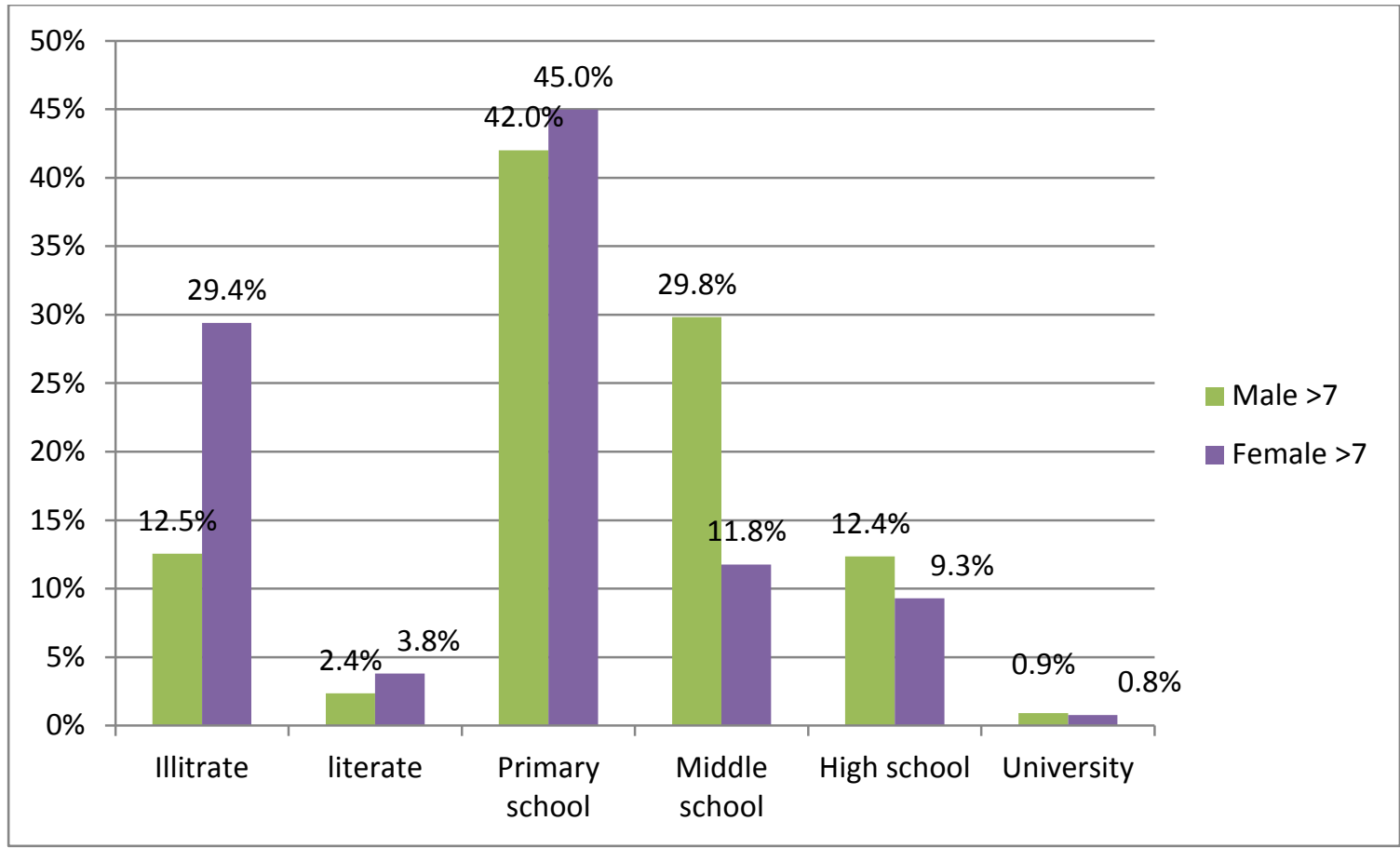

Figure 5.4. Education status of Tenglians, by gender

Elementary education is the only level available in Tengli. The nearest middle school is in Inchehburun, $15 \mathrm{~km}$ away from Tengli. Figure 5.4 shows that $71 \%$ of the men graduating from the primary level go on to the secondary level of education, while only $26 \%$ of the women are able to do so. However, approximately $80 \%$ of women who can afford to go to middle school in Inchehburun continue to high school, but only $41 \%$ of the boys continue. The boys drop out of school to join the family labor force and to support their families. However, girls who can afford to go to Inchehburun can often support themselves, with carpet weaving and needle work, so are able to stay at school and continue to higher education and are most likely able to graduate from university. This analysis clearly shows the overall limitation on the Tenglians, especially for girls, to access education after primary school, and a trend of deprivation of Tenglians from higher education

The present dehyar (member of the village council who is the secretary/head of the 
council) of Tengli is a female university student. The older generation in Tengli believe that a university graduate (only $1 \%$ of the population) can better communicate in the Persian language and is better capable of dealing with government officials and going through administrative processes. This is an indication that in the future, more educated Tenglians are likely to be involved in the rural councils and local administration.

\subsection{Livelihood Strategies analysis}

\subsubsection{Past, present (2008), and future}

Tenglians were asked to rank the importance of their livelihood strategies in the past ten years and in the last 12 months (2008) as high, average high, average low and low. The weighting factors for theses rankings are $1,0.75,0.5$ and 0.25 . Every livelihood is multiplied by its relevant weighting factor as is ranked in each questionnaire. The cumulative sums of those numbers for each livelihood for the past and present time periods, over all of the interviewees, constitutes its significance and is plotted on the y axis in Figure 5.5. Dotted lines in Figure 5.5 are the only livelihood strategies that declined from past to present. The significance value for Tenglians future choices of livelihood are derived from the answers to the question that asked them to rank, from one to eight, their choice of livelihood for supporting their families and providing food in the future. The first and second choices were multiplied by one, the third and fourth by 0.75 , the fifth and sixth by 0.5 and the last two were multiplied by 0.25 . The sums of those numbers for each livelihood strategy are plotted as the significance for each future livelihood choice on Figure 5.5. The relative rankings of the future livelihood strategies that the Tenglians propose are taken as an indication of their wishes and hopes along with a consideration of the feasibility of pursuing that livelihood strategy. 


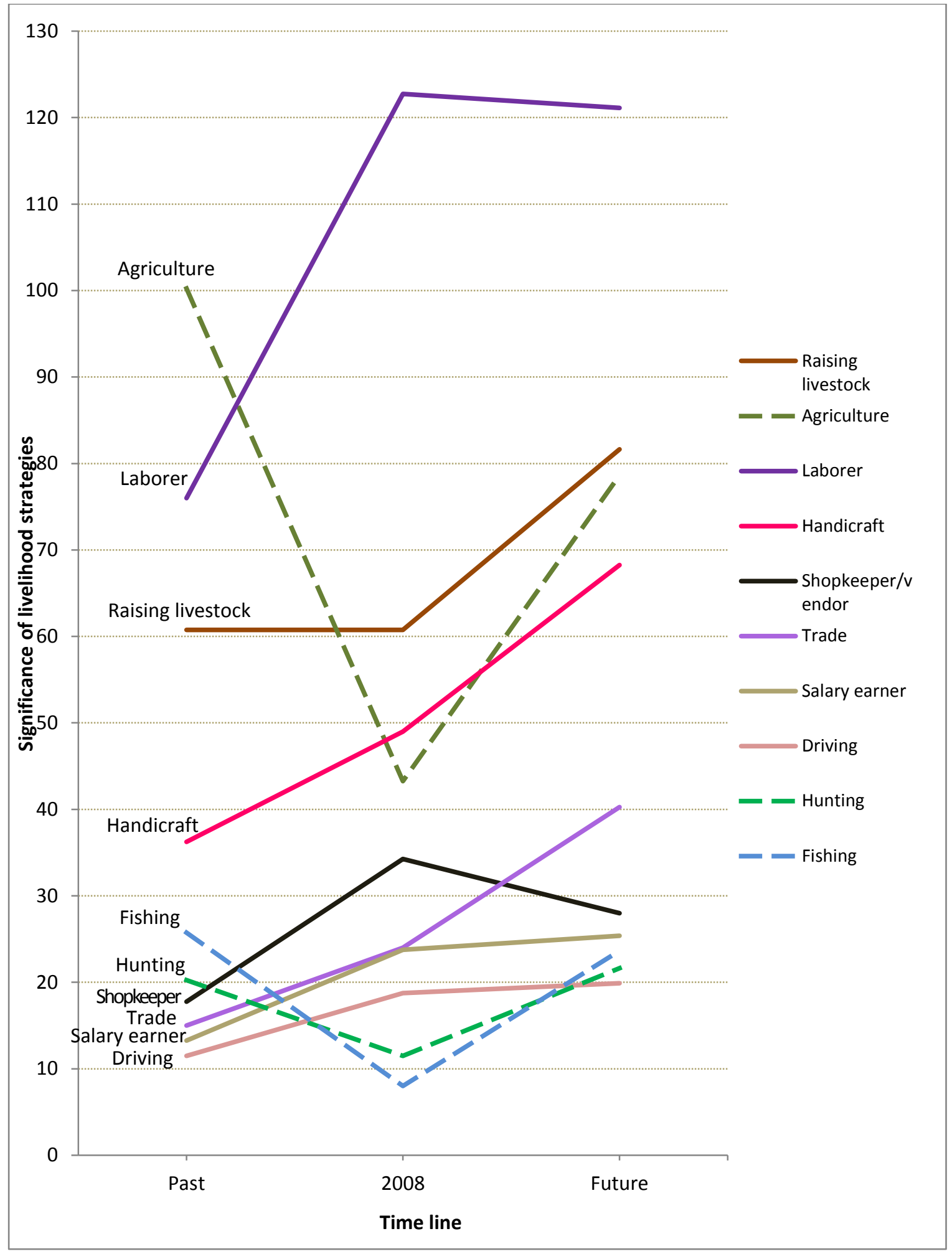

Figure 5.5. Livelihood strategies of Tenglians 
The first four important livelihoods for the Tenglians are: laborer, agriculture, herder and handicraft:

(1) In the foreseeable future, the most important, and most feasible, livelihood strategy for the Tenglians is labor, including wage laborers who load and unload trucks in the market at the Iran-Turkmenistan border, agricultural laborers and shepherds. The importance of wage labor in the AUA region is that it is the only livelihood strategy that is available to the majority of the male population in the Tengli. More than half of the males (53\%) of working age (above 13) are wage laborers. The future trend in Figure 5.5 shows that the Tenglians wish and hope to do less labor work. (2) Agriculture (cultivation) was the most significant livelihood strategy in the past but dropped into fourth most important by 2008. Its trend for the futures shows the sharpest increase in relative position, which demonstrates Tenglians' hopes and wishes to increase their opportunities to be engaged in farming. (3) Livestock herding has been the third most significant livelihood strategy in Tengli in the past and present. Its rank is almost identical with that of agriculture for the future. This is probably not surprising because selling livestock is the main source of cash income and is seen as their security for the future, and is a source of food. (4) Handicraft, consists of carpet weaving and needlework, was the fourth most important livelihood strategy in the past and for the future. Carpet weaving is the main occupation of the Tenglian women, in 115 of the households (51\%), mainly of the middle layers of the Tenglians; the well-off and the poorest households are less involved. The future trend shows that households intend to engage more in these livelihoods, which indicates that the women have a stronger economic weight within the village. 
The relative importance of both fishing and hunting has declined from fifth and sixth most important in the past, to last and second last in the present and future, respectively. The remaining strategies of shop keeping, vending, trading with Turkmenistan, getting salaried jobs and driving have never ranked very high. Most of these livelihood strategies are short term, only involve a small number of households, and, with a few exceptions, do not pay well. Some families manage to get loans or with the savings they raise from their livestock can: rent a stall and become a vendor or a shop keeper; buy a car, become a driver and transport people to and from the border market and adjacent village; trade with Turkmenistan, although this is unreliable because it is limited and relies on an agreement between Iran and Turkmenistan; take salaried jobs with fixed salaries including school teacher, and the lowest positions available in the custom office at the border, such as cleaning and maintenance at the border. The future trends and prospects for these livelihoods are uncertain.

\subsubsection{Wealth categories}

An elder, regarding economic strata of the village, explained:

Traditionally, poor families have few options and become wage labourers or agriculture labourer, average families are those who can support their family members, and well off families can support their family members and also help others.

A group of older Tenglian men agreed upon defining wealth categories (WC) in the village under the current circumstances on the basis of the number of livestock owned. Tenglians raise sheep, cows, and goats. A few families have camels and donkeys but they are not counted in wealth categories. Every 4 sheep is counted as 1 cow, and every goat is counted as 6 sheep or 1.5 cows. Households that possess 0 to10 animals are categorized very poor (WC-I), 11 to 24 animals owned are considered poor (WC-II), 25 
to 49 animals owned are average (WC-III), and 50 and above animals owned are well-off (WC-IV).

Analysis of the livelihood strategies among the wealth categories shows that WC-I comprises 80 households completely without livestock and 8 with 1-10 animals $(39.56 \%$ of total households), whereas WC-II has 70 households (31.11\%), WC-III has 25 households (11.11\%), and WC-IV has 41 households (18.22\%). Every livelihood is multiplied by its relevant weighted factor as ranked in each questionnaire. The sums of those numbers for each livelihood indicate their significance. The scores shown in Figure 5.6 are the significance numbers for each livelihood strategy calculated as percentage for each wealth category ${ }^{101}$.

A cobweb diagram (Figure 5.6) is used to compare livelihood strategies of the above four wealth categories in Tengli. The wealth category analysis shows that Wealth Category I and II, i.e. the poor and the average-low, are dominantly involved in labor work. An interesting inference of this analysis is that even male members of well-off households need to be wage laborers. This demonstrates extremely limited livelihood options for the Tenglians. Minimum livelihood diversity for WC-I is achieved with dominance of wage labor. Wealth Category III, average-high, is more inclined towards labor, shop keeping, and trade with Turkmenistan. Tenglians working as shopkeepers and vendors from average-high families can afford renting stalls and paying for merchandise, have access to credit, and are able to hire laborers from lower wealth categories to work for them.

\footnotetext{
${ }^{101}$ For example significance/score of herding and livestock husbandry for WC-I is calculated as 5.25. WC-I is comprised of 89 households i.e. $39.56 \%$ of the total households of the village. The score in the cobweb for WC-I raising livestock, 13.27 is derived as follow: $100 \times 5.25 / 39.56=13.27$
} 


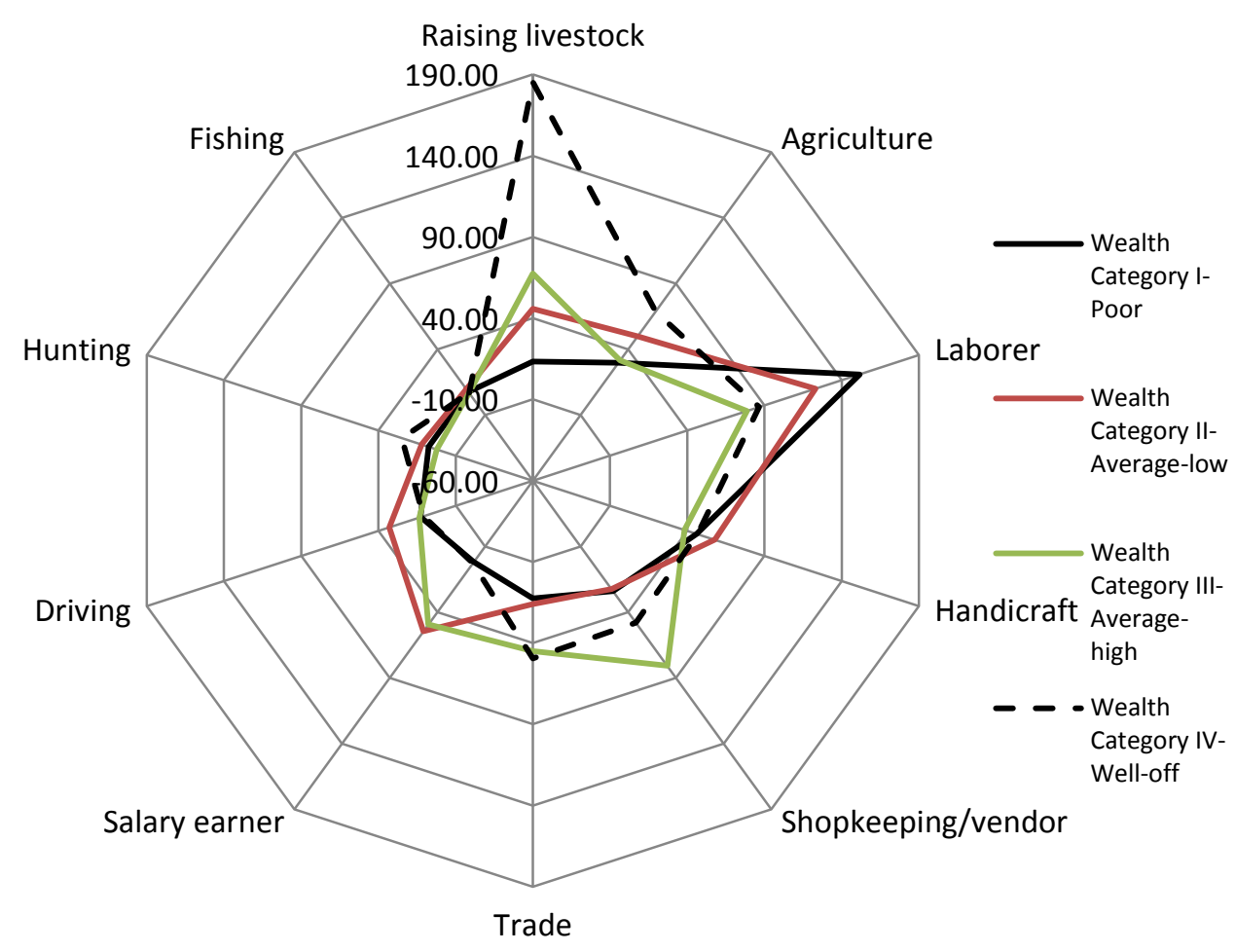

Figure 5.6. Livelihood strategies of Tenglians differentiated by wealth categories

\subsection{Obstacles: access to resources and livelihood}

The Tenglians were asked to rank the obstacles that they encounter in gaining access to resources and pursuing their livelihood strategies. Each obstacle was multiplied by a weight factor corresponding to its significance as answered in each questionnaire i.e. the first ranked obstacle was multiplied by one, the second by $7 / 8$, third by $3 / 4$, fourth by $5 / 8$, fifth by $1 / 2$, sixth by $3 / 8$, seventh by $1 / 4$ and the eighth obstacle was multiplied by 1/8. Figure 5.7 presents these constraints according to their decreasing order of importance.

Those from WC-IV (better off) and WC-III (average high) who have the highest numbers of livestock are engaged in agriculture and livestock breeding as their major 
livelihood strategy. Agriculture is the most decreased livelihood strategy and the majority of males in the village are wage laborers. Nevertheless, 'lack of water for irrigation' is ranked as the most urgent need of Tenglians, and 'lack of labor work', is second. This ranking demonstrates the willingness of the Tenglians, especially from lower wealth categories, to be engaged in agriculture and agriculturally related activities as their major livelihood strategy or as agricultural laborers rather than being dependent on random jobs available at the border loading and unloading trucks. This inference can also be explained by the actual livelihood strategy that most Tenglians are engaged with, labor, and the eagerness of Tenglians to engage more in agriculture and herding in the future (Figure 5.5). The random labor work that is available at the border market is not enough for the male population of Tengli and they do not find it fulfilling.

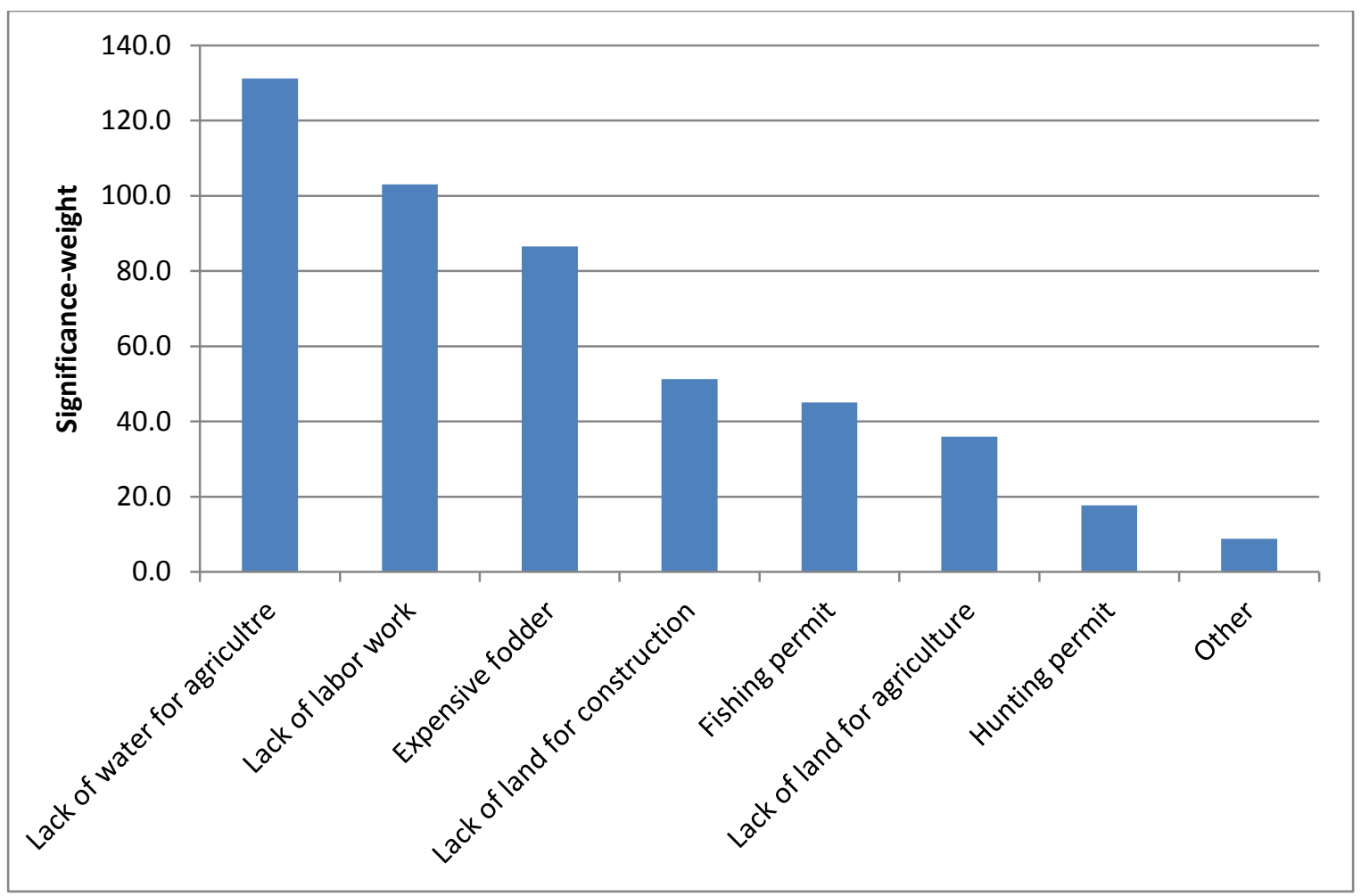

Figure 5.7. Problems Tenglians encounter: access to resources and livelihood 
'Expensive fodder' is a wide-spread problem and the third important obstacle of Tenglians because the majority of them from every Wealth Category at least have a few livestock. The director of the Union of Livestock Breeders ("Drovers hoarding livestock: Increase in red meat prices," 2009) in Tehran explains stock breeders need to have enough cash and credit to purchase fodder for a minimum of 6 months. Fodder is $60-70 \%$ of the total cost of livestock breeders they also need to cover their livelihood expenses. However, they do not have access to enough financial assistance and credit so they often sell their livestock to middle men at a lower price. He added if the government could provide facilities, and credits through the union to the livestock breeders then they could eliminate the middle men and control the price of red meat. The situation for livestock breeding farms is not better. Newspapers report in Golestan 60 livestock breeding farms have recently closed due to high expenses, high interest rates, lack of bank credits, and bureaucratic impediments ("Closing of 60 livestock farms in Golestan," 2011). A livestock farm manager in Golestan explains their expense is increased and their sell price is decreased. The major increase is the price of fodder; corn and wheat increased 40 and $50 \%$ respectively; however milk is sold at the 2009 price, three times less than the end price (“Closing of 60 livestock farms in Golestan," 2011).

Those who engage in agriculture, mostly dry farming, have their own lands or have access to lands of other local landholders in a sharecropping arrangement. What they require is water for irrigation farming. Therefore, in identifying the main impediments they face in pursuing their livelihood strategies, 'lack of land for agriculture' is ranked sixth. Fishing and hunting permits are controlled by the government and are expensive. Obstacles Tenglians encounter regarding agricultural lands, rangelands, land for construction, fishing, and hunting will be discussed, in detail, in Chapter VII. 


\subsection{Loans and debts: access to credits}

In Tengli 127 households (56.4\% of total households) are in debt (Figure 5.8). Their major source of loans is families and friends, reflecting their strong social structure.

The lack of access to official loans and micro-credit is a widespread issue for rural poor in Iran. Some of the underlying reasons are: the limited number of banks that provide micro-credits; distance to banks; high administrative costs of loan processes; lack of assets to use as collateral by the rural poor; and their illiteracy (Bakhshoodeh \& Karami, 2008, p. 70).

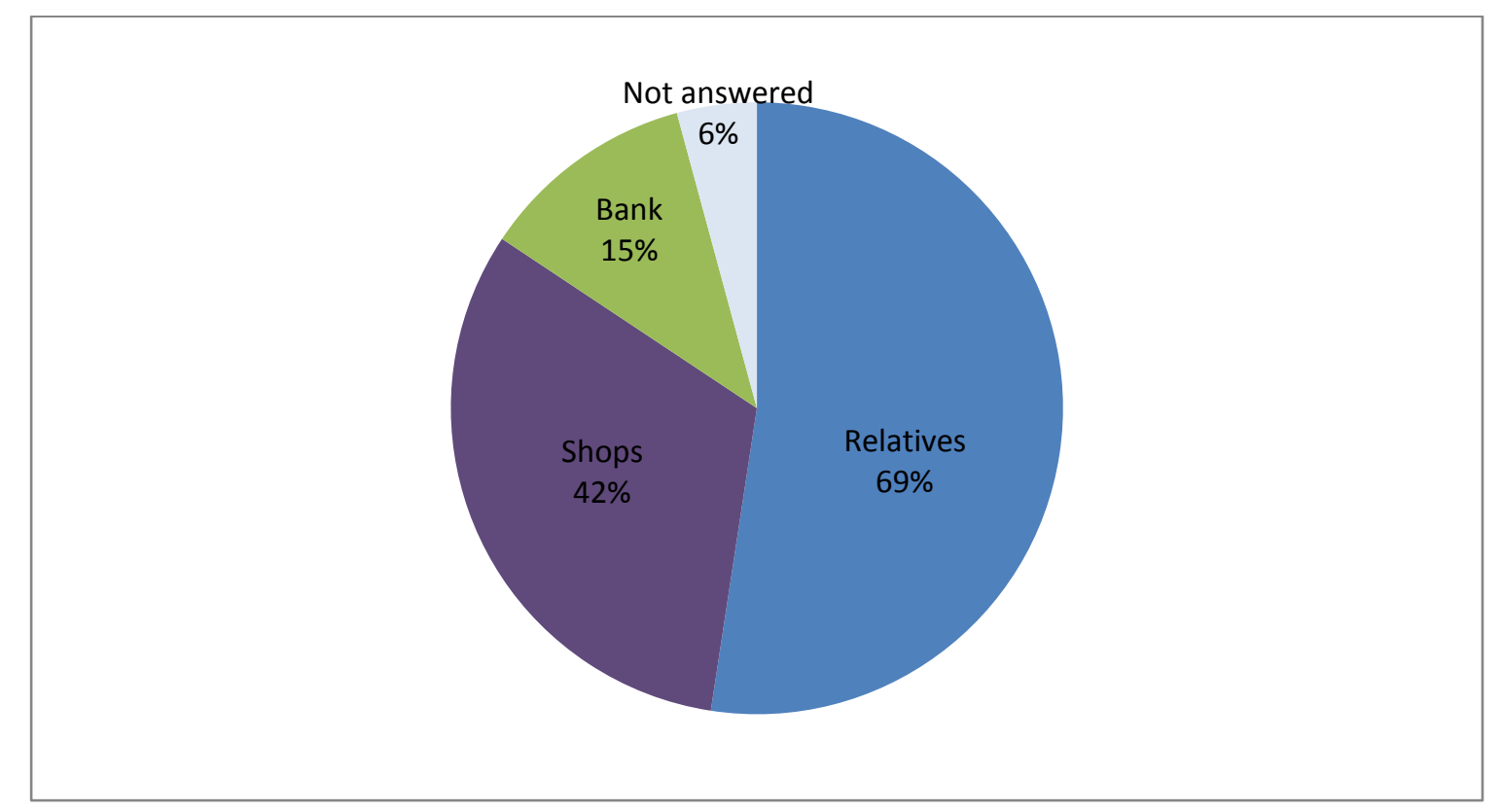

Figure 5.8. Tenglians' debt

The United Nations International Fund for Agricultural Development, in collaboration with the Iranian Agricultural Bank, studied rural finance mechanisms in Iran in 2005 (Prayer-Galletti, 2005). The investigation found that in the sample survey ${ }^{102}$ more than $65 \%$ of rural heads of households have no access to institutional credit

\footnotetext{
102720 sample households from twelve villages in four Provinces in north western part of Iran: Ardabil, East Azerbaijan, Kurdistan and West Azerbaijan (Mansuri, 2005, p. 4).
} 
(Mansuri, 2005, p. 1). The situation is worse for the Turkmen so they need to rely on their own sources of credit, which is based on their social connections. Bank credit is available to those who can put barren land and rangeland conversion and land use change processes in motion, and those who can obtain fisheries permits in the AUA region (see Sections 6.2.1.2, 6.3, and 7.5), neither of which is the case for Tenglians. A blogger writes that banks in Golestan province do not give loans or extend the farmers' loans after two consecutive years of drought, claiming that government officials have not announced the occurrence of drought in this province (Saribakhsh, 2008). In the few weeks when the government announced that all loans to the agriculture sector were extended, the same bank refused to extend the loans of farmers in Golestan Province due to an unclear government circular about details of the extension (Saribakhsh, 2008). This example of an ineffective agriculture loan system in Golestan province shows how farmers can be pushed further into poverty.

An interviewee answeing the question 'what is your day-to-day struggle?' said 'First, feeding my family and then my livestock'. My field data support her statement. Figure 5.9 shows the first three needs of Tenglians for borrowing money are: food, fodder (see Section 7.1.1), and construction/house maintenance (see Section 7.1.4). Agricultural debt is related to expenses pertinent to random farming if they have the opportunity to participate. Other uses include investing e.g. buying a car or becoming a vendor. An interviewee mentioned that: if they could not pay loans back by selling livestock then they rely on women weaving carpet. 


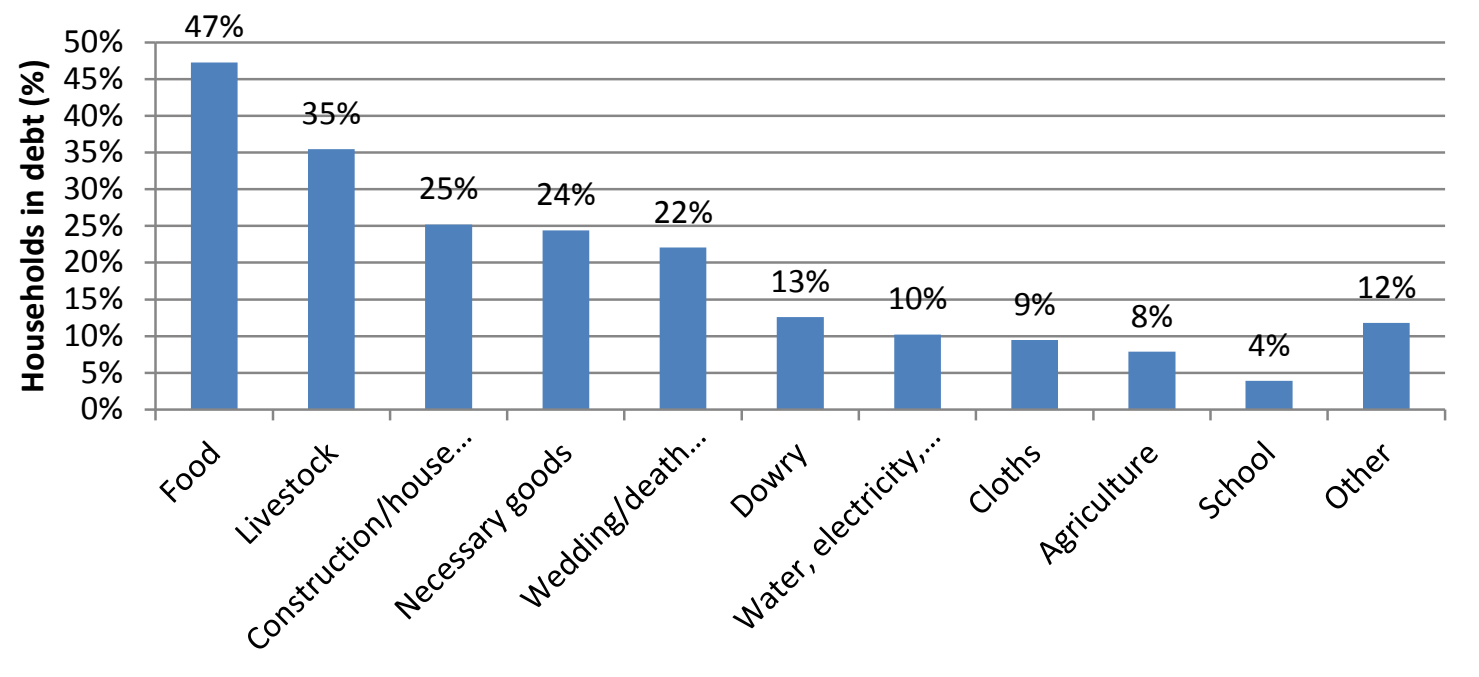

Figure 5.9. Usage of the borrowed money

\subsection{Needs}

Tenglians listed and ranked the necessities that contribute to improvement of the quality of their lives (Figure 5.10). These data demonstrate their living conditions as follow: (1) The climatic condition of the AUA region requires heating in winter. It has harsh winters and lack of access to gas makes it very difficult for Tenglians to heat their homes when only kerosene is available. (2) A doctor visits Tengli only once a week and if they need a doctor during the week they go to Gonbad (70 km away). (3) The village requires secondary and high schools. This will make it possible for girls to continue their studies after the primary school and more boys would be able to afford graduating high school. (4) The village needs a waste management system. Tenglians dump their garbage in an area between the village and Ulmagol. The smell is repulsive in summer and attracts every kind of unwanted pest. (5) An asphalt road and a playground will help their living condition by reducing dust and providing a space for their children. (6) Building a sport facility for the village according to a few mothers would be a response to an escalated 
addiction problem in the region. (7) The village only has two small stores that rarely have all the goods needed by Tenglians for their diet. Since Tenglians lost their agriculture, the village has had a high protein diet, rice is replaced with pasta, and there are few vegetables and fruits. They have only two bakeries, with low quality bread, not enough for their population. A government permit for opening a bakery and providing flour is not easy to obtain.

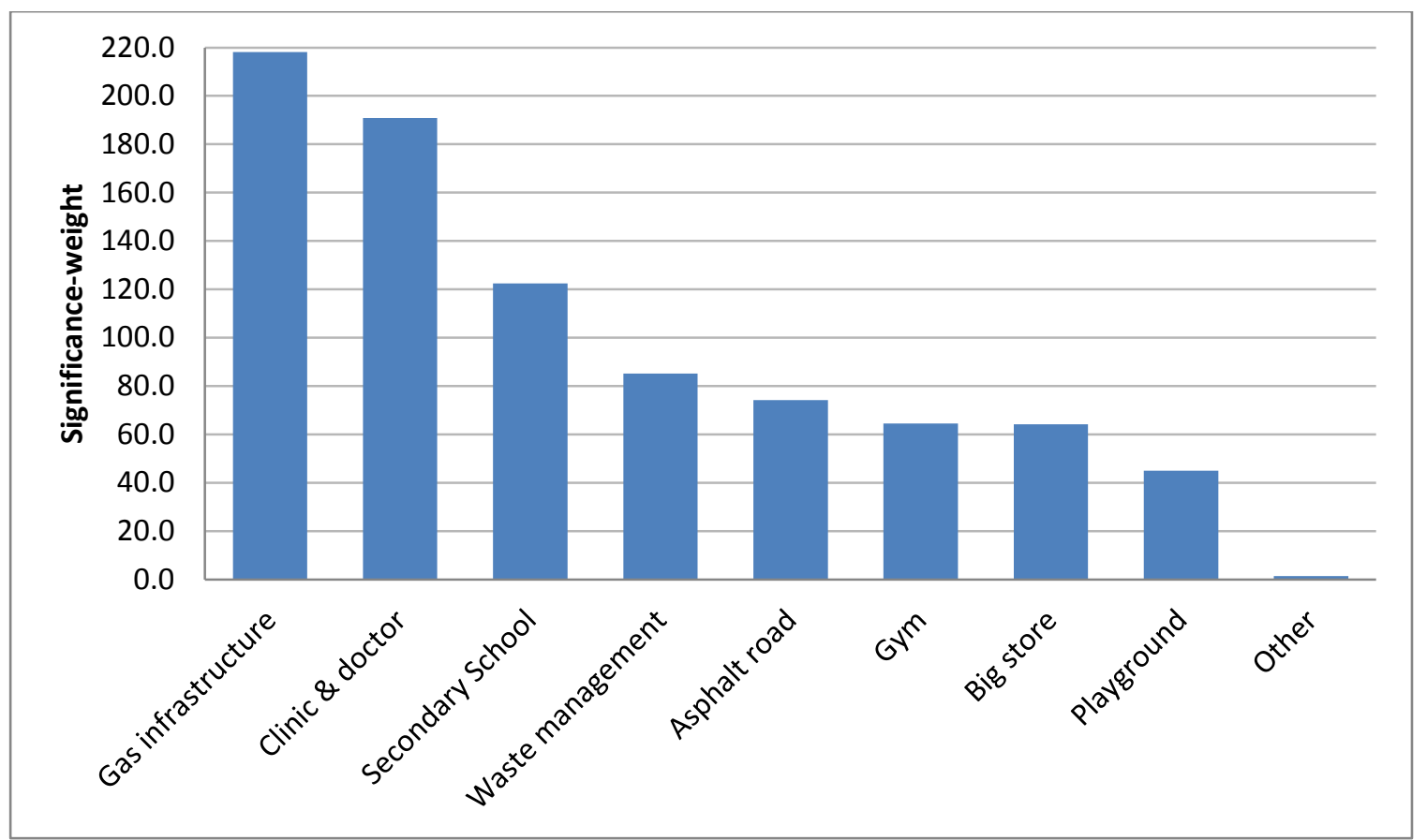

Figure 5.10. Tenglians' needs

\subsection{Conclusion}

Analysis of empirical data on livelihood strategies of Tenglians as of the end of 2008 shows that people-environment interactions have changed through time, and many Tenglians have been disconnected from their land and resources. The trend of past, present and future livelihood strategies of Tenglians shows that those livelihoods which are dependent on nature (agriculture, hunting, and fishing) are declining and are being replaced by wage labors, or, if they were able to borrow money, shopkeeping (a very small number), and most males from every wealth category are wage laborers. Livelihood 
ranking for the future shows that people hope for and have eminent preference to increased use of their land and natural resources (agriculture, raising livestock, fishing, and hunting). Despite this tendency, they do not have access to water, land and financial resources to continue farming; it is difficult to continue raising livestock for the majority of Tenglians because fodder is expensive; and fishing and hunting permits are controlled and limited. The Turkmen have very limited access to resources including: bank credits, basic rights to education, primary health services, and basic infrastructures such as gas, and waste management.

There are two clear implications of the changes in Tenglians' livelihood strategies: a) erosion of traditional knowledge among the Turkmen and b) increased dependency of Tenglians on the state apparatus.

Traditional knowledge: Access affects practices, ideas, and knowledges. Customary land and water use cannot be maintained if access by local communities to their natural resources is not secured. For centuries Turkmen for centuries shaped the landscape with their integrated land and water resource management, but to maintain and enhance this knowledge and practice their customary land, water, and wildlife use, they need to be in daily interaction with nature and their environment. Therefore, access rights to land and resources and their management is a vital requirement for revival and survival of the Atrekians' traditional knowledge. In interviews with younger Tenglians who were involved in fishing and hunting, they tended to ask their elders about available species in the AUA landscape. The generation that was involved in traditional integrated land and water use will be almost non-existent in approximately a decade. The interviewee that stated he could identify the land elevations and depressions for developing a productive channel system was in his 70s in 2008. The Tenglians are disconnected from their land 
and resources, and it is clear that the new generation is not familiar with land, water, and wildlife, and consequently their traditional knowledge pertinent to its landscape is eroding.

Increased dependency to the State: Pushing rural people to labor markets 'only deepens rural inequalities and make them dependent on jobs which only the government or private sector can provide them' (Mosse, 2010, p. 1171). In the context of limited access to resources and credits, and absence of state support for agriculture, local people are pushed towards wage labor against their wishes. The only source of wage labor for Tenglians is the market at the border, and isolated small construction projects. Becoming distant from natural resources by seeking wage labor or other jobs puts Tenglians in a new relation with the state. They lose their independence and compete with each other and also with the majority Persians for access to limited job opportunities that only can be provided by outsiders. In this process they encounter social and political barriers of being ethnic and religious minorities.

Access to rangelands, farmlands and water are the basic requirements for continuing livestock breeding and farming, and access to the wetland resources is essential for fishing and hunting for Tenglians. Arguments of this chapter highlights the need to examine natural resources access processes, current land use conflicts in the AUA area, and power structures involved in shaping the AUA landscape. Local people, despite their geographic proximity, are distant from the lakes, land, and the Atrek's water. The next three chapters examine the processes and networks involved in such topology and explain what is close and what is connected and what is in proximity but out of reach of the Turkmen. 


\section{CHAPTER VI- The politics of state natural resource control}

This chapter examines the webs of power relations at work in the AUA glocal wetlands and their surrounding area in the context of the Iranian political structure. It addresses the following questions: how has the state's power been exercised in the area; what are the state's territorial approaches in the Turkmen Sahra; and where has control over resources been located in the Islamic State. The first section discusses state-building, territorialization of state power and centralized processes, land use and natural resource governance $^{103}$ of the Turkmen Sahra after the coercive sedentarization in the Pahlavi era (Reza Shah, 1926-1940 and Mohammad-Reza Shah, 1941-1979). This background is necessary to understand natural resource governance discussions in the second section regarding the Islamic State's land, water and nature processes and regulations (1979 to present).

Power is at the core of differences in resource access and control over priorities. State land and natural resource governing priorities emerged through the working of various actants, including the motivation and strategies of state actors before and after the revolution, the Turkmen, and their physical environment. Formation of the AUA area, encompassing lakes and the Atrekians villages, is a place-making/remaking process through which actors that are able to mobilize different kinds of resources, engage in political agendas across multiple scales and levels. Place-making develops a normative vision of the place (e.g. land use policies, including conservation territories) and legitimizes what is included and excluded and usually requires policing and regulation.

\footnotetext{
${ }^{103}$ Natural resource governance can be understood as "the interaction among structures, processes and traditions that determine how power and responsibilities are exercised, how decisions are taken, and how citizens or other stakeholders have their say in the management of natural resources-including biodiversity conservation" (Campese, 2009, p. 12).
} 
Hence AUA place-making is part of the political agendas of actors and manifests power relations at work in society at large. The AUA is a function of power geometry, and in the midst of interactions between the dynamic of state (as an actor-network), development and modernity discourses and political aspirations of its various factions, the Turkmen and the Turkmen Sahra (the physical environment). The state's exercise of power and the schemes to enroll humans and non-humans include political and social processes that condition access, control and management of resources, priority setting and decision making.

\subsection{Pahlavi shahs}

In Foucault's analysis of Europe, governmentality developed with the fall of feudalism and the emergence of capitalism, whereby the function of power, from premodern to modern Europe, shifted from 'punitive' to 'disciplinary' (Foucault, 1977, p. $215,216)$ and sovereignty power, and law enforcement became the core of state agendas (see Section 2.3 and its subsections). A similar shift in power happened in Iran, in the Qajar Persia, but through very different processes and not with the same result as in Europe. The major difference is that Qajar Persia was not a feudal society and the changes in Persia in the 1920s were not a typical shift towards capitalism. Nevertheless, sovereignty over territory, development of disciplinary structures and enforcement of regulations began in Iran under Reza Shah with the power geometry of Iranian society shifting from the decentralized system of the Qajar dynasty, with its agrarian system of production and relative autonomy of tribal communities to a highly centralized and militarized government in the 1920s after Reza Shah became king. 
In Iran, the process of common citizenry, centralization, and establishment of state power included an authoritarian administrative system and a highly centralized bureaucracy to socially engineer the Persians towards 'Westernization' and 'improvement'. The discourse of modernization was influenced by the lessons of economic mobilization from World War II and development of capital-intensive agriculture in the US (Scott, 1998, p. 224). Economic development of Third World countries, with predominantly rural societies, was a post-colonial fever of the post-World War II era (Katouzian, 1981, p. 111) and included mainly improvements by the World Bank to infrastructure, education, some social services, bureaucratic and military networks, large scale agricultural and irrigation projects and agro-businesses (Hooglund, 1982, p. 68) and land reform, which was encouraged by Americans (Scott, 1998, p. 224). In Iran, an engineered modernization and development process started before the war under Reza Shah's state building and included projects such as legal codes, unification of society, and social engineering (Scott, 1998, p. 91, 93, 97). Scott argues that authoritarian high modernization, reorganizing human communities in order to make them better objects of political control, and facilitating new forms of farming favored by state policy is common among modern developmentalists (Scott, 1998, p. 224).

The modern nation-state of Iran was concerned with political and economic independence, and the establishment of a powerful centralized state building but not with democracy (Ghorashi, 2003, p. 79) and equal citizenry. The modern nation-state was an imported concept and did not evolve from Iran's civil society of that time (Ghorashi, 2003, p. 79). Unlike Europe, social classes in Iran did not have rights and the 'state's legitimacy was not founded in law and the consent of influential social classes' (Katouzian, 2006, p. 1). Agricultural property was owned by the state and given to 
peasants to work as a privilege but not as a right (Katouzian, 2006, p. 1). Therefore, there were no rights independent of the state, and no law outside the state (Katouzian, 2006, p. 1).

\subsubsection{State building practices}

During the Pahlavi era, for the first time in Persia, administrative techniques and social knowledge were applied to shape social, cultural and economic processes and engineer society in the way favored by the state. In the Reza Shah era, the 'art of government' that deals with raising problems, finding possible solutions, and employing tactics and measures had two main instruments: militarization and a highly centralized bureaucracy. Institutional arrangements were the kernel of state practices through which power was propagated. The development of law, institutions, and knowledge created discipline, central authority and introduced modern amenities (except public health services and drinking water), to create a national identity (however coercive and contrived), and a nation-state with one culture and language, taxation, and policing (Abrahamian, 2009, p. 91). The new state developed roads, railways, and telecommunications, established the first national Iranian bank, created higher education and developed a substantial array of institutions to modernize and centralize government (Katouzian, 1981, p. 108) extending its presence in every corner of the country and every aspect of people's lives.

Statehood and nationalization were constructed through motivations and strategies of actors at different scales. A new power-geometry was established with Reza Shah in the principal role of enrolling actors and mobilizing resources through changes in every dimension of society, including economic, cultural and educational spheres. State 
building was Reza Shah's main goal and his efforts as a 'reformer', modernizer' and even 'secularizer' aimed to expand state power into every dimension of Iranian society, economy and polity (Abrahamian, 2009, p. 72) by securing Iran's border, managing its economy and developing a manageable society by the remaking of tribal communities. Reza Shah's state building had two main pillars (Abrahamian, 2009, p. 66): a) development of an extensive bureaucratic structure through administrative reform to create a highly centralized state; and b) development of a large military with the motto of Khoda (God), Shah, Mihan (state). He considered the threat posed by tribal powers as the main threats to the Iran he envisioned (Katouzian, 2009, p. 203). He used some foreign countries against others and used some tribal military powers to defeat other tribal groups, ultimately disarming all tribes and forcibly settling them. He changed the decentralized Qajar system, in symbiosis with tribal power, into a highly centralized state with the goal of politically pacifying and sedentarizing tribes (Katouzian, 2009, p. 213, 214).

With the establishment of spatial and legal jurisdictions, the nation-state became the central scale of identity and political power in Iran. For the first time, the Iranian government reached into the rural areas (Abrahamian, 2009) and could exercise complete control over the life and economy of rural people. Governors were appointed by and were totally dependent on the central government (Abrahamian, 2009, p. 71). The state was not a single homogenous actor; its network included many social actors and applied numerous political, economic and cultural processes.

'Purification' of nature and society (nature without humans and humans without nature) is the core of the modern state. The purification process becomes necessary for simplifying the entangled assembly of humans and non-humans in real life in order for the modern state to manage its territory and citizens (Castree \& Baaun, 1998, p 33; 
Whitehead et al., p. 15, 16) (See Sections 2.1 and 2.3 and their subsections). Scott explains that for states in early modern Europe a unified measurement system was as essential as a national language, and 'the metric system was at once a means of administrative centralization, commercial reform, and cultural progress' (Scott, 1998, p. 31). The main applications of this unification were for administration of property deeds, legal processes, tax codes, and promotion of a cultural unity. One implication for France was the opening of space for a rational citizenry, French citizenship, equal citizenship and equal rights of citizens, at least in the abstract (Scott, 1998, p. 32).

Reza Shah initiated a similar process in Iran as was used in Europe. He introduced the metric system and a standard system of weights, measures and time for the whole country (Abrahamian, 2009, p. 83) and, for the first time in Iran's history, a central monitoring system for managing society and nature was created; land survey, property registration, and tax calculation became uniform, and a national fiscal plan became feasible. He brought order to the tax system by creating a tax collecting system with the help of the Americans and presented Iran's first comprehensive annual budget (Abrahamian, 2009, p. 67) which became the foundation for establishment of the Plan and Budget Organization.

In the Reza Shah era, the Muslim lunar calendar was replaced with a solar calendar that starts with the ancient Persian New Year, the beginning of spring, and identified the months with Zoroastrian names (Abrahamian, 2009, p. 83). To 'foster national unity in lieu of local sentiments', tribal and traditional clothes were outlawed (Abrahamian, 2009, p. 84). Iranian men had to follow a European dress code of coat, trousers, and a brimmed hat, and were required to have shaved faces or trimmed mustaches (Abrahamian, 2009, p. 84; Beck, 1990, p. 206). Women were encouraged to 
appear in public without a veil and to talk to members of the opposite sex (Abrahamian, 2009, p. 84). Finally, the Chador (long veil) was banned in all public places (Abrahamian, 2009, p. 94). Another policy towards developing a nation-state and 'Persianizing' the new citizens of Iran was adoption of a uniform education system modeled on the French lycées (Abrahamian, 2009, p. 85). The primary education system was greatly expanded throughout Iran using the same books, curriculum and language, and the government banned any language other than Persian in community schools (Abrahamian, 2009, p. 85). Women were encouraged to attend primary schools and a higher education system was established and flourished (Katouzian, 2009, p. 215).

Abrahamian quotes from the British Legation's report dated January 1935, which warned about the Shah's policies regarding religious leaders (Abrahamian, 2009, p. 94):

The Shah, in destroying the powers of the Mullahs, has forgotten Napoleon's adage that the chief purpose of religion is to prevent the poor from murdering the rich. There is nothing to take the place of religious influence, save an artificial nationalism which might well die with the shah, leaving anarchy behind.

However, Reza Shah was a Shi'a muslim who sought to bring religion under the state supervision (Lapidus, 2002, p. 477; Abrahamian, 2002, p. 85) and not to replace it with secular thoughts. He permitted dissection of human bodies in medical schools, restricted public religious mourning to one day and opened mosques to foreign tourists (Abrahamian, 2009, p. 94). The government supervised major mosques by governmentappointed clergies, closed some of the religious schools and controlled those that remained open (Abrahamian, 2009, p. 85; Lapidus, 2002, p. 477). The government supervised the religious school, the Ministry of Education provided a curriculum for theological schools (Lapidus, 2002, p. 477) and the government had the power to decide who could become a member of the Ulama (Shi'a clergy) (Abrahamian, 2009, p. 85). 
Islamic scripture classes were mandatory at schools, with text books designed to abolish any religious skepticism and promote Shi' ism (Abrahamian, 2009, p. 85).

Reza Shah established an array of research institutions, including the Cultural Academy, modeled on the French Academy, the National Heritage Society, the Geography commission, and the journal 'Ancient Iran', to promote ancient Iran and its glorified heritage in order to encourage national unity, to do research and to collect data and knowledge. Part of these institutions' mandate was to replace non-Persian names with Persian or newly created names (Abrahamian, 2009, p. 86). He established the necessary structures to insert politics into history, literature, archeology and architecture (Abrahamian, 2009, p. 87). The Cultural Academy Persianized administrative terms and studied the possibility of changing the Arabic script, before concluding the latter would be impractical. The Geography Commission changed the names of 107 place names (Abrahamian, 2009, p. 87). In this process, the Turkmen Sahra changed to Dasht-e Gorgan (see Section 4.3.2). The most drastic of name changes occurred in 1934 when Reza Shah announced that 'Persia' was associated with Qajar decadence, and henceforth the country would be known as 'Iran', a name that is associated with the 'glories and birthplace of the ancient Aryans ${ }^{104}$ (Abrahamian, 2009, p. 86).

Reza Shah developed a disciplinary force for his vision of an Iranian transition from a 'punitive' to 'disciplinary' society. He introduced the institution of long-term prisons that had not previously existed in Iran, replaced short-term detentions and created

\footnotetext{
${ }^{104}$ Abrahamian, quoting from the British Minister's, 'Annual Report for Persia 1933', states that the journal 'Ancient Iran' in Tehran was: '"echoing" the anti-Semitic notions of the Third Reich' (Abrahamian, 2009, p. 86, 87), and that the nationalism promoted by Reza Shah was influenced by Racism in Europe and racial theorists such as Count Gobineau, who claimed that Iran, because of its 'racial composition, had greater cultural-psychological affinity with Nordic peoples of northern Europe than with the rest of the Middle East' (Abrahamian, 2009, p. 87).
} 
two security organizations ${ }^{105}$. He expanded the state judicial system, modeled on those from France, Switzerland and Italy, and adopted some Shari'a law related to criminal and family law (divorce, custody of children, polygamy and temporary wives) (Katouzian, 2009, p. 214, 215; Abrahamian, 2002, p. 88). He weakened Shari'a law in three important ways (Abrahamian, 2009, p. 88):

a) the legal distinction between Muslims and non-Muslims was abolished; b) the death penalty was restricted to murder, treason, and armed rebellion, and c) longterm imprisonment replaced public corporal punishment.

The new state restructured and strengthened the rural Jandarmeri (police) and expanded the police force into provincial cities (Abrahamian, 2009, p. 70). Reza Shah also developed military establishments (armament factories, repair shops, hospitals, officers clubs, banks, colleges and academies) under his direct supervision. He never was seen without military uniform and was in direct contact with army field offices independent of the administrative system, war minister and premiers and was very lenient and generous towards military personnel (Abrahamian, 2009, p. 70). Reza Shah's administration could 'be truly defined as military monarchy' (Abrahamian, 2009, p. 70).

The conscription law ${ }^{106}$ in 1925 was a guarantee for the Shah's control over every corner of Iran, particularly rural and tribal areas, and had implications far beyond military expansion (Abrahamian, 2009, p. 68). The conscripts 'were drawn first from the peasantry; then from the tribes; and eventually from the urban population' (Abrahamian, 2009, p. 68). For rural areas that were not predominantly Persian speaking, two-thirds of the conscripts had to learn Persian in the first six months of their enrolment in the military

\footnotetext{
${ }^{105}$ The two security organizations (shahrbani and Rokn-e Dovom) were copied from French Deuxieme Bureau that was affiliated to the army (Abrahamian, 2009, p. 70).

${ }^{106}$ The law (Abrahamian, 2009, p. 68): "required all able-bodies makes over the age of twenty-one to serve two full years in active service and another four years in the reserve."
} 
(Abrahamian, 2009, p. 77). They had to leave their homes and 'pay daily allegiance to the Shah, the flag and the state', speak Persian, and interact with people from other locales and ethnicities, Persians and non-Persians (Abrahamian, 2009, p. 77). The conscription law was a tool to convert the tribesmen and peasants into citizens of a nation-state for the first time in Iranian history (Abrahamian, 2009, p. 77). This law came along with laws requiring the issuance of birth certificates, and therefore, mandatory family names, as well as the changing of ethnic and local names to Persian ones (Abrahamian, 2009, p. 77).

The issue of citizenry was not a concern for Reza Shah. He had no regard for civilian rights and his administration was more a military system and dictatorship, for accumulating wealth, with extensive corruption. The electoral law was dysfunctional as Reza Shah screened the list of candidates personally, thus hollowing the Majlis (parliament) as a meaningful institution ${ }^{107}$ (Abrahamian, 2009, p. 73-75). He banned all political parties, closed independent newspapers, censored the press (Lapidus, 2002, p. 477), and even ceased parliamentary immunity to ensure he had control of everyone and every aspect of society (Abrahamian, 2009, p. 133). Reza Shah focused on creating bureaucracy, and industrial economy, with no regards towards the rule of law and democracy (Gheissari \& Nasr, 2006, p. 40). In this period of Iran's history, laws, regulations, and modern mechanisms of government could not provide fair citizenship, political participation or a modern social system while they were functioning under a 'military-bureaucratic lawlessness ${ }^{108}$, executive powers acting over legislative powers,

\footnotetext{
${ }^{107}$ Abrahamian quotes from British Minister's, “Annual Report for Persia (1927)” (Abrahamian, 2009, p. 74): 'The Persian Majles cannot be taken seriously. The deputies are not free agents, any more than elections to the Majles are free. When the Shah wants a measure, it is passed. When he is opposed, it is withdrawn. When he is indifferent, a great deal of aimless discussion takes place.'

${ }^{108}$ For this reason Katouzian (1981, p. 101) calls this period 'pseudo-modernist absolutism'.
} 
and a shah acting above the law (Katouzian, 1981, p. 110; Gheissari \& Nasr, 2006, p. 37; Vahabzadeh, 2012, p. 9).

Reza Shah was very much interested in land. Nevertheless, rural development and agriculture were almost ignored during his era although a few minor laws that strengthened the position of absentee landlords were adopted (Hooglund, 1982, p. 40). In 1936, the General Office for Agriculture was established with the Bureau of Forests and Rangelands Protection as one of its divisions; rangeland use was dealt with by the Ministry of Finance until 1948 (Mesdaghi, 2003, p. 221). Serious consideration of land reform and agricultural and rural development did not happen until Mohammad-Reza Shah came to power.

At the end of his era he was the wealthiest man in $\operatorname{Iran}^{109}$ (Abrahamian, 2009, p. 71; Alamdari, 2005, p. 88). The British Legation in 1932 reported that Reza Shah had a 'land hunger' and intended to 'register the whole Persia into his own name' (Abrahamian, 2009, p. 71). Abrahamian explains (Abrahamian, 2009, p. 71):

[Reza Shah] accumulated these estates in part by outright confiscation, in part by dubious transfer of state properties, in part by irrigating waste lands, and in part by forcing landlords, both large and small, to sell him property at nominal prices.

He registered every piece of land possible in his name, particularly in his home region, Mazandaran, including the Turkmen lands registered by the royal family. Reza Shah acquired 2000 villages, at a rate of 100 per year, as personal estates and when he abdicated in 1941, he was the largest single absentee landlord in the country (Hooglund, 1982, p. 40). On his abdication, these lands were transferred to his son, Mohammad-Reza Shah.

\footnotetext{
${ }^{109}$ Reza Shah accumulated wealth and let his military commanders do so as well, but he discredited them when he felt they were becoming powerful or did not share with him the wealth they collected (Abrahamian, 2009, p. 72).
} 
Under Mohammad-Reza Shah, ethnic groups continued to be perceived as threats so their 'pacification' and de-politicization was a priority. Mohammad-Reza Shah continued his father's modernization processes and nation-state building by Persianizing and nationalizing a heterogeneous population in what was only recently called Iran. This was done by strategically directing every programme towards a homogenous culture based on the Farsi language and Shi'a religion (Kashani-Sabet, 1999, p. 111). Governmentality was practiced by symbolizing Iranian national identity, linguistically, geographically and culturally through an education system instilling the sentiment of love for a homogenous country, and 'assuring the dominance of Persian language and culture' (Kashani-Sabet, 1999, p. 214). Mohammad Reza Shah continued policies to Persianize Iran by providing formal education only in the Persian language, banning the use of any non-Persian languages by teachers and instructors, and in media, publications and broadcasts (Beck, 1990, p. 186). Government officials appointed to non-Persian areas spoke only Persian (Beck, 1990, p. 186). In $20^{\text {th }}$ century Iran, Persian speaking people, known as Persians, were only 45\% of the total population (Beck, 1990, p. 186). This number in 2012 was 55\% (Iran Chamber Society, 2012).

While non-tribal peasants throughout Iran were not necessarily experiencing better economic conditions, the Turkmen bore the extra burden of forced sedentarization under extreme military violence, accompanied by the social, racial, and cultural discrimination (Beck, 1990, p. 206), and being 'forced to assimilate into a Persiancontrolled state and society at the lowest socioeconomic levels' (Beck, 1990, p. 208). Under the Pahlavis, from 1926 to 1979, religious minorities were integrated into the state structure and the politics of modernization, with the exception of Sunni Muslims, 
including the Turkmen, who were members of tribal and ethnic groups that were considered a threat to the state (Beck, 1990, p. 221).

\subsubsection{Coercive sedentarization of the Turkmen}

The Qajars did not have a significant presence outside the capital and foreign agents were more of a presence in tribal territories than were Qajar agents (Beck, 1990, p. 206). In the decentralized Qajar administration, tribes, including the Turkmen, had powers that were parallel to those of the Qajar (Beck, 1990, p. 205). These tribal powers were both a threat to and support for Qajar survival and foreign countries' interests (Beck, 1990, p. 205). Interaction between the state and tribes was changed by the Pahlavi Shahs' state-building practices.

A highly centralized government was formed during Reza Shah's era and, due to its technological advancement and organization, the military powers of the tribes were eliminated (Abrahamian, 2009, p. 92). The coercive sedentarization of Turkmen by Reza Shah escalated in 1924-25. Reza Shah managed to disarm, politically 'pacify', sedentarize and conscript tribesmen, and subsequently adopted policies to abolish their traditional social systems, detach them from their lands, and strip them of their traditional clothing, languages and cultures (Abrahamian, 2009, p. 92). Some tribes were 'civilized' into 'model villages' (Abrahamian, 2009, p. 92).

The development and ownership of Mazandaran, which included the Turkmen Sahra, was Reza Shah's personal dream (Abrahamian, 2009, p. 72). He constructed roads, railways, luxurious hotels, and many factories. His factories were practically run on 'slave labor', with his main source of cheap labor being military conscription and tribesmen (Abrahamian, 2009, p. 72). 
Provincial administration was under the Interior Ministry (Abrahamian, 2009, p. 71). After Reza Shah had disarmed the tribes and added their regions and territories onto neighboring provinces, he remapped the country into fifteen provinces, with arbitrarily defined borders to suit the strategic goals of the state (Katouzian, 1981, p. 110). The Provincial units were created by grouping 'people of similar ethnic and cultural backgrounds' or consolidating 'diverse social groupings in one province' (Amirahmadi, 1986, p. 504). For example, Kurdistan, Loristan, Khuzistan, Baluchestan, and Azarbaijan provinces were dominated by ethnic populations of Kurds, Lors, Arabs, Baluchs, and Azeris respectively but parts of their territories were included in their neighboring provinces. In the Qajar's communication documents Turkmen territories were refered to as Yomutestan (Mikhail Gorgani, 2013) and in the peak of the coercive sedentarization of the Turkmen the region was refered to as the Turkman Steppe (Arfa, 1964, p. 166). However, Reza Shah did not acknowledge the existence of the Turkmen territories (Yomutestan/Turkmen Sahra), an area that was well distinguishable by the land and its Turkmen population. Instead, the provinces of Mazandaran and Khorasan each included a share of the Turkmen lands and the Turkmen population; Mazandaran got the major part of the Turkmen Sahra and Khorasan got the highlands northeast of the Turkmen Sahra (Gorgani, 1979, p. 22, 25). One interviewee believes this division was due to Reza Shah's belief in the superiority of Aryan blood. The visible ethnic minority Turkmen, not of Aryan origin, were subjected to Reza Shah's racial politics. Another reason was Reza Shah's personal interest in the lands of the Turkmen Sahra, which was close to his home town in Mazandaran province. He appropriated all the lands of the Turkmen Sahra, including rangelands, and assigned them as Amlak Pahlavi (Crown Lands), the property of the Pahlavi dynasty (Mansoor Gorgani, 1979, p. 24-28). 
Scott explains that sedentarization is usually justified by a discourse of orderly development and provision of social services such as clinics, sanitation, clean water, infrastructure, education, and that it simultaneously has 'goals of appropriation, security, and political hegemony' (Scott, 1998, p. 191). The settled community whose cohesion is coercively destroyed is more 'amenable to control from above and outside' (Scott, 1998, p. 191). Sedentarization of people is always interrelated with land privatization, marketing of livestock, fence construction, and rangeland and protected lands policy (Blench, 2001; Reid, Galvin, \& Kruska, 2008, p. 12). Sedentarization has had profound effects on the Turkmen as they were abruptly transformed from free, independent people to citizens of the Iranian nation. The government now had to identify, separate, define, register, label, and Persianize the Turkmen and their environment. In this process nature becomes natural resources and every aspect of human life becomes institutionalized, including property rights and taxation. The traditional system of the Turkmen's open access to natural resources was a reflection of their political autonomy at the time of the Qajar and its decentralized system before their sedentarization in the 1920s (see Sections 4.2. and 4.3). Their expectations and livelihood impediments changed radically. Land use was diversifying and intensifying and lands were being divided in terms of tenure and use.

An interviewee remembered that, in 1925, when Reza Shah's agents used military force to settle the Turkmen in the AUA region and burned their yurts, numerous Turkmen crossed the border to the Soviet Union. General Arfa explains in detail a confrontation of the military with the Turkmen tribes that resulted in their fleeing to the Soviet Union camping between the Atrek and the slopes of Kara Kum desert in 1925 (Arfa, 1964, p. 170-185). Subsequently, in the mid-1930s when the Soviet administration became 
stronger and increased its authority in the region, many of the Turkmen returned to Iran under the condition of accepting the Iranian authority and surrendering their arms (Irons, 1975, p. 12). They recall that Reza Shah designated a Turkmen called Manji as his representative in Turkmen Sahra. Manji controlled the Jandarmeri, guarded the border, and used violence to control the Turkmen. They remember that their life from 1930 to 1941 was difficult to bear because of high taxes and forced labor. Among the difficulties, each spring Reza Shah's agents, who were violent and corrupt, went in organized groups protected by Jandermeri, to every village on the Turkmen Sahra and collected rents from the herders for access and use of rangelands. These rent collectors usually had to bribe government officials to get their position, and then collected double or triple the amount of rent that Reza Shah was due from the Turkmen herders (Gorgani, 1979, p. 27, 28). Some Turkmen moved to the other side of the border where the new revolutionary government of the Soviet Union was not yet intervening in their affairs as much as the Iranian government did.

World War II provided a break for the Turkmen. An interviewee remembered that from 1941 to 1947 they had an easier life and there was no effective government control on the border and the Turkmen, especially in the more arid regions, were able to use the lands and pastures on both sides of the Atrek River. They were not forced to pay taxes and there was no forced labor. The Soviets occupied northern Iran from 1941 to 1946 (Irons, 1975, p. 28) and arrested Manji. He was held for seven months and then released to help the Soviets to control the border after the war. He was required to send back the Turkmen who were trying to pass the border into Iran.

After the war, the Iranian administration resumed its policy of forced sedentarization of nomads. The pastoralist nomads who were sedentarized experienced 
expensive natural capital loss because the water, land, and rangelands they relied on came under centralized government control. After sedentarization, the government should have been able to provide access to compensatory factors such as bank credits (Boone, BurnSilver, \& Kruska, 2008, p. 342) to let communities continue their livelihood. The Pahlavi shahs did not plan for social services, and in the development of the Turkmen Sahra instead, 'there was a concerted campaign not only to settle the pastoral nomads but also to eliminate their distinctive culture in terms of language, dress and authority structures' (Blench, 2001, p. 62) and to change their customary practices, and control them politically.

Amirahmadi, in his analysis of provincial disparity in pre-revolutionary Iran, states that as of 1976, the majority of the population in the Relatively Developed Provinces and Intermediate Developed Provinces were Persians, and most of the ethnic minorities resided in the Least Developed Provinces (Amirahmadi, 1989, p. 93). Mazandaran, which encompassed a major part of the Turkmen Sahra, was categorized as an Intermediate Province in terms of literacy, health services, housing availability and quality, and public administrative services (Amirahmadi, 1990, p. 219). The AUA region, administratively part of an Intermediary Developed Province, had the characteristics of the least developed territories.

\subsubsection{Land policies, rural development and the Turkmen}

The formation of a modern state entails separation of nature and society. This process includes territorialization, defined by Whitehead as 'the use of space to control and regulate nature' (Whitehead, Jones, \& Jones, 2007, p. 16) (see Section 2.4.3). 
Territorialization encompasses processes of centralization and institutionalizing knowledge formation.

During the Pahlavi era, natural sciences, technology, and techno-science rationality (Vahdat, 2012, p. 31) for reification of nature and society as two different domains was pursued systematically. The shift from a pre-modern to a modern Iranian state required this simplification in order to make society manageable, and land and nature protection policies were essential for that. Reza Shah (1926-1940) initiated what Latour explains as a modernity 'project' of the separation of nature from society. Mohammad-Reza Shah (1941-1979) continued that process by military and political pacification and sedentarization of tribes, Persianization and state building with emphasis on science, bureaucracy and technology (Vahdat, 2012, p. 32), land reform and economic integration, nationalization of forests and rangelands (Beck, 1990, p. 207) and development of nature protection policies and agencies.

The conception of humans and non-humans as two separate assemblages simplifies the management, collection of data, mapping, and administration of both natural and social resources by the state. The utilitarian goal of the state towards 'nature' changes what is considered as nature into 'natural resources' and makes it available for appropriation and use (Scott, 1998, p. 13). Technical knowledge and science become an essential part of the purified, organized, contained and controlled 'nature' and 'nature' becomes subject to property rights. A common resource with an open access system that is usually practiced in traditional tribal systems cannot fulfill the state's fiscal and political interests (Scott, 1998, p. 39). Land reform, forest and rangeland policies, as well as conservation are among the policies that make society manageable for the modern state and influence people-environmental interaction. Application of a unified measuring 
system was part of the simplification process of the entangled social and natural assemblages that the state needed to identify and control including agricultural lands and rangelands (Scott, 1998, p. 27-31).

Contrary to the experience of European countries where the land tenure system helped the development of capitalism, land tenure in Iran was an obstacle towards a 'developed' and capitalist Iran (Alamdari, 2005, p. 161). In the hope of imposing capitalism from the top down, engineered modernization and land reform took place in Iran during the 1960s (Alamdari, 2005, p. 161).

The economic aspirations behind land reform policies in Iran included industrialization and economic growth, mechanization and economies of scale in agriculture. These were part of the international development discourse of that time. It was argued that land reform, large scale irrigation and agricultural agro-businesses advocated by the World Bank could accelerate industrial growth by taking 'the excess supply of agricultural labor and releasing it for industrialization' (Moghadam, 1996, p. 74 fn14). Land reform in Iran, following American recommendations (Alamdari, 2005, p. 163), was part of the process towards these development goals. Comprehensive land reform was intended to create medium and small scale land owners who would contribute to agricultural development and former landlords who would be engaged in investing in modern industries and participating in the creation of capitalism (Katouzian, 2009, p. 259).

\subsubsection{Land reform}

Mohammad-Reza Shah's land reform had three major stages, two related to land distribution and a third related to agricultural development. It started with the shah re- 
distributing Crown Lands that were acquired by force by his father. He donated those lands to a foundation, called the Pahlavi Foundation, and announced them as Vaqf properties. He had to dissolve the parliament, largely composed of landlords, to prevent resistance and undertook a referendum for his series of reforms, known as the "White Revolution', which included land distribution plans, and nationalization of forest and rangelands (Moghadam, 1996, p. 63).

In 1971, Mohammad-Reza Shah announced the completion of the Land Reform Programme in Iran, declaring 'there is no longer any farmer in the country who does not own his own land' (Hooglund, 1982, p. 71). Ten years, after land reform, more than $90 \%$ of former sharecroppers had become peasant proprietors (Hooglund, 1982, p. 73). The one third of the rural population who were not sharecroppers were left to continue living in villages without resources, and ultimately immigrated to cities (Moghadam, 1996). About $75 \%$ of those who received land, later joined the labor force of the cities or sold their lands for negligible amounts and became agricultural labor because they could not afford the expenses of farming (Moghadam, 1996). A major factor was that the small size of lands they received was not sufficient ${ }^{110}$ (Hooglund, 1982, p. 93). An added burden was that lands distributed had been purchased by the state and were sold to the peasants for two-fifths of that price (Alamdari, 2005, p. 249). The majority of those peasants did not have the capital to pay for the land, and if they were able to acquire loans, the majority could not pay them back (Alamdari, 2005, p. 249). Sometimes, they made deals with landlords to sell some share of their land to the landlords in exchange for cash so

\footnotetext{
${ }^{110}$ Hooglund estimated that every household needed an average of 7 hectares to be able to develop adequate subsistence products in areas without sufficient water, and required leaving land fallow for some months of the year (Hooglund, 1982, p. 93). However during land reform, 75\% of those who received land had less than 7 hectares and could not provide a minimum subsistence for their family (Hooglund, 1982, p. 93).
} 
they could pay for the land (Alamdari, 2005, p. 249). Ultimately, either they lost their land or the remainder was too small, sometimes as little as $1 / 4$ hectare (Alamdari, 2005, p. 249). In summary, the stage-one land policy had serious flaws. Disparity in land allocation among peasants caused a pattern of land ownership inequalities, and the majority of peasant holdings were too small and fragmented for later adaptation of mechanized farming (Hooglund, 1982, p. 88; Moghadam, 1996, p. 67). In the last stage of land reform, the establishment of large scale agro-businesses and farmer cooperation was promoted. However water management was inefficient for large farms and required complete restructuring towards construction of big dams, new technology, and investment. Development within villages was simply not feasible due to the number of villages and their scattered locations and the required extensive investment in infrastructure and the provision of services (Moghadam, 1996, p. 66, 67).

Land reform in isolation does not assure agricultural and rural development, it must be accompanied by reform in other sectors. Credit and price policies were inadequate (Hooglund, 1982, p. 109, 113), medium or long-term credits were not available, and short term credit was insufficient for the integration of livestock and arable farming, through cooperatives, to make a major contribution to the peasant incomes (Lambton, 1984, p. 82). The exclusion of one third of the rural population from any benefit (Moghadam, 1996, p. 64), the increased population of poor peasants, the strategic policy of the government to encourage urban industrial growth, and the allocation of state credits and capital largely to agri-businesses and farm corporations resulted in poverty and insecurity among the peasantry, and a high rate of immigration to cities (Katouzian, 1981, p. 308; Huooglund, 1982, p. 115). Medium-sized land holdings became weak and landlords stayed strong in rural areas. The overall economic impacts of the land policy 
were: a) the wealthy land holders sold their estates to the government and used their capital for non-agrarian production and urban industrial expansion (Alamdari, 2005, p. 228; Katouzian, 1981, p. 308); and b) old relations of production altered, not in favor of peasants and cultivators, but led to large numbers of the rural population being integrated into the urban labor force and urban population (Alamdari, 2005, p. 255; Moghadam, 1996, p. 55, Hooglund, 1981, p. 115).

Hooglund argues that the government did not have the commitment to solve the socio-economic problems of the rural areas, rather it had political goals and (Hooglund, 1982, p. 136):

The principal objective of government policy towards the villages was to assert its own control. Consequently, those policies whose scope was basically socioeconomic had to accord with the overall political aim. Thus, even though the shah and his advisors probably believed in the necessity for rural development, their priorities focused upon the political, rather than the socioeconomic implications of all plans.

The political influence of the state in rural society happened through a change in social relations in villages and the creation of new organizations under the complete control of the state which were later Islamized and used by the Islamic State. These changes included: (a) The Kadkhoda (the headman of the village) had to be appointed by the Minsitry of Interior and act under the supervision of the government ${ }^{111}$ (Hooglund, 1982, p. 131); (b) The House of Justice, which in theory was supposed to be headed by a well-respected elder, in practice drew its members from the same village council members approved by government, usually Kadkhoda or rich peasants (Shakoori, 2001, p. 58); (c) Village Centers (dehbany), and Rural Cultural Houses, established in rural areas across Iran directly introduced universal values (Shakoori, 2001, p. 58) suitable for

\footnotetext{
${ }^{111}$ Kadkhoda(s) were supervised by Dehyar(s) (member and head of village council) who were employees of the Minsitry of Interior (Hooglund, 1982, p. 132).
} 
an Iranian nation-state; and (d) The government created rival power centers, in villages, between village officials and in the literacy, health, and extension and development corps, to entrench its own control and follow its political goals (Hooglund, 1982, p. 136; Lambton, 1984, p. 83). The corps were established 'to implement quickly and uniformly various social and economic programmes which the Shah decided to carry out in the rural areas' (Hooglund, 1982, p. 134), and 'the main function of the corps was to teach the villagers to obey the government bureaucrats' (Shakoori, 2001, p. 58).

\subsubsection{Nationalization of forests and rangelands}

Despite all the actions taken by Pahlavi Shahs to sedentarize the tribes and reduce tribal autonomy, the state's lack of complete control was an ongoing concern. Breaking the social organization of tribes became an important political goal (Moghadam, 1996, p. 63). Along with land reform, nationalization of forests and pasture was vital in consolidation of the state power in rural areas. Tribal social organization was based on communal sharing of land and breaking those lands into pieces for individual households could also break down the social organization of the tribes.

The Nationalization of Forests and Rangeland Act (1962) brought rangelands under state ownership and through all three stages of land reform, rangelands were never considered for redistribution (Hooglund, 1982, p. 79). Using and accessing common rangelands for tribesmen became difficult and limited (Moghadam, 1996, p. 63). Nationalization of forest and rangelands and the limiting of pasture used by tribes and villages were justified on the pretext that rangelands were over-grazed and that government intervention was needed to limit and control their use (Moghadam, 1996, p. 63). The scientific justification was controversial. 
The Nationalization of Forest and Rangeland Act stated that all natural forests and rangelands became public property unless they were already owned by individuals or designated as Crown Lands. The status of the rangelands, lands that Reza Shah illegally made in his own name (Crown Lands) was never questioned by Mohammad-Reza Shah. The land reform law provisions for allocating 'land to the tillers' caused many farmers to start farming on pasture lands in order to claim land ownership (Moghadam, 1996, p. 63). The Ministry of Natural Resources, responsible for implementing the Forest and Rangeland Nationalization law, developed operational regulations and hired staff, including rangeland specialists. The Ministry initiated a rangelands inventory, identifying and assessing rangelands production, and preparing rangeland management plans. For the first time, access to rangelands required a government permit. The primary targets were the tribes and the policy created limitations for the use of common pastures in tribal areas (Moghadam, 1996, p. 72). From the early 1970s, controversies regarding land and pasture policies proliferated based on research conducted by universities in collaboration with the FAO (Mesdaghi, 2003, p. 222; Moghadam, 1996, p. 72). Rangeland experts argued that protection of rangelands cannot happen by strict preservation, rather it requires use, but a controlled use, according to carrying capacity of the rangelands and also customary land use by tribes (Mesdaghi, 2003; Moghadam, 1996, p. 72). The main shortcomings of the management plans were: lack of consideration for local customary land and rangelands management; a focus on long term goals irrespective of their impact on those whose livelihood were dependent on rangelands; and not securing the short term benefits (Moghadam, 1996, p. 72). For example, the Ministry's plan to establish large meat and dairy complexes in tribal areas for supporting stock breeders were judged to be too expensive and was abandoned in 1976 (Moghadam, 1996, p. 72). 
Research on grazing management, rangelands, and fodder production and a scientific inventory of Iran's rangelands received technical and scientific support from FAO (Mesdaghi, 2003, p. 82) and government institutions started holding closed-door seminars to discuss those issues (Moghadam, 1996, p. 70). Two seminars held by government officials in 1976 indicated the negative impacts of the land reform and land and rangelands policies in drastically decreasing rangelands production, but the political implications for control of the tribes were so vital for the state that the criticisms were not well received by authorities and further research on those impacts was not discussed (Moghadam, 1996, p. 78).

Surface water in Iran has been under the control of a government agency since 1943 (Sadr, 2001, p. 5) and was nationalized in 1968 through the 'Iran Water Law and the Manner of Water Nationalization' (Japan International Cooperation \& CTI Engineering International Co, 2010, p. 7). After the Second World War the Turkmen Sahra underwent rapid agricultural and economic development. The lower parts of it had enough water, good soil, flat arable lands, and low population, making it ideal for commercial mechanized agriculture. The change in the land use of the arid portions in the northern part of the Turkmen Sahra was less drastic due to lesser availability of water.

\subsubsection{Nature protection}

The Game Council of Iran was established in 1956 and the first conservation law for regulating hunting, ratified in 1967, introduced the concept of 'Wildlife Parks' and 'Protected Regions' with enforced restrictions on hunting and fishing (Firouz \& Harrington, 1976, p. 8; Firouz, 2005, p. 12). Hunting and fishing was conditional on obtaining a license from the Game Council and the use of forests and rangelands was 
subject to agreements between the Ministry of Agriculture and Natural Resources and the Game Council (Firouz \& Harrington, 1976, p. 8). In Protected Regions, 'the presence or absence of a human population was legally immaterial, but in practice, effort was made to exclude villages and other habitations' (Firouz \& Harrington, 1976, p. 8). In 1967, the Game Council evolved into the Game and Fish Department, a more organized institution to regulate and control hunting and fishing in Iran (Firouz, 2005, p. 12). This was later incorporated into the Environmental Conservation Department and finally in 1974 integrated into a new establishment, the Department of Environment (Firouz, 2005, p. 12) that reported to the Prime Minister. This organization followed the prevailing global discourse and practice of nature protection (see Section 9.3).

The Convention on Wetlands of International Importance, especially as Waterfowl Habitat ${ }^{112}$, was established in 1971 (see Section 1.4.1). The convention's text was approved and opened for signature at a meeting hosted by the Iranian government (Firouz, 2005, p. 14). It was in this era that the AUA was designated as a Wetland of International Importance and since then the Department of Environment (DOE) has had the privilege to speak on behalf of wetlands in Iran.

The coercive sedentarization, land reform, nationalization of rangelands, and 'fortress' approach to nature protection policies and practices before the revolution have been major processes in shaping the Turkmen Sahra, the AUA region, and peopleenvironment interaction and in setting the ground for continuous place-making processes and the politics of resource control by the post-revolutionary state and the Atrekians. These processes changed the intimate interaction of the Turkmen with their environment.

\footnotetext{
112 The name of the convention changed to the Convention on Wetlands and popularly is known as Ramsar Convention
} 


\subsection{The Iranian Islamic State}

After the Islamic revolution, the Turkmen peasants were hopeful that they would be able to resume their livelihood strategies and improve their living conditions by regaining their access over the Turkmen Sahra's natural resources, but it did not happen. Within a month after the revolution the Turkmen, with the help of Fadaiyan (a leftist organization) and activists, began to organize themselves into peasants' councils (Afshar, 1981, p. 1105) similar to their traditional Yashulilar Yighanghi (Council of Elders) across the Turkmen Sahra (Salamaan, 1999, p. 59). Following that, the first Fishermen Council was established in Gomish Tepe (Salamaan, 1999, p. 60). The councils were strong, and successful (Afshar, 1981, p. 1106). If the land was already cultivated, the landlord had to pay $20 \%$ of his product to the councils and after harvest the councils were responsible for managing those lands (Salamaan, 1999, p. 61). Large parcels were cultivated collectively. As with the Turkmen's traditional system, the Yashuli Council, did not have a centralized power system and each council was both an administrative and a production unit (Afshar, 1981, p. 1105). In less than a year, more than 300 councils and 18 peasants' cooperatives, each consisting of 5 to 11 villages, were created in the Turkmen Sahra (Salamaan, 1999, p. 61). During the peasants' council period, the Turkmen Sahra was the only region in Iran where production of cash crops increased (Afshar, 1981, p. 1106). The objectives of the peasants' council in the Turkmen Sahra, as declared in a massive meeting of 15,000 participants, were (Alamdari, 2005, p. 310):

(1) recovery of the lands confiscated by the former regime, (2) real and democratic land reform, (3) reduction in importation of agricultural products in order to protect local agriculture, (4) formation of rural and fishery councils, (5) protection of the fishermen and carpet-weavers of the region. 
The Islamic State appointed Heydar Jam, an ex-military employee of the shah, as the governor of the Turkmen Sahra in 1979 ("The Governor of Gonbad speaks about the 1979 turbulance in Gonbad," 2011). He claimed that the land issues created by the Pahlavi shahs and their coercive policies against the Turkmen were used by the leftist groups to aggravate ethnic and religious differences in the Turkmen Plain and to provoke the Turkmen against the new state using Shi'a/Sunni differences ("The Governor of Gonbad speaks about the 1979 turbulance in Gonbad," 2011). Jam stated 'the Turkmen due to their particular religious beliefs are not political. They used to consider whatever happens as God's will'.

The Islamic State, though not yet a consolidated government, with the help of its militant power responded to the Turkmen with absolute violence. Khalkhali ${ }^{113}$ was dispatched to the region and with the help of the Revolutionary Guards regained government control of the region (Parsa, 1989, p. 261). Khalkhali killed and executed many Turkmen including four of the Turkmen leftist leaders, in 1980 (Parsa, 1989, p. 261; Moaddel, 1993, p. 260). Mansoor Moaddel wrote (Moaddel, 1993, p. 260):

To destroy the peasants' movement in this area [the Turkmen Sahra] and eliminate the influence of the Feda'oyan [the leftist organization helping the Turkmen], the Revolutionary Guards arrested the leaders of the peasants' council for questioning. Later on, their bodies were discovered in a remote area.

Moaddel continues, in 1984 Khalkhali confirmed that he had murdered those people, and quotes Khalkhali (Moaddel, 1993, p. 260):

In Gonbad I executed ninety-four people, including Toomaj Jorjani, Vahedi, and Makhtoom. I myself executed these people. I executed ninety-four people, not just one person...I beat the people of the Turkmen.

\footnotetext{
${ }^{113}$ Khalkhali was a hardline Shi'a cleric appointed by Khomeini as the Chief Justice of Revolutionary Courts and was famous for his summary execution ("Sadeq Khalkhali, Iran's 'hanging judge', died on November 26th, aged 77," 2003).
} 
The councils continued to work for a few more months but ceased altogether after a series of violent clashes between the Revolutionary Guards and the Turkmen (Alamdari, 2005 , p. 298, 304). The state took complete control over the Turkmen Sahra, returned some of the lands to the landlords, and the rest remained under its control. Similar upheavals happened in other ethnic minority regions of Iran, particularly in Kurdistan (Alamdari, 2005, p. 298; Parsa, 1989, p. 262). After the revolution, the most violent struggles were over land in the 'rural areas of almost every province' (Amirahmadi, 1989, p. 102). The land question, particularly in Kurdistan and the Turkmen Sahra, was 'inflamed by ethnic discontent' (Shakoori, 2001, p. 64). A government report on unrest in the Kurdistan region states 'The ministry of Defense has distributed arms among the feudals of the region in order to suppress peasants' and 'the wars (in both Kurdistan and the Turkmen-Sahra) were the result of the common cooperation of regional feudalists and Mr. Chamran, the minister of defense' (Alamdari, 2005, p. 299). The government suppressed the peasants in Turkmen Sahra, Kurdistan, Baluchestan and Khuzistan (Amjad, 1989, p. 139). Amirahmadi argues 'the land question was ultimately tied to the demand for regional autonomy because of the extreme inequality in distribution of agricultural land in the ethnic provinces' and the unequal treatment of the ethnic minorities by the 'Persian-dominated central government' (Amirahmadi, 1989, p. 102). Autonomy, to the national minorities of Iran, was equal treatment and recognition of their cultural identities (Amjad, 1989, p. 138).

The Islamic State abolished peasants' councils formed through grassroots movements, and punished peasants in the Turkmen Sahra and Kurdistan. The 'rebellions', within a month of the revolution, caused the state to understand the need for immediate Islamization of peasants' councils (Schirazi, 1993, p. 268) or for the formation of Islamic 
forms of participatory centers in the rural areas, improvement of rural living conditions and development, and planning for land reform (Alamdari, 2005, p. 308; Shakoori, 2001, p. 164, 165).

Meaningful, land reform never materialized and after years of friction between multiple interest groups, there was only a limited land transfer, to be discussed later in this chapter. The status of the Turkmen rangelands, lands that Reza Shah had illegally put into his own name (Crown Lands), was never questioned by the Islamic State. Those rangelands announced as a nationalized resource in 1962 maintain the same status in the Islamic State (after 1979) without any regard or reference to the fact that they were, for centuries, agricultural and pasture lands of the Yomut Turkmen in Iran.

The Islamic State did respond to rural social and economic problems by major administrative restructuring of the agricultural sector (Shakoori, 2001, p. 70). This restructuring included formation of Jihad Sazandegi (Construction Crusade) and its political and administrative expansion and also formation of Islamic Rural Councils by restructuring pre-revolution Village Councils (see Section 8.2.1).

\subsubsection{Land use, conversion and transfer: institutions, regulations, and processes}

\subsubsection{Jihad Sazandegi}

The Jihad Sazandegi was a powerful political entity that gradually took over land use, land conversion, and transfer and decision-making processes, structures and institutions.

It was an organization founded a few months after the 1979 revolution and was staffed by volunteers. Formation of Jihad Sazandegi was a strategic move to gain the support of rural people who 'traditionally were politically marginal, did not take full part in the revolution [an urban phenomena], or joined it only on the eve of victory' (Shakoori, 
2001, p. 83). Its initial mission was to provide basic assistance to farmers and rural communities, to rehabilitate and develop rural areas (Sulaiman \& Hall, 2005, p. 315), increase literacy in villages and 'propagate Islamic culture and the Islamic Revolution in rural areas' (Shakoori, 2001, p. 82).

Jihad Sazandegi implemented numerous infrastructure and development projects in rural areas but with no coherent strategy or plan for rural development and almost without having relevant scientific knowledge and techniques (Azkia, 2002, p. 105, Shakoori, 2001, p. 166, 169). Jihad Sazandegi's principal employment criterion was being a 'committed Muslim', and that resulted in elimination of many experts from its potential employment resources (Shakoori, 2001, p. 85). It duplicated some of the tasks of the Ministry of Agriculture but, due to the political atmosphere of that time and especially during the Iran-Iraq war, it gained power, expanded, and was able to obtain financial resources that other ministries could not (Azkia, 2002, p. 105). With revolutionary zeal, Jihad Sazandegi implemented notable infrastructure and agricultural projects and also undertook tasks like providing resources, equipment, medical facilities, and volunteers to the front, doing engineering work, and distributing promotional material for the war (Shakoori, 2001, p. 85).

Jihad Sazandegi was established at four levels: district center, the county town, the provincial center and the central council (Shakoori, 2001, p. 83); its tasks were similar to those of the agriculture centers of the Ministry of Agriculture and some of the Ministry of Energy. As it gained more political power, from an inter-ministerial organization, it consolidated its status to a ministry (Ministry of Jihad Sazandegi) in 1983. In 1987, the Forest and Rangeland Organization was integrated into this new ministry ("History of the Forest, Range \& Watershed Management Organization," 2013), which implemented its 
programmes through Rural Islamic Councils (supervised by the Ministry of the Interior) (Sulaiman \& Hall, 2005, p. 315).

In 2000, the Ministry of Agriculture and the Ministry of Jihad Sazandegi integrated and formed the Ministry of Agricultural Jihad with goals of integrating rural policies and plans in a decentralization process of the government and also in downsizing the government structure (Sulaiman \& Hall, 2005, p. 315). There are no data on how effective it was in downsizing the government, but it is clear that decentralization has not happened in its real sense (see Sections 8.2 and 8.2.1). After this integration, Watershed Management, originally under the Ministry of Agriculture was integrated into the Forest and Rangeland Organization in 2002, and was called the Forest, Rangeland and Watershed Management Organization ("History of the Forest, Range \& Watershed Management Organization,” 2013). Since then, the Ministry of Agricultural Jihad and the Regional Offices of the Forest, Rangeland and Watershed Management Organization (called Natural Resources Office) are the only organizations that control land use and land transfer in rural areas. Natural Resources Offices have a division called the Conservation and Land Affairs Department that deals with land issues in regions (“Organizational Structure," 2013). The latter has three affiliated sub-offices: the Conservation and Protection of Natural Resources Office; the Feasibility and Land Exploitation/Utilization Office; and the Land Cadastral Survey Office ("Organizational Structure,” 2013). In this arrangement, Natural Resources Offices are responsible for both leasing of public lands for development projects and for protecting forests and rangelands against development projects. Power is practiced by this ministry through creating and modifying rules and making decisions on how land is used and transferred and even in 
adjudicating disputes. The Iranian Fisheries Organization, the main agency for fisheries and aquaculture management, is also affiliated to the Ministry of Agricultural Jihad.

The Iranian Scientific Society of Forestry reports that integration of the watershed and forest and rangeland organizations into one office has contributed to the ignoring of rangelands and the escalation of land conversion instead of their restoration ("Land transfer as the only solution to problems: A big mistake," 2012). The report explains that the administrative integration has changed the priorities from management and restoration of forest and rangeland to watershed management that is not based on management principles, and to land transfer. Rangelands in major parts of Iran are degraded and need restoration rather than land conversion, however watershed management plans, where available, do not address rangelands restoration and are mostly focused on providing water for agriculture and the construction of related infrastructure ("Land transfer as the only solution to problems: A big mistake," 2012). Moreover, none of them contribute to comprehensive spatial planning.

\subsubsection{Regulations, policies, and processes}

The Majlis ${ }^{114}$, understanding the crucial need for land reform, prepared a radical land reform bill in 1980, and established seven-member Land Transfer Commissions in every region (known as the Sevener Commission), to distribute land throughout the country (Shakoori, 2001, p. 66). The Sevener Commission, though established in 1980, did not transfer any land until 1987. The members of the commission changed in time and currently each Sevener Commission is constituted of three representatives from the Ministry of Agricultural Jihad, one from the Ministry of Interior or Governor-General's

\footnotetext{
${ }^{114}$ Majlis-e Shoray-e Melli (National Consultative Assembly), after the revolution is called Majlis-e Shoray-e Eslami (Islamic Consultative Assembly).
} 
office, and a judge (Islamic Courts), or a representative of Vali-e Faghih and two community-nominated members (Shakoori, 2001, p. 66; Azkia, 2002, p. 109) who are two representatives from the village, elected by the villagers under the supervision of the Ministry of Interior and the Governor-General, and approved by a representative of Vali-e Faghih. The Sevener Committee's main responsibility is to investigate the legitimacy of disputed claims on nationalized lands ("Natural resource laws and regulations," 2013). The judge on the Sevener Commission has the final say on the decisions.

The Land Reform Act went through many changes and as a result, the Sevener Commission did not become active until 1987. The radical Land Reform Act, though approved by the parliament in 1980, was rejected by landlords and some Shi'a clergy (Alamdari, 2005, p. 305). Real land reform would impact major Shi'a clergy institutions, Astan Ghods Razavi ${ }^{115}$ (Holy Foundation of Imam Reza), and Bonyad Mostazafan ${ }^{116}$ (Foundation of the Oppressed) significantly (Alamdari, 2005, p. 301). Due to strong opposition of prominent clerics Khomeini held back the Land Reform Act until it could be investigated by the Shoray-e Negahban ${ }^{117}$ (Guardian Council). The leading Ulama in the Guardian Council, some of them were large property holders (land and factories) themselves, had a conservative interpretation of private ownership and opposed the Law for being against Islamic rules of ownership (Shakoori, 2001, p. 68, 69). Another argument of the Guardian Council, to oppose the Law, was to not seek assistance of the tribal heads to protect borders (assuming that this law could benefit peasants and tribal heads) but instead to arm the landlords, and protect them against peasants, as a viable

\footnotetext{
${ }^{115}$ A foundation managing Vaqf properties of Holy Foundation of Imam Reza

${ }^{116}$ A foundation established after revolution and took over Pahlavi shahs' properties (Alamdari, 2005, p. 301). Later established Bonyad Alavi (Alavi Foundation).

${ }^{117}$ A council established after revolution by Khomeini to assure consistency of the parliament's activities with Islam (see Section 8.1.1.1).
} 
solution to the security of borders (Alamdari, 2005, p. 299). In 1983, with the support of conservative clergies, the Guardian Council rejected the land reform bill that parliament had already passed and banned land distribution on the basis of it not meeting Islamic rules (Alamdari, 2005, p. 305). In 1986, the competing powers regarding land reform, within the state apparatus and among clergy, ended with the success of the Guardian Council and the end of land reform (Alamdari, 2005, p. 309; Shakoori, 2001, p. 69). The Guardian Council resolved the issues by removing from the Act (Alamdari, 2005, p. 306; Shakoori, 2001, p. 65): a) 'the holdings of large landlords whose ownership had been legitimized by the previous regime', and b) active 'cultivated lands'. Although the radical land reform though was approved by Majlis, it never materialized. Instead, the much diluted Land Transfer and Restoration Law, approved by the Guardian Council, was proclaimed in 1987. The Law applies to lands under the state's control, including (Alamdari, 2005, p. 306, 307; Shakoori, 2001, p. 65, 68): a) barren and rangelands that include: lands that do not have a history of cultivation and development, and rangelands that have a history of being fallow and have not been cultivated in the last five consecutive years, and b) developed lands that are confiscated by the Islamic Court and returned to the government.

Land transfer of natural forests, meadows, rangelands in proximity to villages, orchards, and Forest Parks is 'absolutely prohibited' in the Land Transfer and Restoration Act of 1987. The barren and rangelands, although most available, are unsuitable for cultivation. Making them arable would be costly and labor intensive, and require water. Loans from banks and financial institutions are inadequate, and require the peasants and their cooperatives to turn to private brokers who charged much higher interest rates (Alamdari, 2005, p. 307; Shakoori, 2001, p. 94). 
The lack of access to financial mechanisms and sufficient funds, as well as the wording of the law that eligible subjects could be individuals or companies, favor companies over individuals, especially companies that are associated with the state (see Section 8.1.1.2). Consequently, the main beneficiaries for barren, waste, and rangelands are companies with sufficient ties to financial and other powerful institutions, not peasants (Alamdari, 2005, p. 307). Every person making a claim has access to that land for five years in a lease-like arrangement; if they then proved that they had worked on the land they would receive a deed (Azkia, 2002, p. 109). The lands cannot be sold or transferred to a third party and can only be accessed and shared during those five years. Therefore, each person would have only a share of the total land distributed (Azkia, 2002, p. 109). The Ministry of Agricultural Jihad is responsible for land use changes in rural areas. When there is not a spatial master plan (that is the case in almost all the provinces in Iran), land issues, including land use change, is the responsibility of the Conservation and Land Affairs Department (known as Department of Land Affairs) in provincial Natural Resource Offices. Land conversion is conditional upon approval by a working group consisting of key government provincial offices.

Land use change and conversion of rangelands and application to access nationalized lands can happen in three ways:

(1) An applicant (peasant, agriculture graduate, unemployed person, government retiree) who has been granted ownership or an access claim to barren or nationalized rangelands, after approval of the Sevener Commission, is bound to cultivate the land in question as prescribed and set by the Ministry of Agricultural Jihad. Identification of nationalized lands, resolving disputes on those lands and addressing any objections in that regard is the responsibility of the Sevener Commission. (2) A person or company requests 
access to national lands for agricultural and agriculturally relevant activities (e.g. fish farm) and the Ministry of Agricultural Jihad can lease and transfer those lands according to the Land Transfer and Development Act. (3) Ministries, government institutions, their affiliated bodies, and charitable organizations request access to national lands for agricultural or other development purposes. The Land Transfer and Development Act allows the Ministry of Agricultural Jihad to lease and transfer national lands in consultation with a working group and in accordance with relevant government development plans. In all three cases above, depending on the kind of land use and its planning, the land is registered to the claimant(s) if they proved the land was worked for five consecutive years.

In 1995, a Law was ratified to maintain agricultural and orchard land uses and to regulate and limit land conversion ("Agricultural and orchard land use change: Tips and procedures," 2008). In cases of 'necessity' for land use change, a provincial commission under the supervision of the Ministry of Agricultural Jihad takes the decisions. The commission consists of representatives of the provincial Land Affairs Department, the Governor-General's office, Housing and Urbanization, and the Department of Environment ("Agricultural and orchard land use change: Tips and procedures," 2008). The Land Affairs Department, on a case by case basis, can invite representatives from the Ministry of Industry and Mining, the Cultural Heritage Organization, and the Handicraft and Tourism Organization. The Land Transfer and Restoration Act, in 1995, and its ammendments, in 2006, declared that land uses such as fish farms, mushroom culture, beekeeping, silk worm farms, and poultry farms are not considered as land use change in agricultural lands, and by conforming with environmental regulations, they can be carried out without further requirements ("Establishment of agricultural units in villages: Not 
classified as land conversion,” 2006). Supplementary activities involving construction and infrastructure for agricultural development such as irrigation, drainage channels and networks, fencing and road construction between farms need to follow instructions given by the Land Affairs Department. The Land Affairs Department submits a copy of the project and a map showing its coordinates to the relevant provincial Department of Environment (DOE) office. The DOE informs the Land Affairs Department regarding the project's compliance with environmental regulations. Decisions on approvals of a land use change can be revised if the Ministry of Agricultural Jihad agrees to an appeal. In that case, a commission under supervision of the Ministry of Agricultural Jihad with representatives of the Ministry of Housing and Urban Development, the Ministry of Interior (Governor-General's office), and the DOE will review the proposed project.

The head of the Forests, Rangeland and Watershed Management Organization in 2009 reports that, after the 1995 and 2006 amendments to the Land Transfer and Restoration Act, conversion of agricultural lands has been reduced to one sixth of that before 1995 ("Dispossession of 25 thousand hectares of seized lands," 2009). The Cultural Heritage News Agency reports that the Natural Resources Office has neglected its mandate to conserve and protect natural resources and has mainly become 'an agency to transfer national lands' ("Forest and Natural Resource Organization or a land transfer agency," 2009).

A new law, 'Executive Guidelines for Agricultural Development' ratified in 2011, facilitates land conversion (Aflaki, 2012). The head of the Forests, Rangeland and Watershed Management Organization in 2012 reports that, 32 million hectares of rangelands and forests are transferable ("More than 30 million hectares of rangelands availabe for conversion and transfer," 2012). This new law facilitates land conversion of 
low quality rangelands, and also their 99-year lease, instead of their restoration. The main purpose of the new law was stated to increase job opportunities in the agricultural sector, improving food security and production and generally enhancing growth in the agriculture sector. The Provincial Executive Committees ${ }^{118}$ are responsible for implementing the law but DOE is not a member of it (Aflaki, 2012). The regional Cooperation Offices ${ }^{119}$ are responsible for identifying eligible people and other committee members identify lands for transfer. Dr. Kiadaliri, the head of the Iranian Scientific Society of Forestry, in an interview states that in this new Executive Guideline, the Law is not clear about whether national parks, conservation areas and other lands under the DOE authority are exempted from it (Aflaki, 2012). He suggests that a reason why the DOE is not part of the working group is that environmental impacts and adhering to environmental regulations are not considered (Aflaki, 2012). He adds that the impacts and outcomes of previous regulations for land transfer and land use change are not yet evaluated and that any new law to further facilitate land conversion can be destructive to the natural environment, particularly of water resources (Aflaki, 2012). He further notes that the majority of previous land use changes in the name of increasing job opportunities failed due to lack of water and electricity, high expenses and the applicant's lack of expertise (Aflaki, 2012). The previous land use changes led to the lowering of water table in $90 \%$ of the country.

\footnotetext{
${ }^{118}$ Provincial Executive Committees were established with 11 members. The head of the committee is the Governor of each province and the secretary is the Deputy Director of the Governor-General's office (Aflaki, 2012). The other seven members are heads of the Ministry of Jihad Agriculture Provincial Office, the Land Affairs Department, the Natural Resource Office, the Road and Urban Development Organization, the Industry, Mine and Trade Organization, the Economic and the Finance Organization, Cooperation, Wellbeing and Social Affairs, Managers of relevant Banks, and the General Director of Regional Water Organizations. These committees meet when necessary as a working group, and their decisions are official with only six of the members being present (Aflaki, 2012).

${ }^{119}$ Affiliated to the Ministry of Cooperatives, Labour, and Social Welfare
} 
Land conversion in the lower reaches of the Atrek (Inchehburun and the AUA area) includes fish farms. The Iranian Fisheries Organization affiliated to the Ministry of Agricultural Jihad, issues aquaculture licenses and by law is the main agency in fisheries and aquaculture management ${ }^{120}(\mathrm{FAO}, 2013)$. Aquaculture licensing requires preapproval of the Ministry of Agricultural Jihad, the Ministry of Energy and the Department of Environment. An authority in Gorgan Fisheries Company, in an interview, explained these pre-approvals need to be acquired from relevant organizations and submitted to the Fisheries Company by the project proponent: (a) The Natural Resources Office of the Ministry of Agricultural Jihad is responsible for both the identification of land tenure and also approval of land use change. The project proponent needs to submit a proof of ownership of the land which is issued by the Natural Resources Office. The land use change from rangeland to inland aquaculture is allowed by law nevertheless the Fisheries Organization requires the Natural Resources Office to approve the land use change to inland fish farm in every case. (b) The Regional Water Company is the authority to allocate water. (c) The Department of Environment is responsible for consideration of environmental issues and potential impacts of fish farms. EIA study is required for fish farms above 400 hectares however; there are not enough guidelines and regulations to stop those projects which leads to negative environmental impacts. There is no legislation for aquaculture effluent standards and even if an EIA study has been carried out they are not public. Introduction of exotic fish species is regulated by the DOE but transportation of fish for aquaculture purposes is regulated by the provincial Agricultural Jihad. A DOE

\footnotetext{
${ }^{120}$ The Law Concerning the Exploitation and Protection of Aquatic Resources (1976); the Law of Protection and Exploitation of Fisheries Resources (1995); Guidelines for Aquaculture and Fisheries (1999) and its amendment in 2007 (FAO, 2013).
} 
authority pointed out in an interview that practically the only task that the DOE controls is to ensure that the fish farm is not located in national parks and protected areas.

After issuing an aquaculture license the project proponent is introduced to the provincial Jihad organizations which refer them to banks for credits and loans. Bank credits are delivered to project proponents in installments and at different stages of the work starting with $25 \%$ of the total cost to start the construction. The Fisheries Company monitors the work progress in construction and instructs the bank to pay installments to the project proponent. Upon completion of the construction, the Fisheries Company issues an operation license. This is at least a year-long process.

\subsubsection{Water management and allocation: institutions, regulations, and processes}

The Ministry of Energy is responsible for water resource management, dam construction, and power supply in the country. One of its eight legal entities is the Iran Water Resource Management Company established in 2003 to mainly enforce the Fair Water Distribution law (Japan International Cooperation \& CTI Engineering International Co, 2010, p. 5). Its regional representatives are the Regional Water Companies established in every province in $2006^{121}$. Their main tasks are: water (groundwater and surface water) management, planning, development and conservation; construction, operation and maintenance of water utilization infrastructure; distribution of water to users; issuing permits for the use of water (water rights) including the construction of wells, and river basin management (Japan International Cooperation \& CTI Engineering International Co, 2010; “Mission, goals, and activities,” 2013).

\footnotetext{
${ }^{121}$ Establishment of Water and Wastewater Companies for urban areas (1990) and rural areas (1998) was an aim to privatize all the companies that are owned by the state. However, at present, they operate under the auspices of the Mother State Companies: Iran Water Resources Management Company (IWRMC) and Iran National Water and Wastewater Company (INWWC) that are financed by the state's central treasury and are not economically viable (Hashemi, 2012 p. 117).
} 
Regional Water Companies are key actors in land conversion. Every proposal for land use change requires approval by these offices for ensuring their water needs. Farmers are the main actors at the local level by using almost $99 \%$ of groundwater in Iran but they are not involved in the water allocation process (Hashemi, 2012, p. 117). Groundwater in Iran is used by private land owners either in the form of customary rights in Qanat(s) (traditional system of underground water channels) or private wells (Hashemi, 2012, p. 117).

In post-revolutionary Iran, water rights are either customary or licensed: (1) The Fair Water Distribution Act (1982) is based on land rights and recognizes that customary water rights apply to those who have legal proof to water use, particularly in rural areas and for agriculture areas used before the enactment of Water Resources Nationalization Act (1968) (Hashemi, 2012 p. 115). A committee consisting of representatives of the Ministry of Energy, Ministry of Agricultural Jihad and Islamic Rural Council can change the customary water right to a permanent license. (2) Licensed water rights can be requested by the submission of an application to Regional Water Companies by any real and legal entity. Water fees for drinking, industry and agriculture are negligible and vary every year (Japan International Cooperation \& CTI Engineering International Co, 2010, p. 7). This process is associated with the Ministry of Agricultural Jihad and its land use change permits. There are no explicit provisions for environmental water requirement in the existing Fair Water Distribution Act (Hashemi, 2012, p. 159, 243) and Department of Environment is not even a member of the Water Allocation Committee of the Ministry of Energy.

The Water Allocation Directive (established in 2003) is an important shift in water management in Iran. Its Long Term Development Strategies provide a procedure for river basin planning, and Integrated Water Resources Management (IWRM) (Hashemi, 2012, 
p. 118). According to this legislation water allocation decisions should be based on system dynamic simulation and modeling of water resources at basin and sub-basin levels (Hashemi, 2012, p. 118). Water Policy and Allocation Commissions within the Ministry of Energy are responsible for capacity building in Regional Water Companies for river basin management and decision making (Hashemi, 2012, p. 120). The Deputy Minister for Water Affairs announces the approval of the Long-Term Development Strategies of Water Resources by the cabinet (“Iran's Long-Term Water Resources Development Strategies," 2003, p. 4) as:

In accordance with the decision made by the world leaders at the Summit (Johannesburg September 2002) on Sustainable Development, all countries have been obliged to compile their integrated water management plan by 2005 , and fortunately Iran is the only country in the region that has compiled and approved this plan.

This strategy is a wish list for an IWRM plan that is driven by international organizations. After creation of the Water Allocation Directive and approval of the Long Term Water Resources Development Strategies in 2003, no further institutional changes and coordination among relevant provinces took place. Structural changes were essential to balance the benefits throughout the country, and also among stakeholders (Japan International Cooperation \& CTI Engineering International Co, 2010, p. 5). Development of IWRM plans that are the tasks of Regional Water Companies are not feasible goals (Japan International Cooperation \& CTI Engineering International Co, 2010, p. 5), as will be discussed here:

Integrated Water Resources Management $^{122}$ (IWRM) is based on Integrated River Basin Management $^{123}$ (IRBM) and watershed management. IWRM and IRBM require

\footnotetext{
${ }^{122}$ Integrated Water Resources Management (IWRM) can be described as "a process which promotes the coordinated development and management of water, land, and related resources to maximize the resulting
} 
coordinated development and management of land and water, surface and groundwater, upstream and downstream interests and uses, and collective decision-making versus single sector and top-down approaches and decision-making processes. A common feature among different approaches to IWRM and its subsection IRBM is the need for a good science-policy-stakeholders interface (Stålnacke \& Gooch, 2010, p. 157). This entails effective interaction among stakeholders, policy makers, planners, decisionmakers, users, local people, engineers and academics. It requires efficient institutional frameworks (both top-down and bottom-up), and coordination of sectors and agencies through multi-sectoral linkages with support of legal guarantees in the form of policies, strategies and legislations (Stålnacke \& Gooch, 2010, p. 157). A major part of IWRM and the interface explained above is setting up of a transparent multi-sectoral information and expertise knowledge-based system and capacity building (Global Water Partnership, 2000, p. 33). These institutional, legal, administrative, and political reforms are difficult tasks (Global Water Partnership, 2000, p. 33, 34, 47; Stålnacke \& Gooch, 2010, p. 157) and require political will by the policy-makers at the highest possible level to transfer these concepts, IWRM and IRBM, into a real practice. This transition has not happened in Iran. Some of the reasons for this failure are:

(1) There is an 'internal conflict and different perspectives' in the Ministry of Energy regarding water management, allocation, and planning (Hashemi, 2012, p. 121). Approval of the IWRM in terms of Iran's long-term development strategies was driven by economic and social welfare in an equitable manner without compromising the sustainability of vital ecosystems (Global Water Partnership, 2012).

${ }^{123}$ Integrated River Basin Management (IRBM) can be described as "process of coordinating conservation, management and development of water, land and related resources across sectors within a given river basin, in order to maximise the economic and social benefits derived from water resources in an equitable manner while preserving and, where necessary, restoring freshwater ecosystems." (Global Water Partnership, 2000; WWF, 2013). River Basin management Organizations deal with water resource management issues in a river basin, a lake basin, or across an important aquifer. 
international organizations. The Ministry of Energy was in an impulsive dam construction period, and had conflicted opinions about large dams and the necessity of multi-sectoral decision making for water resources. The Office of Macro Planning at the Ministry of Energy has adopted the IWRM principles but that understanding is not common among high level decision-makers. (2) Multiple institutions are involved in overlapping aspects of basin planning and management. The Ministry of Agricultural Jihad and its Forest, Rangeland, and Watershed Management Office have overlapping tasks with the Ministry of Energy. Secondary and tertiary dams and canals are constructed by Regional Water Companies or the Ministry of Agricultural Jihad and quaternary canals are constructed and maintained by the Ministry of Agricultural Jihad (Japan International Cooperation \& CTI Engineering International Co, 2010, p. 7). (3) Political influence and the imbalance of power among actors at national, provincial and local levels is a fundamental problem in water use and allocation (Hashemi, 2012, p. 87). (4) Data and statistics are unreliable and data held at different levels of management are incompatible. There is lack of trust and exchange of data among national and inter-provincial organizations (Hashemi, 2012, p. 87). (5) No action has been taken for the establishment of Integrated River Basin Organizations. They are necessary in order to formulate IRBM plans, to carry out administrative organizations and to provide for capacity building. (6) Upstream and downstream conflict resolution systems are not set up. (7) Malfunction of Environmental Impact Assessment procedures in Iran and the inefficiencies of the Department of Environment and other involved regulatory bodies inhibit the drafting and approval of environmental standards.

In addition to the above impediments, water management reflects the country's priorities and its system of governance. IWRM and IRBM can be successful if they are 
looked at as part of the national sustainable development processes, including efficient Environmental Impact Assessment studies and environmental standards, and part of the country's land use and spatial planning, not as a stand-alone system of governance and administration separate from the rest of the government (Thalmeinerova, 2010, p. 34). Environmental Impact Assessment and spatial planning are problematic processes in Iran (discussed in Sections 6.2.3.2 and 6.2.4 respectively).

There is no common agreement on the usefulness and priority of Integrated Water Resource Management over sectoral approaches to achieve development goals in Iran. The same is the case with mind-frames about sustainable development. There is disagreement about its priority and usefulness, and lack of political will at the higher levels of the government to put this concept into practice (see Sections 6.2.3 and 6.2.4). The ignoring of environmental water requirements throughout the country has negative impacts on wetlands. The Director of the Water and Waste Water Company, in response to the question of why, despite claims by the Ministry of Energy that it has secured environmental water requirements for wetlands, they are drying out, answered that the ministry does what is expected from it and releases required environmental water but it is exploited illegally by water users who dig deep wells along their routes to wetlands and also extract surface waters through channels and pipes ("Illegal diversion of environmental water: Main cause of drying wetlands," 2013). Provincial conflicts on water allocation are dealt with in the Governor Generals' Offices ${ }^{124}$ (Hashemi, 2012, p. 129). Any application for water rights and allocation has to be approved by the district department organization before any consideration (Hashemi, 2012, p. 129). The

\footnotetext{
${ }^{124}$ The provincial Water and Agricultural Commission, a subcommittee under the Provincial Economic and Production Working Group of the Planning Bureau at the Governor's Office
} 
governance mismatch is caused by the basic demarcation for management being the provincial boundaries and not the natural boundaries of river basins.

A study on water management in Lake Urmieh Basin shows that environmental water requirements are only secured through unregulated and overflow waters (Hashemi, 2012, p. 89), so it is not surprising that in AUA region the water requirements of wetlands and the lower reaches of the Atrek are usually provided in spring and winter. A water crisis in Khuzestan (Karun River), drying of Lake Urmieh, and the crisis of the Atrek River Basin are sometimes depicted as ethnic problems. While these crises are happening in ethnic minority regions, water crises are common throughout the country (Koushki, 2011). The competition between the Governor-Generals' Offices and Members of Parliament regarding access to water is a common problem throughout the country due to lack of spatial land use planning and river basin management, and to managerial flaws in the water sector. Ethnic and minority rights issues complicate the problem.

The Zayandeh River is a good example of this common problem nation-wide. This river in Isfahan has been in crisis since 2008, when agriculture in the province collapsed, drinking water became a serious issue for the province, and the Gavkhoni wetland at the lower end of the river dried (Ijadi, 2011). What has happened to the Zayandeh River and its basin is the same syndrome that has happened to most of the river basins of the country, including unplanned dams, no rule of law with regard to water rights and environmental water allocation, prioritized water needs of industries over agriculture, illegal deep wells along rivers, unplanned water diversions, lack of multi-sectoral coordination, and politics of Governor-Generals' Offices. 


\subsubsection{Nature protection}

The management of protected areas and Wetlands of International Importance in Iran is the duty of DOE but the state has the tenure of those lands ${ }^{125}$. The same is the case with nationalized forests and rangelands, under the authority of the Forests, Range and Watershed Management Organization (Ministry of Agricultural Jihad) and water use from the wetlands is the authority of the Regional Water Company (Ministry of Energy).

Department of Environment is the lead agency for environmental protection, and management in the country. Its major tasks are setting environmental regulations, preventing pollution; regulating Environmental Impact Assessment procedures and processes, wildlife and nature protection and conservation, and public awareness ("Mission and duties," 2013).

DOE can control land use in its four management areas (Protected areas, Wildlife Refuge, National Parks, and Ramsar Sites) and any land use change that affects those areas requires DOE's approval. Moreover, DOE in accordance with EIA regulations can accept, reject, or accept upon mitigation, those development projects (such as dams, irrigation, and fish farms) that have potential negative impacts on environment. This chapter argues that these laws are usually ignored or are being modified in favor of developers and towards limiting DOE's authority, and giving less consideration to environmental issues.

The political stance of the Islamic State with regard to the environment is fluid and approaches to environmental issues change with every change in the political atmosphere of the country, change in the cabinet and Majlis, or the appointment of a new

\footnotetext{
${ }^{125}$ Wetlands of International Importance in Iran do not have the same legal support as national parks however have protection levels similar to IUCN categories IV to VI. The discourse and practice of conservation in Iran and its evolvement and the DOE's role will be discussed in Chapter IX.
} 
Director General for DOE. This fluidity opens a space for both opportunities and constraints. Under certain conditions DOE was given more authority with the result that some environmental regulations and laws were set, environmental issues gained political attention, and sustainable development was considered as a core concept in spatial planning (the Fourth Development Plan). However in the last ten years these laws have been selectively practice or enforced, and some were modified in favor of economic growth, with no consideration for environmental issues or conservation with collective movement towards limiting DOE's authority.

The DOE's provincial offices are responsible for implementing national programmes for nature protection and conservation and ensuring mainstreaming of environmental objectives into policies, programmes and sectoral practices of organizations and ministries dealing with resource use and development in order to overcome scale mismatch in environmental management and ensure sustainable development in provinces ${ }^{126}$. Most of these negotiations are carried out in the GovernorGenerals' Offices and since the Fourth Development Plan, DOE Director Generals in all provinces were appointed to national planning and development committees in order to have the opportunity to influence regional and local policy (Ebtekar, 2009, p. 290). However, as explained in the land and water management procedures, DOE provincial offices are either not involved in major decision making processes of land conversion ${ }^{127}$ and water allocation, or their actions are neither timely nor effective. The only issue that they are involved in on a regular basis is aquaculture development in the region. The

\footnotetext{
${ }^{126}$ Hunnam defines conservation mainstreaming as (Hunnam, 2011, p. 1): "enabling the agencies that govern the main economic or resource use sectors - agriculture, forest, rangelands, water, tourism, energy, infrastructure - to incorporate conservation and ecological sustainability measures into their own policies, programs and sectoral practices."

${ }^{127}$ For example Provincial Executive Committees implementing "Executive Guidelines for Agricultural Development" ratified in 2011 (Aflaki, 2012).
} 
ineffectiveness of the Department of Environment (DOE) provincial offices is related to lack of political will by the agencies involved and insufficient and fragmented EIA and environmental regulations.

\subsubsection{Structures and processes}

The highest environmental decision making body for 40 years was the Environmental High Council ${ }^{128}$, a regulatory (legislative) body that, after the revolution, was chaired by the President of the Republic until its dissolution by President AhmadiNejad, in 2007 (Jamshidi, 2013; Mohammadi, 2007). The DOE was the secretariat of the High Council that was a multi-sectoral governmental body responsible for preparing environmental policies and legislation to be submitted to the parliament and approving environmental codes and standards. Since 2007 the DOE has been headed by a state vicepresident reporting to the president. The High Council was re-established by AhmadiNejad in 2008 but this time its mandate and authority was transferred to the cabinet's Infrastructure, Industry, and Environment Commission ${ }^{129}$ ("Environmental High Council is not dissolved," 2010) and the role of the DOE was restricted (Ghasemian, 2009; Jamshidi, 2013; Mirzadeh, 2009). Part of the mandate of this national level, ministerial, and multi-sectoral commission is to: coordinate sectoral ministries and organizations; try to resolve disputes between the Department of Environment and other government institutions: study and approve environmental policies and regulations and when

\footnotetext{
${ }^{128}$ The law for establishment of this council was ratified by parliament in 1974 and amended in 1992 (Mohammadi, 2007).

${ }^{129}$ This is one of the seven permanent commissions of the cabinet. Members of this commission are ministers of Ministries of Oil, Agricultural Jihad, Industry and Mining, Defence and Military Forces, Road, Housing and Urban Development, Interior, and Communication and heads of Atomic Energy Organization, Cultural Heritage Organization, Department of Environment, Rural Development and Marginalized Regions Organization, Central Bank, and Planning and Strategic Supervision Directorate (office of the President), and Scientific and Technical Directorate ("Regulations of Internal Affairs of the Cabinet," 2011).
} 
necessary, submit them to the parliament. A difference between the Environmental High Council before 2007, and the Infrastructure, Industry and Environment Commission is that the former was structured to have four experts from academia and NGOs in addition to the minister's representatives while the latter is composed only of ministers which makes it unlikely that ministry representatives go against their relevant ministerial decisions (Jamshidi, 2013; Mohammadi, 2012).

The Department of Environment is not a ministry and that lowers its legal and political competence in the Islamic State. The DOE, being headed by a vice-president, is considered by international organizations as ranking higher than most line ministries (United Nations Development Programme \& GEF, 2004, p. 8). However, in this framework, if the president and relevant ministries do not have the political will for considering environmental issues, environmental decisions and measures will be marginalized in competition with development projects. The cabinet controls the general affairs of the government and ministries have major legal authority in their specialized fields, In addition the ministries are strong social and political entities with extensive capacities (Abdollahi \& Faryadi, 2010, p. 150). DOE does not have the same political and legal authorities as do the ministries so its function is always dependent on the will of the cabinet (Abdollahi \& Faryadi, 2010, p. 151). DOE can send its proposals for approval to the cabinet through a vice-presidents office and also through the Infrastructure, Industry and Environment Commission. The vice-president who is the head of the DOE can approve draft decisions proposed by the DOE but, to date, that office has only approved some minor draft decisions (such as taxidermy rules); major proposals have been referred to the Infrastructure, Industry and Environment Commission and, upon its approval, to the cabinet (Abdollahi \& Faryadi, 2010, p. 157). Therefore, DOE does not have a high 
position in the government body and is a weak, almost trivial, institution when it comes to conflict resolution with ministers in the cabinet meetings and councils (Abdollahi \& Faryadi, 2010, p. 150, 157).

At the national level, DOE's main channel to negotiate environmental decisions is through the Infrastructure, Industry and Environment Commission, the cabinet, and its High Councils (Abdollahi \& Faryadi, 2010, p. 157). The legislative branch, made up of the elected deputies of the Majlis, has 22 Specialized Commissions which almost parallel the Government Ministries (United Nations Development Programme \& GEF, 2003, p. 12). Agriculture, Water and Natural Resource Commission of the parliament, consisting of water, agriculture, animal husbandry, and environment committees, is responsible for ensuring compliance of the Ministries of Agricultural Jihad and Energy and relevant government bodies with agriculture, animal husbandry, rangelands, watershed, fisheries, environment, natural resource, and meteorological regulations (“Agriculture, Water and Natural Resource Commission,” 2012). The decisions that the Infrastructure Commission has taken to date are in favor of development projects, even those with negative environmental impacts (Abdollahi \& Faryadi, 2010, p. 156; Ghasemian, 2009). The Commission's decisions were in favor of ministries with an obvious tendency towards economic development without consideration for environmental impact and almost never in favor of the DOE and consideration for environmental issues (Jamshidi, 2013; "New tasks for the Department of Environment: Setting standards for school's chairs and desks," 2009). Even those projects for which EIA studies were conducted on time and were disapproved by the DOE for their potential negative environmental impacts, the Infrastructure Commission, as the higher entity, usually votes for the project ("New tasks for the Department of Environment: Setting standards for school's chairs and desks," 
2009). The presidential office, Governor-Generals' Offices, line ministries, and Majlis do not take environmental issues into consideration nor do they grasp its significance and scope in national policies. Nevertheless, the government ratifies international environmental treaties and conventions with almost no discussions in the parliament (Abdollahi \& Faryadi, 2010, p. 174). This contradiction is a reflection of the political strategy of the Islamic State in being present and active in international networks. Conservation discourse in Iran and the role of international organizations will be discussed in Chapter IX.

The lack of political will of the government in stepping towards sustainable development has been obvious in the last decade. In addition to the temporary dissolution of the Environmental High Council, the following examples confirm this trend:

(1) The Infrastructure Commission approved construction of a road through Anzali, a Wetland of International Importance, irrespective of objections by the DOE. The Commission did not even consider any mitigation measure or DOE's proposal for an alternative route that could minimize damage to the wetland (Abdollahi \& Faryadi, 2010, p. 151).

(2) In 2002 the government approved a refinery in Mazandaran, despite regulations that banned petrochemical, refinery and oil related industries in the northern provinces. This law, modified by the cabinet in 2005, exempted the Atrek region and parts of other Northern provinces along the Caspian Sea. Despite that, Ahmadi-Nejad in his trips to this region approved petrochemical plants in wetlands and forest regions of Golestan and Gilan ("Petrochemical industry: Deep wounds in Sofikam," 2007). The EIA studies of these projects are not transparent and public and the only clear part of this process is the final approval of the projects. The construction of the Petrochemical plant 
in Sofikem, Golestan was started in November 2006 before any EIA studies were carried out ("Golestan Petrochemical Plant: Provisional to Environmental Impact Assessment Studies," 2006).

(3) The Infrastructure Commission and the cabinet in 2009 revised the EIA regulations and restricted DOE to informing project proponents only about its four management categories. This revision omitted 'specific ecological areas' that were beyond protected areas and include sensitive ecosystems such as wetlands, lakes, rivers and national natural sites from the law ("Amendments to Articles 105 and 71 of the Thrid and Fourth Development Plan," 2009). This modification indirectly has limited DOE's authority and expands developers' activities to sensitive areas.

(4) In 2009 (November 29), the Infrastructure Commission established a precedent by approving four new protected areas in which they allowed city and rural services and developments, road construction, recreation, and activities related to: the military; the Housing Foundation (including new urban settlements); the Forest, Rangeland, and Watershed Organization (Darvish, 2013).

(5) In 2013 (March 17) the Cabinet ratified regulations for mining activities in provinces. This law (Section $2 \mathrm{~b}$ ) mandates every province to identify potential mining opportunities located in protected areas and plan for their exploitation and also to reactivate abandoned mines ("Provincial mining development regulations," 2013). The cabinet officially asked the mining sector to target protected areas and negated the DOE's authority over its four management areas (Darvish, 2013). A new law is being discussed in the Cabinet for allowing pipelines to pass through protected areas.

The DOE no longer has any role in coordination of 38 fragmented environmental regulations and policies, involving 23 ministries and organizations, out of which 15 are 
overlapping mandates involving 12 ministries and organizations, ${ }^{130}$ all of which have competitive and contradictory agendas. Duplication of mandates in the absence of any coordination mechanism has mostly resulted in no actions taken by relevant organizations (Abdollahi \& Faryadi, 2010, p. 164, 168). Regulations regarding the use of natural resources are mainly for facilitation of use rather than for wise use/sustainable use particularly for mining and forests, and rangelands that are mandates of the Ministries of Industry and Mining and Agricultural Jihad (Abdollahi \& Faryadi, 2010, p. 171).

Abdollahi and Faryadi, from the Faculty of Law, University of Shahid Beheshti, Tehran, in a review of DOE's legal challenges identify the following obstacles (Abdollahi \& Faryadi, 2010, p. 150, 151, 156, 157): a) approval of proposals, in the cabinet and the High Councils, is based on majority vote and not consensus, therefore, if the majority of the ministers are against a proposal from DOE they easily can vote it out; b) only ministers have the right to vote ${ }^{131}$, therefore, the Director of the DOE is excluded from voting in cabinet decision making processes; even when DOE is in a council or committee and has the right to vote it is usually in the minority; c) the ministers have a strong tendency towards economic growth and generally the DOE and its environmental concerns are perceived as a barrier to development and have no priority; and d) if sectoral Ministries and the Cabinet's multi-sectoral High Councils (e.g. Energy, Urban and Architecture Development, Oceanography, Standard Department) take decisions with potential negative environmental repercussions, DOE does not have access to any legal

\footnotetext{
${ }^{130}$ These institutions include, among others, Ministry of Agricultural Jihad and its affiliated bodies (Forest, Rangeland and Watershed Organization, Plant Conservation Organization, Fisheries Company), Ministry of Energy and its affiliated bodies (Water and Wastewater Organization), Ministry of Health, Atomic Energy Organization, Industry and Mining Ministry, Water High Council, Ministry of Interior, Ministry of Oil, Standar Organization (Abdollahi \& Faryadi, 2010, p. 169).

${ }^{131}$ Articles 17 and 18 of the Regulations of Internal Affairs of the cabinet ("Regulations of Internal Affairs of the Cabinet," 2011).
} 
procedure to object to their decisions. There are no terms of reference for conflict resolution or codes of conduct for these councils.

\subsubsection{Environmental Impact Assessment Studies}

EIA reports and environmental evaluation of development projects have not resulted in better site selection or implementation of development projects with less negative environmental impacts in Iran (Alborzi-Manesh, 2009). Site Selection and Environmental Impact Assessment Studies of development projects do not compensate for lack of major multi-sector planning (e.g. spatial planning and land use planning). In the absence of spatial planning (discussed in Section 6.2.4.), the shortcomings in the EIA processes, including disregard of site selection and EIA studies of single projects and no consideration of the cumulative effects of projects in a region are not leading to sustainable development in Iran.

Regulations regarding Environmental Impact Assessment ${ }^{132}$ recognize the DOE as the approving authority of Environmental Impact Assessment (EIA) reports. According to standard procedures and guidelines for implementation of EIA projects, the project proponent is required to prepare and submit environmental feasibility and site selection studies along with the EIA reports for major development projects including dams, petrochemicals, irrigation projects and fish farms ${ }^{133}$.

\footnotetext{
${ }^{132}$ EIA in Iran is enabled by (Soleimani \& Moridnejad, 2012, p. 3): Note 82 of the Law for the Second Year Development Plan, amended by Article 105 and 104 of the Third Development Plan, Article 71 of the Fourth Development Plan, Article 192 of the Fifth Development Plan, Decree 138 (1994), EIA guidelines (1997) and further amendments (2011) approved by Environmental High Council, Other related laws include: Article 50 of the constitution, Environmental Protection and Enhancement Bylaws (1975), Air Pollution Prevention executive Bylaws (1975, amended 1984), Water Pollution Prevention executive Bylaws (1984).

${ }^{133}$ The list of projects that require EIA studies was modified and completed through the years. As of 2011, it includes, among others, almost every oil, gas, and petrochemical plan and facilities, water infrastructures including large dams and its subsidiary constructions (dams higher than 15 meters or lakes larger than 400
} 
Despite the lack of political will in the current government for consideration of environmental issues and sustainable development, a minority of members of parliament constituting the Environment and Sustainable Development Faction ${ }^{134}$ were able to pressure the Agriculture, Water and Natural Resource Commission to request the Bureau of Infrastructure Studies of the Majlis Research Center, to review Iran's EIA regulations (Soleimani \& Moridnejad, 2012).

Even if there was pressure from the DOE to carry out EIA studies and the government was committed to sustainable development, EIA in Iran could still not be effective due to its legal gaps and inefficient mechanisms. The shortcomings include: (a) while EIA reports are obligatory for government's large scale production and service projects, they are not required for medium and small projects, irrespective of the pollution and other negative environmental impacts that may occur (Soleimani \& Moridnejad, 2012, p. 12); (b) The law does not require a mandatory EIA report for projects funded by developers, including private sector and semi-governmental agencies, other than the government agencies (Soleimani \& Moridnejad, 2012, p. 11, 12); (c) most consultants that prepare EIA reports are affiliated with government and their lack of independence affects the results in favor of the project; sometimes the consultants' payments are conditional on DOE approval of the project (Bahram-Sultani, 2012; Soleimani \& Moridnejad, 2012, p. 7); (d) some consultants are not competent and there is no regulation to evaluate and classify them (Soleimani \& Moridnejad, 2012, p. 10); (e) most of the EIA reports are prepared after the project is approved by the government (Bahram-

hectares), irrigation networks between basins at any scale and aquaculture facilities of more than 10 hectares in provinces along the Caspian ("Ratification of the list of projects that require EIA," 2011).

${ }^{134}$ Every eight Member of Parliament can establish a fraction to follow a specific political or technical goal. These factions are not official entities of the parliament with predefined role and terms of reference. 
Sultani, 2012; Soleimani \& Moridnejad, 2012, p. 16); (f) no guidelines are provided for the structure and content of comprehensive EIA reports (Soleimani \& Moridnejad, 2012, p. 12); (g) there is no monitoring system and even if the commission foresees some mitigation measures there is no guarantee that the project proponent will implement those measures due to lack of a follow up and monitoring system being in place (Soleimani \& Moridnejad, 2012, p. 7); (h) the EIA bureau in the DOE does not have the technical and scientific capacity to review the EIA reports (Alborzi-Manesh, 2009; Soleimani \& Moridnejad, 2012, p. 6); (i) public participation does not exist in the EIA procedures (Alborzi-Manesh, 2009; Bahram-Sultani, 2012; Soleimani \& Moridnejad, 2012, p. 9).

Public participation is a pillar of access rights for environmental good governance and EIA procedures are a tool to provide procedural rights to the public to intervene and ensure governments take their views into consideration (Banisar, Parmar, De Silva, \& Excell, 2011, p. 8). Even though the EIA guidelines in Iran are translations of developed countries and international organizations' materials that always have a public participation component, EIA practices in Iran are short in public participation. In Iran, the public participation component of EIA is never put into practice, though is mentioned in most of the guideline (Bahram-Sultani, 2012). Kambiz Bahram-Sultani, asserts that EIA procedures in Iran are 'Iranianized' by ignoring its essential 'participatory' components and turning it into a 'patriarchy' method through which decisions are being made without any public participation (Bahram-Sultani, 2012). EIA processes are not transparent, and the reports are not published and never open for public review.

Irreversible negative impacts of dams built after the revolution are serious consequences of lack of spatial planning and sectoral and regional coordination (Makhdoum, 2008, p. 578). In the absence of spatial plans (see Section 6.2.4), EIA 
studies for dams could play an important role in their failure or success but they proved to be ineffective and inadequate in Iran (Bahram-Sultani, 2012). A Natural Resource authority in Gorgan in an interview explained that dams and channels in Golestan province have been constructed without diligent research and two dams, Boostan and Golestan, on the Gorgan River, are only two examples. He continued that Boostan Dam, constructed in 2006, after a period of heavy rain had accumulated so much sediment that the water depth behind the dam was only $10 \mathrm{~cm}$; Golestan Dam, constructed in the 1990s, was filled by 13 million $\mathrm{m}^{3}$ of sediment after the first flood.

Alborzi-Manesh in a review of EIA studies of Iranian dams argued that (AlborziManesh, 2009): a) if more than one dam is constructed in a river basin, the cumulative effects of multiple dams must be considered, however in Iran dams are studied in isolation; b) the proponents in dam projects are usually government bodies and the consultancy firms feel pressure to manipulate data and tailor the reports in order to identify more positive impacts than negative ones and; c) for many projects that are provisionally approved subject to mitigation measures, the mitigation measures are not undertaken and there is no monitoring system to follow up with those mitigation measures.

Site selection, Environmental Impact Assessment of development projects and evaluation of their singular and cumulative effects, are unable to compensate for lack of major multi-sector planning such as spatial planning and land use planning. At best they could result in better development practices with less negative environmental impact. Even this is not the case in Iran (Alborzi-Manesh, 2009; Bahram-Sultani, 2012). 


\subsubsection{Administration}

In addition to the above major predicaments in legal and policy setting processes at national and provincial levels, the DOE has structural and administrative inadequacies that affect its efficiency and effectiveness as an environmental regulatory institution. The issues include:

(1) The DOE has no inspection and monitoring system for reviewing development projects and ministerial operations. Its only monitoring power is its environmental guards who work at the local level to control poaching in Protected Areas and National Parks. These environmental guards do not have legal support in their encounters with poachers and hunters, are underpaid and are not well trained (Abdollahi \& Faryadi, 2010, p. 159) (see Section 9.3).

(2) The DOE's legal division is not well developed and in cases of environmental complaints does not have the necessary coordinating mechanism for dealing with its provincial offices, the legal offices of other institutions and the judiciary system (Abdollahi \& Faryadi, 2010, p. 162).

(3) DOE does not have enough efficient and well-trained scientific, specialized, and executive staffs (Soleimani \& Moridnejad, 2012, p. 6). This, along with legal limitations, hinders the DOE in meeting its mandates. DOE lacks adequate capacity to: prepare environmental codes, standards and guidelines for environmentally friendly practices for different sectors (Abdollahi \& Faryadi, 2010, p. 159-161); to prepare and disseminate environmental data and reports for consideration by the Majlis and for Ministries to enable these bodies to make more environmental friendly decisions. DOE took some steps towards creation of an environmental statistics database in 2005 (Ebtekar, 2009), but it was not successful and was abandoned. Some statistics and reports 
are prepared in an ad hoc manner by academics, NGOs and international organizations such as the World Bank and the UNDP (Abdollahi \& Faryadi, 2010, p. 161).

DOE, being an inefficient regulatory body and an ineffective EIA regulator, encounters political, legal and administrative obstacles in mainstreaming its environmental objectives and in protecting legally 'protected areas'. It has turned its focus onto what is feasible and achievable and has become an institution that practices 'fortress' conservation, and being a hunting and fishing regulator. Its provincial offices organize the environmental guards. This was DOE's mandate when it was first established almost half a century ago. DOE, unlike ministries, is not officially required to regularly report to the parliament. NGOs and academics are the main challengers of DOE in regard to its operations and decision-making processes (Abdollahi \& Faryadi, 2010, p. 174). Iranian discourse on nature protection and conservation will be discussed in Chapter IX.

\subsubsection{Spatial planning and development plans: decision-making processes and structures}

Land use, land conversion, rural and provincial development plans and national and regional development strategies are components of spatial planning in $\operatorname{Iran}^{135}$. Spatial planning, a multi-sectoral project, has developed on the foundation of land use plans (Karimi, Masha, Jafari, \& Pourasghar Sanghachin, 2011, p. B-478). It facilitates and coordinates horizontal linkages between government sectors, and is the first step towards sustainable development in Iran (Makhdoum, 2008, p. 579).

\footnotetext{
${ }^{135}$ Spatial planning goes beyond traditional land use planning and has a comprehensive scope to integrate policies regarding development and land use with other policies including environmental concerns and health policies.
} 
Discussions about land use planning in Iran started in the 1960s when the Plan and Budget Organization was the authority for developing a national planning system but halted after the revolution until the approval of the First Development Plan ${ }^{136}$ (AlborziManesh, 2012). The First Development Plan after the revolution (1989-1993), also after the ceasefire of the Iran-Iraq war, mandated nationwide land use planning. Spatial planning was approved by the parliament and though required by law, four decades later, has not yet been developed. National and regional spatial plans are identified as part of the second (1994-1999), third (2000-2004), fourth (2005-2009), and fifth (2010-2014) Development Plans ${ }^{137}$ (Karimi et al., 2011, p. B-479).

The planning process was started by the Management and Planning Organization, in 2006, but the organization was dissolved in 2007 and by the end of the Fourth Development Plan many provinces had stopped their relevant programs ${ }^{138}$. Dr. Makhdoum, a renowned expert in land use planning and a pioneer academic teaching land use and spatial planning in Iran was responsible for inspecting development of the regional plans and the final products in each province ("The Fourth Development Plan: A martyr," 2009). In an interview, he notes that after dissolution of the Management and Plan Organization he no longer supervises the regional plans and their preparation

\footnotetext{
${ }^{136}$ After the revolution, planning was halted for five years. During the first ten years after the revolution, annual budgets were prepared on a piecemeal basis, and project development and implementation were ad hoc (Shakoori, 2006, p. 271). This is the period when Jihad Sazandegi was established and expanded to carry out rural development projects and became the main decision making authority in land use management, change, and land transfer.

${ }^{137}$ Makhdoum stated that the fifth Development Plan mandates spatial planning but this time the responsibilities and coordination between sectors and regions are ambiguous and even if it is prepared it lacks consistency and there is no provision for quality control ("The Fourth Development Plan: A martyr," 2009). He added that the fourth Development Plan was advanced in its scope and could establish a comprehensive sectoral-regional planning if it was carried out.

${ }^{138}$ The Fourth Development Plan envisioned the next National Development plan to be synthesized based on regional spatial plans but it never happened ("The Fourth Development Plan: A martyr," 2009).
} 
processes $^{139}$ and no one was appointed after him ("The Fourth Development Plan: A martyr," 2009).

In the absence of the Management and Plan Organization, Ahmadi-Nejad established a Land Use Planning Council in 2010. The Council consists of the President's representative, a few ministers ${ }^{140}$, the head of the Department of Environment and three experts in spatial planning. Ahmadi-Nejad delayed the required appointment of the experts until mid-2012, when he finally appointed the ministers of Ministry of Oil, Industry and Mining, and Energy, the three ministers with the most outstanding record in environmental degradation and with no expertise in spatial planning ${ }^{141}$ (Amin-Shar'i, 2012).

The state continues to delay the effective spatial planning program that is mandated by law, even though it has the financial means, and human resources, and could enhance its expertise. This demonstrates lack of political will for such planning. The Islamic State makes ad hoc territorial planning (spatial) decisions (Amirahmadi, 1986, p. 523) through a number of revolutionary institutions, foundations, and national and regional political powers. Shakoori argues (Shakoori, 2001, p. 98): 'Most agricultural and rural policies initiated after the revolution were politically motivated, and once the short term political objectives had been attained such projects....were either abandoned or left

\footnotetext{
${ }^{139}$ The terms of reference for the land use studies included "analysis and assessment of the natural and environmental status of each province, socio-cultural analysis, economic analysis, evaluation of the spatial structure, analysis of the linkages, security and defensive considerations, future forecasting, land use management, [the use of] Geographical Information System, integration and conclusion." (Karimi et al., 2011, p. B-479). The goals were: coordination of actions and prevention of overlapping and contradictory policies and programmes across sectors and scales (Karimi et al., 2011).

${ }^{140}$ These ministers includes those of the Ministries of the Interior, Intelligence, Agricultural Jihad, Economy and Finance, Housing and Urbanization, Defense and Military.

${ }^{141}$ A blogger in this regard writes that spatial planning without having a common understanding of development and strategic goals and knowledge of spatial planning is of no benefit to the Iranian nation. She argues lack of knowledge and capacity will only produce a degraded land use plan and not a real spatial plan, which can lead to sustainable development (Ayatollahi, 2013).
} 
to fade away.' With lack of such planning, political lobbying and pressure are the main factors behind development projects and land use changes. They are mostly without technical and economic justification (Karimi et al., 2011, p. B-483) and consideration of environmental impacts. The planning system envisioned in the fourth Development Plan could stop overlapping activities of government entities, random political managerial decisions, and financial and bureaucratic corruption. It could put an end to approval of development projects and programmes that result in extensive environmental degradation, uncontrolled land conversions, and social and economic disparity between regions. Kambiz Bahram-Soltani, highlights that, if the government had spatial planning perspectives in its plans, it could improve the living conditions in border regions, and therefore, protect the borders with the help of local people (Bahram-Sultani, 2012) and lower its high security expenses on surveillance.

The fourth national report of the Iranian government to the Convention on Biological Diversity (Department of Environment-Iran, 2010, p. 49) recognizes unsustainable land use, and land conversions as one of the major threats to Iran's biodiversity. The report recognizes the lack of spatial planning at the national and regional levels as a facilitator for these conversions. It argues that 'the main reason for converting land and destroying the key habitats is to facilitate development plans and promoting economic activities', and also that unsustainable exploitation of water resources and practices, such as large dams, destroy local ab-band(s). Makhdoum asserts, in executing the fourth Development Plan, overruling environmental issues was a dominant trend and almost no major projects in Iran had Environmental Impact Assessment report (“The Fourth Development Plan: A martyr," 2009). He concludes the main negative impact of lack of spatial planning for Iran is environmental and natural 
resources degradation (Makhdoum, 2008, p. 578; "The Fourth Development Plan: A martyr," 2009), and account it as 'the most grave threat to biodiversity' (Makhdoum, 2008, p. 578). The government uses 'sustainable development' in a narrow sense when considering the inclusion of environmental policies into development plans ${ }^{142}$. Irrespective of arguments for a broader interpretation put forward by academics, journalists and bloggers, the state is adamant in not expanding 'sustainable development' to social justice and only to use the term as a jargon for consideration of environmental issues in development plans.

\subsubsection{Dissolution of Management and Planning Organization: the transfer of decision making processes}

The Management and Planning Organization was renamed to the Plan and Budget Organization when budgeting was incorporated into its mandate during the MohammadReza Shah era. Twenty years after the revolution, in 1999, state employment affairs were added to its mandate and the name was changed to the Management and Planning Organization (MPO). MPO was acting as an institution, independent from the government until President Ahmadi-Nejad separated the provincial offices of the Organization from its central office in Tehran and put them under supervision of Governor-General's offices, in 2006. After a few months, in 2007, he completely dissolved the Management and Planning Organization.

Ahmadi-Nejad, in one of his provincial visits, stated that the Management and Budget Organization had to be dissolved because it was established by the American government (in 1949); its founders, who were planners of the country, were enemies of the Iranian people' and 'the foundation of planning in that organization was imported

\footnotetext{
${ }^{142}$ For this reason the Sustainable Development Committee is located in the Department of Environment and is not very active.
} 
from beyond our borders' ("Ahmadi-Nejad: Founders of the Management and Budget Organization were enemies of Iran,” 2009). Hard-liners including the Supreme Leader, in support of this change have argued that: a) the MPO was established by Americans and lacked Islamic foundation ("Where does re-establishment of MPO lead to?," 2012); b) its dissolution was a required step towards decentralization and 'increased the influence of cabinet and ministries in drafting the annual budget' ("Iran's MPO to be dissolved," 2007); and c) this was in the direction of downsizing the government system. The Minister of the Interior, the main defender of dissolution of MPO, in an interview stated that the main goal was eliminating bureaucracy and decentralizing ("Dissolution of MPO: Elimination of unncecessary bureaucracy," 2009). He elaborated that the Government has given major authorities to Governor-Generals in provinces and that the President (Ahmadi-Nejad) believes that Governor Generals are 'Presidents' of provinces. The Governor-Generals' offices are responsible to ensure the coordination of all nationally funded policies and programmes and natural resources management and coordination across related sectors at provincial level. In this decentralization process that the state initiated, Governor-Generals became central authorities in financial, political and technical affairs in development of provinces and the leading decision-makers at the provincial level (Zagros project) (These issues will be discussed in Chapter VIII).

Deputy director of the MPO for four years, Alviri, in an interview stated dissolution of MPO was against the constitution ("Dissolution of MPO was irrational," 2009). He added that the MPO and the planning system in Iran were highly centralized and required reforms both in their mandates and administration systems, but that dissolution did not result in any positive change. The MPO was an institution for supervising expenditure and budgeting of the executive offices, including the President's 
office, with a system of checks and balances for the government's budgeting and expenditure (Alfoneh, 2007, p. 4). It was an 'important arm of the civil service' (Ansari, 2007, p. 92), responsible for preparation of development and strategic plans, and the annual budget, and was an independent authority that could monitor development projects, audit and evaluate them, evaluate efficiency and productivity of programmes carried out by government entities, and present transparent reports and information to the president and the parliament ("Dissolution of MPO, due to the Government's superficial and naive point of view," 2012). In brief, dissolution of MPO has disrupted any kind of auditing and control over budgeting of the government ("Dissolution of MPO was irrational," 2009) and hindered the government's downward accountability.

Alviri stated that replacing the MPO with two vice-president Offices ${ }^{143}$ subordinate to the president was in fact transferring all the decision-makings and economic planning from the Council of Ministers and parliament to Mr. Ahmadi-Nejad ("Dissolution of MPO was irrational," 2009; "Dissolution of MPO, due to the Government's superficial and naive point of view," 2012). The new structure gave the authority for planning and also approval and supervision of development projects and investments to the Governor-Generals' Offices with approval of the president. This change facilitated Ahmadi-Nejad's random project approvals in his provincial trips that were prepared on an ad hoc basis by Governor-Generals' offices and their commissioning of the projects to the Islamic Revolutionary Guard Corps (IRGC) and its affiliated bodies without interference of an independent regulatory office. Because of the number of

\footnotetext{
${ }^{143}$ Ahmadi-Nejad's administration passed a motion to establish two directorates, to carry out the responsibilities of MPO under direct supervision of the president: Department of Planning and Strategic Supervision (The Strategic Planning Directorate), and Department of Management and Human Capital Development. Department of Planning and Strategic Supervision is responsible for drafting the annual budget plan and also strategic planning and development, cultural and educational, economic, infrastructure, social, and security plans.
} 
contracts that Ahmadi-Nejad awarded to Khatam Al-Anbia, affiliated to IRGC, a newspaper, E'temad Melli, proclaimed that Khatam Al-Anbia was the winner of the presidential election in 2005 (Alfoneh, 2007, p. 4).

The MPO criticized the bidding processes and the quality of work of the Khatam Al-Anbia subsidiary of IRGC for a number of major projects in Iran and reported on their activities (see Sections 8.1.1.1 and 8.1.1.2). Instead of holding Khatam Al-Anbia accountable, Ahmadi-Nejad abolished the MPO that was an independent authority that could monitor development projects. He brought the planning process under the president's office control, however, the economic trend shows that it has become a domain of the Supreme Leader's affiliates, although highly ranked ministerial offices also have enjoyed their shares of exploitation of resources (see Sections 8.1.1.1 and 8.1.1.2). Alviri, explains since dissolution of MPO the government has lost millions of dollars, many projects are approved with higher prices, supervision of their implementation is not feasible, and evaluation of economic activities of the government is stopped ("Dissolution of MPO was irrational," 2009). The condition is so severe that even Islamic Republic Newspaper reports that the budget deficiency of the government is a consequence of the lack of coordination and planning among government entities that escalated after dissolution of MPO (“Management and planning: Today's necessity,” 2012).

Ahmadi-Nejad began his presidency with a sharp increase in oil prices but MPO was an impediment to his administration's use of money out of the approved budget and also to its influence on the formation of development plans. The first two development plans of the Islamic State identified agriculture as the main axis of development for the 
country ${ }^{144}$. The next three development plans clearly demonstrate the push policy of the 'neo-liberal economic policies of structural adjustment that prioritize industry as an axial sector' (Shakoori, 2006, p. 281). Since the second development plan (1995-1999) emphasis is on reforming the organization of ministries, state agencies and public companies with the aim of transferring their affairs to the private and cooperative sectors (Shokoohi, 1996, p. 41) (see Sections 8.1.1.1 and 8.1.1.2). Ahmadi-Nejad in summer 2006 announced that the Natural Resource sector should not be an obstacle for development (Nopor, 2013) and its first Deputy, Parviz Davoudi in a ceremony for celebration of outstanding Basij (para-militia affiliated to IRGC) members, in November 2007, states ("Lagging behind and growth during the Cold War and its aftermath," 2007):

In development of the five-year-development plans namahraman [outsiders] were involved...they tried to penetrate into [national plans] by introducing programmes that were based on humanism and secularism derived from American and Western policies but their stench disturbed every basij member and basij mentality stopped their infiltration.

He continues to say that environmental standards, controlling economic growth, and population control policies are Western measures to limit economic growth for countries like Iran and also to control the Muslim population in the world ("Lagging behind and growth during the Cold War and its aftermath," 2007).

\subsection{Conclusion}

This chapter explained how the Pahlavi Shahs and subsequently, the Iranian Islamic State, have interacted with the Turkmen tribes of the Iranian portion of the lower Atrek watershed immediately south of the border with Turkmenistan. It argues that the state policies and its modernization projects, coercive sedentarization of the Turkmen to

\footnotetext{
${ }^{144}$ It fails in achieving agricultural development due to the following impediments: budgets are dependent on oil prices, improper direct and indirect interferences by different sections of the state in favor of industrial sector and lack of peasants' participation in the planning process (Shakoori, 2006, p. 280).
} 
convert them to citizens and control them, water and rangeland nationalization regulations and policies, exclusionary land use and conversion policies, and 'fortress' conservation, enacted by the Shahs to control rural areas, have been largely continued for the same purpose by the Iranian Islamic State. Both the pre- and post-revolutionary states have a common ground of top-down development plans by powerful centralized states. Seizing and nationalizing the Turkmen's ancestral lands, and controlling land use and water in the Turkmen Sahra is in part an economic decision and in part an attempt to change norms as to what will be tolerated in the region under the name of development and nation-state building. Their dependence on land and water and their social system were considered points of autonomy/independence of the Turkmen from the central government. Breaking communal sharing of lands was a breakdown of social organization of tribes and consolidation of the state power in rural areas.

The Islamic State's territorial land, water and nature policies and practices facilitate land use change favoring those connected to the power structure of the State. A summary of the findings of the examination of those processes is given below:

(1) Institutional changes in land and water sector are in favor of politically wellconnected ideological institutions, Jihad Sazandegi, and the Governor-Generals' offices. (2) Land conversion is facilitated by land use change and transfer regulations. With the existing processes and structures in place, ties to political centers and entities of the Islamic State are crucial factors in gaining access to and control of land, water and other natural resource. (3) Macro and micro planning are problematic in Iran. Integrated Water Resource Management and Integrated River Basin Management have not been put into practice. Spatial planning has not happened, and with dissolution of the MPO the president and Governor-General's offices have the major control on development of rural 
areas, water allocation, and land use change and development plans are approved in ad hoc basis. (4) The DOE is not able to fulfill its policy setting mandate of environmental protection and enhancement and of mainstreaming environmental objectives into policies, programmes and sectoral practices of ministries and organizations. Practically it acts as an Environmental Guard coordinator. By law, major development projects are allowed even in protected areas, and EIA studies being inefficient and ineffective, cannot stop, improve, or mitigate unsustainable projects of government and government-related organizations. (5) The Government's performance in the last ten years, in planning, land, water and nature protection, indicates no political will for sustainable development. There is not acceptance (a belief-based commitment and need) for sustainable development and environmental considerations at high levels of the government. Economic growth and short term economic benefits have priority in the government's development plans. 


\section{CHAPTER VII- Current land uses and conflicts in the AUA region}

This chapter addresses: how the state's territorial approaches affect the AUA landscape; how the Tenglians pursue their livelihood strategies and access resources; and who loses and who benefits from the Islamic State's territorial policies in the AUA region.

The research set out to investigate the land tenure situation of the Tenglians through the development and administration of a questionnaire. The questionnaire was revised and the interviews for pertinent questions re-done three times, before it became apparent that land tenure in the AUA region was so complex that it could not be fully explored in the limited time available. Nonetheless, focus group discussion, structured interviews, and discussions during the participatory mapping exercise shed light on the complexity of land issues, land conversion patterns, conflicts and power relations in the AUA region.

Map 4.4, a modified, simplified and translated version of the participatory map (Annex D) and Map 7.1, a satellite image of the AUA region (Google Earth, 2013) show the details that are necessary for discussions of this chapter. Discussions and findings of Chapter V regarding livelihood strategies; obstacles; and needs of Tenglians are used to support and validate the arguments of this chapter. 


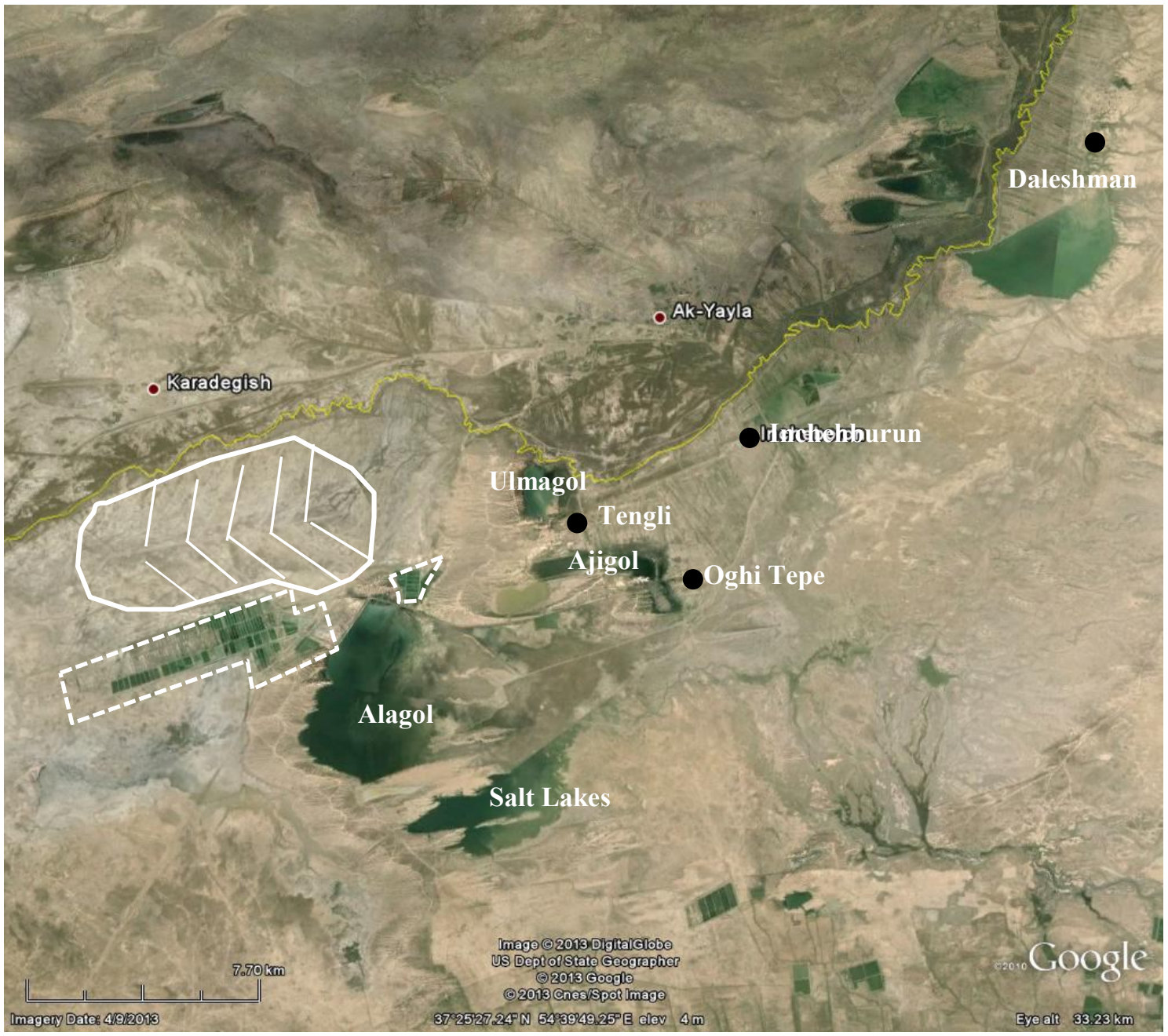

Map 7.1. The AUA region- satellite image (Google Earth, 2013)

Legend: Solid white lines: Tenglians' rangelands allocated to Agriculture (4000 hectares) White dotted lines: Tenglians' rangelands allocated to aquaculture (about 1500 hectares)

\subsection{Land use change in the AUA region}

Before getting into the particularities and specific issues of land use, tenure and access in the AUA region a review of its current land classification, based on arguments of the previous three chapters, is useful. In the AUA region, as of the end of 2008 (the time of field work conducted for this research) land conversion and land transfer involved rangelands that had been nationalized since 1962 (their expropriation by Reza shah as Crown Lands is explained in 6.1.3). All the lands along the Atrek in this region have been 
identified as rangelands, both pre- and post-revolution. One of the reasons for this identification stems from the Turkmen Sahra not being viewed and conceptualized as an integrated social and natural system, and thereby simplifying the complexity of (or homogenizing) the people-environment interactions, customary land use and the Turkmen social arrangement in the AUA region. This simplification commenced with the state building policies of the Pahlavi shahs, and was continued by the Islamic State (discussed in Chapter VI). The identification of the Atrekian's lands as all being 'rangeland' concealed the fact that those lands were used as both rangelands and agricultural lands by the Atrekinas as an integral part of their adaptive and resilient resource management system (discussed in Chapter IV). Parcels of lands for livestock grazing and farming used to change every one or two years. The legal and socio-economic implications of this simplification for the Atrekians started with nationalization of rangelands in the 1960s and continued with the Islamic State and its land and water policies.

Since the revolution, the law has stipulated that these rangelands can be transferred and used for dry farming and fish farming, but may not be irrigated. These lands can be used for other agricultural activities, such as fisheries without going through legal procedures for approval, but for irrigation or other developments only if approved by the provincial Natural Resources Office (see Section 6.2.1.2). A provincial coordinating committee for coordinated and environmentally sound and basin-wide, multi-sectoral discussions on land use change, water use and allocation decisions did not exist.

The DOE, by law, has no authority over water use from the AUA lakes, but is responsible for protecting the lakes' ecosystems. The provincial Governor-General's office and the Governor himself, have the final say in any decisions regarding water 
allocation in the region. The head of the Golestan Justice Department ("Government institutions are the main threats to natural resources," 2008) states that in dealing with environmental lawsuits regarding resource use and land conversion in the province the department is successful in controlling private environmental offenders, but a real challenge for the department is dealing with government institutions that are major threats to natural resources in the province and mange to get permits for large scale development projects and land conversion without consideration for their negative environmental impacts.

\subsubsection{Rangelands}

Every rangeland has an identity card issued by the Forest and Rangeland Organization identifying the tribes that have access right to those lands. This process started at the time of the shahs and is continued by the Islamic State.

An interviewee explained that the Turkmen favored having their rangelands registered in their names instead of the state being their stewards because they could not ensure the government would acknowledge their access to rangelands in difficult political periods. The locals have copies of two letters, written in 1977, from the Forest and Rangeland Organization and Shah's Crown Accounting Bureau (Edareh Hesabdari Ekhtesasi Saltanati), stating that, before inventory of the nationalized rangelands (Crown Lands that people had claims on) for the AUA region and before preparation of a rangeland management plan, the Atrekinas could buy part of those lands. According to these documents the Atrekians were offered the right to buy a total of 1200 hectares of rangelands. The Atrekians made the first payment to Mozayan, the Mohammad-Reza shah's representative. They received a receipt, which shows that the first instalment, of 
250,000 Rials (approximately $\$ 3600$ in 1977), for surveying of the lands, was paid in August 1977, more than a year before the revolution. The second installment, 50 Rials (approximately 0.7 cents in 1977) per hectare, was due after the land survey. After the revolution, this process stopped, because the Forest and Rangeland Organization no longer accepted the legitimacy of the Tenglian's claims to those lands. The lands along Atrek were again pronounced national rangelands and any claims would have had to go through new legal and bureaucratic procedures.

The government has been selling permits to the Atrekians to use the rangelands ever since. The post-revolutionary Ministry of Agricultural Jihad ${ }^{145}$, which is responsible for rangeland inventory and preparation of rangeland management plans, has not yet taken action in the region. The issue of land tenure and land use is still obscure and interviews during the field work indicate that rangeland use is based on random and general formulations and is not a comprehensive rangeland management plan. No new rangeland permits have been issued for the Tenglians since 1987. Feeding livestock is pivotal for Tenglians (see Section 5.3) and having access to natural rangelands is a crucial need, especially for the majority, who are in the lower economic layers of the village.

Rights to rangelands were a traditional tribal arrangement that included the nine tribes populating the four Atrekian villages (see Sections 4.3.2.2 and 4.3.2.3), but changed after the revolution (see Section 6.2.1.2). The government divided them by village without consulting the villagers and in a non-transparent process. Some rangelands which were customarily used by Tengli now belong to Oghi Tepe and some of the Oghi Tepe rangelands have been removed completely. In 2008, when local people

\footnotetext{
${ }^{145}$ A new ministry established by merging Ministry of Agriculture and Jihad Sazandegi (see section 6.2.1.1).
} 
realized the government had divided the rangelands without consulting the people and the village council, they took legal actions to correct these borders. A few interviewees believed the division by village was done to cause conflict between the villages and also to make it easier for the state to limit the Turkmen's access to these rangelands and to convert them to other uses that always favored outsiders. One interviewee expressed displeasure by commenting that 'Our rangelands are given to outsiders mostly for fish farms and the little water that we have is going to them.'

Tenglians identified 'expensive fodder' as the third greatest problem they face in access to resources and pursuing their livelihood strategies (see Section 5.3). Feeding livestock is a serious concern for the Tenglians, so important that one Tenglian in an interview said feeding livestock is as important as feeding themselves. Fodder cost is more critical for lower wealth categories. An interviewee mentions although recently they have fewer livestock, during the months when they do not have access to natural rangelands, they need to share their food (mostly bread) with their livestock. Data on debt in the village supports these statements (see Section 5.4). The majority of the Tenglians are in debt and their first two main reasons for borrowing money are for food (47\%) and livestock fodder (35\%). Tenglians' major source of credit is their relatives. They cannot obtain loans from banks and are not able to pay back the money with the interest. In these circumstances having access to natural rangelands is economically essential to keep their livestock.

Atrekian villagers frustrated by having lost rangelands are showing increased resistance to land conversions that result in losing their rangelands to outsiders. Oghi Tepe and other Atrekian villagers encountered and resisted the Revolutionary Guards in 2005, when some people from Gorgan with a formal permit from the Golestan Natural 
Resources Office, escorted by the Islamic Revolutionary Guard Corps, entered the Oghi Tepe rangelands with the intent to fence 50 hectares of land for a fish farm ("Villagers in Okhi Tepe blocked the consturction of an ab-band," 2005). The Islamic Revolutionary Guard Corps fired their weapons to control the crowd, arrested 30 people from Oghi Tepe, Tengli and Inchehburun, and sentenced them to jail, lashing, and fines (Turkmen Territories Continue To Be Seized, n.d. $)^{146}$.

\subsubsection{Agricultural lands}

After the revolution, most of the Tenglian's lands that had been seized illegally and then 'nationalized' by Pahlavi Shahs were pronounced to be rangelands, even though the Tenglians had used them for centuries for the mixed purpose of grazing and agriculture in a traditional system of integrated land and water management. Tenglians, after they abandoned their customary land and water management in 1984, began to make formal claims for agricultural lands. Some obtained a title deed, but no titles have been registered to Tenglians since 1987. Some of the Tenglians, who registered claims to parcels of land, had hoped that they would receive financial assistance, bank credits, and water allowances to support farming. There have been many uncertainties involved in that process that made Tenglians reluctant to make claims on land. These include: not being sure about the exact whereabouts of the land for which they could make a successful claim; and families (fathers and brothers), who are entitled to some agricultural lands around Tengli, not knowing how much would be allocated to each individual if they tried to legally divide the claimed land among themselves. A few local interviewees pointed out that they are usually reluctant to divide lands because precedent indicates that it is

\footnotetext{
${ }^{146}$ An activist website was accessed on November 19, 2009. It is no longer accessible on-line but the hard copy is available.
} 
costly and the amount of land that each will receive is very small, on average one to three hectares, and is not worth the legal fees, lengthy procedures and bureaucracy. Gaining water rights for irrigation is also a major challenge. Another complication is that, if their land is not cultivated for five consecutive years, they legally lose their rights to that land. The vicious circle of not having water, and not being able to farm in five consecutive years, therefore, losing their land entitlements, has made some of them landless.

Tenglians, from all wealth categories, are willing to engage in agriculture and agriculturally related activities (as owners or laborers) as their major livelihood strategy. They still hope that if the government will give them water they will be able to cultivate their lands as a group and through sharecropping (see Section 5.2). When outsiders come to the region to buy land for a fish farm or other agriculturally related activities, some villagers become motivated to divide their lands and sell some to obtain cash. It is usually easier for outsiders to obtain title to land because they have more money and are more familiar with the bureaucracy. In many cases, the outsiders pay for dividing of the land because for them the cost of land is negligible compared to the value of a fish farm or an agricultural project; the cost of obtaining water rights is reasonable; and access to credits from banks are facilitated by the government. Despite the poor deal for the sellers, some interviewees said that selling those small pieces of land for the little money they receive is better than nothing.

A high ranking official in the Conservation and Land Affairs Department of the provincial Natural Resources Organization in Gorgan was asked about the Turkmen's claims to agricultural lands classified as rangelands in the AUA region. He responded that lands around Tengli and AUA area were rangelands, even at the time of the Shah, and that those lands had been nationalized. He claimed that the Turkmen lie about their 
agricultural past in that area. Even while acknowledging that they had been involved in scattered dry farming, he added that: they became engaged in farming after the revolution only because it was profitable, and even though village council approves the villagers claim, the Natural Resource Office does not accept the village councillors' signatures because the Turkmen are supportive of each other. According to law, the Village Councils are essential contributors in shaping rural areas, but the empirical data indicate that they have little power and influence in determining what happens in the AUA region. Finally, because the documents Tenglians show pertaining to their land tenure do not have coordinates, they do not have legal proof of ownership.

In 1987, about 500 people from four Atrekian villages, Tengli, Oghi Tepe, Daleshman and Inchehburun, approached land authorities with the claim that about 4000 hectares that were classified as rangeland were in reality their traditional ancestral lands used for farming and grazing. They demanded a land use classification change so they could receive water for those lands, which would allow them to continue farming and provide jobs for their families. The request was rejected. The Land Affairs Department stated that the lands are classified as rangelands so their claim is invalid. After years of complaints to the Land Affairs Department, the Land Transfer Commission verbally agreed to transfer the lands in question to the Tenglian claimants for agriculture, but only under the supervision of Jihad Sazandegi. The Fars News Agency confirmed the above and reported that after preliminary study by consulting agencies, a development plan for about 4000 hectares of lands, near Tengli, to restore the lands and increase agricultural efficiency in the lower Atrek basin has been initiated, and the contracting organization is Khatam Al-Anbia ("Land restoration and development in Tengli," 2006). Its current activities are reported as: constructing irrigation and drainage networks, securing water, 
improving soil quality and constructing infrastructure. It adds that the development plan will take five years to complete and then the lands will be transferred to local people and Isargaran (war veterans) for agriculture. Fars News reported rights to water from Alagol and Ulmagol for these lands were approved by the Golestan Regional Water Company ("Land restoration and development in Tengli," 2006). The company later launched the Daneshmand Dam project with a 100 milliard Rials budget (approximately 10 million dollars in 2006) to secure more water for the 4000 hectares ("Agricultural development in northeast Iran: Launching Daneshmand Dam,” 2012). Restoration and development of these lands became the Ministry of Agricultural Jihad's national project ("21 National projects approved by the Minister of Agricultural Jihad, Gobad Kavoos," 2010) with a total budget of 180 milliard Rials (approximately 180 million dollars in 2006) ("Land restoration and development in Tengli,”2006).

Jihad Sazandegi had the responsibility for digging ditches and channels for delivering the irrigation water and the people were promised that the land would be transferred to them when the irrigation work was completed. The Tenglians never received a written commitment for the land transfer from the Land Affairs Department. In 2004, the locals were informed that the land in question belonged to Bonyad Alavi (see Section 8.1.1.2). Bonyad Alavi allocated it to the Islamic Revolutionary Guard Corp and it was given to 20-30 people from the Basij (three of them from Tengli and the others were non-Turkmen).

Regarding disputes about these lands, a DOE authority in Gorgan explained that in December 2005 they received a request from the Ministry of Agricultural Jihad for a land use change of 3800 hectares of the lands in the AUA region, near Tengli, under the name of the 'Tengli Irrigation and Drainage Network Project'. In January 2006, the DOE 
provincial office did not approve the project and informed the DOE central office in Tehran about the decision. In a letter, in April 2006, the DOE in Tehran reconfirmed the decision that was taken by the DOE Gorgan and rejected the project, on the grounds of its threat to the habitats of local terrestrial species such as the Doraj (Francolin) (Francolinus francolinusand) and the Turkmen fox (Vulpes vulpes), and also because of its potential negative impacts on the Alagol, Sofikem No Hunting Zone, and other sensitive ecosystems of the AUA region. The DOE Gorgan repeated its disapproval of the project in many meetings with the Governor-General, the Provincial office of Department of Natural Resources and Watershed in 2005 and 2006. Subsequently, the DOE Gorgan reported to the DOE Tehran that they were under pressure to approve the project. In May 2005, the DOE Gorgan requested that the Land Affairs Department send them the coordinates of the land in question and a complete map of the project. They also enquired if the land had been transferred to Khatam Al-Anbia. The Land Affairs Department, in August 2006, denied any land transfer in the region to Khatam Al-Anbia. However, the DOE Gorgan has a copy of the letter from the Regional Water Organization in Gorgan, dated November 9, 2000, that approved the securing of water for the project from Alagol's southern outlet. The DOE provincial office believes that the Land Affairs Department had transferred the 3800 hectares of land that was for the 'Tengli Irrigation and Drainage Network Project' to Khatam Al-Anbia years before involving the DOE in 2005. The government's agricultural plans for the region go back to the mid-1980s.

A copy of a project document prepared by an engineering company, Mahab Ghods ${ }^{147}$ shows that the company, in 1987 , was assigned to prepare a proposal for 750 hectares of fish farming and 1800 hectares of active agricultural lands for 'Development

\footnotetext{
${ }^{147}$ Mahab Ghods Consulting Engineering Company is a subsidiary of Ministry of Energy.
} 
and water utilization from Alagol lakes'. The next consultancy projects assigned to Mahab Ghods, in 1992 and 1996, were to study development of an irrigation network for about 3000 hectares of new agricultural lands and fish farms in the AUA region, and optimum use of Alagol lakes (Mahab Ghods Consultancy, 1997) ${ }^{148}$.

Between 1987, when the Tenglians started taking legal actions to re-gain access to the lands in question, and 2000, when the Golestan Regional Water Company approved water for the 'Tengli Irrigation and Drainage Network Project', the Department of Natural Resource and Watershed had transferred the lands to Bonyad Alavi or to Khatam Al-Anbia. An academic explained 'nothing in these transactions is transparent and the terms of this transfer are not clear. The lands could have been sold to or leased by Khatam Al-Anbia by Bonyad Alavi or by Natural Resource Organization'. Tenglians being double crossed, in favor of powerful government agencies and outsiders, has caused a major conflict in the region.

\subsubsection{Fish farms}

Fishing was a part of the traditional seasonal activities of the Tenglians and other Atrekinas but fish farming has only recently been introduced. The first and biggest fish farm in the AUA region, Abgasht, was established in 1988 (Mahab Ghods Consultancy, 1997) and most of the land involved was Tengli rangelands. The farm was registered to the Islamic Encyclopedia, with bank credit secured from government banks. In the initial negotiations, the developers stressed their intention to establish the fish farm to create jobs for the people of Tengli. As a result, Tenglians were positive about letting this farm be established on their lands. There was no confrontation or even a request for

\footnotetext{
${ }^{148}$ Two reports 'Tengli Irrigation and Drainage Network Project', and 'Optimum use of Alagol Lakes' were completed in 1997 and 1998 respectively.
} 
compensation. After construction one or two Turkmen were hired, and the rest of the labor was from Gorgan. After eight years the farm was sold to the Municipality of Tehran, which four years later sold it to a businessman who was a member of the Islamic Revolutionary Guard Corps from Gorgan. In mid-2008, the farm was sold again to another non-Turkmen. The fish farm is not cost effective and not all of its 500 hectares are actively in use. However it always has priority in getting water from the Alagol.

A DOE authority in Gorgan explained that the DOE did not approve the Abgasht fish farm and that in 1994, it was illegally drawing water from Ajigol. He explained that at first Abgasht claimed they would use the runoff water and overflow from the Alagol, but against what they claimed, they used their proximity to Alagol to extract water from its southern outlet. In 1999, the DOE took legal action against Abgasht for its illegal abstraction of water from the Alagol and for endangering the endemic fish species of the lake. The DOE Gorgan explained that Abgasht claimed that the Alagol did not have any native fish due to drastic changes in its ecosystem as a result of water channels and the introduction of exotic fish species in the lake, therefore, the DOE had no justifiable objection for the water exploitation of Alagol. Ultimately the DOE could not stop Abgasht. The DOE Gorgan added that with the absence of spatial planning and land use planning of the region, environmental regulations are not strong enough to stop unsustainable land uses.

Similar patterns of land conversion have continued in the AUA region. In 2004, another 1000 hectares close to the Alagol were allocated to about 20 people from Gorgan, Gonbad, Mazandaran and Tehran for a fish farm with a water permit from the Alagol. An interviewee from the provincial Fisheries Company, Ministry of Agricultural Jihad, stated that about 1600 hectares of land in the Tengli area had been converted to fish farms (not 
fully active) and water for all of them is secured from Alagol. A DOE provincial official who was interviewed stated that despite its persistence in not accepting any land use change, and in rejecting almost every project that requires water from the lakes, the lack of legal support and comprehensive EIA guidelines ultimately obliges DOE to grant approval. Fish farms, of more than 1 hectare require EIA only if they are less than $3 \mathrm{~km}$ from the Sea coast and in every other region if they are larger than 400 hectares ("Amendments to Articles 105 and 71 of the Thrid and Fourth Development Plan," 2009). An academic knowledgeable about the AUA regions affirms that fish farms in that climatic condition with high evapotranspiration, and salty soil, are not recommended. However DOE has no objection to fish farms if they are not in lands under its authority (Ramsar Sites, Protected Areas, Wildlife Refuge Areas, and National Parks).

An interviewee said that Tenglians do not apply for fish farm permit because it is a difficult and costly process. It is time consuming, and requires money, knowledge of the administrative system, and understanding of Farsi. The only Tenglian who has a fish farm (a well-off livestock breeder) had the means to address those bureaucratic difficulties. Even though he got a permit, his farm is not in the best location and he is not allowed to get water from the Alagol. The lands close to the Alagol are prime locations for fish farms, but it is not easy to get a permit for those lands without having ties to Bonyads ${ }^{149}$.

In another example, in 2002, a few hundred people from Tengli, Inchehburun, Daleshman, and Oghi Tepe, despite the constraints, established the Inchehburun Fish Cooperation and obtained a fish farm permit. They rebuilt the dike that the nine tribes had constructed manually in the 1960s, near Inchehburun and Daleshman, and constructed the

\footnotetext{
${ }^{149}$ After the revolution many semi-governmental foundations (Bonyads) were established. These foundations are involved in every economic and military aspect of the country. Foundations will be discussed in Chapter VIII.
} 
fish farm. The Golestan Water Company, who had guaranteed water for the fish farm through a channel from the Atrek, did not provide this water. The channel and the impoundment area remained dry and the cooperation was terminated after a few years.

\subsubsection{Housing}

Tenglians ranked 'lack of land for building new houses', as fourth among the impediments to carrying out their daily lives and livelihood strategies (see Section 5.3). Insufficient housing affects the quality of lives of the Tenglians in all the Wealth Categories. Currently married sons stay with their parents and there are households in which three generations live together.

The Tenglians are trying to purchase a parcel of land for building new houses for the village. The land is directly across the Gorgan-Gonbad road from the village, and close to the Ajigol. They require permits from the Department of Environment, the Ministry of Road and Transportation and Bonyad Maskan (Foundation for Housing). The Department of Environment objects because they believe the housing will impact the Ajigol. Almost all the projects which are government sponsored or proposed by people affiliated to the government are being approved in the AUA region, despite the DOE's objection. The Tenglian's housing construction project is the only one that DOE could stop. The Ministry of Road and Transportation is objecting that, because the land is across the Gorgan-Gonbad road from the current residential part of Tengli, car accidents may increase. This objection is despite the fact that the village school is located on the same side of the road as the proposed housing construction project, and elementary school children safely cross the same road every day. Despite this objection, Bonyad Masken 
has approved the project, but the Bakhshdar (The County's Governor) has not signed the permit, as of my last contact with the village, in January 2009.

\subsection{Water}

Water is the most limiting and most valuable natural resource in the AUA area. The lakes and land users need the Atrek's water. Land users from the local people to enterprises, are almost all non-Turkmen, and are in constant competition for the water surplus to the lakes' requirements, water that the lakes are supposed to receive from the Atrek upstream. The survey data reveal that the Tenglians consider that 'lack of water for agriculture' is the most significant obstacle they face in accessing resources and pursuing their livelihoods (see Section 5.3).

Water is an integral part of the Turkmen landscape and a major actor in shaping the AUA region and people-environment interactions. In 1984, five years after the revolution, the nine Atrekian tribes, carried out the last 'tribal land' lottery (see Section 4.3.2), after which each tribe divided their lands among their member households. The Turkmens' traditional open-access land tenure system experienced difficulty after their coercive sedentarization and the nationalization of land and water during the Pahlavi era, but the Tenglians were still able to practice their customary integrated farming and rangeland management because they still had access to their water resources. The Atrek was still flowing and the Tenglians could use its flood water to enhance the fertility of the soil for agriculture and the quality of rangelands on a yearly basis, and to manage water for irrigation of agricultural land and rice paddies. The Islamic State's political strategy and its land, water and nature policies compelled the Atrekians to completely abandon 
their customary system and loosen their connection to land and natural resources by limiting their livelihood strategies related to land, water and nature (see Section 5.2).

The Atrek's flood waters used to reach the Caspian Sea and fish easily entered the lakes. Now, water is no longer abundant and the Atrek no longer reaches the sea. The lakes once had enough water and some rangelands were flooded by water in wet season, which was essential for their enrichment. From the late-1990s, the AUA region has been drastically drier. In the past, there have been dry years with no rain but the land still was flooded by the Atrek's upstream water. A season of drought was not considered a natural disaster by Atrekians. One interviewee explained 'drought is not a bad thing because our lands can rest'. Another interviewee said that the main reason for the Atrek not flooding any longer is because the government does not stop deep wells and use of big capacity pumps all along the Atrek, starting from Qochan up to Dashliburun. He said deep wells are drying up the springs all along the Atrek.

Three provinces share the Atrek basin. The Khorasan Razavi is located in the upper basin (less than 7\%), Khorasan Shomali (North Khorasan) in the middle basin (61\%) and Golestan in the lower reaches (about 31\%) of the Atrek basin ("A seminar to study the Atrek basin," 2011). Currently, there are seven major dams ${ }^{150}$ on the Atrek and studies are being undertaken by the Ministry of Energy for construction of another five ("Dams in Iran: Subwatersheds," 2013).

\footnotetext{
${ }^{150}$ Six dams are in the Golestan's neighboring provinces (North Khorasan and Khorasan Razavi) and Karand Dam, is in Golestan. Iran water Management Company identifies two ab-bands in Golestan: Alagol, and Ulmagol and a small dam, Daneshmand ("Dams in Iran: Subwatersheds," 2013).
} 
In 2009, the Golestan Governor General's Office announced that a land use plan for Golestan is still under development ${ }^{151}$ ("Foundation of development in Golestan: Land use planning," 2009). The Ministry of Energy (2010) reported that its Water Resource Research Institute is finalizing comprehensive studies of the Atrek River Basin for the purpose of developing a solution for the Atrek's water allocation among the three provinces ("Agreement on integrated management and allocation of water for the Atrek basin,” 2010). The Iranian Students' News Agency ${ }^{152}$ reports that a board consisting of representatives of the President's office, the Governor Generals of Khorasan and Golestan and the Regional Water Companies of the two provinces met in April 2011 and discussed water management plans, drought conditions, and water allocation between the two provinces ("Uncertainty in water allocation in the Atrek basin forecloses investments in North Khorasan,” 2011). The board will report to the President.

Amir Taheri argues that 'the IRI [Islamic Republic of Iran] changed the course of the Atrek border river, turning large chunks of Turkmen territory [Turkmensitan] into desert' but Turkmenistan due to political concerns, has not taken actions against Iran (Taheri, 2007, p. 399). Bazar Khabar reports that the Golestan Water company has prepared a report on the future impacts of Shirin Darreh dam on the Atrek, north of Bojnurd, on the Sumbar branch in North Khorasan Province built in 2005, and submitted a copy to the Islamic Republic of Iran Broadcasting in Golestan province ("Impacts of dams on farmers' lives in Golestan," 2011). The report indicates that 'a consequence of the new dam will be reduction of water delivery to Turkmenistan which will create a

\footnotetext{
${ }^{151}$ Preparation for the plan started in 2007 and its Terms of Reference approved in 2009 ("The Terms of Reference for Golestan land use plan," 2009).

${ }^{152}$ This agency is affiliated to Educational Jihad. Educational Jihad established in August 1980 by the Cultural Revolutionary Council, created by Khomeini after revolution, which closed down universities to Islamisize the education system.
} 
challenging situation with the neighboring country' ('Impacts of dams on farmers' lives in Golestan," 2011). The Golestan Regional Water Company indicates on its website that the Atrek Basin does not have enough surface water for more agricultural development, and that under the current circumstances no surface or underground water is available for development of new industrial units and the only source of water for industries can be through treatment of Caspian Sea water (Golestan Regional Water Company, 2010).

The head of the Fishery Organization of Golestan, in the same report by Bazar Khabar ("Impacts of dams on farmers' lives in Golestan," 2011), notes that negotiations between the Governor-General's office and the Regional Water Company of the two provinces of Golestan and North Khorasan were not fruitful and that the water allocated to Golestan province was being reduced to one third of what it was before the construction of the dam. As a result, all the land users (agriculture and fish farms) along the Atrek have seriously suffered and wetlands along the Atrek, including Alagol, were drying out. Raja News ${ }^{153}$ reports that the AUA and Gomishan wetlands along the Atrek are drying out due to changes in the water regime of the Atrek, numerous dams on the river, and deep wells along the Atrek in Khorasan provinces ("Three international wetlands in Golestan are dried out," 2011). In the same report, the Deputy to the Golestan's Governor-General notes that the Regional Water Company of Khorasan, though agreeing with allocating the water necessary for the AUA lakes, released water only a few times, did not respect the agreement and that the amount of water they randomly released was not sufficient for the survival of the wetlands ("Three international wetlands in Golestan are dried out," 2011). Raja News considers the DOE to be

\footnotetext{
${ }^{153}$ Raja News is a conservative Iranian news agency supporting the Supreme Leader (Federal Research Division, 2012, p. 13).
} 
responsible for the lack of success in obtaining enough water from the Atrek to support the downstream wetlands. The Khorasan Newspaper reports that Golestan's General Director of the Ministry of Agricultural Jihad provincial office is concerned about negative impacts on inland fish farms and agriculture in the Atrek basin in Golestan due to a decrease in water delivery by the upper basin provinces and he is discussing the issue with the Governor General's office and the representative of 'Vali-e Faghih' in Golestan (Bahramizadeh, 2011). The same report indicates that the head of Golestan Fisheries Company confirms that a shortage of water in Alagol $a b$-band has caused an estimated 50 milliard Rials (approximately 20 million U.S. Dollars in 2011) loss for investors in the AUA region and contributed to unemployment in the region (Bahramizadeh, 2011). Golestan Members of Parliament have requested collaboration from the Khorasan Members of Parliament in taking the necessary actions to provide water to inland fish farms in the Atrek basin (Bahramizadeh, 2011).

Bahrami filed reports in the Khorasan Newspaper about the Atrek drying up. She had driven along the Atrek from the east in Khorasan to the west in Golestan and ended her report at Alagol (Bahrami, 2010). Her visit started with Ghazanghayeh, north-east of Maraveh Tepe, and continued south-west, to another 19 Turkmen villages that are the closest human settlements along the Atrek before reaching Dashliburun. She reported that the Atrek was completely dry and almost all the agriculture in those villages were destroyed except a few that could pump water from deep wells. She saw some workers extracting gravel from the Atrek's dry bed, and reported that the Shirin Darreh dam has had the major impact in drying out the Atrek. Dashliburun is where the Atrek divides into two main branches one towards Turkmenistan and one towards Iran. A guard for 15 years at the Dashliburun station stated that until 2007 'some water was running in the Atrek, but 
it's been a few years that not a drop is flowing and the river is dried out' (Bahrami, 2010). She further reported that the dryness of the Atrek continues from Dashliburun to Inchehburun and all the way to the AUA wetlands. The drying out of the Atrek has had an immediate impact in its lower reach and that the Alagol and Ulmagol wetland have shrunk in size. She highlights that shortage of water is not only obvious in the drying out of the Atrek but also that the villages along the Atrek are suffering from water shortages so they budget their drinking water. For example, Dashliburun has water for two days and then Inchehburun can have water for two days. Authorities in Dashliburun repeatedly have shown concern about drinking water for Dashliburun. Providing drinking water, one of the main problems this district faces, is encountering a lack of funds which makes this goal impossible to achieve, and a short term goal is to increase the frequency of water brought in by tankers to biweekly ("Drinking water for 17 villages of Dashliburun is provided by tankers," 2005; "Drinking water is one of the main problems of Dashliburun district," 2009; "High cost of providing driking water to Dashliburun," 2010) ${ }^{154}$. Bahrami identified the weak link causing the Atrek's degradation is water mismanagement by the Khorasan Regional Water Company (Bahrami, 2010). She tried to get an interview with that office but after eleven days the Company sent the Khorasan Newspaper a letter indicating that the Khorasan Regional Water Company is not allowed to do any interviews (Bahrami, 2010). What this political rivalry on water among the Governor Generals' offices, the Regional Water Companies, the Ministry of Agricultural Jihad and the water and land sectors of the government means for the AUA wetlands and the Tenglians will be discussed below.

\footnotetext{
${ }^{154}$ The second reference is no longer accessible on-line but the hard copy is available.
} 
Atrekians have no water rights for agriculture and their last chance to resume farming in their ancestral lands were rendered in vain when 4000 hectares of their lands transferred to Sepah (Islamic Revolutionary Guard Corps) and its affiliates (see Section 7.1.2). Acquiring fish farm permit is not feasible for Atrekians and when, despite constraints, a permit was acquired and a fish farm cooperation was established, the Golestan Water Company did not allocate water to the Atrekians' business (see Section 7.1.3). They even have difficulty meeting their basic needs for drinking and domestic use. Due to frequent water shut offs, the Tenglians rely on their traditional water collection system that is collecting rain water from the roof of their houses through eves troughs into tanks on the ground.

The government has facilitated development projects in the AUA region. All the approved industrial plans in the Atrek's riparian zone are $100 \%$ tax free for ten years and all the agricultural plans (e.g. mushroom culture, beekeeping, silk worm farms, fish farms, and poultry farms) are in general completely tax free. The interest rate for repaying loans is as low as 3\% after ten years (Soltanian, 2009). Access to these concessions requires connection to powerful institutions that is usually feasible only for Bonyads and those connected to them (see Section 8.1.1.2).

Currently, the main water users in the AUA region are the Islamic Revolutionary Guard Corps (IRGC), fish farm owners and the wetlands. Water for the 4000 hectares is allocated from the Alagol and Ulmagol ("Land restoration and development in Tengli," 2006) and the Daneshmand Dam (“Agricultural development in northeast Iran: Launching Daneshmand Dam," 2012) and the fish farms receive water from the Alagol ("Fish production in Alagol region after three years of drought," 2012). The local people do not have access to that water either for fish farms or for agriculture. Fish farms require large 
amounts of water because the saline soil first needs to be washed and the evapotranspiration rate is very high in the AUA region. Power plays between Governor Generals' offices for the Atrek's water share were focused on inland fish farms owned by non-locals; they were not an attempt to create job opportunities for the Atrekians. The only Atrekian fish farm (the Inchehburun Cooperative Fish Farm, established in 2002) failed because the Water Company did not allocate water. The only private fish farm owned by a Tenglian, 25-30 hectares, located near Alagol is only allowed to get water from the Atrek channel and the Ajigol. The water from Ajigol is of lower quality than that from Alagol and water from the Atrek is very limited.

The Department of Environment, in speaking for the AUA wetlands, is struggling to ensure sufficient environmental water required for their survival, since they have second priority after the fish farms in the area. The standard depth for water in Alagol, set by the DOE and agreed by water authorities, is $1.68 \mathrm{~m}$, but on a visit to the lake in December 2008 water depth was less than $30 \mathrm{~cm}$; regardless, Abgasht was still extracting water. Interviewees confirmed that Abgasht and other fish farms have priority in getting water even at the expense of the lakes.

An official from the Golestan Regional Water Company, when asked about their priority for water allocation in the AUA region and particularly for water from the Alagol explained that:

The Ostandar [Governor-General] and Ministry of Interior have the main authority for making decisions on land use and water allocation in that area. For now industrial development has priority over agriculture so we do not agree on allocating water for any new agricultural projects.

When questioned as to how they can provide water to industrial units when there is not enough water for fish farms, he asserted that the Alagol and the Atrek can provide 
enough water for the fish farms and current agricultural lands. When told that, on a recent visit, the water level in the Alagol was below the water depth limit agreed by the DOE while Abgasht was extracting water, he replied that it was probably a one-time mistake. His further response to the problems that DOE encountered in securing enough water for the AUA wetlands was: the water authorities have a river basin management plan for the Atrek and the DOE has promised enough water for the lakes from the Atrek in the future. When asked if it was possible to see the plan, he replied that it was still being prepared. In response to the question 'does this river basin management plan take measures to stop illegal wells along the Atrek and control water use in upstream part of the basin', he asked if local people had provided that information. When told that some experts believe that is the case, he responded that,

The Atrek is a transboundary river and policies on the upstream Atrek are only the government's business and you should ask questions only about the AUA wetlands and their ecosystems.

When it was further explained that the AUA wetlands and ecosystems are part of the Atrek River Basin and that the current research was trying to understand how water will be allocated to wetlands and other land uses in the region, he discontinued the interview.

Water is highly political in the region and water allocation plans are neither complete nor transparent. What is clear is that water has become a means for the government to control Atrekians' lives and livelihoods. Without water, they cannot continue farming and will ultimately lose their access to agricultural land. Amir Taheri (Taheri, 2008) reports that the Iranian government imposed central control on water distribution from the Atrek, allocating its major flow of water to state-owned farms and establishments where few Turkmen work and leaving Turkmen farmers who are mostly 
small land-holders without water. Water for Tenglians is perceived to create job opportunities either in irrigation farming or fish farms but, despite all the actions they have taken, they have failed to create job for themselves.

Although the DOE has disagreed with almost all the land use changes and land conversions that have occurred, it has lost almost all the political power struggles over water and land in the region. The DOE's function has been limited to providing approval stamps on land use change and transfer permits and to being a nagging voice in meetings with other government entities. The DOE Gorgan is completely aware of water demands in the AUA region that put the lakes under stress. In an interview, the DOE Gorgan authorities explained that they are in regular meetings with the Regional Water Company, and the Land Affairs Department to secure water for the lakes. In those meetings, the DOE representatives do not discuss land use and spatial planning and water basin management plans for the region that they believe are the keys to ending the unruly land conversions and their negative impacts on the AUA landscape. Their negotiations are mainly focused on the amount of water they need to ensure that the lakes survive as habitats for waterbirds. This limited participation of the DOE is the result of the competing interests of powerful actors in the area and a lack of political will for horizontal multi-sectoral cooperation. A DOE interviewee stated that the DOE has no other option but to approve the projects that potentially have negative impacts on sensitive ecosystems of the area because the DOE does not have the necessary supporting law, required regulations, comprehensive Environmental Impact Assessment guidelines, expertise, and political power to stop the negative land conversions. 


\subsection{Fishing and hunting}

In 1975, the AUA lakes were designated as Wetlands of International Importance under the Ramsar Convention. Initially, this did not affect local people's lives and hardly any locals knew about the designation. After the revolution, in the early-1980s, local people learned of the lakes' protected status when they were advised that their traditional fishing and hunting were illegal if they did not register with the DOE and get a permit. Since that time, interaction between the Turkmen and the DOE has not been smooth. Fishing permits which restrict local people to fishing with rods and hunting permits are sold annually by the DOE. The prices are set by the central DOE office in Tehran, without consulting the provincial offices, and the cost increases by approximately $20 \%$ every year. Provincial DOE offices can issue unlimited number of fishing permits but the number of hunting permits is limited and is decided by the central DOE office.

Armed and intimidating Environmental Guards are always present in the AUA area to enforce the hunting and fishing regulations, and they can arrest 'poachers'. A nonTurkmen fisherman who frequently visits the area and is involved in the organization of a fishing NGO described his fishing trips as very satisfactory regarding fish availability and helpfulness of the DOE Environmental Guards. He stated that:

Non-Turkmen fishing on the lakes are treated appropriately and the DOE guards have tolerance if they didn't abide with regulations but the Turkmen fishers especially those from the villages around the lakes are ill-treated and I witnessed them being beaten by mohitbanan [DOE Environment Guards]....It is like they [the government] give them [the local Turkmen] permission to live.

In 2006, when an Environmental Guard had a disagreement with a Tenglian, he filed a false report accusing the Tenglian of plowing a piece of land that is known to be Francolin habitat. The Tenglian's defense, that it was not plowing season at the time, was rejected by the court and he was sentenced to 100 lashes and payment of a fine. 
A retired DOE employee stated that in the 1970s, the DOE had realized participation of locals was important for the successful protection of the AUA territory, and that Tenglian men had been approached many times, since the designation of the wetlands as a Ramsar Site more than three decades ago, with regard to serving as Environmental Guards. He explained that, in order to convince the Tenglians, the DOE had offered tempting salaries and bonuses that exceeded their average annual income, and moreover it was a secure income. He explained that: 'When we assumed that they were convinced and that we would see them in the DOE office the next day to do the paper work, they never showed up'. His understanding was that they did not want to participate in policing their fellow Turkmen, which they understood as the DOE's role in the area. This perception of the DOE, as an oppressive organization and a policing tool to control the Turkmen and seize their livelihood's resources, is still the dominant perception of the Tenglians. An interviewee in Tengli, a fisherman, asked me:

Do those foreign organizations [the Ramsar Convention] that do not let us fish in our lakes suggest any other way of feeding our families... I indeed want to know and want to listen to them. Maybe they suggest something that we can use to improve our situation.

When I told him that they usually suggest ecotourism, he said 'then they know nothing about us.' The Advisory Mission Report on measures for wise use of wetlands highlight that 'The DOE has worked with the local Municipality to develop a lowintensity tourism/recreation facility at Ulmagol' and claims that 'this facility is providing important alternative livelihood for the local communities' (Moser, 2009, p. 8). Tourism and recreation is a generic/blueprint answer to wise use of wetlands and appears in every guideline. The Ramsar Advisory Report made judgments and recommendations that disregarded the real life of local people (see Sections 7.4. and 9.3.4). 
Tenglians who can afford a gun and pay for the permit engage in subsistence hunting, but this is not a major source of income. A local interviewee stated: 'Hunting brings happiness to the village and is a life style that Tenglians are proud of'. The Ramsar Secretariat, in its Advisory Mission Report, describes the threats prior to inclusion of the AUA site in the Montreux Record, under the headline 'hunting' and explains that Ulmagol and Ajigol are accessible by road and lie close to "two small villages, 'Tengoli' (now 100 families) and 'Ochitappeh' (now 200 families) ${ }^{155}$ (Moser, 2009 , p. 5). The report adds that prior to 1993 , those two lakes were highly disturbed by hunters, which caused both disturbance and over-harvesting, but the Alagol, because it is less accessible, had lower hunting pressure. The wording of the report implies that local people from Tengli and Oghi Tepe were responsible for the disturbance and overharvesting. However, the cause of this high disturbance is not local people; from December 1996 to end of January 2005, the DOE filed 42 illegal hunting cases, only six involved Tenglians, and $20 \%$ of the arrests were in Alagol (Abdoli, Ghaemi, Shakiba, \& Jaffarinejad, 2005, p. 13-15).

Hunting and fishing, restricted by the DOE, are part of the traditional Tenglian life style and is their pride and reassurance of their connection with land and nature. Hunting does not contribute much income and fishing provides food, and when they were permitted to fish with a net, it was a source of income. Tenglians generally believe that nature protection is commanded by 'foreign' organizations and that DOE is the organ to implement their order. Local people hold 'foreigner' organizations and the DOE

\footnotetext{
${ }^{155}$ Difference in spelling can be due to different pronunciations of Tengli and Oghi Tepe. This indicates that the consultant did not read any background material about the region. The data given in the report is wrong. Official government census in 2006 indicates Tengli has 243 families and Oghi Tepe about 150 families.
} 
responsible for cutting their income, interrupting their livelihood and interfering with their lives. For Tenglians, the DOE and the Ramsar Convention are viewed in similar ways; they both are foreigners and outsiders. In this perspective, the topology of power makes the Ramsar Convention powerful and close enough to the AUA region to make Tenglians' lives difficult.

\subsection{Biodiversity, wildlife, and habitats}

The biodiversity (at the ecosystem and species levels) of the region is another agent in the formation of the AUA region, competing for water and interacting with other actors.

The DOE Gorgan understands the sensitivity of the ecosystems along the Atrek, especially from the AUA area towards the Caspian Sea, and has proposed a plan to designate and protect the major part of this area as a 'Sensitive Wetland Region'. A DOE authority in an interview explained that in 2008, following the Third and Fourth Development Plans, DOE Gorgan developed a digital map of the AUA region and introduced a major part of the AUA region as an ecologically sensitive zone, thereby setting a basis for its authority in any decision-making regarding land conversion in the area and enforcement of EIA regulations. DOE's attempt was a dead end since the Cabinet changed the law in 2009, and, instead of 'specific ecological areas', DOE was only mandated to inform the interested parties of the delineation of its four management areas and indirectly its authority was restricted to those territories (see Section 6.2.3.). The performance of the DOE Gorgan provincial office in 2008 indicates its commitment to nature preservation, protection, and conservation of the AUA lakes. However, as explained in this chapter, DOE recommendations for river basin management are 
commonly rejected in higher level negotiations about environmental water allocation to the wetlands, water abstraction from Alagol, and land conversion in the AUA region, and in practice the department's power is limited to control over fishing and hunting in the region.

DOE and its international allies at the Ramsar Convention speak for Ramsar Sites. Arguments presented in this section use Ramsar Information Sheets (RIS) (Ramsar Convention Secretariat, 2013a), and a Ramsar Advisory Mission Report (Moser, 2009) as official documents that speak for the AUA wetlands. Removal of the AUA Site from the Montreux Record and the Ramsar Convention endorsement of the success of the government of Iran in conservation of these wetlands has been promoted in the Iranian media and on the Ramsar Secretariat website. The Secretariat had no hesitation in ascribing this success to the appropriate measures taken by the government of Iran to control hunting, allocate water to the wetlands and control water abstraction from wetlands to the extent that they are no longer threatening the ecological character of the wetlands (Moser, 2009, p. 1). The report asserts that 'there is every indication that these improvements are sustained' (Moser, 2009, p.1).

If the above claims were correct, the AUA wetlands would be the triumphant actor-network in competition with other water users and political entities of the AUA area, but this is not the case. As discussed above the DOE was successful in controlling fishing and hunting in the AUA region but on issues such as water allocation and land-use change, which are critical political issues in the Turkmen Sahra, it has failed. These practices which disregard environmental issues are far from being sustainable. Findings of this research could not support any of the claims made by the consultant regarding the sustainability of measures taken for water use and allocation, control on water abstraction 
from Alagol, land use, habitat conversion, and improvements of biodiversity and wildlife in the AUA landscape. This section highlights and reviews some of the problematic approaches of the AUA Advisory Mission report.

(1) The Ramsar Advisory Mission Report made comments and statements regarding water allocation and management in the AUA area that have been addressed in Section 7.2. The Ramsar Advisory Mission Report regards threats to changes in water quantity of the wetlands as being 'low' and considers the trend as becoming 'better' due to '[an] agreement signed by DOE and the Ministry of Energy at the national level to ensure minimum water flows to the downstream wetlands' (Moser, 2009, p. 6); and also (Moser, 2009, p.6):

Strong cooperation established by DOE with the Water Authority both at [the] provincial and district level. Management regulations have been made for each wetland and a MOU [Memorandum of Understanding] signed with the Water Authority (2000) prescribing the monthly minimum flows to be delivered to the wetlands. An option exists (and has been used) for special release of water from an upstream dam to the wetlands in drought years.

The discussions already presented in Chapters VI and VII indicate that water and land in the Turkmen Sahra are highly political issues and are not as straight-forward as is stated in the Ramsar Advisory Mission Report. The Atrek River is a trans-boundary river, and is shared among three provinces in Iran. Dams on the Atrek, the water demand in three provinces and illegal wells along the Atrek River upstream from Chat, the point of water diversion towards Turkmenistan, are some of the reasons for decreasing amounts of water available to the AUA wetlands. Empirical data in this thesis indicates that the water agencies are not controlling illegal wells along the Atrek, and the provision of environmental water to AUA wetlands by the Ministry of Energy and the regional Water Authority has not been guaranteed, nor is it occurring. 
(2) The report states that direct abstraction of water from Alagol for the Abgasht fish farm and from Ulmagol for local small scale agriculture 'has been controlled through the MOU [Memorandum of Understanding] with the Water Authority [and is] only allowed in times of plentiful supply, by permit' (Moser, 2009, p. 6). The report also indicates that villagers would like to be able to abstract more water for 150-200 ha of land adjacent to the wetlands for agriculture but due to drought conditions it has not been allowed (Moser, 2009, p. 8).

Discussions in Chapters VI and VII, in brief, demonstrate that prioritizing water use is a political process in the Turkmen Sahra. The Governor-General is the influential authority, setting the priorities for water use and allowing permits for water abstraction from Alagol and Ulmagol. Interviews show that villagers' farms and fish farms are not even considered for receiving water. The priority for abstraction of water from Alagol has been given to Abgasht Fish Farm. In 2008, which was a drought period, Abgasht still received water, even though the water level in Alagol was lower than the agreed limit. Water priority is then given to other fish farms (1000 hectares) and finally to the 4000 hectares of Revolutionary Guards' agricultural lands.

In addition to the above water related issues, the Advisory Report has failed to thoroughly examine threats to biodiversity and wildlife, and the issue of habitat conversion in the AUA landscape.

(3) According to the Ramsar database, the AUA sites are owned by the national government; however no information on land tenure/ownership of surrounding areas was reported (Ramsar Convention Secretariat, 2013a). With no basic research, the Ramsar Advisory Mission Report regards habitat conversion in the catchment area as a 'low' threat and the trend as 'stable' because it is 'unlikely that there will be significant 
development of irrigated agriculture' (Moser, 2009, p. 5) and 'some fish ponds have been turned back to wheat fields due to lack of water permits for operation' (Moser, 2009, p. 5). The report only mentions Abgasht and claims that it is not running due to lack of water. The report states that threats of nitrate, phosphate and pesticide pollution are 'low' because there is 'no conversion to agricultural lands allowed nearby' and reports the condition as 'stable' (Moser, 2009, p. 6). The report surprisingly does not mention the 4000 hectares of land conversion by the Islamic Revolutionary Guard Corps and 1000 hectares of fish farms (in addition to 500 hectares of Abgasht). Moreover the only fish pond that is likely to turn back to a wheat field is the smallest one close to Ajigol, owned by a Tenglian, and it even does not have access to Alagol water. Abgasht and all the other fish farms with water permits for water from Alagol are running and their water right is secured by the provincial Water Company.

(4) In 1975, when the AUA wetlands, with their associated marshes and intervening grassy steppe, on the Turkmen Palin were designated as a Ramsar Site, they were 'representative examples of the natural brackish and freshwater lakes characteristic of the vast plains to the east of the Caspian Sea' (Ramsar Convention Secretariat, 2013a, p. 2). In the Ramsar Information Sheet, Alagol was described as 'slightly saline and fed by seepage, springs, rainfall and local runoff, flooding in winter and sometimes drying out completely in summer. The average water depth is 2 meters. When full it overflows westwards' (Ramsar Convention Secretariat, 2013a, p. 2). Lakes Ulmagol and Ajigol were described as 'freshwater lakes fed by local rainfall, mainly in autumn and winter. Both are subject to wider fluctuations in water level, and occasionally dry out completely' (Ramsar Convention Secretariat, 2013a, p. 2). This system has completely changed through time, which can explain some of the recent changes in biodiversity, wildlife and 
habitats in the AUA landscape. The Turkmen, who enhanced the biodiversity of the AUA for centuries were responsible for the formation of the AUA region as an integrated land and water management system, are no longer active participants in their environment and their role in management of their natural resources has been replaced with sectoral approaches controlled by government authorities in the appropriate Ministries that deal with land, water, rangeland, fisheries, and nature protection organizations. The Report failed to acknowledge the role of the local people in the formation of the AUA Ramsar Site and the implications of land, water and nature policies that separate them from their environment. A study in 2011, showed that the impacts of controlled flood water systems are remarkably positive on the rangelands and other habitats of the experimental cases in Iran (Amiraslani \& Dragovich, 2011, p. 5). Use of controlled floodwater is a replica of the traditional land and water management of the Atrekians. The regime of regulated flooding that lasts a few days is necessary for maintenance of ecosystems of the Atrek floodplain and its delta (Kouzmina, 2006, p. 101). Improvement of the ecology of the AUA region will benefit both humans and non-humans, prevent soil erosion and protect water quality by collecting and storing runoff water, provide water for livestock, fish and wildlife, and support local people's livelihoods. This can be studied as a potential and feasible option for the AUA region to improve its surrounding steppes, rangelands and wetland habitats.

(5) The Tenglians collect reeds, jaroo, mushroom and ejoveh but this collection is declining because the resources are decreasing. The DOE does not consider Tenglians' harvest of these resources as being a threat to wetlands, and does not enforce control over their use. Wetlands are the natural habitat for reeds and jaroo, while ejoveh and mushrooms occur in rangelands. This could be an indication of deterioration of wetland 
and rangeland habitats of the region, which would be consistent with the findings of this chapter. Mushrooms and ejoveh are particularly good indicators of rangeland deterioration because they are not a source of income and local people use them moderately only for their own consumption. The water regime and hydrology of the AUA has completely changed through, among other reasons, construction of dams, illegal wells along the Atrek before Chat, construction of many trial and error channels, and land conversion in the AUA region. Consequently, the salinities of the three lakes are changed, Alagol des not over flow anymore, the lakes do not dry out naturally, and the Atrek runoff does not occur. The rangelands are not as rich as they were before.

(6) The Ramsar Advisory Report states that populations of endemic fish species have been reduced due to the introduction of non-native species and that the trend in the future 'may be improving' as a result of measures that have been taken to target fishing at the breeding areas of non-native species and to ban any further introduction of non-native species (Moser, 2009, p. 7). Introduction of exotic species is only one reason for the decline of endemic fish species in the AUA. This simple generic inference about introduction of non-native species is not sufficient to address the problem of endemic fish species in the AUA wetlands. Better understanding of the landscape, the ecological integrity of these ecosystems and the causes of extinction of endemic fish species in these wetlands could lead to better evaluation of effectiveness of the measures being taken to support the endemic fish population. Since the time that the Atrekians stopped being stewards of their environment, three reasons can be identified for deterioration of the Alagol ecosystem and a decline in its endemic fish composition and population: (a) The Atrek reaching the Caspian Sea is vital for survival of the native fish species of the lakes. With the Atrek River becoming so shallow, due to unsustainable water uses, water 
regulations and bad governance, it no longer flows into the Caspian Sea (Kouzmina, 2006, p. 104) changing the ecological conditions in the lakes towards desertification. The ecology of fishes living in rivers in desert ecosystems is dependent on the spatial and temporal variability of flooding and drying patterns. These variations produce particular ecological conditions that 'allow them to survive droughts and major floods while capitalizing on the benefits derived from floods' (Kingsford, Unmack, \& Unmack, 2006, p. 162). (b) Due to construction of many channels and embankments in the AUA region by Jihad Sazandegi, the water regimes and the water quality of the wetlands and consequently the fish habitat which originally supported the endemic species is changed. The embankment (earth dam), which the Atrekians built at the western end of Alagol in the 1960s, partially controlled flooding and the amount of stored water and created a habitat that was suitable for the survival of exotic species (see Section 4.3.2). In 1987 the Jihad Sazandegi restored the old embankment, and increased its height. An interviewee from Gorgan Fisheries Company explained that restoration of that embankment caused a decrease in the water's electrical conductivity, moving from highly saline towards moderately to slightly saline, in the wet season. This contributed to changes in the lake's ecosystem and a drastic decrease in the major endemic fish species in Alagol. (c) The inexperienced Jihad Sazandegi in 1989-90 introduced commercial non-native species into the lakes and caused damage to the lake's ecosystem that led to a decrease its endemic fish population. The DOE prohibited the introduction of exotic fish to Alagol in the mid1990s, but in 2005 the Fisheries Company (Ministry of Agricultural Jihad) proposed that DOE approve another project to introduce exotic fish species in Alagol. The DOE's response was that consideration for any change in the lakes would be conditional on a comprehensive ecological study of the lakes, which is long overdue in any case. 
(7) The extended embankment that Jihad Sazandegi re-built on Alagol (explained in point 6 above) is responsible for an increase in the extent of Alagol when it occasionally receives environmental water or after a few days of rain and simultaneously is responsible for ecosystem fragmentation of the AUA landscape. The Secretariat, in its Advisory Mission Report (Moser, 2009, p. 9), argues that:

Evidence presented and witnessed during the mission indicated that, as a result of a more secure water supply, the marginal wetland habitats around each wetland, particularly Alagol, have developed substantially in area. Indeed wetlands habitats at Alagol alone are now more extensive than the official area of the entire Ramsar Site (1400 ha). As a consequence of these enhancements, the biodiversity of the area has improved both in terms of habitats and species.

The scientific basis of this argument is questionable considering that the increase in Alagol's area cannot be based on a one-visit observation; it requires medium and long term monitoring of environmental water flow, water abstraction from Alagol and the climatic conditions to understand the dynamic relation of land and water in the region. Moreover the temporary extension of Alagol in size, which is conditional on receiving environmental water, is also related to destruction of the traditional controlled flooding system developed by the Atrekians, and instead construction of a higher embankment by Jihad Sazandegi. Consequently, this change in size is at the expense of degradation of the AUA landscape, through fragmentation, which goes against the principles of the ecosystem approach, and the holistic view of conservation and ecological integrity of a landscape. The construction of many dams on the Atrek, changes its water regime and flooding systems, wells along the river, channels and land conversion throughout the landscape, and finally change in the water quality and salinity of the lakes, collectively contribute to changes to the quality of soil, rangelands and sensitive ecosystems of the area, habitat fragmentation, overall biodiversity, and the abundance of endemic fish 
species. There is almost no research on the biodiversity of the surrounding steppes. Increases in the extent of Alagol (due to a one time release of water from the Atrek upstream) may temporarily contribute to the increased number of waterbirds in the three lakes, but this is not an indication of an overall increase of biodiversity in terms of habitat and species in the wider landscape.

(8) The consultant report claims that the biodiversity of the area has been improved both in terms of habitat and species. The only data presented is a graph of total waterbird counts, with no species breakdown of the results, conducted by the Department of Environment from 1998 to 2007. The consultant referred to this data and concluded that as a result of proper mitigation actions of the government of Iran, the AUA wetland habitats were improved and negative change in the ecological character of wetlands was reversed (Moser, 2009, p. 9). Populations of waterbirds, their numbers and species are criteria for designation of a wetland as a Ramsar Site; however the populations of waterbirds reported by the DOE are not necessarily proof for improvement of the AUA wetland habitats and reversal of changes or restoration of damages to its ecological character. High waterbird counts are also related to other factors, such as the no-shoot zone being changed from $2 \mathrm{~km}$ to $7 \mathrm{~km}$ along the border with the Turkmenistan, its strict patrol by both Iranian border guards and DOE's Environment Guards, the quality of wetland ecosystems along the flyways ${ }^{156}$, and climate change. The number of birds in the AUA area is also related to the following two global environmental change issues:

\footnotetext{
${ }^{156}$ Iran is located in the following borad flyways of waders and Anatidae: the West Asia/East Africa Flyway, and the Central Asia Flyway that includes Indian sub-continent (Boere \& Stroud, 2006, p. 41) and include breeding grounds in Western Siberia and (wintering) non-breeding areas in Central Asia, the Indian subcontinent and Africa.
} 
(a) The quality and extent of suitable habitats for migratory species in Central Asia is adversely changed (Kreuzberg-Mukhina, 2007, p. 283). The Aral Sea basin wetlands in the early 1960s included approximately 2600 lakes in the Amu Darya delta; this had fallen to only 400 by 1985 (Kreuzberg-Mukhina, 2007, p. 284). Some artificial water bodies, including 94 water reservoirs and $24,000 \mathrm{~km}$ of channels, replaced the destroyed wetlands (Kreuzberg-Mukhina, 2007, p. 284). These new habitats provide refuge for migratory birds from Western Siberia to the Caspian and African wintering areas but breeding success in these man-made sites was poor. The species composition, number and distribution of water birds have shown major changes (Kreuzberg-Mukhina, 2007, p. 284).

(b) The high number of waterbirds in the AUA area can be an effect of climate change. There is a general increase in the number of waterbirds in the southern coastal zones of Caspian Sea (Barati \& Khalilpoor, 2007, p. 369). Climate change may cause a shift in breeding and wintering zones (non-breeding areas) of waterbirds (Maclean, Rehfisch, Delany, \& Robinson, 2008, p. 3) and as a result new sites are made available to many species (Kreuzberg-Mukhina, 2007b, p 277, 278). A study in Uzbekistan has found out that the meteorological records in the last 100 years shows isotherm shifts in January to have been about $200 \mathrm{~km}$, but the northern limit of the warm wintering zone in that country has shifted to the north by 300-500 km between 1980 and 2006 (KreuzbergMukhina, 2007b, p. 278).

\subsection{Conclusion}

The region is experiencing a water and land crisis that is the ramification of the rivalry among key government and government-related agencies. Ostandari (the 
Governor-General's Office), the Regional Water Company in the Golestan and two Khorasan provinces, the Land Affairs Department of Jihad Sazandegi, Bonyads, and the DOE and its international allies, Ramsar Convention, are the key state actors in the exercise of power in the AUA region within the context of the state's territorial policies. Local people and the biodiversity of the landscape are also active agents of this network of humans and non-humans.

The politics of state natural resource control in the Turkmen steppes are not transparent; nevertheless the state's land and water practices and its performance in the region are indicative of its exclusionary actions towards Tenglians. IWRM, IRBM and even simple River Basin Management are not undertaken for the Atrek basin, although the law and institutions to carry out such study exists. Water allocation to AUA, Tenglians, and other users, is a political decision and the final decision is for the Golestan Governor-General's office mediated by the Golestan Water Company. The State's natural resource control policies (land use, conversion and transfer; and water resource development plans) written and unwritten, transparent and not, are used as leverage towards facilitating land conversion and land use change, marginalizing Tenglians, and empowering Bonyads and Islamic Revolutionary Guard Corps in the AUA region.

Tenglians have had three significant experiences regarding access to their natural resources and pursuing their livelihoods:

(1) Securing water for farming and for fish farms, their solution to create private or cooperative jobs, has failed. Since Tenglians abandoned their customary land use, they are in a constant struggle to secure their access to water and are not eligible for customary water rights. (2) Not having access to financial means (having very limited to no access to bank credit) and not being able to pay for expensive fodder, they cannot afford losing 
their access to natural rangelands. Ensuring their access to rangelands increases their opportunity to keep their livestock (irrespective of the number of animals they own). (3) The recent changes in land use in their rangelands has not provided new job opportunities and not benefited them. Instead, it has attracted outsiders who use their resources and marginalize them further.

These experiences indicate that after the revolution any land use change and land conversion that happened in their territory resulted in allocating more water to those new land users (and ultimately land owners) and less to them to pursue agriculture. Consequently, the majority of the Tenglian male population is distanced from livelihood strategies related to nature and they are becoming wage laborers. Moreover, any land use change is at the expense of losing their rangelands. Rangelands, which are the only resource for which the Islamic State recognizes the Atrekians' right of access, though limited and conditional, are of major importance in the lives of a majority of Tenglians. This analysis may indicate how the future may unfold in the region. The Atrekians now resist land conversion and change in land use from rangelands. Resistance of people of Oghi Tepe and other Atrekian villages in 2005 was an example of this realization.

Discussions of this chapter revealed that the land and water crisis in the region have led to degradation of the landscape, despite the claims of the AUA Advisory Mission Report. Change in the water scheme in the area, dams on the Atrek, increased number of deep wells upstream, construction of numerous trial and error embankments with mixed success, high embankment on the west side of the Alagol, and land use change have all contributed to negative impacts on the AUA landscape. As a result of these changes: Alagol does not over flow anymore and the lakes do not dry out naturally; the Atrek run off does not occur, and therefore, rangelands are not as rich as they were 
before; rangelands and natural vegetation are degraded; and endemic fish species in Alagol are lost. The observation that reeds, jaroo, ejoveh and mushroom appear less frequently in nature indicates a deterioration of wetland and rangeland habitats.

The DOE and Ramsar Convention speak for the AUA, its wildlife, and environmental water needs. The DOE's diverse functions make it a substantial and powerful actor in the AUA place-making processes. It has a substantial role in the state's exercise of power in the study area. Ironically, its role is substantial because of its weak political and legal authority in the Islamic state which renders it unable to influence and modify development policies and practices in the region, which includes political and social processes that condition access, control, and management of the major natural resources, priority setting, and decision making. The DOE, within the framework of its mandates and powers, to date has not been able to: a) enforce 'the rule of law' or its decisions regarding rejection of government projects (industrial and agricultural), and land conversions into fish farms and irrigation agriculture, with potentially adverse effects on the wetlands and their surrounding steppes; and b) ensure allocation of environmental water to the wetlands despite its negotiations with the Golestan Regional Water Company. Practically, the role of the DOE has been limited to legitimizing what has been decided already for the area by the Governor General. However, the DOE can easily, and does, reject the usually small projects that are put forward by the Turkmen unconnected to state power networks. The government strictly enforces a seven kilometre no shooting zone along the border with Turkmenistan, and encourages DOE to seriously pursue its role in policing fishing and hunting in the area which adversely affects the Atrekians' lives and their access to lakes. The DOE, directly and indirectly, contributes to socioeconomic processes and schemes that enroll humans and non-humans and shape the 
networks of relations that discriminate against the Turkmen in favor of Bonyads and those with connections to the government in the AUA region.

Political and social aspects of exclusion go beyond the local and are associated with the wider power geometry that encompasses the rule of law, political participation, and human rights. Contextual analysis of current people-environment interactions in the AUA region, land and water issues, the difficulties of Tenglians in accessing natural resources to pursue their livelihood strategies, and competition between different actors requires an understanding of the Iranian Islamic State and its numerous and varied entities and their power relations. Such discussion entails analysis of the Islamic State's political and ideological aspirations, 'the rule of law' and administrative system and governance in terms of transparency, inclusion and accountability, access to power and decision-making bodies, and finally ethnicity and minority rights. The next chapter addresses these topics. The Ramsar Convention as a significant political actor in the AUA region will be discussed in Chapter IX. 


\section{CHAPTER VIII- The 'rule of law', and political and civil rights}

Where is control over rights located in the Islamic State? This question is addressed by examining power relations within the Iranian Islamic nation-state in terms of: the practice of the rule of law; access to decision making, local level government; administrative and political decentralization; and, ethnicity, minority rights, and equality of opportunity.

Availability of and access to resources, biodiversity and ecosystem services for local people is a matter of 'the rule of law', civil and political rights, and where control over procedural rights (the right to participation in decision-making and access to justice), substantive rights (the right to water, sanitation, adequate housing, education, work, food and adequate standard of living), and cross-cutting rights (being free from discrimination) is located in the state (Campese \& Guignier, 2007, p. 12).

The state's territorial approaches and policies, its control over resources, and the interaction of government and public actors (discussed in Chapters VI and VII) are part of a bigger network of actors comprising the country's power structure and international agencies that shapes the AUA glocal wetlands. Rule of law, political decentralization and governance ${ }^{157}$, democracy and substantive and cross-cutting human rights are essential components of people-environment studies of glocal wetlands.

\subsection{The Islamic State of Iran and its power structure}

After the revolution, Iran's official name was changed to the Islamic Republic of Iran. Many states in the world have 'Republic' somewhere in their official title (Schofield, 2002). The word republic, in its narrow sense, means the state is 'without a

\footnotetext{
157 The various concepts about good governance "always refer to the rules, processes and behaviours by which interests are articulated, resources are managed, and power is exercised in a State or in a society" and applied at different levels (Swiss Agency for Development and Cooperation, 2007, p. 3, 2008, p. 6).
} 
king' and can be applied to any state that is not a monarchy, therefore, the political questions it used to raise in $17^{\text {th }}$ century Europe are largely irrelevant in the $21^{\text {st }}$ century (Schofield, 2002). Some definitions of 'republic' restrict it to states that have provisions for the election of a head of state and have a scheme of representation chosen by citizenry ("Republic," 2009) although that does not necessarily imply that the state is a democracy. The word 'republic' in the title Islamic Republic of Iran ${ }^{158}$ only denotes that a monarch does not rule the country. After the revolution, an electoral scheme, along with an Islamic Shi'a interpretation of statehood, has been set up and practiced. The Islamic State has an electoral system but it also has other decision making entities, Velayat-e Faghih (Supreme Leader) and the supremacy of Shari'a law (Islamic law) that overshadow and contradict the electoral system. The political structure of Iran is a fascinating, unique case of the amalgamation of Shi'a Islam with modern concepts of representation and governance. It will be argued that it has not been able to become a stable system due to its innate contradictions.

The formation of the Islamic Republic of Iran after the revolution was not a uniform act of a political group, rather, it involved motivations and actions of different actors and the new state came to existence through power struggles among radical, moderate and liberal forces. The Iranian Islamic State is not a homogeneous political structure $^{159}$, it encompasses schisms and alliances of actors. Every actor (individuals, institutions, or conglomerates of foundations) is an actor-network and has agency in

\footnotetext{
${ }^{158}$ Khomeini was against the titles: 'Democratic Republic of Iran' and 'Democratic Islamic Republic of Iran' and in an interview he stated: "Islam does not need adjectives such as democratic. Precisely because Islam is everything, it means everything. It is sad for us to add another word near the word Islam, which is perfect" (Abrahamian, 2008, p. 163).

${ }^{159}$ Moslem argues state in the Islamic Republic is "a collection of incoherent power structures that dispense power; that enact, arbitrate, and execute rules; and that allocate resources and values in scociety" (Moslem, 2002, p. 35).
} 
numerous relations and through different trajectories and varied processes. By 1980, the fundamentalists and hardliners had asserted their hegemony in the power bloc, reflected in monopolization of the Majlis, the court system, the Sepah, Jihad Sazandegi, TV, Bonyads, and mosques (Amjad, 1989, p. 142). By the mid-1980s, all political organizations except the Islamic Republic Party were eliminated by the Islamic State. However, the developed Islamic State is by no means a uniform composition of conservative religious actors. In 1989 Rafsanjani, a reformist cleric believing in the absolute power of the Supreme Leader, was open to economic liberalization and true privatization; in 1998, Khatami, a reformist cleric believing in individual rights and democratic institutions; in 2004 Ahmadi-Nejad, a hard-line conservative and non-cleric believing in absolute rule of Shari'a, were successively elected as President.

The rule of Shari'a in Khomeini's approach (explained in the next section) is an indication of absolutism that is hard to negotiate, nonetheless, the Shi'a clergy are divided in their understanding of rule of Shari'a and also of Velayat-e Faghih that was put forward by Ayatollah Khomeini ${ }^{160}$ and is practiced at the time of writing this dissertation. The Iranian Islamic State is a fascinating case of a volatile (therefore multiple, fluid and in constant change) mix of elected and appointed career politicians, Shi'a clerics (from ultra conservative to reformist), Sepah and Basij paramilitia, foundations (Boroujerdi \& Rahimkhani, 2010) and civil society. Understanding the dynamics of these entities in the context of the political structure of the Islamic Republic of Iran nation-state is key to discussions on the rule of law, governance, and human rights in Iran. Examination of the rule of law in Iran entails an analysis of the Iranian State's power networks' dynamic

\footnotetext{
${ }^{160}$ For example, Khomeni was hostile towards two high ranked Ayatollahs, Shariatmadari and Montazeri, for standing up against his essentialist view of Islam and the brutality of the state.
} 
encompassing Velayat-e Faghih, Sepah and Boyads, government and public sectors, and the working of the constitution in terms of Shari'a law and human rights and minority rights.

\subsubsection{The 'rule of law': The paradox of the Islamic State of Iran}

The World Justice Project (the Rule of Law Index report) ${ }^{161}$ investigates how governments perform regarding the rule of law. This is done by quantifying performance (outcomes) of a government's operations and how the rule of law is implemented in practice (Agrast, Botero, Martinez, Ponce, \& Pratt, 2012, p. 186), by 'operationalization of the rule of law dimensions into concrete questions' (Agrast et al., 2012, p. 185) that correspond to the four principles of rule of law (Agrast et al., 2012, p. 9):

[1] The government and its officials and agents are accountable under the law. [2] The laws are clear, publicized and fair, and protect fundamental rights, including the security of persons and property. [3] The process by which the laws are enacted, administered, and enforced is accessible, fair, and efficient. [4] Justice is delivered by competent, ethical, and neutrals who are of sufficient number, have adequate resources, and reflect the makeup of the communities they serve.

The reports (Agrast et al., 2012; Agrast, Botero, \& Ponce, 2011) ranked the government of Iran as last, globally, regarding 'Security and Fundamental Rights ${ }^{162}$. 'Government accountability' is weak in both the reports ${ }^{163}$ and corruption is prevalent

\footnotetext{
${ }^{161}$ The World Justice Project was founded as a presidential initiative of the American Bar Association and in 2010 transitioned into an independent non-profit organization. It established to advance the rule of law worldwide. The Rule of Law Index is a quantitative assessment tool that used to rank 97 countries in 2012 and 66 countries in 2011 based on 9 factors and 54 sub-factors. Countries are ranked globally, regionally and by income group. Iran belongs to Middle East and North African Region and Upper-Middle Income group countries. Questionnaires are filled only for three large cities Tehran, Isfahan and Mashad (Agrast et al., 2012, 2011).

${ }^{162}$ The sub-factors considered include: "absence of crime; civil conflicts is effectively limited; people do not resort to violence to redress personal grievances; equal treatment and absence of discrimination; rights to life and security of the person; due process of law; freedom of opinion and expression; freedom of belief and religion; arbitrary interference of privacy; freedom of assembly and association; fundamental labor rights" (Agrast et al., 2012, p. 100).

${ }^{163}$ Iran ranked 58/66 globally and last in the region in 2011, and 85/97 globally and last in the region in 2012, regarding government accountability. The sub-factors considered include: "government powers limited by legislature; government powers limited by the judiciary; independent auditing and review;
} 
(Agrast et al., 2012, p. 41, 2011, p. 34). Courts, although fairly efficient in terms of fees and time to process, are subject to corruption and political interference (Agrast et al., 2011, p. 34). In 2012, the project reported that 'administrative agencies are relatively effective in enforcing regulations (ranking $41^{\text {st }}$ overall and 11 in upper middle income countries)' (Agrast et al., 2012, p. 41). Regarding 'Open Government and Regulatory Enforcement ${ }^{164}$, Iran ranked 78/97 globally, last in the region and 26/30 in the income upper middle group in 2012 (Agrast et al., 2012, p. 41). Iran's assessment for the subfactors: 'availability of official information' is close to zero, and 'stability of laws' is the lowest in the region and in the upper-middle income group (Agrast et al., 2012, p. 41).

The World Justice Project reports are not based on a complete survey of the country. Questionnaires are completed only for the three large cities: Tehran, Isfahan and Mashad. These cities are well developed and have dominantly Persian populations. Mashad is in Razavi Khorasan province, which shares borders with Afghanistan and Turkmenistan, but its major population is Persian and a major Shi'a shrine is located there. A countrywide survey would likely result in a lower ranking considering the characteristics of the government's practices in the provinces, along the borders, with dominant ethnic minority populations. Moreover, these analyses oversee the wider power geometry of the Iranian state, which includes the Supreme Leader and his domain of authority. The Islamic State in Iran is a complicated system of different entities which

\footnotetext{
government officials sanctioned for misconduct; government powers are subject to non-governmental checks; transition of power subject to the law; absence of corruption in the executive branch; absence of corruption in the judicial branch; absence of corruption by the people and the military; absence of corruption in the legislative branch; government powers limited by legislature" (Agrast et al., 2012, p. 100).

164 The sub-factors considered include: "laws are publicized; the laws are stable; right to petition and public participation; critical information is available; government regulations effectively enforced; government regulations applied without improper influence; administrative proceedings conducted without unreasonable delay; due process in administrative proceedings; and the government does not expropriate without adequate compensation" (Agrast et al., 2012, p. 100)
} 
means that understanding the rule of law in Iran requires widening the scope of study to all components of the Iranian Islamic State rather than only the performance of the government.

The president is head of the government but the most powerful political office in the Islamic State belongs to the head of the state, the Supreme Leader. Differentiation between government (Dowlat) and state (Hokumat) in Iran is crucial in understanding its post-revolution system of power. This dissertation uses the term Islamic State of Iran to refer to all the components of Iran's power structure after the revolution. Namely:

(1) The public sector government (Dowlat), which consists of: a) the legislature and the executive branches (line ministries used to be coordinated through the Management and Planning Organization but Ahmadi-Nejad abolished it in 2007 (see Section 6.2.4), and b) directly elected urban and rural councils (i.e. decentralized local governments coordinated through the Ministry of Interior) and the indirectly elected hierarchy of Islamic councils including county, district, provincial, and high Islamic Councils of Provinces, that are strangely known as 'public non-governmental' (Umumi Gheir Dowlati) bodies (Tajbakhsh, 2006; Tosun \& Yilmaz, 2008).

(2) The state sector (Hokumat) consists of all the agencies under the control of the Supreme Leader including the judiciary, military, Revolutionary Guard Corps and Basij para-militia, radio and television, and foundations (Tajbakhsh, 2006).

Immediately after the revolution, Ayatollah Khomeini created the Assembly of Experts, composed of theologians and committed Muslims, to put its views about an Islamic State based on the Shi'a school of thought and Velayat-e Faghih (that he described in 1971) into practice (Afary \& Anderson, 2005, p. 285). Khomeini described principles of an Islamic government to be (Khomeini, 1971, p. 18): 
The fundamental difference between Islamic government, on the one hand, and constitutional monarchies and republics, on the other is this: whereas the representatives of the people or the monarch in such regimes engage in legislation, in Islam the legislative power and competence to establish laws belongs exclusively to God Almighty. The Sacred Legislator of Islam is the sole legislative power. No one has the right to legislate and no law may be executed except the law of the Divine Legislator. It is for this reason that in an Islamic government, a simple planning body takes the place of the legislative assembly that is one of the three branches of government. This body draws up programs for the different ministries in the light of the ordinances of Islam and thereby determines how public services are to be provided across the country. The body of Islamic laws that exists in the Qur'an and the Sunna has been accepted by the Muslims and recognized by them as worthy of obedience. This consent and acceptance facilitates the task of government and makes it truly belong to the people. In contrast, in a republic or a constitutional monarchy, most of those claiming to be representatives of the majority of the people will approve anything they wish as law and then impose it on the entire population....the law of Islam, a divine command, has absolute authority over all individuals and the Islamic government.

The first political organization banned by the Islamic State was The Democratic National Front due to its strong opposition to the creation of the Assembly of Experts (Abrahamian, 2008, p. 168). Khomeini ordered nomination of Ayatollah(s) for this Assembly and encouraged people to vote. After a controversial election ${ }^{165}$ the Assembly worked in secret, closed sessions and transcripts of the debates were published six years later (Winder, 2005). Only after the creation of the Assembly of Experts, did Khomeini announced that the constitution should be based on the Islamic laws and Velayat-e Faghih that he elaborated in his book 'Islamic Government' in 1971 (Khomeini, 1971). The Assembly drafted an Islamic constitution based on Shari'a law and elaborated on the Velayat-e Faghih which asserts that until the occultation of the twelfth Imam, the Islamic community must be guided and run by Foghaha (theologians/jurists). In the most conservative interpretation of the rule of Shari'a, by fundamentalists and hard-liners in Iran, the state is considered 'an institution and instrument of the divine will' (International

${ }^{165}$ There were several electoral irregularities and fraud (Winder, 2005). 
Federation for Human Rights, 2004). The Supreme Leader is a Jurist who fulfills all of the religious criteria for being a Marja-e taghlid, who is followed and obeyed by Muslims, and he is also 'the one who has been appointed by Allah' and A'immah (God's Messengers) to lead Islamic society as Supreme Leader (Alizadeh, 2013). The new constitutional law acknowledged the absolute supremacy of the rule of Islamic Shi'a Jaffari (a sect of Shi'a Islam) law and supervision of the state by a Faghih (jurisconsult) (Arjomand, 1989, p. 121). However, subjecting political and civil matters to the interpretation of Islamic Shi'a law is a source of abuse of constitutional law, justifiable by divine arbitration/interference. Many political scientists identify this approach as being a theocracy but Kenton Machina rightly asserts that (Machina, 2008, p. 3):

in practice, perhaps a theocracy is really never a theocracy; in practice, a supposed theocracy is a dictatorship of those who claim to speak for God and who thereby set national policy.

Mahdavi argues against the essentialist view of Muslims that assumes Islamic culture is the main barrier to democratization (Mahdavi, 2008, p. 157). He states (Mahdavi, 2008, p. 157):

Islam and democracy are not mutually exclusive; different Islams have played different roles in democratization because different Muslims are exposed to different social, cultural and political contexts. Cultural essentialism is wrong and dangerous. Religious ideas in abstract are neutral; what we need to examine is socio-political trends outside the religious domain.

In post-revolution Iran, Khomeini gained the power to establish a state that in his view was an ideal Shi'a Islamic State. Not all Shi'a clerics follow Khomeini's aspirations for an Islamic State and Velayat-e Faghih. Before the election in 2009, a reformist cleric, Rafsanjani, stated: 'The title of Islamic Republic is not used as a formality. It includes both the republican and Islamic nature' (Quoted in Nader, Thaler, \& Bohandy, 2011, p. 53). A hard-liner cleric, Yazdi, in his response, stated: 'Peoples' support doesn't bring 
legitimacy, but popularity’ (Quoted in Nader et al., 2011, p. 53). In Khomeini's version of Velayat-e Faghih, which has been followed rigidly by Khamenei, legitimacy to the Islamic Republic of Iran is not from its constitution and popular will; it is based on 'the authority conferred by God to the Vali-e Faghih' (Nader et al., 2011, p. 53), a Shi'a dogma (Dabashi, 2008, p. 242). In this context he has 'the right to rule on behalf of God' (Arjomand, 1989, p. 125).

The paradox of the rule of law in Iran arises in the inconsistency in the Iranian constitution, as modified by a few clerics under the supervision of Khomeini after the revolution. They established the absolute supremacy of the rule of Shari'a (Article 4), 'demanding all laws including the constitution to be based on Islamic rules' (Moschtaghi, 2010 , p. 3). The following two dualities are relevant to the arguments of this chapter:

(1) The constitution recognizes the three separate branches of government, executive, legislative and judiciary, and requires independence of the latter from public power (Article 57) however it also identifies a powerful entity called Vali-e Faghih who is bestowed with the power to override and undermine the decisions of the government and to monopolize power through his affiliated institutions ${ }^{166}$ (Abrahamian, 2008, p. 164). In general, the rule of law is universal and no person/office stands beyond it (Mahdavi, 2008, p. 154) but in Iran Vali-e Faghih has the authority to be the law and operates beyond any limitation if he can justify his actions as divine wishes and in accordance to rules of Shi'a Islam. Vali-e Faghih is a cleric who has wide ranging powers and dominance in the power structure of the Iranian Islamic State based on its intellectual, religious and moral attributes, for life (Article 109) (see Sections 8.1.1.1. and 8.1.1.2).

\footnotetext{
${ }^{166}$ Section 8 of the constitution (Articles 107 to 112), Article 96, and Article 157 regarding judiciary are relevant to the Supreme Leader and the Guardian Council ("Constitution of the Islamic Republic of Iran," 2013).
} 
(2) The constitution clearly states that all Iranians of any ethnicity, color, race, language, gender and religious affiliation enjoy equal rights, but the rule of Shari'a law, Shi'a Jaffari, contradicts this provision of the constitutional law. This issue will be discussed in Section 8.3.

A conservative and activist Islamic website (Salahuddin, 2009) outside of Iran considers the hardline Islamic view and practice of Velayat-e Faghih and government's structure in Iran as a 'mish mash of legislative and competing organs that in reality are more akin to a democratic structure and closer to the Western political model' (Salahuddin, 2009). It argues (Salahuddin, 2009):

The position of Supreme Leader is further undermined by the position of the President who assumes an executive role, producing and implementing government policy within his ministerial team. Although subject to the Supreme Leader's approval the President's office potentially creates a political rival with gravitas within a constitutional framework whilst the Supreme Leader adopts a more hands off role.

This radical approach to Velayat-e Faghih and concern for the possibility that modern establishments, such as parliament and people's representation, can become democratic mechanisms resonates with conservatives in Iran, including the Supreme Leader. This concern is instigation for the Supreme Leader to exert more pressure to enforce control mechanisms in order to establish control over the political, economic and social aspects of Iranian society. In this framework any kind of consultation system including parliament, should be at the service of the Supreme Leader (Arjomand, 1989, p. 125). The Supreme Leader stated, in a speech to a group of university faculty ("Meeting with university professors, elites, and the heads of universities and research institutions," 2009): 
Freedom in an Islamic system is a real freedom that is in the Islamic context and the Islamic Republic does not approve the unreal freedom that the west believes in and we are not shy of our stance in this regard.

\subsubsection{Velayat-e Faghih (Supreme Leader)}

The Assembly of Experts is composed of 86 senior clerics, vetted by the Guardian Council and elected by popular vote, appointed Khamenei as Supreme Leader after Khomeini died in 1989. The Assembly has the authority to appoint and supervise the Supreme Leader but, in practice, it acts as a rubber stamp for the decisions of Khomeini (Thaler et al., 2010, p. 29) and his successor, Khamenei. In practice, the Supreme Leader is the Chief of the Iranian Islamic State and there are no checks and balances on his actions. He shadows and controls, directly and indirectly, the administration of justice, legislative and executive sectors of the government, the armed forces including military, Revolutionary Guard Corps (Sepah) and Basij para-militia (as Commander-in-Chief), Foundations (Bonyads), radio and television and intelligence operations. He even has the right to dismiss the president.

The Supreme Leader appoints the head of the Judiciary ${ }^{167}$ who in turn selects other high- level judiciary authorities. The most active courts are 'public courts' that deal with ordinary criminal and civil cases, 'revolutionary courts' for national security matters, and 'press courts' that hear complaints against publishers, editors and media. The Special Clerical Courts that deal with alleged transgressions within clerical establishments lie outside the judiciary system and are supervised directly by the Supreme Leader. The independence of Special Clerical Courts from judiciary and parliamentary laws creates a mechanism to control internal conflicts among clerics which, in that it is based on Shari'a law, is a human rights concern (Moschtaghi, 2010, p. 6). The lack of independence of the

${ }^{167}$ The head of the Judiciary appoints the Chief Supreme Court Justice and the Chief Public Prosecutor. 
Judiciary system, just prosecution and fair trial, and the implications of Fatvah (highlevel clerics judgment in the absence of codified law and formal legislation) and vague and subjective Islamic terms such as Mohareb (a person in enmity to God) and Mofsed fel arz (a person who engages in vice-on-earth/corruption-on-earth), are also major sources of human rights concerns (Moschtaghi, 2010, p. 6). Use of the religious terms Mohareb and Mofsed fel arz and their wide interpretations negate constitutional law regarding fair treatment of Iranian citizens. The judiciary ensures that the Majlis passes laws that conform to Islamic law (Shari'a). The Guardian Council is another pillar of the Islamic State that is under the dominance of the Supreme Leader. The Majlis writes and votes on bills but, before enactment, any law must be reviewed and approved by the Guardian Council (Abrahamian, 2008, p. 167, 191). The Council can reject any bill or other legislation, as was the case with the land reform law in 1980 (see Section 6.2.1.2). Its twelve members supervise the law to ensure it follows Shari'a, and also supervise elections (Amjad, 1989, p. 151). Six of its members are selected by the judiciary and approved by the Majlis and the other six are appointed by the Supreme Leader. The Guardian Council carries out a pre-approval process to filter candidates before every election in the country. It reviews and certifies the competency of candidates for the Assembly of Experts, the Presidency, Majlis, and local councils. The Council is not obliged to give any reason for rejecting candidates or have legal justifications for rejecting a bill (Moschtaghi, 2010).

The presidential election in 2009, that resulted in Ahmadi-Nejad being re-elected for the second time, caused intense tension between people supporting reformists and the state. The Supreme Leader supported Ahmadi-Nejad's presidency (Nader et al., 2011, p. xvi) and Mesbah-Yazdi, an ultra-conservative Ayatollah, affirmed that: 'When a president 
is endorsed by the Vali-e Faghih, obeying the president is like obeying God' (Quoted in Jafari, 2009, p. 27). This created a justified basis for the coercive and violent onslaught of students and protestors by the Sepah and Basij, and led to an extensive wave of arrests and harassment of journalists and government officials who openly supported reformists (Jafari, 2009, p. 29).

In 1988, the Expediency Council (Shoray-e Khebregan) was created to resolve conflicts over legislation that occur between the Majlis and the Guardian Council. The Expediency Council is another mechanism that limits the legislative role of the Majlis; it functions as an advisory board to the Supreme Leader, who appoints its members from religious and political circles for five years, and can reappoint indefinitely.

The Supreme Leader directs foreign and domestic policies. Although the President is the head of the government, the constitution limits his authority, even in the executive branch, particularly with regard to intelligence and security, foreign affairs and oil (Federal Research Division, 2012, p. 13). The Minister of Intelligence and head of IRGC Intelligence, including its subsidiary body, the Quds Forces, report directly to the Supreme Leader. The Ministry of Intelligence and Security is only accountable to the Supreme Leader and its budget is not transparent (Federal Research Division, 2012, p. 24). The President appoints the Minister of Intelligence and Security but the Supreme Leader must approve it and the President cannot dismiss him without the approval of the Supreme Leader (Federal Research Division, 2012, p. 10). The Supreme National Security Council also aligns its policies with the Supreme Leader's views and he oversees the activities of the Council through its representatives (Federal Research Division, 2012, p. 13, 14). 
The Supreme Leader also has his own network of connections in every corner of the country in the form of Provincial Representatives and Friday Prayer Leaders. The comprehensive supervisory power of the Supreme Leader is implemented by his agents who are present in every branch of public power and agencies. Currently, he has the final say and absolute authority in issues of the state, and political and civil society, if he deems it necessary (Moschtaghi, 2010, p. 4). However, what seems to be the Supreme Leader's absolute power is a porous space of multiple actors. His power can be challenged by reformists and civil society, from within his own network and even within the Expediency Council as its power structure changes over time. The Sepah, Basij and Bonyads are actor-networks with resources that make them capable of shifting the power geometry within the Islamic State of Iran.

\subsubsection{Sepah, Basij and Bonyads}

Sepah, Basij and Bonyads are governmental and para-governmental institutions with major economic, political, military and ideological leverage with 'funds that enter them almost impossible to monitor' (Ansari, 2007, p. 81).

Within a week after the revolution, Komiteh-haye Enghelab Islami (the Islamic Revolutionary Committees), and Sepah Pasdaran Enghela Islami known as Sepah (the Islamic Revolutionary Guard Corps) were created in mosques on a voluntary basis, mostly from the urban poor. Komiteh-ha (Committees) were involved in distribution of oil and food. Sepah was a militia and ideological organization created to protect Khomeini and the new state from counterrevolution, opposition, and leftists (Amjad, 1989, p. 137). During the Iran-Iraq war, Khamenei, the present Supreme Leader, was the Minister of Defense and his full support for the IRGC enhanced the involvement of this 
initially voluntary body in the government (Federal Research Division, 2012, p. 15). After he was appointed as Supreme Leader, he facilitated the Sepah becoming a rich, powerful, ideologically oriented cartel that has reshaped the power structure within the Iranian Islamic State.

The Sepah is a major actor in the economic and political networks in Iran, but it is not a uniform institution in terms of direction and aspirations. The Sepah has been indoctrinated, based on the four principles of 'religion, obedience to Supreme Leader, revolutionary character, and fellowship in a people's army' (Alfoneh, 2009, p. 1). These principles are developed by the IRGC's Ideological-Political Directorate (including the Publication and Publicity Bureau) that is headed by a cleric approved by the Supreme Leader (Alfoneh, 2009, p. 1). The IRGC's indoctrination curriculum is not an open source, but inferences on its content can be made based on analysis of the political questions and answers on the Defense and Armed Forces Logistics Ministry website.

Although Khomeini was against involvement of the military forces in politics and Sepah is supposed to serve as a people's army, it has become a force that acts against people in support of the Supreme Leader, Khamenei. The following example of justification of its involvement in politics is given on the Sepah's website (Quoted in Alfoneh, 2009, p. 3):

if a political group active in the country propagates the idea of separation between religion and politics, or if another political party is in favor of providing a foreign government with certain privileges, the Revolutionary Guards considers itself obliged to announce the protest in public since ideals such as the Guardianship of the Jurist and integrity of the country have been attacked.

The theoretical contradiction between being a military force to protect the Supreme Leader and being a people's army is not difficult to justify. The Supreme Leader, leader of the Muslim world, and representative of Imam Zaman, knows best, and 
following his rules and protecting him is for the benefit of the people (Alizadeh, 2013). IRGC in the last three decades has exerted tremendous force against people who are in conflict with the state and has created a hostile wedge between the public and the IRGC (Alfoneh, 2009, p. 3).

Although Khatami never has questioned the legitimacy of Velayat-e Faghih, and believes in the fundamentals of the Islamic revolution, and the rule of Islamic law, his approach to democracy and individual rights was considered, by conservatives, as a dangerous trait for the establishment of the Islamic State. The intelligence unit of the IRGC was developed after Khatami was elected as President. The Supreme Leader did not trust the new President's reformist pro-democracy slogans and how they unfolded, even though the Ministry of Intelligence and Security was controlled by the Supreme Leader and had a mix of directors and staff from reformist to hard-liners (Federal Research Division, 2012, p. 4, 5; Thaler et al., 2010, p. xv). Therefore, the Supreme Leader encouraged and facilitated involvement of the IRGC in politics and expanded and consolidated intelligence services in the IRGC so it could work independently from the Ministry of Intelligence and Security. IRGC has been an active agent in identifying 'antirevolutionaries' in Iran, collecting, analyzing, and producing information inside and outside Iran (Federal Research Division, 2012, p. 3, 37) and also acting as a force of control over civilians.

The Supreme Leader supported Ahmadi-Nejad against reformists and during his presidency, the two intelligence services (IRGC and the Ministry of Intelligence and Security) were more in collaboration than during Ahmadi-Nejad's predecessor, Khatami, when the two intelligence organizations were working parallel but with minimum collaboration (Federal Research Division, 2012, p. 16). While the Ministry of Intelligence 
and Security's main domain of operation is inside Iran and Quds Forces of IRGC operates inside and outside Iran, the Quds Force shares its information with the ministry (Federal Research Divison, 2012). After Ahmadi-Nejad's re-election and the escalation of conflicts between reformists and hard-liners, the Ministry was cleared of high-positioned reformists.

IRGC had a political role in constraining Khatami's administration and in supporting conservative clerics and the Supreme Leader. With the power that the Guardian Council has in filtering lists of candidates in every election, the majority of the 2003 city councils were filled with members or associates of Sepah (Thaler et al., 2010, p. 58). Ahmadi-Nejad has been criticized for creating a new leadership elite that is composed of the security and intelligence community and IRGC members, and particularly for his choice of Governor-Generals (Keddie, 2006, p. 331).

Active involvement of Sepah and its affiliated organizations in the economic sector began after the Iran-Iraq war (Ilias, 2010, p. 8), was enhanced during Khatami's administration, and has flourished since Ahmadi-Nejad became president (Thaler et al., 2010, p. 59, 69). The Supreme Leader, a month before the election of Ahmadi-Nejad in 2005, issued a decree that called for privatization of large scale industries ${ }^{168}$. Sympathizers with the Iranian government argue that this action was taken 'to prepare Iran for possible membership in the World Trade Organization' (American Iranian Council, 2007). The process is not even close to a real privatization, because under the privatization banner, stocks of public economic units are being purchased by state affiliated bodies. Some perceive the privatization efforts of the government as 'a

\footnotetext{
${ }^{168}$ Those industries include large-scale oil and low-end gas industries, mines, foreign trade, many financial institutions, shareholder-owned cooperatives, power generation, many postal services, roads, railroads, aviation, and shipping (“Article 44 of the constitution (Privatization Plan)," 2005).
} 
mechanism for redistributing assets to other parts of the state' (Ilias, 2010, p. 11). In a few hours after availability of an industry for private sector bids, these state-affiliated bodies buy them and, according to a daily newspaper, they are taken out of one pocket and put into another pocket of the state ("Lagging behind and growth during the Cold War and its aftermath," 2007). As a result shares of many national companies that are privatized belong to Sepah and Bonyads (Ilias, 2010, p. 8). Consequently Iranian economic activity is an extreme form of a centralized state-system working similarly to a gigantic cartel with no public checks and balances ("Lagging behind and growth during the Cold War and its aftermath,” 2007). The previously relatively transparent public sector has been transferred into sectors of the state that are 'shielded from public scrutiny' (Alfoneh, 2010, p. 4). These state-affiliated bodies include organizations affiliated to Sepah and Basij and Foundations that are tax exempt and not accountable to the National Auditing Office, Public Audit and the Supreme Court or to supervision by the government.

Sepah has purchased public enterprises and become a major economic, military, industrial, and political conglomerate. Economic privatization in Iran is being monopolized by Sepah through its buying of every major business and enterprise through the Tehran Stock Exchange (Alfoneh, 2010, p. 1) and benefiting from its parallel banking sector that manages its financial activities (Alfoneh, 2010, p. 2). If necessary, Sepah can disqualify its competitors for security reasons (Alfoneh, 2010, p. 5). The financial arms of Sepah and Basij are IRGC's Cooperative Foundation, 'Ansar Financial and Credit Institute' and their many subsidiary bodies including 'Mehr Finance and Credit Institute' which is the largest purchasing entity of the IRGC (Alfoneh, 2010, p. 4).

Gharargah Sazandegi Khatam Al-anbia (known as Khatam-Al-Anbia), the engineering arm of Sepah, is one of the largest industrial contractors in Iran (Thaler et al., 
2010 , p. 59). It is involved in the oil and gas industry, marine, offshore and shipyard industries, telecommunications, airports, mines, dams, water diversion systems, and cultivation. It operates projects that handle billions of dollars (Alfoneh, 2007, p. 3; 2010, p. 2). The Golestan Contractor Guild reports that Khatam Al-Anbia is the only contractor of large development projects in Golestan, including dam construction and a railway route that is part of the Kazakhstan, Turkmenistan and Iran railway project ("Khatam AlAnbia is the only contractor of large development projects in Golestan," 2012). The best option for contractors in Golestan is to sub-contract small projects from Khatam Al-Anbia and its affiliated companies. The Vice-President of the Association of Construction Companies states that allocating all the major projects in the country to state owned contractors such as Khatam Al-Anbia and Bonyad Mostazafan is a reason for delays in the execution of those projects. He adds that government banks and other financial institutions affiliated with the government control funds and the government budget and they provide financial services only to companies affiliated with the government and not with the private sector ("Assigning grand projects to Khatam Al-Anbia: A crtique," 2012).

Basij is a subsidiary of Sepah. Basij is usually labeled by the state officials as being a non-governmental institution or civilian organization, to mute concerns about its dependence on the state and the Supreme Leader. During its initial years Basij was a voluntary institution, which like its umbrella organization, Sepah, fell under the control of the Supreme Leader soon after the Iran-Iraq war. Basij is organized in special units in every sector of society (e.g. for university students, tribes and villages, and factory workers) (Thaler et al., 2010, p. 34). In 2008, the chief of the IRGC stated the 'divine responsibility' of Basij is to support hard-line conservatives (Thaler et al., 2010, p. 62). 
Basij has acted as a 'morality police' force in the streets of Tehran and other major cities, using violence and brutality against people who support political reformists or demand their rights, and was deployed to patrol cities and towns in ethnic regions under the justification of protecting the revolution from within (Thaler et al., 2010, p. 86) and helping police to 'curb security threats' (Thaler et al., 2010, p. 46). Basij has some full time employees but most of the members do not get a salary. It is not clear who is on the Basij's payroll. In poor rural areas, joining Basij is an opportunity to receive benefits such as using its quotas for entering university or for going on pilgrimages. In bigger towns they sometimes offer vocational training. A parallel Basij Al-Zahra exists for women.

Foundations (Bonyads), designated as public but nongovernmental, are trusts with political and economic power in the country. Foundations were established by confiscating banks, real estate, funds and production units owned by the former royal family and its affiliates (Alamdari, 2005, p. 301; Alfoneh, 2010, p. 2, Abrahamian, 2008, p. 178). Bonyad Alavi, Bonyad Mostazafan Enghelab Eslami (the Islamic Revolution Foundation of the Oppressed), the Foundation of Astan Quds Razavi, and Komak-haye Emdaad Imam Khomeini (Imam Khomeini Relief Foundation) are a few of them. The first two are the largest land owners and agribusinesses. Foundations operate hundreds of companies, and according to some estimates are allocated over half of the state budget, and control more than 30 percent of Iran's economy, yet pay no taxes (Bakhtiar, 2007). They are tax exempt or have tax rebates, have priviledges of guaranteed loans and 'enjoy financial benefits, award contracts to the favored few, and confuse the distinction between public and private' (Sciolino, 2000, p. 326). In the fifth Majlis, a budget bill was passed regarding removing the tax-exempt privilege for some of the Foundations, but it was rejected by the Guardian Council. 
Foundations have only a loose line of accountability to the Supreme Leader, who can appoint and remove the directors and where applicable their board of trustees (Maloney, 2004, p. 204). They report directly to the Supreme Leader, not to the parliament, do not fall under the General Accounting Law and are not subject to financial audits (Ilias, 2010, p. 8). They are not required to disclose their financial activities so their wealth is not known (Ilias, 2010, p. 8). Bonyad Mostazafan Enghelab Eslami (the Islamic Revolution Foundation of the Oppressed), the second largest commercial enterprise after the National Iranian Oil Company, is active both in Iran and outside. The Pahlavi Foundation was established when Mohammad-Reza shah succeeded his father. $\mathrm{He}$ donated the lands and properties, that Reza shah had taken illegally, to the Pahlavi Foundation, announcing those properties and lands as Vaqf (religious endowment). The Islamic State took over the Pahlavi Foundation, renamed it Bonyad Alavi and became the owner of major agribusinesses, factories, and lands. After establishment of Bonyad Mostazafan all the factories and agribusinesses were transferred to that foundation but Bonyad Alavi retained ownership of the lands. Finally, Bonyad Alavi fused with that foundation and formed the largest enterprise in Iran. As of 2002, the Islamic Revolution Foundation of the Oppressed controlled about 240,000 hectares of arable land that before the revolution had belonged to private agro-industries (Azkia, 2002, p. 115).

The private sector has become very limited and the major economic actors in Iran are the government sectors that enjoy the revenue from crude oil exports, and quasi-state actors, such as Bonyads and the IRGC (Ilias, 2010, p. 7). Although dominance of Sepah and Bonyads in Iran's economy is well-known by the West, the EU's trade with the Islamic State of Iran tripled between 2000 and 2005 based on the argument that, if Iran can be integrated into the world economy, the Islamic State will be more cautious in 
putting its benefits at risk through its erratic international behavior. This political justification has resulted in more consolidation of the military and paramilitary forces, quasi-state foundations and hard-liners in the country (Alfoneh, 2007, p. 6). The Islamic State of Iran has become a military-industrial complex (Alfoneh, 2007, p. 6) under the leadership of a Shi'a cleric, the Supreme Leader, and the rule of Shari'a law. The state is struggling to legitimize itself by hiding behind a civilian façade and the modern concepts of an electoral system and a popular vote.

\subsection{Political decentralization and access to decision-making process}

The Islamic State uses the term decentralization for its numerous administrative changes and does not differentiate between deconcentration (administrative decentralization) and political decentralization. Deconcentration 'is said to occur when powers are devolved to appointees of the central government' (Agrawal \& Ribot, 1999, p. 475). Political decentralization is different from deconcentration since powers in this case are devolved to actors or institutions that are accountable to the population in their jurisdiction' (Agrawal \& Ribot, 1999, p. 475). It 'aims to achieve one of the central aspirations of just political governance, democratization, or the desire that humans should have a say in their own affairs' (Agrawal \& Ribot, 1999, p. 475).

Elections, which are considered a common mechanism of political decentralization, can only be effective if they are structured in a way that the elected officials are downwardly accountable ${ }^{169}$. When power is devolved to lower level decision-making entities, when lower level actors exercise some autonomy, and when the actors (either elected or appointed) are accountable downwardly, the reform is towards

\footnotetext{
${ }^{169}$ Accountability is: "the ability of citizens, civil society, and the private sector to scrutinize public institutions and governments and to hold them to account" (Odugbemi, 2008, p. 16).
} 
political decentralization (Agrawal \& Ribot, 1999, p. 475). The effectiveness of any political decentralization depends on public sector accountability, which can broaden public participation, responsiveness of empowered local actors, and bring government decision making closer to citizens (Agrawal \& Ribot, 1999, p. 475). Downward accountability broadens participation and can happen through different procedures, such as monitoring by media and NGOs, auditing and evaluation, associations and NGOs political lobbying, and establishing public reporting requirements for governments (Agrawal \& Ribot, 1999, p. 478, 479).

Decentralization appears in the constitution of Iran but it applies only to the lowest tier, municipalities. In Iran, there is a cascading supervision of lower councils by higher councils (United Cities and Local Governments, 2008, p. 208). Obtaining money for operations and services requires constant appeals to the central government, or to the organizations that manage national finances. The central government uses the vagueness in the law to retain most of the powers, leaving municipal authorities with only derisory duties (United Cities and Local Governments, 2008, p. 208).

The central government appoints the heads of provincial governments, and elected officials run municipalities (Tosun \& Yilmaz, 2008). Nonetheless, representation of the people is partial and indirect. First, there is involvement of the Ministry of Interior in both urban and rural municipalities. Second, people elect city or village councils that in turn appoint mayors jointly with the Ministry of Interior (Tosun \& Yilmaz, 2008, p. 8). A large share of expenditures is disbursed through subnational governments that act as agents of the central government ministries and departments. Locally elected representatives have little decision-making power over expenditure (Tosun \& Yilmaz, 2008, p. 7). The highly centralized government fiscal structure, despite having a 
potentially rich, deconcentrated and decentralized government system (Tosun \& Yilmaz, 2008, p. 12) has an ad hoc local revenue system (Tosun \& Yilmaz, 2008, p. 10).

The World Bank reports that in Middle Eastern countries where the ethnic or religious groups in power are minorities, governments are haunted by the fear of the break-up of national unity (United Cities and Local Governments, 2008, p. 208). The Islamic State of Iran is a mosaic of 80 communities and 51\% of the population is Persian (United Cities and Local Governments, 2008, p. 208). The minority ethnic communities in Iran tend to be settled in border areas, and the lack of political will by the Islamic State to commit itself to democratic political decentralization may stem from fear of unrest in those regions.

\subsubsection{Islamic Rural Councils}

The Iranian Islamic State considered the peasants' councils, developed a month after the revolution in the Turkmen Sahra, as a threat and quickly abolished them. The state understood the risk of unrest in the rural areas, and tried, with the active role of the Islamic Revolutionary Guards Corp, to replace the Village Councils, constituted at the time of Mohammad-Reza Shah, with Islamic Councils (Afshar, 1981, p. 1106). The Islamic Rural Council Act was ratified in 1982, but the first election for a Village Islamic Council did not happen until 1998, during the Khatami administration. The reason for postponing the elections was the state's uncertainty in its power to be able to control the council members throughout the rural areas of Iran. A minority of liberal Islamic clerics and politicians supported the councils as decision making institutions and a representation of popular rule, albeit in the context of the clerics' power and authority. The decisions of the Islamic Village Councils had to be in accordance to the rules of Islam, and therefore, 
the councils had planning and implementation roles but not legislative rights, because Islamic law is already inferred by Ulama. The main reason for establishment of the Village Councils was political and the common goal of different factions of the state was the need to replace all the rural organizations, Village Councils (pre-revolution institutions) and Peasants' Councils (grassroots post-revolution institutions), with Islamic ones (Schirazi, 1993, p. 268; Shakoori, 2001, p. 165). This could be done by 'Islamizing the existing ones and throwing out their unwanted member' or by completely abolishing them and setting up new ones (Schirazi, 1993, p. 268). In support of their formation, a spokesman for the parliamentary commission explained that the Islamic Village Councils should function 'as the arm of the Islamic States' (Quoted in Schirazi, 1993, p. 267). Article 6 of the Law's administrative regulations reads (Schirazi, 1993, p. 268):

The holy key task of the Village Councils lies in the preservation of the achievements of the Islamic Revolution and in the efforts that are to be made for enforcing the line of the Imam and in the fight against all the groups that are active against Islam and Islamic people.

The Iran-Iraq war (1980-1988) was another important factor in the immediate setting up of the Islamic Village Councils because a focal task for the Islamic Village Councils was to recruit volunteers for the war and to provide necessary materials and support through Jihad Sazandegi. One member of each council was responsible for addressing the needs of the front (Shakoori, 2001, p. 85). In a competition between the Ministry of Agriculture, Jihad Sazandegi and the Sevener Commissions to set up and control the Islamic Village Councils, Jihad Sazandegi was the winner due to its political power attained during the Iran-Iraq war (Schirazi, 1993).

The councils, which are upwardly accountable to the central state, can build an effective deconcentration that is very different from public participation in decision- 
making and political decentralization. Local councils can be an opportunity for ethnic minorities to have a voice and a 'modicum of self-determination' (Hankla \& Downs, 2010, p. 770). However, this can happen only if an effective political democratic decentralization happens and if power is transferred to those who are downwardly accountable to the population they represent (Ribot, 2004, p. 11). This is not the case in Iran.

Islamic Rural Councils' main roles are to identify village needs, implement programmes, encourage participation, and cooperation with other government instituitions (Mahdidoust, 2004, p. 181). The Councils work under the supervision of the Ministry of Interior (Mahdidoust, 2004, p. 181). A Dehyar (secretary/head of the village council) is appointed by the council to implement its decisions (Sayahi-Kashi, 2004, p. 189). Each province has one representative in the Higher Provincial Council ${ }^{170}$. The Ministry of Interior appoints the heads of the provincial and district administration (Mahdidoust, 2004, p. 175).

Mostafa Azkia of the University of Tehran conducted field research in three villages in different regions during the early years of the Islamic Village Councils, showing that peasants' participation in these councils was very limited and members of the District Village Councils were mostly nominated by government offices ${ }^{171}$ (Schirazi, 1993, p. 270). Council members were not clear about their role and the tasks of rural organizations dealing with rural development issues (Azkia, 2002, p. 108; Shakoori,

\footnotetext{
${ }^{170}$ The hierarchy of councils called for in the constitution is as follows: (1) representatives from the lowest level, directly elected, village councils constitute rural district councils (bakhsh). (2) A county (shahrestan) council include representatives of rural districts and urban councils. (3) County councils have representatives in provincial councils at province level (ostan), provincial government. (4) Representatives of all the provincial councils constitute Higher Provincial Council at the national level (Tajbakhsh, 2005, p. 84).

${ }^{171}$ For example the Rural Service Center
} 
2001, p. 165). Azkia reports that the social composition of the villages and the councils were not proportionate (cited in Schirazi, 1993, p. 270) in the sense that the Council members did not represent all social layers of the village ${ }^{172}$ because most were not elected by the villagers but appointed by Jihad Sazandegi or the Rural Service Centers (Schirazi, 1993, p. 274). Consequently, the councils were not popular among villagers (Azkia, 2002, p. 108). Peasants could participate in implementing construction and infrastructure projects that already had been decided on by the government, irrespective of regional and local differences (Schirazi, 1993, p. 270). Azkia states 'the peasant who is a council member is one because the government wants him to be one and not because he feels the need for it' (Schirazi, 1993, p. 270).

In 1998, Khatami's administration, which constituted the reformist faction of the Islamic State, tried to change the approach to Islamic Rural Councils, at least in theory. Khatami's reformist ideas on 'civil liberty, the governance of law, social justice and elimination of state interference in people's privacy' (Shakoori, 2001, p. 62) called for the Islamic Rural Councils to be solid bases of democracy to enhance public contribution ("Khatami: Councils could promote democracy and encourage public participation," 2002). Ettela'at, the government daily newspaper, reports Khatami as stating at a meeting of councillors that ("Khatami: Councils could promote democracy and encourage public participation," 2002):

Nothing can have as many impacts on promotion of democracy and enhancement of public contribution to their fate as the councils do.' In the same meeting he

\footnotetext{
${ }^{172}$ The bureaucracies in rural areas have a tendency to only deal with wealthier and more informed villagers because the administration system is not compatible with the grass roots, which are shaped by sheer poverty, lack of eduction, and unequal social structures (Shakoori, 2001, p. 139). Shakoori argues: 'The majority of rural people do not have the ability to speak the language of bureaucrats or deal with administrative organisations, and hence are marginalized' (Shakoori, 2001, p. 139).
} 
'urged the councillors to observe transparency in their decisions, the stances they take and in raising their opinion.

Kian Tajbakhsh argues that there is an ambiguity in the understanding of councils in terms of their legal status and their political role (Tajbakhsh, 2006). According to law, councils are the only source of local legislation, and therefore, are subordinate to the executive branch and mandate the provincial executive offices to implement decisions of the council (Tajbakhsh, 2006, p. 5). The scope of areas in which the councils can pass bills is restricted and the councils and municipalities have only a secondary, or almost no, role in economic development planning. This limited role of elected councils is a major obstacle in achieving inclusiveness and accountability (Tajbakhsh, 2000). Four members of the Higher Provincial Council participated in an interview with Khabraonline and highlighted the major problems they encountered as follows ("The Higher Provincial Council round table: The next council will face more challenges," 2013):

(1) The Higher Provincial Council does not have a budget and is run with random help from the government. The Higher Provincial Council's suggestion of allocating 2\% of the revenue of mega-cities to that Council has not been approved by the Majlis. Even some City Councils have no place to convene. Rural Councils are run completely without budgets.

(2) The Executive organs of the provincial governments are in destructive competition with Provincial Councils. Local government should be the responsibility of the councils but the government and Majlis do not have the political will to allow this. People vote for members of parliament based on their local promises and politicians are wary of losing votes if they only focus on national plans. 
(3) The legal mandates of Provincial Councils are ambiguous. Every request for clarification by the Higher Provincial Council to the Majlis has resulted in intervention of the Guardian Council and in more restrictions to the council's authority and limitations on their activities. The main ambiguities in the Council's mandate are structural and legal procedures regarding their role as regulatory and executive bodies. In response, the Guardian Council has taken the executive power of the councils and limited their regulatory power to selection of the Mayor. However, mayors in most of the cities are not approved by the councils and in some provinces the councils have been abolished for not being in accordance with Governor-General's office. In some cities, because of this disagreement, the Governor-General's office has delayed approving mayors' appointments for up to six months, despite the legally mandated period of 35 days.

(4) Members of councils, at all levels, do not get training. Capacity building is a fundamental problem affecting the councillors' ability to do their jobs and meet their goals.

Members of the Higher Provincial Council met with the Supreme Leader in 2011 and pronounced that some of their major problems were the ambiguity of regulatory and executive duties of the councils, lack of budget and funds, and lack of cooperation by government agencies ("Members of the Higher Provincial Council and Municipalities meet with the Supreme Leader," 2011). The Supreme Leader replied that the councils are a demonstration of the importance of public opinion in the Islamic Republic, in contrast to what happens in authoritarian and reactionary states. He highlighted cultural issues as the main task of city and rural councils and referred to the Guardian Council as the right and proper body for resolving disagreements on the regulatory and executive duties of the provincial councils, and that the ultimate resolution is for the Guardian Council to decide. 
He further stated that the main factor in the country's progress is 'moving towards real honor by maintaining and enforcing religion and the religious ambience of cities and rural areas' ("Members of the Higher Provincial Council and Municipalities meet with the Supreme Leader," 2011). He finally asserts that any action that "pleases and causes excitement for enemies and upsets friends' is not acceptable and should be dodged. The response of the Supreme Leader indicates a complete lack of political will to vest more power in councils, and a strong tendency towards maintaining the status quo. The political importance of these council bodies for the state is in establishing a structure that differentiates the Islamic State of Iran from 'authoritarian' regimes.

Khatami and reformists promoted Shahrdari-ha (municipalities) and councils, strangely, as 'civil society organizations' that represent society against the state (Tajbakhsh, 2006, p. 5). A direct implication of this identification is that the government disclaims its responsibility for supporting the councils financially, there is no budget line for councils, and municipal finances are not subject to any accounting (Tajbakhsh, 2006, p. 5). In reality, members of the councils are publicly elected, but councils are not independent civil organizations, therefore, the government should allocate budgets for their operations or foresee a source of funding. The political oversight of identifying councils as civil organizations can be related to the relative autonomy of elected councils from central government, in the 1990's, 'both in terms of not being supervised by the Guardian Council and having local control over how to spend local revenues' (Tajbakhsh, 2006, p. 6). These characteristics were viewed by the reformists as an opportunity to seek democratization and local self-government (Tajbakhsh, 2006, p. 6). Subsequently, volatile power geometries and political situations in Iran put an end to this path. The reformists' simplistic approach and their theoretical denial in disregarding the paradoxes in Shi'a rule 
of law and people's power are reflected very well in the failure of the reformists in practice. The clash of theory and practice of modern Shi'a is also reflected very well in the failure of councils, the substantial paradox of the power geometry in Iran and in the authority of the Supreme Leader (and its tentacles including Sepah and the foundations) spreading over civil society.

After Ahmadi-Nejad took office, new laws were enacted, stating that: a) candidates for Islamic Councils are required to be pre-approved by the Guardian Council, b) the central government, through the Ministry of Interior, has more power to approve and veto council decisions, and c) government contracts are permitted to be granted to the Sepah and Basij affiliated companies (Tajbakhsh, 2006, p. 6). Therefore, the space for local governance/local autonomy is tightened, 'councils have become arms of the central government with limited political influence' (Tajbakhsh, 2000, p. 8), and the government, state and foundations are more than ever in control of urban and rural areas. Essentially, Rural Islamic Councils, supervised by the Ministry of Interior, are institutions to implement the Ministry of Agricultural Jihad programmes (Sulaiman \& Hall, 2005, p. 315), and have been absorbed into the state apparatus (Tajbakhsh, 2000, p. 8).

Decentralization is not a synonym for democracy and can happen in democratic or undemocratic political systems, and be practiced based on undemocratic principles (United Cities and Local Governments, 2008, p. 317). Local self-government, local autonomy, is a constituent of decentralization (United Cities and Local Governments, 2008, p. 316) that 'presupposes freedom of action and organization for the local authority in the context of the law' (United Cities and Local Governments, 2008, p. 317). Reformists' calls for participatory decision-making and democracy could become true if peoples' representation was not partial and there was a wider democratic system in place. 
The absence of a wider democratic system in the country, such as a multi-party system, will turn the councils into 'arms of the central state with limited political influence' (Tajbakhsh, 2000, p. 394). Administrative decentralization brings decision-makers closer to the people they serve and should provide better understanding of their needs, however they rarely empower local people and only 'serve as an extension of central government into the local arena' (Ribot, 2004, p. 10). The socio-economic disparity that exists among provinces cannot be addressed without spatial planning and political will to empower provincial councils and Higher Council of Provinces.

\subsection{Minority rights}

Building civil society, influencing public policy and exerting democratic pressure on the state is problematic in Iran. The Iranian Islamic State's territorial and political undertakings are influenced by the notion that expansion of local politics threatens national unity and escalates ethnic tension (Tajbakhsh, 2000, p. 396). Decentralization, local self-government and councils cannot achieve participatory goals, and bottom-up decision making cannot function if the Iranian Islamic State cannot resolve the issues of ethnicity, minority rights and their fair representation.

The Iranian Constitution ("Constitution of the Islamic Republic of Iran," 2013) clearly states that all Iranians of any ethnicity, color, race, language, gender and religious affiliation enjoy equal rights (Article 19 of the constitution) but recognizing the rule of Shari'a law, and Shi'a Jaffari, contradicts this provision of the constitutional law. Article 115 clearly indicates that the office of the president is restricted to an adherent of the official religion of the Islamic Republic, the Twelver J'afari school of Shi'a Islam (Article 12 of the constitution). Section 3, Articles 19 to 42, of constitutional law is a bill of rights 
guaranteeing basic rights, a second generation of social rights and democratic procedures; however the rule of Shari'a law, Shi'a Jaffari, and the role of the Supreme Leader override provisions of the constitutional law. Only Zoroastrians, Jews and Christians are recognized as religious minorities (Article 13 of the constitution). Iranian Bahaiis, and other 'unofficial minorities', are not recognized as religion minorities, and are even denied rights to higher education. Rule of Shari'a, Shi'a Jaffari law, and its interpretation by Shi'a Jaffari clergies is used as a justification for religious minorities being deprived of access to higher public offices and of gender equality (Article 20 of the constitution). In other words, those religions are allowed, but 'any opinions based on those religions about government necessarily have no weight whatsoever' (Machina, 2008, p. 3). Moreover the system of Gozinesh is an institutionalization of Shi'a discrimination against all 'others'. Gozinesh is a screening process for job applicants, students applying to enter universities and those who seek professional promotions. Applicants must prove their belief in Shi'a Islam and the state. The applicants are assessed for their loyalty and commitment to the state. A Sunni cleric from Sistan-Baluchestan ${ }^{173}$ in an interview stated that even for opening a shop you need to pass Gozinesh and the answers are examined by Sepah (Ghanea \& Hass, 2011, p. 12). Some of the questions are: Have you done anything for the Islamic Republic? Do you believe in Velayat-e Faghih? Did you fight in the Iran-Iraq war? (Ghanea \& Hass, 2011, p. 12). Velayat-e Faghih is against Sunnis' beliefs, so either they have to lie and betray their faith or they stay unemployed and jobless. The very interesting point is that the Sunni representatives in the Majlis should take an oath

\footnotetext{
${ }^{173}$ A province in south-east Iran and neighbor with Pakistan with population of ethnic minorities and some are Sunni.
} 
(Article 67 of the Constitution) to protect the sanctity of Islam and defend the constitution, which is a major part of Velayat-e Faghih.

Sunni members of the Majlis, 19 representatives from 7 provinces, have formed a Sunni Faction. They wrote letters to Ahmadi-Nejad in 2008 and 2011 regarding the unfair treatment of the Sunnis but they never received a response. In November 2011, they wrote a letter to the Supreme Leader and complained about the failure of the government in implementing Articles 12, $15^{174}$ and 19 of the constitution; and the government being adamant in refusing to grant a permit for construction of a Sunni mosque in Tehran that has been requested for many years. They requested formation of a committee to amend Article 115 that excludes Sunni Muslims from being candidates for the presidency ("A letter from the Sunni members of the Majlis to Ali Khamenei- Strong protest against relegious and ethnic discrimination," 2011).

The Cultural Revolution High Council ${ }^{175}$, in 2007, approved an act that stipulated that Sunni religious schooling should be directed by a planning council for Sunni schools, and representatives of the Vali-e Faghih. Sunni representatives in the Majlis and many Sunni clerics protested against this regulation and the interference of the government in both their teachings and schools contradict Article 12 of the constitution ${ }^{176}$. Since 2007, pressure on Sunni clerics has intensified.

\footnotetext{
${ }^{174}$ Article 15: permits the use of local and ethnic languages and the teaching of ethnic literature in schools, while establishing Persian as the official language (Ghanea \& Hass, 2011)

${ }^{175}$ Cultural Revolution High Council is not mentioned in the constitution but is under the supervision of the Supreme Leader and its approved acts regarding social and cultural issues, without going through Majlis and its procedures are regarded as regulations that are effective by a notification by the Head of the Government ("A letter from the Sunni members of the Majlis to Ali Khamenei- Strong protest against relegious and ethnic discrimination," 2011).

${ }^{176}$ Part of the Article 12 reads: "In regions of the country where Muslims following any one of these schools of fiqh [Hanafi, Shafi'i, Maliki, Hanbali, and Zaydi] constitute the majority, local regulations, within the bounds of the jurisdiction of local councils, are to be in accordance with the respective school of figh, without infringing upon the rights of the followers of other schools." ("Constitution of the Islamic Republic of Iran," 2013)
} 
There have been reports of the arrest of Sunni clerics for spreading Sunni teachings in Kurdistan, Baluchestan, Azerbaijan, Khuzestan and Khorasan provinces. Article 3-14 proclaims the security of multifarious rights of all citizens, providing legal protection for all and equality for all before the law ("Constitution of the Islamic Republic of Iran," 1979). Article 14 obligates Muslims to respect the human rights of non-Muslims and to treat them in 'conformity with the ethical norms and principles of Islamic justice and equality' and adds 'this principle applies to all who refrain from engaging in conspiracy or activity against Islam and the Islamic Republic of Iran' (Ghanea \& Hass, 2011, p. 6). The historical record shows that conspiracy and espionage accusations have been used regularly against ethnic and religious minorities since 1979 (Ghanea \& Hass, 2011, p. 6).

The State's action of putting pressure on ethnic minorities arises partially from the fear of separation movements in major ethnic minority territories along the Iranian borders, particularly in Khuzestan, Kurdestan, Sistan Baluchestan, and Azerbaijan provinces. However, the Turkmen in Iran have never been politically and economically motivated to develop secessionist movements. While the Turkmen have ethnic kin in Turkmenistan, the Turkmenistan government has never been keen to develop strong ties with the Turkmen in Iran. The Turkmen government has a stable and strong political and economic relationship with the Islamic State and does not promote any secessionist ambitions (Tahir, 2006). Accusing the Turkmen of secessionism and inflating the issue of security along the Turkmen border due to Turkmen sympathy with Turkmenistan instead of with the Iran nation-state, is an excuse and justification for militarization of the region and establishment of the state apparatus in the Turkmen Sahra, thereby alienating the Turkmen and justifying uprooting them from their ancestral lands. The ideas of local 
councils and local participation are popular among the Turkmen and other ethnic minority communities as indicated by the grassroots movements immediately after the revolution (Samii, 2000, p. 135) (see Section 6.2). The Governor of Gonbad in 1979, in an interview about the Turkmen peasants' movement, stated that the Turkmen, according to their particular religious principles, are not political and they justify and muddle through every problem by connecting it to God's will ("The Governor of Gonbad speaks about the 1979 turbulance in Gonbad," 2011). The peasants' upheaval in 1979 was a grassroots demand for their rights to their ancestral land, water and natural resources. History shows that the Turkmen are a peaceful and hardworking people with no organized political affiliation to right or left. However, they demand equal opportunity for their livelihood and a fair share in decision-making. During the field work for this dissertation, no separationist, antiIranian or anti-Shi'a tendencies were identified in Tengli. A Turkmen interviewee mentioned:

I want to be called an Iranian and a Turkmen. I am an Iranian and want to be treated like any other Iranian and not be deprived of my rights to live because I'm born Sunni. It is not my fault that I was born Sunni in the Turkmen Sahra.

\subsubsection{Turkmen identity and nationhood}

The Turkmen of Iran have developed their identity gradually through their connections and in relation with other actors in their connected networks of humans and non-humans through time. The Turkmen and their environment were one entangled association and part of bigger networks of humans and non-humans (climate, fish, soil, Atrek flood water, open access to commons) of the Turkmen neighboring communities and states, mainly in Iran and Russia. The Russian conquest of Merv in 1884 initiated a sense of Turkmenness that was not subject to any citizenry. They deepened their identity 
as the Turkmen after the Soviet plan of nation-building was introduced (see Sections 4.2, and 4.3.2). The Iranian Turkmen became a subject of citizenship as the political border between Iran and Russia was established in the Qajar era. Their coercive sedentarization by Reza Shah and his nation-building policies fostered the development of the Turkmen identity and their sense of place in Iran. The Pahlavi shahs' policies were continued with the territorial and place-making efforts of the Islamic State.

Drawing on Massey, places are 'a medium through which differentiation is produced' (Massey 2005, p. 199); and are active agents in the formation of themselves and others, the local and global (see Section 2.2 and its subsection). Place-making efforts of the Islamic State and its exclusionary practices of unequal disposition of resources and the Turkmen's sense of place are mutually constituted. The Turkmen in the Turkmen Sahra are ethnic and religious minorities, which struggle to keep their rights to land and natural resources and to emphasize their social rights.

The Pahlavi shahs' notion of Iranian nationalism and the formation of a modern nation-state initiated national-minority consciousness among ethnic tribal groups in Iran (Beck, 1990, p. 270). The State's militarization and exclusionary practices, and ethnic consciousness and exclusionary sense of place have continued in the Islamic State era and have served to intensify/strengthen and deepen the Turkmen identity.

Modernization from above is social engineering that has led to what Vahabzadeh calls 'repressive development' (Vahabzadeh, 2012, p. 9). He explains that repressive development happens when economic, social, and institutional development happens without political development and democracy and the state's authority rests above society (Vahabzadeh, 2012, p. 12-13). Vahabzadeh asserts (Vahabzadeh, 2012, p. 17): 
Nationhood has never been connected to citizenship in Iran, the people remain alienated from the state, as such, Iranians for the most part never felt that they were the right-bearing citizens that belonged to a nation of equals before the law, and the state as the sole representative of the nation became ever more frightening in its might and in its aloofness. The people's alienation from their state is a phenomenon that continues to this day.

Democratization and civil society slogans stay at that problematic stage if they were not materialized in practice through economic and social processes and supported by institutional changes. Vahdat explains (Vahdat, 2012, p. 33):

This type of agency is the antithesis of a universalizable and democratic form of subjectivity and modernity that anchors civil society. Universal empowerment and universal agency constituted the very foundations of rights of citizenship and democratic aspirations and therefore the foundations of civil society.

A clear example of the nation building style of the Islamic State is through its unconventional social services in rural areas that are exclusionary, undemocratic and not transparent. In Tengli, about $20 \%$ of families receive government aid ${ }^{177}$ and many young adults also use services that are provided by Basij. Known as 'poverty alleviation' operations, these actions are not acts of social rights that have developed from the evolution of civil and political rights. Government aid come from Boyad(s) and paragovernmental organizations and their aid programmes are considered nation-building policies of the Islamic State for the purpose of gaining political legitimacy (Saeidi, 2011). These organisations with a strong religious basis help the establishment of the state ideology and also gain political legitimacy for the state. The state also maintains its control over society, especially the vulnerable who easily can become dependent on free aid in absence of other options (see Section 5.6). This is part of the wider state policies to 'decrease the chances of ethnic identities superseding identification with the state' (Samii,

\footnotetext{
177 The free aid is from Komak-hay Emdad Imam Khomeini (Imam Khomeini Relief Foundation) and the state Wellfare Organization. The aid includes small amounts of cash and food staples.
} 
2000, p. 133). Basij also is represented as a voluntary body essential in 'poverty alleviation' in Golestan and is another actor in establishing the government ideology and setting norms on what is socially, politically and culturally accepted by the state. In Golestan province, Basij is a major social, political, cultural control agent that engineers social norms. The head of the Basij in Golestan, in a meeting with representatives of government offices, requested their full and extended cooperation for promotion of the Basij ideology in the province. All the high level government positions in Golestan are occupied by Basij and Sepah members or their affiliates, so they have full support. For example, the Basij in Golestan organizes camps for students to engage them in cultural and religious activities ("17 convoys of Basiji students go to the Rahian Noor camps," 2013; "Reconstruction of villages in deprived areas of Golestan," 2012) and the Basij AlZahra, its women division, organizes classes such as religious principles, painting, and sewing, and organizes pilgrimage to Shi'a holy places ("Pilgrimage of the Basiji Sunni women of Golestan to the holly Mashad," 2013). The camps also provided medical services, but every service includes ideological and religious (Shi'a Islam) propaganda and requires complying with those principles. The Basij camps are very attractive for the young population from rural areas of the province that are deprived of any resources, let alone extracurricular activities. The ultimate goal is not only to convert the Sunnis to Shi'a but to get political legitimacy in the Turkmen villages and make the Turkmen develop a dependence on the state that is not through civil rights but through narrowing down their options and obstructing the building of civil society. 
Ethnic and religious minorities are often intertwined, and the Turkmen, being both ethnic and religious minorities ${ }^{178}$ that are located along an extensive border, have made the Islamic State more aggressive in its territorial policies and in imposing social constraints. The Turkmen definitely do not have equal citizenry rights with non-Turkmen and Shi'a citizens. Here are a few examples:

(1) Representation of the Turkmen in the Majlis is problematic at two levels. First, the role of the Guardian Council in filtering the list of candidates divides the Iranian citizens into insiders and outsiders, us and them (see Section 8.1.1.1). This screening is not particular to the Turkmen. Second, the State's territorial policies divide the Turkmen along regional administrative contours that lower the power of the Turkmen votes.

Local people participate in elections for the Majlis, and vote for Turkmen candidates, disregarding their differences and only because they are Turkmen, but that does not translate into election of Turkmen representatives and the Turkmen's fair representation in the parliament. This is mainly due to the State's many means of changing the population structure of the region and dividing the Turkmen population into administrative patches that directly impacts the power of their votes. A few of these territorial means include: (a) Systematic immigration of Shi'a Kurds and Zabolis from Khorasan Shomali and Sistan Blauchestan ${ }^{179}$ to the Turkmen Sahra and establishment of Zaboli and Kurdish villages in the region and change in provincial territories in a way that the Turkmen population does not exceed the non-Turkmen in districts and provincial divisions; (b) changing the province's territorial divisions, dividing the Turkmen

\footnotetext{
${ }^{178}$ They speak a local dialect of Turkmen, a branch of the Turkic language, and they are Sunni Muslims.

${ }^{179}$ The first small-scale immigration of Zabolis was initiated before revolution but it was escalated after revolution by the government. Turkmen sites report that 250 Zaboli villages are established in Turkmen Sahra and Kurds are also mobilized towards the region.
} 
population along regional administrative divides; and c) changing the electoral districts in every province, resulting in the Turkmen not having a fair number of representatives in the Majlis.

An academic research project examining electoral districts in Golestan province after the revolution ${ }^{180}$ (Ahmadipour, Hafeznia, \& Khojamli, 2011) found that changes in territorial borders of the province have acted to weaken the Turkmens' votes, decrease the chance of a Turkmen entering the Majlis, and deny the Turkmen fair representation. The Iranian Law of Electoral Districts was ratified and amended in 1987, 1995, and 1999 (Ahmadipour et al., 2011). These changes: (a) separate Turkmen cities, villages and districts with high Turkmen population and include them in districts with a dominantly non-Turkmen population; and (b) cause the number of representatives for districts with a dominant Turkmen population to be in conflict with the national standard of one representative for every 150,000 people (Ahmadipour et al., 2011, p. 31, 36). The authors conclude that the changes in the electoral districts do not meet standards regarding the proportion of population and the consequent value of a vote in electoral districts in Golestan province (Ahmadipour et al., 2011, p. 23), and this has resulted in the Turkmen in Golestan being under-represented in the Majlis ${ }^{181}$.

(2) Access to the natural resources of the Turkmen Sahra is getting more difficult and some domains are so completely out of reach for the Turkmen that they are being deprived of their livelihood. Fisheries have become a monopoly of the state. Forests are overexploited by the state so the region is subject to floods and landslides.

\footnotetext{
${ }^{180}$ The research is conducted by a reputable university in Tehran, Tarbiat Modarres.

${ }^{181}$ They concluded this problem can be addressed by allocating one more candidate to Minoodasht, a Turkmen city, and removing a Turkmen city from Gorgan (mainly Persian) and incorporating it into Gonbad Kavous (Turkmen city), where it culturally and socially belongs (Ahmadipour et al., 2011).
} 
Unemployment in Golestan is estimated at $24-30 \%$ in the Iranian media ("Unemployment rate in Golestan: 24-30\%," 2012; "Unemployment rate in Golestan: above 20\%," 2011) and Amnesty International estimates unemployment in the region at $40 \%$ (Amnesty International, 2008a), which is more than the estimated $18 \%$ for the rest of the country ${ }^{182}$. The region is marked by poverty. Systematic immigration of Kurds and Zabolis to the Turkmen Sahra is associated with immigrants, occupying major offices, Governors' offices, government positions, security, police and military, and even labor works. Limitation of the Turkmen in accessing natural resources, losing control and access to their ancestral lands goes along with Sepah, Khatam Al-Anbia, Bonyad Alavi, Zabolis, and Kurds gaining access to the resources that are denied to the Turkmen including bank credit, small and large businesses, and job opportunities. Large-scale businesses and production units are almost all state owned or belong to immigrants, and in some towns they hire migrant workers but not the Turkmen, even for low income labor jobs. Development projects that are state-owned or affiliated to the state do not hire even the educated Turkmen. Even if the recruitment procedure is open for the Turkmen, the applicants have to pass the Gozinesh (see Section 8.3). In short, the government does not allow the Turkmen to enter high level positions; they are dominantly occupied by nonTurkmen, in Golestan and the Turkmen towns in Khorasan provinces.

(3) Addiction is escalating in the Turkmen villages and cities. The price of opium and heroin is cheaper in the Turkmen Sahra than in non-Turkmen areas of the region.

\footnotetext{
${ }^{182}$ The official statistics shows $12.5 \%$ unemployment in urban areas and $8 \%$ in rural areas in early Spring, 2012 ("Statistics Center announced the latest unemployment rate," 2013) but the (unofficial) real number is estimated to be about 18\% ("Current unemployment rate is at least 18\%: Approaches to control unemployment crisis,” 2013).
} 
(4) Turkmen have been killed, are in jail and are tortured or missing for stepping up and demanding their rights to access to the natural resources that are their ancestral heritage, or simply for providing food for their families. In December 2008, a few Turkmen fishermen were killed for illegal fishing in the Caspian Sea ${ }^{183}$ and Bandar-e Turkmen, and a number of the Turkmen from Gomesh Tepe and Chapaqli who protested against the coercive encounter of the IRGC, were arrested and tortured. Amnesty International reported that after a protest against the killing and imprisonment of the fishermen, 200-300 people were arrested from the villages in the region (Amnesty International, 2008a). Later, in May 2008, Amnesty International reported the arrest, unfair trials, and torture of at least six students under 16 (Amnesty International, 2008b). The representative of the Bandar-e Turkmen in the Majlis, a Turkmen himself, complained to the Majlis about the killing of the fishermen and the following mass arrest and stated 'One cannot tell poor villagers that they should continue to live in hunger' (Quoted in Amnesty International, 2008b). Confrontation between the Sepah and the Atrekian villages regarding rangelands in Oghi Tepe had a similar result in 2005 (see Section 7.1.1).

(5) Turkmen are subject to a government campaign to convert to Shi'ism (Taheri, 2008). Shi'a clerics go to Turkmen towns and villages and try to convert them to Shi'ism 'using the promise of jobs and perks as inducements' (Taheri, 2008). The government, for various reasons, make excuses for not granting permits for building Sunni mosques in the

\footnotetext{
${ }^{183}$ Local fisherman are allowed to enter the Caspian Sea to a limit of about $1 \mathrm{~km}$ but due to over exploitation of fish by the state they need to go beyond their assigned limit and sometimes with a storm they even go deeper to the sea. Their complaints about their need to lift fishing limitations for local fishermen never had any response.
} 
Turkmen towns but the number of Shi'a mosques is increasing. Sunni mosques in other cities have been destroyed or closed (Samii, 2000, p. 131).

(6) The Turkmen do not have fair access to higher education. They usually fail the religious tests that are based on Shi'ism. Private universities that are less strict on religious questions have high tuition fees that are beyond the means of the majority of the Turkmen (Tahir, 2006). Their lack of mastery of Persian also reduces their chances to get into higher education (Tahir, 2006). For the Sunni population, putting another obstacle to enter university by going through Gozinesh almost means depriving the young population of the Turkmen of higher education.

(7) The Turkmen women have traditional costumes. The costumes are tight and ankle high. Both their dresses and headscarves are amazingly colorful. The Islamic State dress code for women requires loose robes and headscarves or burkas long enough to cover the ankles, and only dark colors, preferably black. In recent years the government has sent the state dress code costumes to the Turkmen villages for distribution through para-governmental aid organizations and has made it compulsory for the school students to wear those dresses instead of their traditional costumes.

(8) There is a short programme on the Gorgan radio station in the Turkmen language. The Turkmen are not pleased with the low quality of the programme, that the language is mixed with Persian and that the contents of the programme focus on religion. There is a limit on newspapers in the Turkmen language but a small number are published in Golestan province (Amnesty International, 2008a). 'Sahra' the only popular weekly publication in the Turkmen language was closed in 2006 (Tahir, 2006).

(9) The Turkmen are not allowed education in their mother tongue and services are only in the Persian language. 
(10) The Turkmen are not allowed to name their children after their religious figures, e.g. Abubakr, and Omar. Names of the Turkmen cities and villages are being changed to Persian and the name 'Turkmen Sahra' is not being used by the government.

\subsubsection{Politics of place: resistance and opportunities in the AUA region}

Besides territorial natural resources policies and practices of the state discussed in previous chapters, exclusionary social practices of the Islamic State affecting the Tenglians are similar to what is happening in the other Turkmen cities and villages. My observations are that:

(1) Girls, particularly those who have finished high school or are university students join the Basij for possible job opportunities and pilgrimages even though they are to Shi'a shrines. Travel with the Basij is free of charge and they hope that, if they can by luck find a job in the public sector, the Basij will provide them with a recommendation to favor their employment. Therefore, they repeat religious Shi'a slogans and comply with the requirements of the organizers despite their Sunni religious beliefs. (2) The Islamic State dress code was sent to Atrek District, making it compulsory for the Turkmen girls to wear those clothes instead of their traditional costume. (3) No priority is given for development and meeting the basic needs of the Tenglians, including access to gas, a clinic, a middle school, waste management and reliable drinking water, and people still rely on their traditional way of collecting rain water to use in days that drinking water is cut (see Sections 5.3, 5.4, and 5.5). (4) Addiction is becoming widespread in Tengli. It is not an easy topic to talk about in the village. Many believe cheap opium and heroin in the region is a state policy to make their men dependent and non-functional (see Section 5.5). (5) Access to education, for both men and women, in 
Tengli is very limited (see section 5.1.3). (6) There have been attempts to divide the Atrekians, through creating conflicts among the Turkmen villages by dividing their pastures without consulting with villagers (see Section 7.1.1), and also causing division and conflict within the village by making a competition among them for getting free aid and benefits from services that para-governmental agencies provide, and by joining Basij and competing for the negligible cash, food and services they provide.

The porosity of space and its constant change brings opportunities and constraints, therefore, resistance is part of the politics of place. The Turkmens' ethnic consciousness and sense of place is the kernel of this resistance and a reason for mobilization/immobilization of the Turkmen in Iran. Tenglian sense of place stands out in the following examples:

(1) Answers to a survey question asking whether Tenglians have any intention to emigrate to other places for better living conditions and job opportunities are $99 \%$ negative. Despite their strong sense of deprivation and alienation, the Tenglians are reluctant to emigrate, and hope for a better future despite having no economic prospects. This is a strong indication of their sense of place. (2) In the 30 years since the designation of the AUA as a Ramsar Site, the Department of Environment could not recruit a single Turkmen or Tenglian, even by offering good perks and salary, because the environmental tasks include working against other Tenglians (see Section 7.3). (3) Tenglians have a strong sense of community in assisting and helping each other. Analysis of empirical data shows that during difficult times Tenglians borrow money from their relatives and friends (see Section 5.4). They assist families in need in their village and the Turkmen families in other villages. I witnessed during my stay in the village that when someone knocked on her door and asked for money, the lady of the house immediately gave her some money. I 
asked if she knew her, she said: 'No. Probably she was from another village'. I asked why she helped the lady without knowing her, or what she needs the money for. She answered, showing her disappointment in me:

When a Turkmen comes to your door and asks for help she is in need and we help as much as we can. We don't ask what the money is for!

The request for money was not considered begging or solicitation, it was a Turkmen asking for help from another Turkmen. (4) For medical emergencies or shopping, Tenglians do not go to Gorgan, the non-Turkmen city and capital of the province, $71 \mathrm{~km}$ away. They are regular commuters between Tengli and other Turkmen villages and Gonbad, the main Turkmen city in the Turkmen Sahra, $76 \mathrm{~km}$ away. (5) Tenglian women are reluctant to replace their traditional costumes with the state's dress code, particularly for their daughters.

Massey $(1994,1995,2005)$ challenges the hegemonic identity of place and the essentialist view of identity (see Sections 2.2 and 2.2.1). The Tenglians, despite their strong sense of place, are not by any means uniform and homogenous in terms of their political and economic inspirations. The strong sense of place among Tenglians does not imply that Tengli is a homogenous community. There are government informers among Tenglians and people who may betray their community when life gets more difficult. The Turkmen history of experiencing discrimination in the Pahlavi era and its continuation by the Islamic State through constant invasion and exclusionary territorial and civil policies and practices have not made a space for the Turkmen to develop what Massey calls a 'global sense of place'. 


\subsubsection{Global sense of place}

Territorialization and the intricate power geometry of the Islamic State is what have built the civil society in Iran, and achieve a global sense of place for Iranians, a contested and complicated task. State creation of imaginary enemies is an act of power and part of what Foucault describes as governmentality. Developing an image of the Turkmen as enemies of Shi'a, uncultured and backward, plus an image of all the Sistanis in the Turkmen Steppe as invaders and enemies of the Turkmen, are acts of power for shaping social change in favor of the state and the political controllers of the region. The state's propaganda, through some Internet sites, claims that among the Turkmen there are hostile reactions to non-Turkmen immigrants to the Turkmen Sahra, particularly Zaboli people. An activist website in the Turkmen Sahra asserted (Islamic Republic's Efforts to Change the Demographic Structure of Turkmensahra, n.d.) ${ }^{184}$ :

The Turkmen in Turkmen Sahra do not have any problems with the Shiite Persians and Azerbaijani Turks, who are settled in this region and have become a part of the population. They share their happiness and their grievances. This is an indication of the tolerance and hospitality of the Turkmen.

The discontent about the settlement of Zabolis and Kurds in the Turkmen Sahra is not towards a race or ethnicity, it is towards their systematic emigration to Turkmen Sahra and all the social, economic and political actions that are associated with it, which appear to be a calculated strategic plan by the Islamic State to marginalize the Turkmen and deprive them of their lands, livelihood, and culture.

Drawing on Massey, a global sense of place is about accepting the redundancy of the duality of global/local, accepting multiplicity and multiple identities in constant change, and rejecting exclusion (see Sections 2.2 and 2.2.1). The Turkmen and the ethnic

\footnotetext{
${ }^{184}$ An activist website was accessed on November 19, 2009. It is no longer accessible on-line but the hard copy is available.
} 
minorities, as part of the wider Iranian society, are in constant making and remaking through intertwined political, social, cultural and economic processes crossing multiple levels of society. This dissertation argues that the global sense of place for the Turkmen ethnic and religious minorities in Iran, and for all Iranians as a nation, is attainable through entangled processes of civil society building and democracy. A global sense of place is difficult to develop in the context of extreme social, economic and political disparity in an authoritarian state. A strong civil society and a global sense of place are products of intertwined processes of attaining human rights for everyone and tolerance for diversity. When every Iranian considers himself/herself as a 'rights-bearer' agent and participant in his/her community's development and responsible for his/her affairs, 'acknowledge the same right for everyone else', and recognize the agency for all to act in 'accordance with the rules of civil society', then the ethos of civil society is developed (Vahdat, 2012, p. 33). This understanding becomes the foundation for the creation of universal rights (Vahdat, 2012, p. 33), and also for the development of the global sense of place, or what Paymon Akhavan ${ }^{185}$ calls, a new Iranian identity, which is not based on hatred and exclusion and in which every individual can enjoy universal and fundamental human rights (Akhavan, 2012, p. 226, 227). When a strong civil society is taking shape in the country, violation of human rights for religious and ethnic minorities is not only a particular problem of those groups but is perceived by the wider Iranian population as 'an assault on our common humanness' (Akhavan, 2010). This process is necessary for the development of new Iranian and ethnic identities. Paymon Akhavan quoting from Khosro Shemirani states (Quoted in Akhavan, 2012, p. 228):

\footnotetext{
${ }^{185}$ Akhavan is a human rights lawyer based in Montreal.
} 
If we truly are defenders of the rights of all humans, now is the time to raise our voice in unison and cry aloud: For as long as the followers of the Bahai faith are suppressed and imprisoned for their religion and convictions, we are all Bahais!

In the Zayandeh River water crisis in 2008 (see Section 6.2.2), farmers of Isfahan with the help of an NGO, the Society of Support for Farmers of Isfahan, hired two lawyers and raised a legal complaint against the Isfahan Water Company in August 2011. The NGO supporting the Isfahani farmers is an institution with ties to powerful people and religious figures of the province. Its actions are not considered threats to the government so it has an opportunity for political and social manoeuvres. In less than a day the number of plaintiffs increased from 850 to 2200 and was expected to increase to 100,000 ("Plaintiffs of the death of the Zayandeh River," 2011). The case got extensive coverage in the media. After a widespread protest the problem was finally discussed in the parliament and, with pressure from Members of Parliament, finally was considered as a 'national issue'.

Protests of this proportion, legal complaints, political interference by powerful Members of Parliament and finally public support are not likely to happen in ethnic minority regions of the country due to the sensitivity of the Islamic State towards security of borders and its reluctance to recognize minority rights in fear of empowering the ethnic population. The support of Isfahani farmers, in Isfahan, is unlikely to happen in the Turkmen Sahra any time soon, considering the marginalized political and social status of the Turkmen. Mobilization of resources and the establishment of NGOs and grassroots organisations to support farmers' rights to water against the state's powerful apparatus is what the Turkmen need. That can happen through development of a global sense of place by both the Turkmen and non-Turkmen. Establishment of civil organizations and NGOs in the Turkmen Sahra, without being accused of espionage and secessionist intentions, is 
not an easy task and that requires support from national and international organizations and human rights activists.

\subsection{Conclusion}

This chapter argued that the economic and political settings, lack of accountability and transparency by the government system, lack of access to decision-making bodies for the Turkmen, and obstruction of minority rights are important factors in shaping the Turkmen Sahra and the AUA landscape. The Turkmen are not leaning towards secession, and only seek their rights to livelihoods and access to resources and decision-making processes in the context of the Iranian state. The Turkmen, not having political power, and being both at the bottom of the pyramid and the least connected, do not have equal citizenry with other Iranians. The paradox in the Islamic State political system is that rule by Islamic law and Velayat-e Faghih does not allow for the rule of law and a democratic political decentralization. Public political space is a necessary part of public representation and the production of citizenship; citizen groups require equal opportunity to participate in democratic institutions (Ribot, 2007, p. 47). In Iran, the public domain being overwhelmingly controlled by the state has led to institutionalization of 'others' and 'us' (Tohidi, 2009). The state seeks legitimacy by nation building through making the vulnerable Turkmen dependent on free aid from religious para-governmental foundations. Representation is engineered for accountability to higher levels of the state instead of to the people, and responsiveness is to the requirements and needs of the state, the Supreme Leader, Sepah, Basij, and Boyads, instead of to peoples' needs. Concerted territorial policies of the Islamic State that disenfranchise Tenglians are reinforced by policies that directly target the Turkmen ethnicity and their human rights. 
One other important factor shaping the AUA glocal wetland, the conservation discourse and practice in Iran and the role of international organizations, will be addressed in the next chapter. 
CHAPTER IX-Conservation: from discourse to practice

To complete the contextual analysis of the AUA glocal wetlands this chapter focuses on the last issue of how conservation is perceived and understood in Iran. This chapter addresses the following questions: a) What kind of conservation is the goal and how can states engage in socially-just conservation discourse and practice? b) How is conservation discourse in Iran codified, and what are the actors, and power relations involved in that network? This chapter also discusses the position of the AUA in the wider power geometry of global environmental governance, addresses how interests of the Islamic State of Iran and the advisory mission of the Secretariat of the Convention on Wetlands came into alignment behind the AUA conservation project, and how representation of local environment emerged in this process.

\subsection{Discourse of conservation: from 'fortress' and 'command-and-control' to socially-just}

Conservation can be understood in different ways and practiced by significantly varied approaches (see Section 2.4). A valid question is what kind of conservation is our goal?

Conservation is a global business that developed on the back of the strong disciplines of conservation and ecology, and will continue to grow. Environmental degradation, species extinction and habitat loss will continue to happen in the midst of intertwined processes of social, economic and political agendas. It is important to achieve better kinds of conservation practices and policies, and better governance. Multinational organizations, UN agencies, NGOs, state governments, and academia, who are directly involved in developing, practicing and promoting conservation discourse need to answer Machiavelli's question: 'do the ends justify the means?' How far should we go to 
privilege outcomes of biodiversity and nature protection over undemocratic decisionmaking conservation procedures? (Sundberg, 2006, p. 263). Should conservation be at the expense of local people, or how far can we go in the name of nature? Massey explains 'the collision of trajectories in place highlights a conflict which requires a political stance' (Massey, 2005, p. 157). What are the political stances of international conservation organizations and conservation actors in this conflict?

Conservation and preservation policies ${ }^{186}$ started with protection of valuable resources and then shifted their focus to protection of species, and intact habitats, and more recently to conservation with development policies. The shift from a colonial type of preservation in the $19^{\text {th }}$ century, to conservation and protection of biodiversity in the $21^{\text {st }}$ century ends the illusion of separating nature and people (Grumbine, 1998).

'Fortress', 'fences and fine', and 'command-and-control' views of conservation and resource management are exclusionary management systems that have germinated from the notion of separating nature from society, and entail exclusion of local people from protected areas (physically and also politically from policy processes), prevention of consumptive use of their resources, and strict enforcement of law (Hutton, Adams, \& Murombedzi, 2005, p. 342). They entail practices to frame nature, separate it from social context and control any socio-ecological interaction. The discourse of nature, purified nature and nature, as contested, is corollary to conservation practices and environmental politics. These notions of nature lead to a different framing of problems regarding the

\footnotetext{
${ }^{186}$ It is important to distinguish between preservationist and conservationist approaches. A preservationist approach advocates non-use of resources and safeguarding the present situation as it is and in its extreme stance does not allow the evolutionary processes entailed with biodiversity. Conservation unlike preservation is about choice and encompasses a wide range of strategies. It may include protection, preservation, and careful management of natural resources and of the environment. Conservation, preservation and management mean different things to people with different philosophical motivations (instrumental/intrinsic) (Borgerhoff et al., 2005).
} 
causes of natural resource degradation and biodiversity loss, solutions to those problems and available possibilities. Phillips labels the change of perspective from conventional 'fortress' understanding of protected areas to the new emerging participatory conservation as a 'paradigm shift' (Borrini-Feyerabend, Kothari, \& Oviedo, 2004; A. Phillips, 2003). The conventional understanding of protected areas is based on: a belief in protection of pristine nature; management of separate units and territories by central governments, natural resource experts and scientists; controlling the activities of local people with no respect to their needs; benefits for tourists and visitors; and giving preference to national considerations over local ones. 'Participatory conservation' is a new understanding of protected areas that broadens the perspective from specific protected territories, areas or resources to include the surrounding context and puts emphasis on the integration of protected areas in the broader landscape/seascape and the regional and national economy and policy (Borrini-Feyerabend et al., 2004). The paradigm shift in conservation which occurred after the Brundtland Report (1987) and the Earth Summit (1992) was a step towards rethinking the nature/society dualism and moving towards concepts of naturesociety hybrids and socio-ecological systems rather than of pristine nature, reconciliation of conservation and sustainable development, and the consideration of human rights (A. Phillips, 2003). Consequently conservation territories and their classification became more flexible in relation to human interference. There are different sorts of conservation territories ranging from category I of IUCN protected areas, which bans human interference, to Ramsar Sites, which promote 'wise use' of wetlands, and are not necessarily under legal protection. The paradigm shift in conservation occurred parallel with the development of concepts and practices such as sustainable development, wise use and sustainable use of resources. 
The above understandings and the commitment in international circles to the eradication of poverty (at least in theory) initiates policies that focus on sustainable development; sustainable use; socio-economic and cultural equity; rights of indigenous people and local communities; and participatory approaches (A. Phillips, 2003), and more recently leads to conservation based on access-rights, and adoptive co-management. The experience of biosphere reserves and the practice of zoning and buffer zones, the changing concept of national parks, and the debates on the relationships between conservation and development, including debates on ownership of local knowledge, genetic resources, benefit sharing, and intellectual property rights, gave birth to projects and concepts of community-based conservation, community-based natural resource management, and Integrated Conservation and Development Projects ${ }^{187}$ (ICDP) (Borgerhoff, Coppolillo, \& Copolillo, 2005; Zimmerer, Galt, \& Buck, 2004, p. 526)

Participatory conservation is based on an emerging understanding of protected areas as elements of a network which are: a) connected by corridors, stepping stones and biodiversity-friendly land uses; b) open and dynamic systems (beyond equilibrium conditions) that can be managed adaptively ${ }^{188}$; c) focused on conservation and also on ecosystem functions, services, and socio-economic and cultural objectives; d) sensitive to local communities and their needs and concerns; e) run by many partners including local

\footnotetext{
${ }^{187}$ Frank and Blomley describe ICDPs as “....approaches to the management and conservation of natural resources in areas of significant biodiversity value that aim to reconcile the biodiversity conservation and socio-economic development interests of multiple stakeholders at local, regional, national and international levels" (Franks \& Blomley, 2004).

${ }^{188}$ New ecology and theories of multiple equilibria, resilience, and complex adaptive systems have changed the conservationists' position towards more support for community-based management, bottom-up planning, and adoptive co-management (Berkes, 2004). According to Berkes (2004), centralized conservation and environmental management is not a good fit for dealing with complex, non-linear, and unpredictable natural systems, and creates mismatches in management scale.
} 
communities, and indigenous groups (empowered as participants in decision making); f) benefiting primarily the local communities (Borrini-Feyerabend et al., 2004).

Conservation with development is the result of a 'reworking of capitalist modernity as the ecological phase of capital, privatization of nature, the production of commodified nature and a new enclosure movement' (Zimmerer, 2000, p. 357). The combination of conservation and development without any change in market has an inherent contradiction, and seeking a win-win situation might be elusive. Either objectives of conservation and development should be separated (Berkes, 2004), or there should be trade-offs between the two (Garnett, Sayre, \& du Toit, 2007) and the compromise would be development projects that minimize environmental degradation and conservation projects that minimize economic loss (Borgerhoff et al., 2005). Very often there should be a clear prioritization between locally specific conservation and livelihood goals (Upton et al., 2008).

The contribution of conservation areas to development goals and poverty reduction is a complex endeavour and there is no fixed set of conservation strategies to apply to different regions and sub-regions of the world, considering the fundamental differences in their institutional and historical contexts (Naughton-Treves, Holland, \& Brandon, 2005). The nature-society hybrid is crystallized in 'parks with people' projects, including 'conservation with development' and community-based management practices (Zimmerer, 2000). Protected areas in most parts of the world have a higher biodiversity than the surrounding areas beyond the park borders. This characteristic has made them a target for globalization and neoliberal practices in developing countries. Generation of revenue and the economic valuation of resources are forecasts for accumulation of capital in parks and are attractive to governments and businesses in developing countries looking 
for industrial-scale developments and the exploitation of parks (Naughton-Treves et al., 2005; Zimmerer, 2000).

ICDPs have a common theme of generating revenue (e.g., ecotourism, sustainable use of biodiversity, agroforestry), compatible with the park management objectives in buffer zones and of restricting use and access to resources in the core zone of the park (Zimmerer 2000; Naughton-Treves et al. 2005). Since the mid-1990s, international circles have pushed the poverty alleviation and improvement of local livelihood into conservation funding and action. Naughton-Treves et al. (2005), in the Annual Review of Environment and Resources, concluded that ICDPs have limited success in the improvement of social welfare and biodiversity conservation (Naughton-Treves et al., 2005). There is confusion in how to operationalize the multiple objectives, deal with ambiguous mandates, and assess the effectiveness of parks and reserves. The basic question is should ICDPs have 'single or multiple objectives and how to define these' (Wells, McShane, Dublin, O’Connor, \& Redford, 2009, p. 308).

Many conservationists believe that conservation can contribute to poverty reduction in terms of maintaining ecosystem functions and services that support rural livelihoods. However, it is not a solution to poverty if large-scale actors and broader political and economic policies, which shape the rural poor, cannot provide development interventions for education, health care and infrastructure, nor is it if they favor powerful stakeholders such as the pharmaceutical and timber industries (Berkes, 2002; NaughtonTreves et al., 2005). A study on the relationship between poverty and Protected Areas shows that conservation can contribute to poverty locally but is not a significant cause of poverty at the national level (Upton et al., 2008, p. 23). 
The challenge for ICDPs is to generate new approaches to encourage: a) better environmental stewardship in the areas surrounding protected areas and the promotion of sustainable development outside of conservation territories; b) social-ecological systems that are more diversified in terms of livelihood strategies and investment across all kinds of capital assets (social, human, physical, natural, and financial); c) consideration of the role of access to natural resources in the livelihood of the rural poor and the trade-offs among capital assets; and d) decentralized governance, which is based on strong local structures and fair tenure (Garnett et al., 2007; Naughton-Treves et al., 2005). Livelihood strategies of local people are not always compatible with conservation goals, but if equity and empowerment issues could be addressed, livelihoods could become a driving force for conservation (Berkes, 2004, p. 627). It should be recognized that better off local people adjacent to conservation territories (Prtoected Areas) does not necessarily result in more effective biodiversity conservation (Wells et al., 2009, p. 312). The challenge for ICDPs and Biosphere Reserves is shifted from 'Parks vs. people' to 'Park insiders vs. outsiders' (Naughton-Treves et al. 2005, p. 246). ICDP is strongly connected to community-based conservation projects and is now a name for any conservation project that deals with people (Adams, 2009, p. xxiii; Wells et al., p. 307), and shares the same problems that rural development projects have ${ }^{189}$. Biodiversity conservation needs a multi-scalar approach and involvement of vertical and horizontal systems, therefore, enhancement and effectiveness of community involvement in local-level planning requires suitable procedures and structures within planning agencies and dialogue at multiple scales (Abbot et al., 1998, p. 28; Berkes, 2007). Willingness and involvement of

\footnotetext{
${ }^{189}$ Researchers from other fields of enquiry in society-nature domains (e.g. commons management, environmental history, intellectual property rights, environmental justice, and livelihood analysis) shed light on different aspect of the ICDPs and community-based conservation projects (Berkes, 2004).
} 
the agency in power, and those that shape policy outcomes, to participate in dialogues with local communities is essential to meaningful and effective conservation planning (King, 2002, p. 46).

Political ecologists suggest that decentralization (local level environmental governance in and adjacent to conservation territories) is politically necessary for achieving social justice and equity goals of conservation (Neumann, 2005; Zimmerer, 2006b, p. 67). However, a decentralization process is in the context of socio-economic dynamics embedded in local communities. That means decentralization entails 'power effects' of the new order of conservation territory and manifests the complexity of local institutional networks in the context of new spatial forms (Zimmerer, 2006a, p. 11). In this process not all the local groups participate and benefit. Participation of local people has been recognized as a critical element for the success of ICDPs and community-based management projects, and the top-down processes of participation are considered as a reason for their failure (Berkes, 2004). Inclusive, participatory decision-making in conservation and natural resources management is the greatest challenge for participatory projects and the degree of local participation is at the core of that challenge (McCall, 2004). The degree of local participation must be compatible with the objectives and tasks of projects, which are not always geared towards maximum participation (see Section 3.2). The hurdle of achieving good participatory project practice stems from the complexity of the social and political contexts of those projects and the balance in the process of empowerment-marginalization, which revolves around questions of Who? Whose? and What? in a specific project (Corbett et al., 2006, p. 14; Rambaldi, Chambers, McCall, \& Fox, 2006, p. 108, 109; Harris \& Weiner, 1998, p.72): (a) Who: participates; identifies the problem; sets priorities; controls the process; owns the output; accesses the 
information and the will to use it; gains and losses; and benefits from the changes and at whose cost? (b) Whose purposes, questions and solutions, whose knowledge, whose truth and logic, and whose views of the world are being represented? (c) What questions includes, inter alia, what has changed?

Building on the above discussions and on the glocal wetlands analytical framework (see Section 2.4), this thesis argues that glocal wetlands and any conservation project, with the noble goals of protecting nature and the wise use of resources, like any other intervention in socio-ecological systems, must have positive social implications and be socially just in securing, respecting, protecting, and promoting basic human rights or at least not to obscure those rights. These rights include: local people's livelihoods; minority rights; economic, social, political, civil, and cultural rights; and rights to access decisionmaking, information, justice, public participation, equality, water, work, food, health, sanitation, education, and adequate housing (Campese \& Guignier, 2007; Shelton, 2009). Figure 9.1 illustrates how a state can engage in socially-just conservation.

States have different discursive positions about the 'truths' regarding their environmental problems and their solutions (Agrawal, 2005; Hajer \& Versteeg, 2005, p. 178) and they are ultimately responsible for achieving conservation goals and establishing necessary policies, legislation and administrative structures. Along with states, NGOs and multilateral agencies are also duty-bearers of conservation which ensures justice (Shelton, 2009, p. 9). Socially-just conservation is at the intersection of natural resource policies and practices, human rights and social and political processes (Sundberg, 2006). Juanita Sundberg argues (Sundberg, 2006, p. 273):

human rights are a critical variable in conservation; although previously considered separately, these two issues must be thought through and practiced together. On the other hand, conservation policies must include forms of governance that employ, 
but also foster, democratic social relations and procedures. If state and NGO conservationists are seen to be supporting authoritarian measures, their policies may be met with resistance and their tactics may be counterproductive. Moreover, given that both international and national environmental activists tend to come from the professional and elite classes, coercive conservation may be seen as contributing to social authoritarianism.

Socially-just conservation projects, in their ideal setting, use the opportunity to: empower people ${ }^{190}$; emphasize equity and inclusion; focus on people (individuals) as citizens; and highlight the importance of governance (in terms of transparency, inclusiveness and accountability) and seek its enhancement. A State's natural resource and conservation policies ideally can lead to socially-just practices if the rule of law, democratic governance mechanisms and human-rights-relevant policies are in place. Figure 9.1 shows that the traditional sectoral thinking and sectoral approaches in governance, when horizontal connections are weak and the sectors have no interaction with one another, are incapable of mediating changes in policy setting for natural resources, and conservation management. Socially-just conservation which in its ideal form secures local people's livelihoods and their access rights to natural resources, justice, information, and decision-making mechanisms, is feasible through a government's political will to create a space for change by accepting its conceptual principles, setting realistic goals and plans for change, ensuring their institutionalization through laws and procedures, providing the needed authority to facilitate implementation of those plans in the context of socio-economic and institutional realities of the country and the specific characteristics of a place. Government political will and its engagement

\footnotetext{
${ }^{190}$ Chambers defined empowerment as (Chambers, 1983, p. 11): "the process through which, people, and especially poorer people, are enabled to take more control over their own lives, and secure a better livelihood, with ownership of productive assets as one key element."
} 
in socially-just conservation of glocal wetlands connects all players in the conservation network at multiple levels.

Establishing institutional and legal procedures to secure these rights is highly ambitious for countries with less democratic systems, but it is not impossible and can be materialized gradually through rigorous long, medium and short-term global-to-local plans.

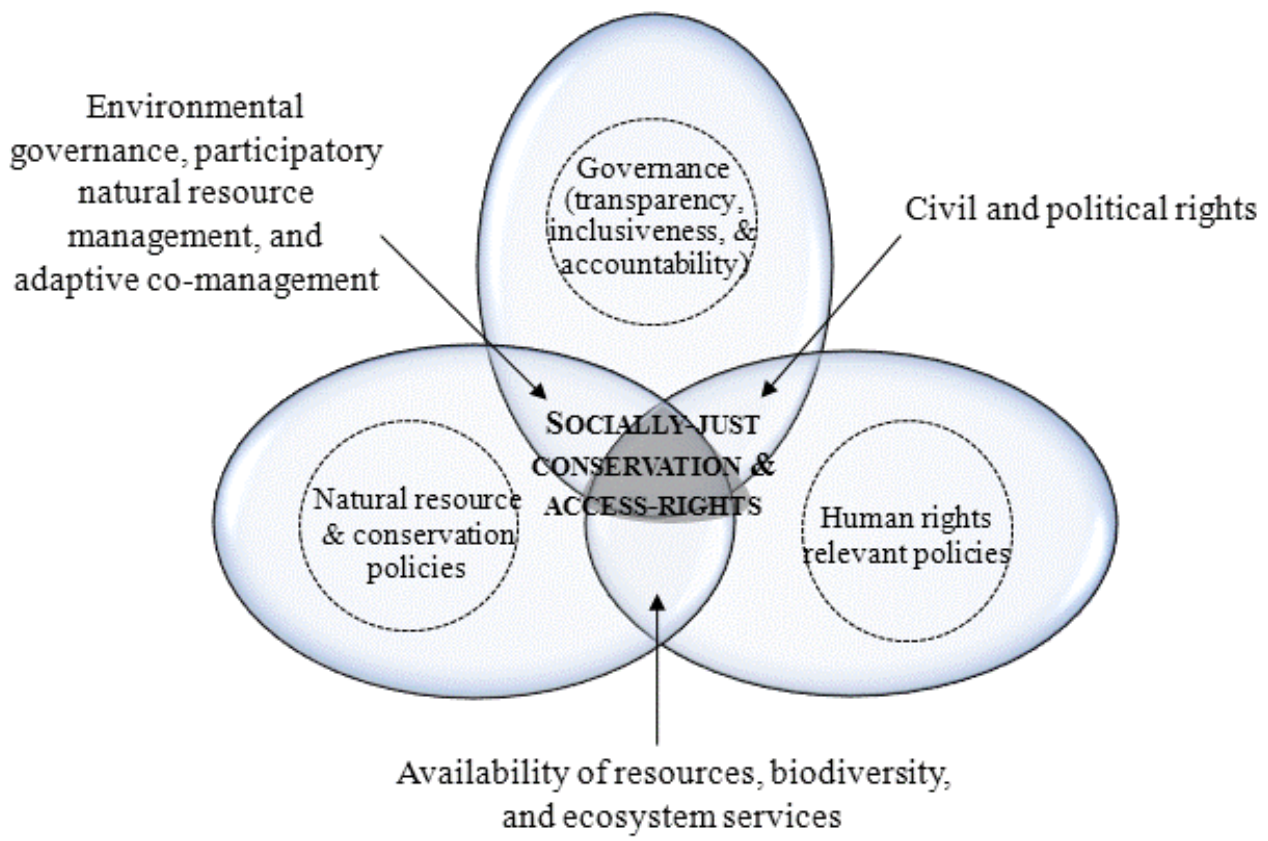

Figure 9.1. Socially-just conservation and access rights The symbols represent:

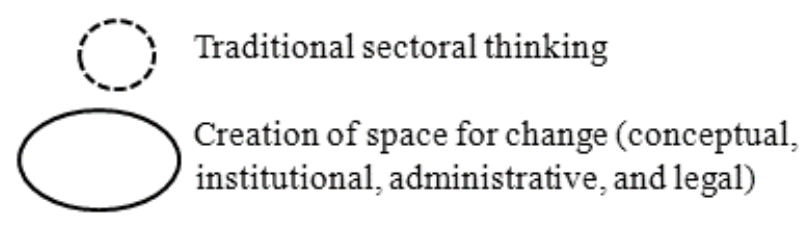

Conservation is a global discourse crossing multiple levels of sociospatial arrangements, and leads to practices that are place-based. The politics of place and governance is the heart of conservation policies and practice. Conservation territories 
recognized as being multilevel and multi-scale undertakings invoke management systems that cross multiple levels and scales. Over-emphasis of any kind of conservation governance (ranging from top-down to bottom-up) as a general prescription without any contextual study deflects attention from the reality of power relations in making a place and provides a space for manipulation of situations and processes in favor of those more powerful and better connected, such as state or village elites, which ultimately may not serve either conservation goals or people's rights. Conservation is neither a threatening external force to a community nor a positive protective agent of nature. Its formation and function in a place depends on 'the construction of that place, the webs of power-relations through which it is constructed, and the way its resources are mobilized' (Massey, 2005, p. 102). Top-down or bottom-up approaches, without due consideration of the context of their application, are the two extreme blunt approaches which create more problems than solutions (Cash et al., 2006). Conservation in its various forms after the paradigm shift in conservation (in late 1980s) and the proliferation of concepts, such as multi-level governance, community-based management, and adoptive co-management, are ambitious political goals for states with less democratic foundations. 'Conservation can be accomplished without democracy' and democracy may not favor nature preservation (Sundberg, 2006, p. 263). As a matter of fact, the command-and-control types of conservation are likely to be easier to enforce in totalitarian systems. States can use those practices in line with their exclusionary policies to control rural areas in their territorial endeavors. 'Fortress' conservation might even sometimes produce good conservation managerial decisions in the short term. However, even if in short term 'the intrinsic rights of nature supersede those of people, the 'protection-by-any-means-necessary' approach is 
likely to fail on pragmatic grounds' (Brechin, Wilshusen, Fortwangler, \& West, 2002, p. 46).

International conservation institutions which are the hub of conservation discourse have produced guidelines, papers, and documents for different kinds of conservation including participatory management and access-right based conservation, which are more democratic. Using these alternatives is a political choice and, moreover, even if they were deployed that will not translate into socially and ecologically sound management of socio-ecological systems in many cases. Rutland and Aylet (2008, p. 633) explain that nature emerges 'contingently from materially heterogeneous relations', and local environment represents matters 'in terms of what gets governed, and how'. They argue that, 'certain approaches to environmental governance, local and otherwise, examine the formation and circulation of discourses that seem to hegemonically orient the actions of state and other actors' (Rutland \& Aylett, 2008, p. 633), however, there is also a link between discourses of environmental governance and 'their material conditions of possibilities' (Rutland \& Aylett, 2008, p. 633).

Community-based management and participatory management of natural resources and conservation projects around the world have not been widely attempted and are difficult to implement (Hutton et al., 2005, p. 363). Those that have not been successful have failed for reasons ranging from the poor quality of project designs to failures in the devolution of power and authority. This does not mean that communitybased management must be replaced with something less difficult (that has usually been 'fortress' conservation); rather, it means that work needs to be done to improve the design and implementation of the procedures to make them better, more efficient and more effective (Hutton et al., 2005, p. 363). 
Discussions on glocal wetlands, seeing the global in the local and localy embedded globalism that is shaped by social differences (Gezon \& Paulson, 2005; Gezon, 2005), and conceptualizing scale as social, fluid and process-based, leave no scope for any scalar trap. This relational thinking helps political ecology divert itself away from its highly problematic propensity to favor micro-scale (or meso-scale) empowerment as the solution to anthropogenic environmental degradation (Brown \& Purcell, 2005, p. 608; Engel-Di Mauro, 2009, p. 118). It also helps conservationists to pay more attention to local conditions and the political agendas of actors at multiple social and geographical scales and levels (see Sections and subsections of 2.3.1, and 2.3.2). Multi-level governance, community-based management, adoptive co-management and local access to resources (physically and politically) may not be sufficient to guarantee socially and ecologically-just conservation, nevertheless lack of access to resources and decisionmaking processes undermines agency, redistribution of resources, and future actions (see Section 2.3.2.1). Empowering the discourse of conservation in terms of governance, human well-being, and rights in the conceptualization of glocal wetlands is about recognition of the agency of the local in production of the global. Community-based management, as a basic structure for more socially just conservation, can be an empowering discourse. Thus, without romanticizing the result of any kind of governance, multi-level governance, theoretically, provides basic flexible structures for accepting a multiplicity of voices and actors. Participatory conservation requires institutional and legal structures, needs to be differential and contextual, and built upon local realities (Mohan, 2007). Success of any governance scheme, in practice, is related to the power geometry of the place and its related processes across multiple levels. Socially, any participatory approach is still better than authoritarian political arrangements in the sense 
that they provide a space of inclusion. It might not be perfect as envisioned in theory, but it still can impact patterns of exclusion in a place (Mohan, 2007, p. 790). Participatory conservation or any space of participation 'allows a form of political learning' and creates ‘spaces of citizenship' (Mohan, 2007, p. 790). Therefore, any attempt to carry out a participatory conservation project in a place can be a practice for claiming citizenship to formulate new rights, or to expand and maintain existing ones. Even if they do not institutionalize as a right, the enactment of participation, though limited and flawed, builds political capital (Mohan, 2007, p. 792) and is a building block for future attempts.

The initial stride for conservation towards participatory management of conservation territories, including glocal wetlands, and for any kind of participatory management of natural resources is: accepting the principles behind those concepts; acknowledging the need for change; and planning, institutionalizing and implementing what will come next. Socially-just conservation, as a nation-wide policy, might seem utopian in the current Iranian context, but participatory management and communitybased management projects can be initiated and negotiated in some places. This requires conservationists, intellectuals, academia, NGOs, international environmental organizations and the state to engage in discourses of nature, purified or contested, and the politics of conservation, 'wise use' and sustainable development, and natural resource management in the Iranian context.

\subsection{Ramsar Convention on Wetlands: 'wise use' of wetlands}

The Convention's mission as adopted by its Contracting Parties in 1999 and revised in 2002 is (Ramsar Convention on Wetlands, 2012a, p. 5): 
the conservation and wise-use of all wetlands through local, regional and national actions and international cooperation, as a contribution towards achieving sustainable development throughout the world.

Weiss, an environmental lawyer, states 'international agreements need to be viewed as living agreements, into which parties continuously breathe life and to which they give new directions by acting as informal legislatures' (Weiss, 1999, p. 103). The Ramsar convention is a good example of this description. The Convention on Wetlands has moved along an evolutionary pathway of conservation from a species protectionist point of view, in the 1970s, to conservation, biodiversity and wise use concepts, at the present time. The official title of the forty-year old Convention is 'Convention on Wetlands of International Importance, Especially as Waterfowl Habitat' but the name used today is 'Convention on Wetlands'. This resulted from the shift of the Convention's focus from protecting waterbird habitats to protecting functions, values and benefits of wetlands as integral parts of land and water systems and for conservation of biodiversity and well-being of communities (B. Phillips, 2001; Ramsar Convention Secretariat, 2013b).

The term 'wise use' was in the original text of the convention (Article 3.1) but it was not easy to conceptualize and practice in the context of the nature protection discourse of the 1970s. The term 'wise use' of wetlands that is at the centre of the Ramsar philosophy was defined for the first time by the Third Conference of the Contracting Parities (COP) in 1987: 'The wise use of wetlands is their sustainable utilization for the benefit of humankind in a way compatible with the maintenance of the natural properties of the ecosystem' (Ramsar Convention on Wetlands, 1987a). The sustainable utilization of wetlands is defined as: 'human use of a wetland so that it may yield the greatest continuous benefits to present generations while maintaining its potential to meet the 
needs and aspirations of future generation' (Ramsar Convention on Wetlands, 1987a).

The annex to resolution V.6 of the convention states (Ramsar Convention on Wetlands, 1993):

In the early years of the Convention, the wise use provision proved to be difficult to apply. Most attention was focused upon the designation of sites onto the Ramsar List in line with global priorities to secure the conservation of internationally important areas. Over time, as the essential need to integrate conservation and development has become recognized throughout the world, the Contracting Parties to the Ramsar Convention have made wise use a central theme for the functioning of the Convention.

The above statement clearly demonstrates the direction of change in the Convention's discourse of conservation from a focus on flora, fauna and their habitats to 'wise use', consistent with the paradigm shift in the global conservation discourse. The convention has moved towards conceptualization of wise use and more holistic approaches (Finlayson, Davidson, Pritchard, Milton, \& MacKay, 2011). Elaboration of the 'wise use' concept was followed by an ecosystem approach and later by participatory management.

By joining the Convention, countries commit to wetland conservation and wise use through the three pillars of action ${ }^{191}$ of the treaty and implementation ${ }^{192}$ of the Convention. The first pillar that is wise use of wetlands requires the Contracting Parties (Ramsar Convention on Wetlands, 2002, p. 6):

\footnotetext{
${ }^{191}$ Three pillars of the Convention are (Ramsar Convention on Wetlands, 2002, p. 5): (1) Achieve wise use of all wetlands, (2) "develop and maintain an international network of wetlands that are important for the conservation of global biological diversity including waterbird flyways and fish populations and for sustaining human life", by appropriate management and wise use of wetlands, and (3) "enhance the conservation and wise use of wetlands using effective international cooperation".

192 "The implementation of the Ramsar Convention is a continuing partnership between the Contracting Parties, the Standing Committee (SC), and the Convention Secretariat, with the advice of the subsidiary expert body, the Scientific and Technical Review Panel (STRP), and the support of the International Organization Partners. Every three years, representatives of the Contracting Parties meet at the Conference of the Contracting Parties (COP), the policy-making organ of the Convention which adopts decisions (Resolutions and Recommendations) to administer the work of the Convention and improve the way in which the Parties are able to implement its objectives." (Ramsar Convention Secretariat, 2013b, p. 33)
} 
working towards the wise use of their wetlands through a wide range of actions and processes contributing to human well-being (including poverty alleviation and water and food security) through sustainable wetlands, water allocation, and river basin management, including establishing national wetland policies and plans; reviewing and harmonizing the framework of laws and financial instruments affecting wetlands; undertaking inventory and assessment; integrating wetlands into the sustainable development process; ensuring public participation in wetland management and the maintenance of cultural values by local communities and indigenous people; promoting communication, education and public awareness; increasing private sector involvement; and harmonizing implementation of the Ramsar Convention with other multilateral environmental agreements.

The Convention moved towards an ecosystem approach ${ }^{193}$ and management schemes that consider wetlands as integrated parts of land and water systems (B. Phillips, 2001). This shift has refined the Convention's vision for the Ramsar List ${ }^{194}$. The Vision now reads (Ramsar Convention on Wetlands, 2002, p. 10):

To develop and maintain an international network of wetlands which are important for the conservation of global biological diversity and for sustaining human life through the ecological and hydrological functions they perform.

The Convention distinguishes between 'naturalness' and 'maintaining the natural properties of a wetland, ${ }^{195}$ and seeks the latter. The Convention recognizes the importance of wetland ecosystems to people as sources of food, water, and, sometimes, income that may assist in poverty alleviation of local people (B. Phillips, 2001). Human use, on a sustainable basis, is compatible with Ramsar principles and wetland conservation.

\footnotetext{
193 "Ecosystem approaches have been developed as an overall strategy for integrated environmental management promoting conservation and sustainable use in an equitable way. They focus on managing environmental resources and human needs across landscapes and are a response to the tendency to manage ecosystems for a single good or service, by trying to balance trade-offs to both human well-being and ecosystem services" (Millennium Ecosystem Assessment, 2005, p. 12)

${ }^{194}$ List of Wetlands of International Importance

${ }^{195}$ Natural properties of the ecosystem are defined as "those physical, biological or chemical components, such as soil, water, plants, animals and nutrients, and the interaction between them" (Ramsar Convention on Wetlands, 1987a)
} 
'Local involvement' in the Ramsar context has been evolved (Ramsar Convention

on Wetlands, 2012a, p. 26):

The evolution of the idea of local involvement in wetland management began with a recognition of the interests in and traditional uses of wetlands by local communities throughout the world. This developed further to recognizing the need to consult local people so that decision-makers and resource managers can take their interests into account. Finally, it became clear that local people need to be actively involved in the decision-making and management processes along with other interest groups.

The Ramsar Handbook for Participatory Skills incorporates the Resolutions and annexed Guidelines adopted by the $7^{\text {th }}$ and $6^{\text {th }}$ Conferences of the Parties ${ }^{196}$ and also provides major lessons learned from participatory management experiences around the world by presenting case studies and discussing methodologies for effective implementation of Participatory Environmental Management as a tool for management and wise use of wetlands (Ramsar Convention Secretariat, 2010a, p. 5). The guidelines are the result of a collaborative effort of Ramsar Partner Organizations and over 200 experts in participatory wetland management around the world (Ramsar Convention Secretariat, 2010a, p. 5).

Recently, the Convention in its evolving path adopted the Millennium Ecosystem Assessment ${ }^{197}$ (MA) approach to wetlands. The Scientific, Technical and Technological Panel (STRP) was requested by COP8 (Resolution VIII.7) to address the Convention's lack of an overall framework for its implementation of 'wise use' (Ramsar Convention

\footnotetext{
${ }^{196}$ Resolutions VII.8 adopted by the 7th Conference of the Contracting Parties (1999) provide 'guidelines for establishing and strengthening local communities' and indigenous people's participation in the management of wetlands' and Resolution VIII.36 'Participatory Environmental Management (PEM) as a tool for management and wise use of wetlands' (Ramsar Convention Secretariat, 2010a).

197 "Millennium Ecosystem Assessment was an international work programme that focused on ecosystem services (the benefits people obtain from ecosystems), how changes in ecosystems services have affected human well-being, how ecosystem changes may affect people in future decades, and response options that might be adopted at local, national, or global scales to improve ecosystem management and thereby contribute to human well-being and poverty alleviation.” (Ramsar Convention Secretariat, 2010c, p. 10)
} 
Secretariat, 2010b, p. 6). The STRP suggested that the MA's Conceptual Framework for Ecosystem and Human Well-Being is relevant and helpful for consideration, particularly where it deals with the interdependence of people and their environment (Ramsar Convention Secretariat, 2010b, p. 6). A team of authors from MA prepared a synthesis report, 'Ecosystems and Human Well-Being: Wetlands and Water' and developed a conceptual framework for delivery of the Ramsar Convention's concept of 'wise use' of wetlands, ecological character, and response to change in the ecological character of wetlands (Millennium Ecosystem Assessment, 2005). The framework provides a multiscalar approach which indicates how and where policy and management interventions and decision-making can be made to deliver the Convention's concept of the wise use of wetlands and maintain ecosystem services for human well-being and poverty reduction (Millennium Ecosystem Assessment, 2005). The synthesis report goes a step further for the Convention to recognize ecosystems as MA describes them, ${ }^{198}$ a hybrid of living and non-living components, and accepts its immediate implications in understanding change in the ecological character of wetlands (Ramsar Convention Secretariat, 2010c, p. 14). The MA conceptual framework identifies 'indirect drivers of change' as demographic, economic (e.g. trade, subsidies, market, and policy framework), socio-political (e.g. governance, institutional and legal framework), science and technology, and cultural and religious factors. The 'direct drivers of change' are identified as changes in local land use and land cover, species removals and/or invasive introductions, eutrophication and pollution, hydraulic infrastructure development, water abstraction, and climate change.

\footnotetext{
198 "Within the MA, ecosystems are described as the complex of living communities (including human communities) and non-living environment (ecosystem Components) interacting (through Ecological Processes) as a functional units which provides inter alia a variety of benefits to people (Ecosystem Services)" (Ramsar Convention Secretariat, 2010c, p. 8)
} 
The MA's 'components of human well-being and poverty reduction' include: health security; environmental security; economic security; cultural security; and equity (Millennium Ecosystem Assessment, 2005, p. 13). The report identifies that responses to direct and indirect changes in the context of environmental management involve (Millennium Ecosystem Assessment, 2005, p. 56):

governance, institutional, legal, technical, economic, or behavioral changes and may operate at local or micro, regional, national, or international level (or a combination of these) and at various time scales.

The synthesis report recognizes that response to a change requires transparent and consultative consideration of all the following: a primary focus on wetlands and water resources; a cross-sectoral approach to address the direct and indirect drivers of change; and trade-offs among different wetland ecosystem services and human-wellbeing (Millennium Ecosystem Assessment, 2005, p. 10 \& 57). The Report asserts that the effectiveness of wetland-focused actions and ecosystem approaches to water resources management can only succeed if institutional settings and environmental governance arrangements are in place. It identifies national and international policy and legislation as the primary components of governance and institutions (Millennium Ecosystem Assessment, 2005, p. 56). The report elaborates certain shortcomings that can create critical conditions and states (Millennium Ecosystem Assessment, 2005, p. 10):

Many of our institutions were not designed to take into account the threats associated with the loss and degradation of ecosystem services; nor were they well designed to deal with the management of common pool resources, a characteristic of many ecosystem services. Issues of ownership and access to resources, the right to participate in decision-making and the regulation of particular types of resource use or discharge of waste can strongly influence the sustainability of ecosystem management and are fundamental determinates of who wins and who loses from changes in ecosystems. 
The Convention has tools to assist the contracting Parties to achieve the wise use goals. The Ramsar Wise Use 'toolkit' contains 21 'Wise Use Handbooks ${ }^{199}$. Some of the handbooks are applicable to specific ecosystems and their processes, and others address direct and indirect drivers of change to ecosystems by providing strategies and discussing relevant interventions. The MA synthesis report identified certain aspects of the 'wise use' approach that are not addressed by the Convention, including the basic materials required for a good life, health, good social relations, security, and freedom of choice and action (Millennium Ecosystem Assessment, 2005, p. 57). In 2012, the $11^{\text {th }}$ meeting of the Conference of the Contracting Parties to the Convention adopted two resolutions, XI.12 and XI. 13, on health and poverty that to some extent fill that gap, but social relations, security and freedom of choice and action are still unaddressed (Ramsar Convention on Wetlands, 2012b, 2012c).

Issues of governance, in terms of democracy, transparency, inclusiveness and accountability, and access rights are almost absent in Ramsar decisions and handbooks. The MA synthesis report for wetlands and water is a very good start for dealing with these difficult tasks.

\subsection{Discourse of conservation in Iran}

Conservation in Iran, as in many other developing countries, was initiated as a globalization phenomenon encouraged by the $\mathrm{IUCN}^{200}$ and executed by the central state

\footnotetext{
${ }^{199}$ The Handbooks cover the following topics: Wise use of wetlands; National Wetland Policies; Laws and institutions; Avian influenza and wetlands; Partnership; Wetland communication, education, participation and public awareness; Participatory skills; Water-related guidance; River basin management; Water allocation and management; Managing ground water; coastal management; Inventory, assessment, and monitoring; Data and information needs; Wetland inventory; Impact assessment; Designating Ramsar Sites; Managing wetlands; Addressing change in wetland ecological character; International cooperation; The Ramsar Convention Strategic Plan (Ramsar Convention Secretariat, 2011).

${ }^{200}$ IUCN was founded in 1948 as the International Union for the Protection of Nature. In 1956, with change in its focus and mandates changed its name to the International Union for Conservation of Nature and
} 
through the collaboration of Iranian intellectuals, bureaucrats, and an elite group of scientists with an honest belief in the 'preservation of Iran's wildlife and its habitats'. Iran adopted the 1970s' global nature protection discourse of 'command-and-control', 'fences and fine' and 'fortress' approaches to conservation and resource management. Coercive management systems for conservation territories in Iran germinated from the notion of separating nature from society and entailed the exclusion of people from conservation territories and strict enforcement of the law for enclosed ecosystems (see Section 8.1). Ideological paradigms of nature protection and wildlife conservation have changed significantly over time and as their relevant discourses evolved so did the structure and practice of nature protection in Iran during the Pahlavi era. Until the revolution, in 1979, these changes included widening the focus of nature protection from species, game and wildlife to ecosystem and habitat protection, highlighting social impacts of development projects, and establishing the Environmental Impact Assessment Bureau in the DOE.

After the Islamic revolution, conservation discourse in Iran has experienced a period of intellectual stagnation. Iranian conservation experts are still practicing and enforcing fortress conservation approaches. In Chapters VI and VII, major predicaments in legal and policy setting processes for nature protection, at national and provincial levels were discussed. These include EIA processes, DOE structural and administrative inadequacies that affect its efficiency and effectiveness as an environmental regulatory institution and how, in practice, DOE is lagging behind other natural resource management organisations in Iran (see Sections 6.1.3.3, 6.2.3, 6.3, 7.3, and 7.4). These discussions demonstrated that the only feasible function for DOE was to follow the goals

Natural Resources. Since 1990 it has been reffered to as the International Union for Conservation of Nature or IUCN- World Conservation Union (IUCN, 2013). 
of conservation as they were set out in the initial years of the Ramsar Convention's establishment about half a century ago; that was species and wildlife protection. While the government agencies are familiar with internationally used terms such as 'wise use', sustainable development, Integrated Conservation and Development projects, participatory management and community-based management, these terms are barren of meaning at the policy level in Iran. Discourses become dominant through the working of power in society. The paradigm shift that has happened in the global evolving of conservation discourse manifests itself in Iran as the rhetoric, not the substance, having changed to the extent necessary to preserve the state's international appearance.

The missing component inhibiting the enhancement of conservation and natural resources policies and practices in Iran lies in the poor state of discourse and research probing into: the implications of nature, as purified or contested, in the Iranian context, and into examining the politics of nature. This knowledge gap should not get diverted to examination of Islamic texts and exploration of the nature loving teachings of Islam, as has been encouraged by government agencies. Examining the teachings of Islam is not a crucial aspect of the conservation dilemma in Iran. The politics of the state towards progress, development and nature are what matters significantly. Research into this discourse should lead to a politics of environmental governance that asks 'governance of what, by whom and to what end' (Bridge \& Perreault, 2009, p. 483) and be the core of conservation practices by framing questions, formulating solutions and deciding on choices of action. If this gap of knowledge could be addressed, political will for participatory management of natural resources and conservation could potentially be produced from the bottom-up. 
Iranian intelligentsia, academics, bureaucrats, journalists and NGOs have not seriously engaged in the discourse of nature/society dualism, nature-society hybridity and the politics of nature. Instead of generalized and blanket recommendations, glocal wetlands require approaches that are context specific and consider the uniqueness of each place and its human and non-human components. Conceptualization of glocal wetlands and socially-just conservation entails taking into account the power geometry of broader networks of actors and stakeholders spanning the global to local, being attentive to local knowledge, and perceptions, and examining socio-economic factors in making of a place, with attention to issues of race, class, and gender and being sensitive to rights, and social justice. Iranians cannot achieve socially just conservation if they do not open up to the discourse of conservation, examine governance and people-environment theories and carry out research on people-environment interaction. The Islamic State's lack of commitment to conservation and its political tendency not to encourage social science research and conservation discourse stress the importance of the roles of international organizations in the country. Currently, international environmental organizations, that could bring the conservation discourse in Iranian society to its next level, neglect their power.

\subsubsection{Social science research}

The notion of contested nature opens arguments about the politics of ecology, who loses and who gains, frames the problems in socio-ecological systems and looks for solutions in social and political domains and does not isolate, essentialize and purify nature. Concepts of governance of conservation and natural resources, participatory management, and integrated conservation with development projects are part of that 
discourse. These concepts need to be negotiated in the Iranian context and become research topics for the social and natural resource sciences. Political ecology, representation of nature and environmental problems, the social and political dimensions of conservation, discursive formations that shape discourses of nature, and theories of power, place, space, and scale should get much stronger in social sciences in Iran. Unfortunately, this is not an easy task in the Islamic State.

A professor in the Department of Environmental Sciences, University of Tehran, in an interview said that he only conducts research on ecosystem modelling because 'unlike socially oriented research, it has no hassle'. Keeping conservation discourse in Iran in the quiet field of pristine nature is a safe strategy for the state. The Islamic State intentionally discourages engagement with social science research and is wary of the production of social knowledges.

The Supreme Leader, in a speech to university faculty members, asserted that two million out of three and a half million total university students in Iran are in the human sciences ${ }^{201}$ and that is a source of concern for him ("Meeting with university professors, elites, and the heads of universities and research institutions," 2009). He states ("Meeting with university professors, elites, and the heads of universities and research institutions," 2009):

This is a worrisome issue because the capacity of universities and research institutions for conducting human and Islamic research at the local level [is low, because] the number of faculty members that believe in the Islamic worldview in the social sciences is not enough for this number of students... Many social sciences are based on materialistic philosophies and disbelief towards the divine Islamic teachings. Teaching [these human sciences] causes disbelief in Islam, and causes fomentation of reservations and doubts in religious and ideological principles in universities...the more the young population and university students

${ }^{201}$ In Iran human sciences includes both humanities and social sciences. 
are obedient and religious, their acts, behaviour and minds will be less harmed and the society can benefit from them more.

He urges the government, Majlis and The High Council of Cultural Revolution to pay serious consideration to this issue. He pronounces that competent professors for the present and future of the Islamic State are those who 'recognize macro-level issues, identify enemies and their goals, set macro-level plans and move towards implementation of those plans' ("Meeting with university professors, elites, and the heads of universities and research institutions," 2009) .

The above statement is a concise description of the political setting of the Islamic State with regard to social science research and researchers. Over the past few decades a number of social scientists have been arrested and accused of plotting against the state. Hajjarian, an Iranian reformist thinker and political scientist, is one of them. After his arrest, in a forced confession video, he states: 'Theories of the human sciences contain ideological weapons that can be converted into strategies and tactics and mustered against the country's official ideology' (Kurzman, 2009). He then states: Weber's notion of patrimonial government is relevant only in countries where 'people are treated as subjects and deprived of all citizenship rights,' which is 'completely incompatible with and unrelated to the current conditions in Iran' (Kurzman, 2009). Conservatives in Iran consider the humanities and social sciences as a mechanism that the West uses to fight and win a 'soft war' in Iran.

Humanities and Social Science research is not encouraged, and university faculties in social sciences are under constant scrutiny by the state. Currently, social science research with policy setting objectives has no prospect in Iran; social science research is not considered useful for decision-making (Farrokhnia, 2009). Though social 
science research is not systematically planned, coordinated, and funded some academics undertake research projects based on their own interests. Political fluctuations and occasional changes in university management may open windows of opportunity for some research. This indicates that research on nature and conservation discourse may be possible in Iran if individual lecturers and academia show interest and take a risk. Considering the disregard of the Islamic State for the humanities and social sciences, the role of academia, intellectuals, journalist, NGOs and international environmental organizations becomes ever more crucial in attempts to create space for discourse on conservation, nature/society duality and hybridity, the politics of nature and peopleenvironment research ranging from anthropocentrism to ecocentrism.

\subsubsection{Experts, academia, intellectuals, and NGOs}

In the predominant absence of social science research for conservation purposes there is no surprise that conservation experts, academia, intellectuals and journalists in Iran have very limited understanding about coercive conservation, participatory management and community-based management in conservation territories. They predominantly campaign for 'fortress' and coercive conservation. During this research in Iran, 12 university professors and experts in environmental management, wildlife ecology, and Protected Area management were interviewed; only one professor, specializing in natural resources management, highlighted the importance of participatory approaches and consideration of local livelihoods in natural resource management and conservation practices and none of them had critical views of coercive conservation and natural resource control. 
Iran has no law supporting and defining NGOs, but NGO-type organizations must seek authorisation by the state and their activities are restricted and controlled (Fadaee, 2012, p. 111). During the reformist government of Khatami, some measures were taken to facilitate NGOs' activities and their participation in DOE's actions through its Participation Bureau, but the Bureau was dissolved after the election of Ahmadi-Nejad and became part of the Public Education Division of the DOE; its goal to support environmental NGOs completely disappeared. As a consequence, 'activists never know how far their actions can go before the NGO is banned or they are arrested (Fadaee, 2012, p. 110). Simin Fadaie studying social movements in Iran states (Fadaee, 2012, p. 110):

Although environmentalism is among the most tolerated issues within the Iranian political context, activists fear that authorities will not tolerate any direct politicization, so they adhere to self-imposed censorship in order to avoid prosecution. This demonstrates the limited level of their activities.

Though communication media are under state control and are often attacked by the state, bloggers and journalists are the only active actor-networks that discuss environmental issues and that question the competency of the institutions involved in working towards achieving sustainable development, natural resource management and conservations goals. These academics, experts, and journalists are stricken by the same syndrome that international environmental organizations in Iran are suffering from. They repeat the 'antipolitic' claims of international environmental organisations regarding conservation without contemplating the political implications of their actions and the goals they set. Iranian conservationists are trapped in the short sightedness of oldfashioned conservation which focuses on 'fortress' conservation goals and practices and uses terms such as 'participation', 'local people's livelihood', and 'sustainable use' as empty words with no social and political weight or reality. The mainstream conservation 
discourse, though it sounds 'scientific', is loaded with politically charged comments that denigrate local people who are taken for granted and never examined in depth. A renowned academic stated (Makhdoum, 2008, p. 580):

The size and number of protected areas of Iran, where other traditional land uses of local communities are permissible, is the largest category of concern. This is followed by Wildlife Refuges. These areas are constantly threatened by invasion by local communities.

He continues (Makhdoum, 2008, p. 580): 'Because there is an insufficient number of rangers, the greatest threat to PA [Protected Areas] is the poaching of animals, plants, and natural features.' He suggests eco-tourism should be promoted and 'the socioeconomic needs of the surrounding population must be considered as a prerequisite for management practices' in protected areas (Makhdoum, 2008, p. 580). In describing the threats to conservation territories, conservationists use terms which are being used by international organizations without considering that these terms hide the political and social contexts of environmental degradation and biodiversity loss processes and flatten the uneven relations of power involved in accessing resources and degrading the environment. In Iran, the gap of knowledge in the politics of nature leads to confusion in the understanding of conservation at theoretical and practical levels, which creates serious social and ecological implications.

A coercive approach to nature protection, conservation and natural resource control is acceptable to and very well supported by the government. Turkmen fishers were killed in Bandar-e Turkmen for fishing illegally (see Section 8.3.1). The Provincial Conservation and Land Affairs Departments under the Forest, Rangeland and Watershed Organization of the Ministry of Agricultural Jihad also has armed units with a mandate to control forest fires and also to police illegal forest and rangeland poachers. The Forest 
Guard Unit is headed by a Commander-in-Chief from the Islamic Revolutionary Guard Corps and its personnel are recruited from the same organization.

Environmental discourse is still in the dark tunnel of the 'fortress' and 'commandand-control' conservation era and another example of its social implications is the bizarre case of a violation of human rights in Iran that has turned into a serious dilemma. Environmental Guards who are usually from low-income economic layers, have been put in an impossible situation. DOE has 2,700 Environmental Guards to police its $13,000,000$ hectares of protected areas ("Environmental Guards are preys of illegal hunters," 2012). The Environmental Guards, in contrast to the Forest Guards who are trained and affiliated to IRGC, have no connections to power networks. They have very difficult working conditions, minimum-to-no training (Abdollahi \& Faryadi, 2010, p. 159), and are not clear about their duties. They are armed and are employed to confront illegal hunters, but are not allowed to fire their arms. They do not have legal protection if they fire their gun to scare illegal hunters and, by mistake, hit them. If an illegal hunter dies, the Environmental Guard responsible will be arrested and, if the family of the deceased do not accept the blood money, the Environmental Guard will be executed! As of August 2012, twelve Environmental Guards are in jail for shooting illegal hunters, one of them is waiting for execution, and 113 Guards have been killed in these confrontations (“Escalating number of wildlife defenders," 2013; Kolahi, Sakai, Moriya, \& Makhdoum, 2012, p. 757). A wildlife ecologist and university professor explained that DOE could solve this problem by simply taking the guns (that make the Guards a target for illegal hunters) from them and training them in how to confront poachers and hunters when not armed ("Environmental Guards are preys of illegal hunters," 2012). 
Iranian conservationists are engulfed in studies of flora and fauna but are not familiar with techniques such as Rapid Rural Appraisal and participatory research or if they are they have no use for its application because 'fortress conservation' recognizes no need for understanding local people, their knowledge, livelihood, and well-being. Ecosystem modelling, understanding flora and fauna of ecosystems and producing ecological knowledge of an area as the only basis for creation of conservation territories and evaluation of their effectiveness, without examining the social construction of a place, the politics of nature and natural resources, local people's livelihoods, and the wider socio-economic processes of a place will most likely lead to marginalization of already marginalized people. This is how conservationists, unwittingly and unwantedly, have become an alliance that enforces exclusionary and suppressive government policies. The case study in this dissertation provides an example of such an involuntary cooperation of the environmental experts of DOE and the Ramsar Convention.

\subsubsection{The State's political agenda}

The website of the DOE states that Iran works closely with International Environmental Multilateral Agreements, treaties and organizations ${ }^{202}$ and is actively involved in three internationally funded conservation and biodiversity projects: the Conservation of the Asiatic Cheetah in Iran, the Iranian Wetlands Conservation Project, and the Conservation of Biodiversity in the Central Zagros Landscape Conservation Zone, co-sponsored by the United Nations Development Programme (UNDP), the Global

\footnotetext{
${ }^{202}$ The Ramsar Convention, the Convention on the International Trade in Endangered Species (CITES), the Convention on Biological Diversity, the Convention on Climate Change, the United Nations Environment Programme, the World Conservation Union (IUCN), the South Asian Conservation Environment Programme, the Convention on Conservation of Migratory Species, the Kyoto Protocol, and the Basel Convention
} 
Environment Facility (GEF), and the Government of Iran ("Natural Environment Division," 2013).

The Conservation of the Asiatic Cheetah in Iran, and the Iranian Wetlands Conservation Projects when evaluated by their implementers, were represented and praised as being ecologically and socially successful projects. The head of the DOE, in response to constant criticism of the Conservation of the Asian Cheetah project, claims that the project is successful and refers to IUCN's director of cat species projects when stating that 'the project is described as a model for conservation of threatened species in the Middle East and the actions taken by the government of Iran are praised' ("A Memorandom of Undertanding for the second phase of the Asian Cheetah Project," 2013). The Iranian Wetland Conservation Project had wide media coverage by both the government of Iran and UNDP. A report prepared by the UNDP field office in Iran (United Nations Development Programme-Iran, 2012, p. 1) states:

In the following report, UNDP has sought to document the transformational changes produced by this successful project, focusing on participatory processes, civil society engagement and leveraging national involvement.

The project, Conservation of Biodiversity in the Central Zagros Landscape Conservation Zone, had a Mid-Term Evaluation by an independent reviewer in 2011 (Hunnam, 2011). He concluded that the goal of the project, which was biodiversity conservation mainstreaming and developing a strategy to introduce it, has failed to be achieved. He states (Hunnam, 2011, p. 1):

[The goals of the project] have not been adequately understood, explained or applied by those guiding and managing the Zagros Project. Instead, the Project Executing Agency, DOE, and the management team have reverted to a more conventional approach, centered on DOE and its main strategy of Protected Areas, rather than on the mainstream sectoral agencies and the need to secure biodiversity conservation across the wider landscape and multiple natural resource uses. As a consequence, even after 6 years there is little progress to report towards 
introducing integrated management of natural resources and biodiversity conservation in the Zagros Mountains.

It is interesting that the only project that had an independent reviewer has been considered a failure, and the other two that were reviewed by the project implementers have become symbols of the Islamic State's successful holistic approach to ecological issues (““Conservation of Iranian Wetlands' project: signed,” 2013).

The Iranian National Biodiversity Strategy and Action Plan, a UNDP initiative, was developed in 1998 but has not yet been implemented. Preparation of a spatial land use planning system has been delayed for more than three decades. There is no sign of gaps in EIA regulations being addressed, and no attempt has been made in mainstreaming conservation and development projects. Previous discussions on nature protection and its institutional, administrative and legal shortcomings, and conservation discourse provide enough evidence to claim that, in the current economic and political context, the Islamic State is not in favor of socially and ecologically sound conservation, and sustainable development decisions, and the government does not have the political will, commitment, or effective political engagement to create space for such change, despite the publicity by international organizations and the Islamic State.

This questions the extent of the Islamic State's active participation in international environmental organizations. Iran's Ministry of Foreign Affairs officers are among the chairs, vice-chairs and coordinators for many multilateral environmental agreements: the Intergovernmental Panel on Climate Change, the Regional Organization for Protection of Marine Environment, the United Nations Framework to Combat Desertification, the Convention on Biological Diversity, the Basel Convention, the Montreal Protocol, the Caspian Environment Program, the United Nations Commission on Sustainable 
Development, the World Summit on Sustainable Development, the United Nations Environment Programme, and the Global Environment Facility.

The Head of the Working Group for Research on International Organizations, the Islamic State's Center for Strategic Research, has discussed strategies on how to improve the position of the Islamic State in international organizations, including creating effective promotional space and media and 'using the potential of the Iranian NGOs in International Organizations' at national, regional and international levels (Tabatabaie, 2008). The Islamic State is well aware of how such rhetoric can be used as a tool to enhance their image in the international arena. However, these approaches are put forward in a political context in which neither of these processes are free to flourish because they are under government control. The intergovernmental environmental organizations, with the claim of being apolitical entities, essentially act as effective political means, that provide good niches for the Iranian government to subsidize its political crisis in the international arena and enhance its image. Validation of the Government of Iran from the international organizations and projects gains it an image of being an environmentally responsible system, even though it is not headed towards sustainable development and nature conservation and environmental issues rank very low among its concerns. Conservation is a mask that allows the Iranian government to keep up its appearance in the international arena and to gain global status while not having a true commitment to implementation of those treaties. The Islamic State extends conservation territories in the country by designating more wetlands as being of 'international importance' and 'Protected Areas' but destroys the existing ones in the name of economic growth. 
The Iran National Report submitted to the Tenth meeting of the Conference of the Parties, the Convention on Wetlands, 2008, reports the change in the designated Ramsar Administrative Authority from the Department of Environment to the International Economic Affairs and Specialized Agencies of the Ministry of Foreign Affairs (Ramsar Convention Secretariat, 2008, p. 6). This shift was needed for two reasons: a) the inefficiency of the DOE in engaging and participating in international negotiations; and b) the highly political importance of the Ramsar Convention providing an opportunity for the Islamic State to be present in international arenas. Iran has been hosting many international meetings for the Ramsar Convention and has an active presence in the international arena of environmental governance.

\subsubsection{The AUA Ramsar Advisory Mission: discourse of 'wise use'}

The Ramsar Convention has the tools and mechanisms to involve in the discourse of conservation and 'wise use' concepts through its Advisory Missions to Montreux Sites. At the time of the AUA Advisory Missions to the AUA, 2009, all the Handbooks of the Convention for implementation of 'wise use' of wetlands, as discussed in this chapter, and the resolutions of the $10^{\text {th }}$ Conference of the Parties, including the strategic plan for 2009-2015, were available. Let us examine what the AUA Advisory Mission achieved.

The Ramsar Convention lacks compliance and enforcement provisions ${ }^{203}$, so no country is legally bound without its consent. Recommendations, resolutions, and guidelines passed by the member states at the Conference of the Parties are referred to as

\footnotetext{
203 "Compliance refers to the extent to which the behaviour of states conforms to the rules set out in a treaty; implementation involves specific actions taken by states within their own legal systems to make a treaty operative; enforcement denotes measures to force state compliance and implementation; and effectiveness focuses on whether the objectives of the treaty are actually achieved. Compliance does not guarantee effectiveness but is usually a necessary condition unless the treaty itself is so weak that compliance requires no changes in behaviour" (Vig, 1999, p. 17).
} 
soft law (Kruchek, 2003; Verschuuren, 2008; Weiss, 1999). Kruchek asserts that, 'the commitment to promote wise use will likely remain rhetorical or operationally ineffective unless each country translates this broad concept into detailed legislation' (Kruchek, 2003, p. 3). Soft law is part of international law and is considered as providing legally non-binding norms. In certain areas in international law, the negotiation of legally nonbinding instruments is increasing more than those of the formal international conventions (Weiss, 1999, p. 104). Moreover, legally nonbinding agreements are pivotal because "nongovernmental actors participate in the definition and implementation of soft law norms' (Vig, 1999, p. 16). International law is implemented through national, provincial and local laws. Agreements evolve over time and compliance by countries also changes. The common reasons for individual states not fully complying with the obligations of international treaties are lack of capacity or lack of political will (Faure \& Lefevere, 2005, p. 173; McCormick, 2005, p. 83; Weiss, 1999, p. 108). States might find some provisions of these treaties in their interests and comply with them and violate others (Faure \& Lefevere, 2005, p. 173). Sands and Peel explain that soft law plays an important role in the 'likely future direction of formally binding obligations, by informally establishing acceptable norms of behaviour, and by "codifying" or reflecting rules of customary law' (Sands \& Peel, 2005, p. 52). For example, in human rights law, many instruments began as nonbinding commitments. Vig explains that 'the substance of public international law increasingly reflects concern with moral issues such as human rights and intergenerational equity and extends to many areas heretofore considered private' (Vig, 1999, p. 16).

Recommendations, resolutions and guidelines adopted by contracting parties to the Ramsar Convention 'explain, amplify or supplement the provisions of the 
Convention' (Kruchek, 2003, p. 145) and indicate how treaty obligations can be interpreted (Verschuuren, 2008, p. 5). These texts may achieve a binding effect over time but currently they are not legally binding documents and can be disregarded by member states even if non-compliance is counter to international public opinion (Faure \& Lefevere, 2005; Kruchek, 2003; Verschuuren, 2008; Weiss, 1999)

The Secretariat 'of the Convention is not responsible for national implementation, although it may facilitate agreed activities with national agencies and others' (Finlayson, 2012, p. 139). However the Secretariat has two mechanisms that can influence national practices and discourse of conservation and 'wise use': project development and approval for Small Grant Funds; and Advisory Missions for Montreux Sites. A wetland being listed as a Montreux Site is an obvious indication that the Contracting Party could not achieve 'wise use' of the wetlands and has not been able to apply the 'wise use' guidelines approved by the Conference of the Parties. When a Contracting Party, fails the Secretariat of the Convention has a crucial role to play.

The Secretariat of the Convention stresses that a Ramsar Advisory Mission is a technical support mechanism that provides international expertise in giving advice on appropriate actions (Ramsar Convention Secretariat, 2010, p. 12, 24) and its main objective is to provide assistance to countries in 'solving the problems or threats that make inclusion in the Montreux Record necessary' (Ramsar Convention Secretariat, 2013c). Pritchard et. al (Pritchard, Dereliev, Dufour, Ognimba, \& Watha-Ndoudy, 2010, p. 5) clarifies the role of Advisory Missions and asserts that they are:

not necessarily expected [to] generate ideas and insights that have not already been thought of, but it will cast them in a new light, bring independent scrutiny, and distill those issues that have particular relevance to the requirements and the adopted guidance of the Convention. 
Ramsar Advisory Missions provide opportunities for the authorities 'to test and demonstrate the quality (thoroughness, precaution, transparency, consistency, etc.) of the decision-making processes involved, in the context of Ramsar requirements' (Pritchard, Dereliev, Dufour, Ognimba, \& Watha-Ndoudy, 2010, p. 5). Pritchard states the Convention 'has no legal 'enforcement' procedure, but has 'accountability' mechanisms, and these create strong political pressure for countries to "do the right thing" (Pritchard, 2003, p. 20). The Ramsar Convention Manual (Ramsar Convention Secretariat, 2013b, p. $14,15)$ asserts that failure to comply with the commitments of the Convention could have implications:

[It could] lead to political and diplomatic discomfort in high-profile international fora or the media, and would prevent any Party concerned from getting the most, more generally, out of what would otherwise be a robust and coherent system of checks and balances and mutual support frameworks. Failure to meet the treaty's commitments may also impact upon success in other ways, for example, in efforts to secure international funding for wetland conservation.

Furthermore, Pritchard (Pritchard, 2003, p. 20), in a review of the Convention's current situation and future prospects, states:

Ramsar, unlike some other international treaties, has managed to avoid becoming too politicised. Knowledgeable wetland specialists usually undertake governmental responsibility for implementing Ramsar. These people often do not have high political authority, and a future priority must be to strengthen their partnership with other sectors.

The report approves the claims of the government of Iran, regarding the existence of a concerted effort that addresses adverse ecological characteristics of the AUA by national, provincial, and local inter-sectoral coordination, provision of alternative livelihood for local people and 'wise use' of wetlands. Despite the image of success developed by the Iranian propaganda system, the DOE and the Ramsar Secretariat, the 
political will of the Iranian government and its effective engagement in conservation, wise use of wetlands and good governance in the AUA are seriously contestable.

The findings of this research strongly suggest that the assessment by the Ramsar Advisory Mission seriously overstates the 'success' of the Iranian Government (see Sections 7.3, and 7.4.), and does not support any of the claims made by the consultant regarding: local people's livelihoods, sustainability of measures taken for water use and allocation, control on water abstraction from Alagol, land use, habitat conversion, and improvement of biodiversity and wildlife in the AUA landscape. These issues are critical political issues in the Turkmen Sahra and are far from being sustainable in the context of the current economic and political circumstances.

The challenging issues regarding the AUA Advisory Mission Report, and its inferences and recommendations (see Sections 7.3 and 7.4) highlight the complexity of ecological change in the AUA area and the importance of comprehensive hydrology, ecology, soil, and water studies along with socio-economic and political examinations.

Acknowledging the political nature of water and land issues in the AUA area could have given an opportunity for the Ramsar Convention to contribute to restoration of the AUA, recommend and give advice on possible measures for integration of wetlands into river basin management to maintain the ecological character of wetlands, and enhance environmental sustainability; but the process failed. The major problems with the advisory report are that it considers the hydrological and land use changes and the relevant policies in the AUA area to be positive, not giving adequate consideration to whether the ecosystem approach was used in assessing the integrity of the ecological systems, and concluding that the wetland habitats and species are being improved, all without conducting adequately diligent research. The claims of the report are also 
problematic for not considering and valuing the social component of the landscape, the loss of traditional knowledge concerning water and land use management by the Turkmen, loss of their traditional livelihood strategies, loss of their connection with nature, and their marginalization. This discussion returns us to the importance of studying natural and social together rather than using sectoral approaches that divide nature and society into two unrelated realms. Any ecological change needs to be examined in its wider socio-economic and political context, and its social impacts understood as part of the change process. Only then can it be labeled as a positive/negative management practice or an improving/degrading ecological change.

The Ramsar Advisory Mission and its hasty, brief and inadequately researched report, is problematic in that it represents the process of the mission, its objectives, and the report as a scientific and technical mechanism, in a political vacuum, with no power asymmetries. This representation simplifies the driving forces in ecological change in the AUA and denies the complexities involved in the area. In short, it establishes a 'wise use' discourse that is not consistent with the recent evolvement of the Convention's guidelines based on the Millennium Ecosystem Assessment synthesis. Moreover, it undermines the credibility of the Ramsar Secretariat in its ability to recognize, acknowledge, and deal with its social and political impacts in the field. The Advisory Mission, by making political decisions under the cover of technical advice, denies the social and political aspects of conservation and 'wise use' and the possible cross-sectoral responses dealing with uncertainties in decision-making processes. The objectives of the Advisory Mission (Moser, 2009, p. 4), to 'verify the report submitted by the government' in addressing the threats to wetlands, to "verify the statements made from meetings with the various stakeholders', and to provide recommendations for management and monitoring of the 
site, were not and cannot be apolitical. The lacunae in the Ramsar Advisory Mission Report have assisted in enhancing the authority of the Iranian central government in the Turkmen Sahra and the AUA region and its control over resources to the disadvantage of both the ecological system of the region and the Turkmen.

The Advisory Mission to the AUA and the report are products of uneven power relations between the Ramsar Secretariat, the DOE, the government's regional and local authorities and the local people. Through the interactions of numerous networks and power relations, the Ramsar Secretariat exercised power and became a strong political actor in different ways. The report is now part of a political process in the development of environmental discourse in Iran that legitimizes unjust command-and-control conservation practices in the AUA:

(1) The report created 'knowledge' about the AUA and developed a distorted picture of the AUA landscape. This 'knowledge' was not founded on the current status of conflicts over land use and water management in the AUA landscape and the Turkmen Sahra. The report highlighted potential threats from local people (hunting, water for agriculture, fish farms) but did not identify major stakeholders and did not even mention the powerful political entities in the AUA area such as IRGC, the Foundations, and major non-Turkmen water users such as the new fish farms that are extensively being developed in the AUA area. The consultant did not even meet with any land and water authority in the region. Finally, the report made comments and conclusions that ignore the political nature of water and land use in the AUA region that has been working towards the marginalization of the Tenglians.

(2) The third objective of the Ramsar Convention Advisory Mission was to provide recommendations regarding maintenance of the ecological character of the site 
and livelihoods of the local people. The consultant had the opportunity to acknowledge this gap of information but seriously failed. The Advisory Mission Report approved a recreation facility at Ulmagol as a measure for wise use of the lake and claimed that 'This facility is providing important alternative livelihood for the local communities' (Moser, 2009, p. 8). Making such a strong statement and assuming tourism 'is providing important alternative livelihood' for local people in the AUA region without examining and knowing their livelihood strategies, priorities and constraints is a common, but inexcusable practice of fortress conservation and command-and-control management of conservation territories. It is an exercise of power that will shape the power geometry of the AUA landscape to the disadvantage of the Turkmen, its long-term stewards.

(3) The Advisory Mission enabled the Iranian government in developing its image as a competent scientific and technical authority in the AUA area, politically committed to conservation of the environmental commons, and accepted in global conservation governance. This translates into approval of the 'fortress' and 'command-and-control' discourse of conservation that is practiced by the state at the national and local level and also bestow a high status to the Islamic State at the global level of conservation governance. This is most unfortunate for the Ramsar Convention's credibility.

The Ramsar Convention Secretariat in alliance with the DOE and its active involvement in territorial practices of the government of Iran should open the discussion to ecological and social ramifications of the resource control politics crossing the global to local levels. Although the old school of conservation considers conservation to be a value-free scientific field of enquiry with seamless, straight-forward, and linear relations, as reflected in the Advisory Mission to the AUA, it is rather a complicated nature-society hybrid project, with hidden networks crossing international, national and local scales. 


\subsection{Conclusion}

Conservation does not have a universal meaning and is not a uniform practice of fixed rules in abstract (see Section 2.4). Conservation discourse has evolved at the global level from 'fortress' to 'participatory' management of conservation territories. Conceptualization of glocal wetlands requires this discourse to move further toward socially-just conservation in terms of governance, human rights and space of change in policies, regulations and institutions. It is crucial to understand that socially-just conservation is a choice! Conservation is acceptable, and maybe more feasible, when local people's livelihoods are sustained and when social justice is met. Socially-just conservation requires the political will of governments and international organisations.

Conservation discourse in Iran has been motivated internationally and is making state institutions engage with intellectuals and scientists, nature and wildlife. It was evolving positively until the Islamic revolution, but has lagged behind since then. The paradigm shift that has happened in global conservation discourse in the 1980s did not prevail in the Islamic State's endeavours in conservation and natural resource management, 'wise use' and sustainable development. In Iran, a knowledge pool on nature-society interactions is almost non-existent and Iranian conservationists do not have in-depth knowledge of the evolution of nature protection concepts toward 'wise use' and sustainable development that started in the 1980s. Intellectuals, academia and NGOs are little engaged in the discourses of nature (purified or contested), nature/society duality and hybridity, and the politics of nature and have not examined governance and peopleenvironment theories, nor have they conducted research on people-environment interactions in the Iranian context. Involvement of journalists, media, and academia is necessary for the initiation of discussions on the above topics and for engagement with 
conservation discourse as a socionature field of enquiry rather than as pure nature. Therefore, questions of: 'Who loses; who gains; and at whose cost?' have not been examined and addressed in the context of natural resource access and management in Iran. Environmental journalists, NGOs, scientists and researchers need to become familiar with approaches and concepts of political ecology and engage in discussions and research on social and political aspects of conservation in the world and in Iran.

This chapter argues that the Ramsar Convention Secretariat is an active agent in formation of conservation discourse in Iran. Through the interaction of its numerous networks and power relations, the Ramsar Secretariat has exercised power to, among other things: create an image of the AUA; legitimize 'command-and-control' conservation practices; and enable the Iranian government in undeservedly developing its image as an efficient scientific and technical authority in the AUA region, at national and international levels, in global governance of the environmental commons.

Any claim or statement in the assertions of the Iranian government's commitment to conservation goals has political and social ramifications, which cross international, national and local levels, and should be treated with caution. The mutual relationship between the global and local infers that in these processes the Islamic State also has had impact on and shaped the Ramsar Secretariat. The Secretariat helped the DOE to remove the AUA glocal wetlands from the Montreux Record and put it back on the Ramsar List based on faulty analysis. This transaction, that might be justified as a sound political decision for providing better legal protection for the wetlands by being in the Ramsar List rather than in the Montreux Record, has turned the Secretariat into a careless actor that, legitimizes the development of 'knowledge' about local people, people-environment interactions, and natural resource management, policies and institutions without thorough 
investigation. In light of its findings from the multi-scalar and contextual analysis of the AUA site, this thesis demonstrates that the Ramsar Secretariat in this Advisory Mission Report violated the principles of 'wise use' in the context of the Convention, when it followed the path of endorsing 'command-and-control' and 'fortress' conservation. The Ramsar Convention lost the opportunity to enhance conservation and wise use of AUA wetlands in the following ways: (a) by not identifying the gaps in environmental regulations, legal procedures and EIA regulations; (b) by not identifying measures to address the issue of integrating conservation and development and mainstreaming wetland conservation into sectoral development; (c) by not providing an opportunity for intellectuals, journalists and academics to engage in discussions of conservation governance and evaluation of possibilities and constraints in the Iranian context; and (d) most importantly, by not investigating local people's livelihood, priorities and options in order to establish a foundation of respect and consideration for local people, and employ participatory practices to understand people-environment interaction.

This thesis argues that conservation projects are similar to development projects and their social footprints need be evaluated. What are the social footprints of the Ramsar Convention Secretariat in the AUA? Development of evaluating, measuring and reporting systems to allow the contracting parties to the convention to be able to assess, manage, and report the impact of applying Ramsar Convention guidelines and principles across levels, on affected communities, local people, and society, as part of a monitoring system for adaptive co-management, would be a step towards socially-just and responsible conservation and 'wise use' principles. The Ramsar Secretariat is as responsible as national governments. The political alliance of global and national environmental 
institutions and structures have had and will have impacts on the local livelihoods, access to natural resources, marginalization of the local people of the AUA, and the development of fortress conservation. The Ramsar Convention Secretariat needs to acknowledge its role as a political player rather than claiming only being a technical advisor and be aware of its political and social impacts crossing multiple levels. Conservation is a social construct and the Ramsar secretariat needs to engage with socially-just conservation in a more effective way in order to acknowledge, control, assess, and amend its social impacts. Because conservation organizations have given themselves the right, have the power, and built the power relations to speak for nature, does not mean that their social impacts are justifiable and they are safe from public scrutiny. Even neo-liberal institutions, such as the World Bank, are expected to take steps to turn their practices towards socially-just development and environmental actions by 'explicit and systematic integration of human rights into WBG operations' (Herberston, Thompson, \& Goodland, 2010, p. 2). 


\section{CHAPTER X-Conclusion}

Any territory with border delineation in its core is intended to include some people and exclude others. Designation of any piece of ecosystem as a conservation territory is a place-making process, which is a manifestation of power relations performing in society and crossing many scales and levels. This place-making is associated with creation of an object, in this case AUA glocal wetland, for the purpose of conservation in order to be governed by the central government and its territorial policies. Designation of AUA as a Ramsar Site in the 1970s, its inclusion in the Montreux Record in the 1990s and then back to the Ramsar List in the 2000-10s was a process of making and re-making place which demonstrates power relations and power-geometry performing in society at large. The state has been most involved in the lengthening of the AUA actor-network through the enrolment and mobilization of other actors and building the necessary associations among government and para-governmental agencies (Department of Environment, Ministry of Agricultural Jihad, Governor-General Office, Ministry of Energy, Sepah, Basij and Bonyads, and international conservation allies (Ramsar Convention Secretariat) across several scales. State exercise of power and the schemes to enrol humans and nonhumans includes the following processes: coercive sedentarization of the Turkmen to convert them to 'Citizen' and to control them; water and pasture nationalization; exclusionary land use and water policies of the state during the time of Shah and the Islamic State; and 'fortress' conservation facilitated by international conservation organizations and implemented by the Islamic State.

The AUA glocal wetland as a Montreux and Ramsar Site is a tale of composite power effects of: 
(a) the broad development trajectory of the Iranian state emphasizing economic growth, and rapid industrialization and not having the political will for sustainable development, spatial planning, and Integrated Water Resources Management and River Basin Management; (b) the urge of the Iranian state to control water flow of the Atrek to Turkmenistan and the Turkmen steppes, through damming and diverting water, and controling land use in the region; (c) the strategic actions of the Islamic State to turn the Turkmen in the Turkmen steppes to landless people, disassociate them from their environment, and push them towards becoming wage laborers and more dependent on the state; (d) the persistence of local people and their reluctance to emigrate, and their hope for a better future despite having no economic prospect; (e) the habitat and ecosystem sensitivity of the AUA region and their deterioration due to bad governance of the commons and land and water decisions of the State; (f) the strategic planning of the Iranian state to participate in conservation treaties, to improve its position in international organizations and to strengthen its voice in international arenas; (g) the failed advisory mission of the Secretariat of the Convention on Wentlands by approving the enforcement of 'fortress' and 'command-and-control' conservation policies in the AUA, and not recognizing environmental policy gaps, nor biodiversity, and water and natural resource management shortcomings; and (h) lack of productive engagement with conservation discourse (nature/society duality and hybridity, coercive conservation and politics of nature) and research on theoretical foundations and practical implications of more advanced approaches to conservation including, participatory management and adaptive co-management in Iran by academics, conservationists, environmental journalists, and intellectuals. 
This research, by introducing and employing the glocal wetlands analytical framework, and through a multi-scalar and contextual analysis, argues that removal of the AUA wetlands from the Montreux Record at the request of the Islamic State and endorsement of the Ramsar Advisory Mission was not a socially and ecologically sound project. It has failed both in conserving wetlands and helping local livelihoods, despite the claims of the Secretariat of the Convention and the Islamic State. Measures such as water allocation, land-use change, and livelihood of the Turkmen in the Turkmen Sahra have always been sensitive political issues. Arguments of this thesis reveal that the politics in the Turkmen Sahra tend to remain critical through processes such as state and nation building, territoriality, and control over resources and conservation, which does compromise certainty and stability in the AUA region, despite what is depicted in the Advisory Mission Report.

Local people, despite their geographic proximity, are distant from the lakes, land and the Atrek's water. The processes and networks involved in such topology explain what is close and what is connected and what is in proximity but out of reach of the Turkmen. This dissertation explained that: development in the Turkmen Sahra is based on poor planning and almost no planning at any scale, from a simple land use planning to spatial planning, IWRM, and IRBM; Village Councils have accomplished very little in local governments; Tenglians' access to their ancestral lands and water and wetlands resources has been negligible; land conversions have favored Sepah, Basij and Bonyad(s); water allocation has gone to state-owned and non-Turkmen enterprises in the AUA region; and the Tenglians have been pushed to become cheap labor in the border market, and have become dependent on free aid from religious para-governmental foundations. Concerted territorial policies of the Islamic State, which are consistently disenfranchising 
Tenglians also include policies directly targeting the Turkmen ethnicity, religious belief and human and minority rights.

\subsection{Contribution to Knowledge: Theory}

This dissertation contributes to the field of political ecology, and peopleenvironment interaction and to two bodies of literature: political ecology and conservation by its explicit engagement with relational thinking of place, space, scale and power and discourse of conservation.

Given the prominence of dealing with ecological change in Montreux Sites this dissertation conceptualizes Ramsar Sites as glocal wetlands and proposes an analytical framework for their study (see Section 2.4); it suggests context-specific methodologies and participatory methods that can contribute to their examination, and highlights the use of counter-mapping (see Sections 3.1, and 3.2). The glocal wetlands analytical framework is developed based on viewing conservation territories through the lens of socionature and relational notions of space, place, scale, and power rather than as pristine nature and broadens the scope of studies to webs of power relations criss-crossing multiple levels and scales. It contributes to the emerging literature seeking to understand conservation territories as nature-society hybrids and provides a more robust knowledge and understanding of people-environment interaction in terms of livelihood strategies, access to resources, governance, and power geometry.

Building on the theorization of glocal wetlands, this thesis elaborates on the concept of socially-just conservation and how states can engage in that kind of conservation and argues that the state's natural resource and conservation policies ideally 
can lead to socially-just practices if the rule of law, democratic governance mechanisms and relevant human-rights policies are in place.

\subsection{Policy relevance}

This dissertations has developed glocal wetlands analytical framework to analyzing social-ecological systems and acquiring the breadth of knowledge required for addressing a range of natural resource and conservation policy concerns at multiple levels. Arguments and findings of each chapter are given in their respective conclusion sections (Sections $4.4 ; 5.6 ; 6.3 ; 7.5 ; 8.4$; and 9.5 ). The relevance of these findings to policy development including recommendations for future actions at the local, national and global levels are summarized below:

(1) The findings of this research contribute to the global pool of indigenous and local knowledge. It explains the traditional resource use and land and water management of the Turkmen in the AUA region. The Atrekians' spatial knowledge of AUA and its surrounding steppes, their resources, land and water peculiarities of the region, and the Atrek's flooding scheme enabled them to shape a unique place with distinct microclimate that is distinct from the surrounding steppe. The Atrekians' traditional flood water harvest is a potential solution to the processes of desertification in the AUA and enhancement of biodiversity of the landscape. Documenting the wealth of the Turkmen traditional knowledge about wildlife, land, pasture, and water management and examining their possible application in the Turkmen Sahra is a useful step towards sustainable development of the region.

(2) This dissertation demystifies social construction of the AUA, examines the AUA as a nature-society hybrid. In a historical analysis it concludes that the Turkmen 
were knowledgeable stewards of their land, water and natural resources and were skillful land and water managers. Tenglians were active agents in formation of the AUA landscape that was the source of their livelihoods, as farmers, herders, fishers and hunters, and an attraction for biodiversity before it was designated as a Wetland of International Importance. The landscape that the Turkmen shaped provided support for their livelihood and also for the biodiversity of the region.

In this process this dissertation: (a) gives voice to Atrekians and makes them visible by documenting and mapping their land use and conflicts in contemporary Iran. It provides a basis for acknowledgement of the rights of the local people, tenure and access to land and natural resources; and (b) builds a foundation for informed debates, by all players, about: conservation and development initiatives; and land and water policies and practices in the AUA region and the rights of Atrekians and Tenglians.

Efforts of the state to control the region encompass a wide range of economic, social and cultural policies and practices. Atrekians who lost their access rights to their ancestral lands and water due to the state's territorial policies seek their right to access resources to continue farming and resist becoming wage laborers. They are not separatists and only seek their right to livelihood.

An interesting and challenging future study could examine: how to develop the political will for achieving sustainable development in the Turkmen Sahra, which is a case of a socio-ecological system in the midst of complicated geo-political, ethnic, sociopolitical, and economic networks; and explore strategies and mechanisms for building the political will for a development concept and practice that will be socially inclusive and ecologically just. 
(3) Examining the traditional land and water management of the Atrekians; the politics of the state natural resource control; land use change and water conflicts in the AUA region; and 'the rule of law' and political and civil rights, have shed light on several reasons that contributed to the Atrekians losing access to their ancestral lands and water in the Islamic State. Acknowledgement of these arguments and findings is a keystone in the legitimate claim of the Tenglians to their lands and water rights. A summary of this analysis is given below:

(a) The Islamic State does not recognize that the Crown Lands and nationalized rangelands were in fact the Turkmen lands that were illegally taken from them by the Pahlavi Shahs. (b) Classification of the Atrekian's land as rangeland by the Islamic State entails a major simplification and purification of the Atrekian's complicated customary land use system. The Atrekian's integrated land and water management system, collectively used land and water, and open access to land, and does not fit the division of rangelands and cultivatable land that is required by law. (c) The Islamic State's exclusionary land and water policies have resulted in complete abolishment of the Atrekians' traditional integrated land and water management and open access system (in 1984), after which each tribe divided their lands among their member households, entitling each to a few hectares (the majority were entitled to less than 10 hectares). However, after this division, most Atrekians did not know the exact locations and size of their lands. The financial burden of land claims for small parcels, the whereabouts of which are also not clear, was too great. (d) The lack of legal documents proving the rights of the nine tribes over collectively used land and water and lack of records of intra/intertribal negotiations has worked against the Turkmen's claim to their ancestral lands and water. Moreover, during the land distribution period, at the time of Shah, most of the 
Turkmen could not file claims to their lands because their claim to a specific parcel of land had to be filed within 6 months from the day of its advertisement and with the illiteracy, lack of logistics and minimal communication services available to the Turkmen, this time frame was not practical (Gorgani, 1979). (e) The Turkmen, to gain legal tenure of their ancestral lands and customary water rights, have to go through unfamiliar legal and bureaucratic processes that usually require legal assistance beyond the means of Atrekian peasants. Atrekians not having political ties to the state apparatus, lacking access to adequate financial means to pay legal fees, and the cost of the resources they are entitled to, and having language impediments, are all obstacles in dealing with the governmental bureaucracy.

These findings highlight the significance of examining and revising land classification from the Caspian coast to the AUA region. Such action would have a better result if it were undertaken by institutions that are independent of the Ministry of Agricultural Jihad and its subsidiaries and, preferably, were conducted by universities or NGOs.

(4) This research contributes to the process of critical thinking of Iran's conservation and natural resource policies by employing, for the first time, a political ecology approach to analyze conservation discourse and practices in Iran, and sheds light on ecological, social and political implications of those practices at multiple levels and scales. It suggests that addressing the gap of knowledge and conducting research regarding implications of nature, as purified or contested, in the Iranian context, and the politics of nature, are good steps towards elevating the conservation discourse in Iran from its stagnation, lagging behind the global conservation discourse. Conceptualization of glocal wetlands and socially-just conservation suggests that research on people- 
environment interactions in conservation territories in Iran should: take into account the power geometry of broader networks of actors and stakeholders spanning the global to local; be attentive to local knowledge, and perceptions; examine socio-economic factors in making of a place, with attention to issues of race, class, and gender; and be sensitive to rights and social justice.

(5) Mainstreaming environmental concerns and integration of wetlands into river basin management is a crucial step to maintain the ecological character of wetlands, and environmental sustainability in Iran. This process requires mainstreaming conservation and nature protection in natural resources management. This thesis sheds light on some primary topics for future research necessary to achieve this goal in Iran:

Local level: In the absence of spatial planning and with the "uneven presence of political players' in the Turkmen Sahra, an 'uneven development' has occurred in the region and this is distinctly reflected in the ecological degradation of the Turkmen Sahra and also in the marginalization of the Turkmen. This dissertation recommends that better management decisions and policies would result if, before initiating new conservation measures in the AUA region, the following actions would take place: (a) Preparing a simple land use plan for the AUA region considering hydrology, climate, soil, and flora and fauna in both aquatic and terrestrial ecosystems. (b) Conducting research on the AUA landscape for better understanding of the AUA ecological requirements. This study should incude terrestrial ecosystems and sensitive areas of the regions (e.g. Sofikam no hunting zone). (c) Studying the Atrek Basin and mechanisms for employing an Integrated Water Resources Management approachin the absence of spatial planning.

National level: Mainstreaming environmental concerns requires substantial work at the national level, and cooperation among different sectors of the government. The aim 
is to ensure that decisions that will affect natural resources and biodiversity, take into account various sectors of natural resource managers and users, including local livelihoods. This dissertation sheds light on some of the priority issues regarding environmental policies, legislation and processes, especially: (a) the identification of gaps, overlappings, and contradictions in environmental regulations and policies (regarding natural resources, biodiversity conservation, and protected areas), legal procedures, and EIA regulations; (b) enhancement of the public participation in decisionmaking process in EIA procedures; (c) establishment of efficient processes that provide access to information by the public and facilitate information sharing among government agencies; (d) establishment of mechanisms to improve accountability of the DOE; and (e) improvement of the access to justice when rights to information, participation in decisionmaking and livelihood security are violated.

(6) The Ramsar Convention should be more diligent towards the reality of a place, and carry out livelihood strategy analysis for local people and case-specific and contextspecific research in every Advisory Mission, instead of a generic dictate of ecotourism for wetland inhabitants. The glocal wetlands analytical framework provides an opportunity for the Secretariat to engage in complicated nature-society hybrid projects, with hidden networks crossing international, national and local levels, and prevents short sightedness that stems from concepts of nature/society duality that consider conservation as a valuefree scientific field of enquiry with seamless, straight-forward, and linear relations, as reflected in the Advisory Mission Report to the AUA.

(7) Claims of applying apolitical approaches to conservation and natural resource management lead to ineffective conservation solutions and potential negative social impacts. Though there is no law that makes international conservation organizations 
accountable for the social impacts of their actions in developing countries, their credibility is at stake. Given the prominence of Advisory Missions in dealing with ecological change in Montreux Sites, this thesis aims to contribute to building a space for change in that process by: (a) drawing attention to social and political implications of their seemingly technical advice before they make any kind of direct interventions in local affairs under the name of science and nature protection; (b) highlighting the role of the Secretariat in the development of conservation discourses in developing countries; and (c) stressing the need for development of a system of reporting on social foot prints of applying the Convention's guidelines and resolutions. 
List of References

17 convoys of Basiji students go to the Rahian Noor camps. (2013, September 3). Golestan Basiji Students [in Farsi]. Retrieved from http://golestan.beest.ir/?q=node/1239

21 National projects approved by the Minister of Agricultural Jihad, Gobad Kavoos. (2010, September 23). Fars News Agency [in Farsi]. Retrieved from http://www.farsnews.com/printable.php?nn=8907010623

A letter from the Sunni members of the Majlis to Ali Khamenei- Strong protest against relegious and ethnic discrimination. (2011). International Campaign for Human Rights in Iran. Retrieved from http://persian.iranhumanrights.org/1390/10/sunni_mps/

A Memorandom of Undertanding for the second phase of the Asian Cheetah Project. (2013, October 3). Students' News Agency [in Farsi]. Retrieved from

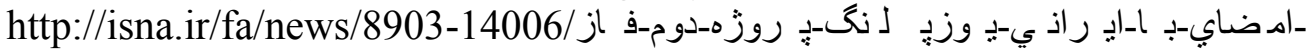
ت ن فاهـ نامه

A seminar to study the Atrek basin. (2011, May 1). Water News Network [in Farsi]. Retrieved from http://www.wnn.ir/html/index.php?name=News\&file=article\&sid=10407

Abbot, J., Chambers, R., Dunn, C., Harris, T., Merode, E. d., Porter, G., ... de Merode, E. (1998). Participatory GIS: opportunity or oxymoron? Participatory Learning and Action Notes, 33, 27-34.

Abdoli, A., Ghaemi, R., Shakiba, M., \& Jaffarinejad, M. (2005). Promoting protection status of wetlands in Golestan: bird count, habitat evaluation [in Farsi]. Deaprtment of Environment- Golestan.

Abdollahi, M., \& Faryadi, M. (2010). Legal Challenges of the Department of Environment Iran. Environmental Sciences [in Farsi], 7(4), 143-180. Retrieved from http://www.sid.ir/fa/VEWSSID/J_pdf/77113890411.pdf

Abrahamian, E. (2009). A history of modern Iran. Cambridge: Cambridge University Press.

Abrams, P. (1988). Notes on the difficulty of studying the state. Journal of Historical Sociology, 1(1), 58-89.

Adams, W. M. (1993). Indigenous use of wetlands and sustainable development in West Africa. The Geographical Journal, 159(2), 209-218. 
Adams, W. M. (2009). Overview of four volumes: Conservation. In W. Adams (Ed.), Conservation Vol. I. London, Sterling VA: Earthscan Publications Limited.

Afary, J., \& Anderson, K. (2005). Foucault and the Iranian revolution: Gender and the seductions of Islamism. The University of Chicago Press.

Aflaki, A. (2012, March 16). Experts' critique of land transfer regulations of natural resources. Hamshahrionline [in Farsi]. Retrieved from http://www.hamshahrionline.ir/details/163784

Afshar, H. (1981). An assessment of Agricultural Development Policies in Iran. World Development, 9(11-12), 1097-1108.

Agnew, J. (1987). Place and Politics: The Geographical Mediation of State and Society. Winchester: Allen and Unwin.

Agnew, J. (1998). Geopolitics: revisioning world politics. Routledge.

Agnew, J. (2005). Sovereignty regimes: Territoriality and state authority in contemporary world politics. Annals of the Association of American Geographers, 95(2), 437-461.

Agnew, J. (2011). Space and Place. In J Agnew \& D. N. Livingstone (Eds.), The SAGE Handbook of Geographical Knowledge. Sage Publications Ltd.

Agrast, M., Botero, J., Martinez, J., Ponce, A., \& Pratt, C. (2012). World Justice Project Rule of Law Index 2012. Washington DC: The World Justice Project.

Agrast, M., Botero, J., \& Ponce, A. (2011). World Justice Project Rule of Law Index 2011. Washington DC: The World Justice Project.

Agrawal, A. (2005). Environmentality. Duke University Press.

Agrawal, A., \& Ribot, J. (1999). Accountability in decentralization: A framework with South Asian and West African cases. The Journal of Developing Areas, 33(4), 473502.

Agreement on integrated management and allocation of water for the Atrek basin. (2010, May 29). Ministry of Energy News Web [in Farsi]. Retrieved from http://50.22.218.42-static.reverse.softlayer.com/vdcgwz9q.ak9u34prra.html

Agricultural and orchard land use change: Tips and procedures. (2008, July 30). Aftab [in

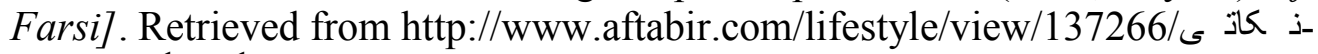

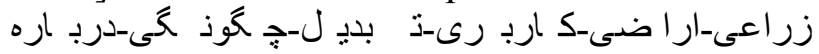

Agricultural development in northeast Iran: Launching Daneshmand Dam. (2012, September 10). Ministry of Agricultural Jihad News [in Farsi]. Retrieved from 
http://www.maj.ir/portal/Home/ShowPage.aspx?Object=Event\&CategoryID=4b789 d48-cd31-43a2-b92f-05f4c53a2394\&LayoutID=005ad7ed-f813-48c6-a161d303e3618ab3\&ID=2f56b031-752e-4a70-bfec-32cc0b3da0ce

Agriculture, Water and Natural Resource Commission. (2012). Majlis IRI Broadcasting [in Farsi]. Retrieved March 27, 2013, from http://majlestv.ir/TextVersion/Detail/?Id=39\&Serv=12

Ahmadi-Nejad: Founders of the Management and Budget Organization were enemies of Iran. (2009). Aftabnews [in Farsi]. Retrieved from http://aftabnews.ir/fa/print/88241

Ahmadipour, Z., Hafeznia, M., \& Khojamli, A. (2011). Analysis of electoral districts of Golestan province after revolution. Geopolitics [In Farsi], 7(1), 14-40.

Akhavan, P. (2010). A lecture on the Baha'i Community, human rights, and the construction of a new Iranian identity. Iran Press Watch. Retrieved from http://www.iranpresswatch.org/post/5708

Akhavan, P. (2012). The Baha'i Community, Human Rights, and the Construction of a New Iranian Identity. In R. Jahanbegloo (Ed.), Civil Society and Democracy in Iran. Lexington Books.

Alamdari, K. (2005). Why the Middle East Lagged Behind: The Case of Iran. Maryland: University Press of America.

Albert, M. (1999). On boundaries, teritory and postmodernity: an international relations perspective. In D. Newman (Ed.), Boundaries, Territory and Postmodernity. Portland: Frank Cass.

Alborzi-Manesh, M. (2009, March 14). A review of Environmental Impact Assessment of Dams in Iran. Hamshahrionline [in Farsi]. Retrieved from http://hamshahrionline.ir/print/77198

Alborzi-Manesh, M. (2012, September 3). Three ministers who are appointed for spatial planning. Sabz Press [in Farsi]. Retrieved from http://isdle.ir/news/index.php?news=8735

Alcorn, J. (2000). Borders, rules and governance: Mapping to catalyze change in policy and management. Gatekeeper Series No. 90. London: International Institute for Environment and Development.

Alfoneh, A. (2007). How Intertwined are the Rovolutionary Guards in Iran's Economy? American Enterprise for Public Policy Research, No. 3(October). Retrieved from http://www.aei.org/files/2007/10/22/20071022_MEno3g.pdf 
Alfoneh, A. (2009). Indoctrination of the Revolutionary Guards. American Enterprise for Public Policy Research, No. 2(February). Retrieved from http://www.aei.org/files/2009/02/20/02-23906 MEO Alfoneh-g.pdf

Alfoneh, A. (2010). The Revolutionary Guards' Looting of Iran's Economy. American Enterprise for Public Policy Research, No. 3(June). Retrieved from http://www.aei.org/files/2010/06/23/03-MEO-2010-g.pdf

Alizadeh, A. A. (2013). The Supreme Leader: Elected or Appointed. Imam Reza Netwrok. Retrieved from http://www.imamreza.net/eng/imamreza.php?id=9452

Allen, J. (2008). Power. In Companion to Political Geography. Wiley.

Allen, J. (2009). Three spaces of power: territory, netwroks plus a topological twist in the tale of domination and authority. Journal of Power, 2(2), 197-212.

Allen, J. (2011a). Topological twists: Power's shifting geographies. Dialogues in Human Geography, 1(3), 283-298.

Allen, J. (2011b). Making space for topology. Dialogues in Human Geography, 1(3), $316-318$.

Amendments to Articles 105 and 71 of the Thrid and Fourth Development Plan. (2009). Majlis Research Center [in Farsi]. Retrieved April 15, 2013, from http://rc.majlis.ir/fa/law/show/136329

American Iranian Council. (2007). Recent Development in the Iranian Economy. AIC Update, 4(55).

Amin-Shar'i, F. (2012). Re: Spatial planning in Iran by its three opponent ministers [Web log message, 2012, September 19] [in Farsi]. Retrieved from http://emarc.blogfa.com/1391/06

Amir Arjomand, S. (1989). Constitution-making in Islamic Iran: The impact of theocracy on the legal order of a nation-state. In J. Starr \& J. F. Collier (Eds.), History and power in the study of law: New directions in legal anthropology. Ithaca \& London: Cornell University Press.

Amirahmadi, H. (1986). Regional planning in Iran: A survey of problems and policies. The Journal of Developing Areas, 20(4), 501-530.

Amirahmadi, H. (1989). The state and territorial social justice in postrevolutionary Iran. International Journal of Urban and Regional Research, 13(1), 92-120.

Amirahmadi, H. (1990). Revolution and economic transition: The Iranian experience. Albany: State University of New York Press. 
Amiraslani, F., \& Dragovich, D. (2011). Combating desertification in Iran over the last 50 years: An overview of changing approaches. Journal of Environmental Management, 29(1), 1-13.

Amjad, M. (1989). Iran: From royal dictatorship to theocracy. Greenwood Press.

Amnesty International. (2008a). Iran: Craintes de torture- Jamshid Arazpour; Haji Aman Khadivar; ainsi que 200 à 300 autres personnes. (January 25, 2008). Retrieved from http://www.amnesty.org/fr/library/asset/MDE13/016/2008/fr/a4009cf4-cb5e-11dcb181-d35374267ce9/mde130162008eng.html

Amnesty International. (2008b). Iran: Further Information on Fear of torture. (May 22, 2008). Retrieved from http://www.amnesty.org/en/library/asset/MDE13/072/2008/en/80613b65-28aa-11dd88e3-17bcbb296f4e/mde130722008eng.html

Ansari, A. (2007). Iran under Ahmadinejad: The Politics of Confrontation. London: Routledge for the International Institute for Strategic Studies (Paper 393).

Appadurai, A. (1996). Modernity at large: Cultural dimensions of globalization. Minneapolis: University of Minnesota Press.

Arfa, H. (1964). Under Five Shahs. London: John Murray.

Armitage, D. (2008). Governance and the commons in a multi-level world. International Journal of the Commons, 2(1), 7-32.

Arshi, Z. (1977). Turkmen of Iran [in Farsi]. Safa Verlag.

Article 44 of the constitution (Privatization Plan). (2005). Iranian Privatization Organization [in Farsi]. Retrieved from http://www.ipo.ir/index.aspx?siteid=1\&pageid=891

Assigning grand projects to Khatam Al-Anbia: A crtique. (2012, August 21). Transport and Industry News Network [in Farsi]. Retrieved from http://www.tinn.ir/prtjomevhuqeyoz.fsfu.html

Ayatollahi, M. (2013). Re: Minsitry of Housing is not the right institution to prepare the Iranian land use plan [Web log message, 2013, 18 August] [in Farsi]. Retrieved from http://maryam-ayatollahi.blogfa.com/post-221.aspx

Azkia, M. (2002). Rural society and revolution in Iran. In E. Hooglund (Ed.), Twenty Years of Islamic Revolution: Political and Social Transition in Iran since 1979. Syracuse University Press. 
Bahrami, Z. (2010, November 24). The Atrek in Golestan: dried out. Khorasan News [in Farsi]. Retrieved from

http://www.khorasannews.com/News.aspx?type $=1 \& y e a r=1389 \&$ month $=9 \&$ day $=3 \& \mathrm{i}$ $\mathrm{d}=1032294$

Bahramizadeh, I. (2011, May 30). Lack of water: Golestan fish farms go out of business. Khorasan News [in Farsi]. Retrieved from http://www.khorasannews.com/News.aspx?type=1\&year=1390\&month=3\&day=9\&i $\mathrm{d}=2370076$

Bahram-Sultani, K. (2012, July 8). A Review of "Iranianized” Environmental Impact Assessment Methods: Omitting Public Participation. Shargh [in Farsi]. Retrieved from http://www.sharghnewspaper.ir/News/91/04/18/36108.html

Bakhshoodeh, M., \& Karami, A. (2008). Determinants of poor accessibility to microcredits in rural Iran. Proceedings of International Conference on Applied Economics (Kastoria, Greece, May 2008), 67-71.

Bakhtiar, A. (2007, January 25). Ahmadinejad's Achilles Heel: The Iranian Economy. Payvand Iran News [in Farsi]. Retrieved from http://www.payvand.com/news/07/jan/1295.html\#_edn7

Banisar, D., Parmar, S., De Silva, L., \& Excell, C. (2011). Moving From Principles to Rights. Position paper leading up to Rio +20 . The Access Initiative and Article 19. Retrieved from http://www.accessinitiative.org/resource/moving-principles-rights

Barati, A., \& Khalilpoor, O. G. (2006). Changes in abundance and diversity of waders and wintering waterfowl on the southern coast of the Caspian Sea. In G. C. Boere, C. A. Galbraith, \& D. A. Stroud (Eds.), Waterbirds around the world. Edinburgh, UK.: The Stationery Office.

Barfield, T. J. (1990). Tribes and State Relations: The Inner Asian Perspective. In P. Khoury \& J. Kostiner (Eds.), Tribes and state formation in the Middle East. Berkeley: University of California Press.

Barker, G., \& Gilbertson, D. (2000). Living at the margine: themes in the archaeology of drylands. In G. Barker \& D. Gilbertson (Eds.), The archaeology of drylands: living at the margin. Taylor \& Francis e-Library.

Bartholomew, J. G. (1922). Persia, 1922 Map. 1:4,000,000. In Bartholomew and Co. (Ed.), The Times survey atlas of the world (p. 53). The Times. Retrieved from http://www.davidrumsey.com/luna/servlet/detail/RUMSEY 8 1 3145 450003:Pers ia--The-Edinburgh-Geographical-

?qvq=q:Full_Title="Persia.+The+Edinburgh+Geographical+Institute, + John+Barthol omew\&Co.”The+Times“"+atlas.+(London:+The+Times,+1922)"; lc:RUMSEY 8 1 $\& m i=0 \& \operatorname{trs}=1$ 
Beazley, H., \& Ennew, J. (2006). Participatory methods and approaches: tackling the two tyrannies. In Doing development research. Sage Publications.

Beck, L. (1990). Tribes and the State in Nineteenth-and Twentieth-Century Iran. In P. Khoury \& J. Kostiner (Eds.), Tribes and state formation in the Middle East. Berkeley: University of California Press.

Beck, L. (1998). Use of Land by Nomadic Pastoralists in Iran: 1970-1998. Bulletin Series Yale School of Forestry and Environmental Studies, 103(Middle Eastern Natural Environments).

Berchin, S. R., Wilshusen, P., Fortwangler, C. L., \& West, P. (2002). Beyond the square wheel: Toward a more comprehensive understanding of biodiversity conservation as soical and political process. Society \& Natural Resources, 15, 41-64.

Berkes, F. (2002). Cross-scale institutional linkages: perspectives from the bottom up. In E. Ostrom, T. Dietz, N. Dolsak, P. C. Stern, S. Stonich, \& E. U. Weber (Eds.), The drama of the commons. Washington, DC: National Academy Press.

Berkes, F. (2004). Rethinking community-based conservation. Conservation Biology, $18(3), 621-630$.

Berkes, F. (2007). Community-based conservation in a globalized world. Proceedings of National Academy of Sciences of the United States of America, (September 2007), 104(39), 15188-15193.

Biermann, F., Betsill, M., Gupta, J., Kanie, N., Lebel, L., Liverman, D., ... Zondervan, R. (2010). Earth System Governance: A Research Framework. International Environmental Agreements, 10, 277-298.

Blaikie, P. M. (1999). A review of political ecology: issues, epistemology, and anlaytical narratives. Zeitschrift für Wirtschaftsgeographie, 43, 131-147.

Blench, R. (2001). You can't go home again: Pastoralism in the new millennium. London: Overseas Development Institute. Overseas Development Institute.

Blok, A. (2010). Topologies of climate change: actor-netwrok theory, relational-scalar analytics, and carbon-market overflows. Environment \& Planning D: Society \& Space, 28, 896-912.

Boere, C. G., \& Stroud, D. A. (2006). The flyway concept: what it is and what it isn't. In G. C. Boere, C. A. Galbraith, \& D. A. Strout (Eds.), Waterbirds around the world. Edinburgh, UK.: The Stationery Office.

Boone, R. B., BurnSilver, S., \& Kruska, R. S. (2008). Comparing landscape and infrustructureal heterogeneity within and between ecosystems. In K. A. Galvin, R. S. 
Reid, R. H. Behnke, \& N. T. Hobbs (Eds.), Fragmentation in Semi-Arid and Arid Landscapes. Springer.

Borgerhoff, M., Coppolillo, M., \& Copolillo, P. (2005). Conservation: Linking Ecology, Economics, and culture. Princeton and Oxford: Princeton University Press.

Boroffka, N., Obernhansli, H., Achatov, G., Aladin, N., Baipakov, K., Erzhanova, A., ... Wunnemann, B. (2005). Human settlements on the northern shores of Lake Aral and water level changes. Mitigation and Adaptation Strategies for Global Change, 10, $71-85$.

Boroujerdi, M., \& Rahimkhani, K. (2010). Iran's Power Structure. In R. Wright (Ed.), The Iran Primer. United States Institute of Peace.

Borrini-Feyerabend, G., Kothari, A., \& Oviedo, G. (2004). Indigenous and local communities and protected areas: towards equity and enhanced conservation. Gland, Switzerland and Cambridge, UK: IUCN.

Braun, B. (2009). Nature. In N. Castree, D. Demeritt, D. Liverman, \& B. Rhoads (Eds.), A Companion to Environmental Geography. Wiley-Blackwell.

Braun, B., \& Castree, N. (1998). Actors, netwroks and the politics of hybridity. In B. Braun \& N. Castree (Eds.), Remaking reality: Nature at the millennium. London: Routledge.

Braun, B., \& Wainwright, J. (2001). Nature, Poststructuralism, and Politcs. In N. Castree \& B. Braun (Eds.), Social Nature: Theory, Practice and Politics. Oxford: Blackwell Publishing.

Brenner, N. (2001). The limits to scale? Methodological reflections on scalar structuration. Progress in Human Geography, 25(4), 591-614.

Bridge, G., \& Perreault, T. (2009). Environmental Governance. In N. Castree, D. Demeritt, D. Liverman, \& B. Rhoads (Eds.), A Companion to Environmental Geography. Wiley-Blackwell.

Brown, J. C., \& Purcell, M. (2005). There's nothing inherent about scale: politicla ecology, the local trap, and the politics of development in the Brazilian Amazon. Geoforum, 36, 607-624.

Brubaker, R. (1996). Nationalism reframed. Cambridge: Cambridge University Press.

Brunckhorst, D. J. (2005). Integration research for shaping sustainable regional landscapes. Journal of Research Practice, 1(2), Article M7. Retrieved from http://jrp.icaap.org/index.php/jrp/article/view/16/28 
Bryant, R. L. (1992). Political Ecology: An Emerging Research Agenda in Third-World Studies. Political Geography, 11(1), 12-36.

Bryman, A. (2001). Social research methods. Oxford University Press.

Burgess, J., Clark, J., \& Harrison, C. M. (2000). Knowledges in action: An actor network analysis of a wetland agri-environment scheme. Ecological Economics, 35(1), 119132.

Callon, M. (1986). Some elements of a sociology of translation: domestication of the scallops and the fishermen of St Brieuc Bay. In Law, power, action and belief: a new sociology of knowledge? Routledge.

Campese, J. (2009). Rights-based approaches to conservation: An overview of concepts and questions. In J Campese, T. C. H. Sunderland, T. Greiber, \& G. Oviedo (Eds.), Rights-based approaches: Exploring issues and apportunities for conservation. Bogor, Indonesia: Center for International Forestry Research (CIFOR) and and The International Union for Conservation of Nature (IUCN). Retrieved from http://www.cifor.org/publications/pdf_files/Books/BSunderland0901.pdf

Campese, Jessica, \& Guignier, A. (2007). Human Rights- A brief introduction to key concepts. Policy Matters- IUCN Commission on Environmental, Economic \& Social Policy, 15, 10-26.

Cash, D. W., Adger, W. N., Berkes, F., Garden, P., Lebel, L., Olsson, P., ... Young, O. (2006). Scale and cross-scale dynamics: Governance and inforamtion in a multilevel world. Ecology and Society, 11(2), 8.

Castree, N. (2005a). Nature. London and New York: Routledge.

Castree, N. (2005b). Editorial: The epistemology of particulars- Human geography, case studies and "context." Geoforum, 36(5), 541-544.

Castree, N., \& Braun, B. (1998). The construction of nature and the nature of construction. In B. Braun \& N. Castree (Eds.), Remaking reality: Nature at the millennium. London: Routledge.

Castree, N., \& MacMillan, T. (2001). Dissolving dualism: Actor-networks and the reimagination of nature. In N. Castree \& B. Braun (Eds.), Social Nature: Theory, Practice and Politics. Blackwell Publishing.

Castree, N., \& MacMillan, T. (2004). Old news: Representation and academic novelty. Environment and Planning A, 36, 469-480.

Chambers, R. (1983). Rural development: Putting the last first. London: Longman. 
Chambers, R. (1994a). Participatory Rural Appraisal (PRA): challenges, potentials and paradigm. World Development, 22(10), 1437-1454.

Chambers, R. (1994b). The origins and practice of participatory rural appraisal. World Development, 22(7), 953-969.

Chambers, R. (1994c). Participatory Rural Appraisal (PRA): analysis of experience. World Development, 22(9), 1253-1268.

Chambers, R. (2006). Participatory Mapping and Geographic Information Systems: Whose map? Who is Empowered and Who Disempowered? Who Gains and Who Lose? The Electronic Journal on Information Systems in Developing Countries, $25(2), 1-11$.

Chapin, M., Lamb, Z., \& Threlkeld, B. (2005). Mapping indigenous lands. Annual Review of Anthropology, 34, 619-638.

Chavoshian, S. A., Takeuchi, K., \& Funada, S. (2005). An overview of transboundary and shared water resources management in Iran: Technical challenges and solutions. Proceedings of International Symposium on Role of Water Sciences in Transboundary River Basin Management, United Nations University, Asian Institute of Technology, and Thammasat University (Ubon Ratchathani, Thailand, 10-12 March 2005), 189-195.

Closing of 60 livestock farms in Golestan. (2011, July 5). Aftabnews [in Farsi]. Retrieved from http://aftabnews.ir/vdcfexdyvw6dmya.igiw.html

"Conservation of Iranian Wetlands" project: signed. (2013, June 14). Fars News Agency [in Farsi]. Retrieved from http://www.ghatreh.com/news/nn13977920/????-??????????-????-????-???-?????-?????-?????????-???

Constitution of the Islamic Republic of Iran. (1979). World Intellectual Property Organization [translated to English]. Retrieved from http://www.wipo.int/wipolex/en/text.jsp?file_id=197757

Constitution of the Islamic Republic of Iran. (2013). Majlis Research Center [in Farsi]. Retrieved July 12, 2013, from http://rc.majlis.ir/fa/content/iran_constitution

Corbett, J., Rambaldi, G., Kwaku Kyem, P., Weiner, D., Muchemi, J., McCall, M. K., \& Chambers, R. (2006). Overview: Mapping for change- the emergence of a new practice. Participatory Learning and Action Notes, 54, 13-19.

Cosgrove, D. (2000). Sense of place. In The Dictionary of Human Geography. Blackwell Publishing. 
Cox, K. (1997). Globalization and its politics in question. In K. R. Cox (Ed.), Spaces of globalization: reasserting the power of the local. New York: The Guilford Press.

Cox, K., \& Mair, A. (1989). Levels of abstraction in locality studies. Antipode, 21(2), $212-231$.

Cronon, W. (1992). A place for stories: Nature history and narrative. Journal of American History, 78, 1347-1376.

Cumming, G. S., Cumming, D. H., \& Redman, C. L. (2006). Scale mismatches in socialecological systems: Causes, consequences, and solutions. Ecology and Society, 11(1), 14-33.

Current unemployment rate is at least 18\%: Approaches to control unemployment crisis. (2013, August 11). EghtesadOnline [in Farsi]. Retrieved from http://www.eghtesadonline.com/fa/content/23672/????????-?????-?????-??????

Dabashi, H. (2008). Iran: A People Interrupted. New York: The New Press.

Dalby, S. (1999). Globalization or global apartheid? In D. Newman (Ed.), Boundaries, Territory and Postmodernity. Portland: Frank Cass.

Dams in Iran: Subwatersheds. (2013). Iran Water Resource Management Company [in Farsi]. Retrieved March 10, 2013, from http://daminfo.wrm.ir/fa/dam/secondary

Darvish, M. (2013, April 10). The government signed a death penalty for the environment. Kaleme [in Farsi]. Retrieved from http://www.kaleme.com/1392/01/21/klm-139603/

De Nartino, L., \& Novikov, V. (2008). Environment and Security: Transforming Risks into Cooperation (the Case of the Eastern Caspian Region). United Nation Environment Programme, United Nation Development Programme, United Nations Economic Commission for Europe, Organisation for Security and Co-operation in Europe, Regional Environmental Center for Central and Easter Europe, North Atlantic Trea.

Dean, M., \& Henman, P. (2004). Governing society today: editors' introuction. Alternatives, 29, 483-494.

Del Casino, V., \& Hanna, S. (2006). Beyond the "Binaries": A methodological intervention for interrogating maps as representational practices. ACME (An International E-Journal for Critical Geographies), 4(1), 34-56.

Demeritt, D. (1998). Science, social constructivism and nature. In B. Braun \& N. Castree (Eds.), Remaking reality: Nature at the millennium. London and New York: Routledge. 
Demeritt, D. (2001a). Being Constructive about Nature. In N. Castree \& B. Braun (Eds.), Social Nature: Theory, Practice and Politics. Oxford: Blackwell Publishing.

Demeritt, D. (2001b). The Construction of Global Warming and the Politics of Science. Annals of the Association of American Geographers, 91(2), 307-337.

Demeritt, D. (2002). What is the social construction of nature? A typology and sympathetic critique. Progress in Human Geography, 26(2), 767-790.

Department of Environment-Iran. (2008). Information for assessing possible removal of a listed site from the Montreux Record (Alagol, Ajigol, and Almagol wetlands) [this is the exact title of the report submitted to the Ramsar Secretariat by the DOE]. Department of Environment. Retrieved from www.ramsar.org/pdf/key_montreux_iran_alagol.pdf

Department of Environment-Iran. (2010). Iran National Report on the Implementation of the Convention on Biological Diversity. Convention on Biological Diversity. Retrieved from http://www.cbd.int/doc/world/ir/ir-nr-04-en.pdf

Dewan, M., \& Famouri, J. (1964). The Soils of Iran. Rome: Food and Agriculture Organization of the United Nations.

Dispossession of 25 thousand hectares of seized lands. (2009, January 31). Alef News [in Farsi]. Retrieved from http://alef.ir/vdch6wnx.23nwwdftt2.html?39998

Dissolution of MPO was irrational. (2009, May 25). Khabaronline [in Farsi]. Retrieved from http://www.khabaronline.ir/detail/9157/

Dissolution of MPO, due to the Government's superficial and naive point of view. (2012, December 22). Kaleme [in Farsi]. Retrieved from http://www.kaleme.com/1391/10/02/klm-125656/?theme=fast

Dissolution of MPO: Elimination of unncecessary bureaucracy. (2009, February 10). Fars News Agency [in Farsi]. Retrieved from http://www.farsnews.com/printable.php?nn=8711220584

Doolittle, W. (2006). Agricultural manipulation of floodplains in the southern Basin and Range Province. Catena, 65, 179-199.

Doreen Massey on Space [Interview with Doreen Massey, 2013, February 1]. (2013). Social Science Bites. Retrieved from http://www.socialsciencespace.com/2013/02/podcastdoreen-massey-on-space/

Dreyfus, H., \& Rainbow, P. (1983). Michel Foucault: Beyond sttructuralism and hermeneutics (2nd ed.). Chicago: University of Chicago Press. 
Drinking water for 17 villages of Dashliburun is provided by tankers. (2005, September 10). Golshane Mehr [in Farsi]. Retrieved from http://www.golshanemehr.ir/article.php?id=1696

Drinking water is one of the main problems of Dashliburun district. (2009, July 21). Sahra [in Farsi]. Retrieved from http://www.iranturkmenleri.ir/sahra/sahra307/307 sahra_1.pdf

Drovers hoarding livestock: Increase in red meat prices. (2009, December 1). Fars News Agency [in Farsi]. Retrieved from http://www.farsnews.com/newstext.php?nn=8809100448

Dwyer, C., \& Limb, M. (2001). Introduction: doing qualitative research in geography. In M. Limb \& C. Dwyer (Eds.), Qualitative Methodologies for geographers- issues and debates. New York: Arnold Publishers.

Dzurik, A. (2003). Water resources planning. Rowman \& Littlefield Publishing Group.

Ebtekar, M. (2009). Iran's Environmental Policy in the Reform Period (1997-2006). International Journal of Environmental Studies, 66(2), 289-296.

Economic Commission For Europe. (2011). Second assessment of transboundary rivers, lakes and groundwaters. New York \& Geneva: United Nations Publications.

Edgar, A. L. (2004). Tribal nation: The making of Soviet Turkmenistan. Princeton and Oxford: Princeton University Press.

Elborz Mountains. (2013). In Encyclopedia Britanica Online. Encyclopedia Britanica Inc. Retrieved from http://www.britannica.com/EBchecked/topic/182171/ElburzMountains/

Engel-Di Mauro, S. (2009). Seeing the local in the global: Political ecologies,, worldsystems, and the question of scale. Geoforum, 40, 116-125.

Environmental Guards are preys of illegal hunters. (2012, August 7). Hamshahrionline [in Farsi]. Retrieved from http://www.hamshahrionline.ir/details/180207

Environmental High Council is not dissolved. (2010, January 11). Mardomsalari [in Farsi]. Retrieved from http://www.mardomsalari.com/template1/News.aspx?NID=69438

Escalating number of wildlife defenders. (2013, January 26). Hamshahrionline [in Farsi]. Retrieved from http://www.hamshahrionline.ir/details/198981

Escobar, A. (1995). Encountering Development: The Making and Unmaking of the Third World. Princeton, New Jerssey: Princeton University Press. 
Escobar, A. (1996). Constructing Nature: Elements for a Post-structuralist Political Ecology. In R. Peet \& M. Watts (Eds.), Liberation Ecologies: Environment, Development and Social Movements. London: Routledge.

Escobar, A. (2001). Culture sits in places: reflections on globalism and subaltern strategies of localization. Political Geography, 20, 139-174.

Establishment of agricultural units in villages: Not classified as land conversion. (2006, August 29). Fars News Agency [in Farsi]. Retrieved from http://www.farsnews.com/newstext.php?nn=8506070268

Evans, A. (1997). Statistics. In L. Ostergaard (Ed.), Gender and Development. Routledge.

Fadaee, S. (2012). Social Movements in Iran: Environmentalism and Civil Society. Routledge.

FAO. (2013). National Aquaculture Legislation Overview-Iran (Islamic Republic of). Retrieved from http://www.fao.org/fishery/legalframework/nalo_iran/en

Farrokhnia, R. (2009). Socio-cultural restrictions and difficulties of social science research in Iran. Asian Social Science, 5(7), 144-151.

Faure, M., \& Lefevere, J. (2005). Compliance with International Environmental Agreements. In N. J. Vig, R. S. Axelrod, \& D. L. Downie (Eds.), The Global Environment: Institutions, Law and Policy. Earthscan Publications Limited.

Federal Research Divison. (2012). Iran's Ministry of Intelligence and Security: A profile. Washington DC: The Library of Congress, Federal Research Division. Retrieved from www.fas.org/irp/world/iran/mois-loc.pdf

Finlayson, M. (1996). Ramsar's "Montreux Record": analysis and recommendations. Ramsar Convnetion Secretariate. Retrieved from http://www.ramsar.org/cda/en/ramsar-activities-partnershipindex-private-ramsar-smontreux/main/ramsar/1-63-506-98^16952_4000_0

Finlayson, M. (2012). Forty years of wetland conservation and wise use. Aquatic Conservation: Marine \& Freshwater Ecosystems, 22, 139-143.

Finlayson, M., Davidson, N., Pritchard, D., Milton, R., \& MacKay, H. (2011). The Ramsar Convention and Ecosystem- Based Approaches to the Wise Use and Sustainable Development of Wetlands. Journal of International Wildlife Law and Policy, 14, 176-198.

Firouz, E. (2005). The complete fauna of Iran. New York: I. B. Tauris Publishers. 
Firouz, E., \& Harrington, F. A. (1976). Iran: Concepts of Biotic Community Conservation. Morges, Switzerland: IUCN.

Fish production in Alagol region after three years of drought. (2012, July 22). Mehr News [in Farsi]. Retrieved from http://www.mehrnews.com/TextVersionDetail/1654835

Fletcher, R. (2010). Neoliberal environmentality: Towards a poststructuralist political ecology of the conservation debate. Conservation and Society, 8(3), 171.

Forest and Natural Resource Organization or a land transfer agency. (2009, August 10). Cultural Heritage News Agency [in Farsi]. Retrieved from http://www.chn.ir/news/Print/?Section=1\&id=31869

Forsyth, T. (2008). Political ecology and the epistemology of social justice. Geoforum, $39,756-764$.

Foucault, M. (1972). The archeology of knowledge and discourse on language. London: Tavistock Publications.

Foucault, M. (1977). Discipline and Punish. New York: Vintage Books.

Foucault, M. (1978). The history of sexuality (Vol. I: An Introduction). New York: Pantheon Books.

Foucault, M. (1984). The Foucault Reader. (P. Rainbow, Ed.). New York: Pantheon Books.

Foucault, M. (2008). The Birth of Biopolitics (Lectures at the College De France 197879). (M. Senellart \& M. Foucaut, Eds.). Palgrave Macmillan.

Foundation of development in Golestan: Land use planning. (2009, June 30). Islamic Republic News Agency [in Farsi]. Retrieved from http://www.irna.ir/View/Fullstory/Tools/PrintVersion/?NewsId=566265

Fox, J. (1998). Mapping the commons: the social context of spatial information technologies. The Common Property Resource Digest, 45, 1-4.

Fox, J., Suryannata, K., Hershock, P., \& Pramono, A. H. (2005). Introduction: Mapping power- Ironic effects of spatial information technology. In J. Fox, K. Suryannata, \& P. Hershock (Eds.), Mapping communities: ethics values, practice. Honolulu, U.S.: East-West Center.

Fox, J., Suryannata, K., Hershock, P., \& Pramono, A. H. (2006). Mapping power: Ironic effects of spatial information technology. Participatory Learning and Action Notes, $54,98-105$. 
Fox, S. (2000). Communities of Practice, Foucault and Actor-Netwrok Theory. Journal of Management Studies, 37(6), 853-867.

Franks, P., \& Blomley, T. (2004). Fitting ICD into project framework: A CARE perspective. In T. O. McShane \& M. P. Wells (Eds.), Getting biodiversity projects to work: towards more effective conservation and development workshop. New York: Columbia University Press.

Galafassi, P. (2010). Location of Major Turkmen Tribes (16th to 19th Centuries). Retrieved May 24, 2010, from http://www.turkotek.com/salon_00132/salon.html

Ganjanapan, A. (1994). The Northern Thai land tenure system: local customs versus national laws. Law \& Society Review, 28(3), 609-622.

Garnett, S. T., Sayre, J., \& du Toit, J. (2007). Improving the effectiveness of interventions to balance conservation and development: a conceptual framework. Ecology and Society, 12(1), 2.

Geiss, P. (2003). Pre-Tsarist and Tsarist Central Asia: Communal Commitment and Political Order in Change. U.K.: RoutledgeCurzon.

Gezon, L. L. (2005). Finding the global in the local: local struggles in northern Madagascar. In S. Paulson \& L. L. Gezon (Eds.), Political ecology across spaces, scales, and social groups. Rutgers Univ Press.

Gezon, L. L., \& Paulson, S. (2005). Place, power, difference- multiscale research at the dawn of the twenty-first century. In S. Paulson \& L. L. Gezon (Eds.), Political ecology across spaces, scales, and social groups. Rutgers University Press.

Ghanea, N., \& Hass, B. (2011). Seeking justice and an end to neglect: Iran's minorities today. Minority Rights Group International. Retrieved from www.minorityrights.org/download.php?id=939

Ghasemian, M. (2009, June 2). No Actions Have Been Taken to Save the Environment. Iranian Students Scientific Portal [in Farsi]. Retrieved from http://www.daneshju.ir/forum/sitemap/t-67114.html

Gheissari, A., \& Nasr, V. (2006). Democracy in Iran: history and the quest for liberty. Oxford and New York: Oxford University Press.

Ghorashi, G. R. (2003). Economic globalization and the prospect for democracy in Iran. In A. Mohammadi (Ed.), Iran encountering globalization: problems and prospects. RoutledgeCurzon.

Gibson, C. C., Ostrom, E., \& Ahn, T. K. (2000). The concept of scale and the human dimensions of global change: a survey. Ecological Economics, 32, 217-239. 
Gibson-Graham, J. K. (2005). Poststructural Interventions. In E. Sheppard \& T. J. Barnes (Eds.), A Companion to Economic Geography. Blackwell Publishing.

Global Water Partnership. (2000). Integrated Water Resources Management. Technical Advisory Committee Background Papers Series, No 4. Stockholm: Global Water Partnership. Retrieved from http://www.gwp.org/Global/GWPCACENA_Files/en/pdf/tec04.pdf

Global Water Partnership. (2012). What is Integrated Water Resources Management? Retrieved from http://www.gwp.org/The-Challenge/What-is-IWRM/

Golestan Petrochemical Plant: Provisional to Environmental Impact Assessment Studies. (2006, March 24). Golshane Mehr [in Farsi]. Retrieved from http://www.golshanemehr.ir/article.php?id=7022

Golestan Regional Water Company. (2010). Investment Opportunities in Golestan Water Sector [in Farsi]. Retrieved November 13, 2010, from http://www.gsrw.ir/uPortal.aspx?GroupsID=150

Google Earth. (2013, September 4). Alagol, Ulmagol, Ajigol region (37 25’27.24“ N, 54 39' 49. 25” E).

Gorgani, Mansoor. (1979). Issue of land in Turkmen Sahra [in Farsi]. Tehran, Iran.

Gorgani, Mikhail. (2013). Re: A brief political history of the Turkmen in Iran [Web log message, 2013, September 11] [in Farsi]. Retrieved from http://nemoneagh.blogfa.com/post/56

Government institutions are the main threats to natural resources. (2008, December 20). Sahra [in Farsi]. Retrieved from http://www.iranturkmenleri.ir/sahra/sahra283/sahra283page8.pdf

Gregory, D. (2000). Human geography and space. In The Dictionary of Human Geography. Blackwell Publishing.

Gregory, D. (2004). Palestine and the "War on Terror." Comparative Studies of South Asia, Africa and the Middle East, 24(1), 183-195.

Griffin, L. (2012). Where is power in governance? Why geography matters in the theory of governance. Political Studies Review, 10, 208-220.

Grumbine, R. E. (1998). Using biodiversity as a justification for nature protection in the U.S. In J. B. Callicott \& M. P. Nelson (Eds.), The Great New Wilderness Debate. The University of Georgia Press. 
Hajer, M., \& Versteeg, W. (2005). A Decade of Discourse Analysis of Environmental Politics: Achievements, Challenges, Perspectives. Journal of Environmental Policy \& Planning, 7(3), 175-184.

Hankla, C., \& Downs, W. (2010). Decentralisation, governance and the structure of local political institutions: lessons for reform? Local Government Studies, 36(6), 759-783.

Haraway, D. (1992). The Promises of Monsters: A Regenerative Politics for Inappropriate/d Others. In L. Grossberg, C. Nelson, \& P. Treichler (Eds.), Cultural Studies (pp. 295-337). New York: Routledge.

Haripriya, R., \& Kull, C. (2009). What makes ecology "political"?: rethinking "scale" in political ecology. Progress in Human Geography, 33(1), 28-45.

Harley, J. B. (1989). Deconstructing the map. Cartographica, 26(2), 1-23.

Harris, T., \& Hazen, H. D. (2006). Power of Maps: (counter) mapping for conservation. ACME (An International E-Journal for Critical Geographies), 4(1), 99-130.

Harris, T., \& Weiner, D. (1998). Empowerment, marginalization, and communityintegrated GIS. Cartography and Geographic Information Systems, 25(2), 67-76.

Harris, T., \& Weiner, D. (2002). Implementing a community-integrated GIS: perspectives from South African fieldwork. In W. Craig, T. Harris, \& D. Weiner (Eds.), Community participation and Geographic Information Systems. New York: Taylor \& Francis Group.

Hashemi, M. (2012). A socio-technical assessment framework for integrated water resources management (IWRM) in Lake Urmia Basin, Iran. Newcastle University (Doctoral dissertation). Retrieved from https://theses.ncl.ac.uk/dspace/handle/10443/1332

Herberston, K., Thompson, K., \& Goodland, R. (2010). A Roadmap for Integrating Human Rights into the World Bank Group. World Resources Institute.

High cost of providing driking water to Dashliburun. (2010, March 15). Keyhan [in Farsi]. Retrieved from http://www.kayhan.ir/881224/11.htm

Hill, D. R. (1992). Physics and mechanics, civil and hydraulic engineering, industrial processes, and manufacturing, and craft division. In A. Dani \& V. Masson (Eds.), History of Civilizations of Central Asia, Volume IV-The age of achievement: AD 750 to the end of the fifteenth century, Part Two: the achievements. Paris: UNESCO.

Hirschl, R. (2010). Constitutional theocracy. President and Fellows of Harvard College. 
History of the Forest, Range \& Watershed Management Organization. (2013). Forest, Range \& Watershed Management Organization [in Farsi]. Retrieved from http://www.frw.org.ir/AboutUS/HistoryOrganization/pageid/37/language/faIR/Default.aspx

History of Turkmenistan. (2012). Embassy of Turkmensitan in Washington DC. Retrieved October 15, 2013, from http://turkmenistanembassy.org/history-of-turkmenistan/

Hooglund, E. (1982). Land and Revolution in Iran, 1960-1980. Austin: University of Texas Press.

Howitt, R. (2008). Scale. In J. A. Agnew, K. Mitchell, \& G. Toal (Eds.), A Companion to Political Geography. Wiley.

Hunnam, P. (2011). Conservation of Biodiversity in the Central Zagros Landscape Conservation Zone: Mid-Term Evaluation Report. Government of the Islamic Republic of Iran, United Nations Development Programme, Global Environment Facility, Project number. PIMS 2278. Retrieved from http://erc.undp.org/evaluationadmin/manageevaluation/viewevaluationdetail.html?ev alid $=5072$

Hutchinson, C., \& Toledano, J. (1993). Guidelines for demonstrating geographical information systems based on participatory development. International Journal of Geographical Information Systems, 7(5), 453-461.

Hutton, J., Adams, W. M., \& Murombedzi, J. (2005). Back to the barriers? Changing narratives in biodiversity conservation. Forum for Development Studies, 2, 341-370.

Ijadi, J. (2011, August 28). Ecological and social crisis and struggle in Iran. Gooya News [in Farsi]. Retrieved from http://news.gooya.com/politics/archives/2011/09/128552.php

Ilias, S. (2010). Iran's Economic Conditions: U.S. Policy Issues. U.S.: Congressional Research Service, The Library of Congress, Foreign Affairs, Defense, and Trade Division.

Illegal diversion of environmental water: Main cause of drying wetlands. (2013, March 1). Moj News Agency [in Farsi]. Retrieved from http://www.mojnews.com/fa/Miscellaneous/ViewContents.aspx?Contract=cms_Cont ents_I_News\&r=1138648

Impacts of dams on farmers' lives in Golestan. (2011, July 19). Bazarkhabar [in Farsi]. Retrieved from http://www.bazarkhabar.ir/News.aspx?ID=2022 
International Federation for Human Rights. (2004). Discrimination against religious minorities in Iran. Retrieved from http://www.fidh.org/Discrimination-againstreligious

Iran Chamber Society. (2012). Persian Language and Literature. Iran Chamber Society. Retrieved from http://www.iranchamber.com/literature/articles/persian_language.php

Iran's Long-Term Water Resources Development Strategies. (2003). Public Relations and International Affairs Bureau of Iran Water Resources Managment Company. Retrieved October 05, 2010, from www.wrm.ir/ravabet/documents \develop \latin.pdf

Iran's MPO to be dissolved. (2007, July 10). Bazar Dispatch. Retrieved from http://bazardispatch.blogspot.ca/2007/07/irans-management-and-planning.html

Irons, W. (1971). Variation in political stratification among the Yomut Turkmen. Anthropological Quarterly, 44(3), 143-156.

Irons, W. (1974). Nomadism as a Political Adaptation: The Case of the Yomut Turkmen. American Ethnologist, 1(4), 635-658.

Irons, W. (1975). The Yomut Turkmen: A Study of Social Organization Among a Central Asian Turkic-speaking Populaiton. Museum of Anthropology, The University of Michigan.

IUCN. (2013). About IUCN. Retrieved from https://www.iucn.org/about/

Jafari, P. (2009). Rupture and Revolt in Iran. International Socialism, 124.

Jamshidi, M. (2013, March 17). A Review of the Government performance in Evnironment Sector: A Worksheet that is not defendable. Sabz Press [in Farsi]. Retrieved from http://isdle.ir/news/index.php?news=9054

Japan International Cooperation \& CTI Engineering International Co. (2010). The Study on Integrated Water Resources Management for Sefidrud River Basin in the Islamic Republic of Iran (Vol. 1). Japan International Cooperation Agency. Retrieved from http://www.wrm.ir/planning/pdf/mov5.pdf

Jessop, B., Brenner, N., \& Jones, M. (2008). Theorizing sociospatial relations. Environment and planning. D: Society and Space, 26, 389-401.

Jones, S. (2008). Political ecology and land degradation: how does the land lie 21 years after Blaikie and Brookfield's Land Degradation and Society? Geography Compass, 2(3), 671-694. 
Karimi, S., Masha, A., Jafari, H. R., \& Pourasghar Sanghachin, F. (2011). A critique review of land use planning in Iran. Proceedings of the 12th International Conference on Environmental Science and Technology (Phodes, Greece, September 2011), B476-B484.

Kashani-Sabet, F. (1999). Frontier fictions: Shaping the Iranian nation, 1804-1946. Princeton, New Jerssey: Princeton University Press.

Katouzian, H. (1981). The political economy of modern Iran: Despotism and PseudoModernism, 1926-1979. Hong Kong: The Macmillan Press.

Katouzian, H. (2006). State and society in Iran: The eclipse of the Qajars and the emergence of the Pahlavis. New York: I. B. Tauris Publishers.

Katouzian, H. (2009). The Persians: ancient, medieval, and modern Iran. Yale University Press.

Katz, C. (1994). Playing the field: questions of fieldwork in geography. The Professional Geographer, 46(1), 67-72.

Katz, C. (2001). On the Grounds of Globalization: A Topography for Feminist Political Engagement. Globalization and Gender, 26(4), 1213-1234.

Keddie, N. (2006). Modern Iran-Roots and Results of Revolution. New Haven \& London: Yale University Press.

Keely, J., \& Scoones, I. (2000). Knowledge, power and politics: The environmental policy-making process in Ethiopia. The Journal of Modern African Studies, 38(1), 89-120.

Kepe, T., Bissonnette, J., \& Roberts, D. J. (2008). Commentary: Why are students attracted to political ecology? Environment and Planning A, 40(11), 2539-2543.

Khatam Al-Anbia is the only contractor of large development projects in Golestan. (2012, April). Gloestan Contractor Guild News Portal [in Farsi]. Retrieved from http://peymankaranegolestan.blogfa.com/post-7.aspx

Khatami: Councils could promote democracy and encourage public participation. (2002, May 8). Ettela'at International. Retrieved from http://www.ettelaat.com/etbarchive/2002/05/07May/P8.pdf

Khiva, khanate of. (2013). In The Columbia Encyclopedia. The Columbia University Press. Retrieved from http://www.encyclopedia.com/doc/1E1-Khiva-kh.html 
Khomeini, R. (1971). Islamic Government [Hokumat-i Islami, translated to English by Hamid Algar]. Virtual Vendee. A Center for Traditionalist and Integrist Studies. Retrieved from http://www.wandea.org.pl/khomeini-pdf/hukumat-i-islami.pdf

Khwarazm. (2013). In The Columbia Encyclopedia. The Columba University Press. Retrieved from http://www.encyclopedia.com/doc/1E1-Khwarazm.html

Kiabi, B., Ghaemi, R., \& Abdoli, A. (1999). Wetlands and riverine ecosystems of Golestan province [in Farsi]. Department of Environment, Golestan Provincial Office.

King, B. H. (2002). Towards a participatory GIS: evaluating case studies of participatory rural appraisal and GIS in the developing world. Cartography and Geographic Information Systems, 29, 43-52.

Kingsford, R. T., Georges, A., \& Unmack, P. J. (2006). Vertebrates of desert rivers. In R. Kingsford (Ed.), Ecology of Desert Rivers. Cambridge University Press.

Kolahi, M., Sakai, T., Moriya, K., \& Makhdoum, M. (2012). Challenges to the Future Development of Iran's Protected Areas System. Environmental Management, 50, 750-765.

Koushki, S. (2011). Re: Water and Politics in Iran [Web log message, 2011, October 4] [in Farsi]. Retrieved from http://koushki.com/?p=1521

Kouzmina, J. V. (2006). Soil salinization and floodplain ecosystems of south-west Turkmenistan. In M. . Khan, B. Böer, G. . Kust, \& H. J. Barth (Eds.), Sabkha Ecosystems Vol II: West and Central Asia. Springer.

Kreuzberg-Mukhina, E. A. (2006a). The Aral Sea Basin: changes in migratory and breeding waterbird population due to major human-induced changes to the region's hydrology. In G. C. Boere, C. A. Galbraith, \& D. A. Stroud (Eds.), Waterbirds around the world. Edinburgh, UK.: The Stationery Office.

Kreuzberg-Mukhina, E. A. (2006b). The effect of habitat change on the distribution of waterbirds in Uzbekistan and the possible implications of climate change. In G. C. Boere, C. A. Galbraith, \& D. A. Stroud (Eds.), Waterbirds around the world. Edinburgh, UK.: The Stationery Office.

Kruchek, B. (2003). Extending wetlands protection under the Ramsar treaty's wise use obligation. Arizona Journal of International Law, 20(2), 409-442.

Kurzman, C. (2009, November 1). Reading Webber in Tehran. The Chronicles of Higher Education. Retrieved from http://chronicle.com/article/Social-Science-on-Trial-in/48949/ 
Lagging behind and growth during the Cold War and its aftermath. (2007, December 1). Aftab [in Farsi]. Retrieved from

http://www.aftabir.com/articles/view/economy_marketing_business/economic_scien

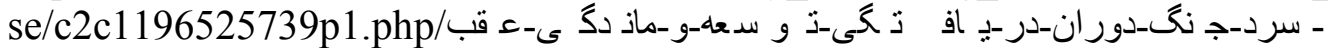

Lambton, A. S. K. (1984). Review: Land and revolution in Iran. Iranian Studies, XVII(1).

Land restoration and development in Tengli. (2006, August 20). Fars News Agency [in Farsi]. Retrieved from http://www.farsnews.com/newstext.php?nn=8505290554

Land transfer as the only solution to problems: A big mistake. (2012, July 29).

Hamshahrionline [in Farsi]. Retrieved from http://www.hamshahrionline.ir/details/179108

Lapidus, I. (2002). A history of Islamic societies (2nd ed.). Cambridge University Press.

Latour, B. (1986). The powers of association. In The Sociological Review. Routledge and Kegan Paul plc.

Latour, B. (1993). We have never been modern. Harvard University Press.

Latour, B. (1998). To modernise or ecologise? That is the question. In B. Braun \& N. Castree (Eds.), Remaking reality: Nature at the millennium. London and New York: Routledge.

Latour, B. (1999). On recalling ANT. In J. Law \& J. Hassard (Eds.), Actor network theory and after. Oxford: Blackwell Publishing.

Latour, B. (2004). Politics of nature: How to bring the sciences into democracy. Harvard University Press.

Latour, B. (2005). Reassembling the social: An Introduction to Actor-Network-Theory. Oxford University Press.

Latour, B. (2011). Politics of nature: East and West perspectives. Ethics and Global Politics, 4(1), 71-80.

Law, J. (2004). And if the global were small and noncoherent? Method, complexity, and the baroque. Environment and Planning D, 22(1), 13-26.

Leek, K. (2007). Rural Livelihood Strategies and Natural Resources in Oudomaxy, Lao $P D R$. Universtiy of Natural Resources and Applied life Sciences, Vienna, Austria.

Lewis, R. A. (1996). Early Irrigation in West Turkestan. The Annals of the Association of American Geographers, 56(3), 467-491. 
Lloyd-Evans, S. (2006). Focus Groups. In V. Desai (Ed.), Doing development research. Sage Publications.

Long, N. (1997). Agency and Constraint, Perceptions and Practices. A Theoretical Position. In H. de Haan \& N. Long (Eds.), Images and Realities of Rural Life. Assen: van Gorcum.

Machina, K. (2008). Secular Nation-State vs. Islamic Nation-State. Illinois State University LILT. Retrieved from http://lilt.ilstu.edu/kfmachin/ids254/Secular vs Islamic Nation-State.pdf

Maclean, I. M. D., Rehfisch, M. M., Delany, S., \& Robinson, R. A. (2008). Migratory waterbirds and climate change. UNEP/AEWA Secretariat. Retrieved from http://www.unepaewa.org/publications/popular_series/migratory_birds_climate_change.pdf

Mahab Ghods Consultancy. (1997). Final report (Vol. 1): Optimum use of Alagol Lakes [in Farsi]. Theran: Mahab Ghods Engineering Consultancy.

Mahdavi, M. (2008). Rethinking Structure and Agency in Democratization: Iranian Lessons. International Journal of Criminology and Sociological Theory, 1(2), 142160.

Mahdidoust, H. (2004). Country Report- Islamic Republic of Iran (2). In C. Wijayaratna (Ed.), Role of Local Communities and Institutions in Integrated Rural Development. Asian Productivity Organization.

Majd, M. G. (2013). The Great Famine \& Genocide in Iran: 1917-1919 (2nd Editio.). University Press of America.

Makhdoum, M. (2008). Management of protected areas and conservation of biodiversity in Iran. International Journal of Environmental Studies, 65(4), 563-585.

Maloney, S. (2004). Islamism and Iran's Postrevolutionary Economy: The Case of the Bonyads. In M. Tétreault \& R. Denemark (Eds.), Gods, Guns, and Globalization. U.S.: Lynne Rienner Publisher.

Mamedova, N. (2009). Russia ii: Iranian-Soviet Relations (1917-1991). In Encyclopedia Iranica. Retrieved from http://www.iranicaonline.org/articles/russia-ii-iraniansoviet-relations-1917-1991

Management and planning: Today's necessity. (2012, December 31). Islamic Republic Newspaper [in Farsi]. Retrieved from http://www.jomhourieslami.com/1391/13911011/13911011_01_jomhori_islami_sar _magaleh_0001.html 
Mansfield, B. (2005). Beyond rescaling: reintegrating the "national" as a dimension of scalar relations. Progress in Human Geography, 29(4), 458-473.

Mansoori, J. (1995). Wetlands of Islamic Republic of Iran. In D. A. Scott (Ed.), A Directory of Wetlands in the Middle East. IUCN and International Waterfowl and Wetlands Research Bureau.

Mansuri, B. (2005). Rural micro finance support project. Tehran, Iran: International Enterprise for Development of Rural Micro Finance Services. Retrieved from http://www.ruralpovertyportal.org/documents/654016/101613/Rural+Micro+Finance +Support+Project.pdf/f76e0524-653d-4690-8a90-7bf28ab70578?version=1.0

Marston, S. A. (2000). The social construction of scale. Progress in Human Geography, 24(2), 219-242.

Marston, S. A., \& Smith, N. (2001). States, scales, and households: limits to scale thinking? A response to Brenner. Progress in Human Geography, 25(4), 615-619.

Massey, D. (1993). Power-geometry and a progressive sense of place. In J. Bird, B. Curtis, T. Putnam, G. Robertson, \& L. Tickner (Eds.), Mapping the futures: Local cultures, global change. London and New York: London and New York Routledge.

Massey, D. (1994). A Global Sense of Place. In D. Massey (Ed.), Space, Place and Gender. University of Minnesota Press.

Massey, D. (1995). Places and their pasts. History Workshop Journal, (39), 182-192.

Massey, D. (1999). Power-Geometries and the Politics of Space-Time. Heidelberg: Institute of Geography, University of Heidelberg.

Massey, D. (2003). Some times of space. In S. May (Ed.), Olafur Eliasson:The Weather Project. London: Tate Publishing.

Massey, D. (2004). Geographies of responsibility. Geografiska Annaler: Series B, Human Geography, 86B(1), 5-18.

Massey, D. (2005). For space. Sage Publications Ltd.

Massey, D. (2006). Landscape as a Provocation: Reflections on Moving Mountains. Journal of Material Culture, 11(1-2), 33-48.

Massey, D. (2009). Concepts of space and power in theory and in political practice. Documents d'anàlisi geogràfica, (55), 15-26.

Massey, D. (2010). Is the world getting larger or smaller? Open Democracy-free thinking for the world, December. Retrieved from 
http://www.opendemocracy.net/globalization-

vision_reflections/world_small_4354.jsp

McAfee, M. . (1999). Selling nature to save it? Biodiversity and the rise of green developmentalism. Environment and Planning D: Society and Space, 17(2), 133154.

McCall, M. K. (2003). Seeking good governance in participatory-GIS: A review of processes and governance dimensions in applying GIS to participatory spatial planning. Habitat International, 27(4), 549-573. Retrieved from http://dx.doi.org/10.1016/S0197-3975(03)00005-5

McCall, M. K. (2004). Can Participatory GIS strengthen local-level planning? Suggestions for better practice. The 7th International Conference on GIS for Developing Countries (GISDECO 2004), 10-12 May 2004, University Teknologi Malaysia, Johor Malaysia.

McCall, M. K. (2005). Nexus of GeoData Analysis \& Local Spatial Knowledge: Applications of P-Mapping and PGIS to issues in NRM and Community Development [Working Draft]. The Netherlands: Faculty of Geo-Information Science and Earth Observation of the University of Twente. Retrieved from http://www.iapad.org/publications/ppgis/ITKNRMmapsLitReview_IAPAD.pdf

McCall, M. K. (2006). Precision for whom? Mapping ambiguity and certainty in participatory GIS. Participatory Learning and Action Notes, 54, 114-119.

McChesney, R. (2008). The Built Environment. On-line Histories of Central Asia, The Eurasia Programme, Social Science Research Council. Retrieved from http://onlinehistories.ssrc.org/centralasia/environment/default.aspx?id=1276

McCormick, J. (2005). The Role of Environmental NGOs in International Regimes. In N. J. Vig, R. S. Axelord, \& D. L. Downie (Eds.), The Global Environment: Institutions, Law and Policy. Earthscan Publications Limited.

McLachlan, K. (1990). The neglected garden: The politics and ecology of agriculture in Iran. London: I. B. Tauris \& Co. Ltd.

Meentemeyer, V. (1989). Geographical perspectives of space, time, and scale. Landscape Ecology, 3(3-4), 163-173. doi:10.1007/BF00131535

Meeting with university professors, elites, and the heads of universities and research institutions. (2009). The Khamenei News Portal [in Farsi]. Retrieved from http://www.leader.ir/langs/fa/?p=contentShow\&id=5814\# 
Members of the Higher Provincial Council and Municipalities meet with the Supreme Leader. (2011, April 30). Khamenei News Portal [in Farsi]. Retrieved from http://farsi.khamenei.ir/news-content?id=12346

Mesdaghi, M. (2003). Range Management in Iran [in Farsi]. Mashad: Astan-e Ghods-e Razavi Publications.

Messer, N., \& Townsley, P. (2003). Local Institutions and Livelihoods: Guidelines for Analysis. FAO. Retrieved from http://www.fao.org/docrep/006/y5084e/y5084e00.htm\#Contents

Millennium Ecosystem Assessment. (2005). Ecosystem and Human Well-Being:

Wetlands and Water Synthesis. Washington, DC: World Resources Institute.

Mirzadeh, H. (2009, April 14). Environment High Council- An ambiguous phrase in the Government's language. Etemaad [in Farsi]. Retrieved from http://etemaad.ir/released/88-01-25/279.htm

Mission and duties. (2013). Department of Environment-Iran [in Farsi]. Retrieved from http://www.doe.ir/portal/Home/Default.aspx?CategoryID=042f86ab-589e-4d399ba6-96c21f49cb1c

Mission, goals, and activities. (2013). Iran Water Resource Management Company [in Farsi]. Retrieved March 13, 2013, from http://portal.wrm.ir/Pages/mission.aspx

Moaddel, M. (1993). Class, politics, and ideology in the Iranian revolution. New York: Columbia University Press.

Moghadam, F. (1996). From Land Reform To Revolution: The Political Economy of Agricultural Development in Iran, 1962-1979. London: Tauris Academic Studies.

Mohammad, R. (2001). 'Insiders' and/or “outsiders": positionality, theory and praxis. In M. Limb \& C. Dwyer (Eds.), Qualitative Methodologies for geographers-issues and debates. New York: Arnold Publishers.

Mohammadi, A. (2007, August 5). Dissolution of Environmental High Council and its legal importance. Mountain Watch [in Farsi]. Retrieved from http://mountainwatch.persianblog.ir/post/365

Mohammadi, A. (2012, February 29). Tempting Use of Protected Areas. Etemaad [in Farsi]. Retrieved from http://www.magiran.com/ppdf/nppdf/3291/p0329123430131.pdf

Mohan, G. (2007). Participatory development: from epistemological reversals to active citizenship. Geography Compass, 1(4), 779-796. 
Moinee, A. (1965). Geography and historical geography of Gorgan and Gorgan Plain [in Farsi]. Tehran, Iran: Ta'b Iran Press Company.

Mojtahed-Zadeh, P. (2006). Boundary politics and international boundaries of Iran. Boca Raton, USA: Universal Publishers.

Mojtahed-Zadeh, P., \& Hafeznia, M. (2003). Perspectives on the Caspian Sea Dilemma: An Iranian construct. Eurasian Geography and Economics, 44(8), 607-616.

Moncrieffe, J. (2011). Relational Accountability: Complexities of Structural Injustice. London and New York: Zen Books.

Moore, A. (2008). Rethinking scale as a geographical category: from analysis to practice. Progress in Human Geography, 32(2), 203-225.

Moore, M. (2010). Briefing Note, The Ramsar Convention. Australia: New South Wales Irrigators' Council. Retrieved from http://www.nswic.org.au/pdf/Briefings/100702 Ramsar Convention Briefing Paper.pdf

Moradi, A. (2009). A glimpse into the hitroy of the Turkmen by Safar Khatibi [in Farsi]. Turkmen Shahra Media. Retrieved from http://web4.crystone.se/turkmensahramedia.com/q/q_ffar.php?ffar_id=30

More than 30 million hectares of rangelands availabe for conversion and transfer. (2012, September 30). Mehr News [in Farsi]. Retrieved from http://www.mehrnews.com/TextVersionDetail/1708340

Moschtaghi, R. (2010). Rule of Law in Iran. Rule of Law Working Paper Series Nr. 11. Berlin: Koetter/Schuppert. Retrieved from http://wikis.fuberlin.de/download/attachments/22347860/Moschtaghi+Iran.pdf

Moser, M. (2009). Ramsar Advisory Mission: No. 60, Islamic Republic of Iran (14-16 May 2009). The Ramsar Convention Secretariat. Retrieved from http://www.ramsar.org/cda/en/ramsar-documents-rams-ram60/main/ramsar/1-31112^23827_4000_0

Moslem, M. (2002). The state and factional politics. In E. Hooglund (Ed.), Twenty Years of Islamic Revolution: Political and Social Transition in Iran since 1979. Syracuse University Press.

Mosse, D. (2010). A Relational Approach to Durable Poverty, Inequality and Power. Journal of Development Studies, 46(7), 1156-1178.

doi:10.1080/00220388.2010.487095

Mukhamejanov, A. R. (2000). Natural Life and the Manmade Habitat in Central Asia. In C. E. Bosworth \& M. S. Asimov (Eds.), History of civilization of Central Asia: 
Volume IV - The age of achievement-Part Two: The achievements. UNESCO Publishing.

Munkacsi, K. (1994). Dividing the Chodor. Thomas Cole Antique Rugs and Textile. Retrieved from http:/www.tcoletribalrugs.com/article51CHODOR.html

Murdoch, J. (1998). The spaces of actor-network theory. Geoforum, 29(4), 357-374.

Murdoch, J. (2006). Post-structuralist geography: a guide to relational space. Sage Publications Ltd.

Murdoch, J., \& Marsden, T. (1995). The Spatialization of Politics: Local and National Actor-Spaces in Environmental Conflict. Transactions of the Institute of British Geographers, 20(3), pp. 368-380.

Nader, A., Thaler, D., \& Bohandy, S. (2011). The next supreme leader: succession in the Islamic Republic of Iran. U.S.: RAND National Defence Research Institute.

Natural Environment Division. (2013). Department of Environment-Iran [in Farsi]. Retrieved from http://www.doe.ir/Portal/Home/Default.aspx?CategoryID=17194ac6-7de5-4737adb3-961fb5056f08

Natural resource laws and regulations. (2013). Forest, Range \& Watershed Management Organization [in Farsi]. Retrieved from

http://www.frw.org.ir/GhavaninManabeTabee/pageid/61/language/faIR/Default.aspx

Naughton-Treves, L., Holland, M. B., \& Brandon, K. (2005). The role of protected areas in conserving biodiversity and sustainable local livelihoods. Annual Review of Environment and Resources, 30, 219-252.

Nesbitt, M., \& O’Hara, S. (2000). Irrigation agriculture in Central Asia: a long-term perspective from Turkmenistan. In G. Barker \& D. Gilbertson (Eds.), The Archaeology of Drylands: Living at the Margin. Taylor \& Francis e-Library.

Neumann, R. P. (2004). Nature-state-territory: toward a critical theorization of conservation enclosures. In R. Peet \& M. Watts (Eds.), Liberation Ecologies: Environment, Development and Social Movements (2nd ed.). Routledge.

Neumann, R. P. (2005). Making political ecology. U.K.: Hodder Arnold.

Neumann, R. P. (2008). Probing the (in)compabilities of social theory and policy relevance in Piers Blaikie's political ecology. Geoforum, 39, 728-735. 
Neumann, R. P. (2009). Political ecology: theorizing scale. Progress in Human Geography, 33(3), 398-406.

Neumann, R. P. (2010). Political ecology II: theorizing region. Progress in Human Geography, 34(3), 368-374.

New tasks for the Department of Environment: Setting standards for school's chairs and desks. (2009, May 12). Etemaad [in Farsi]. Retrieved from http://www.etemaad.ir/Released/88-02-22/213.htm

Nichol, J. (2007). Turkmenistan: Recent developments and U.S. interests. U.S.: Congressional Research Service, The Library of Congress, Foreign Affairs, Defense, and Trade Division. Retrieved from http://www.hsdl.org/?view\&did=712999

Nopor, M. (2013). Re: Forests are not rangelands! [Web log message, 2013, January 22] [in Farsi]. Retrieved from http://mohsennopor.blogfa.com/post/169/\%D8\%AC\%D9\%86\%DA\%AF\%D9\%84$\% \mathrm{DA} \% 86 \% \mathrm{D} 8 \% \mathrm{~B} 1 \% \mathrm{D} 8 \% \mathrm{~A} 7 \% \mathrm{DA} \% \mathrm{AF} \% \mathrm{D} 8 \% \mathrm{~A} 7 \% \mathrm{D} 9 \% 87-$ $\% \mathrm{D} 9 \% 86 \% \mathrm{D} 9 \% 8 \mathrm{~A} \% \mathrm{D} 8 \% \mathrm{~B} 3 \% \mathrm{D} 8 \% \mathrm{AA}$

O'Donova, E. (1883). Travels and Adventures East of the Caspian During the Years 1879-80-81 Including Five Months' Residence Among the Tekkés of Merv, Volume 1. New York: G. P. Putnam's Sons.

Odugbemi, S. (2008). Public Opinion, the Public Sphere, and Quality of Governanve: An Exploration. In S. Odugbemi \& T. Jacobson (Eds.), Governance Reform: Under Real-World Conditions. The World Bank.

Organizational Structure. (2013). Forest, Range \& Watershed Management Organization [in Farsi]. Retrieved from http://www.frw.org.ir/AboutUS/nemodartashkilati/pageid/1813/language/faIR/Default.aspx

Paasi, A. (2004). Place and region: looking through the prism of scale. Progress in Human Geography, 28(4), 536-546.

Paasi, A. (2011). Geography, space and the re-emergence of topological thinking. Dialogues in Human Geography, 1(3), 299-303.

Parsa, M. (1989). Social Origins of Iranian Revolution. Rutgers University Press.

Paulson, S., Gezon, L. L., \& Watts, M. (2003). Locating the Political in Political Ecology: An Introduction. Human Organization, 62(3), 205-217. 
Paulson, S., Gezon, L. L., \& Watts, M. (2005). Politics, Ecologies, Genealogies. In Susan Paulson \& L. L. Gezon (Eds.), Political ecology across spaces, scale, and social groups. Rutgers University Press.

Peet, R. (1998). Modern Geographical Thoughts. U.K.: Blackwell Publishing.

Peluso, N. L. (1993). Coercing conservation?: The politics of state resource control. Global environmental change, 3(2), 199-217.

Peluso, N. L. (1994). Rich forests, poor people: Resource control and resistance in Java. University of California Press.

Peluso, N. L. (1995). Whose woods are these? counter-mapping forest territories in Kalimantan, Indonesia. Antipode, 27, 383-406. Retrieved from http://onlinelibrary.wiley.com/doi/10.1111/j.1467-8330.1995.tb00286.x/abstract

Peluso, N. L., \& Vandergeest, P. (2001). Genealogies of the political forest and customary rights in Indonesia, Malaysia, and Thailand. The Journal of Asian Studies, 60(3). Retrieved from http://journals.cambridge.org/abstract_S0021911800009487

Perramond, E. P. (2007). Tactics and strategies in political ecology research. Area, 39(4), 499-507.

Petrochemical industry: Deep wounds in Sofikam. (2007, August 26). Etemaad Melli [in Farsi]. Retrieved from http://www.magiran.com/npview.asp?ID=1471375

Phillips, A. (2003). Turning ideas on their head: the new paradigm for protected areas. The George Wright Forum, 20(2). Retrieved from http://www.uvm.edu/ snrsprng/vermont.pdf

Phillips, B. (2001). Ramsar rebuttal on importance of the Wise Use principle. Ramsar Convention Secretariat, Gland, Switzerland. Retrieved from http://www.ramsar.org/cda/en/ramsar-documents-wurl-laws-ramsar-rebuttalon/main/ramsar/1-31-116-165^22489_4000_0_

Pilgrimage of the Basiji Sunni women of Golestan to the holly Mashad. (2013, August 28). Basijnews [in Farsi]. Retrieved from http://www.basijnews.ir/index.php?q=content/\%D8\%A7\%D8\%B9\%D8\%B2\%D8\% A7\%D9\%85-\%D8\%A8\%D8\%A7\%D9\%86\%D9\%88\%D8\%A7\%D9\%86$\%$ D8\%A7\%D9\%87\%D9\%84-\%D8\%B3\%D9\%86\%D8\%AA$\% \mathrm{D} 8 \% \mathrm{~A} 8 \% \mathrm{D} 9 \% 86 \% \mathrm{D} 8 \% \mathrm{AF} \% \mathrm{D} 8 \% \mathrm{~B} 1 \% \mathrm{D} 8 \% \mathrm{AA} \% \mathrm{D} 8 \% \mathrm{~B} 1 \% \mathrm{DA} \% \mathrm{~A} 9 \% \mathrm{D} 9 \% 85 \%$ D9\%86-\%D8\%A8\%D9\%87-\%D8\%A7\%D8\%B1\%D8\%AF\%D9\%88\%DB\%8C$\% \mathrm{D} 8 \% \mathrm{~B} 2 \% \mathrm{DB} \% 8 \mathrm{C} \% \mathrm{D} 8 \% \mathrm{~A} 7 \% \mathrm{D} 8 \% \mathrm{~B} 1 \% \mathrm{D} 8 \% \mathrm{AA} \% \mathrm{DB} \% 8 \mathrm{C}-$ \%D9\%85\%D8\%B4\%D9\%87\%D8\%AF\%D9\%85\%D9\%82\%D8\%AF\%D8\%B3 
Plaintiffs of the death of the Zayandeh River. (2011, August 15). JahanNews [in Farsi]. Retrieved from http://jahannews.com/vdch6znz623n6kd.tft2.html

Ponomarenko, S., \& Fet, V. (2013). Western Asia: Along the cost of the Caspian Sea in Russia, Kazakhstan, Turkmenistan, and Iran. World Wildlife Fund. Retrieved from http://worldwildlife.org/ecoregions/pa1308

Poole, P. (1995). Indigenous peoples, mapping \& biodiversity conservation: An analysis of current activities and opportunities for applying geomatics technologies. Washington DC: Biodiversity Support Program.

Pothukuchi, K. (2007). Book review: Jonathan Murdoch, Post-structuralist Geographies: A guide to relational space. Planning Theory, 6(1), 100-104.

Pourkarim, H. (1965). The Turkmen of Iran (1). Honar va Mardom [in Farsi], Feb$\operatorname{Mar}(41-42), 29-42$.

Pourkarim, H. (1967). The Turkmen of Iran (4). Honar va Mardom [in Farsi], December(63), 25-33.

Pourkarim, H. (1968a). Inchehburun (1). Honar va Mardom [in Farsi], August(71), 4355.

Pourkarim, H. (1968b). The Turkmen of Iran (5). Honar va Mardom [in Farsi], January(64), 55-62.

Prayer-Galletti, M. (2005). Challenging policy agenda faced by IFAD project in Iran. Making a Difference in Asia and the Pacific, Nov./Dec. Retrieved from http://www.ifad.org/newsletter/pi/7.htm\#5

Pritchard, D. (2003). World co-operation for wetlands: the Ramsar Convention. World Birdwatch, 25(1), 18-20. Retrieved from http://seabirds.birdlife.org/action/change/ramsar/wbw_ramsar_article.pdf

Pritchard, D., Dereliev, S., Dufour, A., Ognimba, R., \& Watha-Ndoudy, N. (2010). Ramsar Advisory Missions: No. 66, Cayo-Loufoualeba, Republic of Congo (June 2010). The Ramsar Convention Secretariat. Retrieved from http://www.ramsar.org/pdf/ram/ram_rpt_66e.pdf

Proctor, J. (2001). Solid Rock and Shifting Sands. In Social Nature: Theory, Practice and Politics. Oxford: Blackwell Publishing.

Provincial mining development regulations. (2013). Majlis Research Center [in Farsi]. Retrieved April 25, 2013, from http://rc.majlis.ir/fa/law/show/840518 
Quan, J., Oudwater, N., Pender, J., \& Martin, A. (2001). GIS and participatory approaches in natural resources research (Best Practice Guidelines). Chatham, UK: Natural Resources Institute.

Rabino, H. L. (1928). Mazandaran and Astarabad. London: Luzac \& Co.

Rambaldi, G. (2004). Who owns the map legend? The 7th International Conference on GIS for Developing Countries (Universiti Teknologi Malaysia, Johor Malaysia, May 2994).

Rambaldi, G., Chambers, R., McCall, M. K., \& Fox, J. (2006). Practical ethics for PGIS practitioners, facilitators, technology intermediaries and researchers. Participatory Learning and Action Notes, 54, 106-113.

Rambaldi, G., McCall, M. K., Kwaku Kyem, P., \& Weiner, D. (2006). Participatory spatial information management and communication in developing countries. The Electronic Journal on Information Systems in Developing Countries, 25(1), 1-9.

Rambaldi, G., \& Weiner, D. (2004). Track on international Perspectives. Summary Proceedings: the 3rd International Conference on Public Participation GIS (University of Wisconsin-Madison, Wisconsin, USA, July 2004).

Ramsar Convention on Wetlands. (1987a). Information on wise use of wetlands specified under Article 3 of the Ramsar Convention-Annex to Recommendation 3.3. Wise use of wetlands. Retrieved from http://www.ramsar.org/cda/en/ramsar-documents-resolinformation-on-wise-use/main/ramsar/1-31-107^23129_4000_0

Ramsar Convention on Wetlands. (1987b). The Convention on Wetlands text, as amended in 1982 and 1987. Retrieved from http://www.ramsar.org/cda/en/ramsar-documentstexts-convention-on/main/ramsar/1-31-38^20671_4000_0_

Ramsar Convention on Wetlands. (1993). Annex to resolution V.6. Additional Guidance for the Implementation of the Wise Use Concept. Retrieved from http://www.ramsar.org/cda/en/ramsar-documents-resol-additional-guidancefor/main/ramsar/1-31-107\%5E20915_4000_0

Ramsar Convention on Wetlands. (1996). Resolution VI.1: Working definitions of ecological character, guidelines for describing and maintaining the ecological character of listed sites, and guidelines for operation of the Montreux Record. Retrieved from http://www.ramsar.org/cda/en/ramsar-documents-resol-resolution-vi1-working/main/ramsar/1-31-107^20929_4000_0

Ramsar Convention on Wetlands. (2002). The Ramsar Strategic Plan 2003-2008. Retrieved from http://www.ramsar.org/pdf/key_strat_plan_2003_e.pdf 
Ramsar Convention on Wetlands. (2012a). The Ramsar Strategic Plan 2009-2015 as adopted by Resolution X.1 (2008) and adjusted for the 2013-2015 triennium by Resolution XI.3 (2012). Retrieved from http://www.ramsar.org/pdf/strat-plan-2009e-adj.pdf

Ramsar Convention on Wetlands. (2012b). Resolution XI.12 Wetlands and health: taking an ecosystem approach. Retrieved from http://www.ramsar.org/pdf/cop11/res/cop11-res12-e.pdf

Ramsar Convention on Wetlands. (2012c). Resolution XI.13 An Integrated Framework for linking wetland conservation and wise use with poverty eradication. Retrieved from http://www.ramsar.org/pdf/cop11/res/cop11-res13-e.pdf

Ramsar Convention Secretariat. (2007). Ramsar Information paper 2: What is the Convention on Wetlands? Ramsar Convention Secretariat. Retrieved from http://www.ramsar.org/pdf/about/info2007-02-e.pdf

Ramsar Convention Secretariat. (2008). Iran National Report on the Implementation of the Ramsar Convention on Wetlands. Retrieved from http://www.ramsar.org/pdf/cop10/cop10_nr_iran.pdf

Ramsar Convention Secretariat. (2009a). Iranian Site Removed from the Montreux Record. Retrieved from http://www.ramsar.org/cda/en/ramsar-news-latest-iraniansite-removed/main/ramsar/1-26-76^23828_4000_0

Ramsar Convention Secretariat. (2009b). The Ramsar Information Sheet on Wetlands of International Importance. Retrieved from http://www.ramsar.org/cda/en/ramsardocuments-info-ramsar-information/main/ramsar/1-31-59^21254_4000_0

Ramsar Convention Secretariat. (2010a). Addressing change in wetland ecological character of Ramsar Sites and other wetlands. Ramsar handbooks for the wise use of wetlands, 4th edition, vol. 19. Ramsar Convention Secretariat, Gland, Switzerland.

Ramsar Convention Secretariat. (2010b). Rarticipatory Skills: Establishing and strengthening local communities' and indigenous people's participation in the management of wetlands. Ramsar handbooks for the wise use of wetlands, 4th edition, vol. 7. Ramsar Convention Secretariate, Gland, Switzerland.

Ramsar Convention Secretariat. (2010c). Wise use of wetlands: Concepts and approaches for the wise use of wetlands. Ramsar handbooks for the wise use of wetlands, 4th edition, vol. 1. Ramsar Convention Secretariate, Gland, Switzerland.

Ramsar Convention Secretariat. (2011). Ramsar Handbooks for the wise use of wetlands. Retrieved from http://www.ramsar.org/cda/en/ramsar-pubshandbooks/main/ramsar/1-30-33_4000_0 
Ramsar Convention Secretariat. (2012). Iran National Report on the Implementation of the Ramsar Convention on Wetlands. Retrieved from http://www.ramsar.org/pdf/cop11/nr/cop11-nr-iran.pdf

Ramsar Convention Secretariat. (2013a). Information Sheet on Ramsar Wetlands- Lake Alagol, Lake Ulmagol and Lake Ajigol. Ramsar Sites Information Service, Ramsar Convention Secretariat, Gland, Switzerland. Retrieved from http://sites.wetlands.org/reports/ris/2IR014en.pdf

Ramsar Convention Secretariat. (2013b). The Ramsar Convention Manual: a Guide to the Convention on Wetlands, 6th ed. Ramsar Convention Secretariat, Gland, Switzerland. Retrieved from http://www.ramsar.org/pdf/lib/manual6-2013-e.pdf

Ramsar Convention Secretariat. (2013c). Applications of the Ramsar Advisory Mission. Retrieved from http://www.ramsar.org/cda/en/ramsar-documentsrams/main/ramsar/1-31-112_4000_0

Rass, N. (2013). Participatory Project Formulation Course. FAO: Working Group on Participatory Approaches and Methods. Retrieved from http://www.fao.org/Participation/english_web_new/content_en/about.html

Ratification of the list of projects that require EIA. (2011). Majlis: Legal and Majlis Affairs [in Farsi]. Retrieved March 26, 2013, from http://hvm.ir/lawdetailnews.asp?id=47338

Reconstruction of villages in deprived areas of Golestan. (2012, September 22). Hamshahrionline [in Farsi]. Retrieved from http://www.hamshahrionline.ir/details/185321

Regulations of Internal Affairs of the Cabinet. (2011). Presidential Executive Deputy Portal [in Farsi]. Retrieved March 27, 2013, from http://ejraee.ir/2772

Reid, R. S., Galvin, K. A., \& Kruska, R. S. (2008). Global significance of externsive grazing lands and pastoral societies: An introduction. In K. A. Galvin, R. S. Reid, R. H. Behnke, \& N. T. Hobbs (Eds.), Fragmentation in Semi-Arid and Arid Landscapes. Springer.

Republic. (2009). In The Concise Oxford Dictionary of Politics. Retrieved from http://www.oxfordreference.com.proxy.library.carleton.ca/view/10.1093/acref/97801 99207800.001.0001/acref-9780199207800-e-1155? rskey $=$ SiO0Fx\&result $=1236 \& q=$

Ribot, J. (2004). Waiting for Democracy: The Politcs of Choice in Natural Resource Decentralization. Washington DC: World Resources Institute.

Ribot, J. (2007). Representation, citizenship and the public domain in democratic decentralization. Development, 50(1), 43-49. 
Ribot, J., \& Peluso, N. L. (2003). A Theory of Access. Rural sociology, 68(2), 153-181.

Robbins, P. (2004). Political Ecology: A Critical Introduction (1st ed.). Blackwell Publishing.

Robbins, P. (2008). The State in Political Ecology: A Postcard to Political Geography from the Field. In K. Cox, M. Low, \& J. Robinson (Eds.), The SAGE Handbook of Political Geography. Sage Publications Ltd.

Robbins, P. (2012). Political Ecology: A Critical Introduction (2nd Ed.). Hoboken, NJ, USA: John Wiley \& Sons.

Rocheleau, D. E. (2008). Political ecology in the key of policy: From chains of explanation to webs of relation. Geoforum, 39, 716-727.

Rocheleau, D. E. (2011). Rooted Networks, Webs of Relations, and the Power of Situated Science- Bring the Models Back Down to Earth in Zambrana. In M. J. Goldman, P. Nadasdy, \& M. D. Turner (Eds.), Knowing Nature: Conversations at the Intersection of Political Ecology and Science Studies. University of Chicago Press.

Rocheleau, D. E., Thomas-Slayter, B., \& Edmunds, T. (1995). Gendered resource mapping. Cultural Survival Quarterly, 4, 62-68.

Routledge, P., Cumbers, A., \& Nativel, C. (2007). Grassrooting network imaginaries: Relationality, power, and mutual solidarity in global justice networks. Environment and Planning A, 39(11), 2575-2592.

Rowland, N. J. (2010). Actor-Network State: Integrating Actor-Netwrok Theory and State Theory. International Sociology, 25(6), 818-841.

Rutland, T., \& Aylett, A. (2008). The work of policy: actor networks, governmentality, and local action on climate change in Portland, Oregon. Environment and planning: D, Society and space, 26(4), 627-646.

Sadeq Khalkhali, Iran's “hanging judge”, died on November 26th, aged 77. (2003, December 13). The Economist. Retrieved from http://www.economist.com/node/2282169

Sadr, K. (2001). Water markets and pricing in Iran. In N. Faruqui, A. Biswas, \& M. Bino (Eds.), Water Management in Islam. IDRC/UNU Press.

Saeidi, A. (2011). Spiritual Progression Conference- Lancaster University. Retrieved from http://www.religionandsociety.org.uk/publications/podcasts/show/spiritual_progressi on_conference_ali_saeidi 
Sala, R. (2003). Historical Survey of Irrigation Practices in West Central Asia.

Laboratory of Geo-archeology, Centre of Geologo-Geographical Research, Minsitry of Educaiton and Science, Kazakhstan. Retrieved from

http://www.google.ca/url?sa $=$ t\&rct $=\mathrm{j} \& \mathrm{q}=\&$ esrc $=$ s\&source=web\&cd $=4 \& v e d=0 \mathrm{CDs}$

QFjAD\&url=http://www.lgakz.org/Texts/LiveTexts/CAsiaIrrigTextEn.doc\&ei=Ajhk UtvmA-

b4yQHK8YHIAw\&usg=AFQjCNHK39t7_ftZ2AdloGk1oAQmqZdH7w\&sig2=hUx Yn5pVpf-qOAo9qSwNog\&bvm=bv.54934254,d.aWc

Salahuddin, A. (2009). Is Iran an Islamic State? Khalifah. Retrieved from http://www.khilafah.com/index.php/concepts/political-concepts/7007-is-iran-anislamic-state

Salamaan, K. (1999). The Turkmen. Ketab Jomeh [in Farsi], 35, 54-61. Retrieved from http://irpress.org/index.php?title= هانُركم

Salzman, P. (2002). Pastoral nomads: some general observations based on research in Iran. Journal of Anthropological Research, 58(2), 245-264.

Salzman, P. (2004). Pastoralists: Equality, Hierarchy, and the State. Westview Press.

Samii, A. W. (2000). The nation and its minorities: Ethnicity, unity and state policy in Iran. Comparative Studies of South Asia, Africa and the Middle East, 20(1-2), 128137.

Sands, P., \& Peel, J. (2005). Environmental Protection in the Twenthy-first Century: Sustainable Development and International Law. In N. J. Vig, R. S. Axelord, \& D. L. Downie (Eds.), The Global Environment: Institutions, Law and Policy. Earthscan Publications Limited.

Saribakhsh. (2008). Re: Unknown situation [Web log message, 2008, November 4] [in Farsi]. Retrieved from http://bustansaribakhsh.persianblog.ir/post/103

Sayahi-Kashi, J. (2004). Country Report- Islamic Republic of Iran (3). In C. M. Wijayarantna (Ed.), Role of Local Communities and Institutions in Integrated Rural Development. Asian Productivity Organization.

Sayre, N. F. (2005). Ecological and geographical scale: parallels and potential for integration. Progress in Human Geography, 29(3), 276-290.

Sayre, N. F. (2009). Scale. In N. Castree, D. Demeritt, D. Liverman, \& B. Rhoads (Eds.), Companion to Environmental Geography. Wiley-Blackwell.

Schirazi, A. (1993). Islamic development policy: the agrarian question in Iran. Boulder \& London: Lynne Rienner Publisher. 
Schofield, M. (2002). Plato: Republic. In Routledge Encyclopedia of Philosophy. Routledge. Retrieved from http://www.rep.routledge.com/article/A088SECT14?ssid=373289832\&n=5\#

Schroeder, R. (2000). Beyond Distributive Justice: Resource Extraction and Environmnetal Justice in the Tropics. In C. Zerner (Ed.), People, plants and justice: The politics of nature conservation. New York: Columbia University Press.

Sciolino, E. (2000). Persian Mirrors: The Elusive Face of Iran. New York: The Free Press.

Scott, J. (1998). Seeing like a state: how well-intentioned efforts to improve the human condition have failed. Yale University Press.

Shakoori, A. (2001). The state and rural development in post-revolutionary Iran. New York \& Hampshire: Palgrave.

Shakoori, A. (2006). Planning and Agricultural Development in Iran. Critique: Critical Middle Eastern Studies, 15(3), 265-282.

Shelton, D. H. (2009). A right-based approach to conservation. In T. Greiber (Ed.), Conservation with Justice. A Rights-based Approach. Gland, Switzerland: IUCN, Environmental Law centre.

Shokoohi, A. (1996). Public Administrative Reform for Economic Transformation in Iran: The Legal Framework. Asian Review of Public Administration, 8(2), 33-44.

Silver, J. J. (2008). Weighing in on Scale: Synthesizing Disciplinary Approaches to Scale in the Context of Building Interdisciplinary Resource Management. Society and Natural Resources, 21(10), 921-929.

Sir Hertslet, E. (1891). Treaties, \& Conventions Concluded Between Great Britain and Persia: And Between Persia and Other Foreign Powers, Wholly or Partially in Force on the 1st April, 1891. London: Butterwortss and Harrisn and Sons.

Sletto, B. (2002). Boundary making and regional identities in a globalized environment: rebordering the Nariva Swamp, Trinidad. Environment and Planning D: Society and Space, 20, 183-208.

Smith, N. (1984). Uneven Development. New York: Blackwell Publishing.

Sneddon, C. (2003). Reconfiguring scale and power: The Khong-Chi-Mun project in northeast Thailand. Environment and Planning A, 35(12), 2229-2250.

Sokal, A. (1996). A physicist experiments with cultural studies. Lingua France, 6(MayJune). 
Soleimani, E., \& Moridnejad, A. (2012). A Comparative Study of Environmental Impact Assessment Laws and Regulations- Iran and selected countries (Industrial and developing countries and views and concepts of international organization) (in Farsi]. Majlis Research Center. Retrieved from http://rc.majlis.ir/fa/report/show/820756

Soltanian. (2009, September 5). Development of the Atrek riparian zone. Ministry of Energy, Golestan Rural Water and Wastewater Company Portal [in Farsi]. Retrieved from http://abfargmosh.ir/news.php?id=29

Soule, M. (1995). The social siege of nature. In M. Soule \& G. Lease (Eds.), Reinventing Nature? Responses to Postmodern Deconstruction. Washington DC: Island Press.

Soule, M., \& Lease, G. (1995). Preface. In M. Soule \& G. Lease (Eds.), Reinventing Nature? Responses to Postmodern Deconstruction. Island Press.

Staeheli, L. A., \& Mitchell, D. (2009). Politics of Place. In R. Kitchin \& N. Thrift (Eds.), International Encyclopedia of Human Geography. Elsevier.

Stålnacke, P., \& Gooch, G. (2010). Integrated water resources management. Irrigation and Drainage Systems, 24, 155-159.

Statistical Centre of Iran. (2006). 2006 Census: Village Tengli [in Farsi]. Statistical Centre of Iran.

Statistics Center announced the latest unemployment rate. (2013, May 18). Ayandeonline [in Farsi]. Retrieved from http://ayandeonline.com/?a=content.id\&id=132

Sulaiman, R., \& Hall, A. (2005). Extension policy at the national level in Asia. Plant Production Science, 8(3), 308-319.

Sundberg, J. (2006). Conservation, Globalization, and Democratization: Exploring the Contradictions in the Maya Biosphere Reserve, Guatemala. In Globalization and New Geographies of Conservation. Chicago and London: The University of Chicago Press.

Swiss Agency for Development and Cooperation. (2007). Governance as a transversal theme: An implementation guide. Bern, Switzerland: Swiss Agency for Development and Cooperation and Swiss Federal Department of Foregin Affairs.

Swiss Agency for Development and Cooperation. (2008). Rule of Law, Justice Sector Reforms and Development Cooperation. Bern, Switzerland: Swiss Agency for Development and Cooperation and Swiss Federal Department of Foregin Affairs. 
Swyngedouw, E. (1997). Neither Global nor Local: "Glocalization" and the politics of scale. In K. R. Cox (Ed.), Spaces of globalization: reasserting the power of the local. New York: The Guilford Press.

Swyngedouw, E. (2004). Globalisation or "glocalisation"? Networks, territories and rescaling. Cambridge Review of International Affairs, 17(1), 25-48.

Swyngedouw, E. (2010). Place, Nature and the Question of Scale: Interrogating the Production of Nature. Berlin: Brandenburgische Akademie der Wissenschaften.

Swyngedouw, E., \& Heynen, N. C. (2003). Editorial: Urban Political Ecology, Justice and the Politics of Scale. Antipod, (Special Issue: Urban Political Ecology, Justice and the Politcs of Scale), 898-918.

Sykes, P. M. (1902). Ten Thousand Miles in Persia or Eight Years in Iran. London: Murray.

Tabatabaie, S. A. (2008). Strategies to improve Iran's position in international ogranizations. Center for Strategic Research. Retrieved from http://www.csr.ir/departments.aspx?lng=fa\&abtid=08\&\&depid=45\&\&semid $=138$

Taheri, A. (2007). The Caspian. American Foreign Policy Interests, 29, 395-399.

Taheri, A. (2008, January 14). Iran's Latest Ethnic Revolt. New York Post.

Tahir, M. (2006). Turkmen identity on the wane in Iran. Institute For War \& peace Reporting. Retrieved from http://iwpr.net/report-news/turkmen-identity-wane-iran

Tajbakhsh, K. (2000). Political decentralization and the creation of local government in Iran: Consolidation or transformation of the theocratic state? Social Research, 67(2), 377-404.

Tajbakhsh, K. (2005). Planning culutre in Iran: Centralization and decentralization and local governance in the twentieth century. In S. Bishwapriya (Ed.), Comparative Planning Cultures. Taylor \& Francis Group.

Tajbakhsh, K. (2006). Provinces, Localities and the Limits of Local politics under the Islamic Republic of Iran. In Iran Under President Ahmadinejad. Woodrow Wilson International Center for Scholars.

Taylor, P. (1982). A materialistic framework for political geography. Transactions of the Institute of British Geographers, 7(1), 15-34.

Thaler, D., Nader, A., Chubin, S., Green, J. D., Lynch, C., \& Wehrey, F. (2010). Mullahs, Guards, and Bonyads: An Exploration of Iranian Leadership Dynamics. U.S.: RAND National Defence Research Institute. 
Thalmeinerova, D. (2010). Introduction to Integrated Water Resources Management. Global Water Partnership. Retrieved from www.sswm.info/.../GWP ny Introduction to IWRM.ppt?

The Fourth Development Plan: A martyr. (2009, July 29). Farhikhtegan online [in Farsi]. Retrieved from http://farheekhtegan.ir/content/view/960/50/

The Governor of Gonbad speaks about the 1979 turbulance in Gonbad. (2011, April 24). Rajanews [in Farsi]. Retrieved from http://rajanews.com/PrintFriendly.asp?id=85963

The Higher Provincial Council round table: The next council will face more challenges. (2013, February 15). Khabaronline [in Farsi]. Retrieved from http://www.khabaronline.ir/detail/277154

The Terms of Reference for Golestan land use plan. (2009, August 8). Iran Studen Correspondents Association [in Farsi]. Retrieved from http://www.iscanews.ir/fa/PrintableNewsItem.aspx?NewsItemID-318723

Thornton, J., Steel, A., \& Rast, W. (1996). Reservoirs. In D. Chapman (Ed.), Water quality assessments: A guide to the use of biota, sediments, and water in environmental monotoring (2nd Editio.). UNESCO/WHO/UNEP.

Three international wetlands in Golestan are dried out. (2011, August 17). Rajanews [in Farsi]. Retrieved from http://www.rajanews.com/Detail.asp?id=98243

Tohidi, N. (2009). Ethnicity and Religious Minority Politics in Iran. In A. Gheissari (Ed.), Contemporary Iran: economy, society, politics. Oxford University Press.

Toranly. (2006). Re: Socio-polical staus of the Turkmen in the early 19th century Iran and their main motivations for uprising [Web log message, 2006, September, 7]. Retrieved from http://dagdan.blogspot.ca/2006/09/blog-post.html

Tosun, M., \& Yilmaz, S. (2008). Centralization, Decentralization, and Conflict in the Middle East and North Africa. Policy Research Working Paper No. 4774. The World Bank.

Tripathi, N., \& Bhattarya, S. (2004). Integration Indigenous knowledge and GIS for participatory natural resource management: state-of-the-practice. The Electronic Journal on Information Systems in Developing Countries, 17(3), 1-13.

U.S. Army Map Service. (1958). Gasan-Kuli, U.S.S.R.; Iran. Western Siberia (2nd-AMS ed.). 1:250,000, Sheet NJ 40-9, Series N502. Washington DC: U.S. Army. Retrieved from http://www.lib.utexas.edu/maps/ams/western_siberia/txu-oclc-6559336-nj40-92nd-ed.jpg 
Uncertainty in water allocation in the Atrek basin forecloses investments in North

Khorasan. (2011, May 2). Iranian Students' News Agency [in Farsi]. Retrieved from http://isna.ir/fa/print/9002-07682/\%D9\%85\%D8\%B9\%D8\%A7\%D9\%88\%D9\%86-

$\% \mathrm{D} 8 \% \mathrm{~A} 7 \% \mathrm{D} 8 \% \mathrm{~B} 3 \% \mathrm{D} 8 \% \mathrm{AA} \% \mathrm{D} 8 \% \mathrm{~A} 7 \% \mathrm{D} 9 \% 86 \% \mathrm{D} 8 \% \mathrm{AF} \% \mathrm{D} 8 \% \mathrm{~A} 7 \% \mathrm{D} 8 \% \mathrm{~B} 1-$

$\%$ D8\%AE\%D8\%B1\%D8\%A7\%D8\%B3\%D8\%A7\%D9\%86-

$\% \mathrm{D} 8 \% \mathrm{~B} 4 \% \mathrm{D} 9 \% 85 \% \mathrm{D} 8 \% \mathrm{~A} 7 \% \mathrm{D} 9 \% 84 \% \mathrm{D} 9 \% 8 \mathrm{~A}-$

$\% \mathrm{D} 9 \% 86 \% \mathrm{D} 8 \% \mathrm{~A} 7 \% \mathrm{D} 9 \% 85 \% \mathrm{D} 8 \% \mathrm{~B} 4 \% \mathrm{D} 8 \% \mathrm{AE} \% \mathrm{D} 8 \% \mathrm{~B} 5-$

$\% \mathrm{D} 8 \% \mathrm{~A} 8 \% \mathrm{D} 9 \% 88 \% \mathrm{D} 8 \% \mathrm{AF} \% \mathrm{D} \%$ \%86

Unemployment rate in Golestan: 24-30\%. (2012, May 20). Aftabnews [in Farsi].

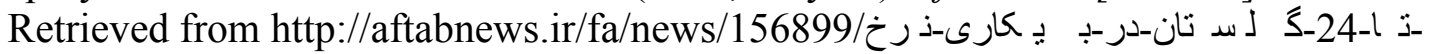
در صد-30

Unemployment rate in Golestan: above 20\%. (2011, August 29). Shomal News [in Farsi]. Retrieved from http:/www.shomalnews.com/view/49790/??? ?????? ?? ????? ????? 20 ???????/

UNESCO. (2013). Biosphere Reserves: zoning schemes. Man and Biosphere Programme. Retrieved from http://www.unesco.org/new/en/naturalsciences/environment/ecological-sciences/biosphere-reserves/maincharacteristics/zoning-schemes/

United Cities and Local Governments. (2008). Decentralization and Local Democracy in the World. The World Bank and United Cities and Local Governments.

United Nations Development Programme \& GEF. (2003). Conservation of Iranian Wetlands Project Brief. United Nations Development Programme, Global Environment Facility. Retrieved from http://www.google.ca/url?sa $=$ t\&rct $=\mathrm{j} \& \mathrm{q}=\&$ esrc $=$ s\&source $=$ web\&cd $=1 \&$ ved $=0 \mathrm{CCw}$ QFjAA\&url=http://www.thegef.org/gef/sites/thegef.org/files/gef_prj_docs/GEFProje ctDocuments/Biodiversity/Iran - Conservation of Iranian Wetlands/Iran wetlands brief 15 July 2003.doc.doc\&ei=EDVPUsrfHuioyAHX8ICoCg\&usg=AFQjCNHkzwSXpvhMio4L EdmkEyPUdpXYlw\&sig2=kvns2OXjuWgUMTFRKoeGRQ\&bvm=bv.53537100,d. $\mathrm{aWc}$

United Nations Development Programme \& GEF. (2004). Conservation of Biodiversity in the Central Zagros Landscape Conservation Zone Project Brief. United Nations Development Programme, Global Environment Facility. Retrieved from http://www.thegef.org/gef/sites/thegef.org/files/gef_prj_docs/GEFProjectDocuments /Biodiversity/Iran - Central Zagros Mountain Forests/28 July 2278 IRA Zagros Project Brief Revised.pdf

United Nations Development Programme-Iran. (2012). Conservation of Iranian Wetlands Project Report. United Nations Development Programme. Retrieved from http://www.undp.org.ir/DocCenter/reports/CIWP report_FINAL.pdf 
Upton, C., Ladle, R., Hulme, D., Jiang, T., Brockington, D., \& Adams, W. M. (2008). Are poverty and protected areas establishment linked at national scale? Oryx, 42(1), 1925.

Vahabzadeh, P. (2012). Civil Society in Iran: The Story of a Century-Long Struggle. In R. Jahanbegloo (Ed.), Civil Society and Democracy in Iran. Lexington Books.

Vahdat, F. (2012). Theorizing Civil Society in Contemporary Iran. In R. Jahanbegloo (Ed.), Civil Society and Democracy in Iran. Lexington Books.

Vambery, A. (1864). Travels in Central Asia. London: Murray.

Vambery, A. (1880). The Turcomans between the Caspian and Merv. Journal of the Anthropological Institute of Great Britain and Ireland, 9, 337-344.

Vambery, A. (1885). Will Russia Conquer India? In J. Knowles (Ed.), The Nineteenth Century: A Monthly Review XVII (Vol. 17, pp. 25-42). London: KEGAN Paul, TRENCH and Co.

Van Lieshout, M., Dewulf, A., Aarts, N., \& Termeer, C. (2011). Do scale frames matter? Scale frame mismatches in decision making process of a "mega farm" in a small dutch village. Ecology and Society, 16(1), 38.

Vayda, A. P., \& Walters, B. B. (1999). Against Political Ecology. Human Ecology, 27(1), $167-179$.

Verschuuren, J. (2008). Ramsar soft law is not soft at all. Milieu en Recht, 35(1), 28-34.

Vig, N. J. (1999). Introduction: Governing the International Environment. In N. J. Vig \& R. S. Axelord (Eds.), The Global Environment: Institutions, Law and Policy (1st ed.). Earthscan Publications Limited.

Villagers in Okhi Tepe blocked the consturction of an ab-band. (2005, September 14). Golshane Mehr [in Farsi]. Retrieved from http://www.golshanemehr.ir/article.php?id=1737

Watts, M. (2000a). Political Ecology. In E. Sheppard \& T. Barnes (Eds.), A Companion to Economic Geography. Malden: Blackwell Publishing.

Watts, M. (2000b). Contested Communities, Malignant Markets, and Gilded Governance: Justice, Resource Extraction, and COnservation in the Tropics. In C. Zerner (Ed.), People, plants and justice: The politics of nature conservation. New York: Columbia University Press. 
Watts, M., \& Peet, R. (2004). Liberating political ecology. In R. Peet \& M. Watts (Eds.), Liberation ecologies: Environment, development, social movements (2nd Ed.). Routledge.

Weiss, E. B. (1999). The Emerging Structure of International Environmental Law. In N. J. Vig \& R. S. Axelord (Eds.), The Global Environment: Institutions, Law and Policy (1st ed.). Earthscan Publications Limited.

Wells, M., McShane, T., Dublin, H., O'Connor, S., \& Redford, K. (2009). The future of Integrated Conservation and Development Projects. In W. M. Adams (Ed.), Conservation Vol. III. London, Sterling VA: Earthscan Publications Limited.

Whatmore, S. J. (2002). Hybrid Geographies: Natures, Cultures, Spaces. Sage Publications Ltd.

Where does re-establishment of MPO lead to? (2012, July 11). Fars News Agency [in Farsi]. Retrieved from http://www.farsnews.com/newstext.php?nn=13910420001353

Whitehead, M., Jones, R., \& Jones, M. (2007). The Nature of the State: Excavating the Political Ecologies of the Modern State. New York: Oxford University Press.

Whittle, A., Suhomlinova, O., \& Mueller, F. (2010). Funnel of Interests: The Discursive Translation of Organizational Change. The Journal of Applied Behavioral Science, $46(1), 16-37$.

Willis, K. (2006). Interviewing. In V. Desai (Ed.), Doing development research. Sage Publications.

Winder, J. (2005). Iran 1979. Princeton University, Constitution Writing \& Conflict Resolution: Data \& Summaries. Retrieved from http://www.princeton.edu/ pcwcr/reports/iran1979.html

Woolgar, S. (1988). Science, the Very Idea. Chichester: Tavistock Publications.

Wright, R. E. (2008). The Khiva Khanate and the Chodor. A Compilation of Notes Concerning the Nture and Origins of Textiles. Retrieved from http://www.richardewright.com/0508_khiva.html

Wright, R. E. (2010). Caspian Turkmens. A Compilation of Notes Concerning the Nture and Origins of Textiles. Retrieved from http://www.richardewright.com/0610_caspian_turkmens.html

WWF. (2013). Integrated River Basin Management: A holistic approach. Retrieved April 18, 2013, from http://wwf.panda.org/about_our_earth/about_freshwater/rivers/irbm/ 
Zabihi, M. (1984). Gorgan-Nameh [in Farsi]. (I. Afshar, Ed.). Tehran, Iran: Babak Publications.

Zimmerer, K. S. (2000). The Reworking of Conservation Geographies: Nonequilibrium Landscapes and Nature-Society Hybrids. Annals of the Association of American Geographers, 90(2), 356-369.

Zimmerer, K. S. (2006a). Geographies Prespectives on Globalization and Environmental Issues: The Inner-Connections of Conservation, Agriculture, and livelihoods. In K. S. Zimmerer (Ed.), Globalization and New Geographies of Conservation. Chicago and London: The University of Chicago Press.

Zimmerer, K. S. (2006b). Cultural ecology: at the interface with political ecology-the new geographies of environmental conservation and globalization. Progress in Human Geography, 30(1), 63-78.

Zimmerer, K. S., \& Bassett, T. J. (2003a). Approaching Political Ecology: Society, Nature, and Scale in Human-Environment Studies. In K. S. Zimmerer \& T. J. Bassett (Eds.), Political ecology: an integrative approach to geography and environmentdevelopment studies. New York: The Guilford Press.

Zimmerer, K. S., \& Bassett, T. J. (2003b). Future Direction in Political Ecology. In K. S. Zimmerer \& T. J. Bassett (Eds.), Political ecology: an integrative approach to geography and environment-development studies. The Guilford Press.

Zimmerer, K. S., Galt, R. E., \& Buck, M. V. (2004). Globalization and Multi-spatial Trends in the Converage of Protected-Area Conservation (1980-2000). Ambio, 33(8), $520-529$.

Zonn, I., Kostianoy, A., Kosarev, A., \& Glantz, M. (2010). Atrek (Etrek). In The Caspian Sea Encyclopedia. Verlag Berlin Heidelberg: Springer. 


\section{Appendix A- Fieldwork calendar}

Fieldwork calendar from October13 to December 24, 2008

\begin{tabular}{|c|c|}
\hline Oct. 13 & $\begin{array}{l}\text { - Meeting with a sociology professor in the Institute of Communication, } \\
\text { Tehran }\end{array}$ \\
\hline Oct. 15 & $\begin{array}{l}\text { - Arrived Gorgan and made myself familiar with the local coordinator } \\
\text { and his family } \\
\text { - Meeting with authorities in DOE Golestan provincial office arranged } \\
\text { by the local coordinator. I informed them about starting the fieldwork } \\
\text { that I discussed with them a year ago (November 2007) }\end{array}$ \\
\hline Oct. 17 & $\begin{array}{l}\text { - Introductory meeting with a few members of the village council and a } \\
\text { few elders in Tengli coordinated by local coordinator. I explained the } \\
\text { purpose of my research and asked their permission to stay and work in } \\
\text { their village. I mentioned all the points which were included in my } \\
\text { ethics application. They welcomed me and showed interest in the } \\
\text { research. }\end{array}$ \\
\hline Oct. 18 & - Return to Tehran \\
\hline $\begin{array}{l}\text { Oct. } 21 \\
\& 26\end{array}$ & $\begin{array}{l}\text { - Meeting with a sociology professor in the University of Shahid } \\
\text { Beheshti, Tehran }\end{array}$ \\
\hline Oct. 27 & $\begin{array}{l}\text { - Arrived Gorgan } \\
\text { - Visited DOE Golestan with my local coordinator and submitted a } \\
\text { copy of the research proposal to the head of the DOE Golestan } \\
\text { provincial office. }\end{array}$ \\
\hline Oct. 30 & $\begin{array}{l}\text { - Arrived Tengli and settled in the house I stayed until end of my } \\
\text { fieldwork in Tengli. } \\
\text { - Met with elders coordinated by local coordinator. } \\
\text { - The local coordinator left for Gorgan. }\end{array}$ \\
\hline Oct. 31 & $\begin{array}{l}\text { - Visited a hired shepherd and his family in their yurt with an elder and } \\
\text { his family and had a tour of the area seeing their livestock, and } \\
\text { rangelands and also the landscape around Ulmagol. Took pictures of } \\
\text { the area. }\end{array}$ \\
\hline Nov. 1 & $\begin{array}{l}\text { - Visited local families with my hostess and attended a baby shower. I } \\
\text { met an enthusiastic young woman, who showed interest in the project } \\
\text { and asked me if she could be involved. I briefed her about my research } \\
\text { and also the details of the field work in the village and asked her to } \\
\text { think about it and talk to her husband and his family and then let me }\end{array}$ \\
\hline
\end{tabular}




\begin{tabular}{|c|c|}
\hline & know if she is still willing to assist me. \\
\hline Nov. 2 & $\begin{array}{l}\text { - Conducted a focus group on wealth ranking and Tenglians' concern } \\
\text { regarding their livelihood strategies and access to resources. } \\
\text { - The research assistant informed me that her family supports her in her } \\
\text { decision to become my assistant. }\end{array}$ \\
\hline Nov. 3 & $\begin{array}{l}\text { - Meeting with the research assistant. We reviewed and revised the draft } \\
\text { questions for semi-structured interviews on livelihood and well-being. } \\
\text { She suggested } 12 \text { families to be interviewed from different wealth } \\
\text { categories. }\end{array}$ \\
\hline Nov. 4 & $\begin{array}{l}\text { - My assistant and I interviewed } 10 \text { households and she interviewed } \\
\text { another } 2 \text { families the next day on her own. }\end{array}$ \\
\hline Nov. 5-7 & $\begin{array}{l}\text { - The shepherd's son drove me to a hospital in Gorgan. I stayed two } \\
\text { days in hospital for abdominal infection. }\end{array}$ \\
\hline Nov. 8 & $\begin{array}{l}\text { - Revising and redrafting the questionnaire based on the findings of the } \\
\text { preliminary interviews carried out November } 3 \text { and } 4 \text { and all the other } \\
\text { interviews until that day. }\end{array}$ \\
\hline Nov. 9 & $\begin{array}{l}\text { - Interviewed with an elder and a hunter about hunting, fishing, and } \\
\text { livestock breeding. This information is used to revise and redraft the } \\
\text { questionnaire. }\end{array}$ \\
\hline Nov. 10 & $\begin{array}{l}\text { - Met the Governor of Dashliburun in Inchehburun. } \\
\text { - Met with the village representatives, and local coordinator, and } \\
\text { informed them about my meeting with the Governor. We think the } \\
\text { questionnaire needs to be changed. } \\
\text { - Met with an elder about reviewing the questionnaire. }\end{array}$ \\
\hline Nov. 11 & $\begin{array}{l}\text { - Met with an elder and we prepared a herding and farming seasonal } \\
\text { calendar. This calendar is discussed, modified and cross checked by } \\
\text { more members of the community on Nov } 16 \text { and } 19 \text {. } \\
\text { - Interviewed an elder, and revised the questions regarding livestock } \\
\text { and agriculture in the questionnaire. }\end{array}$ \\
\hline Nov. 12 & $\begin{array}{l}\text { - Conducted a focus group for preparation of a seasonal calendar by } \\
\text { women. Twelve women attended the focus group. } \\
\text { - Read and revised the questionnaire with the research assistant and two } \\
\text { other volunteers. }\end{array}$ \\
\hline Nov. 13 & $\begin{array}{l}\text { - It was a hunting day. I talked to a hunter and took a picture of him and } \\
\text { the hunted birds } \\
\text { - The research assistant came along with } 8 \text { other girls who were willing }\end{array}$ \\
\hline
\end{tabular}




\begin{tabular}{|c|c|}
\hline & $\begin{array}{l}\text { to assist in completing the questionnaires. I briefed the surveyors } \\
\text { about the goals of research and explained the purpose of each } \\
\text { question. We read and discussed all the questions and revised the } \\
\text { questionnaire. }\end{array}$ \\
\hline Nov. 14 & $\begin{array}{l}\text { - Finalized the questionnaire. } \\
\text { - The research assistant sent the final version for photocopy. } \\
\text { - Interviewed an elder about herding in the AUA region and the quality } \\
\text { of rangelands. }\end{array}$ \\
\hline Nov. 15 & $\begin{array}{l}\text { - Surveyors started their work. } \\
\text { - Interviewed an elder about life in Tengli in the past and at present. } \\
\text { - Visited Ajigol, Ulmagol, salt lake, and the only local fish pond with } \\
\text { an elder and his family. Took pictures of the visited sites. }\end{array}$ \\
\hline Nov. 16 & $\begin{array}{l}\text { - Participatory mapping with women. } \\
\text { Interviewed an elder and his son and prepared a seasonal calendar of } \\
\text { hunting, and fishing. We revised the farming, and herding seasonal } \\
\text { calendar. } \\
\text { - The research assistant in a meeting with surveyors, listed all the } \\
\text { households, divided the village into nine parts, and handed out the } \\
\text { questionnaires to the surveyors. }\end{array}$ \\
\hline Nov. 17 & $\begin{array}{l}\text { - Interviewed with two women from two different economic layers and } \\
\text { prepared two seasonal calendars. } \\
\text { - Interview an elder about the time line, history of the village and the } \\
\text { Atrekians traditional land use system as he remembered (this time line } \\
\text { later discussed and revised by four more village elders in a meeting on } \\
\text { Nov. 27) } \\
\text { - A group meeting with all the surveyors. I reviewed all the completed } \\
\text { questionnaires and we discussed the discrepancies. }\end{array}$ \\
\hline Nov. 18 & $\begin{array}{l}\text { - Meeting with surveyors: checked the completed questionnaires and } \\
\text { asked for clarification and redone where necessary. }\end{array}$ \\
\hline Nov. 19 & $\begin{array}{l}\text { - Meeting with elders to discuss the traditional land and water use and } \\
\text { cross checking the farming and herding calendar. } \\
\text { - Meeting with surveyors: checked the filled questionnaires and asked } \\
\text { for clarification and redone where necessary. }\end{array}$ \\
\hline Nov. 20 & $\begin{array}{l}\text { - Revised the questions on agriculture and added a new set of questions } \\
\text { for land ownership. Met with all the surveyors and briefed them } \\
\text { individually and asked them to revisit the households to fill in the one } \\
\text { page on land ownership. I finally had to drop this page. }\end{array}$ \\
\hline Nov. 20 & - Interview with two university professors teaching Natural Resource \\
\hline
\end{tabular}




\begin{tabular}{|c|c|}
\hline & Management and Law in Gorgan \\
\hline $\begin{array}{l}\text { Nov. 21- } \\
24\end{array}$ & $\begin{array}{l}\text { - Took } 98 \text { completed questionnaires with me to Tehran. I separated the } \\
\text { first page from the remaining pages and stored them in two different } \\
\text { safe places. }\end{array}$ \\
\hline Nov. 25 & $\begin{array}{l}\text { - Met with surveyors: checked the filled questionnaires and asked for } \\
\text { clarification and redone. }\end{array}$ \\
\hline Nov. 26 & $\begin{array}{l}\text { Participatory mapping with four knowledgeable men and discussions } \\
\text { on traditional land and water use and their problems regarding land } \\
\text { use, tenure, and access to natural resources. } \\
\text { - Met with a retired DOE Environmental Guard. }\end{array}$ \\
\hline Nov. 27 & $\begin{array}{l}\text { - Interviewed an elder and discussed and cross checked the time line } \\
\text { history and their traditional land use system. } \\
\text { - Met with surveyors, checked the filled questionnaires and asked for } \\
\text { clarification and redone where necessary. }\end{array}$ \\
\hline Nov. 28 & $\begin{array}{l}\text { - Went to Gonbad with an elder and his family. He gave me copies of } \\
\text { old documents as a proof that they have paid for their lands at the time } \\
\text { of Mohammad-Reza Shah. }\end{array}$ \\
\hline Nov. 29 & $\begin{array}{l}\text { - Back to the village. } \\
\text { - Met with surveyors, checked the filled questionnaires, and asked for } \\
\text { clarification and redone if necessary }\end{array}$ \\
\hline Nov. 30 & $\begin{array}{l}\text { - Conducted a focus group on pair-wise ranking of problems. } \\
\text { - Met with surveyors, checked the filled questionnaires and asked for } \\
\text { clarification and redone where necessary. } \\
\text { - Farewell with the village surveyors and the research assistant. I paid } \\
\text { them, we took pictures and a few of them asked for my address. }\end{array}$ \\
\hline Dec. 1 & $\begin{array}{l}\text { - Went to the office of the Governor of Dashliburun, in Inchehburun but } \\
\text { he was not at his office and I put a farewell note. } \\
\text { - Left for Gorgan with my local coordinator and we visited Alagol and } \\
\text { its surrounding area including fish farms. } \\
\text { - Interviewed the director of the Provincial office of Forests and Natural } \\
\text { Resources. } \\
\text { - Interviewed a Law professor, Golestan University }\end{array}$ \\
\hline Dec. 2 & $\begin{array}{l}\text { - Interviewed a professor teaching rangeland management, Golestan } \\
\text { University } \\
\text { - Gave a talk at a class, Golestan University, about participatory } \\
\text { Conservation and Protected Areas conservation }\end{array}$ \\
\hline
\end{tabular}




\begin{tabular}{|c|c|}
\hline Dec. 3 & $\begin{array}{l}\text { - Met with a highly educated Turkmen. He volunteered to translate the } \\
\text { - Atrekians' old documents. } \\
\text { - Interviewed two experts in Golestan Fisheries Organization. } \\
\text { - Interview the deputy of the DOE Golestan provincial office. } \\
\text { - Interview a member of an amateur fishing society in Gorgan who } \\
\text { applied for permit every year. }\end{array}$ \\
\hline Dec. 4 & - Interviewed the director of the DOE Golestan provincial office. \\
\hline Dec. 5 & $\begin{array}{l}\text { - Interviewed an expert in Golestan Fisheries Organization } \\
\text { - Interviewed the Director of Planning and Development Division of } \\
\text { Golestan Regional Water Company. }\end{array}$ \\
\hline Dec. 6 & $\begin{array}{l}\text { - Interviewed a professor of Natural Resource Management, Golestan } \\
\text { University. } \\
\text { - Interviewed experts and staff of Golestan DOE provincial office. }\end{array}$ \\
\hline Dec. $7-15$ & $\begin{array}{l}\text { - Left Gorgan for Tone-kabon, a Caspian city, where my uncle was } \\
\text { waiting for me. Two civic holidays gave me the opportunity to take a } \\
\text { break for a week before going to Tehran. }\end{array}$ \\
\hline Dec. 16 & $\begin{array}{l}\text { - Collected the Tengli census data at Statistics Iran. } \\
\text { - Hired a reliable graduate student to scan the questionnaires, my notes, } \\
\text { participatory maps, and my other field data. }\end{array}$ \\
\hline Dec. 20 & $\begin{array}{l}\text { - Interviewed, appointed officer at Mahab Ghods consultancy firm that } \\
\text { conducted studies for the Ministry of Energy regarding future } \\
\text { development in AUA region. } \\
\text { - Interviewed one of the officers working on the study of ecosystems of } \\
\text { the AUA for the above project }\end{array}$ \\
\hline Dec. 22 & - Sent two boxes of books, publications and my notes to Ottawa \\
\hline Dec. 23 & $\begin{array}{l}\text { - Sent a CD containing scanned copy of questionnaires, my notebook, } \\
\text { pictures, and all the data I collected during this field work to } \\
\text { Switzerland by a Swiss friend to get mailed to Ottawa. } \\
\text { - Stored the questionnaires in a safe place. After receiving the CD in } \\
\text { Ottawa, the questionnaires were disposed. }\end{array}$ \\
\hline Dec. 24 & $\begin{array}{l}\text { - Met with the appointed officer in Mahab Ghods and got a copy of } \\
\text { their report on the AUA region } \\
\text { - Left Tehran for Amsterdam carrying only my note book. Arrived } \\
\text { Ottawa on December } 25 \text {. }\end{array}$ \\
\hline
\end{tabular}


Appendix B- Fieldwork verbal script

My name is Parastu, I am a student from Carleton University in Canada. Canada is an ocean away from your beautiful area. I am here to conduct a study. I want to understand about the plants, birds, fish, water and land in your area, to know how important they are for you, and how different members in your village use natural resources of Alagol, Ulmagol and Ajigol. One of the aims of my study is to understand your needs and those things that make your life easier and happier. I also want to study the obstacles that you face in conserving your natural resources, and providing food and income for yourself and your family. You might wonder why I have chosen your village to study. This is because I am very fond of Turkmens. I love your music and culture. Moreover the number of birds and fish in your area are decreasing year by year and you have access to less water as years go by. With your help I want to find out if there is a way to conserve birds, fish, water and land and at the same time allow you to have a better life and enjoy the natural resources and beauty of wetlands, the way that your ancestors have enjoyed.

I used to work with Department of Environment, about 12 years ago, and also with the United Nations, until 5 years ago, but not anymore. My bosses are my teachers in Canada. My teacher and my university want to make sure that I respect you and that I don't take much of your time. They don't want me to become a burden to your community. If I do not do a good job, or if at any moment you feel that I am a burden please let me know, tell me about it and we'll find a solution. You also can write or talk to my teachers: Scott Mitchell, Department of Geography and Environmental Studies, Carleton University, 1125 Colonel By Drive, Ottawa, Ontario K1S 5B6, Canada, Tel: 613- 520-2600 ext. 2695, E-mail: Scott_Mitchell@carleton.ca, and Prof. Antonio Gualtieri, Carleton University Research Ethics Committee, Carleton University, 1125 Colonel By Drive, Ottawa, Ontario K1S 5B6, Canada, Tel: 613-520-2517, E-mail: ethics@,carleton.ca. After I leave you may contact me at my address at my school: Department of Geography and Environmental Studies, Carleton University, 1125 Colonel By Drive, Ottawa, Ontario K1S 5B6, Canada, Tel: 613- 520-2600 ext. 2695, E-mail: pmardaka@connect.carleton.ca.

During the study, I will be speaking with almost everyone in the community, provided you are willing. Those who would like to will participate in some activities that I will organize. There will be no material compensation for your participation. However, I will do my best to provide food and tea during meetings. Most of these activities, for example drawing a map of your area, indicating important places and areas for your livelihood and culture using local names, will last about two hours. I will also be organizing short meetings with small groups of men and women to discuss several topics such as your customs, and traditional use of fish, birds, plants, water and land in your village, and also about how you feed your family and what your activities are in different seasons. Each activity may take one hour or so. At the end of my stay a questionnaire will be filled in for every household with the help of young people in your village. The 
questions are about how you feed your family and use the natural resources of the lakes for your livelihood.

Those who participate in group activities or discussions will do so on a volunteer basis. Participants in each activity or interview will remain unidentified to people outside of your village. Nobody except those actually filling out the questionnaire will know what answers were provided by which household, because there will be no names on the questionnaire papers. Anyone can decline to answer the whole questionnaire, or any part of it.

Your safety and wellbeing is my ultimate concern. I will not ask any question about illegal hunting and fishing in the village and around the lakes so I think in this way I will not put you at any risk, and I'm safeguarding your privacy. Still, if at any time you do not wish to answer any of my questions, there is no problem. You can decline answering any question you think is inappropriate. If there is any important issue that you want me to know and you think I am ignorant of please enlighten me. If you do not want me to observe or visit you, please let me know and I'll stop. Even if you participated in a discussion at first but then later you changed your mind, there will be no problem, and no hard feelings. If you want to you can even ask me to erase all the discussions that we had from my notebook. During our conversations I will write a few notes in a notebook so that I don't forget important points: I will not tape record anything. If I decide to take a picture I will first ask your permission, and will not leave your village without showing you the pictures. If you think you want me to take any picture of you or your wetlands please let me know and I'll do that.

All my notes and pictures will be kept with me and nobody else will have access to them. I am the only one who will use the notes when I write the results of my study. I will show that report to my teacher and will publish it in a scientific journal. I will send you any publication that I write about your village and lakes. 


\section{Appendix C- The Atrekians' old documents}

The first agreement dated 1933:

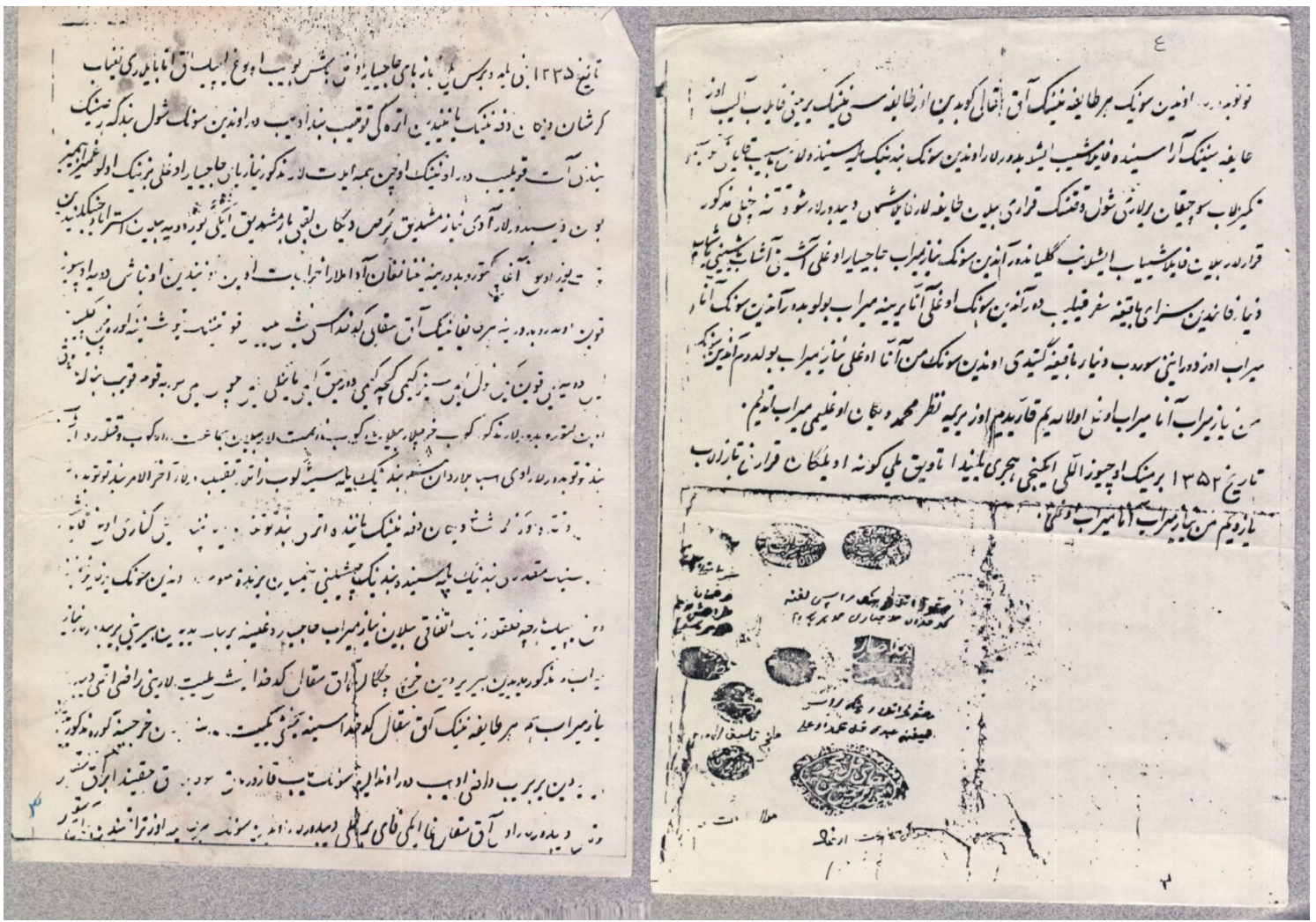


The second agreement dated 1943:

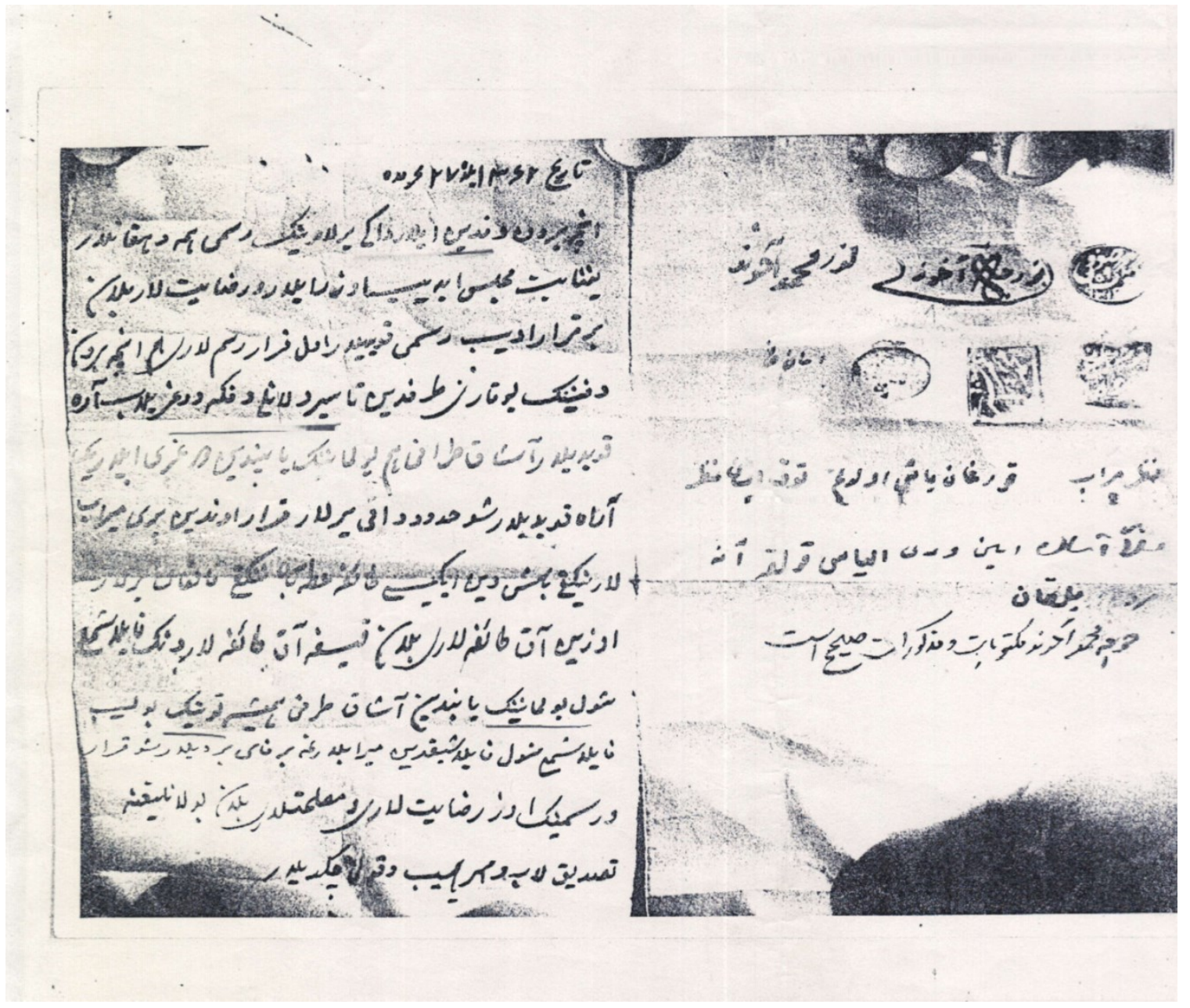




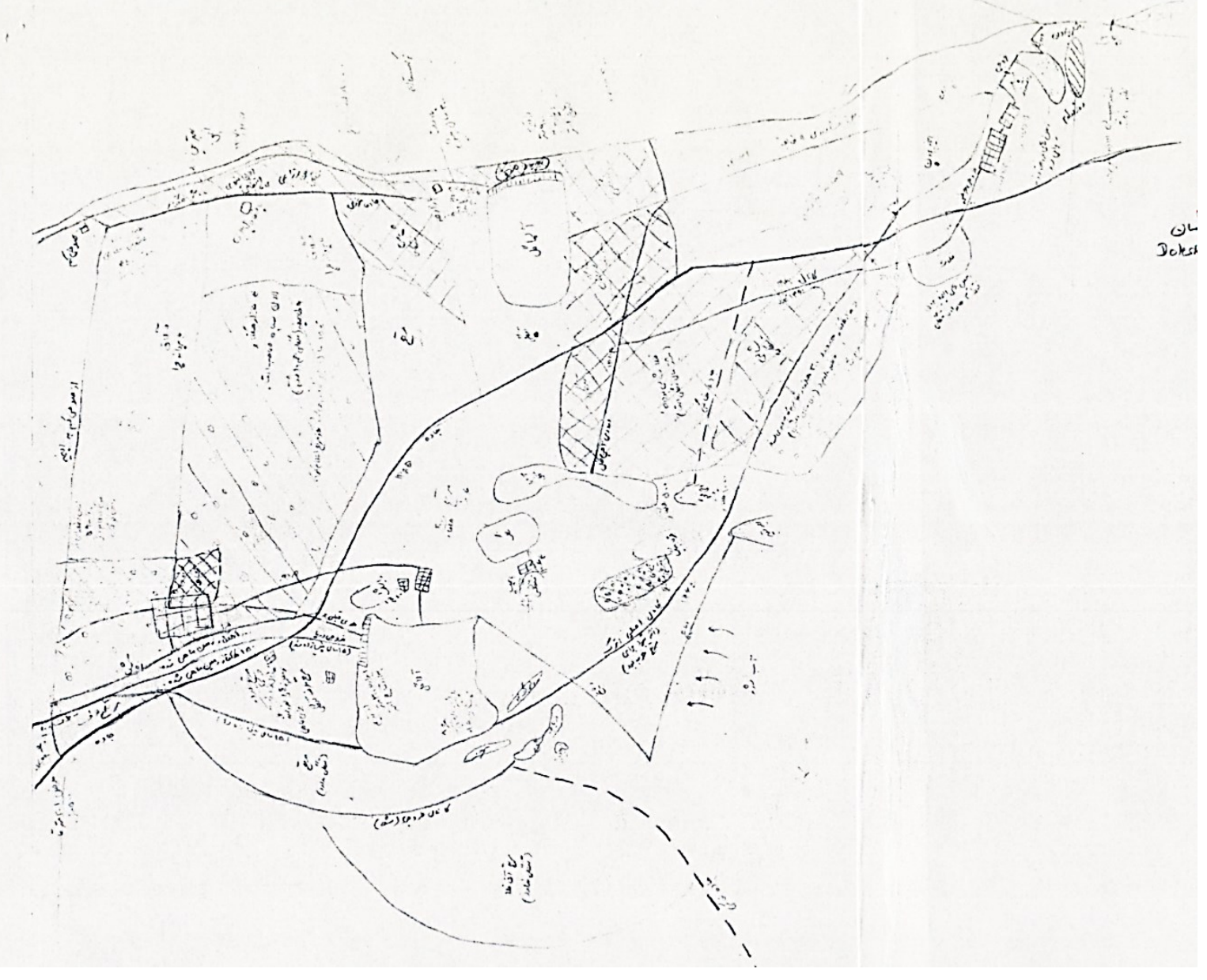

